NIST NCSTAR 1-6D

Federal Building and Fire Safety Investigation of the World Trade Center Disaster

\title{
Global Structural Analysis of the Response of the World Trade Center Towers to Impact Damage and Fire
}

\section{(Chapters 1-3)}

Mehdi S. Zarghamee

Yasuo Kitane

Ömer O. Erbay

Therese P. McAllister

John L. Gross 

Federal Building and Fire Safety Investigation of the World Trade Center Disaster

\section{Global Structural Analysis of the Response of the World Trade Center Towers to Impact Damage and Fire}

Mehdi S. Zarghamee

Yasuo Kitane

Ömer O. Erbay

Simpson Gumpertz \& Heger Inc.

Therese P. McAllister

John L. Gross

Building and Fire Research Laboratory

National Institute of Standard and Technology

September 2005

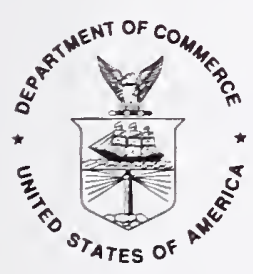

U.S. Department of Commerce

Carlos M. Gutierrez, Secretary

Technology Administration

Michelle O'Neill, Acting Secretary for Technology

National Institute of Standards and Technology

William Jeffrey, Director 


\section{Disclaimer No. 1}

Certain commercial entities, equipment, products, or materials are identified in this document in order to describe a procedure or concept adequately or to trace the history of the procedures and practices used. Such identification is not intended to imply recommendation, endorsement, or implication that the entities, products, materials, or equipment are necessarily the best available for the purpose. Nor does such identification imply a finding of fault or negligence by the National Institute of Standards and Technology.

\section{Disclaimer No. 2}

The policy of NIST is to use the International System of Units (metric units) in all publications. In this document, however, units are presented in metric units or the inch-pound system, whichever is prevalent in the discipline.

\section{Disclaimer No. 3}

Pursuant to section 7 of the National Construction Safety Team Act, the NIST Director has determined that certain evidence received by NIST in the course of this Investigation is "voluntarily provided safety-related information" that is "not directly related to the building failure being investigated" and that "disclosure of that information would inhibit the voluntary provision of that type of information" (15 USC 7306c).

In addition, a substantial portion of the evidence collected by NIST in the course of the Investigation has been provided to NIST under nondisclosure agreements.

\section{Disclaimer No. 4}

NIST takes no position as to whether the design or construction of a WTC building was compliant with any code since, due to the destruction of the WTC buildings, NIST could not verify the actual (or as-built) construction, the properties and condition of the materials used, or changes to the original construction made over the life of the buildings. In addition, NIST could not verify the interpretations of codes used by applicable authorities in determining compliance when implementing building codes. Where an Investigation report states whether a system was designed or installed as required by a code provision, NIST has documentary or anecdotal evidence indicating whether the requirement was met, or NIST has independently conducted tests or analyses indicating whether the requirement was met.

\section{Use in Legal Proceedings}

No part of any report resulting from a NIST investigation into a structural failure or from an investigation under the National Construction Safety Team Act may be used in any suit or action for damages arising out of any matter mentioned in such report (15 USC 281a; as amended by P.L. 107-231).

National Institute of Standards and Technology National Construction Safety Team Act Report 1-6D Natl. Inst. Stand. Technol. Natl. Constr. Sfty. Tm. Act Rpt. 1-6D, 476 pages (September 2005)

CODEN: NSPUE2 


\section{ABSTRACT}

Simpson Gumpertz \& Heger Inc (SGH) developed global models of the World Trade Center (WTC) towers using finite elements to gain an understanding of the roles of the aircraft impact damage and the subsequent fires in the WTC towers with respect to structural stability and sequential failures of components and subsystems and to determine the probable sequence of structural responses that led to initiation of global collapse. The study was conducted as part of the investigation on the WTC disaster by the National Institute of Standards and Technology (NIST).

The developed finite-element global models of the WTC towers simulated the structural performance of the part of the buildings in and above the aircraft impact zone. These models captured the nonlinear responses of the towers subjected to the aircraft impact damage and the subsequent fire effects. The nonlinearities included in the global models were temperature-dependent material properties such as thermal expansion, plasticity and creep of metals, large deflection and the resulting instability, and failure modes of members and connections.

NIST provided temperature-dependent nonlinear material properties, estimates of aircraft impact damage to structural members, and temperature time histories of structural elements, which were used as input in this study.

The finite element analyses (FEA) of the global models and of the component and subsystem models showed that the key structural responses that led to the collapse of the towers were as follows: 1) floor sagging caused by the failure of thermally-weakened truss members, resulting in pull-in forces between the floor and the exterior wall, and in some cases, disconnection of the floor from the exterior wall; 2) downward displacement of the core due to aircraft impact damage and shortening of the remaining core columns from increased load, plasticity, creep of steel at high temperatures, and buckling resulting from fire-induced high temperatures, and unloading of the core; 3) bowing and buckling of exterior walls caused by the pull-in forces and loss of lateral support from the sagged floors, and floor/wall disconnections at high temperatures; and 4) redistribution of gravity loads among the columns locally, among the exterior walls, and between the exterior walls and the core, resulting from impact damage, relative thermal expansion, shortening of core columns, tilting of the tower above the impact zone, and bowing and buckling of exterior walls.

In WTC 1, the aircraft impact caused damage to the north and south walls, floors, some core columns, and insulation. The subsequent fires caused sagging of the floors on the south side of the office area, where insulation was damaged, and inward bowing of the south wall. The damage to the core columns resulted in local load redistribution to the remaining core columns. The subsequent fire-induced high temperatures caused the core to displace downward from plasticity and high creep strains in high stress and high temperatures. The downward displacement of the core resulted in load redistribution from the core to the exterior walls. With continuously increased bowing, the entire width of the south wall buckled inward. The section of the building above the impact zone tilted to the south as instability progressed horizontally to the adjacent east and west walls. Global collapse occurred as potential energy of the falling upper structure exceeded the strain energy capacity in the deforming structural members. 
In WTC 2, the aircraft impact caused damage to the south and north exterior walls, floors, and columns in the southeast corner of the core. The floor damage and the subsequent fires caused sagging of the floors and local floor/wall disconnections, and resulted in bowing and buckling of the east wall. The damage to the core columns and fire-induced high temperatures resulted in local load redistribution to the remaining core columns in the southeast corner, which redistributed the core column loads to the east and south wall columns, as the core leaned toward the south and east. With continuously increased bowing, the entire width of the east wall buckled inward. The section of the building above the impact zone tilted to the east and south as instability progressed horizontally to the adjacent north and south walls. Global collapse occurred when the potential energy of the falling upper structure exceeded the strain energy capacity in the deforming structural members.

The results of global analysis of both WTC 1 and WTC 2 showed that global collapse of both towers was initiated by the instability of the exterior walls pursuant to their excessive inward bowing which progressed horizontally to adjacent walls.

Keywords: Collapse, creep, large deflection, nonlinear finite element analysis, plasticity, stability, structural response to damage, structural response to fire, World Trade Center. 


\section{TABLE OF CONTENTS}

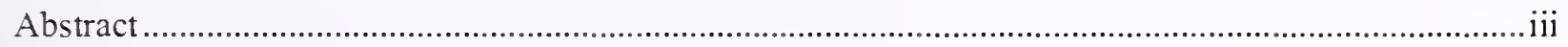

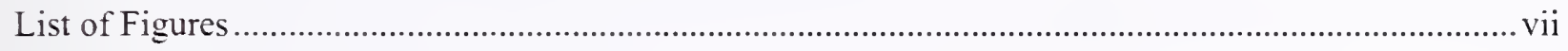

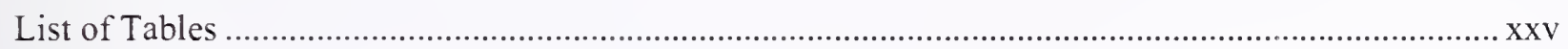

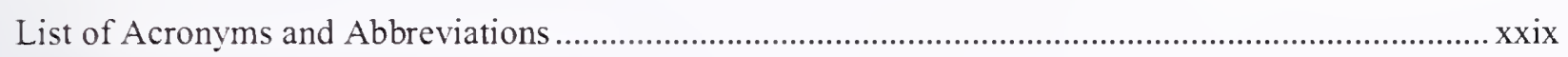

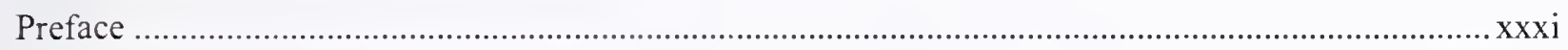

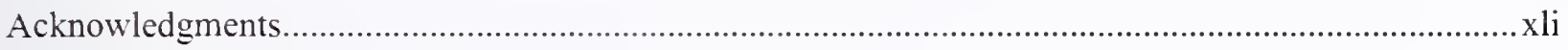

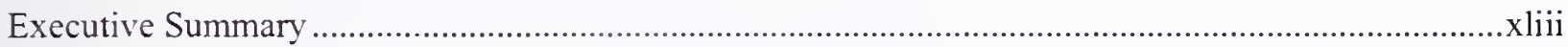

\section{Chapter 1}

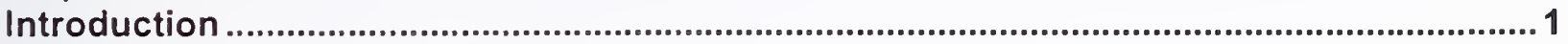

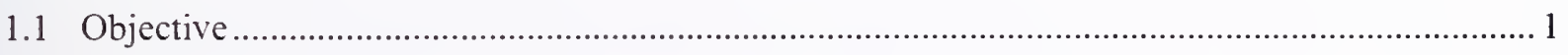

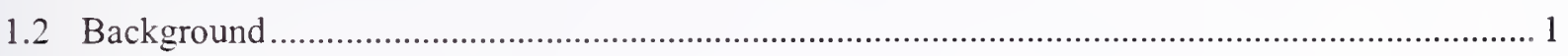

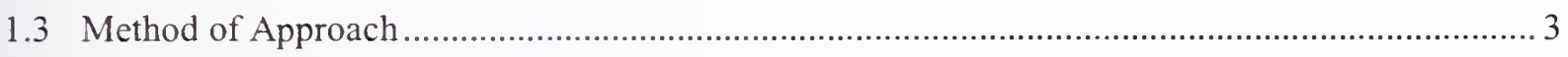

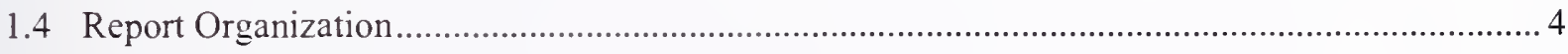

\section{Chapter 2}

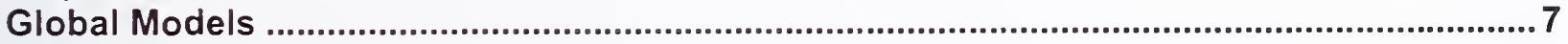

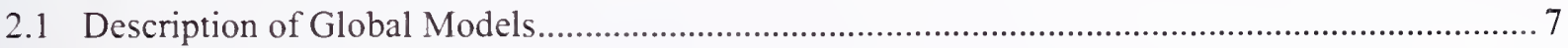

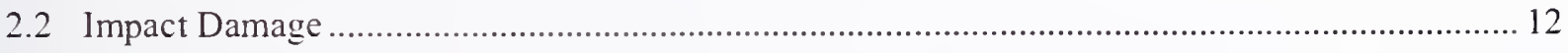

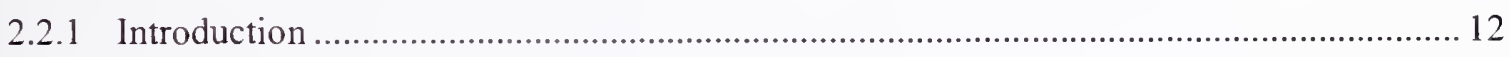

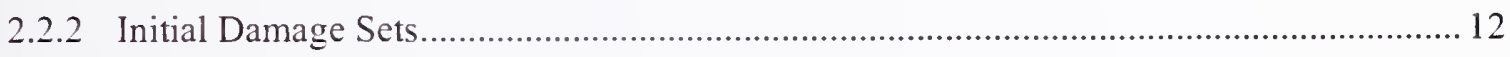

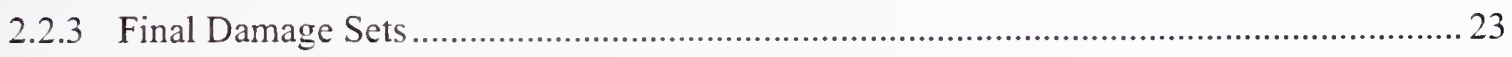

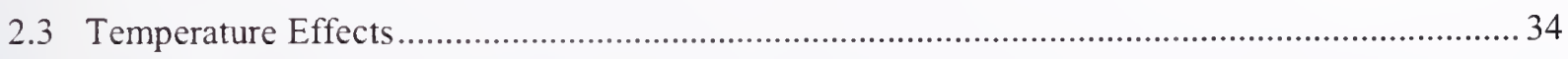

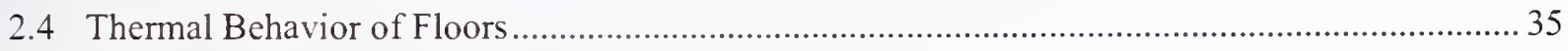

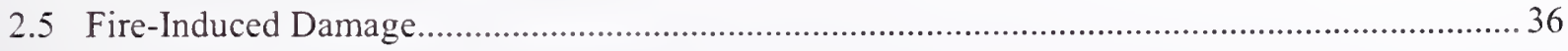

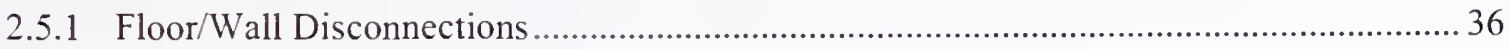

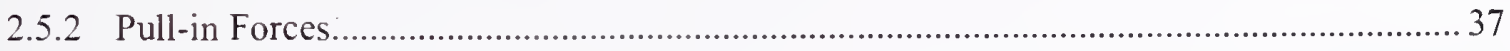

2.5.3 Floor/Wall Disconnections and Pull-in Forces Included in the Global Model.................. 39

\section{Chapter 3}

Isolated Wall and Core Model Analyses ...............................................................61 61

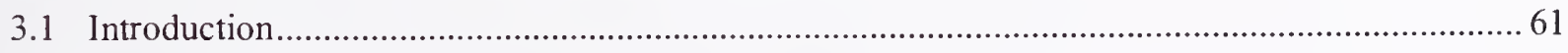

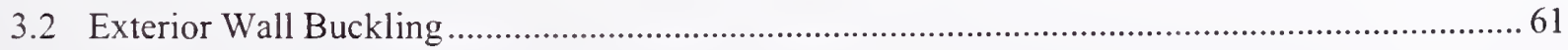


3.2.1 Finite Element Analysis of WTC 1 Exterior Wall ..................................................... 65

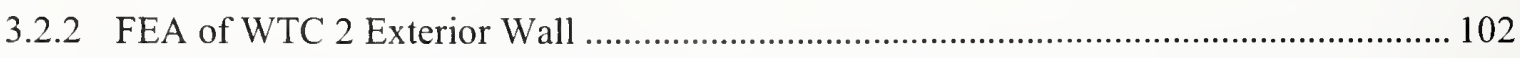

3.3 Core Column Shortening and Downward Displacement of Core ........................................... 134

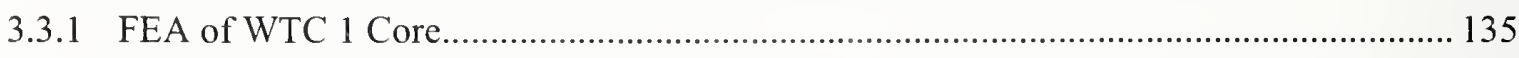

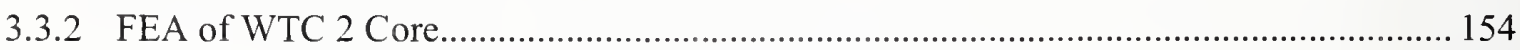

\section{Chapter 4}

Global Analysis

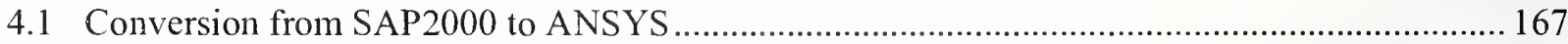

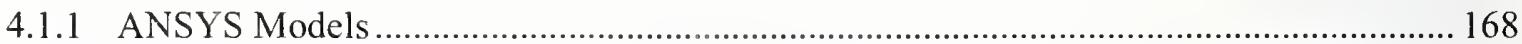

4.1.2 Validation of Translated ANSYS Global Models .................................................. 170

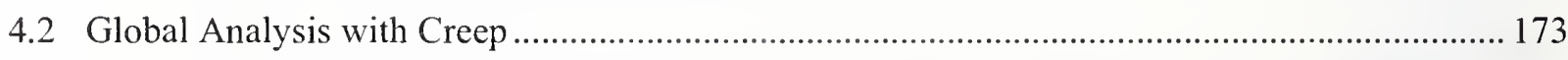

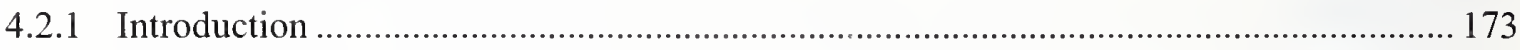

4.2.2 Modifications to the Global Model with Creep and Inelastic Buckling of Columns ....... 173

4.2.3 Boundary Conditions and Loading Steps .............................................................. 179

4.2.4 Simulation of WTC 1 Collapse ................................................................................ 179

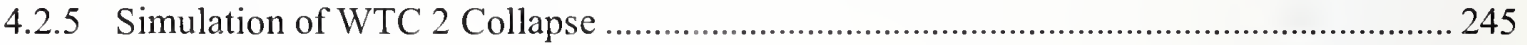

\section{Chapter 5}

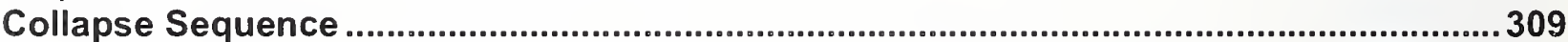

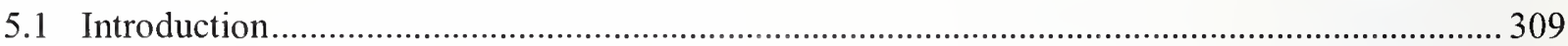

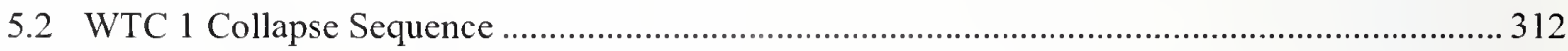

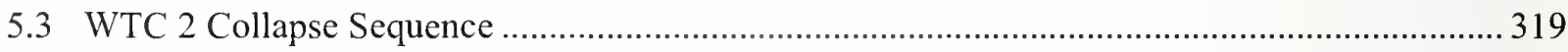

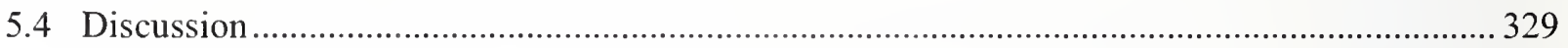

\section{Appendix A}

FEA of Floors

Appendix B

Floor Truss Dynamic Response Due to Impact of Dropping Floor 


\section{LIST OF FIGURES}

Figure $\mathrm{P}-1$. The eight projects in the federal building and fire safety investigation of the WTC disaster. xxxiii

Figure 2-1. Column designations. 11

Figure 2-2. Structural damage condition on the exterior walls of WTC 1 for all cases of impact damage.

Figure 2-3. Structural damage condition on the exterior walls of WTC 2 for all cases of impact damage.

Figure 2-4. Core columns and core beams in the WTC 1 global model without aircraft impact damage.

Figure 2-5. Core columns and core beams in the WTC 2 global model without aircraft impact damage 15

Figure 2-6. Case $A_{\mathrm{i}}$ structural damage condition on the core columns of WTC 1. 15

Figure 2-7. Case $\mathrm{C}_{\mathrm{i}}$ structural damage condition on the core columns of WTC 2 . 16

Figure 2-8. Revised Case $C_{i}$ structural damage condition on the core columns of WTC 2. 16

Figure 2-9. Case $A_{i}$ insulation damage conditions for WTC 1 floor trusses and beams. 17

Figure 2-10. Case $A_{i}$ structural damage conditions for WTC 1. 18

Figure 2-11. Case $C_{i}$ insulation damage conditions for WTC 2 floor trusses and beams.

Figure 2-12. Case $C_{i}$ Structural damage conditions for WTC 2 floors. 20

Figure 2-13. Case $D_{i}$ insulation damage conditions for WTC 2 floor trusses and beams. 21

Figure 2-14. Case $D_{i}$ Structural damage conditions for WTC 2 floors. .22

Figure 2-15. Case A structural damage condition on the core columns of WTC 1. 23

Figure 2-16. Case C structural damage condition on the core columns of WTC 2. 24

Figure 2-17. Case B structural damage condition on the core columns of WTC 1 (including heavily damaged columns).

Figure 2-18. Case D structural damage condition on the core columns of WTC 2 (including heavily damaged columns). 25

Figure 2-19. Case A insulation damage condition for WTC 1 floor trusses and beams...... 26

Figure 2-20. Case A structural damage condition for WTC 1 floors. 27

Figure 2-21. Case C insulation damage condition for WTC 2 floor trusses and beams........................28

Figure 2-22. Case C structural damage condition for WTC 2 floors. 29

Figure 2-23. Case B insulation damage conditions for WTC 1 floor trusses and beams. 30

Figure 2-24. Case B structural damage conditions for WTC 1 floors. 31

Figure 2-25. Case D insulation damage conditions for WTC 2 floor trusses and beams. 32 
Figure 2-26. Case D structural damage conditions for WTC 2 floors.

Figure 2-27. Comparison of vertical displacement of a simplified truss model at Column 333 extracted from the full floor model of Floor 96 of WTC 1 for Case $\mathrm{B}_{\mathrm{i}}$ temperature condition at $40 \mathrm{~min}$ with and without creep.

Figure 2-28. Locations of floor/wall disconnections and pull-in forces for the global analysis of

WTC 1 between $0 \mathrm{~min}$ and $10 \mathrm{~min}$ for Case B conditions.

Figure 2-29. Locations of floor/wall disconnections and pull-in forces for the global analysis of WTC 1 between $10 \mathrm{~min}$ and $20 \mathrm{~min}$ for Case B conditions.

Figure 2-30. Locations of floor/wall disconnections and pull-in forces for the global analysis of WTC 1 between $20 \mathrm{~min}$ and $30 \mathrm{~min}$ for Case B conditions.

Figure 2-31. Locations of floor/wall disconnections and pull-in forces for the global analysis of WTC 1 between $30 \mathrm{~min}$ and $40 \mathrm{~min}$ for Case B conditions.

Figure 2-32. Locations of floor/wall disconnections and pull-in forces for the global analysis of

WTC 1 between $40 \mathrm{~min}$ and $50 \mathrm{~min}$ for Case B conditions.

Figure 2-33. Locations of floor/wall disconnections and pull-in forces for the global analysis of WTC 1 between $50 \mathrm{~min}$ and $60 \mathrm{~min}$ for Case B conditions 46

Figure 2-34. Locations of floor/wall disconnections and pull-in forces for the global analysis of WTC 1 between $60 \mathrm{~min}$ and $70 \mathrm{~min}$ for Case B conditions.

Figure 2-35. Locations of floor/wall disconnections and pull-in forces for the global analysis of WTC 1 betwcen $70 \mathrm{~min}$ and $80 \mathrm{~min}$ for Case B conditions.

Figure 2-36. Locations of floor/wall disconnections and pull-in forces for the global analysis of WTC 1 between $80 \mathrm{~min}$ and $90 \mathrm{~min}$ for Case B conditions.

Figure 2-37. Locations of floor/wall disconnections and pull-in forces for the global analysis of WTC 1 between $90 \mathrm{~min}$ and $100 \mathrm{~min}$ for Case B conditions.

Figure 2-38. Locations of floor/wall disconnections and pull-in forces for the global analysis of WTC 2 between $0 \mathrm{~min}$ and $10 \mathrm{~min}$ for Case D conditions.

Figure 2-39. Locations of floor/wall disconnections and pull-in forces for the global analysis of WTC 2 between $10 \mathrm{~min}$ and $20 \mathrm{~min}$ for Case D conditions.

Figure 2-40. Locations of floor/wall disconnections and pull-in forces for the global analysis of WTC 2 between $20 \mathrm{~min}$ and $30 \mathrm{~min}$ for Case D conditions.

Figure 2-41. Locations of floor/wall disconnections and pull-in forces for the global analysis of WTC 2 between $30 \mathrm{~min}$ and $40 \mathrm{~min}$ for Case D conditions.

Figure 2-42. Locations of floor/wall disconnections and pull-in forces for the global analysis of WTC 2 between $40 \mathrm{~min}$ and $50 \mathrm{~min}$ for Case D conditions.

Figure 2-43. Locations of floor/wall disconnections and pull-in forces for the global analysis of WTC 2 between $50 \mathrm{~min}$ and $60 \mathrm{~min}$ for Case D conditions.

Figure 3-1. Isolated exterior wall segments from WTC 1 and WTC 2 (horizontal lines show spandrels and vertical lines show column).

Figure 3-2. Boundary conditions applied on the isolated exterior wall segment on the south wall of WTC 1. 
Figure 3-3. Case A temperature condition of south wall columns of WTC 1 at $10 \mathrm{~min} . \ldots \ldots \ldots \ldots \ldots . . . . . . . .66$

Figure 3-4. Case A temperature condition of south wall columns of WTC 1 at $20 \mathrm{~min}$....................66

Figure 3-5. Case A temperature condition of south wall columns of WTC 1 at $30 \mathrm{~min}$.................... 67

Figure 3-6. Case A temperature condition of south wall columns of WTC 1 at $40 \mathrm{~min}$................... 67

Figure 3-7. Case A temperature condition of south wall columns of WTC 1 at $50 \mathrm{~min}$....................6 67

Figure 3-8. Case A temperature condition of south wall columns of WTC 1 at $60 \mathrm{~min}$.....................6 68

Figure 3-9. Case A temperature condition of south wall columns of WTC 1 at $70 \mathrm{~min}$....................68

Figure 3-10. Case A temperature condition of south wall columns of WTC 1 at $80 \mathrm{~min}$.................... 68

Figure 3-11. Case A temperature condition of south wall columns of WTC 1 at $90 \mathrm{~min}$.................... 69

Figure 3-12. Case A temperature condition of south wall columns of WTC 1 at 100 min.................. 69

Figure 3-13. Case A temperature condition of south wall spandrels of WTC 1 at 10 min.................. 69

Figure 3-14. Case A temperature condition of south wall spandrels of WTC 1 at $20 \mathrm{min...................70}$

Figure 3-15. Case A temperature condition of south wall spandrels of WTC 1 at 30 min.................. 70

Figure 3-16. Case A temperature condition of south wall spandrels of WTC 1 at $40 \mathrm{~min}$.................... 70

Figure 3-17. Case A temperature condition of south wall spandrels of WTC 1 at 50 min................... 71

Figure 3-18. Case A temperature condition of south wall spandrels of WTC 1 at 60 min................... 71

Figure 3-19. Case A temperature condition of south wall spandrels of WTC 1 at 70 min................... 71

Figure 3-20. Case A temperature condition of south wall spandrels of WTC 1 at 80 min.................. 72

Figure 3-21. Case A temperature condition of south wall spandrels of WTC 1 at $90 \mathrm{~min} \ldots \ldots \ldots \ldots \ldots \ldots . . . . . . . .72$

Figure 3-22. Case A temperature condition of south wall spandrels of WTC 1 at 100 min................. 72

Figure 3-23. Response of Isolated south wall model of WTC 1 after aircraft impact.......................... 73

Figure 3-24. Vertical displacements of isolated south wall model of WTC 1 for Case A temperature condition (downward displacement is negative).......................................... 74

Figure 3-25. Out-of-plane displacements of isolated south wall model of WTC 1 for Case A temperature condition (inward displacement is positive).

Figure 3-26. Axial load in columns of isolated south wall modcl of WTC 1 for Case A temperature condition (compression is negative).

Figure 3-27. Plastic strain in columns of isolated south wall model of WTC 1 for Case A temperature condition at $100 \mathrm{~min}$ (compressive strain is negative).

Figure 3-28. Axial load in columns of south wall of WTC 1 at $100 \mathrm{~min}$ : isolated wall model for Case A temperature condition compared to global model without creep for Case Ai conditions (compression is positive).

Figure 3-29. Responses of isolated south wall model of WTC 1 after corrective loads from the global model were applied (Case A temperature condition at $100 \mathrm{~min}$ ).

Figure 3-30. Total additional vertical load versus additional vertical displacement during pushdown analysis of isolated south wall model of WTC 1 for Case A temperature condition (compression is positive). 
Figure 3-31. Additional vertical load per column at different additional vertical displacements during push-down analysis of isolated south wall model of WTC 1 for Case A temperature condition (compression is positive).

Figure 3-32. Response of isolated south wall model of WTC 1 to Case A temperature condition and push down at the end of the push-down analysis. 80

Figure 3-33. Location of the out-of-plane supports and floor/wall disconnections between exterior wall and the floor (WTC 1 south wall for Case B conditions at $100 \mathrm{~min}$ ). 82

Figure 3-34. Case B temperature condition of south wall columns of WTC 1 at $10 \mathrm{~min}$. 82

Figure 3-35. Case B temperature condition of south wall columns of WTC 1 at $20 \mathrm{~min}$. 83

Figure 3-36. Case B temperature condition of south wall columns of WTC 1 at $30 \mathrm{~min}$. 83

Figure 3-37. Case B temperature condition of south wall columns of WTC 1 at $40 \mathrm{~min}$. 83

Figure 3-38. Case B temperature condition of south wall columns of WTC 1 at $50 \mathrm{~min}$. 84

Figure 3-39. Case B temperature condition of south wall columns of WTC 1 at $60 \mathrm{~min}$. 84

Figure 3-40. Case B temperature condition of south wall columns of WTC 1 at $70 \mathrm{~min}$. 84

Figure 3-41. Case B temperature condition of south wall columns of WTC 1 at $80 \mathrm{~min}$. 85

Figure 3-42. Case B temperature condition of south wall columns of WTC 1 at $90 \mathrm{~min}$. 85

Figure 3-43. Case B temperature condition of south wall columns of WTC 1 at $100 \mathrm{~min}$ 85

Figure 3-44. Case B temperature condition of south wall spandrels of WTC 1 at $10 \mathrm{~min}$ 86

Figure 3-45. Case B temperature condition of south wall spandrels of WTC 1 at $20 \mathrm{~min}$. 86

Figure 3-46. Case B temperature condition of south wall spandrels of WTC 1 at $30 \mathrm{~min}$. 86

Figure 3-47. Case B temperature condition of south wall spandrels of WTC 1 at $40 \mathrm{~min}$. 87

Figure 3-48. Case B temperature condition of south wall spandrels of WTC 1 at $50 \mathrm{~min}$ 87

Figure 3-49. Case B temperature condition of south wall spandrels of WTC 1 at $60 \mathrm{~min}$ 87

Figure 3-50. Case B temperature condition of south wall spandrels of WTC 1 at $70 \mathrm{~min}$ 88

Figure 3-51. Case B temperature condition of south wall spandrels of WTC 1 at $80 \mathrm{~min}$ 88

Figure 3-52. Case B temperature condition of south wall spandrels of WTC 1 at $90 \mathrm{~min}$. 88

Figure 3-53. Case B temperature condition of south wall spandrels of WTC 1 at $100 \mathrm{~min}$. 89

Figure 3-54. Vertical displacement of isolated south wall model of WTC 1 for Case B temperature condition (downward displacement is negative).

Figure 3-55. Out-of-plane displacement of isolated south wall model of WTC 1 for Case B temperature condition (inward displacement is positive).

Figure 3-56. Axial load in columns of isolated south wall model of WTC 1 for Case B temperature condition (compression is negative).

Figure 3-57. Plastic strain in columns of isolated south wall model of WTC 1 for Case B temperature condition at $100 \mathrm{~min}$ (compressive strain is negative).

Figure 3-58. Axial load in columns of south wall of WTC 1 at 100 min: isolated wall model for Case B temperature condition compared to global model without creep for Case $\mathrm{A}_{\mathrm{i}}$ conditions (compression is positive). 
Figure 3-59. Response of isolated south wall model of WTC 1 after corrective loads from the global model were applied (Case B temperature condition at $100 \mathrm{~min}$ ).

Figure 3-60. Total additional vertical load versus additional vertical displacement during pushdown analysis of isolated south wall model of WTC 1 for Case B temperature condition (compression is positive).

Figure 3-61. Additional load per column at different additional vertical displacements during push-down analysis of isolated south wall model of WTC 1 for Case B temperature condition (compression is positive).

Figure 3-62. Response of isolated south wall model of WTC 1 to Case B temperature condition and push-down.

Figure 3-63. Locations of floor/wall disconnections and pull-in forces used between $80 \mathrm{~min}$ and 100 min of Case B temperature for south wall of WTC 1.

Figure 3-64. Response of isolated south wall model of WTC 1 at $80 \mathrm{~min}$ of Case B temperature condition with floor/wall disconnections and $6 \mathrm{kip}$ pull-in forces over five floors.

Figure 3-65. Response of isolated south wall model of WTC 1 at $90 \mathrm{~min}$ of Case B temperature condition with floor/wall disconnections and $6 \mathrm{kip}$ pull-in forces over five floors.

Figure 3-66. Response of isolated south wall model of WTC 1 at $100 \mathrm{~min}$ of Case B temperature condition with floor/wall disconnections and 6 kip pull-in forces over five floors.

Figure 3-67. Axial load in columns between Floors 98 and 99 of isolated south wall model of WTC 1 at $80 \mathrm{~min}, 90 \mathrm{~min}$, and $100 \mathrm{~min}$ of Case B temperature condition with floor/wall disconnections and $6 \mathrm{kip}$ pull-in forces over five floors (compression is positive)

Figure 3-68. Column temperatures on the east wall of WTC 2 for Case C temperature condition at $10 \mathrm{~min}, 20 \mathrm{~min}$, and $30 \mathrm{~min}$.

Figure 3-69. Column temperatures on the east wall of WTC 2 for Case C temperature condition at $40 \mathrm{~min}, 50 \mathrm{~min}$, and $60 \mathrm{~min}$.

Figure 3-70. Location of the out-of-plane supports and floor/wall disconnections between exterior wall and the floor (WTC 2 east wall for Case C conditions at $60 \mathrm{~min}$ ).

Figure 3-71. Vertical displacement of isolated east wall model of WTC 2 for Case C temperature distribution (downward displacement is negative; displacements scaled ten times).

Figure 3-72. Vertical displacement of isolated east wall model of WTC 2 for Case C temperature distribution at $60 \mathrm{~min}$ (downward displacement is negative; displacements scaled ten times).

Figure 3-73. Out-of-plane displacement of isolated east wall model of WTC 2 for Case C temperature condition (inward displacement is positive; displacements scaled ten times).

Figure 3-74. Out-of-plane displacement of isolated east wall model of WTC 2 for Case C temperature distribution at $60 \mathrm{~min}$ (inward displacement is positive; displacements scaled ten times).

Figure 3-75. Axial load on columns of isolated east wall model of WTC 2 under Case C temperature condition (compression is negative).

Figure 3-76. Axial load on columns of isolated east wall model of WTC 2 for Case C temperatures distribution at $60 \mathrm{~min}$ (compression is negative). 
Figure 3-77. Comparison of axial load in columns at Floor 83 of isolated east wall model of WTC 2 at $60 \mathrm{~min}$ for Case $\mathrm{C}$ temperature conditions and the global model without creep for Case $\mathrm{C}_{\mathrm{i}}$ conditions (compression is positive).

Figure 3-78. Vertical and out-of-plane displacements of isolated east wall model of WTC 2 after column forces were corrected to those of global modal without creep for Case $C_{i}$ conditions (displacements scaled ten times).

Figure 3-79. Vertical and out-of-plane displacements of isolated east wall model of WTC 2 after Case $\mathrm{C}$ temperature condition and push down analysis (displacements scaled five times).

Figure 3-80. Axial load on east wall columns of isolated east wall model of WTC 2 after Case C temperature condition and push-down (compression is negative)....

Figure 3-81. Additional vertical load versus additional vertical displacement during push-down analysis of isolated east wall model of WTC 2 for Case C temperature condition.....

Figure 3-82. Variation of additional vertical load applied to columns of isolated east wall model of WTC 2 at different levels of additional vertical displacements imposed after Case C temperature condition (compression is positive).

Figure 3-83. Column tempcratures on the east wall of WTC 2 for Case D temperature condition at $10 \mathrm{~min}, 20 \mathrm{~min}$, and $30 \mathrm{~min}$.

Figure 3-84. Column temperatures on the east wall of WTC 2 for Case D temperature condition at $40 \mathrm{~min}, 50 \mathrm{~min}$, and $60 \mathrm{~min}$.

Figure 3-85. Location of the out-of-plane supports and floor/wall disconnections between exterior wall and the floor (WTC 2 east wall for Case D conditions at $60 \mathrm{~min}$ ).

Figure 3-86. Vertical displacement of isolated east wall model of WTC 2 for Case D temperature condition (downward displacement is negative; displacements scaled ten times).

Figure 3-87. Vertical displacement of isolated east wall model of WTC 2 for Case D temperature condition at $60 \mathrm{~min}$ (downward displacement is negative; displacements scaled ten times).

Figure 3-88. Out-of-plane displacement of isolated east wall model of WTC 2 for Case D temperature condition (inward displacement is positive; displacements scaled ten times).

Figure 3-89. Out-of-plane displacement of isolated east wall model of WTC 2 for Case D temperature condition at $60 \mathrm{~min}$ (inward displacement is positive; displacements scaled ten times).

Figure 3-90. Axial load on east wall columns of isolated east wall model of WTC 2 for Case D temperature condition (compression is negative).

Figure 3-91. Axial load on east wall columns of isolated east wall model of WTC 2 for Case D temperature condition at $60 \mathrm{~min}$ (comprcssion is negative).

Figure 3-92. Comparison of axial load in columns at Floor 83 of isolated east wall model of WTC 2 at $60 \mathrm{~min}$ for Case D temperature conditions and the global model without creep for Case $C_{i}$ structural damage condition and Case $D_{i}$ temperature condition (compression is positive). 
Figure 3-93. Vertical and out-of-plane displacements of columns of isolated east wall model of WTC 2 after column forces were corrected to those of global model without creep for Case $C_{i}$ structural damage condition and Case $D_{i}$ temperature condition (displacements scaled ten times).

Figure 3-94. Vertical and out-of-plane displacements of isolated east wall model of WTC 2 after Case D temperature condition and push down (displacements scaled five times)....

Figure 3-95. Axial load on east wall columns of isolated east wall model of WTC 2 after Case D temperature condition and push down (compression is negative).

Figure 3-96. Additional vertical load applied to columns versus additional vertical during displacement for push-down analysis of isolated east wall model of WTC 2 for after Case D temperature condition (compression is positive; see Fig. 3-95 for column locations).

Figure 3-97. Variation of additional vertical load applied to columns of isolated east wall model of WTC 2 at different levels of additional vertical displacements imposed after Case D temperature condition (compression is positive).

Figure 3-98. Out-of-plane displacements of the east wall of WTC 2 estimated by NIST from photographs (inward displacement is positive; displacements are in in.).

Figure 3-99. Out-of-plane displacement of isolated east wall model of WTC 2 with 0.5 kip and 5.0 kip pull-in force with uniform magnitude distribution at $20 \mathrm{~min}$ and $18 \mathrm{~min}$ (inward displacement is positive).

Figure 3-100. Out-of-plane displacement of isolated east wall model of WTC 2 with 0.5 kip pull-in force with uniform magnitude distribution at $32 \mathrm{~min}$ (inward displacement is positive).

Figure 3-101. Out-of-plane displacement of isolated east wall model of WTC 2 with nonuniform pull-in force with magnitude of $1.0 \mathrm{kip}$ on the south half and $4.0 \mathrm{kip}$ on the north half (inward displacement is positive).

Figure 3-102. Out-of-plane displacement of isolated east wall model of WTC 2 with nonuniform pull-in force with magnitude of $1.5 \mathrm{kip}$ on the south half and $5.0 \mathrm{kip}$ on the north half (inward displacement is positive).

Figure 3-103. Isolated core models

Figure 3-104. Vertical displacement of isolated core model of WTC 1 after aircraft impact (downward displacement is negative).

Figure 3-105. Vertical displacement of isolated core model of WTC 1 for Case A temperature condition at $10 \mathrm{~min}$ (downward displacement is negative).

Figure 3-106. Vertical displacement of isolated core model of WTC 1 for Case A temperature condition at $20 \mathrm{~min}$ (downward displacement is negative).

Figure 3-107. Vertical displacement of isolated core model of WTC 1 for Case A temperature condition at $30 \mathrm{~min}$ (downward displacement is negative).

Figure 3-108. Vertical displacement of isolated core model of WTC 1 for Case A temperature condition at $40 \mathrm{~min}$ (downward displacement is negative).

Figure 3-109. Vertical displacement of isolated core model of WTC 1 for Case A temperature condition at $50 \mathrm{~min}$ (downward displacement is negative) 
Figure 3-110. Vertical displacement of isolated core model of WTC 1 for Case A temperature condition at $70 \mathrm{~min}$ (downward displacement is negative).

Figure 3-111. Vertical displacement of isolated core model of WTC 1 for Case A temperature condition at $100 \mathrm{~min}$ (downward displacement is negative).

Figure 3-112. Horizontal displacement of isolated core model of WTC 1 for Case A temperature condition at $100 \mathrm{~min}$.

Figure 3-113. Axial load in columns of isolated core model of WTC 1 after aircraft impact (compression is negative).

Figure 3-114. Axial load in columns of isolated core model of WTC 1 for Case A temperature condition at $100 \mathrm{~min}$ (compression is negative).

Figure 3-115. Plastic strain in columns of isolated core model of WTC 1 for Case A temperature condition at $100 \mathrm{~min}$ (compressive strain is negative).

Figure 3-116. Vertical displacement after push down of isolated core model of WTC 1 for Case A temperature condition (downward displacement is negative)....

Figure 3-117. Total additional vertical load versus additional vertical displacement during pushdown analysis of isolated core model of WTC 1 for Case A temperature condition (compression is positive).

Figure 3-118. Additional axial load (kip) in columns at Floor 98 when the total axial load reached the maximum during push down analysis of isolated core model of WTC 1 for Case A temperature condition (compression is positive).

Figure 3-119. Vertical displacement of isolated core model of WTC 1 for Case B temperature condition at $10 \mathrm{~min}$ (downward displacement is negative)

Figure 3-120. Vertical displacement of isolated core model of WTC 1 for Case B temperature condition at $20 \mathrm{~min}$ (downward displacement is negative)

Figure 3-121. Vertical displacement of isolated core model of WTC 1 for Case B temperature condition at $30 \mathrm{~min}$ (downward displacement is negative)...

Figure 3-122. Vertical displacement of isolated core model of WTC 1 for Case B temperature condition at $40 \mathrm{~min}$ (downward displacement is negative)

Figure 3-123. Vertical displacement of isolated core model of WTC 1 for Case B temperature condition at $50 \mathrm{~min}$ (downward displacement is negative)

Figure 3-124. Vertical displacement of isolated core model of WTC 1 for Case B temperature condition at $70 \mathrm{~min}$ (downward displacement is negative)

Figure 3-125. Vertical displacement of isolated core model of WTC 1 for Case B temperature condition at $100 \mathrm{~min}$ (downward displacement is negative).

Figure 3-126. Horizontal displacement of isolated core model of WTC 1 for Case B temperature condition at $100 \mathrm{~min}$.

Figure 3-127. Axial load in columns of isolated core model of WTC 1 for Case B temperature condition at $100 \mathrm{~min}$ (compression is negative).

Figure 3-128. Plastic strain in columns of isolated core model of WTC 1 for Case B temperature condition at $100 \mathrm{~min}$ (compressive strain is negative)

Figure 3-129. Vertical displacement after push down of isolated core model of WTC 1 for Case B temperature condition (downward displacement is negative) 
Figure 3-130. Total additional vertical load versus additional vertical displacement relationship obtained from push down analysis of isolated core model of WTC 1 for Case B temperature condition (compression is positive).

Figure 3-131. Additional axial load (kip) in columns at Floor 98 when the total axial load reached the maximum during push down analysis of the WTC 1 core for Case B temperature condition (compression is positive).

Figure 3-132. Vertical displacement of isolated core model of WTC 2 for Case C temperature condition (downward displacement is negative)

Figure 3-133. Vertical displacement of isolated core model of WTC 2 for Case C temperaturc condition at $60 \mathrm{~min}$ (downward displacement is negative).

Figure 3-134. Axial load in core columns of isolated core model of WTC 2 for Case C temperature condition at $60 \mathrm{~min}$ (compression is negative).

Figure 3-135. Axial plastic strains in core columns of isolated core model of WTC 2 for Case C temperature condition at $60 \mathrm{~min}$ (compressive strain is negative).

Figure 3-136. Vertical displacement after push down of isolated core model of WTC 2 for Case C temperature condition (downward displacement is negative).

Figure 3-137. Additional average vertical load versus additional vertical displacement during pushdown analysis of isolated core model of WTC 2 for Case C temperature condition (compression is positive; core column locations are shown in Fig. 3-136).

Figure 3-138. Vertical displacement of isolated core model of WTC 2 for Case D temperature condition (downward displacement is negative).

Figure 3-139. Vertical displacement of isolated core model of WTC 2 for Case D temperature condition at $60 \mathrm{~min}$ (downward displacement is negative)

Figure 3-140. Axial load in core columns of isolated core model of WTC 2 for Case D temperature condition at $60 \mathrm{~min}$ (compression is negative).

Figure 3-141. Axial plastic strains in core columns of isolated core model of WTC 2 for Case D temperature condition at $60 \mathrm{~min}$ (compressive strain is negative).

Figure 3-142. Vertical displacement after push down of isolated core model of WTC 2 for Case D temperature condition (downward displacement is negative).

Figure 3-143. Additional average vertical load versus additional vertical displacement during pushdown analysis of isolated core model of WTC 2 for Case D temperature condition.

Figure 4-1. Coordinate system used in the analysis models.

Figure 4-2. Office and core area floors and core beams.

Figure 4-3. Location and IDs of outriggers and supporting columns.

Figure 4-4. Displaced shape of WTC 1 at the end of gravity analysis.

Figure 4-5. Displaced shape of WTC 2 at the end of gravity analysis.

Figure 4-6. Comparison of vertical displacement between WTC 1 models with and without construction sequence.

Figure 4-7. Comparison of vertical displacement between WTC 2 models with and without construction sequence. 
Figure 4-8. Vertical displacement of exterior wall of WTC 1 before aircraft impact (downward displacement is negative).

Figure 4-9. Vertical displacement of exterior wall of WTC 1 after aircraft impact for Case B conditions (downward displacement is negative).

Figure 4-10. Vertical displacement of exterior wall of WTC 1 at $80 \mathrm{~min}$ for Case B conditions (downward displacement is negative).

Figure 4-11. Vertical displacement of exterior wall of WTC 1 at $100 \mathrm{~min}$ for Case B conditions (downward displacement is negative).

Figure 4-12. Vertical displacement of north wall of WTC 1 before aircraft impact.

Figure 4-13. Vertical displacement of north wall of WTC 1 after aircraft impact for Case B conditions (downward displacement is negative).

Figure 4-14. Vertical displacement of north wall of WTC 1 at $80 \mathrm{~min}$ for Case B conditions (downward displacement is negative).

Figure 4-15. Vertical displacement of north wall of WTC 1 at $100 \mathrm{~min}$ for Case B conditions with 5 kip pull-in forces (downward displacement is negative).

Figure 4-16. Vertical displacement of east wall of WTC 1 before aircraft impact (downward displacement is negative).

Figure 4-17. Vertical displacement of east wall of WTC 1 after aircraft impact for Case B conditions (downward displacement is negative).

Figure 4-18. Vertical displacement of east wall of WTC 1 at $80 \mathrm{~min}$ for Case B conditions (downward displacement is negative).

Figure 4-19. Vertical displacement of east wall of WTC 1 at $100 \mathrm{~min}$ for Case B conditions with 5 kip pull-in forces (downward displacement is negative).

Figure 4-20. Vertical displacement of south wall of WTC 1 before aircraft impact (downward displacement is negative).

Figure 4-21. Vertical displacement of south wall of WTC 1 after aircraft impact for Case B conditions (downward displacement is negative).

Figure 4-22. Vertical displacement of south wall of WTC 1 at $80 \mathrm{~min}$ for Case B conditions (downward displacement is negative).

Figure 4-23. Vertical displacement of south wall of WTC 1 at $100 \mathrm{~min}$ for Case B conditions with

5 kip pull-in forces (downward displacement is negative).

Figure 4-24. Vertical displacement of core of WTC 1 before aircraft impact (downward displacement is negative).

Figure 4-25. Vertical displacement of core of WTC 1 after aircraft impact for Case B conditions (downward displacement is negative).

Figure 4-26. Vertical displacement of core of WTC 1 at 50 min for Case B conditions (downward displacement is negative).

Figure 4-27. Vertical displacement of core of WTC 1 at $80 \mathrm{~min}$ for Case B conditions (downward displacement is negative).

Figure 4-28. Vertical displacement of core of WTC 1 at 100 min for Case B conditions with 5 kip pull-in forces (downward displacement is negative). 
Figure 4-29. Vertical displacement of core columns of WTC 1 before aircraft impact (downward displacement is negative).

Figure 4-30. Vertical displacement of core columns of WTC 1 after aircraft impact for Case B conditions (downward displacement is negative).

Figure 4-31. Vertical displacement of core columns of WTC 1 at $80 \mathrm{~min}$ for Case B conditions (downward displacement is negative)...

Figure 4-32. Vertical displacement of core columns of WTC 1 at $100 \mathrm{~min}$ for Case B conditions with $5 \mathrm{kip}$ pull-in forces (downward displacement is negative). 204

Figure 4-33. Vertical displacement at Floor 99 of WTC 1 before aircraft impact. 205

Figure 4-34. Change in vertical displacement at Floor 99 of WTC 1 from the time before impact to the time after impact for Case B conditions.

Figure 4-35. Change in vertical displacement at Floor 99 of WTC 1 from the time before impact to $50 \mathrm{~min}$ for Case B conditions...... 206

Figure 4-36. Change in vertical displacement at Floor 99 of WTC 1 from the time before impact to $80 \mathrm{~min}$ for Case B conditions. 206

Figure 4-37. Change in vertical displacement at Floor 99 of WTC 1 from the time before impact to $100 \mathrm{~min}$ for Case B conditions with 5 kip pull-in forces.

Figure 4-38. Out-of-plane displaccment of south wall of WTC 1 before aircraft impact (inward displacement is positive).

Figure 4-39. Out-of-plane displacement of south wall of WTC 1 after aircraft impact for Case B conditions (inward displacement is positive). 208

Figure 4-40. Out-of-plane displacement of south wall of WTC 1 at $80 \mathrm{~min}$ (at the end of Analysis Step 17) for Case B conditions (inward displacement is positive).

Figure 4-41. Out-of-plane displacement of south wall of WTC 1 at $100 \mathrm{~min}$ for Case B conditions with 5 kip pull-in forces (inward displacement is positive).

Figure 4-42. Time history of maximum out-of-plane displacement of south wall of WTC 1 for Case B conditions with 5 kip pull-in forces (from Analysis Step 18 to Step 21).

Figure 4-43. Out-of-plane displacement of south wall of WTC 1 at $100 \mathrm{~min}$ for Case B conditions with 4 kip pull-in forces (inward displacement is positive).

Figure 4-44. Axial load in exterior columns of north wall of WTC 1 before aircraft impact (compression is negative).....

Figure 4-45. Axial load in exterior columns of north wall of WTC 1 after aircraft impact for Case $\mathrm{B}$ conditions (compression is negative).

Figure 4-46. Axial load in exterior columns of north wall of WTC 1 at $80 \mathrm{~min}$ for the Case B conditions (compression is negative).

Figure 4-47. Axial load in exterior columns of north wall of WTC 1 at $100 \mathrm{~min}$ for Case B conditions with $5 \mathrm{kip}$ pull-in forces (compression is negative).

Figure 4-48. Axial load in exterior columns of east wall of WTC 1 before aircraft impact (compression is negative)

Figure 4-49. Axial load in exterior columns of east wall of WTC 1 after aircraft impact for Case B conditions (compression is negative). 
Figure 4-50. Axial load in exterior columns of east wall of WTC 1 at $80 \mathrm{~min}$ for the Case B conditions (compression is negative).

Figure 4-51. Axial load in exterior columns of east wall of WTC 1 at $100 \mathrm{~min}$ for the Case B conditions with $5 \mathrm{kip}$ pull-in forces (compression is negative).

Figure 4-52. Axial load in exterior columns of south wall of WTC 1 before aircraft impact (compression is negative).

Figure 4-53. Axial load in exterior columns of south wall of WTC 1 after aircraft impact for Case B conditions (compression is negative).....

Figure 4-54. Axial load in exterior columns of south wall of WTC 1 at $80 \mathrm{~min}$ for Case B conditions (compression is negative).

Figure 4-55. Axial load in exterior columns of south wall of WTC 1 at $100 \mathrm{~min}$ for Case B conditions with $5 \mathrm{kip}$ pull-in forces (compression is negative).

Figure 4-56. Variation of axial load in exterior columns at Floor 98 of north wall of WTC 1 for Case $\mathrm{B}$ conditions with 5 kip pull-in forces (compression is positive).

Figure 4-57. Variation of axial load in exterior columns at Floor 98 of east wall of WTC 1 for Case B conditions with 5 kip pull-in forces (compression is positive).

Figure 4-58. Variation of axial load in exterior columns at Floor 98 of south wall of WTC 1 for Case B conditions with 5 kip pull-in forces (compression is positive).

Figure 4-59. Variation of axial load in exterior columns at Floor 98 of west wall of WTC 1 for Case $\mathrm{B}$ conditions with 5 kip pull-in forces (compression is positive).

Figure 4-60. Axial load in core columns of WTC 1 before aircraft impact (compression is negative)

Figure 4-61. Axial load in core columns of WTC 1 after aircraft impact for Case B conditions (compression is negative).

Figure 4-62. Axial load in core columns of WTC 1 at $80 \mathrm{~min}$ for Case B conditions (compression is negative).

Figure 4-63. Axial load in core columns of WTC 1 at $100 \mathrm{~min}$ for Case B conditions with 5 kip pull-in forces (compression is negative).

Figure 4-64. Axial load in columns at Floor 98 of WTC 1 before aircraft impact (compression is positive).

Figure 4-65. Axial load in columns at Floor 98 of WTC 1 after aircraft impact for Case B conditions (compression is positive).

Figure 4-66. Axial load in columns at Floor 98 of WTC 1 at $80 \mathrm{~min}$ for Case B conditions (compression is positive).

Figure 4-67. Axial load in columns at Floor 98 of WTC 1 at $100 \mathrm{~min}$ for Case B conditions with 5 kip pull-in forces (compression is positive).

Figure 4-68. Maximum demand-to-capacity ratio for axial load in core columns between Floor 93 and Floor 99 of WTC 1 before aircraft impact.

Figure 4-69. Maximum demand-to-capacity ratio for axial load in core columns between Floor 93 and Floor 99 of WTC 1 after aircraft impact for Case B conditions. 
Figure 4-70. Maximum demand-to-capacity ratio for axial load in core columns between Floor 93 and Floor 99 of WTC 1 at 80 min for Case B conditions.

Figure 4-71. Maximum demand-to-capacity ratio for axial load in core columns between Floor 93 and Floor 99 of WTC 1 at 100 min for Case B conditions with 5 kip pull-in forces.

Figure 4-72. Maximum elastic-plus-plastic strain for columns between Floor 93 and Floor 99 of WTC 1 before aircraft impact (compressive strain is positive; strain values are in percent).

Figure 4-73. Maximum elastic-plus-plastic strain for columns between Floor 93 and Floor 99 of WTC 1 after aircraft impact for Case B conditions (compressive strain is positive; strain values are in percent).

Figure 4-74. Maximum elastic-plus-plastic strain for columns between Floor 93 and Floor 99 of WTC 1 at $10 \mathrm{~min}$ for Case B conditions (compressive strain is positive; strain values are in percent).

Figure 4-75. Maximum elastic-plus-plastic strain for columns between Floor 93 and Floor 99 of WTC 1 at 40 min for Case B conditions (compressive strain is positive; strain values are in percent).

Figure 4-76. Maximum elastic-plus-plastic strain for columns between Floor 93 and Floor 99 of WTC 1 at 80 min for Case B conditions (compressive strain is positive; strain values are in percent).

Figure 4-77. Maximum elastic-plus-plastic strain for columns between Floor 93 and Floor 99 of WTC 1 at 100 min for Case B conditions with 5 kip pull-in forces (compressive strain is positive; strain values are in percent).

Figure 4-78. Maximum elastic-plus-plastic-plus-creep strain for columns between Floor 93 and Floor 99 of WTC 1 at 10 min for Case B conditions (compressive strain is positive; strain values are in percent).

Figure 4-79. Maximum elastic-plus-plastic-plus-creep strain for columns between Floor 93 and Floor 99 of WTC 1 at 40 min for Case B conditions (compressive strain is positive; strain values are in percent).

Figure 4-80. Maximum elastic-plus-plastic-plus-creep strain for columns between Floor 93 and Floor 99 of WTC 1 at 80 min for Case B conditions (compressive strain is positive; strain values are in percent).

Figure 4-81. Maximum elastic-plus-plastic-plus-creep strain for columns between Floor 93 and Floor 99 of WTC 1 at 100 min for Case B conditions with 5 kip pull-in forces (compressive strain is positive; strain value are in percent).

Figure 4-82. Axial load (kip) in core columns at Floor 105 of WTC 1 at $100 \mathrm{~min}$ for Case B conditions with $5 \mathrm{kip}$ pull-in forces (compression is positive).

Figure 4-83. Tension demand-to-capacity ratio for core column splices at Floor 106 of WTC 1 at $100 \mathrm{~min}$ for Case B conditions with 5 kip pull-in forces.

Figure 4-84. Primary load path within the hat truss of WTC 1.

Figure 4-85. Location of the hat truss connections in the primary load path.

Figure 4-86. Vertical displacement of exterior wall of WTC 2 for Case D conditions (downward displacement is negative). 
Figure 4-87. Vertical displacement of exterior wall of WTC 2 for Case D conditions (downward displacement is negative).

Figure 4-88. Vertical displacement at Floor 83 of WTC 2 for Case D conditions (downward displacement is positive).

Figure 4-89. Vertical displacement at Floor 83 of WTC 2 for Case D conditions (downward displacement is positive; note the tilt toward east and south).

Figure 4-90. Total displacements of WTC 2 above Floor 86 at 43 min of Case D conditions (deformed shape magnified 20 times). Note the tilt toward east and south.

Figure 4-91. Vertical displacement of core of WTC 2 for Case D conditions (downward displacement is negative).

Figure 4-92. Vertical displacement of core of WTC 2 for Case D conditions (downward displacement is negative).

Figure 4-93. Vertical displacement of 800 series core columns of WTC 2 for Case D conditions (downward displacement is negative).

Figure 4-94. Vertical displacement of 800 series core columns of WTC 2 for Case D conditions (downward displacement is negative).

Figure 4-95. Vertical displacement of 900 series core columns of WTC 2 for Case D conditions (downward displacement is negative).

Figure 4-96. Vertical displacement of 900 series core columns of WTC 2 for Case D conditions (downward displacement is negative).

Figure 4-97. Vertical displacement of 1000 series core columns of WTC 2 for Case D conditions (downward displacement is negative).

Figure 4-98. Vertical displacement of 1000 series core columns of WTC 2 for Case D conditions (downward displacement is negative).

Figure 4-99. Out-of-plane displacement of the east wall of WTC 2 for Case D conditions (inward displacement is positive).

Figure 4-100. Out-of-plane displacement of the east wall of WTC 2 for Case D conditions (inward displacement is positive).

Figure 4-101. Variation of maximum inward bowing of the east wall of WTC 2 over time for Case D conditions.

Figure 4-102. Lateral displacements above Floor 86 of WTC 2 in the x-direction (north-south) for Case D conditions.

Figure 4-103. Lateral displacements above Floor 86 of WTC 2 in the y-direction (east-west) for Case D conditions.

Figure 4-104. Axial load in the east wall of WTC 2 for Case D conditions (compression is negative)

Figure 4-105. Axial load in the east wall of WTC 2 for Case D conditions (compression is negative)

Figure 4-106. Axial load in the south wall of WTC 2 for Case D conditions (compression is negative). 
Figure 4-107. Axial load in the south wall of WTC 2 for Case D conditions (compression is negative).

Figure 4-108. Axial load in the north wall of WTC 2 for Case D conditions (compression is negative).

Figure 4-109. Axial load in the north wall of WTC 2 for Case D conditions (compression is negative).

Figure 4-110. Axial load in the east and the west wall columns at Floor 83 of WTC 2 for Case D conditions (compression is positive).

Figure 4-111. Axial load in the south and the north wall columns at Floor 83 of WTC 2 for Case D conditions (compression is positive).

Figure 4-112. Axial load in 800 series core columns of WTC 2 for Case D conditions (compression is negative).

Figure 4-113. Axial load in 800 series core columns of WTC 2 for Case D conditions (compression is negative).

Figure 4-114. Axial load in 900 series core columns of WTC 2 for Case D conditions (compression is negative)

Figure 4-115. Axial load in 900 series core columns of WTC 2 for Case D conditions (compression is negative).

Figure 4-116. Axial load in 1000 series core columns of WTC 2 for Case D conditions (compression is negative).

Figure 4-117. Axial load in 1000 series core columns of WTC 2 for Case D conditions (compression is negative).

Figure 4-118. Core column loads (kip) at Floor 83 of WTC 2 for Case D conditions (compression is positive)

Figure 4-119. Core column loads (kip) at Floor 83 of WTC 2 for Case D conditions (compression is positive)

Figure 4-120. Axial load in Floor 83 columns of WTC 2 for Case D conditions (compression is positive).

Figure 4-121. Maximum elastic-plus-plastic strains for columns between Floor 78 and Floor 83 of WTC 2 for Case D conditions (compressive strain is positive; strain values are in percent).

Figure 4-122. Maximum elastic-plus-plastic strains for columns between Floor 78 and Floor 3 of WTC 2 for Case D conditions (compressive strain is positive; strain values are in percent).

Figure 4-123. Maximum elastic-plus-plastic-plus-creep strains for columns between Floor 78 and Floor 83 of WTC 2 for Case D conditions (compressive strain is positive; strain values are in percent).

Figure 4-124. Axial load in core columns (kip) at Floor 105 (at hat truss level) of WTC 2 for Case D conditions (compression is positive).

Figure 4-125. Axial load in core columns (kip) at Floor 105 (at hat truss level) of WTC 2 for Case D conditions (compression is positive). 
Figure 4-126. Progressive failure of core column splices at Floor 105 of WTC 2 (compression is positive; values are in kip).

Figure 4-127. State of core column splices at Floor 105 of WTC 2.

Figure 4-128. Axial force in hat truss members of WTC 2 for Case D conditions (tension is positive)

Figure 4-129. Axial force in hat truss members of WTC 2 for Case D conditions (tension is positive).

Figure 4-130. Axial stress in hat truss members of WTC 2 for Case D conditions (tension is positive).

Figure 4-131. Axial stress in hat truss members of WTC 2 for Case D conditions (tension is positive).. 298

Figure 4-132. Primary load path within the hat truss of WTC 2........................................................ 301

Figure 4-133. Location of hat truss connections that were in the primary load path. 301

Figure 5-1. Vertical displacement of the truss model under thermal loading. 311

Figure 5-2. Catenary action in the floor system.

Figure 5-3. Total column loads at Floor 98 of the south wall of WTC 2 global model for Case B conditions (compression is positive).

Figure 5-4. Vertical displacements of full floor models of WTC 1 for Case Bi temperature condition at $100 \mathrm{~min}$ (downward displacement is negative).

Figure 5-5. Loss of vertical supports obtained in Floor 97 and Floor 98 full floor models of WTC 1 for Case Bi temperature condition at $100 \mathrm{~min}$ (1x displacement magnification).

Figure 5-6. Inward bowing of exterior columns of the South wall of WTC 1 at 10:23 a.m. (97 min after impact). Displacements were estimated by NIST from the analysis of this photograph.

Figure 5-7. Inward bowing of south wall of WTC 1 global model with creep at 100 min for Case B conditions with $5 \mathrm{kip}$ pull-in forces ( $5 \mathrm{x}$ displacement magnification). 318

Figure 5-8. Collapse initiation and tilting of WTC 1 (view from the northeast). 318

Figure 5-9. Vertical displacements of full floor models of WTC 2 for Case $D_{i}$ temperature condition at $40 \mathrm{~min}$ (downward displacement is negative).....

Figure 5-10. Floor sagging observed on the east wall of WTC 2 at different times.

Figure 5-11. Total column loads at Floor 83 of the east wall of WTC 2 global model for Case D conditions (compression is positive).

Figure 5-12. Maximum elastic + plastic + creep strain magnitudes for columns between Floor 78 and Floor 83 of WTC 2 global model for Case D conditions at $20 \mathrm{~min}, 30 \mathrm{~min}$, and $40 \mathrm{~min}$ (compressive strain is positive; strain values are in percent). 326

Figure 5-13. Inward bowing of the east wall of WTC 2 global model for Case D conditions at $43 \mathrm{~min}$ at the instant of collapse initiation (deformed shape scaled four times).

Figure 5-14. Inward bowing of exterior columns of the west wall of WTC 2 just before collapse. 
Figure 5-15. Total displacements of WTC 2 global model above Floor 86 for Case D conditions at 43 min at collapse initiation (note the tilt toward east and south; deformed shape magnified 20 times) 328

Figure 5-16. Initiation of Collapse of WTC 2. Note the tilt toward east and south........................... 328

Figure 5-17. Full floor model of Floor 96 of WTC 1 for Case $B_{i}$ temperature condition at 100 min. ... 330 
This page intentionally left blank. 


\section{LIST OF TABLES}

Table P-1 Federal building and fire safety investigation of the WTC disaster.............................xxxii

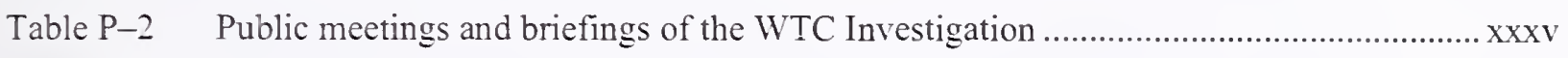

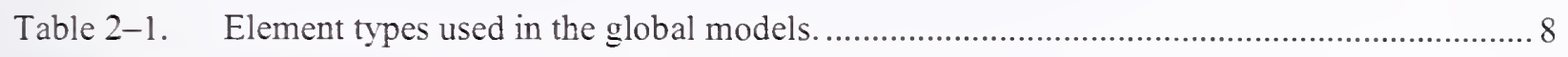

Table 2-2. Temperatures of exterior seats at east wall of Floor 82 of WTC 2 .............................5 51

Table 2-3. Demand-to-capacity ratios of exterior seats at east wall of Floor 82 of WTC 2

predicted by the full floor model ...................................................................... 52

Table 3-1. Analysis steps conducted on WTC 1 isolated exterior wall model.................................. 64

Table 3-2. Analysis steps conducted on WTC 2 isolated exterior wall model................................... 64

Table 4-1. Conversion from SAP2000 element types to ANSYS element types............................. 168

Table 4-2. Comparison of maximum displacements and base reactions of WTC 1 from

translated ANSYS and SAP2000 models.

Table 4-3. Comparison of maximum displacements and base reactions of WTC 2 obtained from translated ANSYS and SAP2000 models.

Table 4-4. Comparison of axial forces in randomly selected elements from WTC 1 model at the end of gravity analysis.

Table 4-5. Comparison of axial forces in randomly selected elements from WTC 2 model at the end of gravity analysis.

Table 4-6. Global model properties before and after modifications for computational efficiency. .... 174

Table 4-7. Comparison of total column loads between WTC 1 models with and without construction sequence

Table 4-8. Comparison of total column loads between WTC 2 models with and without construction sequence

Table 4-9. Analysis steps of WTC 1 ANSYS global model.

Table 4-10. Total column loads at Floor 98 of WTC 1 for Case B conditions.

Table 4-11. Total column loads at Floor 105 of WTC 1 for Case B conditions.

Table 4-12. Total column loads on the north wall of WTC 1 for Case B conditions.

Table 4-13. Change in total column loads on the north wall of WTC 1 for Case B conditions from the state before aircraft impact.

Table 4-14. Total column loads on the east wall of WTC 1 for Case B conditions.

Table 4-15. Change in total column loads on the east wall of WTC 1 for Case B conditions from the state before aircraft impact. 
Table 4-16. Total column loads on the south wall of WTC 1 for Case B conditions. .228

Table 4-17. Change in total column loads on the south wall of WTC 1 for Case B conditions from the state before aircraft impact............................................................................... 228

Table 4-18. Summation of total column loads on the west wall of WTC 1 for Case B conditions....... 229

Table 4-19. Change in total column loads on the west wall of WTC 1 for Case B conditions from the state before aircraft impact......

Table 4-20. Total column loads on the core of WTC 1 for Case B conditions.

Table 4-21. Change in total column loads on the core of WTC 1 for Case B conditions from the state before aircraft impact.

Table 4-22. Change in total column loads before and after aircraft impact. (Loads after impact) (Loads before impact)

Table 4-23. Change in total column loads after aircraft impact and at $80 \mathrm{~min}$ for Case B conditions. (Loads at $80 \mathrm{~min}$ ) - (Loads After Impact)

Table 4-24. Change in total column loads at $80 \mathrm{~min}$ and at $100 \mathrm{~min}$ for Case $\mathrm{B}$ conditions. (Loads at $100 \mathrm{~min})-($ Loads at $80 \mathrm{~min})$......

Table 4-25. Tension capacity of core column splices at Floor 106

Table 4-26. Axial load in core columns at Floor 105 of WTC 1 for Case B conditions 240

Table 4-27. Demand-to-capacity ratio for axial load in outriggers of WTC 1 for Case B conditions (outrigger IDs are indicated in Fig. 4-3).

Table 4-28. Demand to capacity ratio for axial load in exterior columns supporting outriggers at Floor 107 of WTC 1 for Case B conditions.

Table 4-29. Demand and capacity of the hat truss connections (kip) in the primary load path at 80 min (connection IDs are shown in Fig. 4-85).

Table 4-30. Analysis Steps of WTC 2 ANSYS global model with Case D conditions. 245

Table 4-31. Total column loads (kip) at Floor 105 at different stages of splice failures at $40 \mathrm{~min}$ (compression is positive).

Table 4-32. Demand-to-capacity ratios for outriggers of WTC 2 for Case D conditions (outrigger IDs are shown in Fig. 4-3).

Table 4-33. Demand to capacity ratios for columns supporting outriggers at Floor 107 of WTC 2 for Case D conditions.

Table 4-34. Demand and capacity of the hat truss connections (kip) in the primary load path at 40 min (connection IDs are shown in Fig. 4-133). 302

Table 4-35. Total column loads at Floor 83 of WTC 2 for Case D conditions. 302

Table 4-36. Total column loads at Floor 105 of WTC 2 for Case D conditions. 303

Table 4-37. Change in total column loads before and after aircraft impact. (Loads After Impact) (Loads Before Impact).... 303

Table 4-38. Change in total column loads between $40 \mathrm{~min}$ and $43 \mathrm{~min}$. (Loads at $43 \mathrm{~min}$ ) (Loads at $40 \mathrm{~min}$ ) 303

Table 4-39. Total column loads over the height for the east wall of WTC 2 for Case D conditions.... 304 
Table 4-40. Total column loads over the height for the south wall of WTC 2 for Case D conditions.

Table 4-41. Total column loads over the height for the north wall of WTC 2 for Case D conditions. 306

Table 4-42. Total column loads over the height for the west wall of WTC 2 for Case D conditions.

Table 4-43. Total column loads over the height for the core of WTC 2 for Case D conditions.

Table 5-1. Summary of main events that led to the collapse of WTC 1. 312

Table 5-2. Observations on WTC 1 provided by NIST.

Table 5-3. Total column loads at Floor 98 and Floor 105 of WTC 1 global model for Case B conditions.

Table 5-4. Summary of main events that led to the collapse of WTC 2

Table 5-5. Observations on WTC 2 provided by NIST.

Table 5-6. Total column loads at Floor 83 and Floor 105 of WTC 2 for Case D conditions. 
This page intentionally left blank. 


\section{LIST OF ACRONYMS AND ABBREVIATIONS}

\section{Acronyms}

ARA Applied Research Associates, Inc.

ASTM American Society for Testing and Materials

BPS Building Performance Study

CAEAI Computer Aided Engineering Associates, Inc.

FEMA Federal Emergency Management Agency

FEA finite element analysis

LERA Leslie E. Robertson Associates

NIST National Institute of Standards and Technology

PANYNJ The Port Authority of New York and New Jersey

SEAoNY Structural Engineers Association of New York

SGH Simpson Gumpertz \& Heger Inc.

USC United States Code

WTC World Trade Center

\section{Abbreviations}

$\begin{array}{ll}{ }^{\circ} \mathrm{C} & \text { degrees Celsius } \\ { }^{\circ} \mathrm{F} & \text { degrees Fahrenheit } \\ \mathrm{ft} & \text { feet } \\ \text { in. } & \text { inch } \\ \mathrm{L} & \text { liter } \\ \mathrm{m} & \text { meter } \\ \mu \mathrm{m} & \text { micrometer } \\ \mathrm{min} & \text { minute } \\ \mathrm{S} & \text { second } \\ \mathrm{lb} & \text { pound } \\ \mathrm{kip} & \text { a force equal to } 1,000 \text { pounds } \\ \text { pcf } & \text { pound per cubic foot }\end{array}$


psf pound per square foot

psi pound per square inch

ksi $\quad 1,000$ pounds per square inch 


\section{PREFACE}

\section{Genesis of This Investigation}

Immediately following the terrorist attack on the World Trade Center (WTC) on September 11, 2001, the Federal Emergency Management Agency (FEMA) and the American Society of Civil Engineers began planning a building performance study of the disaster. The week of October 7 , as soon as the rescue and search efforts ceased, the Building Performance Study Team went to the site and began its assessment. This was to be a brief effort, as the study team consisted of experts who largely volunteered their time away from their other professional commitments. The Building Performance Study Team issued its report in May 2002, fulfilling its goal "to determine probable failure mechanisms and to identify areas of future investigation that could lead to practical measures for improving the damage resistance of buildings against such unforeseen events."

On August 21, 2002, with funding from the U.S. Congress through FEMA, the National Institute of Standards and Technology (NIST) announced its building and fire safety investigation of the WTC disaster. On October 1, 2002, the National Construction Safety Team Act (Public Law 107-231), was signed into law. The NIST WTC Investigation was conducted under the authority of the National Construction Safety Team Act.

The goals of the investigation of the WTC disaster were:

- To investigate the building construction, the materiais used, and the technical conditions that contributed to the outcome of the WTC disaster.

- To serve as the basis for:

- Improvements in the way buildings are designed, constructed, maintained, and used;

- Improved tools and guidance for industry and safety officials;

- Recommended revisions to current codes, standards, and practices; and

- Improved public safety.

The specific objectives were:

1. Determine why and how WTC 1 and WTC 2 collapsed following the initial impacts of the aircraft and why and how WTC 7 collapsed;

2. Determine why the injuries and fatalities were so high or low depending on location, including all technical aspects of fire protection, occupant behavior, evacuation, and emergency response;

3. Determine what procedures and practices were used in the design, construction, operation, and maintenance of WTC 1,2, and 7; and

4. Identify, as specifically as possible, areas in current building and fire codes, standards, and practices that warrant revision. 
NIST is a nonregulatory agency of the U.S. Department of Commerce's Technology Administration. The purpose of NIST investigations is to improve the safety and structural integrity of buildings in the United States, and the focus is on fact finding. NIST investigative teams are authorized to assess building performance and emergency response and evacuation procedures in the wake of any building failure that has resulted in substantial loss of life or that posed significant potential of substantial loss of life. NIST does not have the statutory authority to make findings of fault nor negligence by individuals or organizations. Further, no part of any report resulting from a NIST investigation into a building failure or from an investigation under the National Construction Safety Team Act may be used in any suit or action for damages arising out of any matter mentioned in such report (15 USC 281a, as amended by Public Law 107-231).

\section{Organization of the Investigation}

The National Construction Safety Team for this Investigation, appointed by the then NIST Director, Dr. Arden L. Bement, Jr., was led by Dr. S. Shyam Sunder. Dr. William L. Grosshandler served as Associate Lead Investigator, Mr. Stephen A. Cauffman served as Program Manager for Administration, and Mr. Harold E. Nelson served on the team as a private sector expert. The Investigation included eight interdependent projects whose leaders comprised the remainder of the team. A detailed description of each of these eight projects is available at http://wtc.nist.gov. The purpose of each project is summarized in Table $\mathrm{P}-1$, and the key interdependencies among the projects are illustrated in Fig. $\mathrm{P}-1$.

\section{Table P-1. Federal building and fire safety investigation of the WTC disaster.}

Technical Area and Project Leader

Analysis of Building and Fire Codes and Practices; Project Leaders: Dr. H. S. Lew and Mr. Richard W. Bukowski

Baseline Structural Performance and Aircraft Impact Damage Analysis; Project Leader: Dr. Fahim H. Sadek

Mechanical and Metallurgical Analysis of Structural Steel; Project Leader: Dr. Frank W. Gayle

Investigation of Active Fire Protection Systems; Project Leader: Dr. David D. Evans; Dr. William Grosshandler Reconstruction of Thermal and Tenability Environment; Project Leader: Dr. Richard G. Gann

Structural Fire Response and Collapse Analysis; Project Leaders: Dr. John L. Gross and Dr. Therese P. McAllister

Occupant Behavior, Egress, and Emergency Communications; Project Leader: Mr. Jason D. Averill

Emergency Response Technologies and Guidelines; Project Leader: Mr. J. Randall Lawson

Project Purpose

Document and analyze the code provisions, procedures, and practices used in the design, construction, operation, and maintenance of the structural, passive fire protection, and emergency access and evacuation systems of WTC 1,2, and 7 .

Analyze the baseline performance of WTC 1 and WTC 2 under design, service, and abnormal loads, and aircraft impact damage on the structural, fire protection, and egress systems.

Determine and analyze the mechanical and metallurgical properties and quality of steel, weldments, and connections from steel recovered from WTC 1,2 , and 7 .

Investigate the performance of the active fire protection systems in WTC 1, 2, and 7 and their role in fire control, emergency response, and fate of occupants and responders.

Reconstruct the time-evolving temperature, thermal environment, and smoke movement in WTC 1,2, and 7 for use in evaluating the structural performance of the buildings and behavior and fate of occupants and responders.

Analyze the response of the WTC towers to fires with and without aircraft damage, the response of WTC 7 in fires, the performance of composite steel-trussed floor systems, and determine the most probable structural collapse sequence for WTC 1,2, and 7.

Analyze the behavior and fate of occupants and responders, both those who survived and those who did not, and the performance of the evacuation system.

Document the activities of the emergency responders from the time of the terrorist attacks on WTC 1 and WTC 2 until the collapse of WTC 7 , including practices followed and technologies used. 


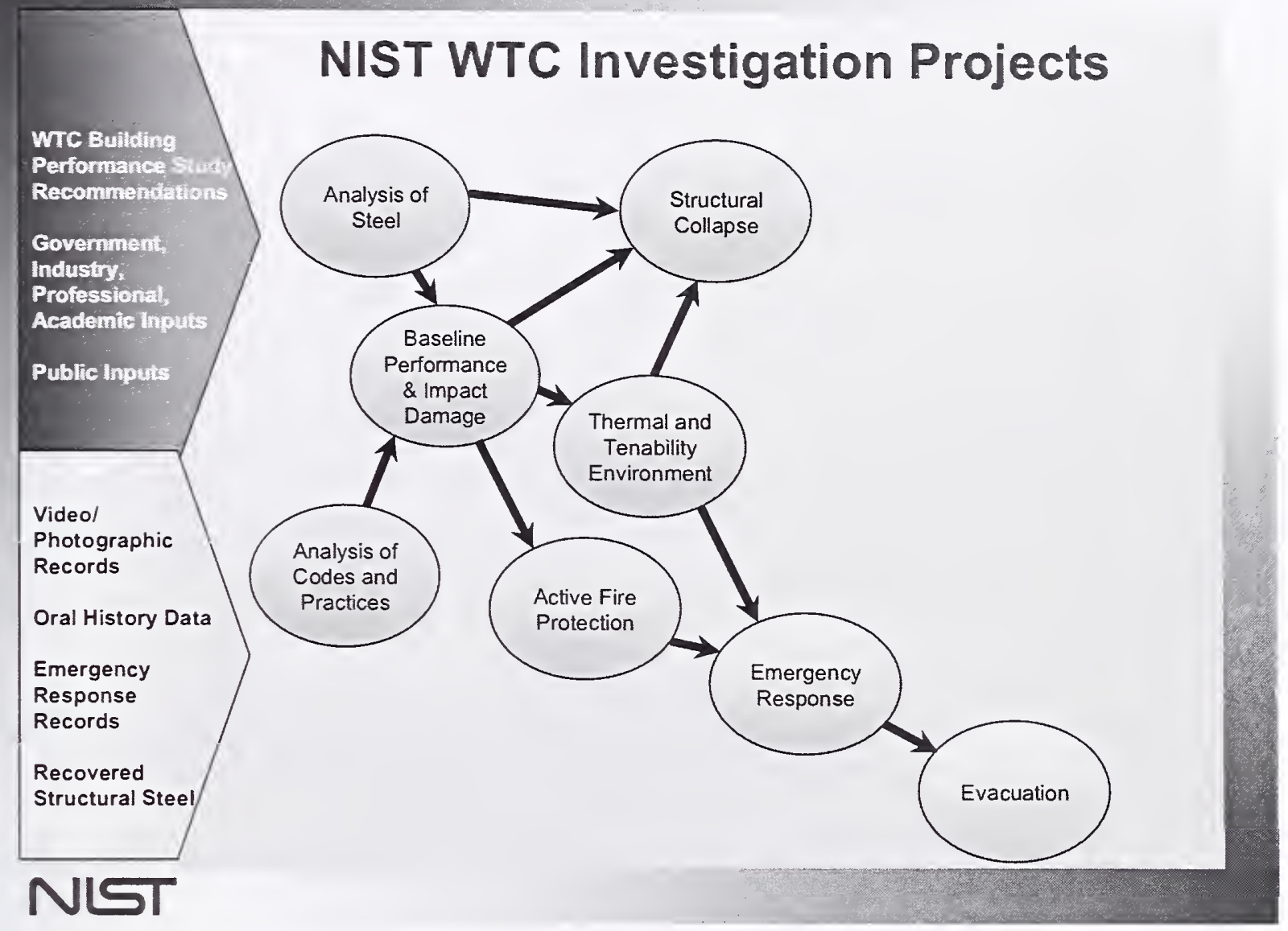

Figure P-1. The eight projects in the federal building and fire safety investigation of the WTC disaster.

\section{National Construction Safety Team Advisory Committee}

The NIST Director also established an advisory committee as mandated under the National Construction Safety Team Act. The initial members of the committee were appointed following a public solicitation. These were:

- Paul Fitzgerald, Executive Vice President (retired) FM Global, National Construction Safety Team Advisory Committee Chair

- John Barsom, President, Barsom Consulting, Ltd.

- John Bryan, Professor Emeritus, University of Maryland

- David Collins, President, The Preview Group, Inc.

- Glenn Corbett, Professor, John Jay College of Criminal Justice

- Philip DiNenno, President, Hughes Associates, Inc. 
- Robert Hanson, Professor Emeritus, University of Michigan

- Charles Thornton, Co-Chairman and Managing Principal, The Thornton-Tomasetti Group, Inc.

- Kathleen Tierney, Director, Natural Hazards Research and Applications Information Center, University of Colorado at Boulder

- Forman Williams, Director, Center for Energy Research, University of California at San Diego

This National Construction Safety Team Advisory Committee provided technical advice during the Investigation and commentary on drafts of the Investigation reports prior to their public release. NIST has benefited from the work of many people in the preparation of these reports, including the National Construction Safety Team Advisory Committee. The content of the reports and recommendations, however, are solely the responsibility of NIST.

\section{Public Outreach}

During the course of this Investigation, NIST held public briefings and meetings (listed in Table P-2) to solicit input from the public, present preliminary findings, and obtain comments on the direction and progress of the Investigation from the public and the Advisory Committee.

NIST maintained a publicly accessible Web site during this Investigation at http://wtc.nist.gov. The site contained extensive information on the background and progress of the Investigation.

\section{NIST's WTC Public-Private Response Plan}

The collapse of the WTC buildings has led to broad reexamination of how tall buildings are designed, constructed, maintained, and used, especially with regard to major events such as fires, natural disasters, and terrorist attacks. Reflecting the enhanced interest in effecting necessary change, NIST, with support from Congress and the Administration, has put in place a program, the goal of which is to develop and implement the standards, technology, and practices needed for cost-effective improvements to the safety and security of buildings and building occupants, including evacuation, emergency response procedures, and threat mitigation.

The strategy to meet this goal is a three-part NIST-led public-private response program that includes:

- A federal building and fire safety investigation to study the most probable factors that contributed to post-aircraft impact collapse of the WTC towers and the 47-story WTC 7 building, and the associated evacuation and emergency response experience.

- A research and development (R\&D) program to (a) facilitate the implementation of recommendations resulting from the WTC Investigation, and (b) provide the technical basis for cost-effective improvements to national building and fire codes, standards, and practices that enhance the safety of buildings, their occupants, and emergency responders. 


\section{Table P-2. Public meetings and briefings of the WTC Investigation.}

\begin{tabular}{|c|c|c|}
\hline Date & Location & Principal Agenda \\
\hline June 24,2002 & New York City, NY & $\begin{array}{l}\text { Public meeting: Public comments on the Draft Plan for the } \\
\text { pending WTC Investigation. }\end{array}$ \\
\hline August 21,2002 & Gaithersburg, MD & Media briefing announcing the formal start of the Investigation. \\
\hline December 9,2002 & Washington, DC & $\begin{array}{l}\text { Media briefing on release of the Public Update and NIST request } \\
\text { for photographs and videos. }\end{array}$ \\
\hline April 8, 2003 & New York City, NY & $\begin{array}{l}\text { Joint public forum with Columbia University on first-person } \\
\text { interviews. }\end{array}$ \\
\hline April 29-30, 2003 & Gaithersburg, MD & $\begin{array}{l}\text { NCST Advisory Committee meeting on plan for and progress on } \\
\text { WTC Investigation with a public comment session. }\end{array}$ \\
\hline May 7,2003 & New York City, NY & Media briefing on release of May 2003 Progress Report. \\
\hline August $26-27,2003$ & Gaithersburg, MD & $\begin{array}{l}\text { NCST Advisory Committee meeting on status of the WTC } \\
\text { investigation with a public comment session. }\end{array}$ \\
\hline September 17,2003 & New York City, NY & $\begin{array}{l}\text { Media and public briefing on initiation of first-person data } \\
\text { collection projects. }\end{array}$ \\
\hline December 2-3, 2003 & Gaithersburg, MD & $\begin{array}{l}\text { NCST Advisory Committee meeting on status and initial results } \\
\text { and release of the Public Update with a public comment session. }\end{array}$ \\
\hline February 12, 2004 & New York City, NY & $\begin{array}{l}\text { Public meeting on progress and preliminary findings with public } \\
\text { comments on issues to be considered in formulating final } \\
\text { recommendations. }\end{array}$ \\
\hline June 18, 2004 & New York City, NY & Media/public briefing on release of June 2004 Progress Report. \\
\hline June $22-23,2004$ & Gaithersburg, MD & $\begin{array}{l}\text { NCST Advisory Committee meeting on the status of and } \\
\text { preliminary findings from the WTC Investigation with a public } \\
\text { comment session. }\end{array}$ \\
\hline August 24, 2004 & Northbrook, IL & $\begin{array}{l}\text { Public viewing of standard fire resistance test of WTC floor } \\
\text { system at Underwriters Laboratories, Inc. }\end{array}$ \\
\hline October 19-20, 2004 & Gaithersburg, MD & $\begin{array}{l}\text { NCST Advisory Committee meeting on status and near complete } \\
\text { set of preliminary findings with a public comment session. }\end{array}$ \\
\hline November 22, 2004 & Gaithersburg, MD & $\begin{array}{l}\text { NCST Advisory Committee discussion on draft annual report to } \\
\text { Congress, a public comment session, and a closed session to } \\
\text { discuss pre-draft recommendations for WTC Investigation. }\end{array}$ \\
\hline April 5, 2005 & New York City, NY & $\begin{array}{l}\text { Media and public briefing on release of the probable collapse } \\
\text { sequence for the WTC towers and draft reports for the projects on } \\
\text { codes and practices, evacuation, and emergency response. }\end{array}$ \\
\hline June 23,2005 & New York City, NY & $\begin{array}{l}\text { Media and public briefing on release of all draft reports for the } \\
\text { WTC towers and draft recommendations for public comment. }\end{array}$ \\
\hline $\begin{array}{l}\text { September 12-13, } \\
2005\end{array}$ & Gaithersburg, MD & $\begin{array}{l}\text { NCST Advisory Committee meeting on disposition of public } \\
\text { comments and update to draft reports for the WTC towers. }\end{array}$ \\
\hline $\begin{array}{l}\text { September } 13-15 \text {, } \\
2005\end{array}$ & Gaithersburg, MD & $\begin{array}{l}\text { WTC Technical Conference for stakeholders and technical } \\
\text { community for dissemination of findings and recommendations } \\
\text { and opportunity for public to make technical comments. }\end{array}$ \\
\hline
\end{tabular}

- A dissemination and technical assistance program (DTAP) to (a) engage leaders of the construction and building community in ensuring timely adoption and widespread use of proposed changes to practices, standards, and codes resulting from the WTC Investigation and the R\&D program, and (b) provide practical guidance and tools to better prepare facility owners, contractors, architects, engineers, emergency responders, and regulatory authorities to respond to future disasters.

The desired outcomes are to make buildings, occupants, and first responders safer in future disaster events. 


\section{National Construction Safety Team Reports on the WTC Investigation}

A final report on the collapse of the WTC towers is being issued as NIST NCSTAR 1. A companion report on the collapse of WTC 7 is being issued as NIST NCSTAR 1A. The present report is one of a set that provides more detailed documentation of the Investigation findings and the means by which these technical results were achieved. As such, it is part of the archival record of this Investigation. The titles of the full set of Investigation publications are:

NIST (National Institute of Standards and Technology). 2005. Federal Building and Fire Safety Investigation of the World Trade Center Disaster: Final Report on the Collapse of the World Trade Center Towers. NIST NCSTAR 1. Gaithersburg, MD, September.

NIST (National Institute of Standards and Technology). 2006. Federal Building and Fire Safety Investigation of the World Trade Center Disaster: Final Report on the Collapse of World Trade Center 7. NIST NCSTAR 1A. Gaithersburg, MD.

Lew, H. S., R. W. Bukowski, and N. J. Carino. 2005. Federal Building and Fire Safety Investigation of the World Trade Center Disaster: Design, Construction, and Maintenance of Structural and Life Safety Systems. NIST NCSTAR 1-1. National Institute of Standards and Technology. Gaithersburg, MD, September.

Fanella, D. A., A. T. Derecho, and S. K. Ghosh. 2005. Federal Building and Fire Safety Investigation of the World Trade Center Disaster: Design and Construction of Structural Systems. NIST NCSTAR 1-1A. National Institute of Standards and Technology. Gaithersburg, MD, September.

Ghosh, S. K., and X. Liang. 2005. Federal Building and Fire Safety lwvestigation of the World Trade Center Disaster: Comparison of Building Code Structural Requirements. NIST

NCSTAR 1-1B. National Institute of Standards and Technology. Gaithersburg, MD, September.

Fanella, D. A., A. T. Derecho, and S. K. Ghosh. 2005. Federal Building and Fire Safety Investigation of the World Trade Center Disaster: Maintenance and Modifications to Structural Systems. NIST NCSTAR 1-1C. National Institute of Standards and Technology. Gaithersburg, MD, September.

Grill, R. A., and D. A. Johnson. 2005. Federal Building and Fire Safety Investigation of the World Trade Center Disaster: Fire Protection and Life Safety Provisions Applied to the Design and Construction of World Trade Center 1, 2, and 7 and Post-Construction Provisions Applied after Occupancy. NIST NCSTAR 1-1D. National Institute of Standards and Technology. Gaithersburg, MD, September.

Razza, J. C., and R. A. Grill. 2005. Federal Building and Fire Safety Investigation of the World Trade Center Disaster: Comparison of Codes, Standards, and Practices in Use at the Time of the Design and Construction of World Trade Center 1,2, and 7. NIST NCSTAR 1-1E. National Institute of Standards and Technology. Gaithersburg, MD, September.

Grill, R. A., D. A. Johnson, and D. A. Fanella. 2005. Federal Building and Fire Safety

Investigation of the World Trade Center Disaster: Comparison of the 1968 and Current (2003) New 
York City Building Code Provisions. NIST NCSTAR 1-1F. National Institute of Standards and Technology. Gaithersburg, MD, September.

Grill, R. A., and D. A. Johnson. 2005. Federal Building and Fire Safety Investigation of the World Trade Center Disaster: Anlendments to the Fire Protection and Life Safety Provisions of the New York City Building Code by Local Laws Adopted While World Trade Center 1, 2, and 7 Were in Use. NIST NCSTAR 1-1G. National Institute of Standards and Technology. Gaithersburg, MD, September.

Grill, R. A., and D. A. Johnson. 2005. Federal Building and Fire Safety Investigation of the World Trade Center Disaster: Post-Construction Modifications to Fire Protection and Life Safety Systents of World Trade Center 1 and 2. NIST NCSTAR 1-1H. National Institute of Standards and Technology. Gaithersburg, MD, September.

Grill, R. A., D. A. Johnson, and D. A. Fanella. 2005. Federal Building and Fire Safety Investigation of the World Trade Center Disaster: Post-Construction Modifications to Fire Protection, Life Safety, and Structural Systems of World Trade Center 7. NIST NCSTAR 1-1I. National Institute of Standards and Technology. Gaithersburg, MD, September.

Grill, R. A., and D. A. Johnson. 2005. Federal Building and Fire Safety Investigation of the World Trade Center Disaster: Design, Installation, and Operation of Fuel Systen for Energency Power in World Trade Center 7. NIST NCSTAR 1-1J. National Institute of Standards and Technology. Gaithersburg, MD, September.

Sadek, F. 2005. Federal Building and Fite Safety Investigation of the World Trade Center Disaster: Baseline Structural Performance and Aircraft Impact Damage Analysis of the World Trade Center Towers. NIST NCSTAR 1-2. National Institute of Standards and Technology. Gaithersburg, MD, September.

Faschan, W. J., and R. B. Garlock. 2005. Federal Building and Fire Safety Investigation of the World Trade Center Disaster: Reference Structural Models and Baseline Perfornance Analysis of the World Trade Center Towers. NIST NCSTAR 1-2A. National Institute of Standards and Technology. Gaithersburg, MD, September.

Kirkpatrick, S. W., R. T. Bocchieri, F. Sadek, R. A. MacNeill, S. Holmes, B. D. Peterson, R. W. Cilke, C. Navarro. 2005. Federal Building and Fire Safety Investigation of the World Trade Center Disaster: Analysis of Aircraft Impacts into the World Trade Center Towers, NIST

NCSTAR 1-2B. National Institute of Standards and Technology. Gaithersburg, MD, September.

Gayle, F. W., R. J. Fields, W. E. Luecke, S. W. Banovic, T. Foecke, C. N. McCowan, T. A. Siewert, and J. D. McColskey. 2005. Federal Building and Fire Safety Investigation of the World Trade Center Disaster: Mechanical and Metallurgical Analysis of Structural Steel. NIST NCSTAR 1-3. National Institute of Standards and Technology. Gaithersburg, MD, September.

Luecke, W. E., T. A. Siewert, and F. W. Gayle. 2005. Federal Building and Fire Safety Investigation of the World Trade Center Disaster: Contemporaneons Structural Steel Specifications. NIST Special Publication 1-3A. National Institute of Standards and Technology. Gaithersburg, MD, September. 
Banovic, S. W. 2005. Federal Building and Fire Safety Investigation of the World Trade Center Disaster: Steel Inventory and Identification. NIST NCSTAR 1-3B. National Institute of Standards and Technology. Gaithersburg, MD, September.

Banovic, S. W., and T. Foecke. 2005. Federal Building and Fire Safety Investigation of the World Trade Center Disaster: Damage and Failure Modes of Structural Steel Components. NIST NCSTAR 1-3C. National Institute of Standards and Technology. Gaithersburg, MD, September.

Luecke, W. E., J. D. McColskey, C. N. McCowan, S. W. Banovic, R. J. Fields, T. Foecke, T. A. Siewert, and F. W. Gayle. 2005. Federal Building and Fire Safety Investigation of the World Trade Center Disaster: Mechanical Properties of Structural Steels. NIST NCSTAR 1-3D. National Institute of Standards and Technology. Gaithersburg, MD, September.

Banovic, S. W., C. N. McCowan, and W. E. Luecke. 2005. Federal Building and Fire Safety Investigation of the World Trade Center Disaster: Physical Properties of Structural Steels. NIST NCSTAR 1-3E. National Institute of Standards and Technology. Gaithersburg, MD, September.

Evans, D. D., R. D. Peacock, E. D. Kuligowski, W. S. Dols, and W. L. Grosshandler. 2005. Federal Building and Fire Safety Investigation of the World Trade Center Disaster: Active Fire Protection Systems. NIST NCSTAR 1-4. National Institute of Standards and Technology. Gaithersburg, MD, September.

Kuligowski, E. D., D. D. Evans, and R. D. Peacock. 2005. Federal Building and Fire Safety Investigation of the World Trade Center Disaster: Post-Construction Fires Prior to Septenber 11, 2001. NIST NCSTAR 1-4A. National Institute of Standards and Technology. Gaithersburg, MD, September.

Hopkins, M., J. Schoenrock, and E. Budnick. 2005. Federal Building and Fire Safety Investigation of the World Trade Center Disaster: Fire Suppression Systems. NIST NCSTAR 1-4B. National Institute of Standards and Technology. Gaithersburg, MD, September.

Keough, R. J., and R. A. Grill. 2005. Federal Building and Fire Safety Investigation of the World Trade Center Disaster: Fire Alarm Systems. NIST NCSTAR 1-4C. National Institute of Standards and Technology. Gaithersburg, MD, September.

Ferreira, M. J., and S. M. Strege. 2005. Federal Building and Fire Safety Investigation of the World Trade Center Disaster: Smoke Management Systems. NIST NCSTAR 1-4D. National Institute of Standards and Technology. Gaithersburg, MD, September.

Gann, R. G., A. Hamins, K. B. McGrattan, G. W. Mulholland, H. E. Nelson, T. J. Ohlemiller, W. M. Pitts, and K. R. Prasad. 2005. Federal Building and Fire Safety Investigation of the World Trade Center Disaster: Reconstruction of the Fires in the World Trade Center Towers. NIST NCSTAR 1-5. National Institute of Standards and Technology. Gaithersburg, MD, September.

Pitts, W. M., K. M. Butler, and V. Junker. 2005. Federal Building and Fire Safety Investigation of the World Trade Center Disaster: Visual Evidence, Damage Estimates, and Timeline Analysis. NIST NCSTAR 1-5A. National Institute of Standards and Technology. Gaithersburg, MD, September. 
Hamins, A., A. Maranghides, K. B. McGrattan, E. Johnsson, T. J. Ohlemiller, M. Donnelly, J. Yang, G. Mulholland, K. R. Prasad, S. Kukuck, R. Anleitner and T. McAllister. 2005. Federal Building and Fire Safety Investigation of the World Trade Center Disaster: Experiments and Modeling of Structural Steel Elements Exposed to Fire. NIST NCSTAR 1-5B. National Institute of Standards and Technology. Gaithersburg, MD, September.

Ohlemiller, T. J., G. W. Mulholland, A. Maranghides, J. J. Filliben, and R. G. Gann. 2005. Federal Blilding and Fire Safety Investigation of the World Trade Center Disaster: Fire Tests of Single Office Workstations. NIST NCSTAR 1-5C. National Institute of Standards and Technology. Gaithersburg, MD, September.

Gann, R. G., M. A. Riley, J. M. Repp, A. S. Whittaker, A. M. Reinhorn, and P. A. Hough. 2005. Federal Building and Fire Safety Investigation of the World Trade Center Disaster: Reaction of Ceiling Tile Systems to Shocks. NIST NCSTAR 1-5D. National Institute of Standards and Technology. Gaithersburg, MD, September.

Hamins, A., A. Maranghides, K. B. McGrattan, T. J. Ohlemiller, and R. Anleitner. 2005. Federal Building and Fire Safety Investigation of the World Trade Center Disaster: Experiments and Modeling of Multiple Workstations Buming in a Compartment. NIST NCSTAR 1-5E. National Institute of Standards and Technology. Gaithersburg, MD, September.

McGrattan, K. B., C. Bouldin, and G. Forney. 2005. Federal Building and Fire Safety Investigation of the World Trade Center Disaster: Computer Simnlation of the Fires in the World Trade Center Towers. NIST NCSTAR 1-5F. National Institute of Standards and Technology. Gaithersburg, MD, September.

Prasad, K. R., and H. R. Baum. 2005. Federal Building and Fire Safety Investigation of the World Trade Center Disaster: Fire Structure Interface and Thermal Response of the World Trade Center Towers. NIST NCSTAR 1-5G. National Institute of Standards and Technology. Gaithersburg, MD, September.

Gross, J. L., and T. McAllister. 2005. Federal Building and Fire Safety Investigation of the World Trade Center Disaster: Structural Fire Response and Probable Collapse Seqnence of the World Trade Center Towers. NIST NCSTAR 1-6. National Institute of Standards and Technology. Gaithersburg, MD, September.

Carino, N. J., M. A. Starnes, J. L. Gross, J. C. Yang, S. Kukuck, K. R. Prasad, and R. W. Bukowski. 2005. Federal Building and Fire Safety Investigation of the World Trade Center Disaster: Passive Fire Protection. NIST NCSTAR 1-6A. National Institute of Standards and Technology. Gaithersburg, MD, September.

Gross, J., F. Hervey, M. Izydorek, J. Mammoser, and J. Treadway. 2005. Federal Building and Fire Safety Investigation of the World Trade Center Disaster: Fire Resistance Tests of Floor Truss Systems. NIST NCSTAR 1-6B. National Institute of Standards and Technology. Gaithersburg, MD, September.

Zarghamee, M. S., S. Bolourchi, D. W. Eggers, Ö. O. Erbay, F. W. Kan, Y. Kitane, A. A. Liepins, M. Mudlock, W. I. Naguib, R. P. Ojdrovic, A. T. Sarawit, P. R Barrett, J. L. Gross, and 
T. P. McAllister. 2005. Federal Building and Fire Safety Investigation of the World Trade Center Disaster: Contponent, Connection, and Subsystem Structural Analysis. NIST NCSTAR 1-6C. National Institute of Standards and Technology. Gaithersburg, MD, September.

Zarghamee, M. S., Y. Kitane, Ö. O. Erbay, T. P. McAllister, and J. L. Gross. 2005. Federal Building and Fire Safety Investigation of the World Trade Center Disaster: Global Strnctural Analysis of the Response of the World Trade Center Towers to Impact Damage and Fire. NIST NCSTAR 1-6D. National Institute of Standards and Technology. Gaithersburg, MD, September.

McAllister, T., R. W. Bukowski, R. G. Gann, J. L. Gross, K. B. McGrattan, H. E. Nelson, L. Phan, W. M. Pitts, K. R. Prasad, F. Sadek. 2006. Federal Building and Fire Safety Investigation of the World Trade Center Disaster: Structural Fire Response and Probable Collapse Sequence of World Trade Center 7. (Provisional). NIST NCSTAR 1-6E. National Institute of Standards and Technology. Gaithersburg, MD.

Gilsanz, R., V. Arbitrio, C. Anders, D. Chlebus, K. Ezzeldin, W. Guo, P. Moloney, A. Montalva, J. Oh, K. Rubenacker. 2006. Federal Building and Fire Safety Investigation of the World Trade Center Disaster: Structural Analysis of the Response of World Trade Center 7 to Debris Damage and Fire. (Provisional). NIST NCSTAR 1-6F. National Institute of Standards and Technology. Gaithersburg, MD.

Kim, W. 2006. Federal Building and Fire Safety Investigation of the World Trade Center Disaster: Analysis of September 11, 2001, Seisnrogram Data. (Provisional). NIST NCSTAR 1-6G. National Institute of Standards and Technology. Gaithersburg, MD.

Nelson, K. 2006. Federal Building and Fire Safety Investigation of the World Trade Center Disaster: The Con Ed Sibstation in World Trade Center 7. (Provisional). NIST NCSTAR 1-6H. National Institute of Standards and Technology. Gaithersburg, MD.

Averill, J. D., D. S. Mileti, R. D. Peacock, E. D. Kuligowski, N. Groner, G. Proulx, P. A. Reneke, and H. E. Nelson. 2005. Federal Building and Fire Safety Investigation of the World Trade Center Disaster: Occupant Behavior, Egress, and Emergency Communication. NIST NCSTAR 1-7. National Institute of Standards and Technology. Gaithersburg, MD, September.

Fahy, R., and G. Proulx. 2005. Federal Building and Fire Safety Investigation of the World Trade Center Disaster: Analysis of Published Accounts of the World Trade Center Evacuation. NIST NCSTAR 1-7A. National Institute of Standards and Technology. Gaithersburg, MD, September.

Zmud, J. 2005. Federal Building and Fire Safety Investigation of the World Trade Center Disaster: Technical Documentation for Survey Administration. NIST NCSTAR 1-7B. National Institute of Standards and Technology. Gaithersburg, MD, September.

Lawson, J. R., and R. L. Vettori. 2005. Federal Building and Fire Safety Investigation of the World Trade Center Disaster: The Emergency Response Operations. NIST NCSTAR 1-8. National Institute of Standards and Technology. Gaithersburg, MD, September. 


\section{ACKNOWLEDGMENTS}

The Authors would like to thank Glenn R. Bell and Ronald O. Hamburger of Simpson Gumpertz \& Heger Inc. (SGH) for reviewing the report and assisting in its revision. The assistance of the SGH internal Structural Performance Review Committee (Glenn R. Bell, Ronal O. Hamburger, and Pedro J. Sifre) and the Computation/Modeling Review Committee (Said Bolourchi, Atis A. Liepins, and Peter R. Barrett of Computer Aided Engineering Associates, Inc., an SGH subconsultant in this project) is acknowledged. The authors would also like to thank the technical staff of Computer Aided Engineering Associates, Inc., for their effort at converting SAP2000 finite element models to ANSYS and for their assistance in finite element modeling in ANSYS. 
This page intentionally left blank. 


\section{EXECUTIVE SUMMARY}

\section{E.1 INTRODUCTION}

Simpson Gumpertz \& Heger Inc. (SGH) developed global models of the World Trade Center (WTC) towers using finite elements and performed analyses of the global models to gain an understanding of the roles of the aircraft impact damage and the subsequent fires in the WTC towers in the structural stability and sequential failures of components and subsystems and to determine the probable sequence of structural responses that let to the global collapse initiation. The study was conducted as part of the investigation of the WTC disaster by the National Institute of Standards and Technology (NIST).

The work presented in this report was performed as a part of Project 6 of the NIST WTC investigation. This report complements the work performed by SGH on the structural response to the fire environment of connections such as truss seats and knuckles, components such as trusses and columns, and subsystems including full floors and exterior walls of the WTC towers.

Global analyses of the WTC towers were also guided by observations. NIST examined photos and videos for visual evidence, damage estimates, and timeline of the collapse process in NIST NCSTAR 1-5A. A trial and error procedure was used in this study, which was (1) to identify the major observations at different times during the collapse process, (2) to determine the deviation between the observations and calculations, and to identify the likely assumptions that led to such deviations, and (3) to use the observations to correct the state of the structure at that time and continue the calculation to collapse initiation point. Actual observations based on NIST's examination of photos and videos are summarized in Tables E-1 and E-2 for WTC 1 and WTC 2, respectively. Columns that are referenced by column numbers can be located in Fig. E-1. 
Table E-1. Observations on WTC 1 provided by NIST.

\begin{tabular}{|c|c|c|}
\hline Time & $\begin{array}{l}\text { Time } \\
\text { from } \\
\text { Impact } \\
(\text { min) }\end{array}$ & Observation \\
\hline $8: 46: 26$ & 0 & $\begin{array}{l}\text { Aircraft impact on the north wall of WTC I between Floor } 93 \text { and Floor } 99 \text { and Columns } 112 \\
\text { and } 151 \text {. }\end{array}$ \\
\hline $9: 25: 28$ & 39 & Fire on west side of south wall. \\
\hline $9: 40$ & 54 & $\begin{array}{l}\text { No bowing of columns was observed between Columns } 301 \text { and } 323 \text { on the east side of south } \\
\text { wall. }\end{array}$ \\
\hline $10: 18: 43$ & 92 & $\begin{array}{l}\text { Smoke suddenly expelled on Floor } 92 \text { north wall; Floor } 94 \text { east side of north wall; Floor } 95 \\
\text { to Floor } 98 \text { on west side of north wall; Floor } 95 \text { and Floor } 98 \text { on north side of west wall; } \\
\text { lower floor on south side. }\end{array}$ \\
\hline $10: 22: 59$ & 97 & $\begin{array}{l}\text { Inward bowing from Floor } 95 \text { to about Floor } 99 \text { between Columns } 308 \text { and } 326 \text { (maybe to } \\
340 \text { ) on the south wall, maximum amplitude approximately } 55 \text { in. at Floor } 97 \text {. }\end{array}$ \\
\hline $10: 28: 18$ & 102 & $\begin{array}{l}\text { Smoke puff out of north edge and center of west wall; smoke and debris clouds out of the } \\
\text { north, east, and west walls on Floor } 98 \text {. Fire out of windows on the north, east, west, and } \\
\text { south walls between Floor } 92 \text { and Floor } 98 \text {, and on Floor } 104 \text {. }\end{array}$ \\
\hline $10: 28: 20$ & 102 & $\begin{array}{l}\text { WTC } 1 \text { begant to collapse. First exterior sign of collapse was at Floor } 98 \text {. Rotation of at least } \\
8 \text { degrees to the south occurred before the building section began to fall vertically under } \\
\text { gravity. }\end{array}$ \\
\hline
\end{tabular}

Table E-2. Observations on WTC 2 provided by NIST.

\begin{tabular}{|c|c|c|}
\hline Time & $\begin{array}{c}\text { Time } \\
\text { from } \\
\text { Impact } \\
\text { (min) }\end{array}$ & Observation \\
\hline 9:03 & 0 & Aircraft impact on the south wall of WTC 2 between Floors 77 and 85, Columns 404 to 443 . \\
\hline $9: 21$ & 18 & $\begin{array}{l}\text { Columns of the east wall bowed inward over the entire width of Floors } 78 \text { to } 83 \text {; maximum of } \\
7-9 \text { in. at Floor } 80 .\end{array}$ \\
\hline $9: 38$ & 35 & Floor 83 disconnections on the east wall appeared to extend. \\
\hline $9: 54$ & 51 & $\begin{array}{l}\text { Columns of the east wall bowed inward between Floor } 78 \text { and Floor } 84,12-20 \text { in. at Floor } 80 . \\
\text { East side of Floor } 83 \text { draped between Columns } 310 \text { to } 342 .\end{array}$ \\
\hline $9: 59$ & 56 & $\begin{array}{l}\text { WTC } 2 \text { began to collapse. } \\
\text { Column splices failed at every third panel and columns sprung back from inward bowing as } \\
\text { collapse initiated on the east wall near the northeast corner } \\
\text { Smoke and debris clouds were expelled from Floor } 81 \text { on the east, north, and west walls of the } \\
\text { building. } \\
\text { WTC } 2 \text { appeared to tilt around the base of Floor } 82 \text { and initial downward motion was visible at } \\
\text { the same location. } \\
\text { Tilt of approximately } 3 \text { to } 4 \text { degrees to the south and } 7 \text { to } 8 \text { degrees to the east occurred before } \\
\text { building section fell. } \\
\text { Kink (change in slope) on the southeast corner near Floor } 94 \text { (halfway along building section } \\
\text { above failure). } \\
\text { Kink (change in slope) and offset about at the Floor } 106 \text {. }\end{array}$ \\
\hline
\end{tabular}




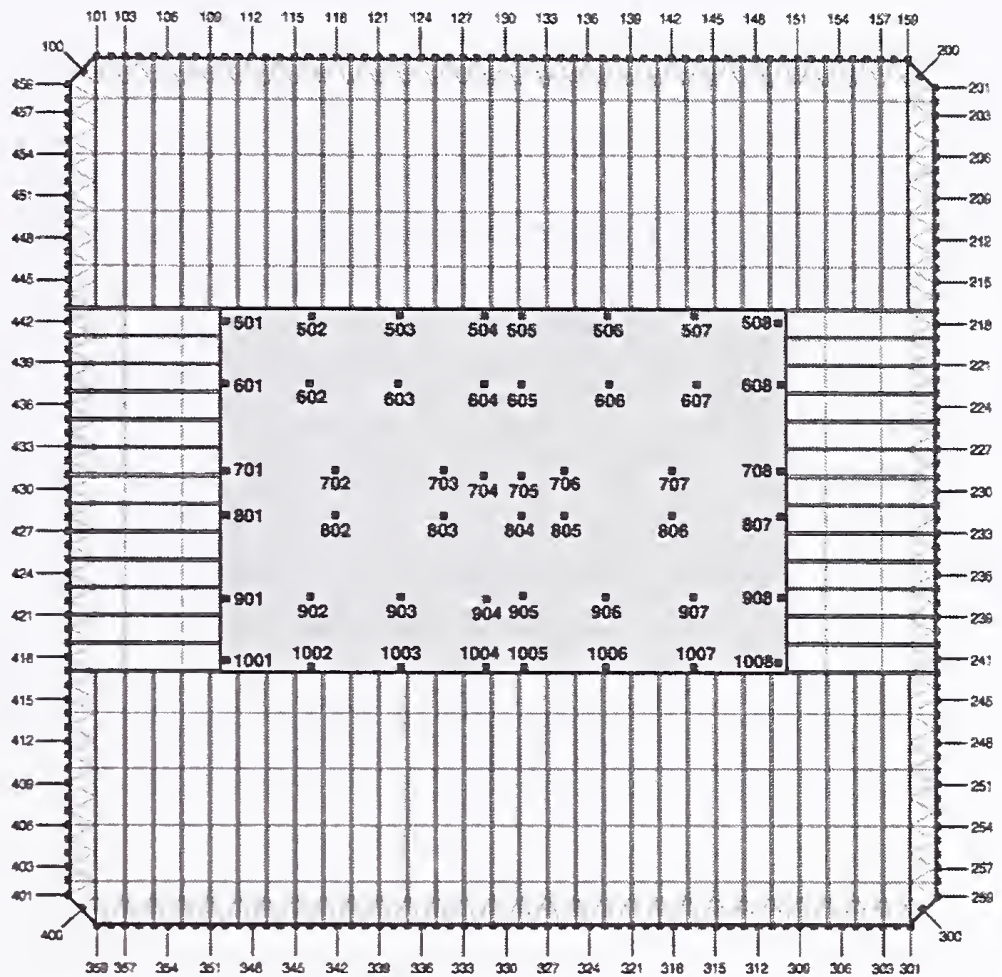

(a) WTC 1

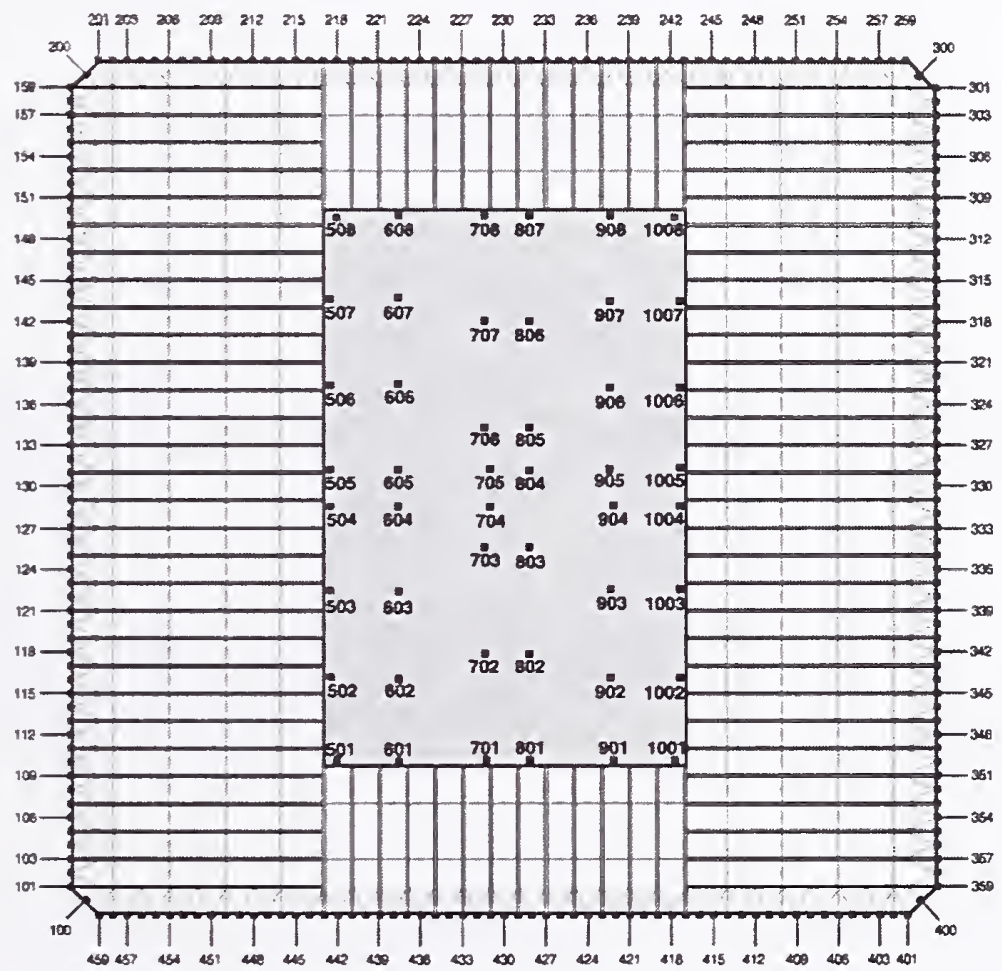

(b) WTC 2

Figure E-1. Column designations. 


\section{E.2 GLOBAL MODEL ANALYSIS}

\section{E.2.1 Global Models}

SGH developed global finite-element structural models of WTC towers in ANSYS to perform collapse analysis of WTC 1 and WTC 2 subjected to the combined effects of gravity and thermal loads. The geometry, the connectivity, and the member shapes of the global models for WTC 1 and WTC 2 were obtained from an ANSYS model converted from the reference SAP2000 model developed by NIST (NIST NCSTAR 1-2) and the study conducted by SGH on components and subsystems of the WTC towers. The global models were then modified by truncating the models below the aircraft impact zone and including changes to the modeling of columns, trusses, and slabs to capture the failure modes calculated in the structural analysis of components, connections, and subsystems of the WTC towers. Material properties of steel were modified to include: temperature-dependent material properties, such as thermal expansion, elastic properties, isotropic hardening plasticity, and creep. In addition, global models allowed geometrically nonlinear analysis and large deflection effects needed for elastic and inelastic structural instability at high temperatures.

\section{E.2.2 Impact Damage}

Aircraft impact damage to the structural members and the fireproofing of steel members of the WTC towers were determined in NIST NCSTAR 1-2 and NIST NCSTAR 1-6. In the global analysis the severed exterior wall columns, spandrels, core columns, core beams, and parts of the floors were removed at the appropriate stage of analysis.

The NIST investigation identified four aircraft impact damage sets (two damage sets for each tower) consisting of an impact damage condition and a fireproofing damage condition. These damage sets were named Case A and Case B for WTC 1 and Case C and Case D for WTC 2. Case B and Case D damage sets were used in the final global analyses. Case B and Case D impact damage sets for columns are shown in Figs. E-2 to E-5, where severed columns are shown as missing vertical lines. For comparison, core columns and beams before aircraft impact are shown in Figs. E-6 and E-7 for WTC 1 and WTC 2, respectively. (Note that the global models included only core beams that had moment connections; hence, Figs E-3 and E-5 do not show all the core beams that existed in the WTC towers.)

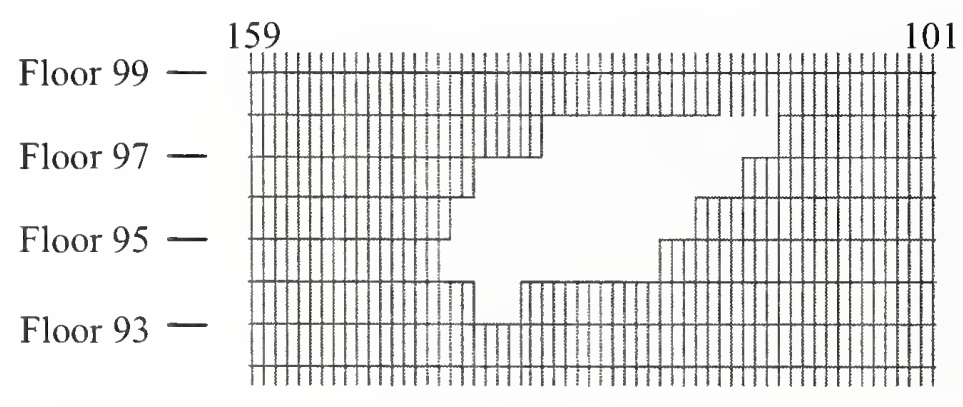

(a) North face
101359

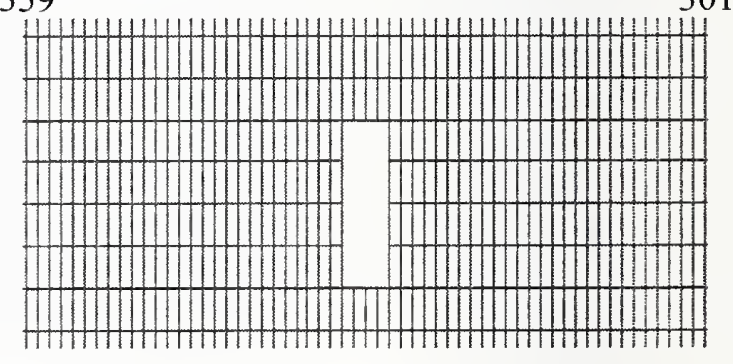

(b) South face

\section{Figure E-2. Structural damage condition on the exterior walls of WTC 1 for all cases of impact damage.}




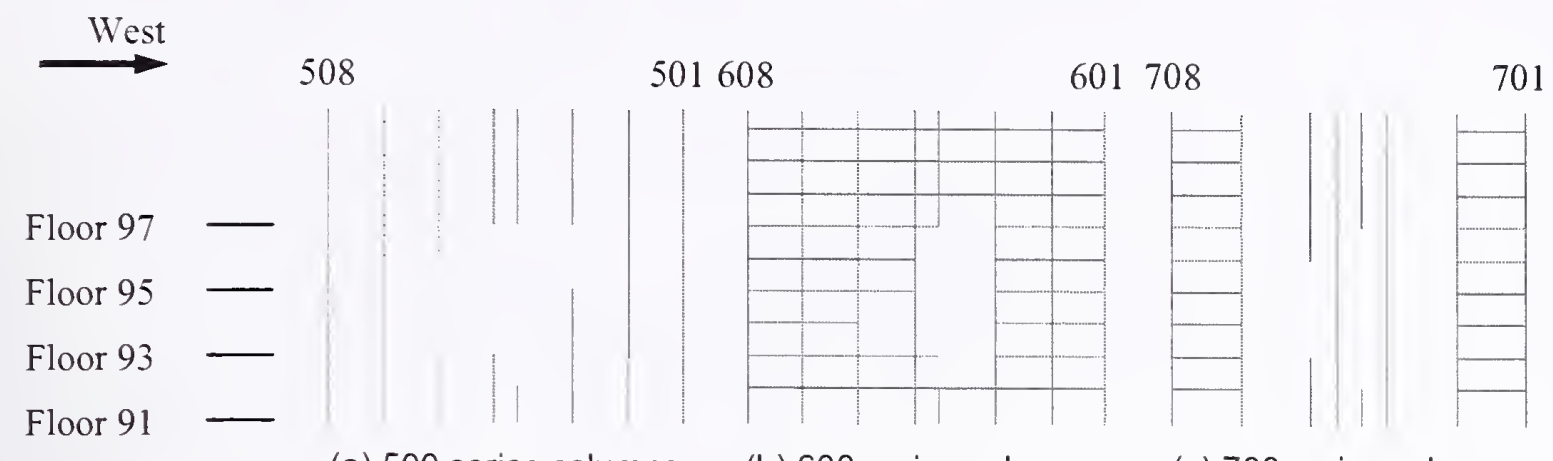

(a) 500 series columns

(b) 600 series columns

(c) 700 series columns

807

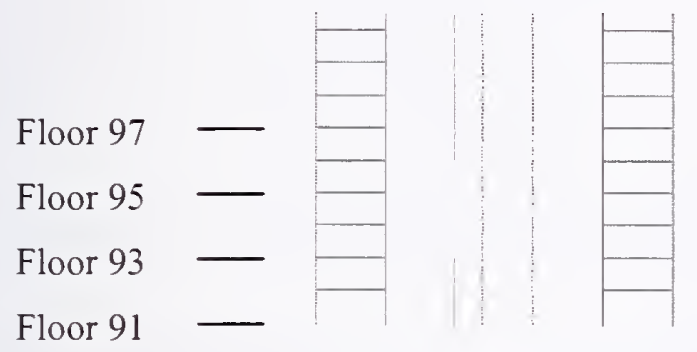

(a) 800 series columns
801908

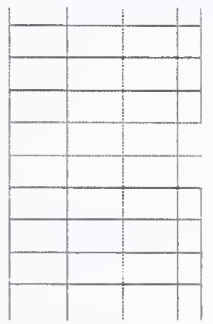

(b) 900 series columns

901

Figure E-3. Case B structural damage condition on the core columns of WTC 1 (including heavily damaged columns).

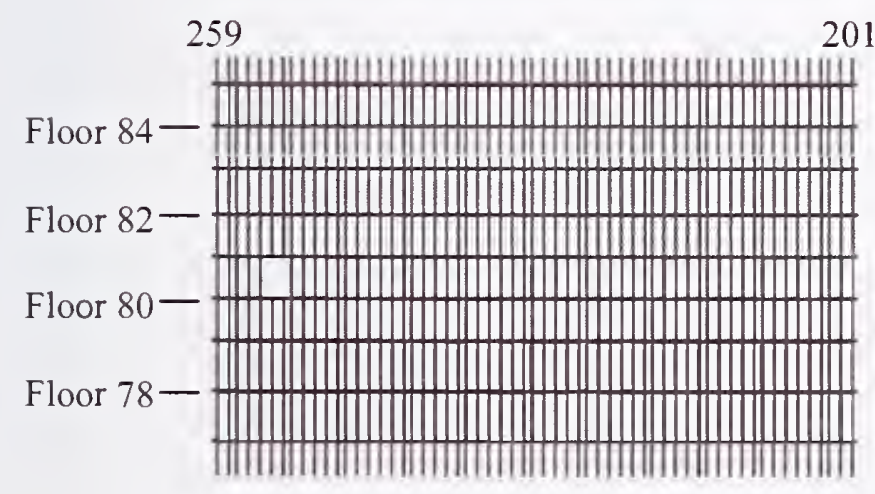

(a) North Face

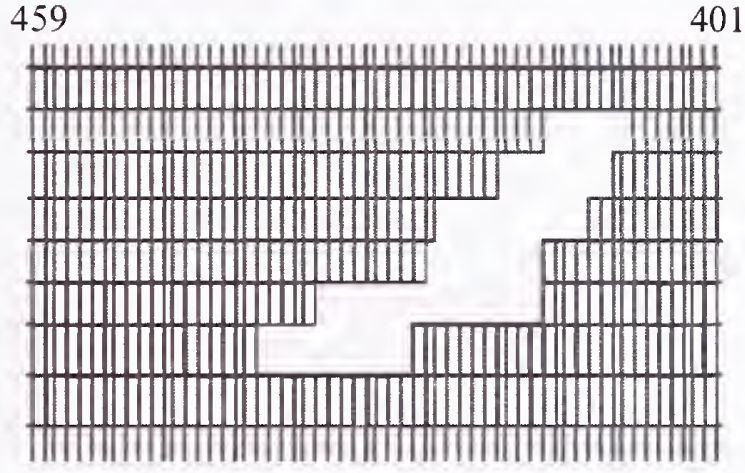

(b) South Face

Figure E-4. Structural damage condition on the exterior walls of WTC 2 for all cases of impact damage. 


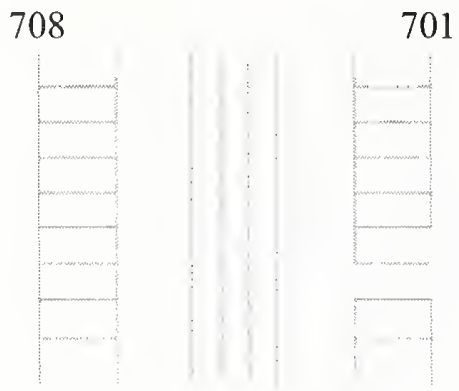

(a) 700 series columns
$701 \quad 807$

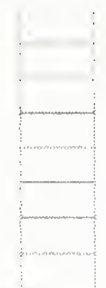

801

— Floor 81

— Floor 79

- Floor 77

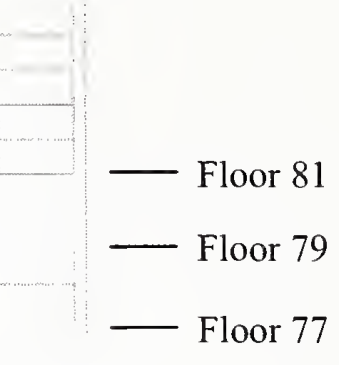

(b) 800 series columns

908

$901 \quad 1008$

1001

North

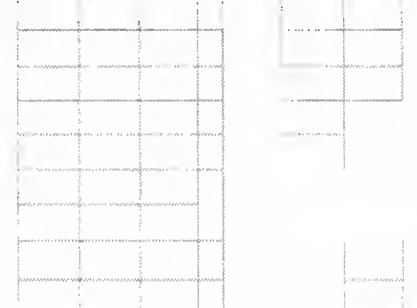

(c) 900 series columns

(d) 1000 series columns

Figure E-5. Case D structural damage condition on the core columns of WTC 2 (including heavily damaged columns).

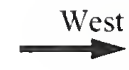

508

$\begin{array}{ll}\text { Floor } 99 & - \\ \text { Floor } 97 & - \\ \text { Floor 95 } & - \\ \text { Floor 93 } & - \\ \text { Floor 91 } & -\end{array}$

(a) 500 series columns

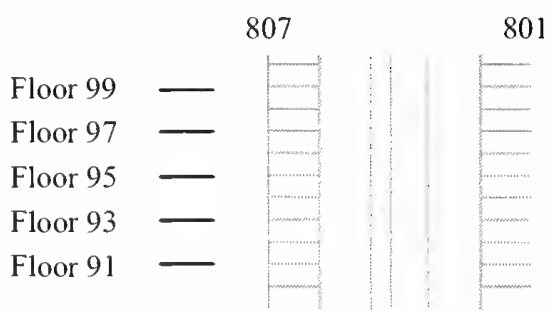

(d) 800 series columns
501

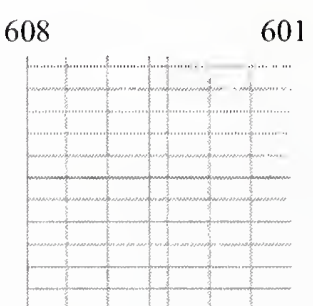

(b) 600 series columns

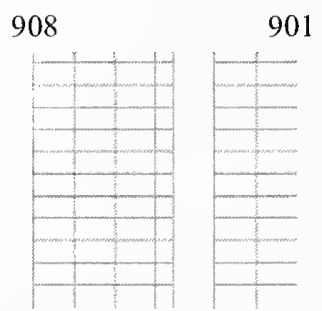

(e) 900 series columns

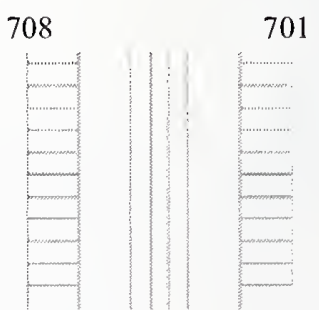

(c) 700 series columns

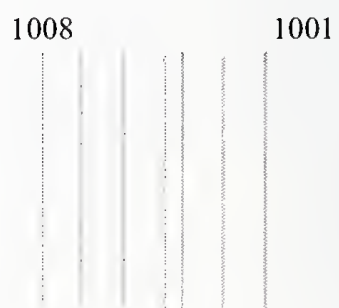

(f) 1000 series columns

Figure E-6. Core columns and core beams in the WTC 1 global model without aircraft impact damage. 


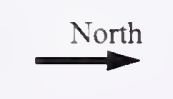

508

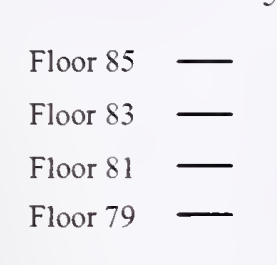

(a) 500 series columns
$807 \quad 801$

$\begin{array}{ll}\text { Floor } 85 & - \\ \text { Floor } 83 & - \\ \text { Floor } 81 & - \\ \text { Floor } 79 & -\end{array}$

(d) 800 series columns

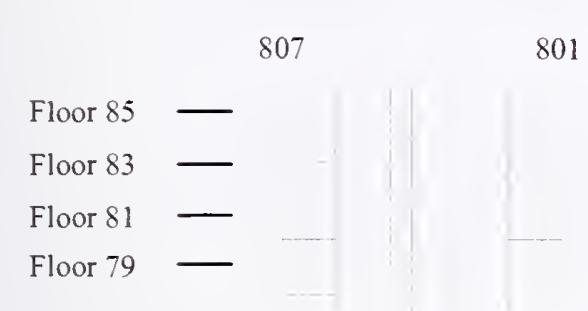

608

601

708

701

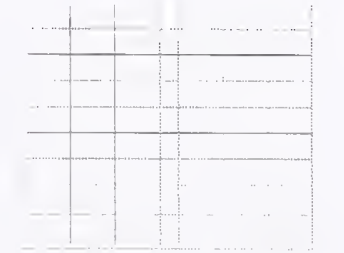

(b) 600 series columns

908

901

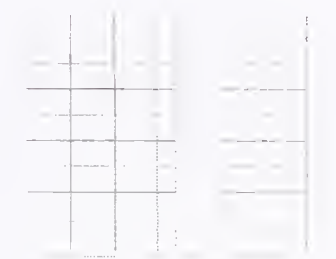

(e) 900 series columns

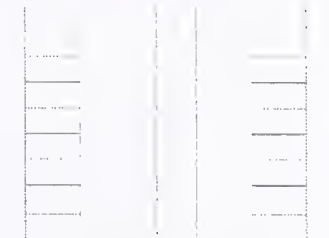

(c) 700 series columns

1008

1001

\section{Figure E-7. Core columns and core beams in the WTC 2 global model without aircraft impact damage.}

\section{E.2.4 Loads and Boundary Conditions in the Global Models}

The global models were fully restrained at the base of the vertica! springs. The loads on the structure consisted of gravity loads and temperature loads. The gravity loads included dead load and live load (equal to 25 percent of the design live load). Temperature loads consisted of temperature time histories provided by NIST based on their fire dynamics and heat transfer analyses performed for different conditions of structural and fireproofing damage. Temperature data were provided for every structural node at 10 min intervals. Temperatures between the 10 min intervals were determined by linear interpolation.

\section{E.2.5 Fire-Induced Damage}

It was not practical to develop global models that could capture all the failure modes found in the study of components, connections, and subsystems, and to perform global analyses within a reasonable time period. Since detailed modeling of the floors was not included in the global models, important floor behavioral modes could not be captured directly from the global analyses. Key floor behavioral modes include sagging that imposed pull-in forces on the exterior wall and failure of support of the trusses at the exterior wall resulting in local disconnection of the floor from the exterior wall. Moreover, the sagging and the resulting bowing of the exterior walls calculated from the full floor model did not match the observed inward bowing. To account for these effects, the pull-in forces on the exterior wall and floor/wall disconnections were input into the global models as fire-induced damage at certain points in time, as illustrated in Figure E-8. Fire-induced damage calculated by the full floor models were then calibrated to the damage observed by NIST through their examination of photographs and videos during the heating period up to the final collapse. In addition, the magnitudes of pull-in forces were determined 
by trial and error to match the observed inward bowing of exterior walls using the isolated exterior wall models from the global models.

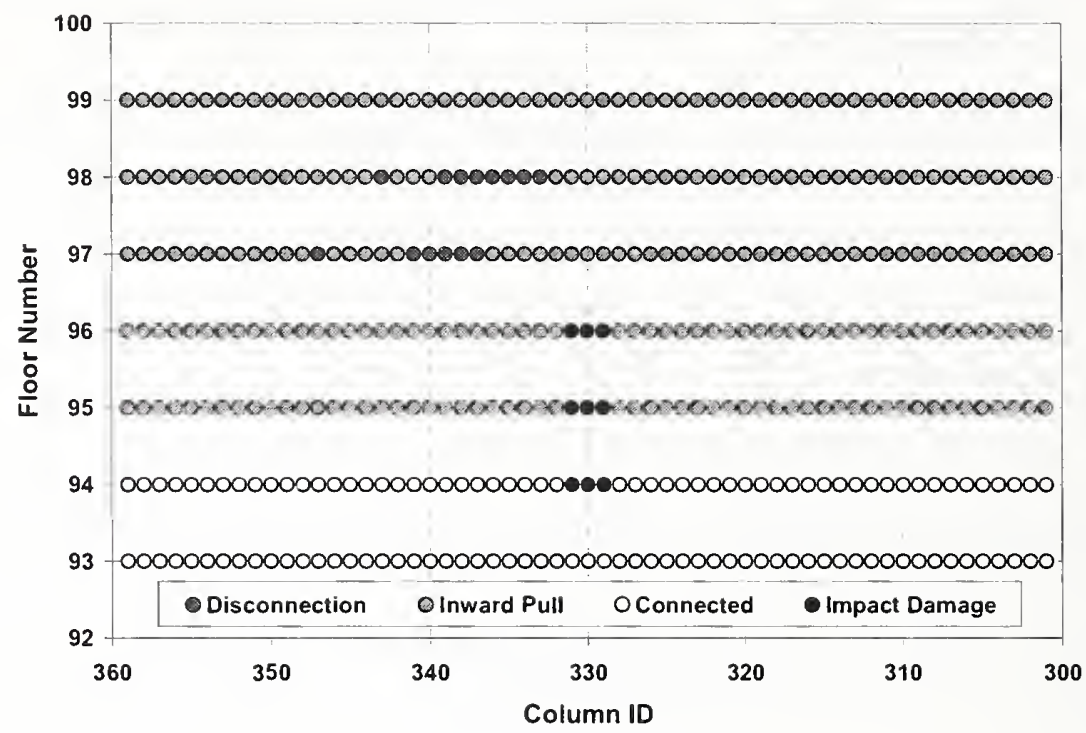

(a) South wall of WTC 1 between $80 \mathrm{~min}$ and $90 \mathrm{~min}$

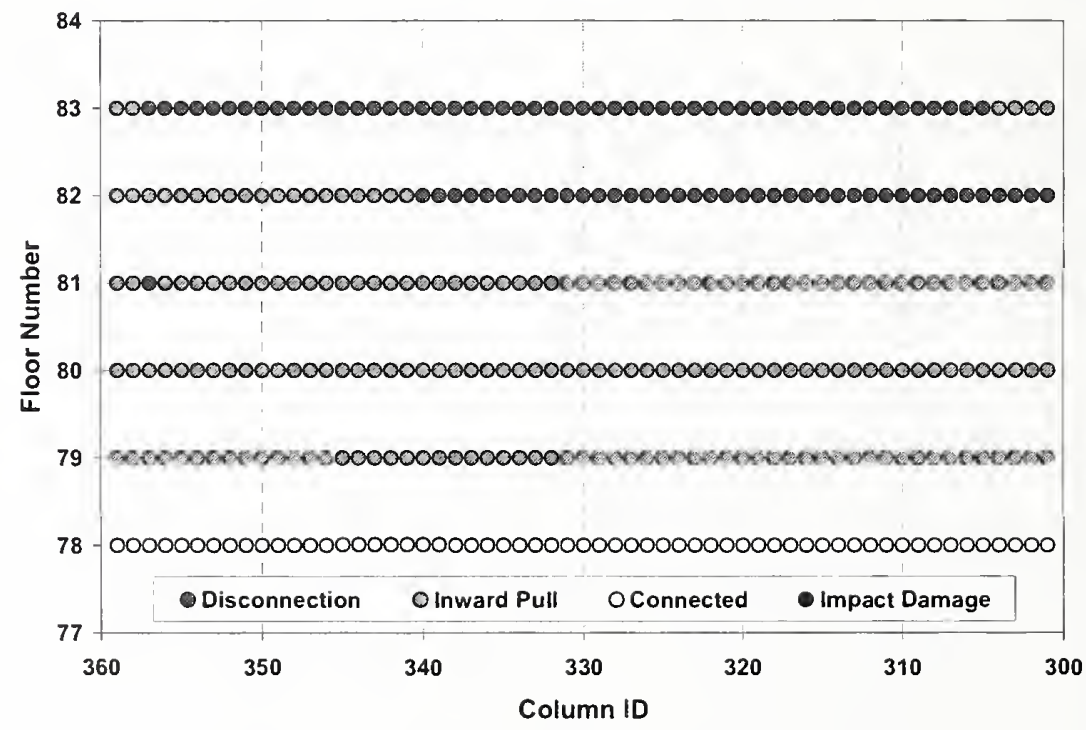

(b) East wall of WTC 2 between $40 \mathrm{~min}$ and $50 \mathrm{~min}$

Figure E-8. Examples of locations of floor/wall disconnections and pull-in forces used in the collapse analyses of the global model with creep. 


\section{E.3 COLLAPSE SEQUENCE}

The final global models were developed based on the following assumptions:

- Floor subsystem was modeled by plate elements with elastic properties without ability to simulate sagging and its effect on the development of pull-in forces and floor/wall disconnections. Pull-in forces resulting from floor sagging and floor/wall disconnections were determined based on the results of full floor models and isolated wall models and modified by visual observations. They were input in the global model analyses at different times as fireinduced damage.

- Spandrels were modeled by beam elements. Axial degree of freedom of the beam elements representing spandrels was released to enhance numerical efficiency and avoid thermallyinduced buckling. The exterior wall subsystem analysis showed that large deformations and buckling of spandrels would not affect the stability of exterior columns significantly.

- Columns were modeled to capture inelastic buckling, but not the kink-type buckling initiated by the local buckling of plates and resulting in significant distortion of the cross section. The analysis of columns showed that when buckling occurs on a column that spans several floors and is at high temperatures, inelastic buckling, rather than kink-type buckling, governs its load deformation characteristic.

- The sections below the impact zones were removed, and the vertical stiffness of the removed sections was replaced with equivalent vertical springs. Preliminary analyses of the global models showed that sections below the impact zone did not contribute much to the overall behavior of the towers.

- Construction sequence was not considered to enhance computational efficiency. A comparative study showed that the total column load on each face of the exterior wall increased by 7 to 15 percent, and the total column load on the core decreased by about 10 percent, by neglecting the construction sequence.

- Structural members that were severed or heavily damaged by aircraft impact were removed from the final global models before gravity loads were applied to enhance computational efficiency.

- Break elements were not used in the final global models to represent component failures such as failure of column splices. However, the results of the global model analyses were examined to determine whether any component failure occurred and to what extent its failure impacted the collapse sequence.

The key structural events common to both towers are discussed below.

- Sagging of floors caused by the elevated steel temperatures resulting from loss of fireproofing. Elevated temperature caused buckling of the truss web diagonals, with the floor deforming into a catenary. The catenary action in this study refers to the combined action that results when the bending capacity of the truss is exceeded and additional load is carried 
by the floor system acting as a tensile structure. Sagging of the floor resulted in pull-in forces at floor/exterior wall connections, and led to inward bowing of the exterior wall

- Bowing and buckling of the entire exterior wall of a tower under the combined effects of temperature, the redistributed gravity load, pull-in force from sagging floors, and loss of lateral support due to sagging or floor/wall disconnections. Floors deformed into catenaries did not restrain the exterior wall columns from buckling.

- Downward displacement of the core due to severed core columns from the aircraft impact and redistributed column loads to non-severed core columns, and shortening of the core columns caused by buckling, plasticity, and creep of core columns at elevated temperatures.

- Redistribution of gravity loads among exterior and interior columns resulting from damage due to aircraft impact, restrained thermal expansion, shortening of core columns, tilting of the tower above the impact region, and bowing and buckling of exterior walls. Redistribution of the loads from aircraft impact or fire-induced damaged columns, both in the core and exterior walls, was primarily to the neighboring columns. Redistribution of gravity loads from the core to the exterior walls and from the exterior walls to the core was primarily through the hat truss. Redistribution between adjacent exterior walls was primarily through the spandrels, and to a lesser extent through the hat truss. Major load redistribution mechanisms were as follows:

- Aircraft impact reduced the load on the impacted wall and on the opposite wall through the pivoting action of the hat truss, and increased the load on side walls.

- Thermal expansion caused increased loads in thermally restrained members.

- Shortening of core columns caused a redistribution of the load from the core to the exterior walls.

- Tilting of the tower redistributed the load among the exterior walls, resulting in increased load on the compressed part of the exterior walls.

- Buckling of the exterior wall caused rapid unloading of the buckled wall and of the opposite wall through the pivoting action of the stiff hat truss and increased the load on the other two exterior walls.

The collapse sequences of the two towers are discussed separately below.

\section{E.3.1 WTC 1 Collapse Sequence}

The aircraft impacted the north wall of WTC 1 at 8:46 a.m. The aircraft severed exterior columns and floors on the north side of the tower and core columns and floor members between Floor 93 and Floor 98. The subsequent fires weakened structural subsystems, including the core columns, floors, and exterior walls. The core displaced downward, the floors sagged, and the south exterior wall bowed inward. At 10:28 a.m., about $102 \mathrm{~min}$ after the aircraft impact, WTC 1 began to collapse. The collapse sequence of WTC 1 consists of five main structural events: 1) aircraft impact, 2) unloading of core, 3) sagging of floors and floor/wall disconnections, 4) inward bowing of south wall, and 5) buckling of south wall and collapse initiation. 
Aircraft Impact. The aircraft impacted WTC 1 at the north wall. The aireraft severed or heavily damaged Columns 112 to 151 between Floors 94 and 98 on the north wall. After breaching the building's perimeter, the aircraft continued to penetrate into the building. The north office area floor system sustained severe structural damage between Columns 112 and 145 at Floors 94 to 98 . Core Columns 503, $504,505,506,604,704,706,805$, and 904 were severed or heavily damaged between Floor 92 and Floor 97. The aircraft also severed a single exterior panel at the center of the south wall from Columns 329 to 331 between Floor 93 and Floor 96. In summary, 38 of 59 columns of the north wall, three of 59 columns of the south wall, and nine of 47 core columns were severed or heavily damaged. In addition, thermal insulation on floor framings and columns were damaged from the impact area to the south perimeter wall, primarily through the center of WTC 1 and over one-third to one-half of the core width.

Gravity loads in the columns that were severed were redistributed mostly to the neighboring columns. Due to the severe impact damage to the north wall, the wall section above the impact zone moved downward. The hat truss resisted the downward movement of the north wall and rotated about its eastwest axis, which reduced the load on the south wall. As a result, the north and south walls each carried about 7 percent less gravity loads at Floor 98 after impact, the east and west walls each carried about 7 percent more loads, and the core carried about 1 percent more gravity loads at Floor 98 after impact. Column 705 buckled, and Columns 605 and 804 showed minor buckling.

Unloading of Core. Temperatures in the core area rose quickly, and thermal expansion of the core was greater than the thermal expansion of the exterior walls in early stages of the fire. This increased the gravity loads in the core columns until $10 \mathrm{~min}$ after impact. The additional gravity loads from adjacent severed columns and high temperatures caused high plastic and creep strains to develop in the core columns in the early stages of the fire. More columns buckled inelastically due to high temperatures. Creep strain continued to increase to the point of collapse. By $30 \mathrm{~min}$, the plastic-plus-creep strains exceeded thermal expansion strains. Due to high plastic and creep strains and inelastic buckling of core columns, the core columns shortened, and the core displaced downward. At $100 \mathrm{~min}$, the downward displacement of the core at Floor 99 became 2.0 in. on the average.

The shortening of core columns was resisted by the hat truss, which unloaded the core with time and redistributed the gravity loads from the core to the exterior walls. As a result, the north, east, south, and west walls at Floor 98 carried about 12 percent, 27 percent, 10 percent, and 22 percent more gravity loads, respectively, at 80 min than the state immediately after the impact, and the core carried about 20 percent less loads. The net increase in the total column load on the south wall, where exterior wall failure initiated, was only about 10 percent due to core downward displacement. At $80 \mathrm{~min}$, the total core column loads reached their maximum. As the floor pulled in starting at $80 \mathrm{~min}$ on in the south side, the south exterior wall began to shed load to adjacent walls and the core.

Sagging of Floors and Floor/Wall Disconnections. The long-span trusses of Floor 95 through Floor 99 sagged due to high temperatures. While the fires were on the north side and the floors on the north side sagged first, the fires later reached the south side and the floors on the south side sagged. Full floor models underestimated the extent of sagging because cracking and spalling of concrete and creep in steel under high temperatures were not modeled, and because the extent of insulation damage was conservatively estimated. The sagging floors pulled in the south wall columns over Floors 95 to 99 . In addition, the exterior seats on the south wall in the hot zone of Floors 97 and 98 began to fail due to their reduced vertical shear capacity at around $80 \mathrm{~min}$, and by $100 \mathrm{~min}$ about 20 percent of the exterior seats on 
the south wall of Floors 97 and 98 failed. Partial collapse of floor may have occurred at Floors 97 and 98 , resulting from the exterior seat failures, as indicated by the observed smoke puff at $92 \mathrm{~min}$ (10:19 a.m.), but this phenomenon was not modeled.

Bowing of South Wall. The exterior columns on the south wall bowed inward as they were subjected to high temperatures, pull-in forces from the floors beginning at $80 \mathrm{~min}$, and additional gravity loads redistributed from the core. Figure E-9 shows the observed and the estimated inward bowing of the south wall at 97 min after impact (10:23 a.m.). Since no bowing was observed on the south wall at $69 \mathrm{~min}$ (9:55 a.m.), it is estimated that the south wall began to bow inward at around $80 \mathrm{~min}$ when the floors on the south side began to substantially sag. The inward bowing of the south wall increased with time due to continuing floor sagging and increased temperatures on the south wall (Fig. E-10). At 97 min (10:23 a.m.), the maximum bowing observed was about 55 in.

Buckling of South Wall and Collapse Initiation. With continuously increased bowing, as more columns buckled, the entire width of the south wall buckled inward. Instability started at the center of the south wall and rapidly progressed horizontally toward the sides. As a result of the buckling of the south wall, the south wall significantly unloaded, redistributing its load to the softened core through the hat-truss and to the south side of the east and west walls through the spandrels. At $100 \mathrm{~min}$, the north, east, and west walls at Floor 98 carried about 7 percent, 35 percent, and 30 percent more gravity loads than the state immediately after impact, and the south wall and the core carried about 7 percent and 20 percent less loads, respectively. The section of the building above the impact zone tilted to the south (observed at about $8^{\circ}$ ) as column instability progressed rapidly from the south wall along the adjacent east and west walls (see Fig. E-11), resulting in increased gravity load on the core columns. The release of potential energy due to downward movement of building mass above the buckled columns exceeded the strain energy that could be absorbed by the structure. Global collapse ensued. 


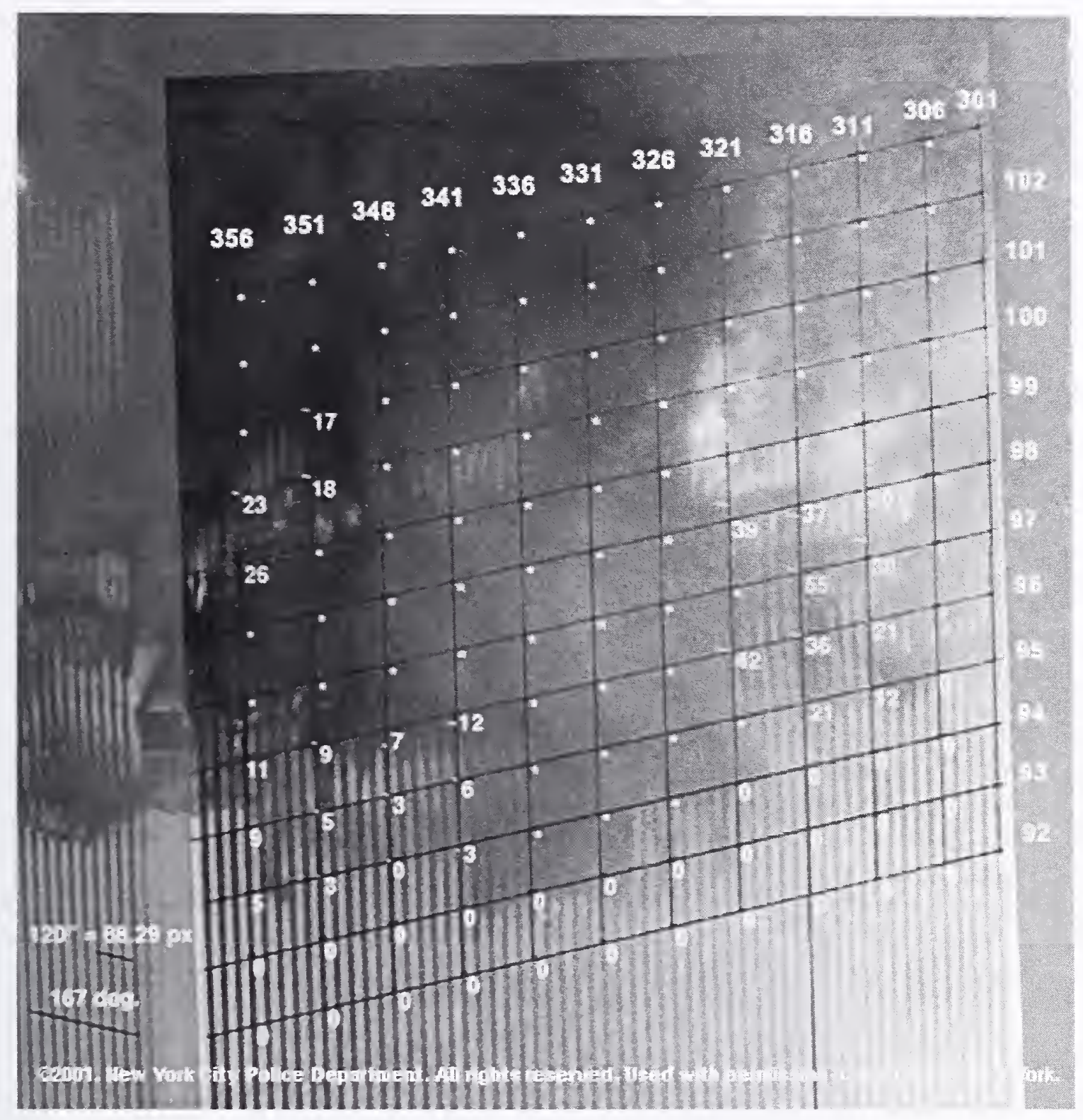

Figure E-9. Inward bowing of the south wall of WTC 1 at 10:23 a.m. Displacement estimated by NIST. 


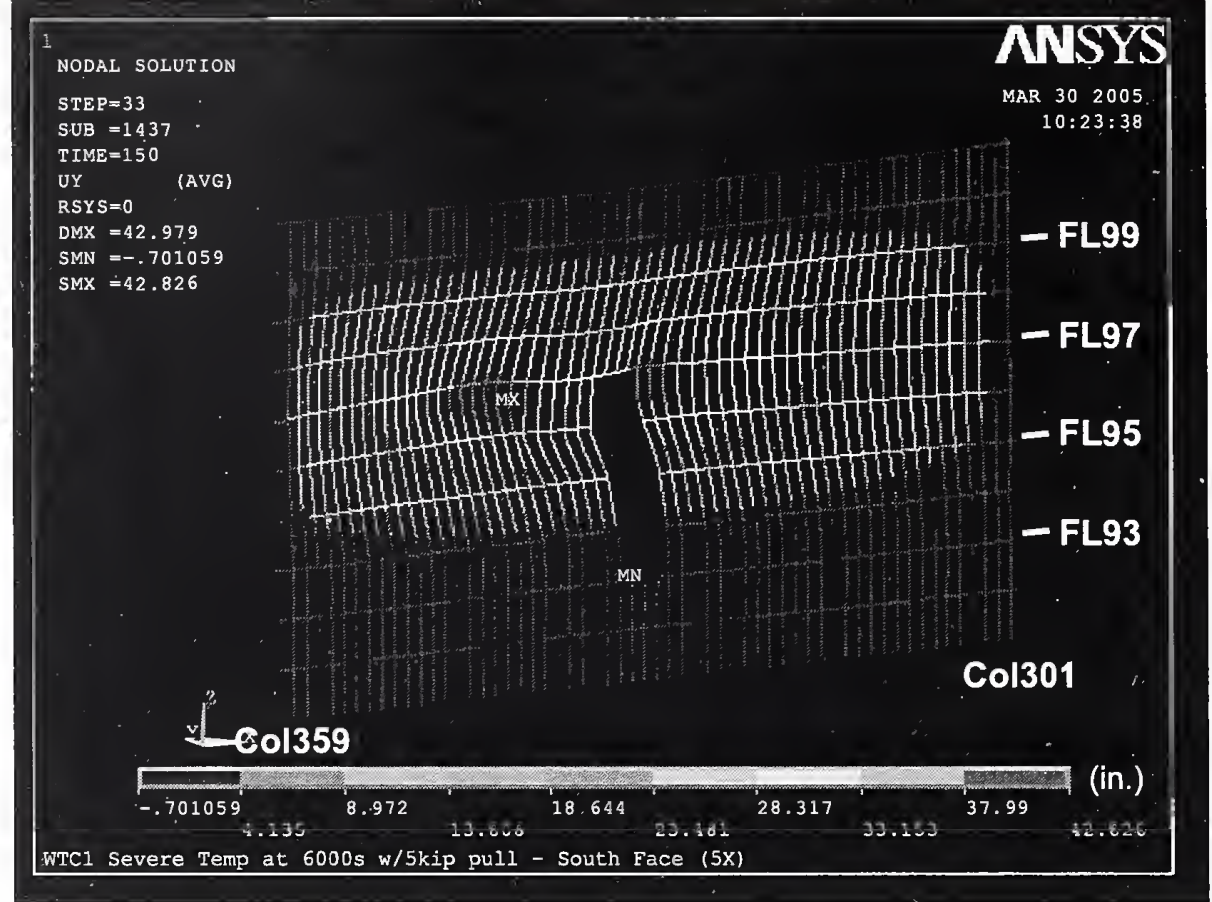

Figure E-10. Inward bowing of south wall of WTC 1 global model with creep at $100 \mathrm{~min}$ for Case B conditions with 5 kip pull-in forces ( $5 x$ displacement magnification).

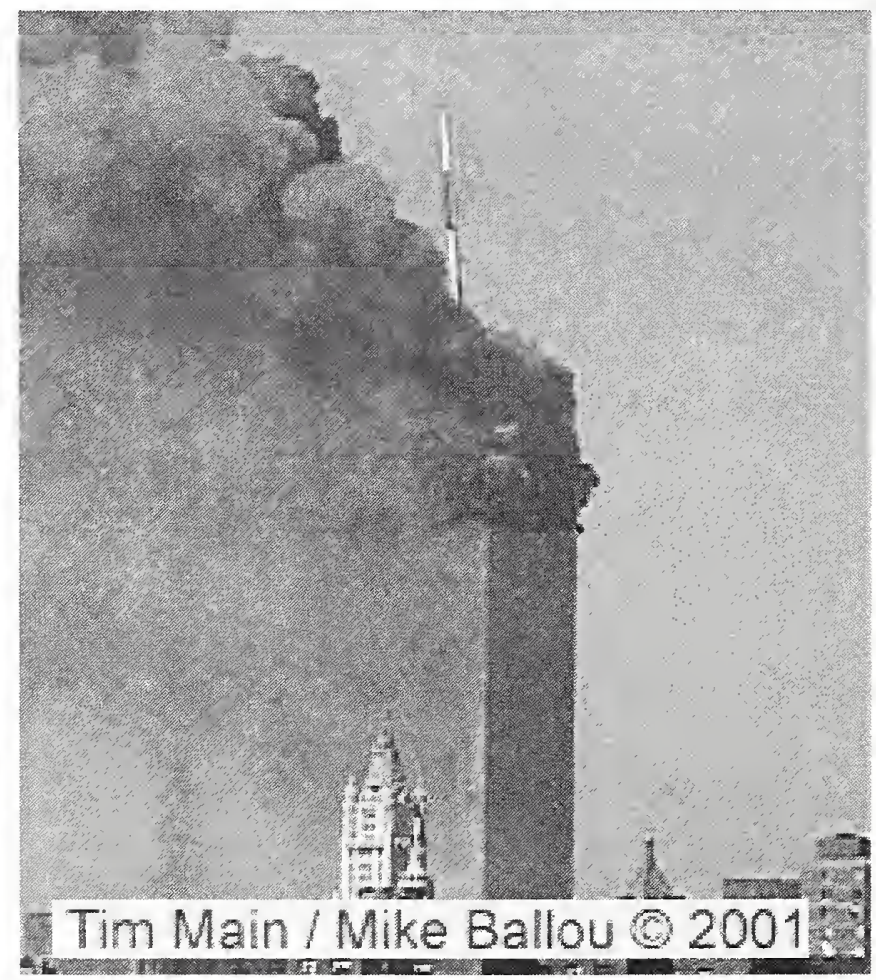

Figure E-11. Collapse initiation and tilting of WTC 1 (view from the northeast). 


\section{E.3.2 WTC 2 Collapse Sequence}

The aircraft traveling in a north-northeast direction impacted the south wall of WTC 2 at 9:03 a.m. The aircraft mostly severed columns and floors that were on the east side of the building between Floor 78 and Floor 84. The subsequent fires were also on the east side of the building. At 9:59 a.m., about 56 min after the aircraft impact, the building started to collapse with the east wall buckling inward, followed by tilting of the building above Floor 82 to the east and south. The collapse sequence of WTC 2 consists of five main structural events: 1) aircraft impact, 2) sagging of floors and floor/wall disconnections, 3) bowing of the east wall, 4) unloading and tilting of core, and 5) buckling of east wall and collapse initiation.

Aircraft Impact. The aircraft impacted the south wall of WTC 2, severing a number of exterior columns on the south wall from Floor 78 to Floor 84 . The south office area floor system sustained severe structural damage between Columns 410 and 436 from Floor 79 to Floor 83 . Core columns 701, 702, $801,802,803,901,903,1001,1002,1003$, and 1004 were severed or heavily damaged between Floor 77 and Floor 84 . The aircraft also severed Column 253 of the north wall. The aircraft damaged the floor framing and core columns at the southeast corner of the core. In summary, 32 of 59 columns of the south wall, two of 59 columns of the north wall, and 11 of 47 core columns were severed or heavily damaged. Thermal insulation was damaged from the impact area through the east half of the core to the north and east exterior walls. The floor truss seat connections over about one-quarter to one-half of the east side of the core were severed on Floor 80 and Floor 81 and over about one-third of the east wall on Floor 83.

Gravity loads in the columns that were severed on the south wall and in the southeast corner of the core were redistributed to adjacent intact columns and also to the columns on the east wall. In this redistribution, the total axial load on the core columns reduced by 6 percent, and the total axial load on the north wall columns reduced by 10 percent. The total axial load on the east wall columns increased by 24 percent, and the total axial load on the west and south wall columns increased by 2 percent to 3 percent. The large increases in loads in the east wall resulted from their proximity to the severed core columns at the southeast corner of the core. The total load on the south wall at Floor 83 did not change, as some of the loads from the core area were redistributed to that wall through the hat truss.

At Floor 105, splices in the columns at the southeast corner of the core failed (Columns 1001 and 1002 and most likely Columns 701,801,901,902, and 1003). This increased the core tendency to lean toward southeast and also increased the vertical downward displacement of the core at the impact zone. After the core column splices failed, 73 percent of the loads released from the failing core columns were redistributed through the hat truss to the exterior walls.

About 20 percent (= $227 \mathrm{kip} / 1,263 \mathrm{kip})$ of the redistributed load at the hat truss level of the south wall was transferred through columns and the rest of the load (about 1,000 kip) was transferred to the columns of the east and west walls through the spandrels.

After load redistribution following impact, the core was prevented from tilting excessively toward the east by the north and the south exterior walls through the action of floors and the hat truss.

Sagging of Floors and Floor/Wall Disconnections. Aircraft impact and high temperatures due to subsequent fires caused Floors 79 through 83 to sag. The sag was greater at Floor 80 and Floor 81 where the truss seats on the east side of the core failed at aircraft impact. High temperatures weakened the truss 
seats on the east exterior wall and caused truss seats to fail at Floor 83 and Floor 82 (see Fig. E-12) which in turn increased the sag in those floors. Floor sagging induced pull-in forces on the east wall columns, beginning approximately $10 \mathrm{~min}$ after impact and increasing with time.

Bowing of East Wall. The east wall columns bowed inward as a result of increasing temperatures (reduced strength and stiffness) and pull-in forces induced by sagging floors. The inward bowing in the east wall increased with time due to the combined effects of pull-in from sagging floors, increased axial loads, and a continuous increase in plastic and creep strains. As columns bowed, they shed load to adjacent unbowed columns, but the total column load on the east wall did not change significantly after impact until buckling of the east wall started near the collapse time.

Unloading and Leaning of Core. With increasing time and temperatures, the core columns developed high plastic and creep strains, especially on the east side of the core. Plastic and creep strains exceeded the thermal expansion strains beginning about $30 \mathrm{~min}$ after the aircraft impact. High plastic and creep strains caused unloading on the east side core columns. This increased leaning of the core toward the east and transferred more loads to the east wall. Calculations showed that resistance to core leaning was provided by the north and south exterior walls, partly through the floors and partly through the hat truss. Leaning of the core resulted in tilting of the upper part of the tower as the east wall buckled.

Buckling of East Wall and Collapse Initiation. With continuously increased bowing and axial loads, the entire width of the east wall buckled inward (Fig. E-13). The instability started at the center of the wall and rapidly progressed horizontally toward the sides. As a result of the buckling of the east wall, the east wall significantly unloaded, redistributing its load to the softened core through the hat truss and to the east side of the south and north walls through the spandrels (see Fig. E-14). The section of tower above the buckled wall suddenly moved downward, and the building tilted toward the east (see Fig. E-15).

The section of the building above the impact zone tilted to the east and south (observed at about $7^{\circ}$ to $8^{\circ}$ to east and about $3^{\circ}$ to $4^{\circ}$ to south, Fig. E-16) as column instability progressed from the east wall to the adjacent south and north walls. The release of potential energy due to downward movement of the building mass above the buckled columns exceeded the strain energy that could be absorbed by the structure. Global collapse ensued. 


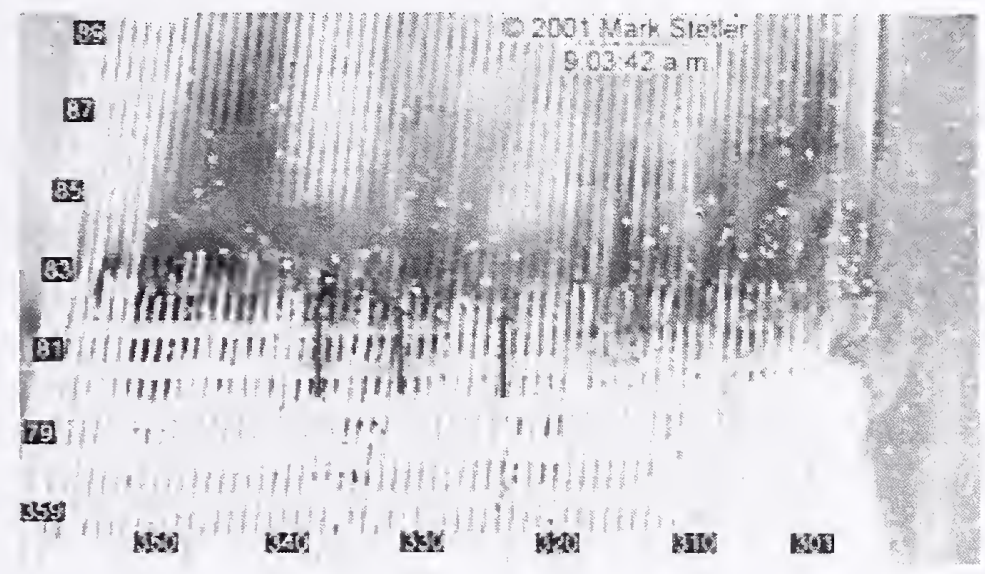

(a) After impact damage

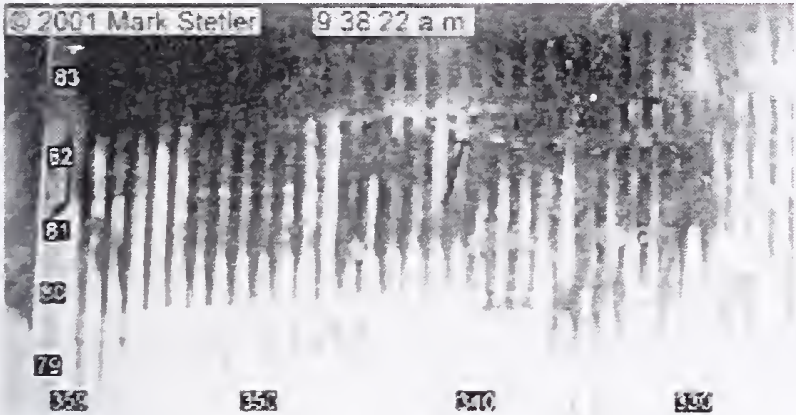

(b) South side at 9:38 a.m. (35 min after impact)

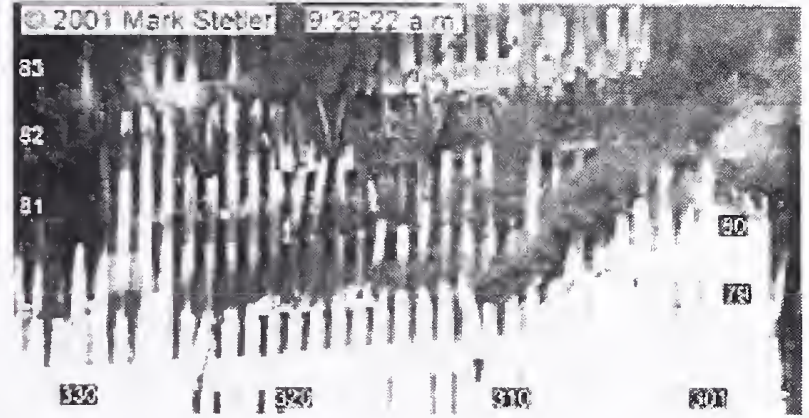

(c) North side at 9:38 a.m. (35 min after impact)

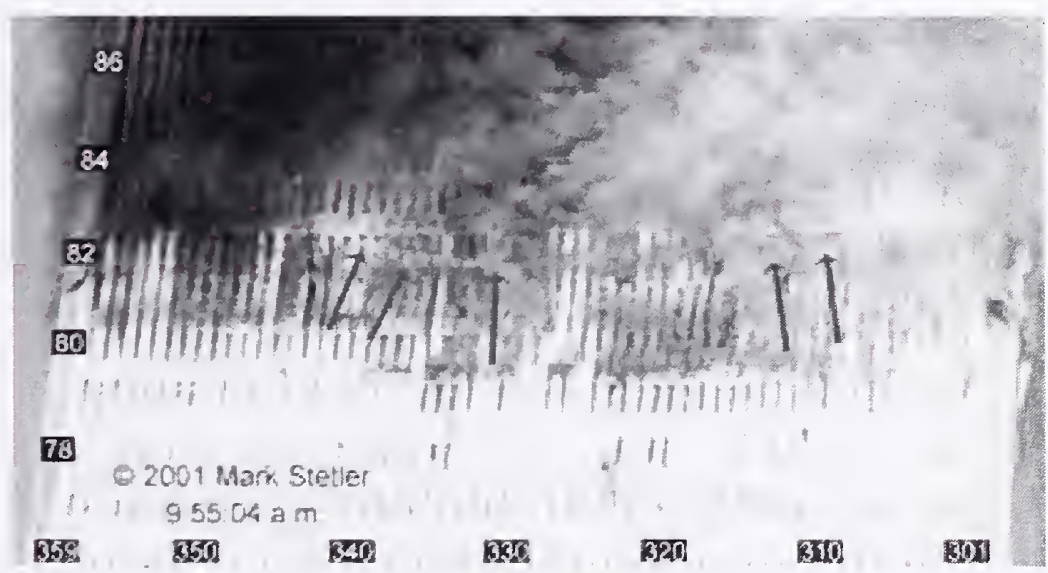

(d) At 9:54 a.m.

(51 min after impact)

Figure E-12. Floor sagging observed on the east wall of WTC 2 at different times. 


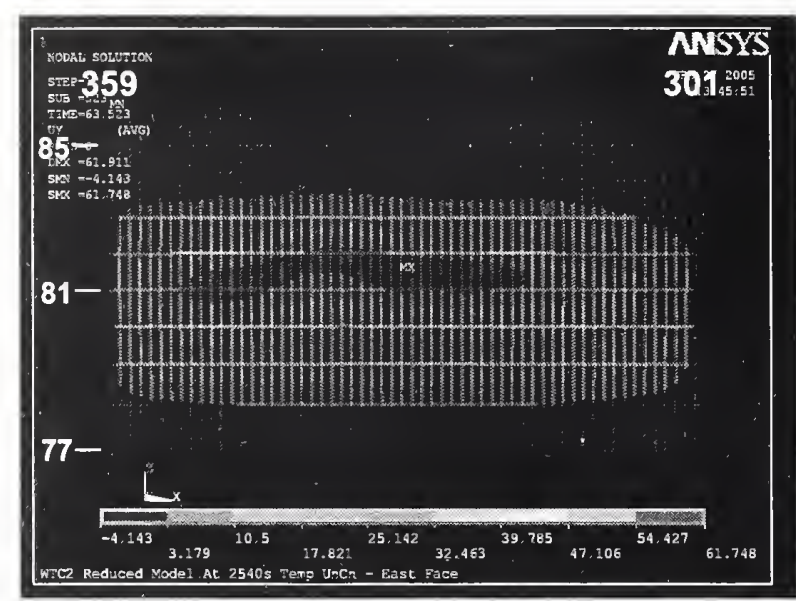

(a) View from east

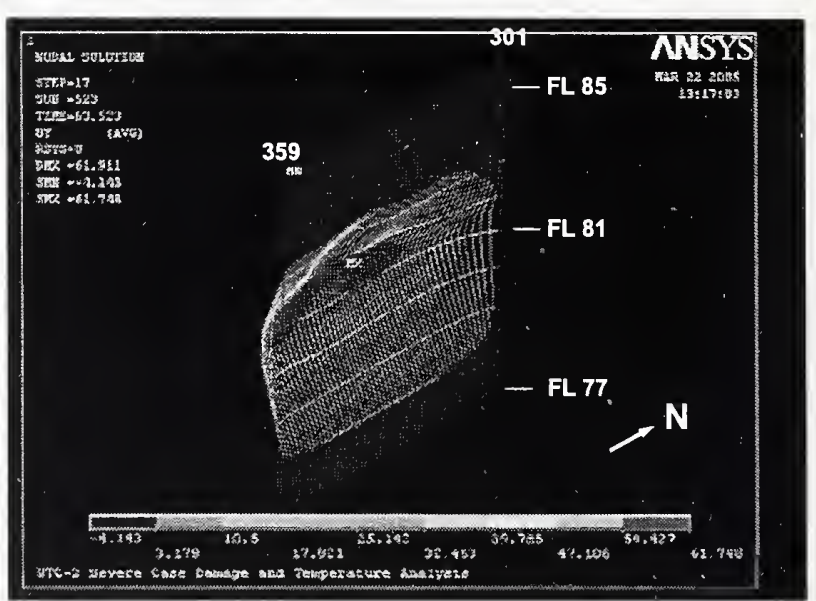

(b) View from southeast

Figure E-13. Inward bowing of the east wall of WTC 2 global model for Case D conditions at $\mathbf{4 3} \mathrm{min}$ at the instant of collapse initiation (deformed shape scaled four times).

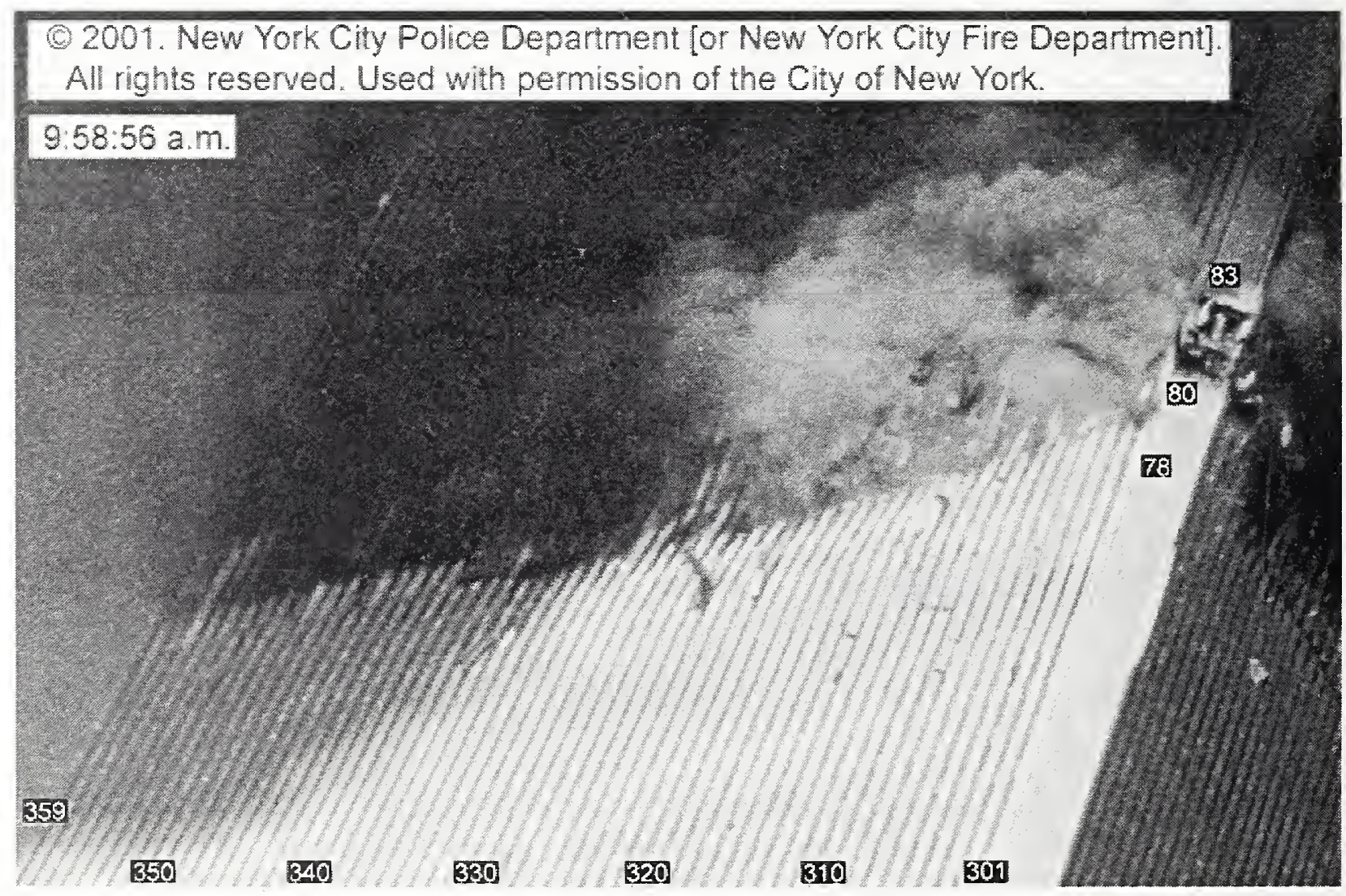

Figure E-14. Inward bowing of exterior columns of the west wall of WTC 2 just before collapse. 


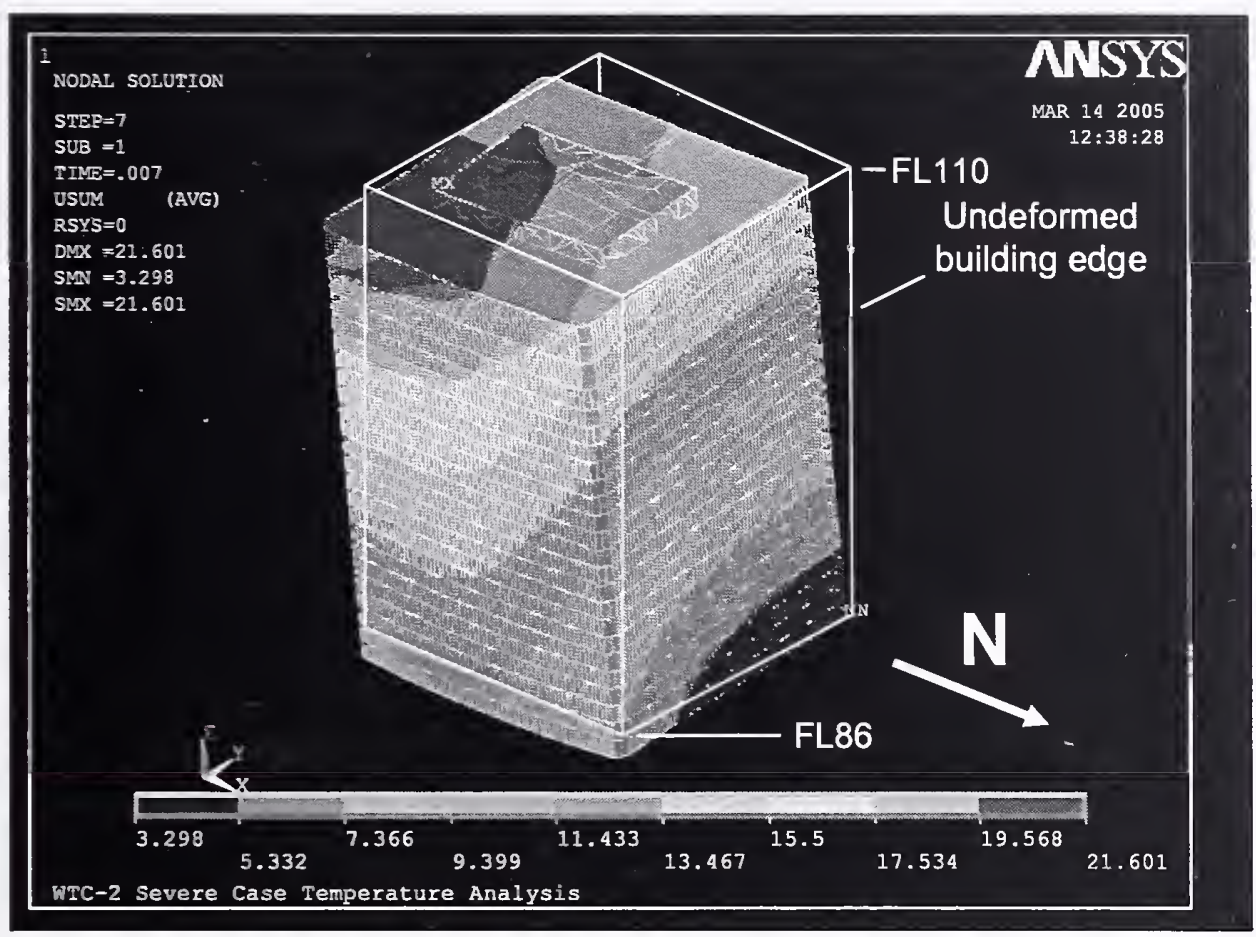

Figure E-15. Total displacements of WTC 2 global model above Floor 86 for Case D conditions at $43 \mathrm{~min}$ at collapse initiation (note the tilt toward east and south; deformed shape magnified 20 times).

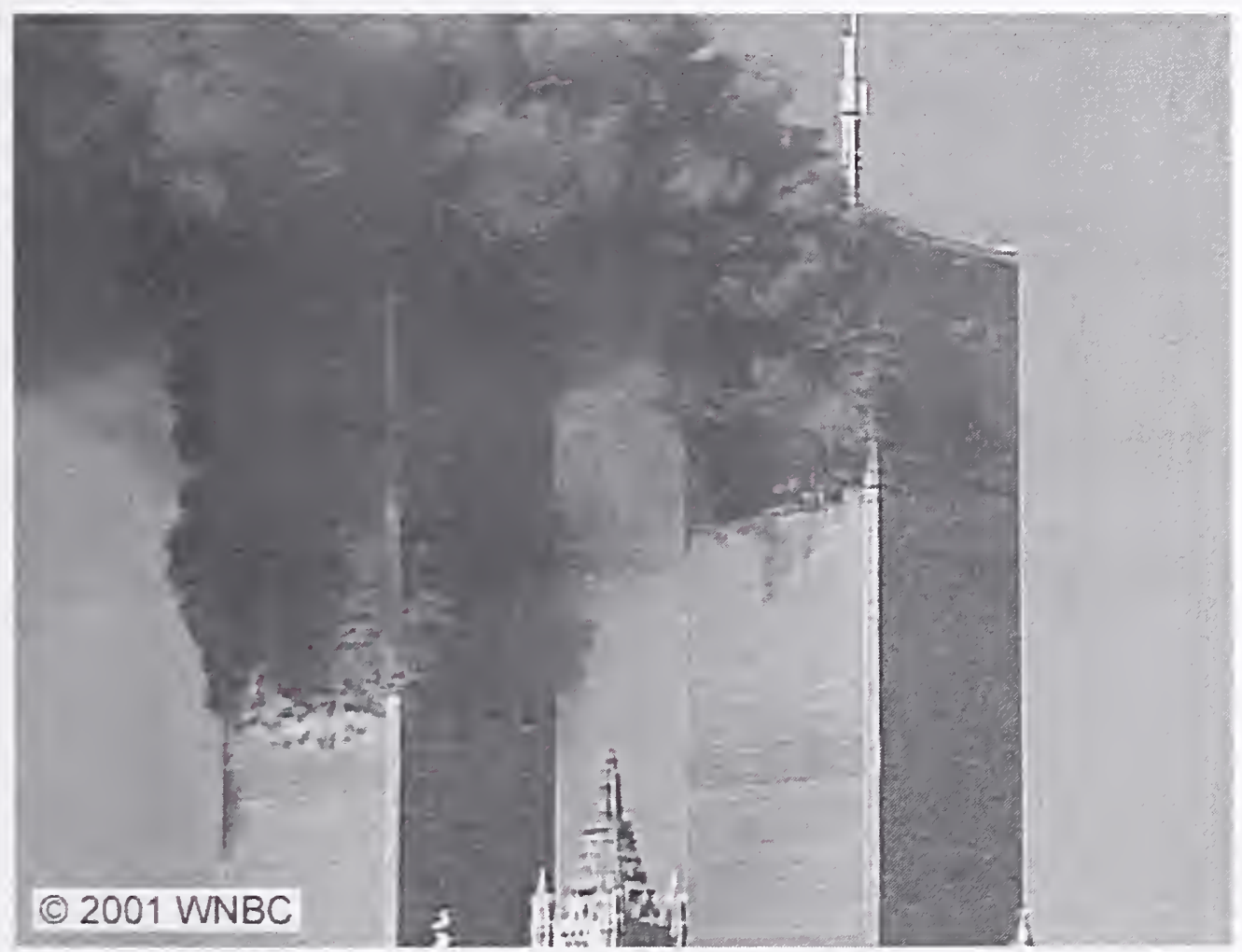

Figure E-16. Initiation of collapse of WTC 2. Note the tilt toward east and south. 
This page intentionally left blank. 


\section{Chapter 1 \\ INTRODUCTION}

\section{$1.1 \quad$ OBJECTIVE}

The objective of this report is to present the results of finite element analyses (FEA) performed by Simpson Gumpertz and Heger Inc. (SGH) on global models of the World Trade Center (WTC) towers. The purpose of the analyses is to determine the roles of aircraft impact damage and of subsequent fires in the probable sequence of structural responses that led to global collapse of the WTC towers.

This report complements the work that SGH performed on the structural response of components in the WTC towers, such as trusses and columns, connections such as truss seats and knuckles, and subsystems including full floors and exterior walls to the fire environment. Results were reported in NIST NCSTAR $1-6 C^{1}$.

\section{$1.2 \quad$ BACKGROUND}

On the morning of September 11, 2001, two Boeing 767 aircraft were hijacked after they left Boston's Logan International Airport for Los Angeles. At 8:46 a.m., American Airline Flight 11, traveling from the north at an estimated speed of 440 miles per hour, impacted near the center of the north face of WTC 1 between Floor 94 and Floor 98, 1,100 ft above the plaza level. At 9:03 a.m., United Airlines Flight 175, traveling at an estimated speed of 540 miles per hour from the south, impacted the south face of WTC 2 between Floor 78 and Floor 84, $901 \mathrm{ft}$ above the plaza level (NIST NCSTAR 1).

Although both WTC towers suffered substantial damage over several floors, they withstood the aircraft impact damage without global collapse. Subsequent fires, ignited with aircraft fuel and fed by the building and aircraft contents, led to the collapse of the two towers. The collapse of WTC 2 occurred at 9:59 a.m., 56 min after impact. and the collapse of WTC 1 occurred at 10:28 a.m., 102 min after impact (NIST NCSTAR 1).

Since the collapse of these tall steel frame buildings were unprecedented, questions were raised about the safety of tall steel buildings in fires. Before drawing conclusions regarding the safety of tall steel buildings in fire, it is necessary to understand how and why the WTC towers collapsed. Various aspects of the WTC towers and their collapses have been investigated by many researchers and engineers (Bažant and Zhou 2002, FEMA 2002, Kausel et al. 2002, Levy and Abboud 2002, Usmani et al. 2003). NIST initiated a comprehensive investigation of the WTC disaster on August 21, 2002, and SGH was retained under contract in October, 2003. The work presented in this report was performed by SGH as part of Project 6 of the NIST WTC Investigation.

1 This reference is to one of the companion documents from this Investigation. A list of these documents appears in the Preface to this report. 
Aircraft impact damage to the structural components of the WTC buildings were investigated and reported in NIST NCSTAR 1-2 and NIST NCSTAR 1-2B. Thesc studies assessed structural damage and thermal insulation damage caused by aircraft impact. Although the computed aircraft impact damage to the exterior wall system of each building can be validated from the many photographs and videos taken, aircraft impact damage to the interior columns and floor systems and to the insulation cannot be validated using this same tcchnique.

NIST performed a fire dynamics study to cstimate the thermal input to the building following the aircraft impact. The fire dynamics analysis depends on the distribution of the building and aircraft contents following the impact, the spread of aircraft fuel throughout the structure upon impact, the amount of fuel that ignited and burned off immediately upon impact, and the availability of air in fire-involved areas, flowing through broken windows and through damaged interior partitions and structures to support continued combustion. Of these factors, only the distribution of broken windows on the exterior of the building can be verified, through examination of photographic and video evidence. Other factors were estimated and validated against recorded smoke plumes and other data. These calculations were performcd by NIST and were reported in NIST NCSTAR 1-5 and NIST NCSTAR 1-5F.

Based on the results of the fire dynamics model, NIST calculated the steel and concrete temperatures at various times from the time of aircraft impact for the estimated extcnt of remaining insulation. Before aircraft impact, WTC 1 had thicker insulation on floor trusses in the areas principally involved in the fires than did WTC 2. The columns, spandrels, and core beams had similar insulation in both of the towers. No insulation had been applied to the steel deck supporting the concrete slabs in either building, though there was overspray from application of insulation to the trusses. Based on the path of the debris determined from the aircraft impact analysis, NIST estimated the extent of the insulation that was dislodged from the structural components of the WTC towers. These estimates considered insulation to be removed only in areas where direct impact from debris was predicted. Possible additional dislodgement of insulation due to the shock and resulting vibration from the aircraft impact was neglected. The extent of dislodged insulation predicted by the aircraft impact analysis is discussed in NIST NCSTAR 1-6A, and the calculation of steel and concrete temperatures is presented in NIST NCSTAR 1-5G.

NIST determined mechanical and metallurgical properties of structural steel recovered from the WTC towers. NIST also estimated the mechanical properties of WTC steel for elevated temperatures. Results were reported in NIST NCSTAR 1-3 and NIST NCSTAR 1-3D. Temperature-dependent mechanical properties of WTC steel include modulus of elasticity, Poisson's ratio, coefficient of thermal expansion, yield strength, tensile strength, and nonlinear stress-strain relationship. NIST also predicted temperaturedependent creep properties for the WTC steels.

Prior to the development of the global finite element models of the WTC towers, SGH used hand and finite element analyses to study the structural behavior of subcomponents such as knuckles and connections, components, and subsystems. Results from structural analyses of truss seats and knuckles were used in a detailed model of a slice of a floor that included a single truss and a section of slab, which was referred to as the truss model. It was found that when subjected to elevated temperatures, the trusses sagged after diagonal web members buckled. Based on the truss model analyses, a simplified truss model was constructed and used in a model of a typical full floor. Full floor model analyses showed that in a fire environment floors sagged significantly at areas where insulation was dislodged, and exterior seats failed under extreme tcmperatures causing floors to disconnect from the exterior wall. The structural 
performance of columns and exterior walls was studied with the analysis of single column and exterior wall subsystem models, which gave guidance in choosing element size and type for exterior columns in the global model that captured inelastic buckling behavior under elevated temperatures.

SGH developed global models that would simulate the key failure modes discovered in the analysis of components and subsystems. In addition, certain damage that could not be accurately modeled without significant loss of computational efficiency, such as certain fire-induced damage, were introduced to the global models at appropriate times. Types of fire-induced damage that were important in the collapse analysis of the global model included sagging of the floors that applied pull-in forces on the exterior columns and disconnections of floors from the exterior walls. The fire-induced damage incorporated in the global model is discussed in detail in Section 2.5 .

\subsection{METHOD OF APPROACH}

SGH developed global finite element structural models of the WTC towers in ANSYS, based on reference structural models developed in SAP2000 (NIST NCSTAR 1-2A), and based on the studies that SGH conducted on components and subsystems of the WTC towers (NIST NCSTAR 1-6C). Owing to the existing limits of computational software and hardware, all potential structural behaviors and failure modes that could contribute to the collapse of the WTC towers were not explicitly included in the global models. A single global model that included all structural behaviors and failure modes would not be practical due to the extremely large time period required for analyses.

An alternative approach, a trial and error procedure, was used in this study to (1) perform global structural time history analyses for an assumed set of fire-induced damage, (2) identify major observations of subsequent fire-induced structural damage at different times up to the initiation of collapse, (3) determine the deviation between the calculated and observed fire-induced damage, (4) develop a structural explanation of the deviation, and (5) use the observed fire-induced damage to correct the state of the structure at that time and continue the calculation. This approach reduced the error margin (hence increased the accuracy) of the results due to epistemic uncertainties in modeling and load estimation by updating the response of the WTC towers according to observed facts at specific time points.

In developing the global models, the knowledge obtained from extensive investigation of components' and subsystems' responses to various temperature-dependent nonlinear actions was utilized. The pertinent structural actions and failure modes between and within components and subsystems that were obtained from the isolated model investigations allowed us to include or represent in a more efficient way all essential nonlinear responses in the global models without sacrificing accuracy and computation time. The important features of the detailed component and subsystem models and their influence on the global building response during the collapse process are discussed in NIST NCSTAR 1-6C. Similar discussions for two additional substructure models isolated from the global models (isolated core and exterior wall models) are provided in Chapter 3 of this report.

As discussed earlier, collapse analyses of the WTC towers were also guided by observations from the photos and videos taken during the collapse process. Visual evidence, damage estimates, and the timeline of the collapse process are reported in NIST NCSTAR 1-5A. The key observations of collapse sequences of the WTC towers are presented in Chapter 5. 
The global and subsystem models were capable of capturing material nonlinearities due to plasticity and creep in steel, geometric nonlinearities due to large deflection, and elastic and inelastic buckling of the columns and other structural members at high temperatures.

The global models developed in this study were first validated against the SAP2000 models under gravity loads. Then, aircraft impact damage was included in these models by removing corresponding elements based on results from Project 2. Impact damage is discussed in detail in Section 2.2. The global models with impact damage were then subjected to temperature time histories derived from reconstructed fires in the WTC towers in Project 5.

Based on the results from FEA of the isolated and global models and the results of component and subsystem models, collapse sequences of WTC 1 and WTC 2 were identified as a conclusion of this study.

\subsection{REPORT ORGANIZATION}

This report presents results from the isolated models and the global models of the WTC towers. All the results are based on FEA and hand calculations. The "observed values" when used refer to the estimates obtained from photographs and videos.

This report consists of six chapters:

- Chapter 1 serves as an introduction of this report and includes objectives, background, and methods of approach of this study.

- Chapter 2 introduces the global models of WTC 1 and WTC 2. It gives general descriptions of the global models and of temperatures and aircraft impact and fire-induced damage used in the global model analyses.

- Chapter 3 gives the results from FEA of isolated wall and core models subjected to gravity and thermal loadings. The results shown in this chapter do not form a major link in the chain of collapse sequence arguments and may be skipped by those interested only in this chain of arguments.

- Chapter 4 describes the details of the global models and presents the results of FEA of the global models with creep subjected to gravity and thermal loadings.

- Chapter 5 presents the collapse sequences of WTC 1 and WTC 2 concluded from this study and provides supporting evidence.

- Chapter 6 provides a list of references.

This report also includes three appendices:

- Appendix A summarizes the results from FEA of full floor models.

- Appendix B summarizes a study on dynamic response of a floor to impact from collapse of a floor above. 
- Appendix C summarizes the results of FEA of the global models without creep subjected to gravity and thermal loadings. The analyses presented in this appendix are preliminary global analyses and were primarily used to get a better understanding of the interaction between various structural components in the overall global response of the towers. 
This page intentionally left blank. 


\section{Chapter 2 \\ GLOBAL MODELS}

\subsection{DESCRIPTION OF GLOBAL MODELS}

Simpson Gumpertz\& Heger Inc. (SGH) developed two different finite element models to simulate the global structural behavior of the World Trade Center towers, WTC 1 and WTC 2, incorporating the aircraft impact damage and the fire environment that followed the impact. The finite elcment models of the towers were developed using ANSYS commercial structural analysis software package. The finite element models were developed to determine the roles of aircraft impact damage and of subsequent fircs in the probable sequence of structural responses that led to global collapse of the WTC towers.

SGH obtained the basic building geometry, member types and cross sections, and their connectivity from models developed by Leslie E. Robertson Associates (LERA) as described in Chapter 4 of the National Instiutute of Standards and Technology (NIST) NCSTAR 1-6C. LERA developed the original models using SAP2000 structural analysis software.

The observation of photographic and video evidence of the behavior of both structures, following the time of aircraft impact and until collapse initiation, strongly suggested that nonlinear bchavior and structural collapse initiation occurred within the upper portions of the structures, generally above the zonc of aircraft impact. Therefore, to reduce the model size and improve solution time, the model of WTC 1 was truncated at Floor 89, five floors below the zone of impact, and a series of equivalent vertical linear springs were introduced at the base of this truncated model to represent the stiffness of the interior columns and exterior walls beneath the level of truncation. Similarly, the model of WTC 2 was truncated at Floor 73. This truncation is believed to have negligible effect on the predictcd behavior of the structure.

As a first step in the analyses, the truncated SAP2000 models were converted to ANSYS. While the geometry from the SAP2000 model was directly transferable to ANSYS, it was necessary to substitute the elements with those from ANSYS element library. Table 2-1 summarizes the elemcnt types used in the ANSYS global models. The element names used in the table correspond to specific ANSYS (ANSYS, Inc. 2004) element formulations. All element types listed in Table 2-1 have tempcrature-dependent material properties.

In the original SAP2000 models, LERA represented the structural floors as rigid constraints with no outof-plane stiffness. In order to capture the potential behavior of the floor slabs in transferring loads between the core and the exterior walls, these rigid constraints were replaced with grids of plate elements with the same membrane stiffness as the compositc floor system (slab and trusscs). Floors in the global models were not intended to capture floor response and failure modes during fires. Important failure modes were identified in the truss and full floor analyses and incorporated into the global modcls as floor/wall disconnections and pull-in forces at appropriate time intervals. See Chapter 7 in NIST NCSTAR 1-6C and Chapter 2 in this report for a detailed discussion of how floor behavior was modeled in the global analyses. 
SGH next performed a series of modifications to the models, to simulate the structural damage resulting from the aircraft impacts and the effects of fire. The damage to the exterior walls was modeled by removing structural elements in a pattern that replicated the damage observed in available photographic and video evidence. The damage to interior structural elements was modeled based on aircraft impact simulations reported in NIST NCSTAR 1-2. The effects of fire damage to the structure were also included in the global models, based on thermal predictions developed by NIST, and the results of structural analyses performed by SGH of individual structural subsystems, including individual floor trusses, entire floor assemblies, and portions of exterior walls. Since projection of these subsystem analyses to global behavior entailed substantial uncertainty, visual photographic and video evidence of the behavior of the exterior structure were also used to benchmark the projections from the subsystem analyses.

The models were also modified to include a number of nonlinear behavioral modes including:

- Geometric nonlinearity associated with large deflections,

- Nonlinearity in stress-strain behavior as a function of applied loading and thermal effects, as described in Chapter 3 of NIST NCSTAR 1-6C,

- Creep behavior as the time-dependent effect of sustained stress and elevated temperatures on strain as described in Chapter 3 of NIST NCSTAR 1-6C,

- Failure of a connection between elements, resulting in a complete loss of load transfer ability and deformation compatibility.

The converted ANSYS models were validated against the SAP2000 models by comparing gravity load response, natural frequencies, and mode shapes.

Table 2-1. Element types used in the global models.

\begin{tabular}{|c|l|l|l|}
\hline Name & Element Type & \multicolumn{1}{|c|}{ Description } & \multicolumn{1}{|c|}{ Usage in the Model } \\
\hline BEAM188 & $\begin{array}{l}\text { 3-D linear finite } \\
\text { strain beam }\end{array}$ & $\begin{array}{l}\text { BEAM188 is a linear (2-node) or a quadratic beam } \\
\text { element in 3-D based on Timoshenko beam theory. } \\
\text { Each node has six degrees of freedom or seven degrees } \\
\text { of freedom (6+warping). Shear deformation effects are } \\
\text { included. This element is supported for plasticity, creep, } \\
\text { large deflection. A cross-section can be a built-up } \\
\text { section referencing more than one material. Creep strain } \\
\text { is calculated by implicit time integration method. }\end{array}$ & $\begin{array}{l}\text { Exterior columns } \\
\text { Core columns } \\
\text { Core beams } \\
\text { Spandrels } \\
\text { Hat truss members }\end{array}$ \\
\hline BEAM24 & $\begin{array}{l}\text { 3-D thin-walled } \\
\text { beam }\end{array}$ & $\begin{array}{l}\text { BEAM24 is a 3-D beam element of arbitrary open or } \\
\text { closed cross-section with axial, bending, and St. Venant } \\
\text { torsional capabilities. Each node has six degrees of } \\
\text { freedom. The element has plastic, creep, large } \\
\text { deflection, and shear deflection capabilities. Creep } \\
\text { strain is calculated by explicit time integration method. }\end{array}$ & Core columns \\
\hline SHELL63 & $\begin{array}{l}\text { 4-node elastic } \\
\text { shell }\end{array}$ & $\begin{array}{l}\text { SHELL63 has both bending and membrane capabilities. } \\
\text { The element has six degrees of freedom at each node: } \\
\text { three translations and three rotations. Large deflection } \\
\text { capability is also included. }\end{array}$ & Floors \\
\hline
\end{tabular}




\begin{tabular}{|l|l|l|l|}
\hline \multicolumn{1}{|c|}{ Name } & \multicolumn{1}{|c|}{ Element Type } & \multicolumn{1}{|c|}{ Description } & Usage in the Model \\
\hline SHELL181 & $\begin{array}{l}\text { 4-node finite } \\
\text { strain shell }\end{array}$ & $\begin{array}{l}\text { SHELL181 is a 4-node shell element with six degrees of } \\
\text { freedom at each node: three translations and three } \\
\text { rotations. Plasticity, creep, and large deflection } \\
\text { capabilities are supported. In nonlinear analyses, } \\
\text { change in shell thickness is accounted for. SHELL181 } \\
\text { may be used for layered applications. }\end{array}$ & Floors \\
\hline LINK8 & 3-D truss & $\begin{array}{l}\text { LINK8 is a uniaxial tension-compression element with } \\
\text { three degrees of freedom at each node. It has plasticity, } \\
\text { creep. and large deflection capabilities. }\end{array}$ & $\begin{array}{l}\text { Vertical springs at } \\
\text { the base }\end{array}$ \\
\hline
\end{tabular}

Damage modified the geometry and connectivity of and load distribution in the towers. Types of damage included in the global models were aircraft impact damage to the exterior wall that were visible and documented by photos and videos and interior damage resulting from the movement of aircraft impact debris through the interior space of the towers which were obtained from the aircraft impact analyses.

Structural damage caused by the fires, such as disconnection of the floor from the exterior wall, was determined from the structural analysis of the full floor subsystems. Some structural behaviors caused by the fires were not adequately captured by the full floor analysis, such as pull-in forces at the floor/wall connections. The pull-in forces were estimated through additional analyses with exterior wall models that were conducted to estimate the pull-in force required to match the observed inward bowing of the exterior walls.

The models were then analyzed for the effects of gravity and temperature loads. Gravity loads considered included: the dead load of the structure itself; superimposed dead load consisting of the estimated weights of ceilings. mechanical and electrical equipment, thermal insulation, and floor finishes; and live load, taken as 25 percent of design live load specified in the original construction documents. The use of 25 percent of the design live load as service live loads is discussed in NIST NCSTAR 1-2. Wind loads were negligible and were not considered (see NIST NCSTAR 1-6 for the recorded wind data).

Due to the height of the structures, substantial column shortening occurred under the application of dead loads. If these loads were applied to the model while the stiffness of the hat trusses was present, the hat trusses would restrain the downward deflection of the columns and in the process experience higher levels of stress. These stresses did not occur in the real buildings, because the columns experienced most of their dead load-induced shortening before the hat trusses were erected. In order to account for this effect, except for those simulations in which the effect of creep was also considered, the sequence of construction was considered during gravity load application. The loading of the structure was staged so that the stiffness of the hat trusses was not present when dead loads below Floor 106 level were applied. Construction sequence effects were not considered in the global analyses that included creep cffects to enhance computational efficiency. The effect of construction sequence is discussed in more detail in Section 4.2.2. 
Thermal loading of a structure resulted in several effects:

- restrained axial thermal expansion of members causing local redistribution of loads, e.g., heated columns of WTC towers that attracted more load,

- differential thermal expansion across member depth, resulting in bowing if unrestrained or bending moment if restrained,

- reduction in the stiffness and strength of members, and

- high creep strain when accompanied by high stress.

SGH applied thermal loading in the form of temperature time histories. NIST developed these temperature time histories using gas dynamic and heat transfer models. Each temperature time history corresponded to a unique set of assumptions regarding the extent of impact damage to the structure, glazing, fire separation elements, and insulation. Each temperature time history was defined discretely at 10 min time intervals which were linearly interpolated for times in between.

The behavior of columns in the two structures was significant to the collapse behavior of the towers. Throughout this report reference is made to the behavior of various columns and lines of columns, using the specific column numbering system found in the original PANYNJ structural drawings ${ }^{1}$. In WTC 1, columns in the exterior north wall were assigned a number ranging from 101 at the west end to 159 at the east end. Columns in the exterior east wall were assigned a number ranging from 201 at the north end to 259 at the south end. Columns in the exterior south wall were assigned a number ranging from 301 at east end to 359 at the west end. Columns in the west wall were numbered sequentially from 401 at the south end to 459 at the north end. Columns 100, 200, 300 and 400 were located, respectively, at the northwest, northeast, southeast and southwest building corners. Within the rectangular core of the structure, there were six rows of either seven or eight columns each. Columns of the northern-most row were numbered 501 through 508 with column 501 located at the west end and 508 at the east end. Successive rows of columns, reading from north to south were designated 601-608, 701-708, 801-807, 901-908, and 1001-1008. This numbering scheme is illustrated in Fig. 2-1 (a). The column numbering system used for WTC 2 is similar. However, for WTC 2 Columns 101-159 were located along the west wall, Columns 201-259 along the north wall, 301-359 along the east wall, and Columns 401-459 along the south wall. Column 100 was located at the southwest corner, 200 at the northwest corner, 300 at the northeast corner and 400 at the southeast corner. In the core of WTC 2, Columns 501-508 were located along the extreme west side of the core and Columns 1000-1008 along the extreme east side of the core with the $600,700,800$, and 900 series columns arranged progressively from west to east. Figure 2-1 (b) illustrates the column numbering system used in WTC 2.

1 The technical data required to conduct the analyses of the WTC towers reported herein were obtained from drawings that were provided by the Port Authority of New York and New Jersey (PANYNJ) and their contractors. 


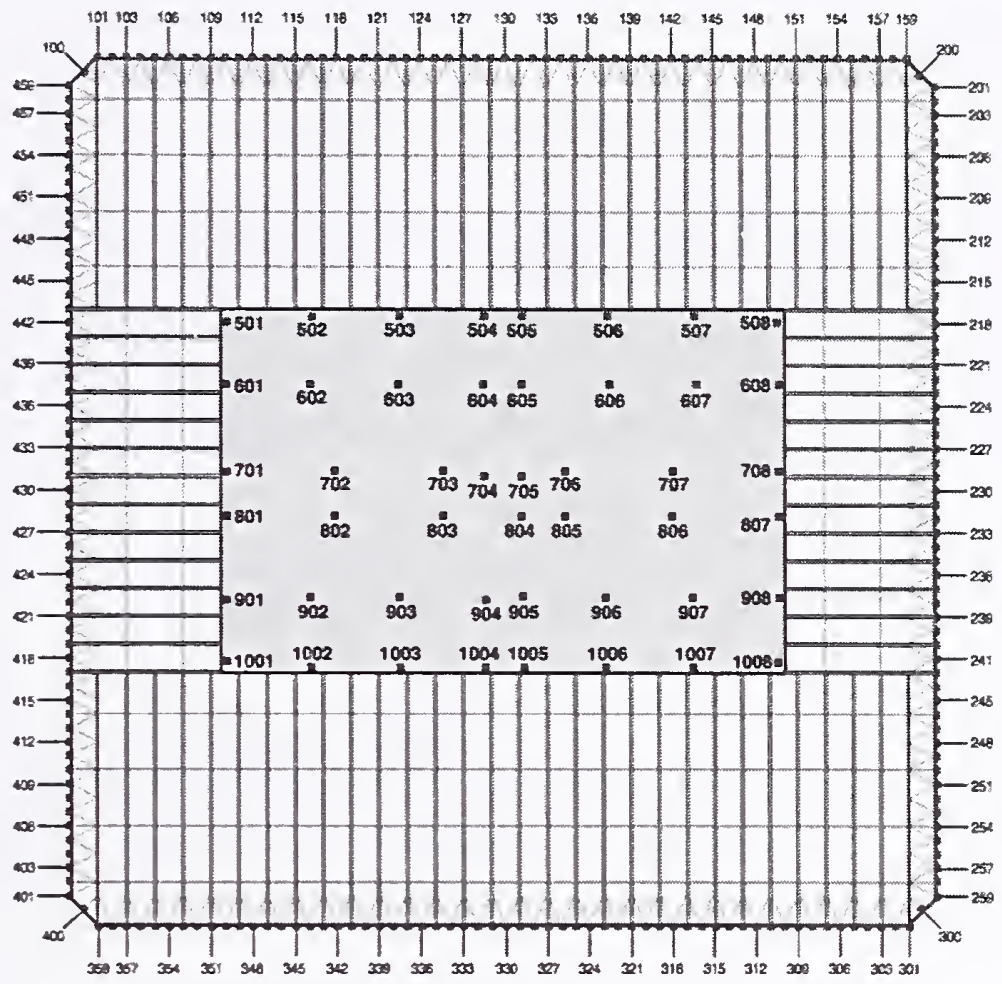

(a) WTC 1
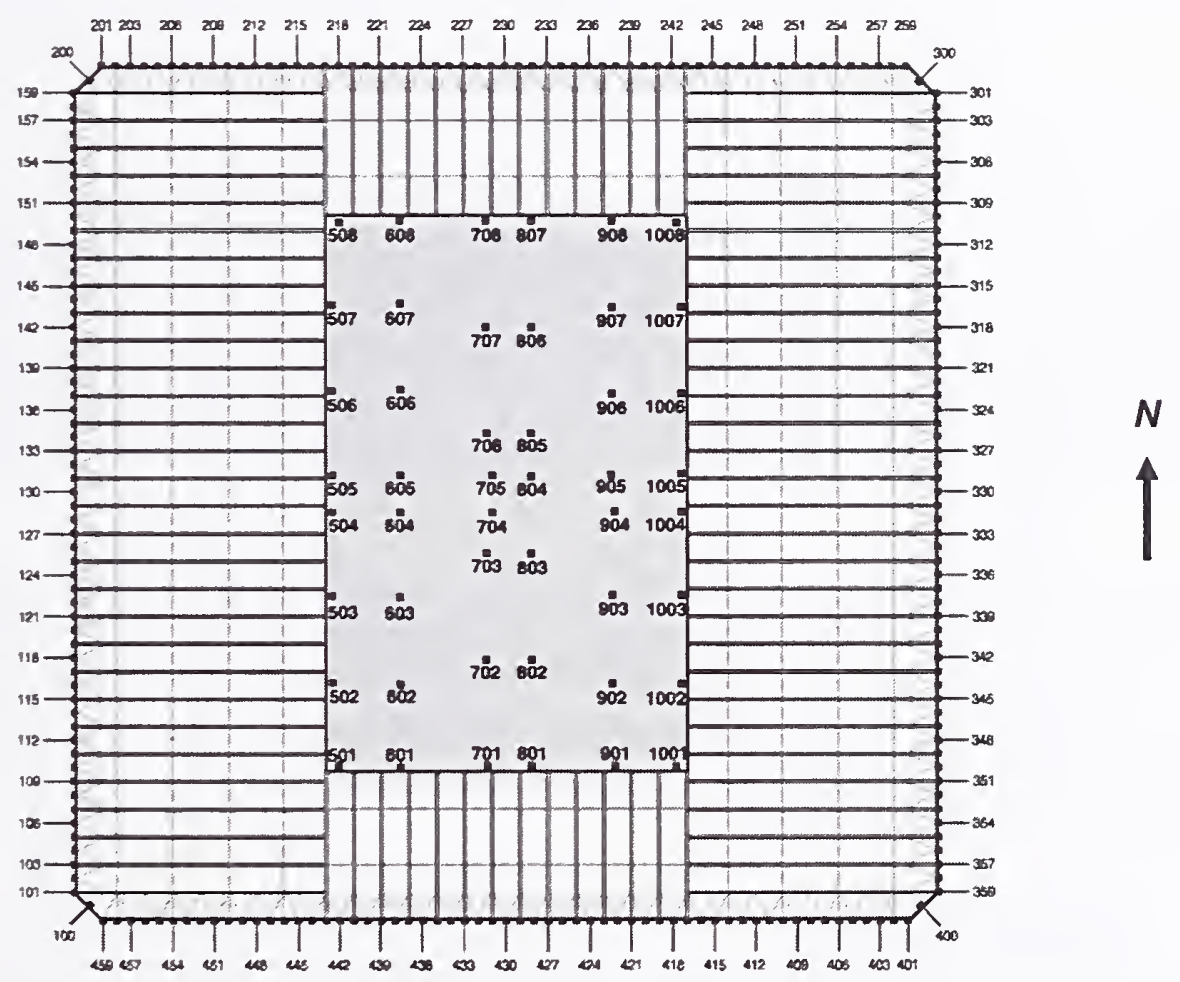

(b) WTC 2

Figure 2-1. Column designations. 


\section{$2.2 \quad$ IMPACT DAMAGE}

\subsubsection{Introduction}

The extent of aircraft impact damage to the structural components of the WTC towers has been separately investigated as part of NIST Project 2 and was reported in NIST NCSTAR 1-2 and NIST NCSTAR 1-2B. SGH incorporated the results of these studies into the global models of the WTC towers to characterize the aircraft impact damage to exterior columns and spandrels, core columns, beams, and floors. Specifically, those elements identified in the aircraft impact studies as severed or heavily damaged were removed from the global models.

NIST's investigation initially identified two sets of aircraft impact damage for each of the two towers, consisting of a structural damage condition, which was damage to the structure, and a insulation damage condition, which affected the temperatures in members. These damage sets represent a base case and a more severe case of damage estimates. They were named as Case $A_{i}$ and Case $B_{i}$ for WTC 1 and Case $C_{i}$ and Case $\mathrm{D}_{\mathrm{i}}$ for WTC 2. These initial damage sets were used in early analyses to study the structural response of full floor subsystem models and global models without creep. The results of the full floor subsystem analyses were presented in Section 5.4 of NIST NCSTAR 1-6C and summarized in Appendix A of this report. The results of the global model analyses without creep are discussed in Section 4.1 of this report.

NIST refined the initial damage sets at later stages of the investigation and renamed them as Case $\mathrm{A}$ and Case B for WTC 1 and Case C and Case D for WTC 2. These damage sets were used in isolated wall and isolated core models and global models with creep. The results of the isolated wall and core models are discussed in Chapter 3, and the results of the global model analyses with creep are discussed in Section 4.2 of this report.

For each tower, the impact damage on the exterior columns and spandrels was primarily obtained from photographs and video footage that were taken before and during the collapse of the buildings. For this reason, the impact damage on the exterior columns and spandrels were the same for all damage sets for each tower. The differences between damage sets existed in the way that the impact damage was defined for the core columns, core beams, and floors. The initial and final damage sets are summarized in Sections 2.2.2 and 2.2.3.

The difference between Case $A_{i}$ and Case $B_{i}$, Case $C_{i}$ and Case $D_{i}$, Case A and Case B, and Case C and Case $\mathrm{D}$ damage sets are the structural damage condition in core columns and beams, floors, and the extent of insulation damage that ensued from the abrasion of flying debris on the structural components. The differences in insulation damage condition resulted in different temperatures of the structural components. For this reason, each impact damage set has an associated temperature set. Temperature sets have the same names as the impact damage sets.

\subsubsection{Initial Damage Sets}

Case $A_{i}$, Case $B_{i}$, Case $C_{i}$, and Case $D_{i}$ damage sets were the initial aircraft impact damage sets defined by NIST. In terms of structural damage condition in exterior columns, Case $\mathrm{A}_{i}$ and Case $\mathrm{B}_{\mathrm{i}}$ and similarly Case $C_{i}$ and Case $D_{i}$ damage sets were identical. For this reason, only one set of structural damage condition in exterior columns is presented for each tower. The structural damage condition for the floors 
and core columns was not provided for Case $\mathrm{B}_{i}$ of WTC 1 , and the structural damage condition for the core columns was not provided for Case $D_{i}$ of WTC 2. The damage sets presented in this section were used in the full floor subsystem models and global models without creep.

The severed columns and spandrels on the exterior walls of WTC 1 and WTC 2 are shown in Figs. 2-2 and 2-3. For comparison, core columns and beams before aircraft impact are shown in Figs. 2-4 and 2-5 for WTC 1 and WTC 2, respectively. The severed columns in the core area for Case $A_{i}$ of WTC 1 and for Case $C_{i}$ and revised Case $C_{i}$ are shown in Figs. 2-6, 2-7, and 2-8. The core column series that are not shown in these figures did not include severed columns. Since global models included only core beams that had moment connections at the ends as described in Chapter 4 , these figures do not show all the core beams that existed in the WTC towers. The difference between Case $\mathrm{C}_{\mathrm{i}}$ and revised Case $\mathrm{C}_{\mathrm{i}}$ is only in the impact damage to the core columns (see Figs. 2-7 and 2-8). Revised Case $\mathrm{C}_{\mathrm{i}}$ damage was received later and, consequently, was not included in some of the earlier analyses. The associated temperature sets are identical.

Case $A_{i}$, Case $C_{i}$, and Case $D_{i}$ floor impact damage conditions are shown in Figs. 2-9 throuth 2-14. The figures show damage to structural elements, including slabs and supporting steel framing, as well as to the insulation on the framing. The shell elements of the floors and beam elements of core beams were removed from the global models at appropriate locations to replicate the areas of structural damage indicated in these figures. For regions where the floor slab was coarsely meshed in the global models, the elements were removed in such a way as to capture force discontinuities resulting from the structural damage in that region. This sometimes resulted in the removal of a somewhat larger floor area in the global models than indicated in Figs. 2-10, 2-12, and 2-14.

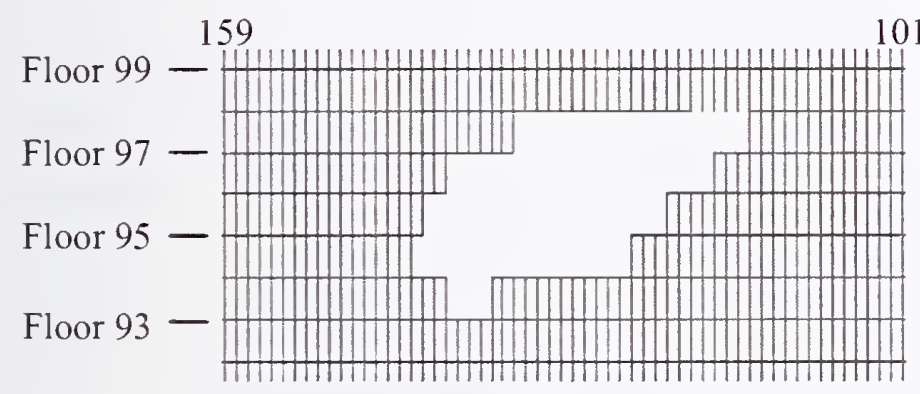

(a) North face
101359

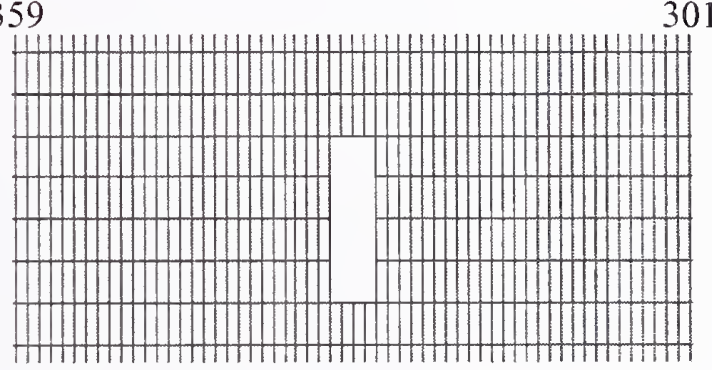

(b) South face

Figure 2-2. Structural damage condition on the exterior walls of WTC 1 for all cases of impact damage. 


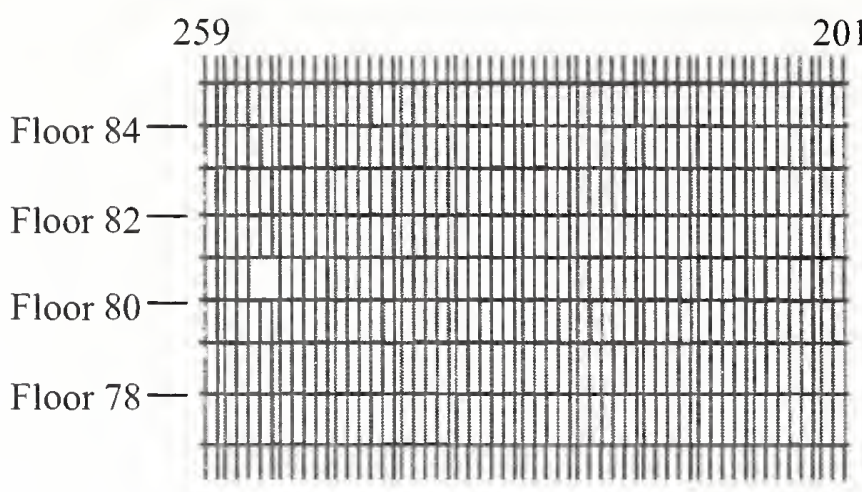

(a) North face
201459

401

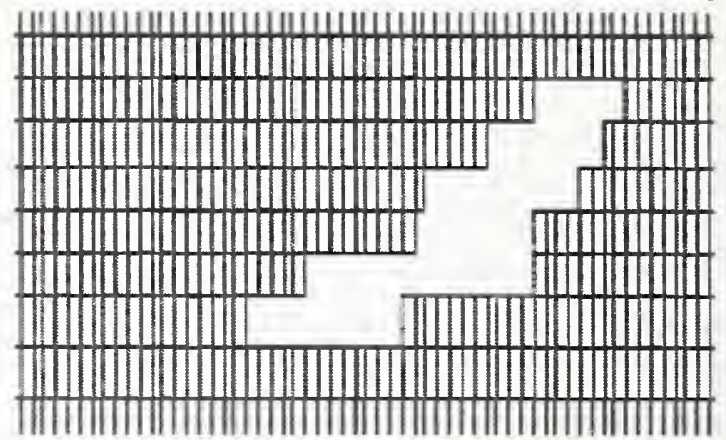

(b) South face

Figure 2-3. Structural damage condition on the exterior walls of WTC 2 for all cases of impact damage.

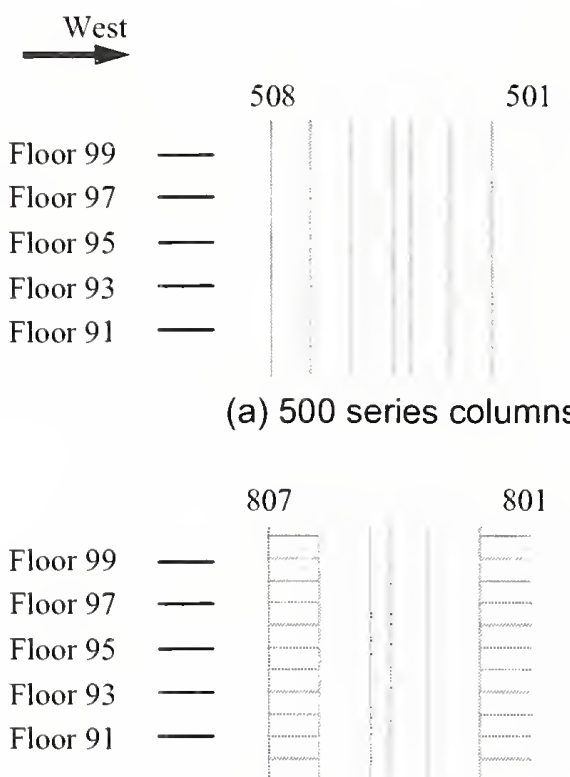

(d) 800 series columns

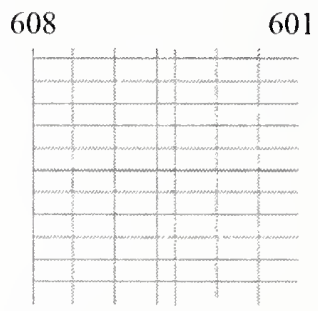

(b) 600 series columns

908

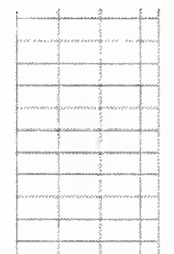

(e) 900 series columns
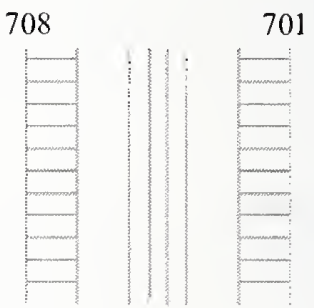

(c) 700 series columns
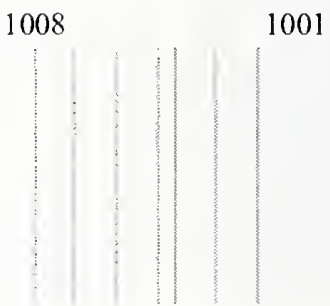

(f) 1000 series columns

Figure 2-4. Core columns and core beams in the WTC 1 global model without aircraft impact damage. 


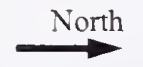

508

501

608

601

708

701

Floor $85-$

Floor 83

Floor $81-$

Floor $79-$

(a) 500 series columns

(b) 600 series columns
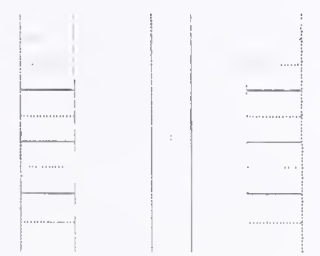

807

$80 \mathrm{i}$

908

901

(c) 700 series columns

$\begin{array}{ll}\text { Floor } 85 & - \\ \text { Floor } 83 & - \\ \text { Floor } 81 & - \\ \text { Floor } 79 & -\end{array}$

(d) 800 series columns

(e) 900 series columns

(f) 1000 series columns

Figure 2-5. Core columns and core beams in the WTC 2 global model without aircraft impact damage.

West

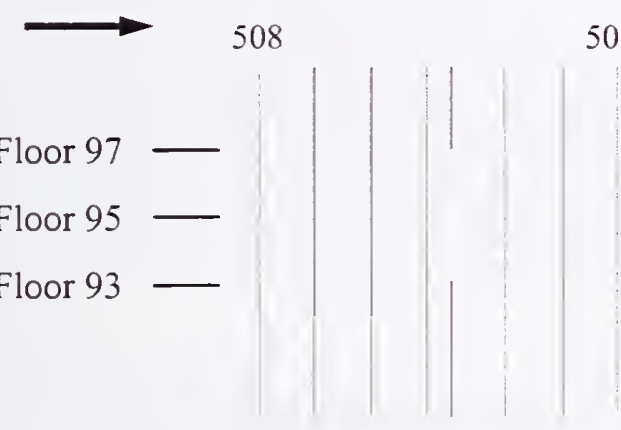

(a) 500 series columns

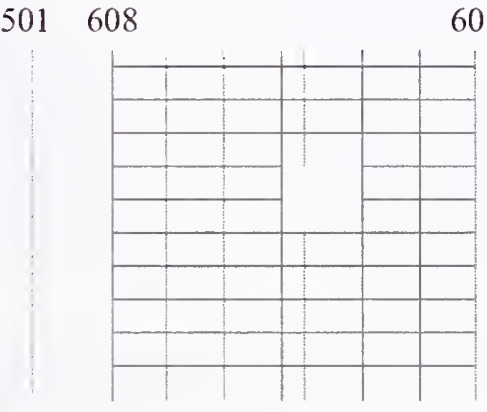

(b) 600 series columns

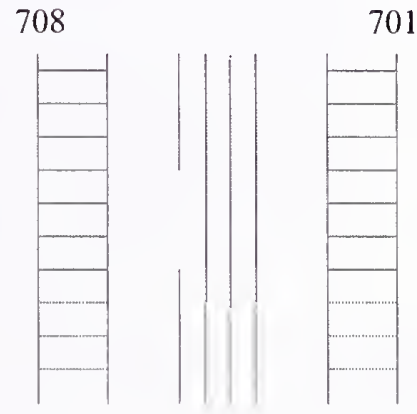

(c) 700 series columns

Figure 2-6. Case $A_{i}$ structural damage condition on the core columns of WTC 1. 


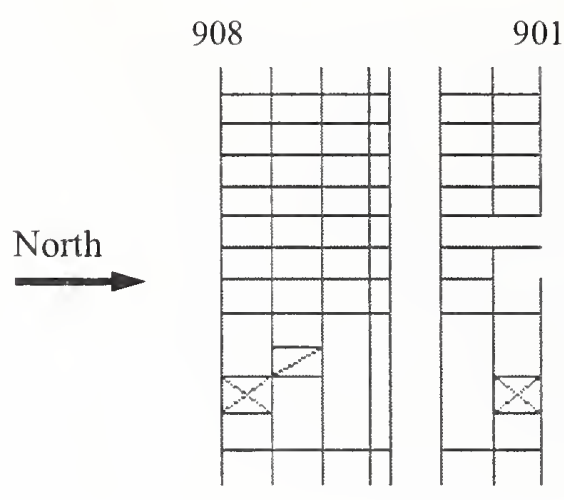

(a) 900 series columns

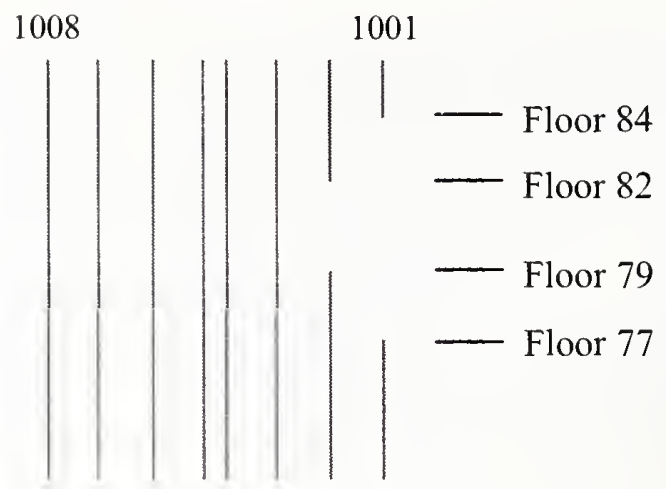

(b) 1000 series columns

Figure 2-7. Case $C_{i}$ structural damage condition on the core columns of WTC 2.

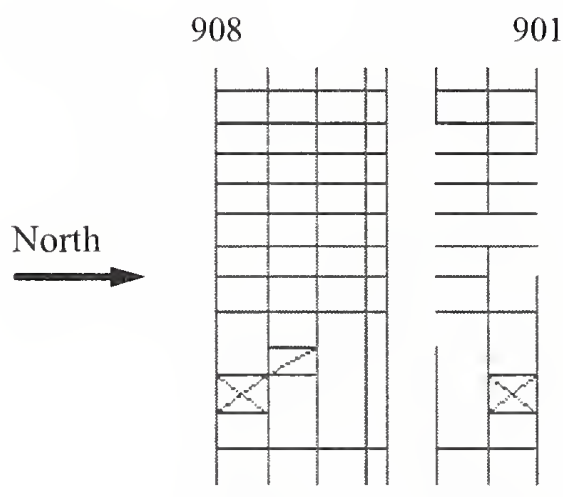

(a) 900 series columns

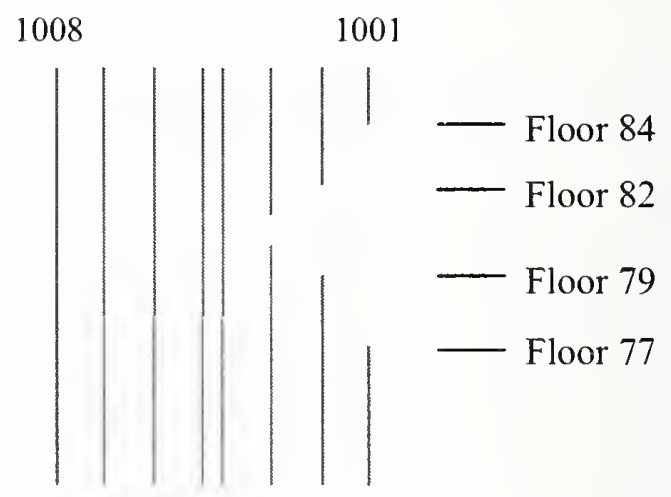

(b) 1000 series columns

Figure 2-8. Revised Case $C_{i}$ structural damage condition on the core columns of WTC 2. 


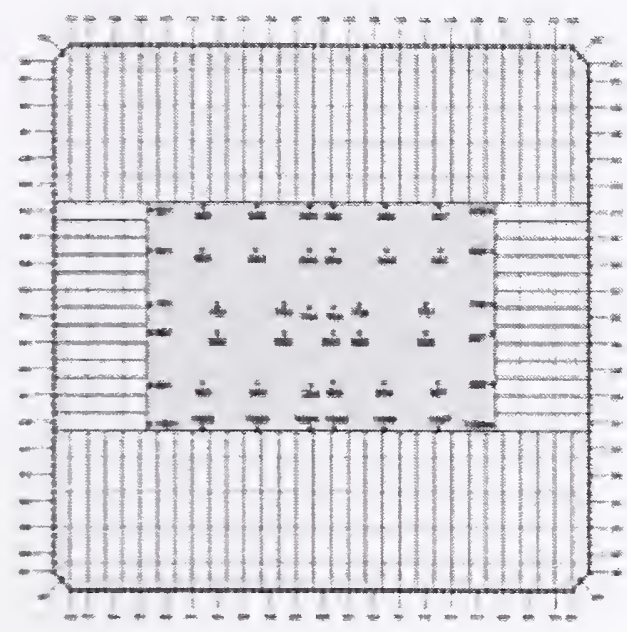

(a) Floor 94

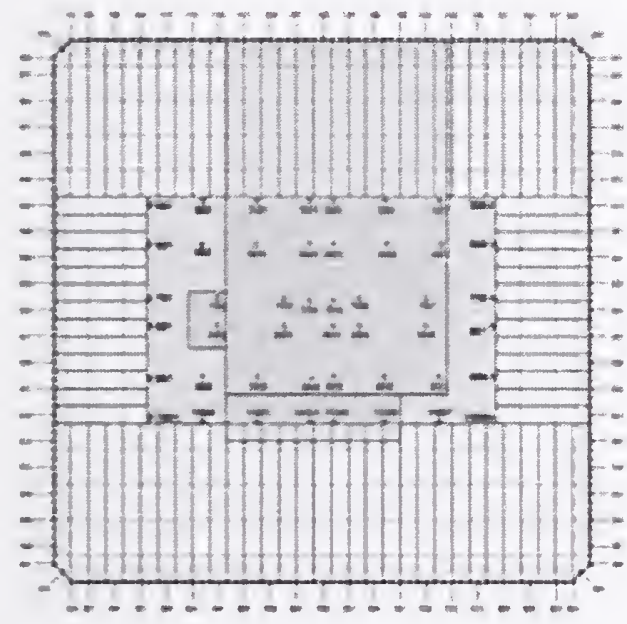

(c) Floor 96

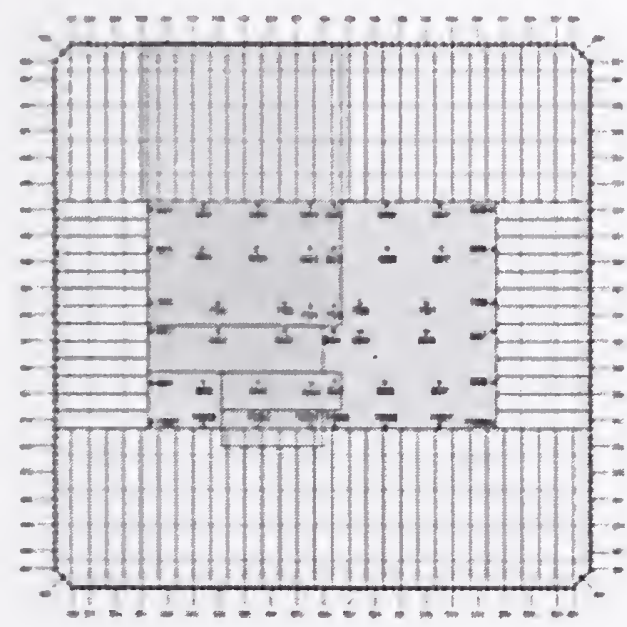

(e) Floor 98

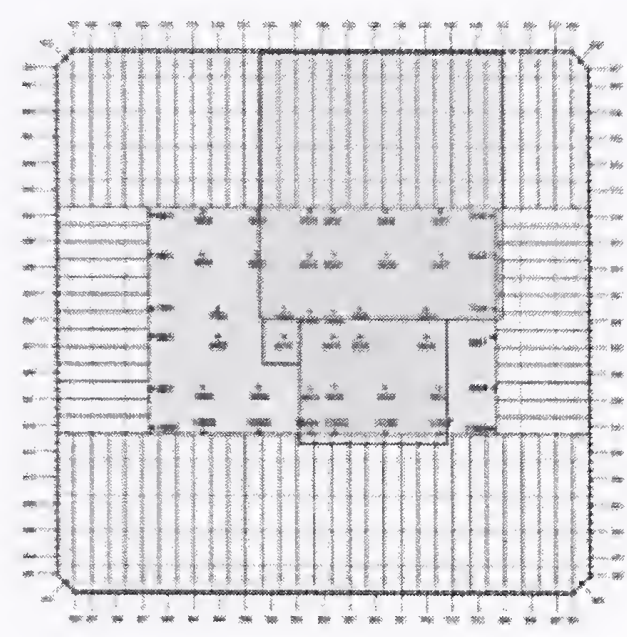

(b) Floor 95

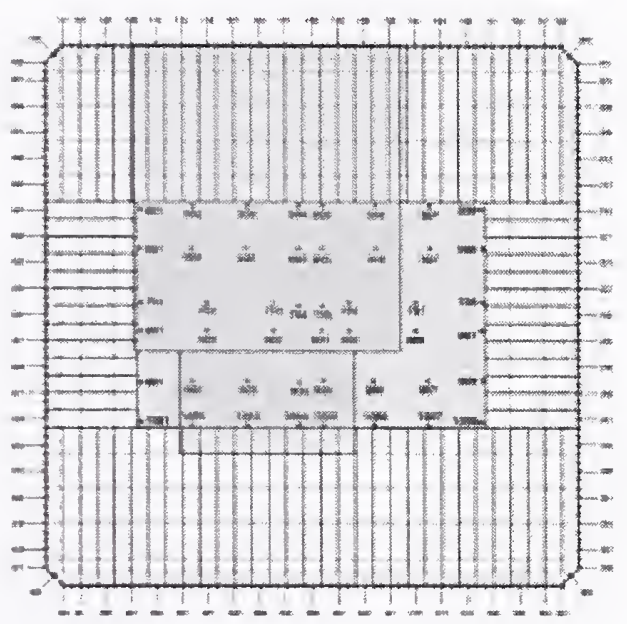

(d) Floor 97
$N$

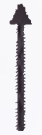

Insulation damage to

core beams and trusses

Figure 2-9. Case $A_{i}$ insulation damage conditions for WTC 1 floor trusses and beams. 


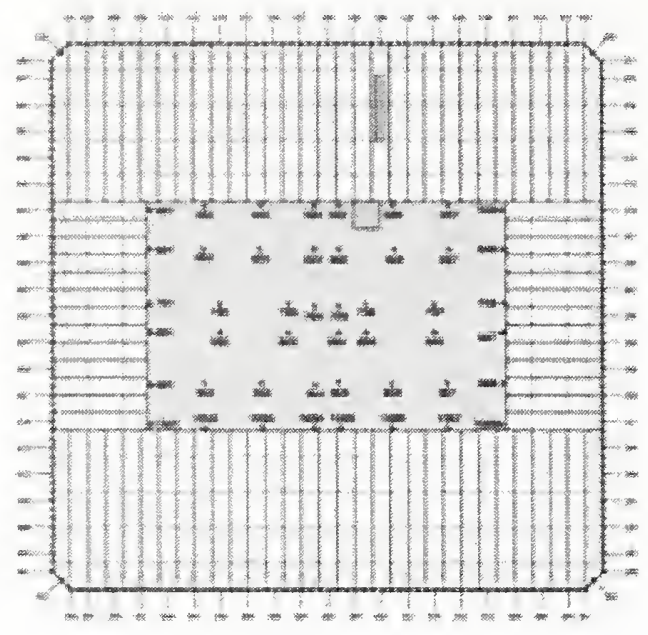

(a) Floor 94

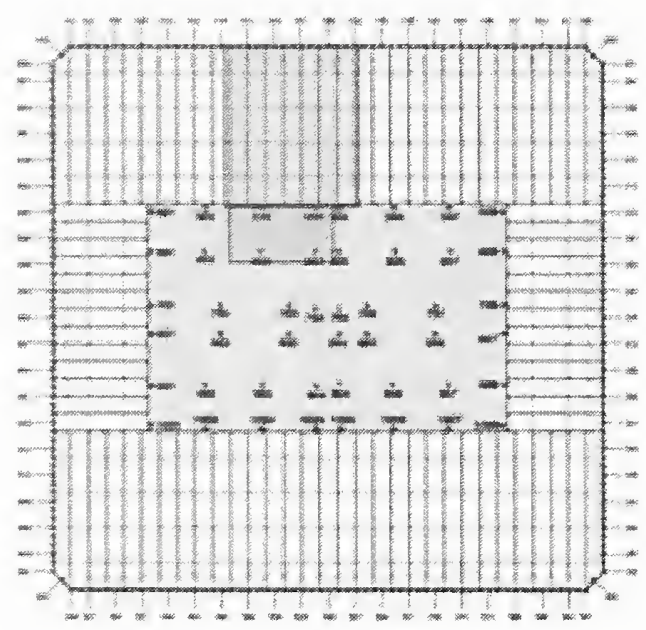

(c) Floor 96

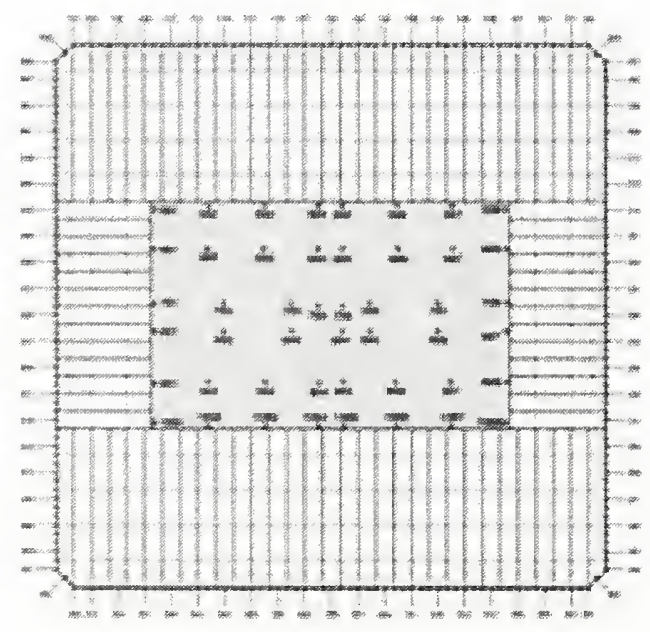

(e) Floor 98

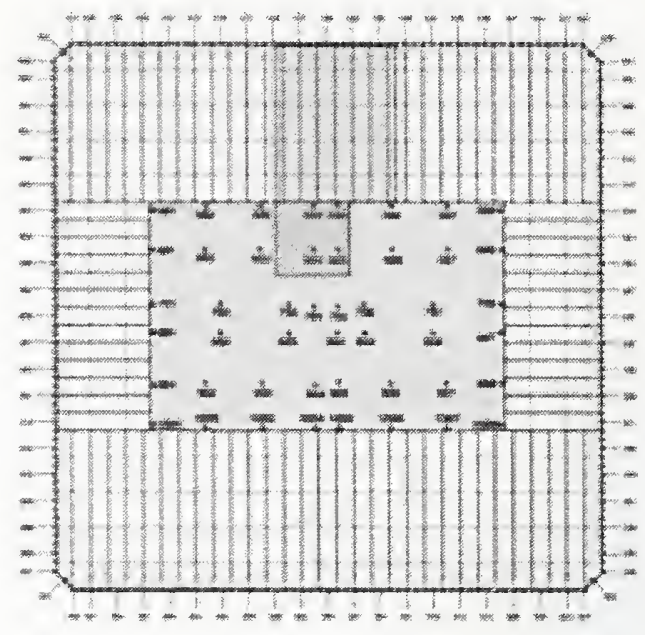

(b) Floor 95

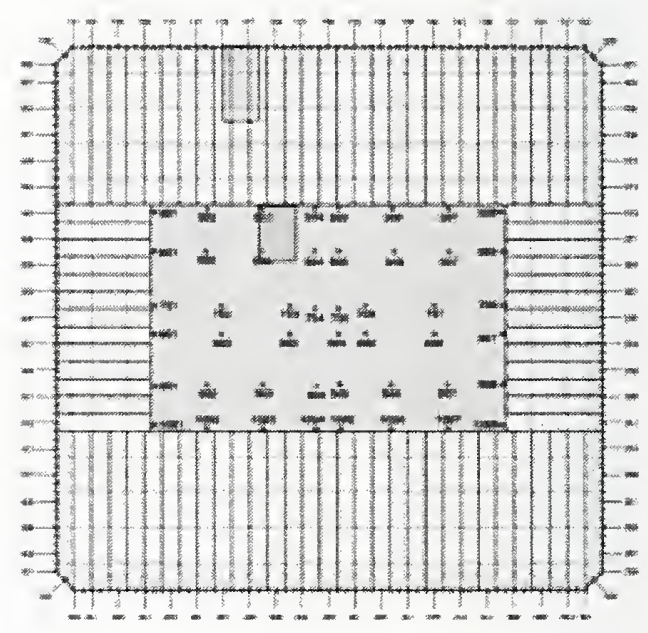

(d) Floor 97

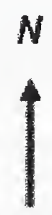

Structural damage to concrete slab, core beams, and trusses

Figure 2-10. Case $A_{i}$ structural damage conditions for WTC 1. 


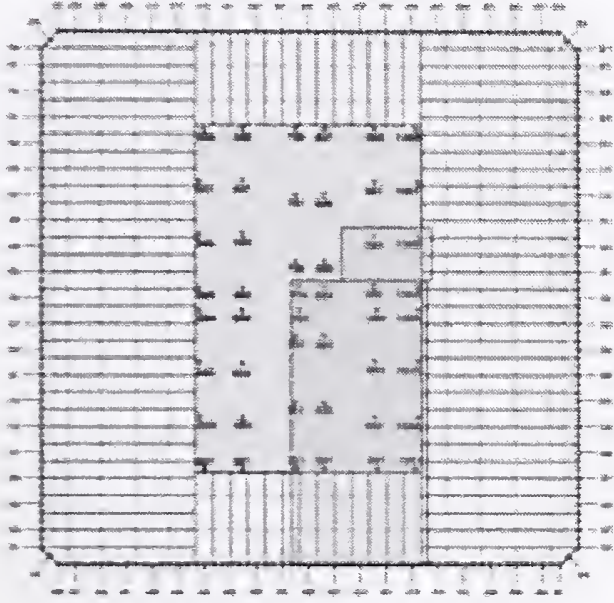

(a) Floor 79

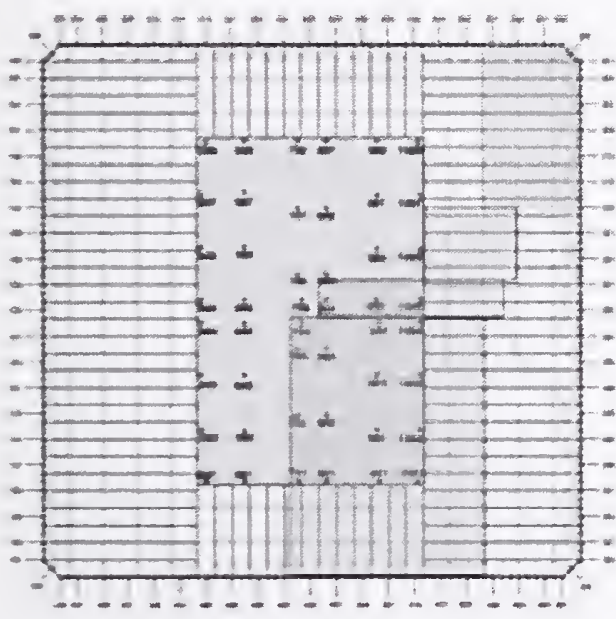

(c) Floor 81

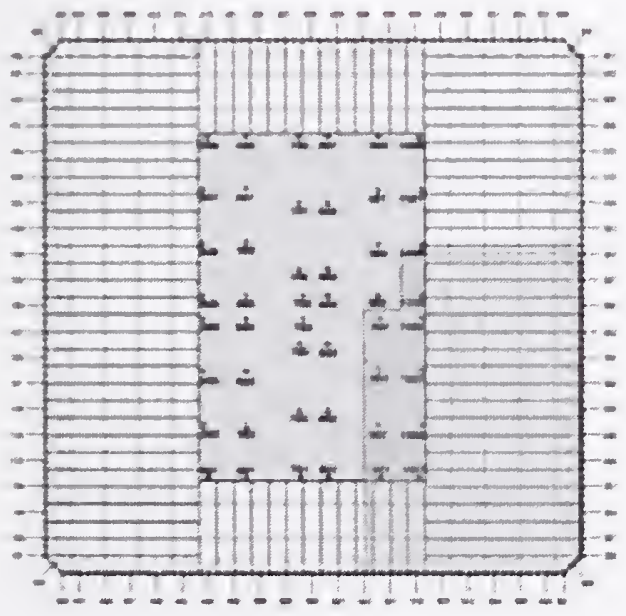

(e) Floor 83

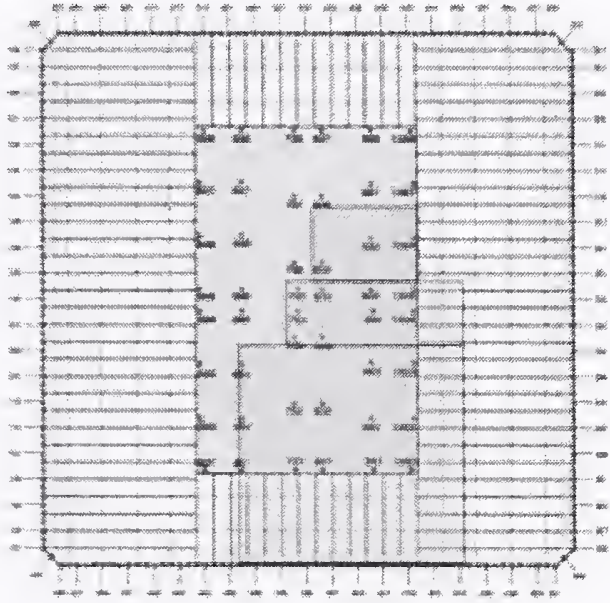

(b) Floor 80

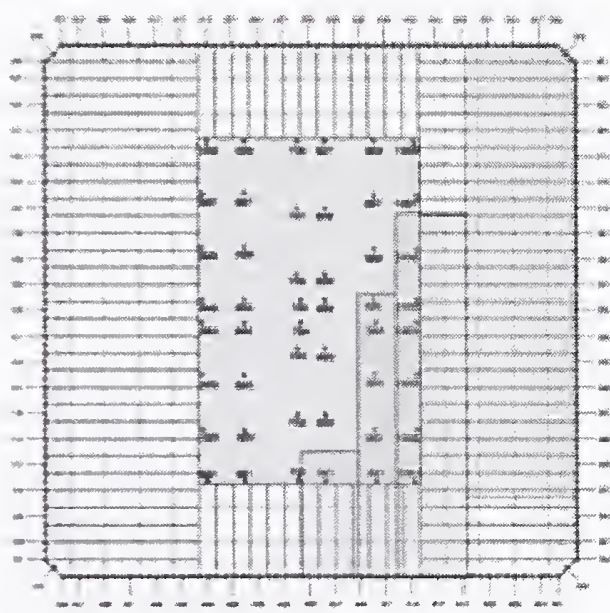

(d) Floor 82

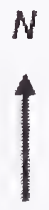

Insulation damage to

core beams and trusses

Figure 2-11. Case $C_{i}$ insulation damage conditions for WTC 2 floor trusses and beams. 


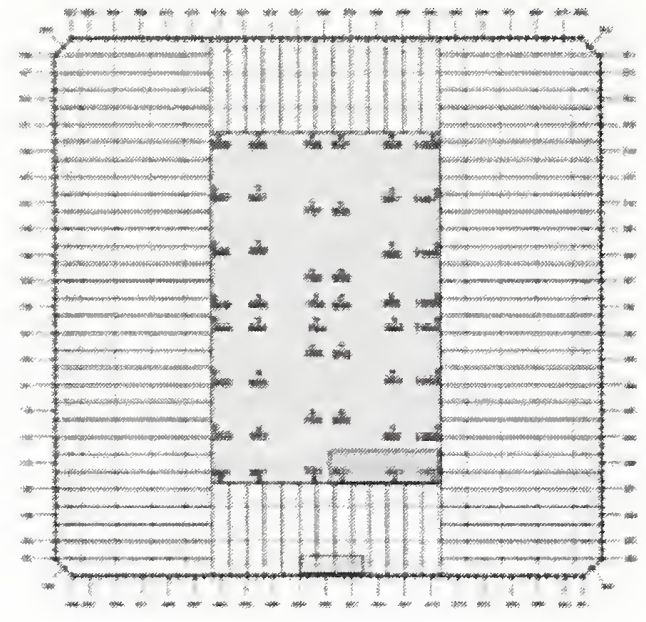

(a) Floor 79

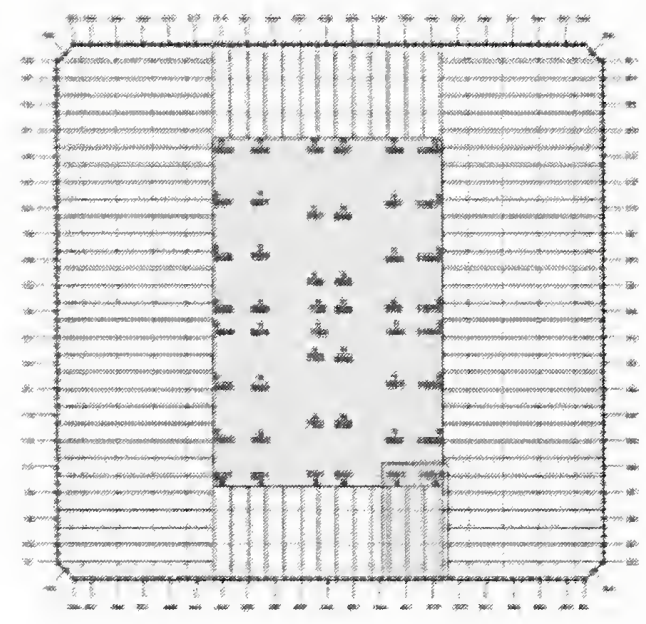

(c) Floor 81

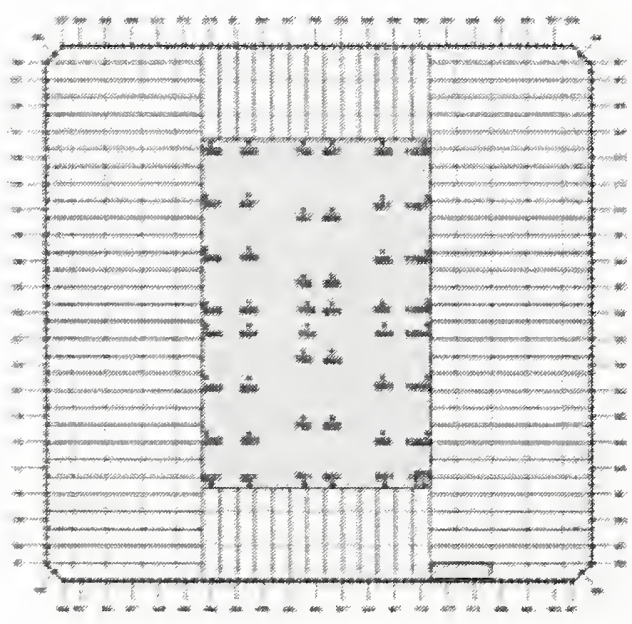

(e) Floor 83

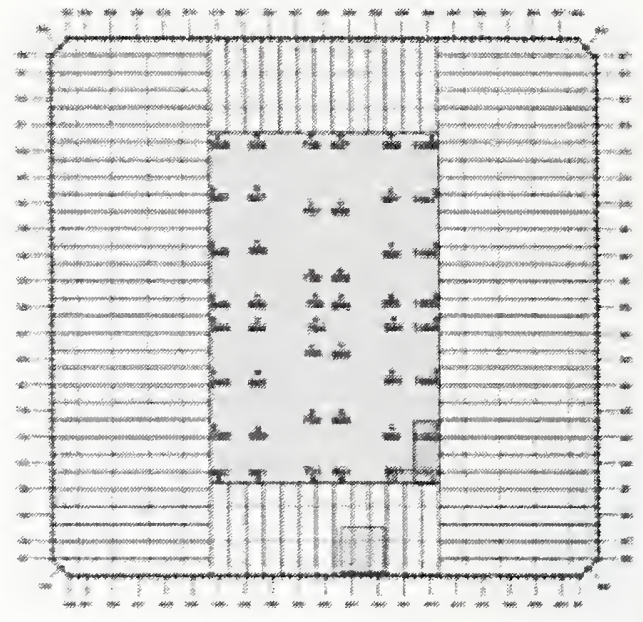

(b) Floor 80

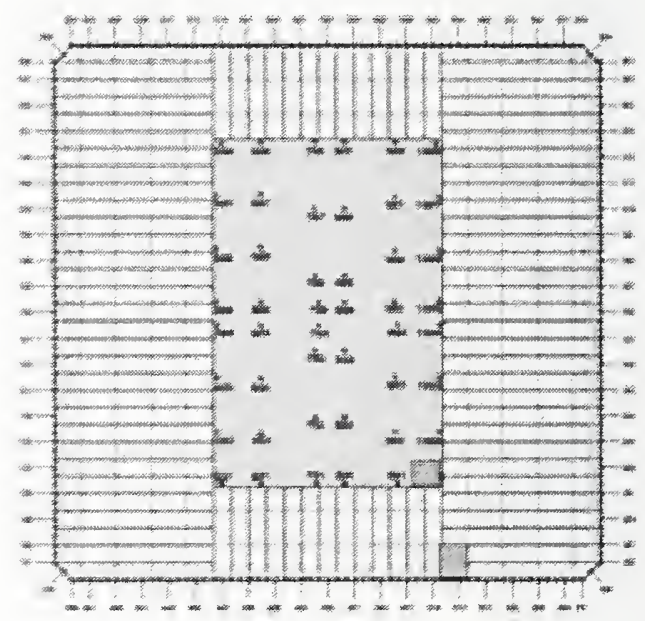

(d) Floor 82

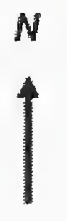

Structural damage to concrete slab, core beams, and trusses

Figure 2-12. Case $C_{i}$ Structural damage conditions for WTC 2 floors. 


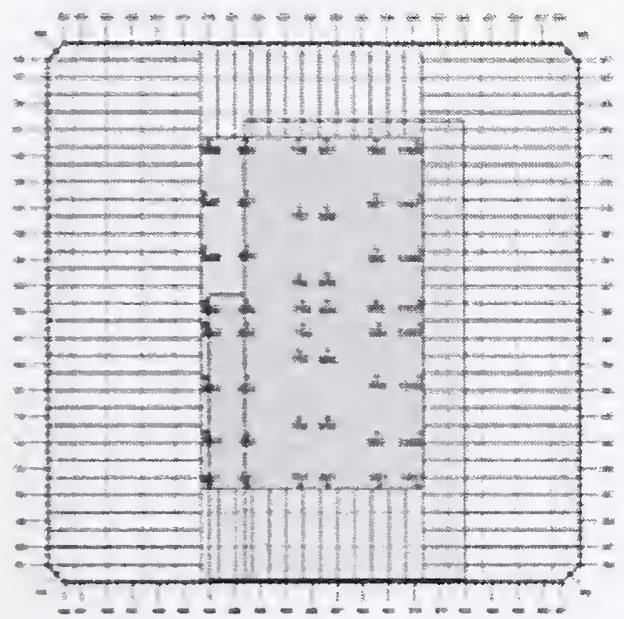

(a) Floor 79

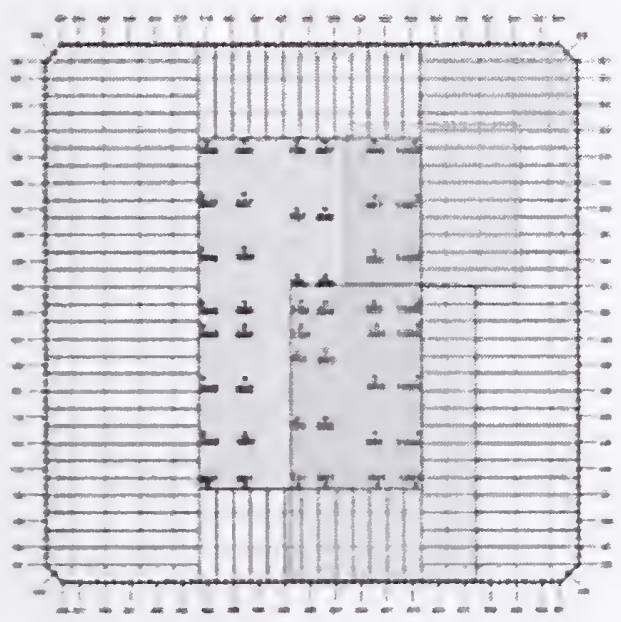

(c) Floor 81

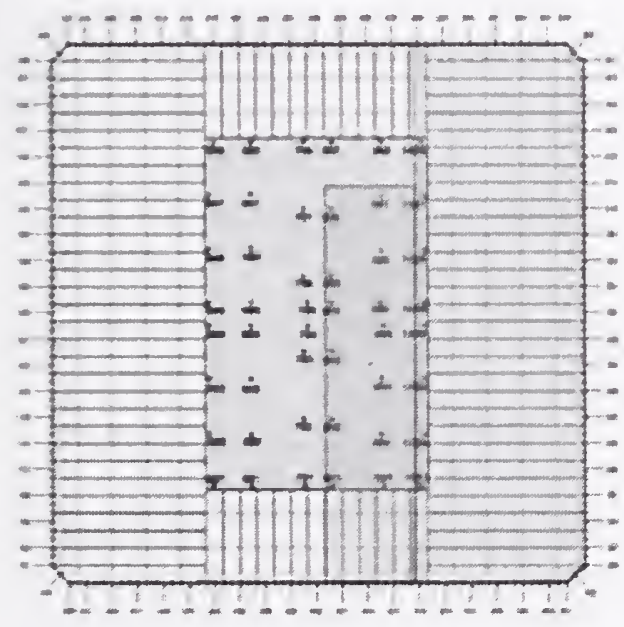

(e) Floor 83

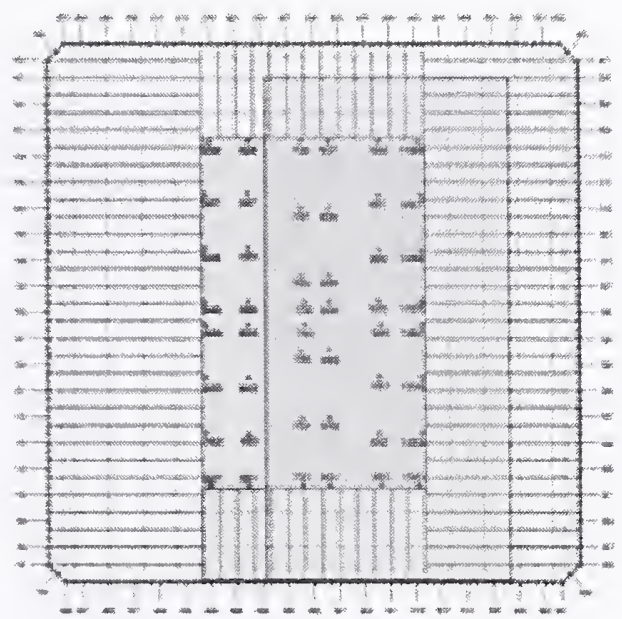

(b) Floor 80

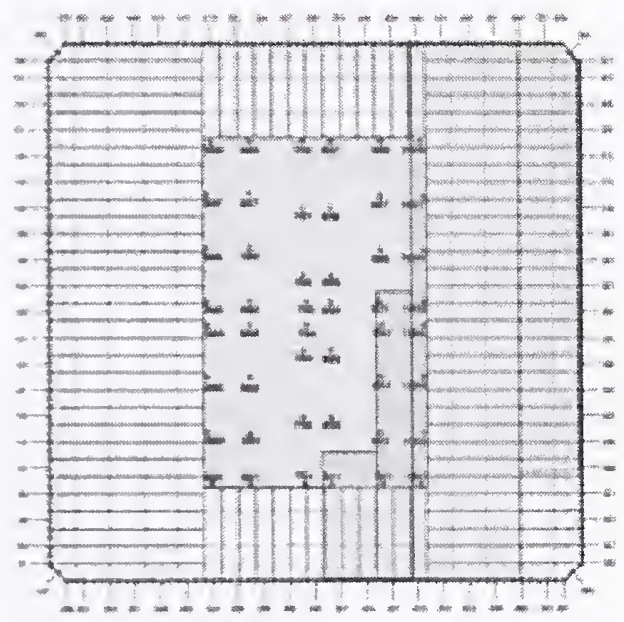

(d) Floor 82

$$
\uparrow
$$

Irisulation damage to core beams and trusses

Figure 2-13. Case $D_{i}$ insulation damage conditions for WTC 2 floor trusses and beams. 


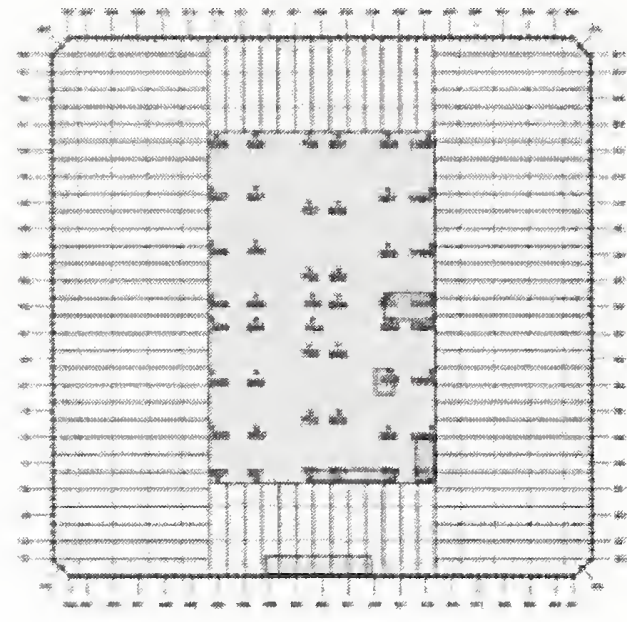

(a) Floor 79

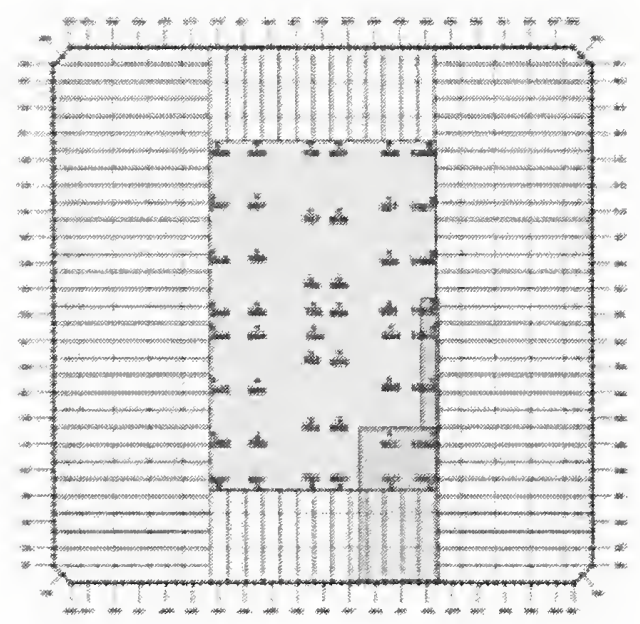

(c) Flonr 81

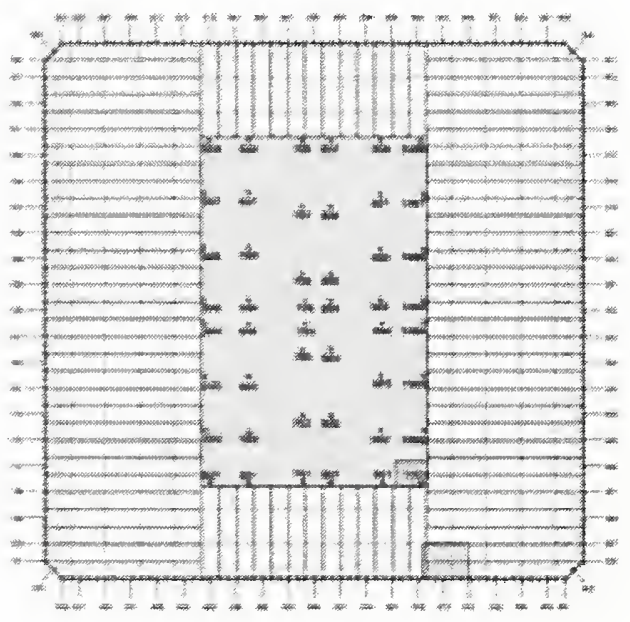

(e) Floor 83

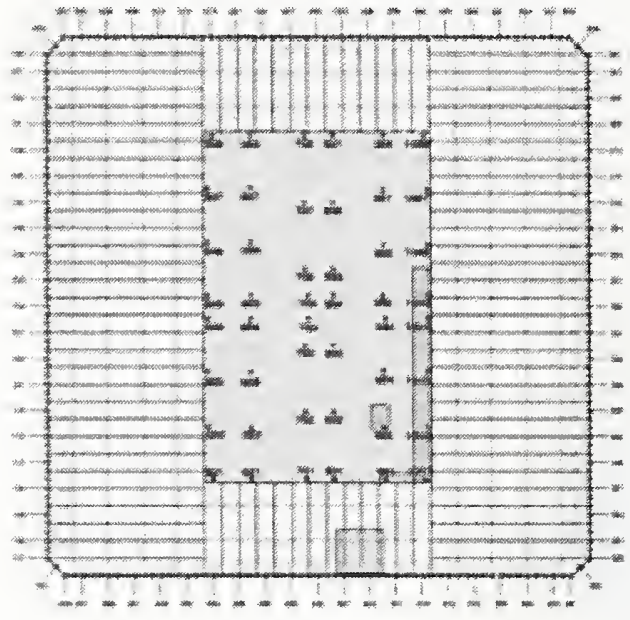

(b) Floor 80

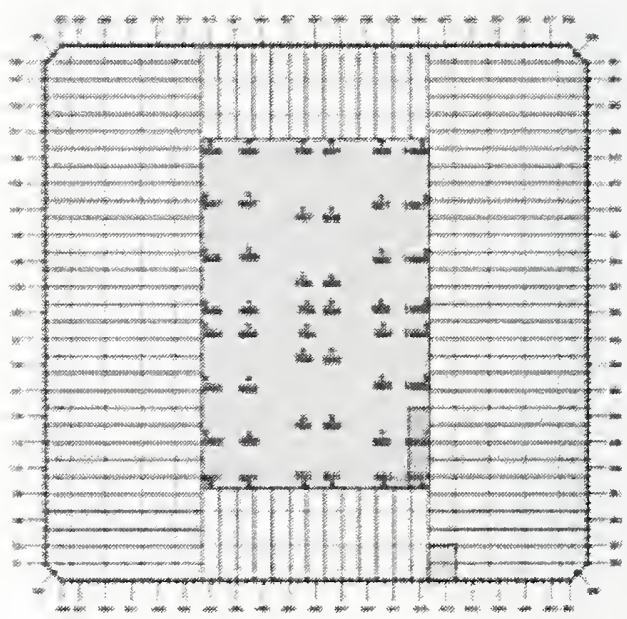

(d) Floor 82

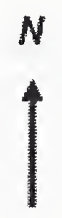

Structural damage to cancrete slab, core beams, and trusses

Figure 2-14. Case $D_{i}$ Structural damage conditions for WTC 2 floors. 


\subsubsection{Final Damage Sets}

NIST provided a series of final damage sets for use in the global analyses. Two sets were provided for each of the two buildings, together with temperature time history data sets computed by NIST based on the damage set. The final damage sets for WTC 1 were designated Case A and Case B, respectively, representing different scenarios of aircraft impact damage to the structure and thermal insulation. The final damage sets for WTC 2 were designated Case C and Case D. The exterior wall damage contained in the final damage sets are identical to those in the contained in the initial damage sets, described in the previous section and illustrated in Figs. 2-2 and 2-3. However, the projected damage to floor and core elements differed from the initial damage sets. The final damage sets were used in SGH analyses of the isolated wall models, the isolated core models, and the global analyses with creep.

The severed columns in the core area of WTC 1 for Case A and Case B and WTC 2 for Case C and Case D are shown in Figs. 2-15 through 2-18. For Case B and Case D structural damage condition, heavily damaged core columns were also considered as severed and removed from the analysis. Columns removed from the global models are shown as missing vertical lines in these figures. For WTC 2, core column 902 was assigned a moderate damage state after aircraft impact at Floor 79 and Floor 80 by NIST. The preliminary analyses showed that this column buckled after aircraft impact and caused numerical problems in the temperature time history analyses. Therefore, in the Case D damage set, this column was also treated as heavily damaged and removed from the model. The core column series that are not shown in Figs. 2-15 through 2-18 did not include severed columns for all the cases or heavily damaged columns for Case B of WTC 1 and Case D of WTC 2.

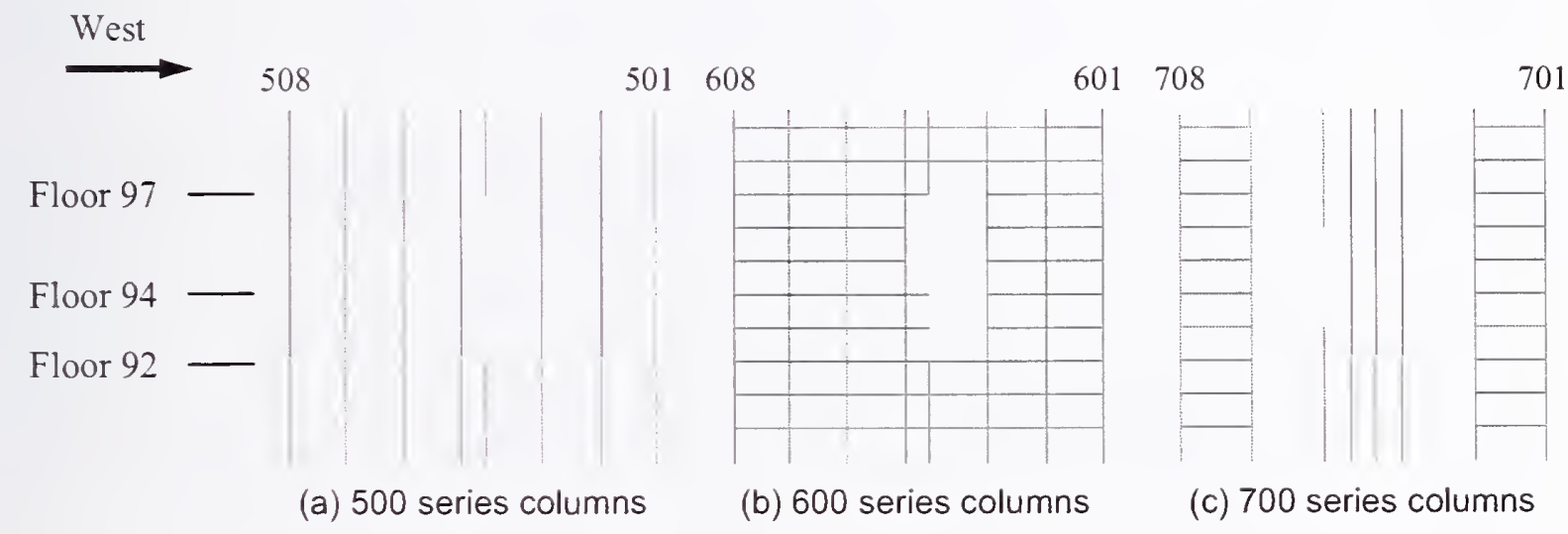

Figure 2-15. Case A structural damage condition on the core columns of WTC 1. 


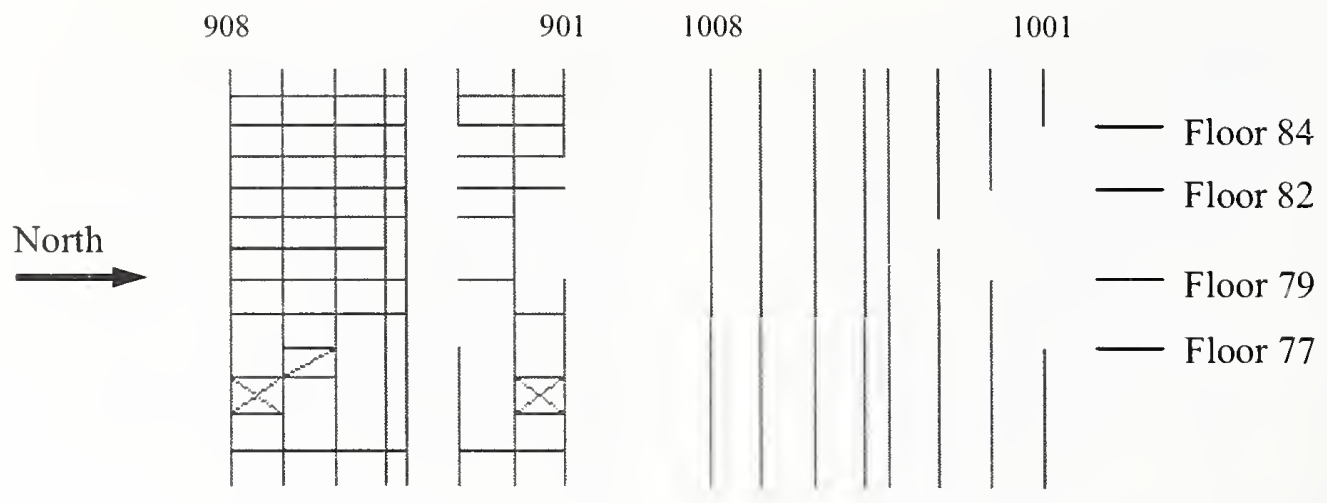

(a) 900 series columns

(b) 1000 series columns

Figure 2-16. Case C structural damage condition on the core columns of WTC 2.

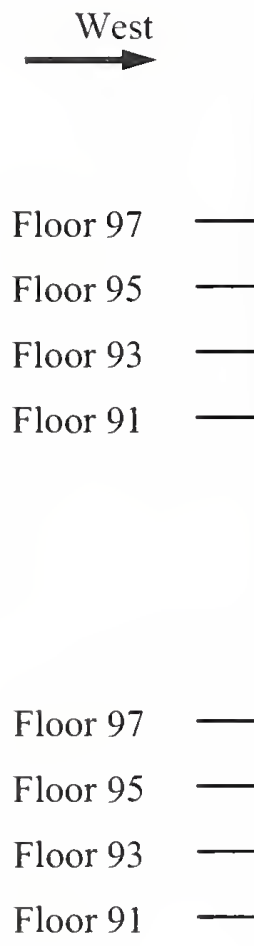

508

501608

601708

701

807

(a) 500 series columns

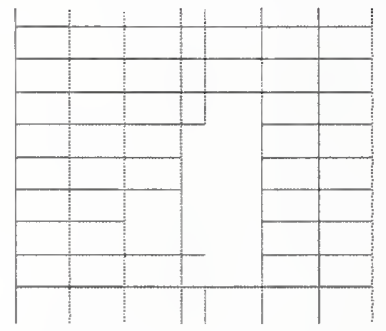

(b) 600 series columns

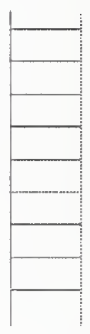

(c) 700 series columns

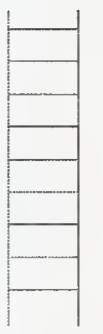

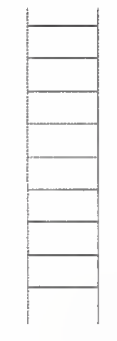

(a) 800 series columns
801908
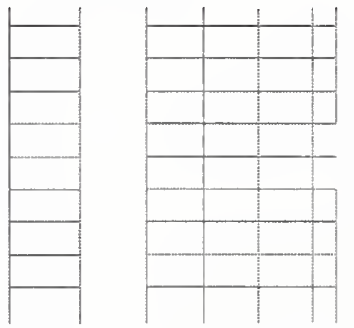

(b) 900 series columns

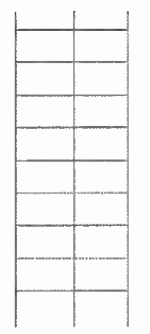

901

Figure 2-17 Case B structural damage condition on the core columns of WTC 1 (including heavily damaged columns). 


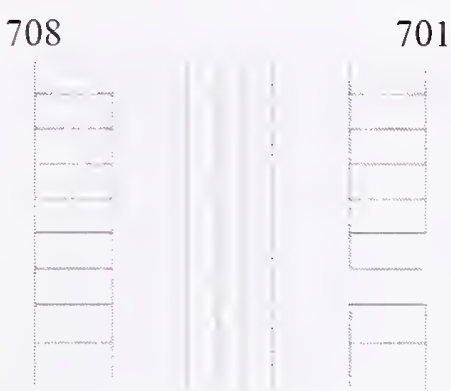

(a) 700 series columns
$701 \quad 807$

908

901

1008

(b) 800 series columns

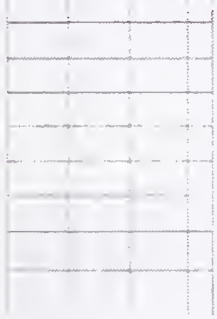

(c) 900 series columns
801

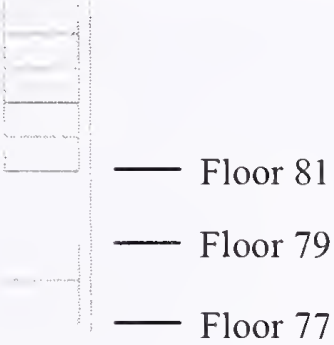

Floor 77

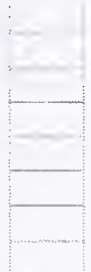

North

1001

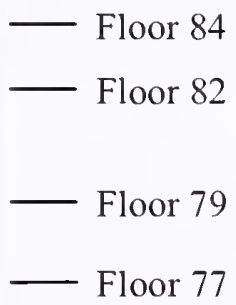

(d) 1000 series columns

Figure 2-18. Case D structural damage condition on the core columns of WTC 2 (including heavily damaged columns).

The floor insulation and structural damage conditions are shown in Figs. 2-19 and 2-20 for Case A, in Figs. 2-23 and 2-24 for Case B, in Figs. 2-21 and 2-22 for Case C, and in Figs. 2-25 and 2-26 for Case D.

The shell elements of the floors and beam elements of core beams were removed from the global models at appropriate locations to replicate the areas of structural floor damage indicated in these figures. For the regions where the floor slab was coarsely meshed, the elements were removed in such a way as to capture force discontinuities resulting from the structural damage in that region. This sometimes resulted somewhat larger floor openings than indicated in Figs. 2-20, 2-22, 2-24, and 2-26. However, as discussed in Chapter 4, the dead and live loads of the floor system were applied as concentrated loads to the connecting columns; this minimized the effect of slightly larger floor openings. 


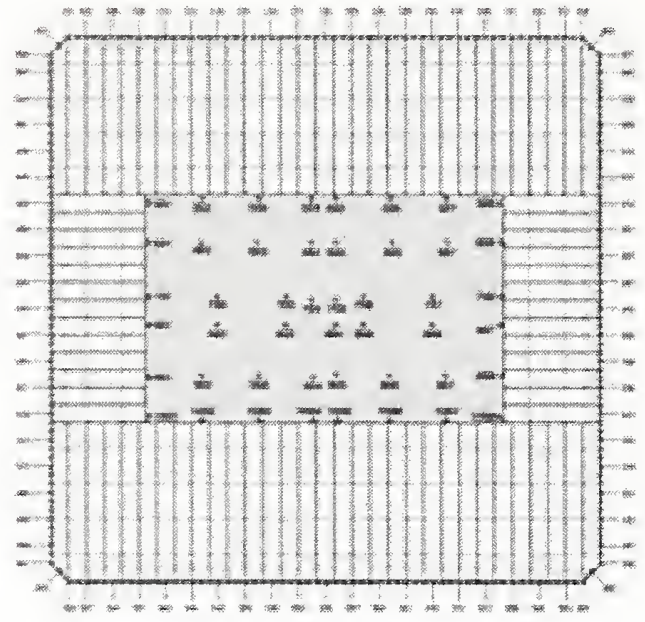

(a) Floor 94

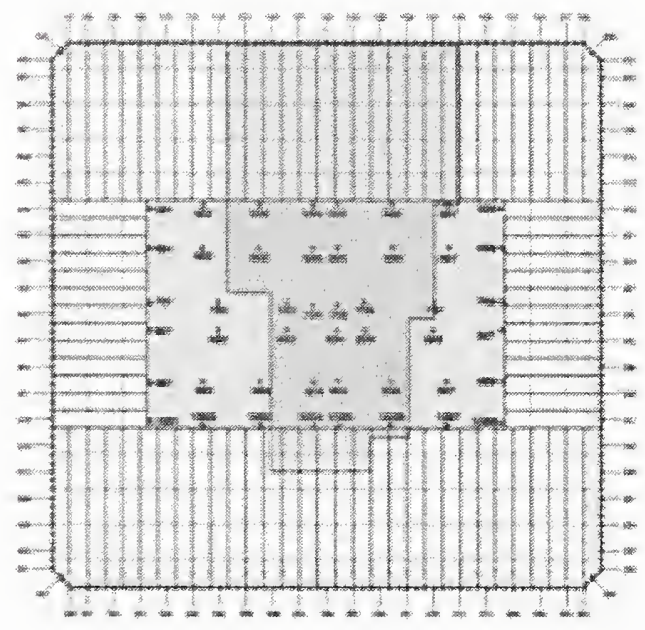

(c) Floor 96

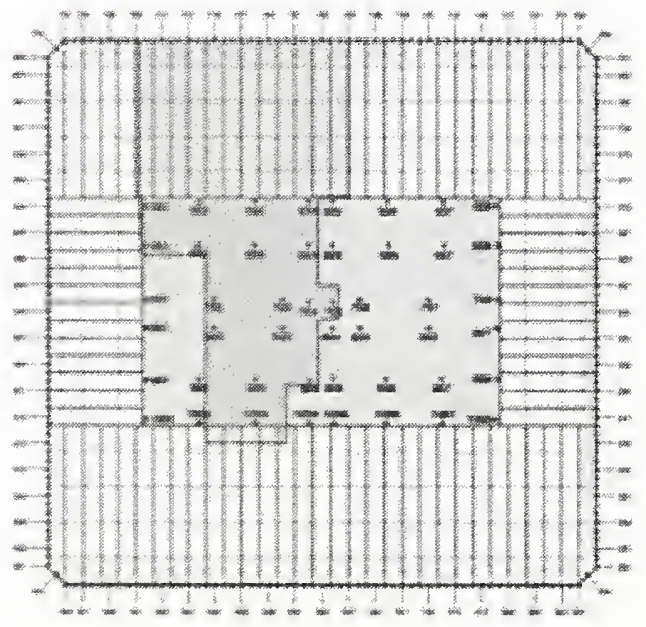

(e) Floor 98

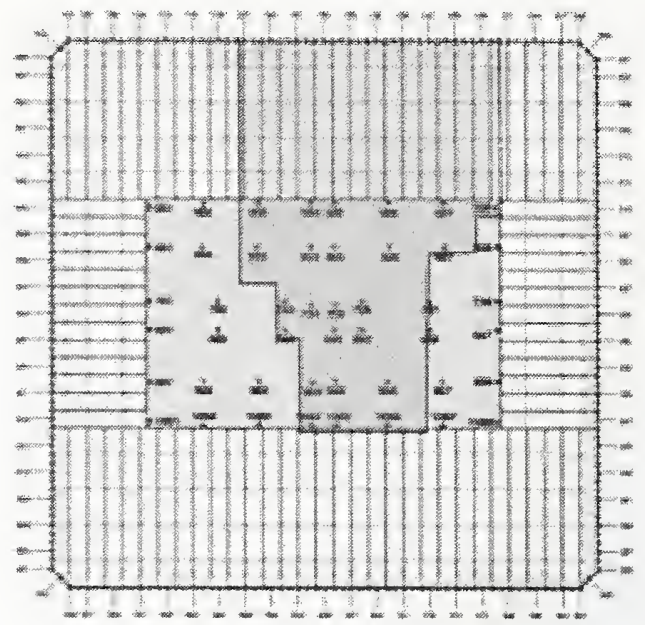

(b) Floor 95

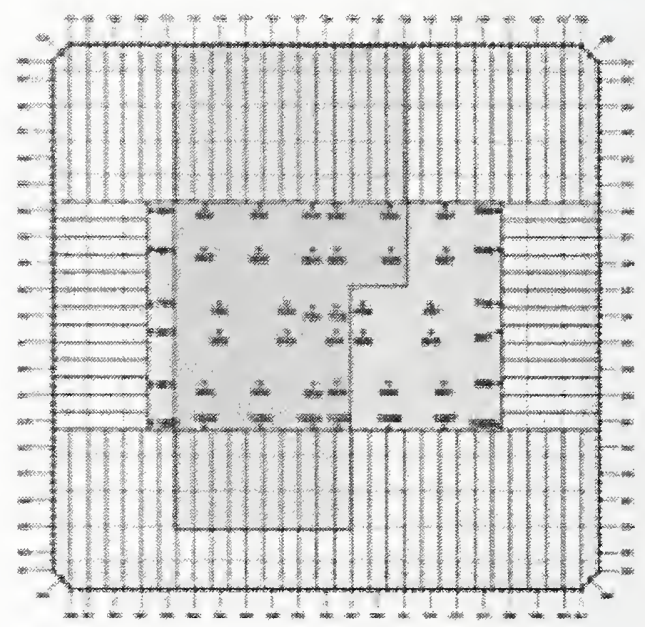

(d) Floor 97

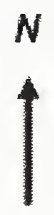

Insulation damage to core beams and trusses

Figure 2-19. Case A insulation damage condition for WTC 1 floor trusses and beams. 


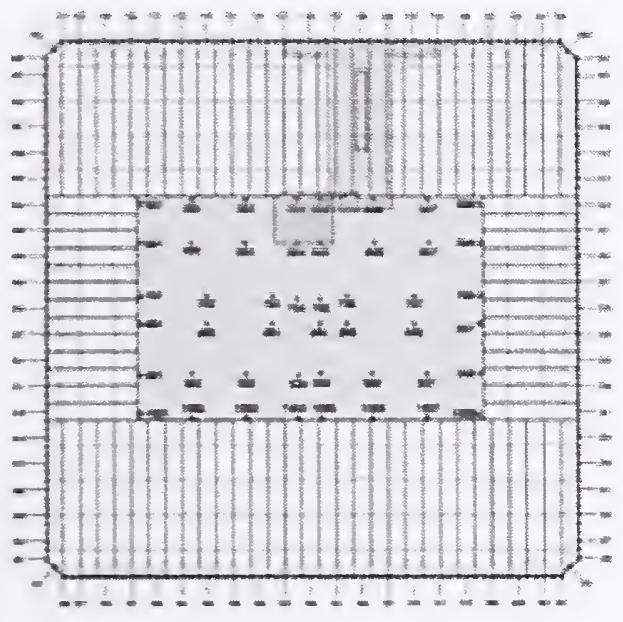

(a) Floor 94

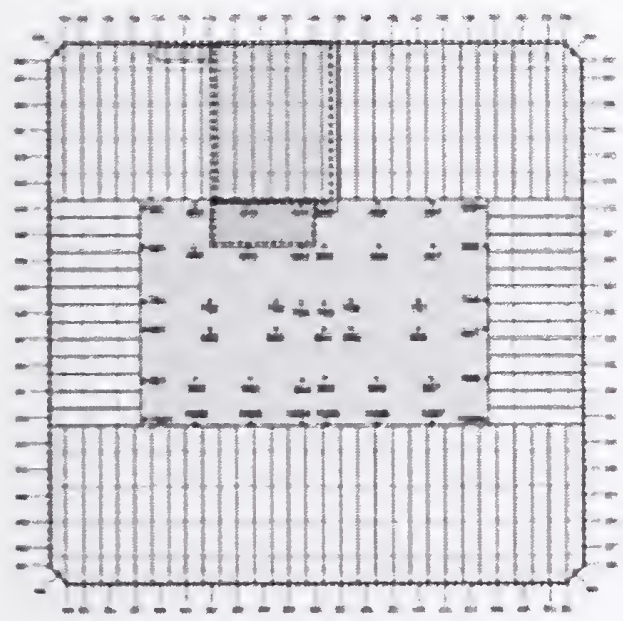

(c) Floor 96

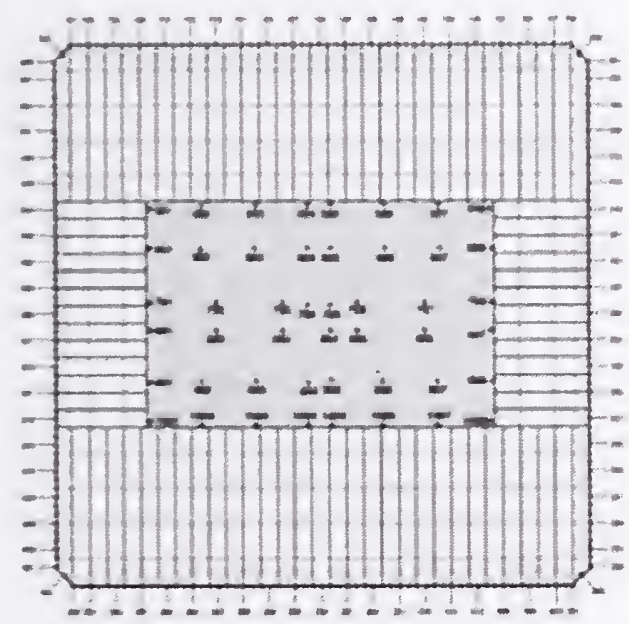

(e) Floor 98

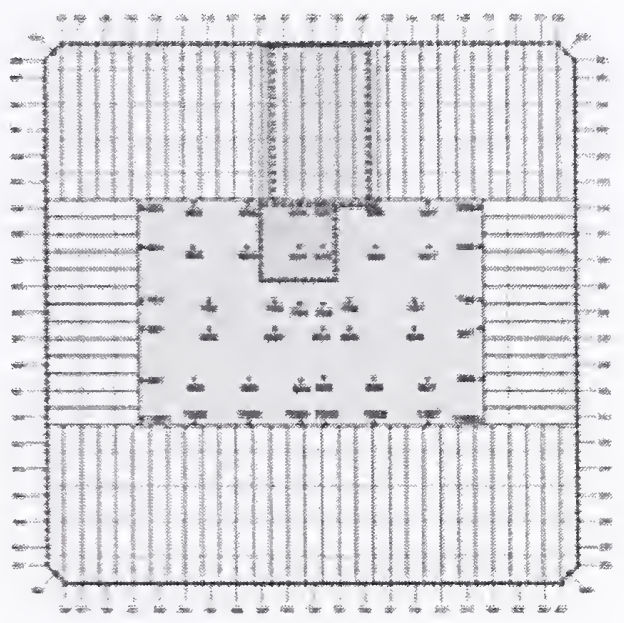

(b) Floor 95

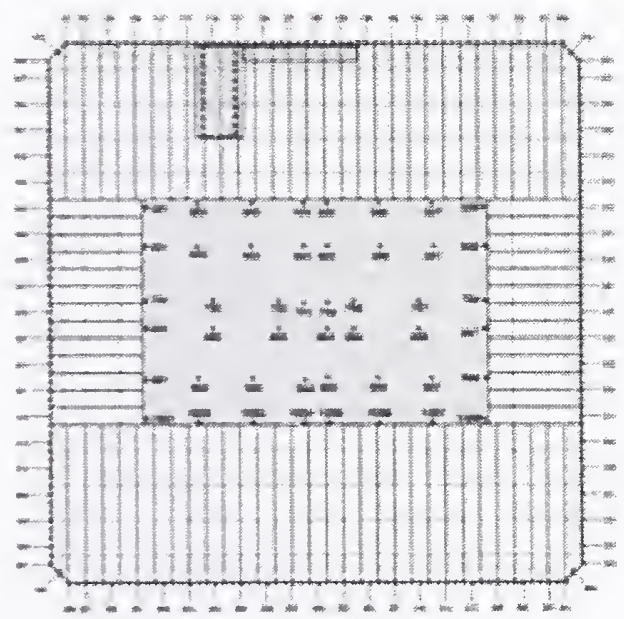

(d) Floor 97

$$
\begin{aligned}
& N \\
& 4
\end{aligned}
$$

Structural damage to concrete slab, core beams, and trusses

Severed floor area

Figure 2-20. Case A structural damage condition for WTC 1 floors. 


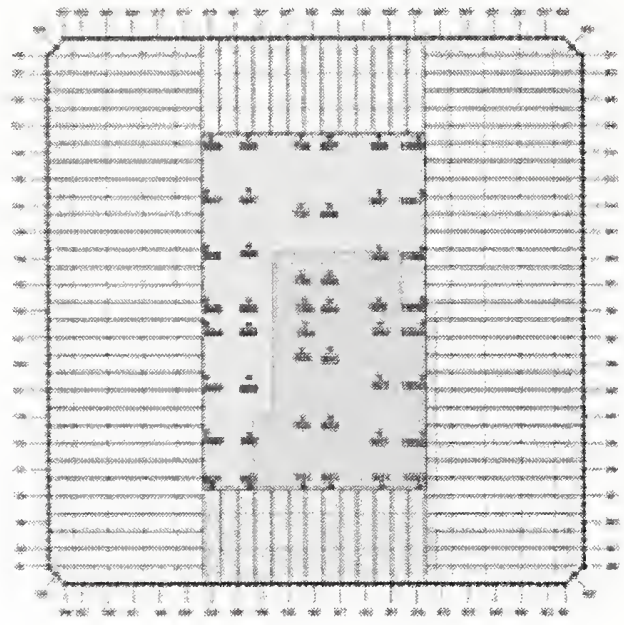

(a) Floor 79

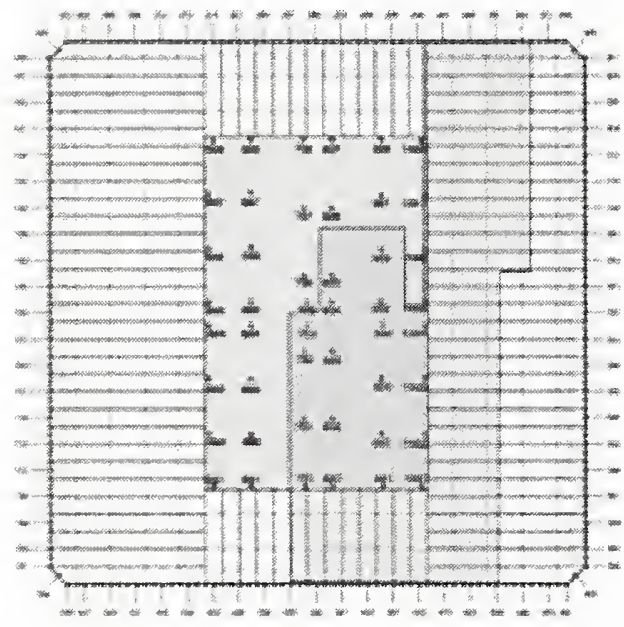

(c) Flour 81

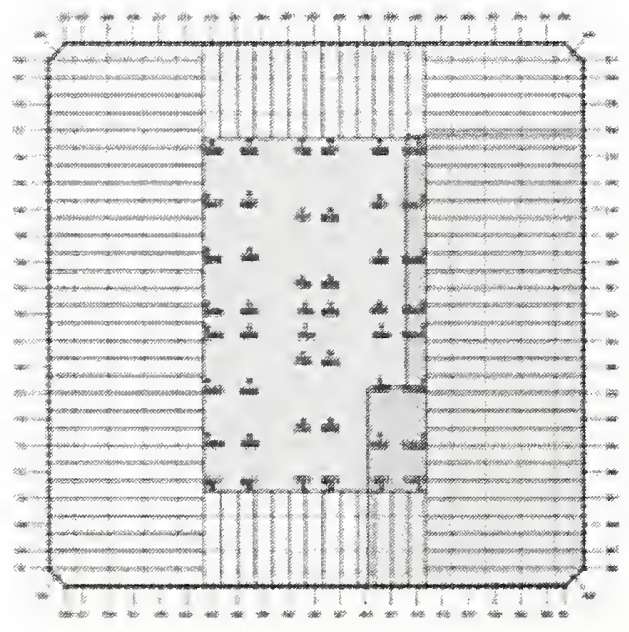

(e) Floor 83

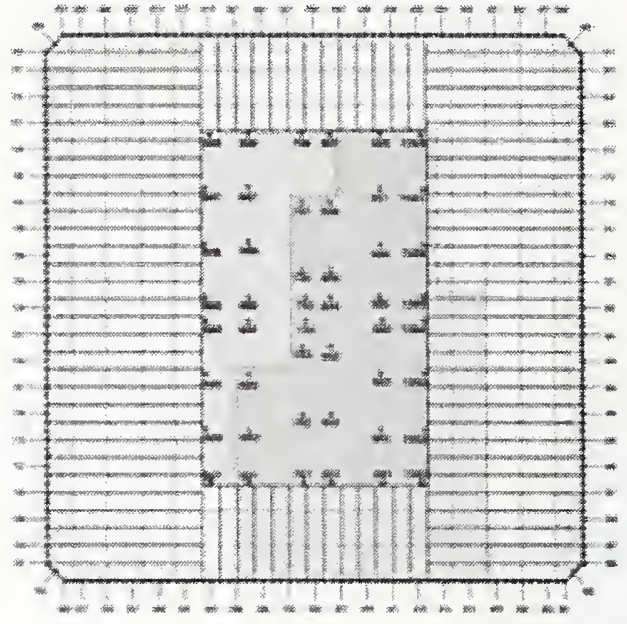

(b) Floor 80

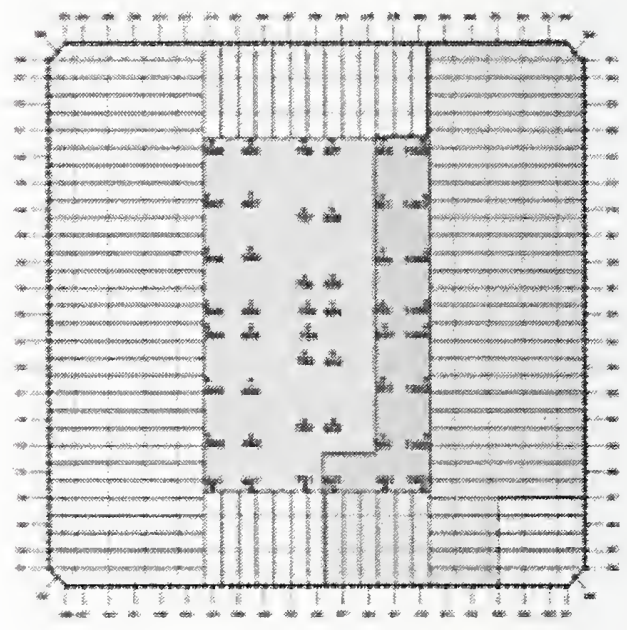

(d) Floor 82

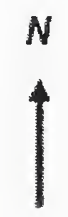

Insulation damage to core beams and trusses

Figure 2-21. Case C insulation damage condition for WTC 2 floor trusses and beams. 


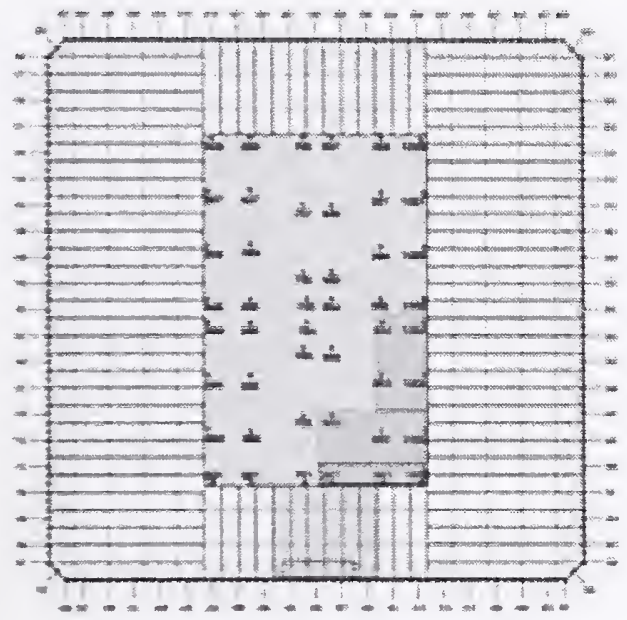

(a) Floor 79

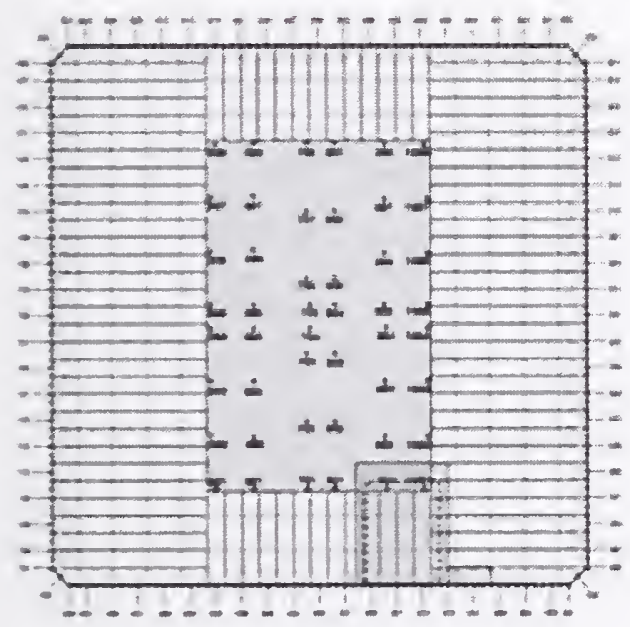

(c) Floor 81

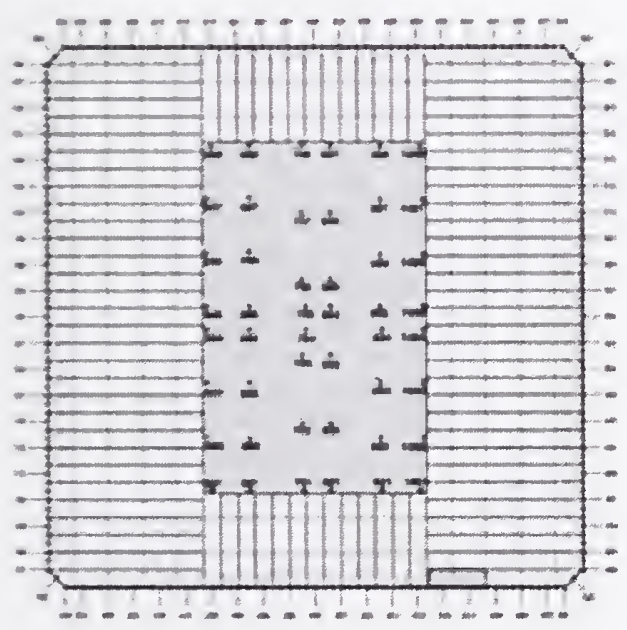

(e) Floor 83

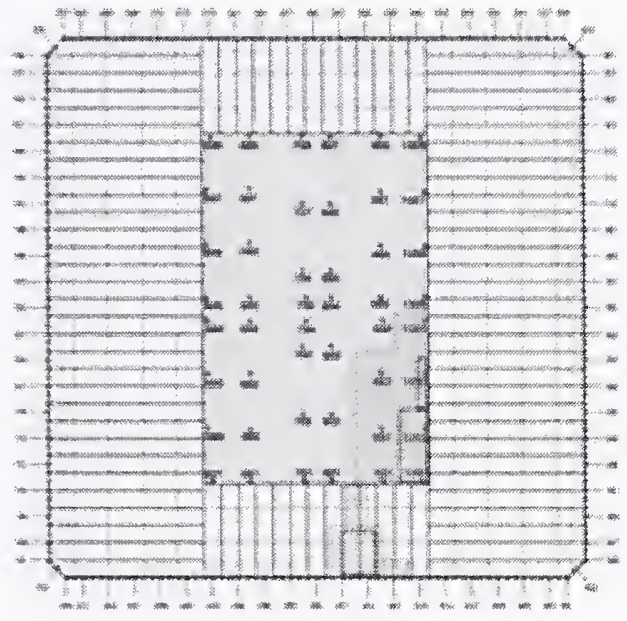

(b) Floor 60

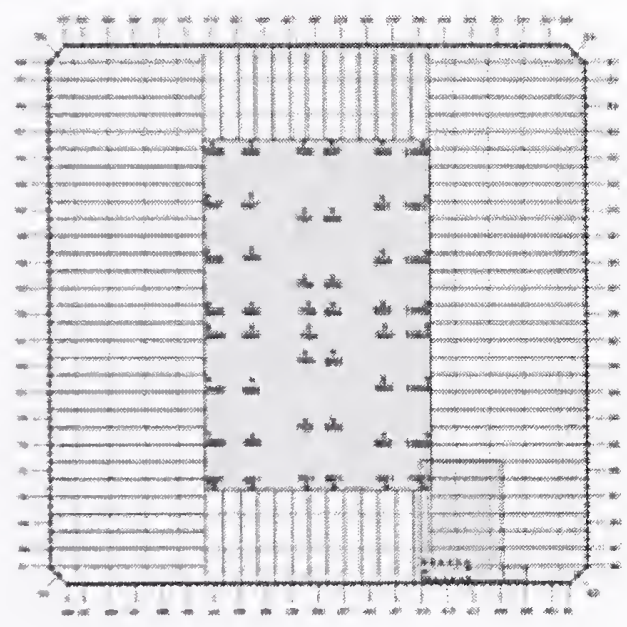

(d) Floor 82

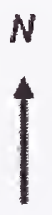

Structural damage to concrete slab, core beams, and trusses

Severed floor area

Figure 2-22. Case C structural damage condition for WTC 2 floors. 


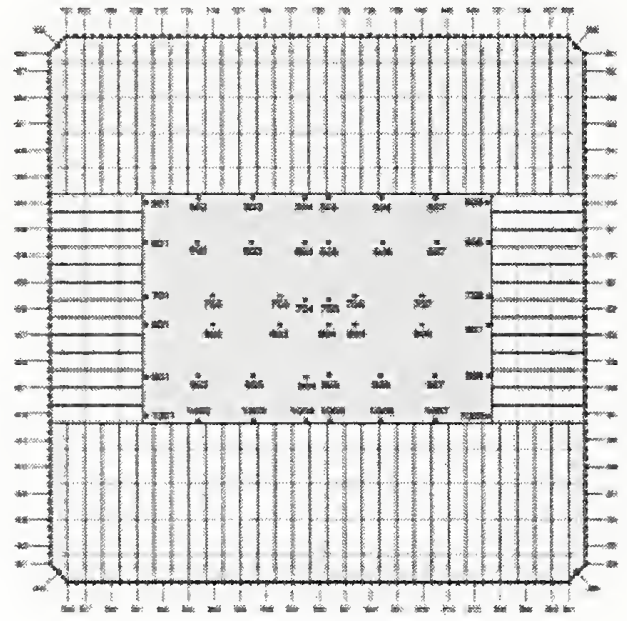

(a) Floor 94

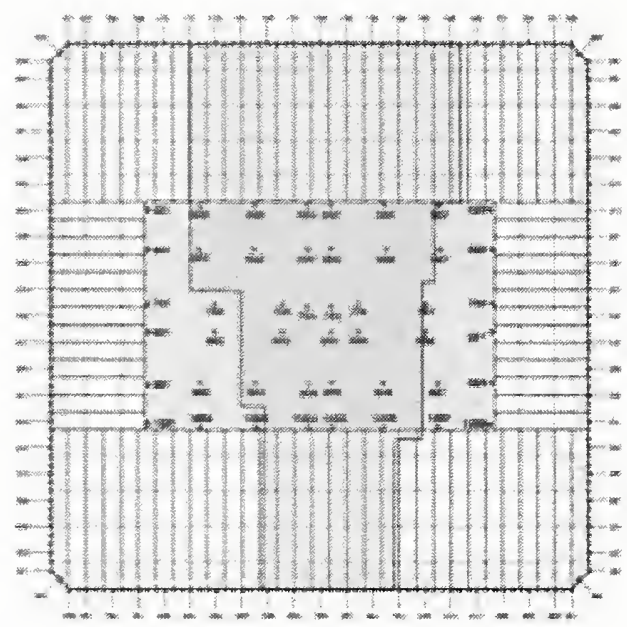

(c) Floor 96

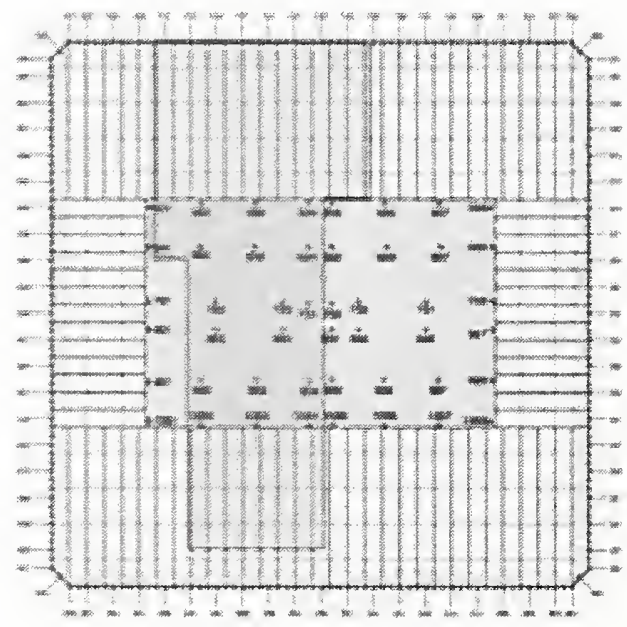

(e) Floor 98

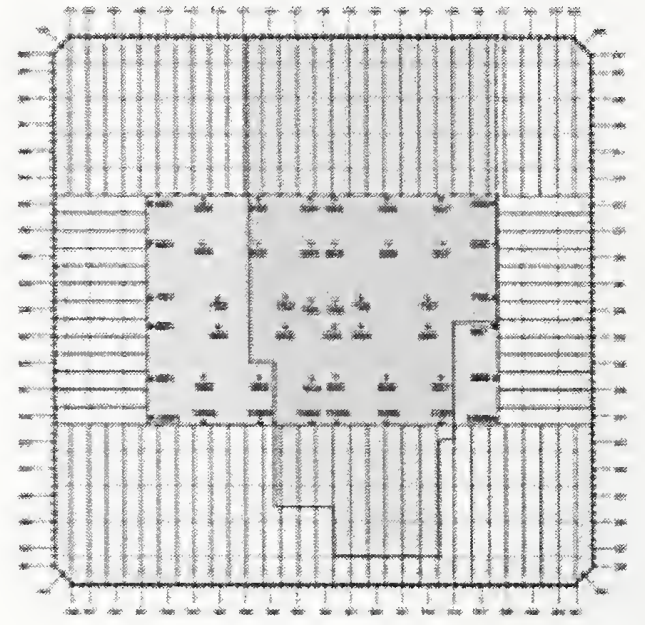

(b) Floor 95

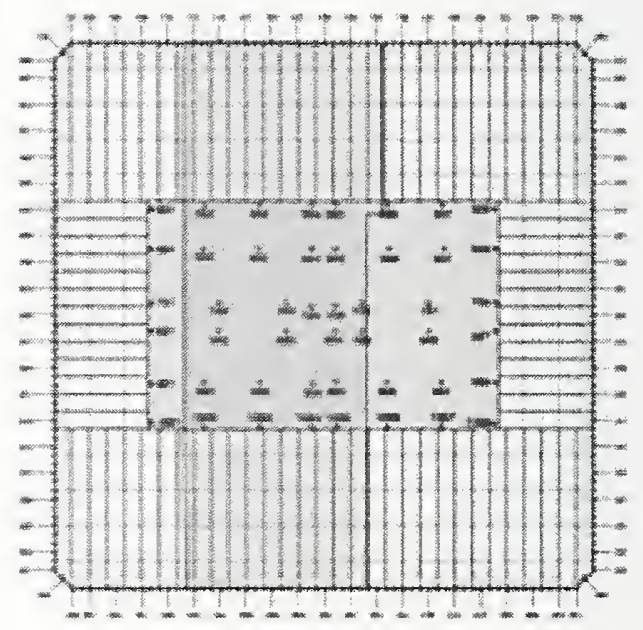

(d) Floor 97

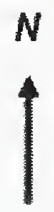

Insulation damage to core beams and trusses

Figure 2-23. Case B insulation damage conditions for WTC 1 floor trusses and beams. 


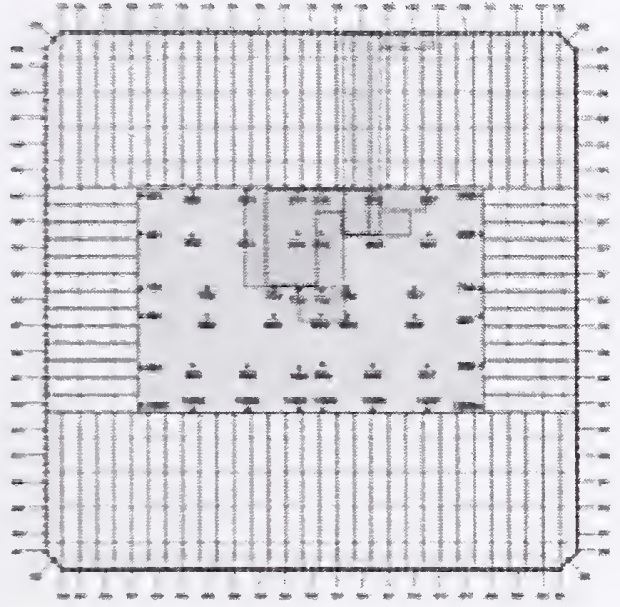

(a) Floor 94

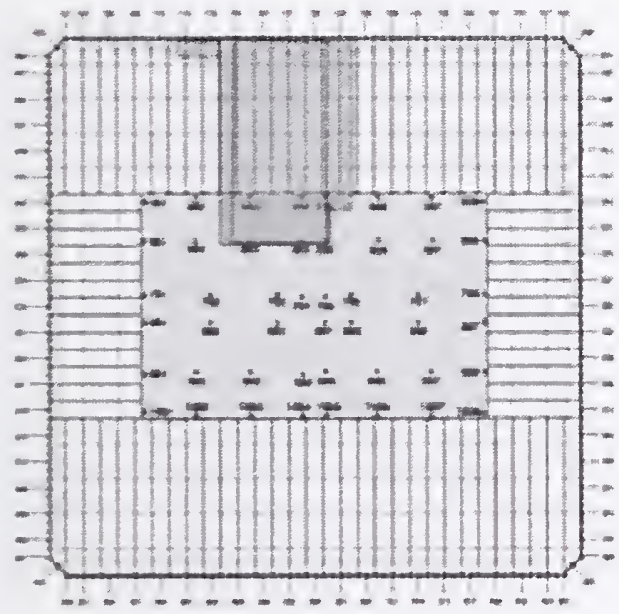

(c) Floor 96

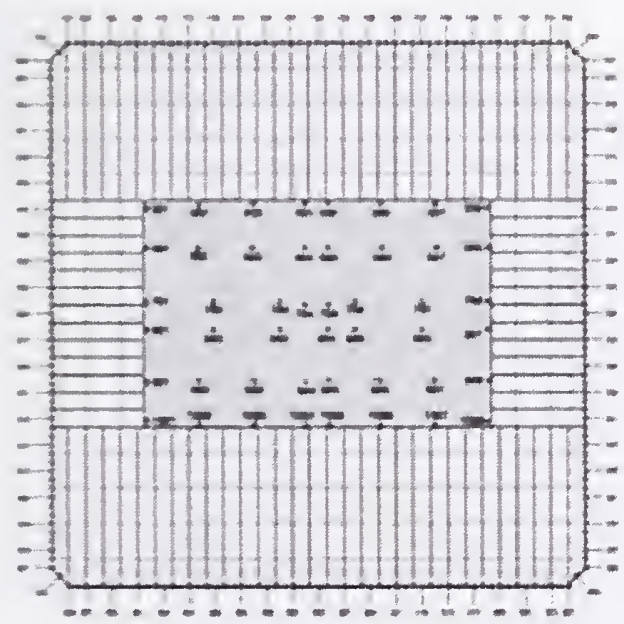

(e) Floor 98

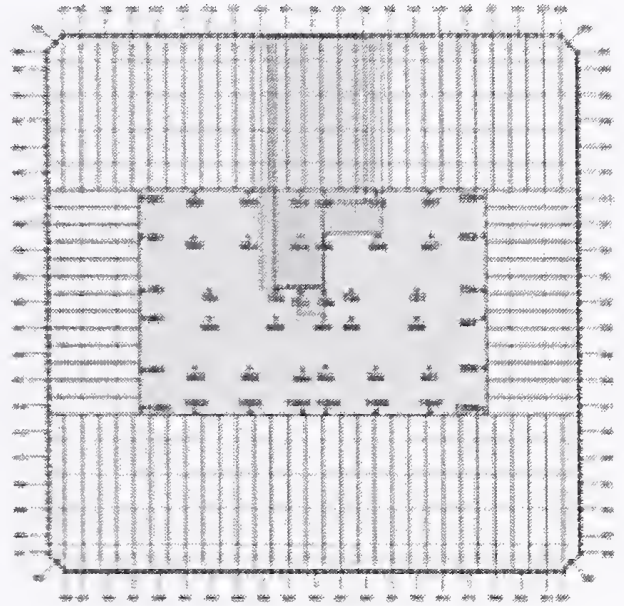

(b) Floor 95

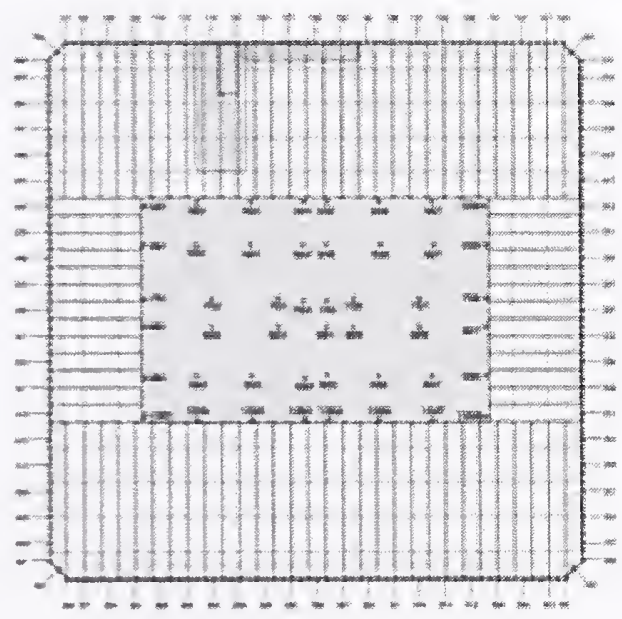

(d) Floor 97

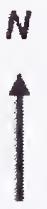

Structural damage to concrete slab, core beams, and trusses

Severed floor area

Figure 2-24. Case B structural damage conditions for WTC 1 floors. 


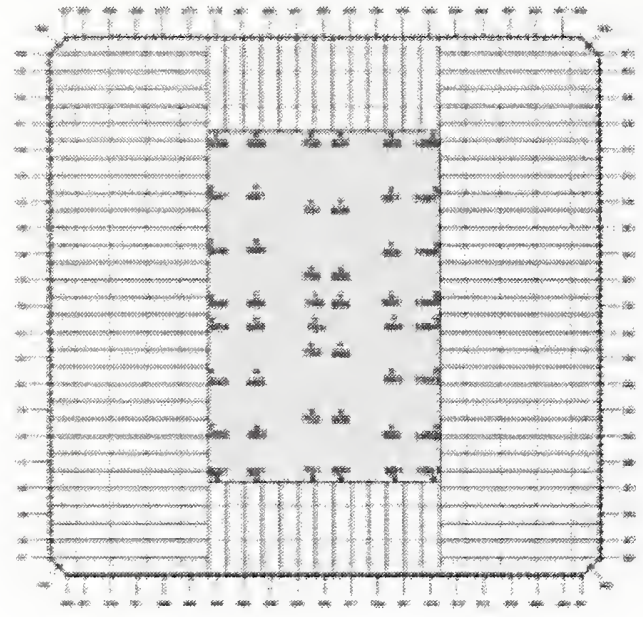

(a) Floor 78

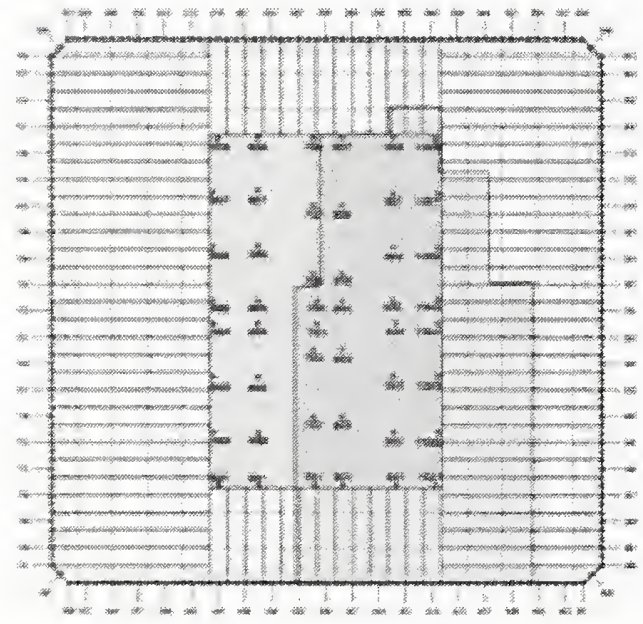

(c) Floor 80

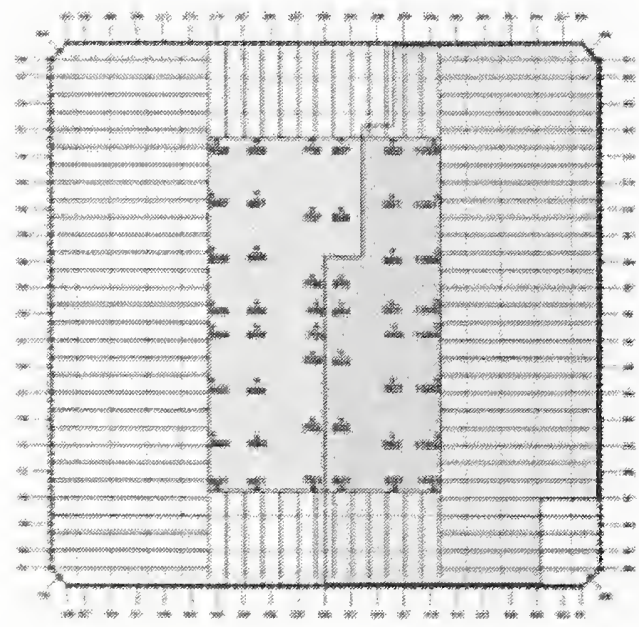

(e) Floor 82

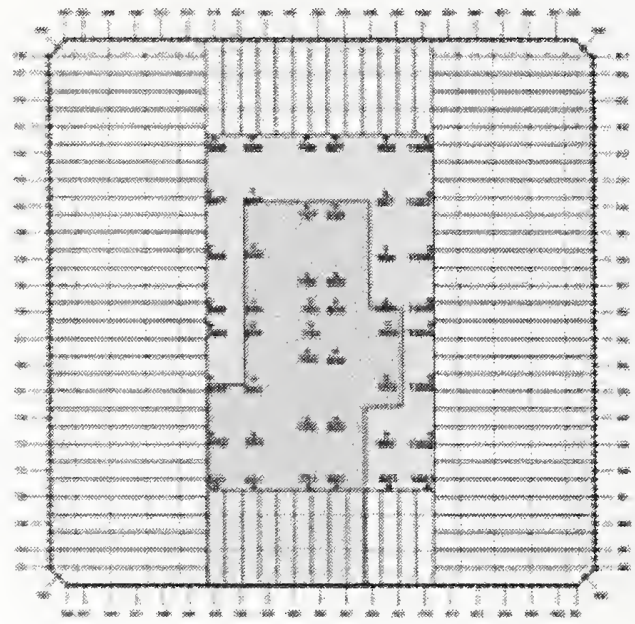

(b) Floor 79
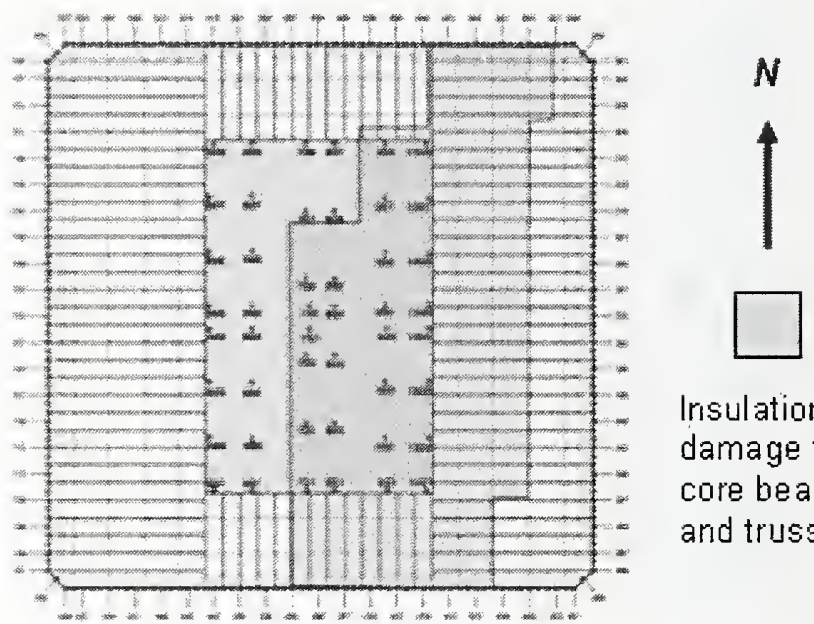

Insulation damage to core beams and trusses

(d) Floor 81

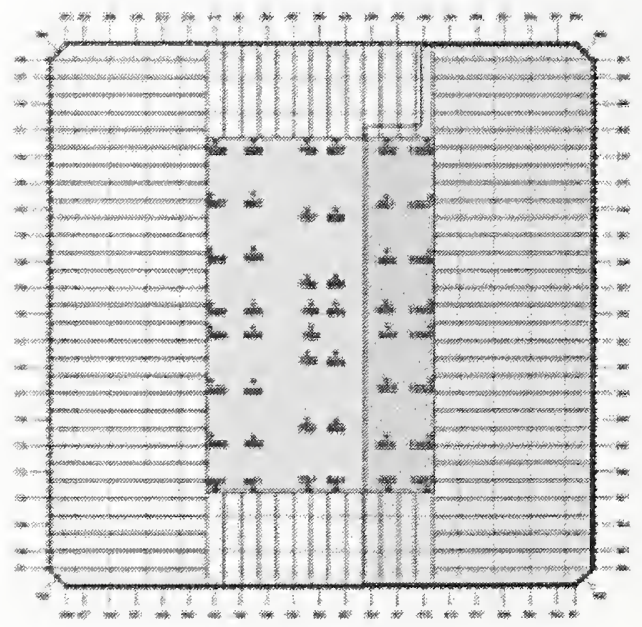

(f) Floor 83

Figure 2-25. Case D insulation damage conditions for WTC 2 floor trusses and beams. 


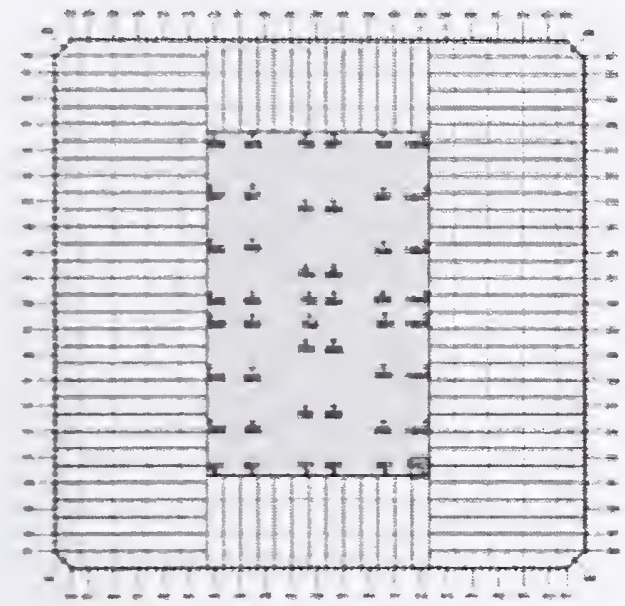

(a) Floor 78

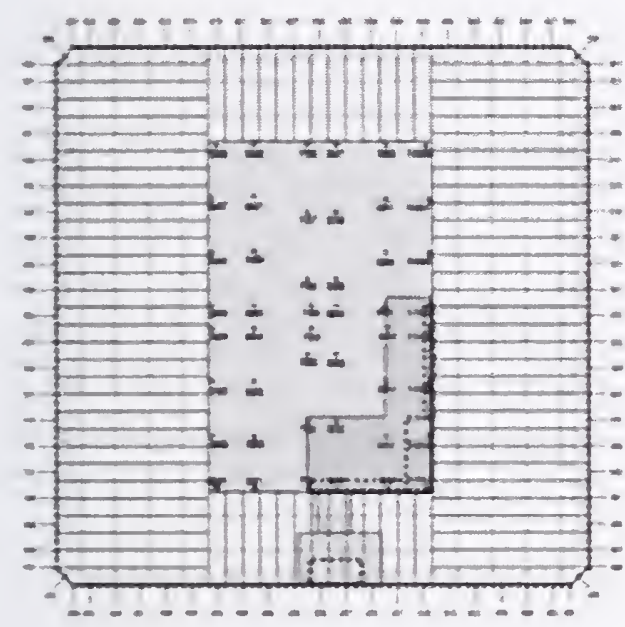

(c) Floor 80

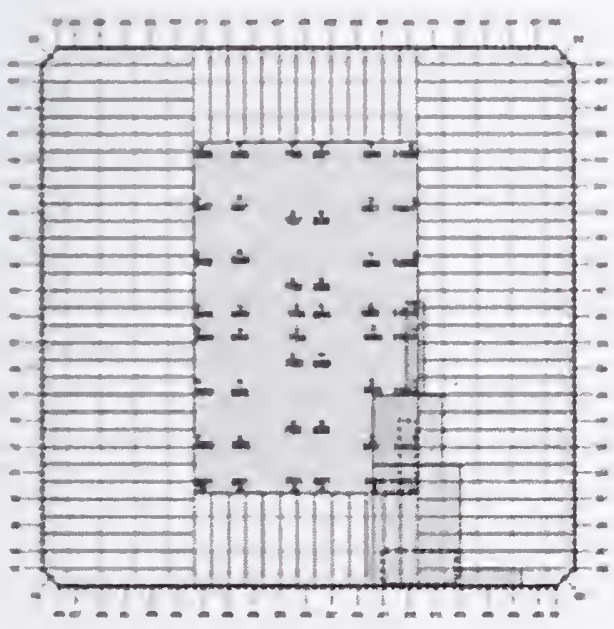

(e) Floor 82

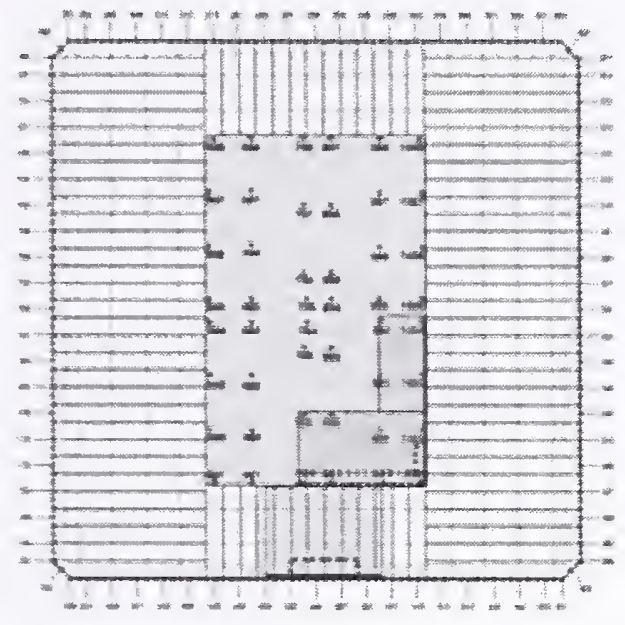

(b) Floor 79

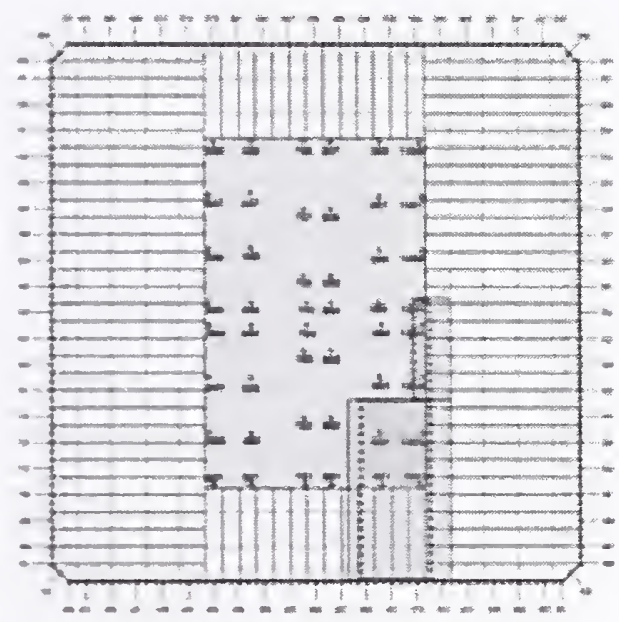

(d) Floor 81

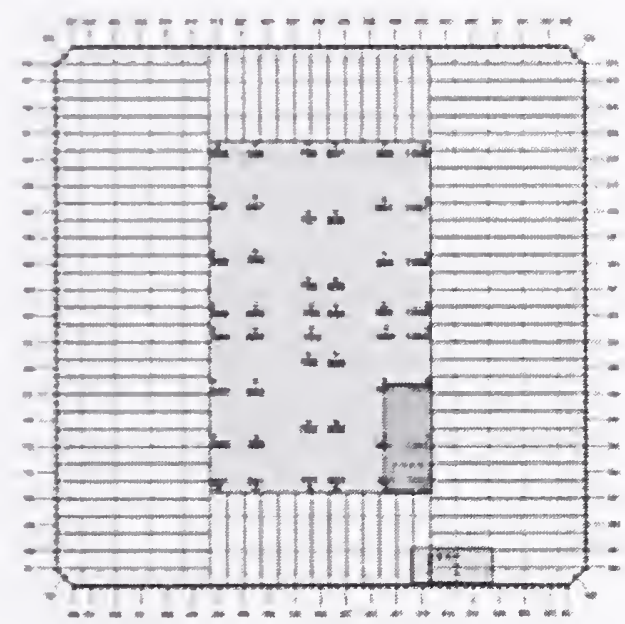

(f) Floor 83

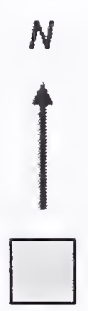

Structural damage to concrete slab, core beams, arid trusses<smiles>[CH]1[CH]CC1</smiles>

Severed floor area

Figure 2-26. Case D structural damage conditions for WTC 2 floors. 


\section{$2.3 \quad$ TEMPERATURE EFFECTS}

The fires resulting from the combustion of the jet fuel, followed by the combustion of building contents and the debris from the aircraft produced high-temperature gases that in turn increased the temperature of the exposed structural members. Fire is dynamic in nature. As fire consumes combustible materials in the area of ignition, the high temperature gases produced by the fire spread to other areas of the building, heating the structure and igniting combustible contents in these other areas. Even as the fire spreads, it consumes the fuel in areas already involved, extinguishing itself and allowing the structure in those areas to cool. As a result of this behavior, the temperature of the exposed structural members in the two towers varied with time, from the instant of aircraft impact until the final collapse. NIST performed a series of computational fluid dynamics analyses to predict the distribution with time of gas temperatures in various locations in the structures and also to produce temperature time histories for the structural members in the affected areas of the buildings. These analyses are reported in NIST NCSTAR 1-5.

In the analyses performed by NIST, a key factor in the calculation of the temperature distribution for the structural members was the extent of insulation that was in place after the impact. NIST assumed that any damage to the insulation was by direct abrasion from flying debris created as the aircraft impacted, disintegrated, and transited across the building. A series of aircraft impact analyses were performed to predict the pattern of debris flow as well as the probable damage to structural members inside the building. In these analyses, the trajectories of the debris flow and, therefore, of the extent and distribution of insulation damage predicted was dependent on the estimted values for aircraft speed and direction of travel, point of impact on the structure, and impact trajectory. The several damage sets $\left(\right.$ Case $A_{i}$, Case $B_{i}$, Case $C_{i}$, etc.) resulted from variation in the values of these parameters and, therefore, the estimated damage and temperature time histories. One temperature time history data set was derived for each set of structural and insulation damage ${ }^{2}$. As discussed in Section 2.2, Case $C_{i}$ and revised Case $C_{i}$ have the same temperature time histories for structural components.

The high temperature gases produced by the fires primarily heated the floor trusses and the bottom face of the slabs through convection and the top face of the slabs through radiation. The temperatures predicted in the structural members depended on the extent of insulation assumed to be in place and on the material properties and geometry of the structural members. In the actual buildings, the temperature in the structural members varied through the length and cross section and changed with time. The temperature at every node in the global models was calculated by interpolation of temperatures from the thermal analysis, which had a much finer mesh than the global structural models. A linear temperature gradient was assumed across column cross sections and along the length of members. To reduce data handling, the continuous temperature time histories were replaced with piecewise linear time-histories without significant loss of accuracy. Consequently, snapshots of the spatial distribution of temperature were taken at $10 \mathrm{~min}$ intervals, initiating at the time of impact and extending through the time of collapse (or approximately the time of collapse) for each of the buildings (see NIST NCSTAR 1-5G for more discussion of the 10 min intervals).

\footnotetext{
2 Temperature cases were formerly called by different names. Case $\mathrm{A}_{\mathrm{i}}$ and Case $\mathrm{C}_{\mathrm{j}}$ conditions were called "baseline case", and Case $B_{1}$ and Case $D_{i}$ conditions were called "maximum damage case". Case A and Case $C$ conditions were called "best estimate case" or "realistic case", and Case B and Case D conditions were called "upper bound case" or "severe case". These former temperature case names may appear on graphics produced in ANSYS.
} 
Structural response of a building to fire-induced temperature is a complex phenomenon involving the following phenomena:

- Axial thermal expansion of members as they heat and thermal contraction of members as they cool; if these members are restrained, this expansion and contraction can induce a change in the stress distribution in the structure.

- Differential thermal expansion of members across their cross section if they are heated unevenly, resulting in bowing of the members along their length; if members are under significant compression, this bowing can lead to onset of buckling.

- Significant reduction in modulus of elasticity and strength of steel and concrete as temperature increases beyond $500{ }^{\circ} \mathrm{C}$ (NIST NCSTAR 1-6C).

- Creep in steel at high stresses and high temperatures.

Creep is a time-dependent phenomenon and, in the analyses that SGH performed, was found to have resulted in shortening of core columns with high temperatures and high stresses.

In the global models, NIST-provided temperatures were applied to structural members between Floor 93 and Floor 99 in WTC 1 and between Floor 79 and Floor 83 in WTC 2. In each case, the temperatures were applied to exterior columns, spandrels, core columns and beams, and floor slabs.

In general, temperatures were assigned to the node locations in the global models. The distribution of temperature was assumed to be uniform throughout the member cross section except in the case of the exterior columns where temperature gradients within the cross section were considered in the direction normal to the exterior walls.

All temperatures reported in this study are in units of ${ }^{\circ} \mathrm{C}$.

\subsection{THERMAL BEHAVIOR OF FLOORS}

It was not practically possible to develop global models that could capture all structural behaviors or failure modes found in the study of components and subsystems and to perform the global analysis within a reasonable time period. To enhance computational efficiency, selected modeling details were omitted in the global models, and structural behaviors or failure modes that could not be captured by the global models were introduced in the global analysis as fire-induced damage at appropriate points in time.

Key failure modes of the floor subsystem were identified in NIST NCSTAR 1-6C for components and subsystems subjected to temperature time histories. These analyses indicated that as floor system temperature increased, web diagonals in the floor trusses buckled, allowing the floors to sag. In extreme cases, the analyses showed loss of vertical support for individual trusses, as either the truss seats supporting the trusses lost strength and failed under the influence of vertical gravity loads or sagging of the trusses caused them to walk off the supporting seats.

This floor truss behavior was incorporated into the finite element models of entire individual floors that are referred to as full floor models. The models included representation of the floor slabs, trusses, beams, and columns that extended full height to the floors immediately above and below the level under 
consideration. When an entire full floor model was subjected to the temperature time histories, the analyses showed that the floors sagged in areas where insulation was damaged and that individual floor trusses lost their vertical support at the exterior wall in some areas. However, it was found that these full floor models could not accurately capture the pull-in forces that the sagging floors were expected to apply to the exterior walls. Discussions on these pull-in forces can be found in Section 2.5.2.

Since detailed modeling of the floors was not included in the global analysis models, important floor behavioral modes could not be captured in these global analyses. Key floor behavioral modes include floor sagging that imposes pull-in forces on the exterior wall and loss of support of the trusses at the exterior wall resulting in local disconnection of the floor from the exterior wall. To account for these effects, pull-in forces on the exterior wall and disconnections of the floors from the wall were introduced in the global analyses at appropriate times as fire-induced damage. In the process of developing the fireinduced damage, the behaviors predicted by the full floor model analyses as well as the damage observed by NIST in their review of photographic and video evidence were both considered.

\subsection{FIRE-INDUCED DAMAGE}

Disconnections of the floors from the exterior walls caused by fire-induced connection failure between the floor and the exterior wall and pull-in forces on the exterior wall exerted by sagging floors were included in the global analyses as fire-induced damage. The locations of the floor/wall disconnections and the locations and magnitudes of the pull-in forces were determined based on a combination of the results from the full floor model analyses, the results from the isolated wall model analyses, and the actual observations in photographic and video evidence of WTC 1 and WTC 2.

\subsubsection{Floor/Wall Disconnections}

In areas where the connection of the floor to the exterior wall failed and the floor was locally disconnected from the exterior wall, the floor could no longer provide out-of-plane support for the wall at the locations of floor/wall disconnections, which resulted in a reduction of the buckling capacity of the exterior columns. In order to simulate this behavior in the global analyses, the connection between floor and wall elements was removed. When either one of the following conditions was encountered in the full floor analyses, the floor was disconnected from the exterior wall in the global model as it lost vertical support:

- Gusset plate failure + seat failure due to vertical shear

- Gusset plate failure + bolt shear-off + truss walk off the truss seat

Most disconnections obtained in the full floor models were due to the first of these conditions.

NIST performed extensive review of the available photographic and video evidence of the condition of the two towers prior to their collapse. Some of the photographs NIST reviewed were taken immediately after the aircraft impacts, while others were taken at various times leading up to the collapse. From this visual evidence, NIST constructed a time-variant map of the locations of observed floor/wall disconnections. During the global analyses, floor/wall disconnections were introduced at those locations and those times indicated in NIST's damage maps, if these disconnections had not previously been 
indicated by the full-floor analyses. Although FEA results and the observations were generally in good agreement, the visual evidence suggested a somewhat greater extent of floor/wall disconnections.

\subsubsection{Pull-in Forces}

When the floor sagged while it was still connected to the exterior wall, the floor developed tensile forces that tended to pull the exterior wall inward. There were four types of structural elements that connectcd the floor system to the exterior wall system: 1) diagonal strap anchors that extended from the top chords of trusses to the spandrel (they are referred to as strap anchors in this report), 2) headed studs on the spandrels that extended into the floor slab edges, 3) gusset plates that were horizontal field-welded plates that joined the top chords of the trusses to the spandrels, and 4) seat bolts that fastened bearing angles to the seats that were attached to the spandrels.

Pull-in force was applied to the exterior column in the global analyses, where either one of the following conditions was encountered in the full floor analyses:

- Gusset plate failure + bolt shear-off + significant deflection (>25 in.) of the floor slab in that area (floor remains vertically connected)

- Tensile force between the exterior wall and the floor system

However, locations and magnitudes of pull-in forces were not accurately simulated by the full floor models for the following reasons:

- The full floor models did not and could not have an accurate set of boundary conditions on the columns. Columns extended from one floor below to one floor above, and the top and bottom of exterior columns were restrained in the direction normal to the exterior wall. These boundary conditions could not accurately portray the thermally-induced movements of floors above and below the floor being analyzed and could not accurately capture the stiffness of columns in the exterior walls. Photographs of the towers taken before collapse indicated that the exterior walls bowed inward over a height of several floors. Bowing of exterior columns as observed could not be captured in the floor model because the boundary condition of a full floor model could not be formulated to represent the observed bowing of the exterior wall over several floors.

- In the actual buildings, the strap anchors and studs must have been capable of transmitting a significant amount of force between the floor system and exterior wall. However, the full floor analysis with the strap anchors and studs resulted in sequential failure of these components and an extremely slow convergence in the analyses. Because these components were found to fail at early stages of fire, these elements were then removed from all the full floor models to obtain solution within a reasonable period of time. Therefore, in these analyses, the only structural elements in the full floor model that could transfer horizontal interface forces between the floor system and the exterior walls were the gusset plates and seat bolts. This caused premature failure of the gusset plates and seat bolts in the analyses, which resulted in horizontal floor/wall disconnections. In addition, friction between bearing angles and seats was not modeled in the full floor analyses. Therefore, the full-floor model did not show significant tension at the floor/exterior wall interface. In the real structures, 
tension forces could develop between the floor system and walls following failure of the gusset plates and seat bolts through the mechanism of friction between the truss seats and bearing angles and through the strap anchors that had not failed.

- There is considerable uncertainty as to what the actual capacity of the strap anchor system was to transfer pull-in forces from the floors to the walls. Assuming that the strap anchors were installed as shown on the PANYNJ drawings, with only the minimum length and size of welds specified actually installed, the tensile capacity of the strap anchor system was controlled by the strength of weld at the strap anchors to the truss the top chords. Typically, 5/16 in., 4 in long fillet welds were specified for this joint. For a pair of floor trusses, joined to the wall by a pair of diagonal strap anchors, this translates into a computed tensile capacity of $68 \mathrm{kip}$ at room temperature and $6.6 \mathrm{kip}$ at $800{ }^{\circ} \mathrm{C}$. In full floor model analyses that incorporated the strap anchors, these capacities were used. However, if longer welds were provided, say in excess of 6 in., or somewhat larger fillets were actually placed, the ultimate tensile strength of the strap anchor (1-1/2 in. x 5/8 in. flat plate) could have controlled the capacity of this system. In such a case, the strap anchors for a pair of floor trusses could develop a $101 \mathrm{kip}$ tension force at room temperature and a $9.8 \mathrm{kip}$ tension force at $800{ }^{\circ} \mathrm{C}$.

- Assuming a coefficient of friction of 0.33 and vertical reaction at an exterior seat of $13 \mathrm{kip}$, the friction force can be as much as $4.3 \mathrm{kip}$ for a pair of trusses. The capacity of the two $5 / 8$ in.-diameter seat bolts present in each pair of trusses in shear is 44 kip at room temperature and $4.0 \mathrm{kip}$ at $800{ }^{\circ} \mathrm{C}$. Therefore, at elevated temperature, the combined action of friction and bolts could develop on the order of an 8 kip tension force at the exterior seat.

- Creep at high temperature was found to significantly increase the sag of a floor system. A thermal response analysis of a simplified truss model removed from the full floor model showed a significant increase in vertical deflection when creep was considered, as shown in Fig. 2-27. However, full floor models were made with BEAM188/189 element types and were not run with creep due to inherent convergence problems of BEAM188/189 when used under thermal loadings with materials having temperature-dependent creep property.

- In the full floor models, crushing or cracking of the concrete slab was neglected. Extreme temperatures can crack and spall concrete, further reducing the floor stiffness, and increasing both the floor sag and the floor/wall pull-in forces.

- NIST may have underestimated the amount of thermal insulation that was damaged by the aircraft impacts. The estimates developed by NIST were limited to the insulation on sections of framing that were exposed to direct abrasion by the debris field, predicted in the impact analyses. Potential loss of insulation due to impact shock and vibration effects was not included. More severe insulation damage would have resulted in higher temperatures of the trusses than those used in the full floor analyses. This in turn would result in larger areas in which the floors would have sagged. 


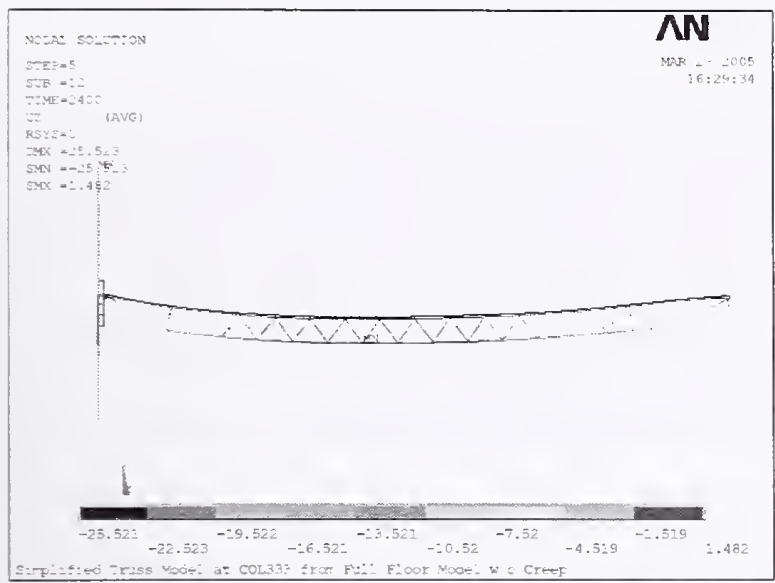

(a) Iviode witnout creep

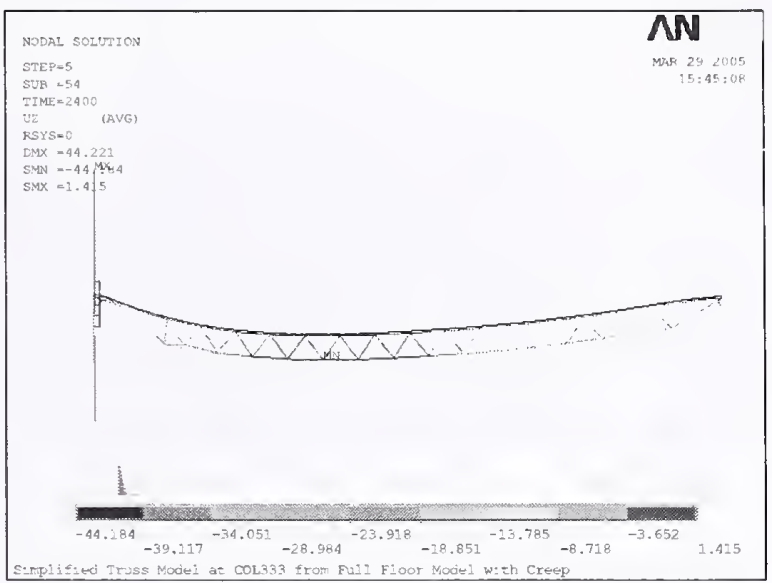

(b) Model with creep

\section{Figure 2-27. Comparison of vertical displacement of a simplified truss model at Column 333 extracted from the full floor model of Floor 96 of WTC 1 for Case $B_{i}$ temperature condition at $\mathbf{4 0} \mathrm{min}$ with and without creep.}

Given these uncertainties and inaccuracies in the evaluation of the likely magnitude and location of pullin forces on the exterior wall, in the global analyses, pull-in forces were applied in some locations where the full floor analyses did not predict the development of such behavior. The magnitude and location of pull-in forces were selected by trial and error to produce a computed bowing of the exterior walls that matched that observed in the photographic and video evidence, as discussed in Chapter 3.

In the actual buildings, floor attachment to the exterior wall occurred continuously along the length of the wall. Headed studs were spaced uniformly along the length of the wall. Pairs of trusses, with truss seats and gusset plates were present at alternate column locations, and diagonal strap anchors connected to the columns between those supporting trusses. Therefore, pull-in forces were applied to columns attached to trusses as well as those attached to strap anchors.

\subsubsection{Floor/Wall Disconnections and Pull-in Forces Included in the Global Model}

In the global models, nodal couplings tied the exterior columns to the floors. The nodal couplings were removed at locations of floor/wall disconnections. If disconnections were projected to occur or were observed in visual evidence at a time intermediate to the 10 min intervals used in the analyses, for example, between $10 \mathrm{~min}$ and $20 \mathrm{~min}$, they were imposed starting at the earlier time point, in this example, at $10 \mathrm{~min}$. Once a portion of a floor was disconnected from the exterior wall, it remained disconnected for the remainder of the analysis. Similarly, pull-in forces were also applied to the global models at the beginning of the 10 min time intervals in which they were predicted to occur or were observed, and they were maintained at a constant level for the 10 min time interval.

Outward expansion of the floors was not included in the global models. Floor analyses showed that the floors initially pushed exterior column outward by a few inches. However, significant outward bowing was not observed and several inches of outward deflection of exterior columns would not affect the global stability of the towers. 


\section{WTC 1}

Figures 2-28 to 2-37 show the locations of floor/wall disconnections and pull-in forces imposed on the WTC 1 global model for Case B conditions. Each figure covers a 10 min time interval, the first initiating at $0 \mathrm{~min}$, when the initial impact occurred, and the last initiating at $90 \mathrm{~min}$. Until $80 \mathrm{~min}$, the locations of floor/wall disconnections and pull-in forces were determined solely on the basis of full floor model analyses. After $80 \mathrm{~min}$, the observations from the photographic and video evidence were also considered in determining these events to capture floor/wall disconnections and pull-in locations that were not evident in the full floor analyses. Section 3.2.1 discusses the process used to incorporate the actual observations.

As is discussed in Chapter 5, inward bowing of the exterior south wall of WTC 1 was actually observed at 10:23 a.m., about 97 min after the aircraft impact (NIST NCSTAR 1-6), while inward bowing of the south wall was not observed in photos or videos at 9:55 a.m. (about $69 \mathrm{~min}$ after the aircraft impact). The observed inward bowing extended from Floors 95 to 99 between Columns 308 to 326 (possibly to 340 ), and the maximum bowing estimated by NIST from photographs was about 55 in. at Floor 97 . Subsystem analyses of the full floors and the exterior walls suggested that this observed bowing of the south wall was caused by sagging of the floors. As the floors sagged, they imposed tension force on the exterior wall, and the exterior wall was pulled in. However, sagging of floors in such a wide range over five floors was not predicted by the full floor model analyses. Possible reasons for floor sagging in areas not predicted by the full floor analyses include loss of insulation outside of the areas considered by NIST when formulating the temperature time histories, the additional structural softening caused by concrete cracking and spalling, and debris weight from different sources including the aircraft, accumulation of debris from the impact, and partial floor collapse, none of which were modeled in the full floor analyses. To match the observations, the south wall was assumed to be pulled in by the floors between Floor 95 and Floor 99 across the entire width of the wall except at locations of floor/wall disconnections, starting at 80 min. The magnitude of the pull-in force was determined, by trial and error, by matching the observed bowing magnitude as discussed in Section 3.2.1. The pull-in forces were selected as 4 or 5 kip per column. Results from the analysis with 5 kip pull-in forces are presented in Chapter 4. 

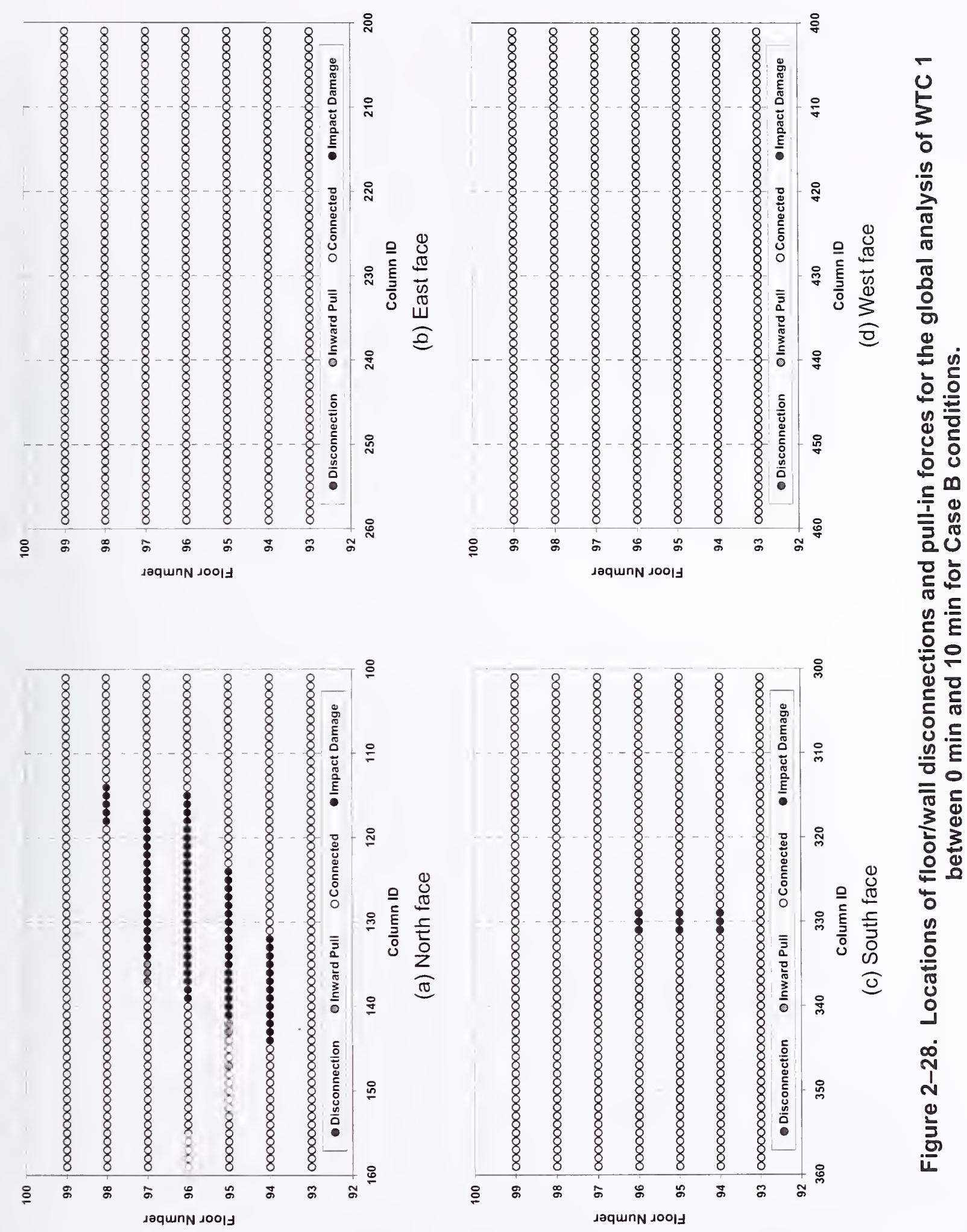

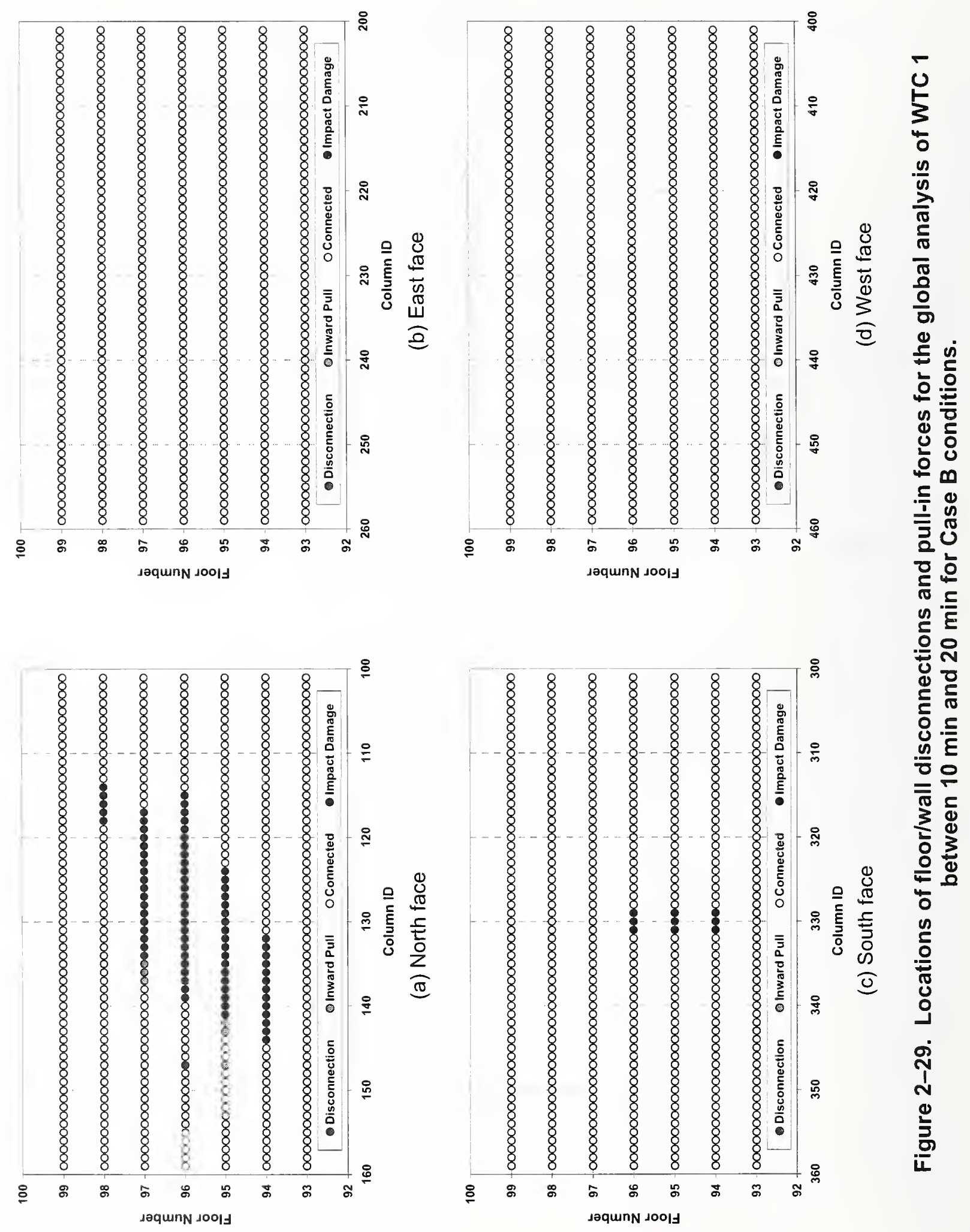

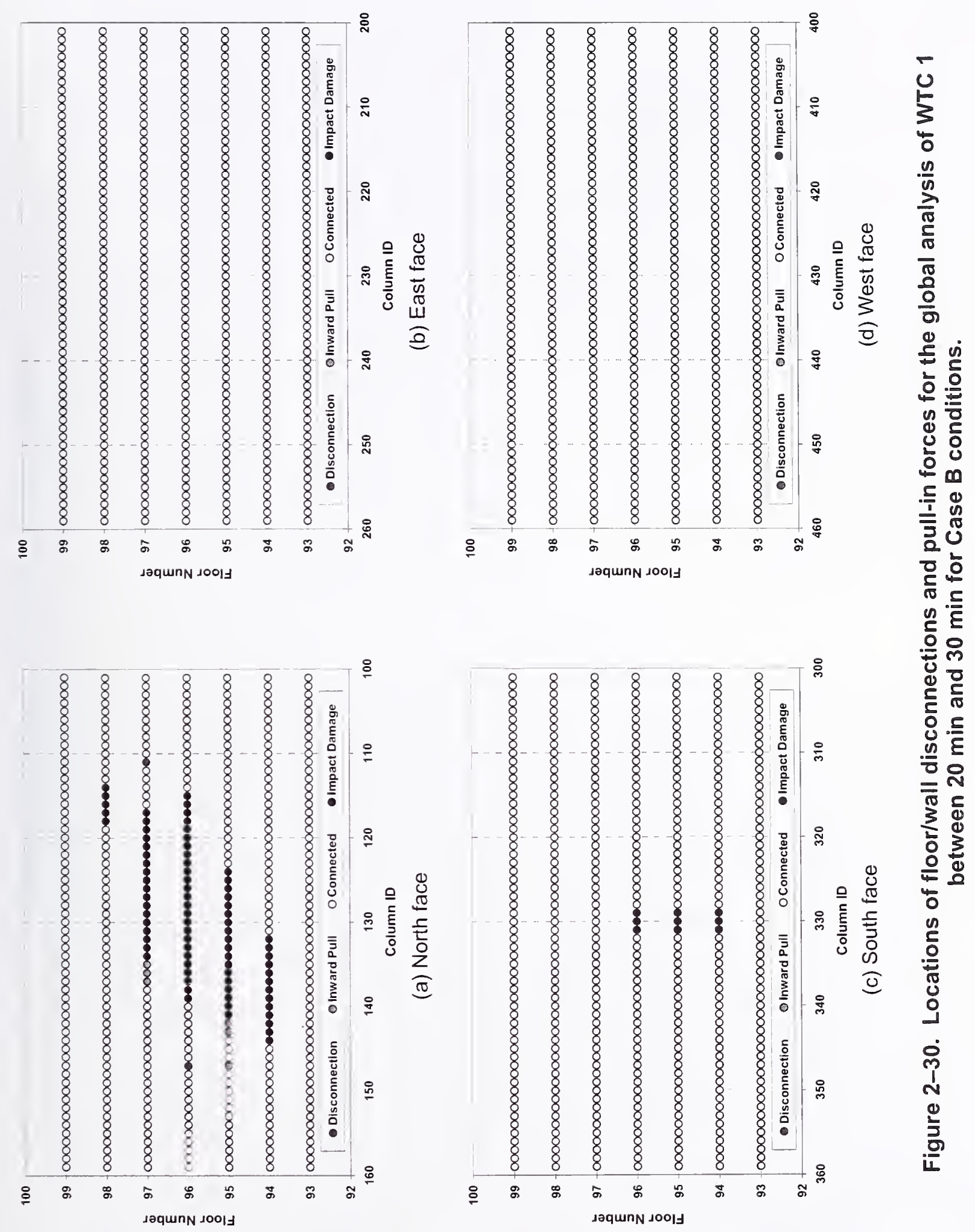

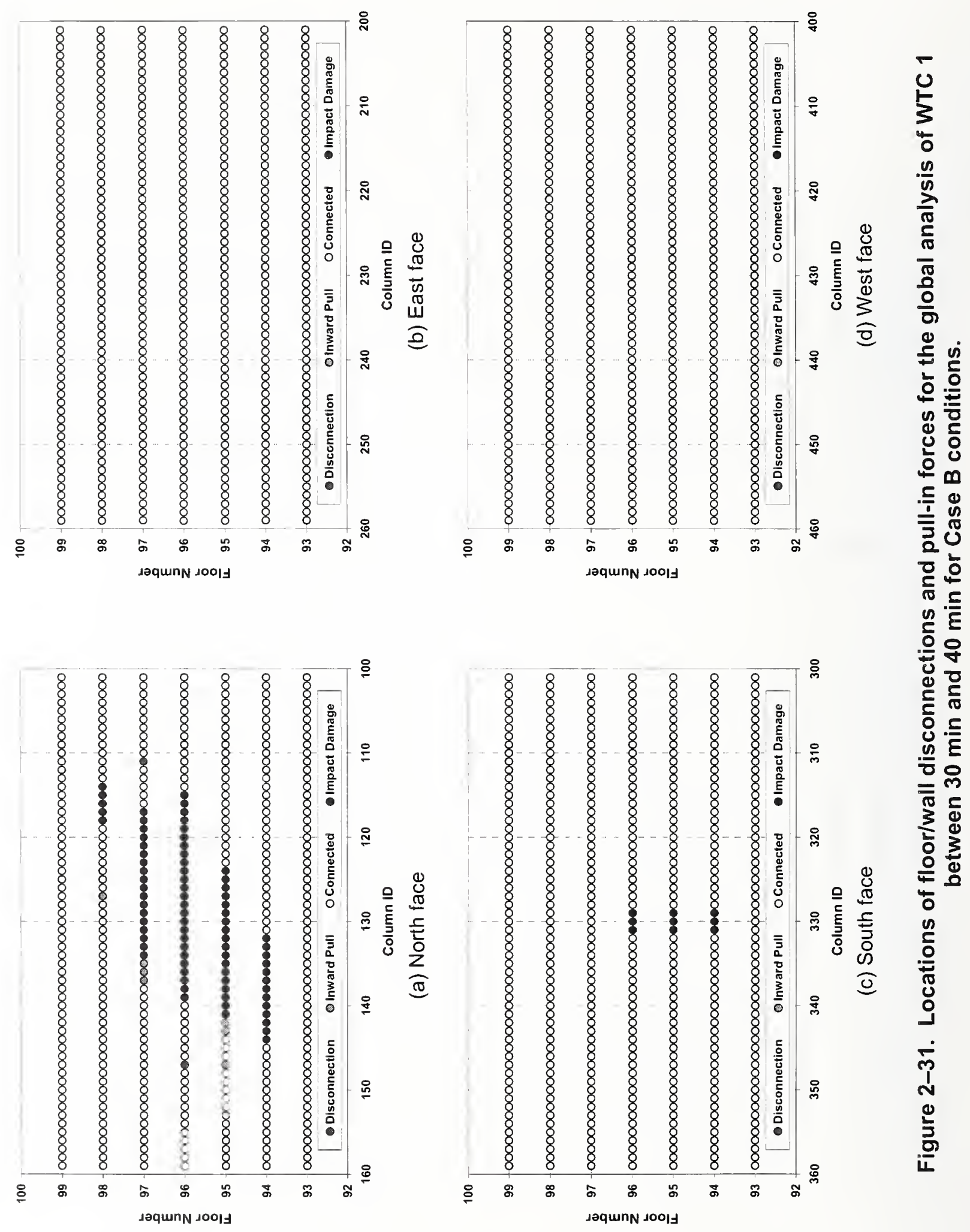

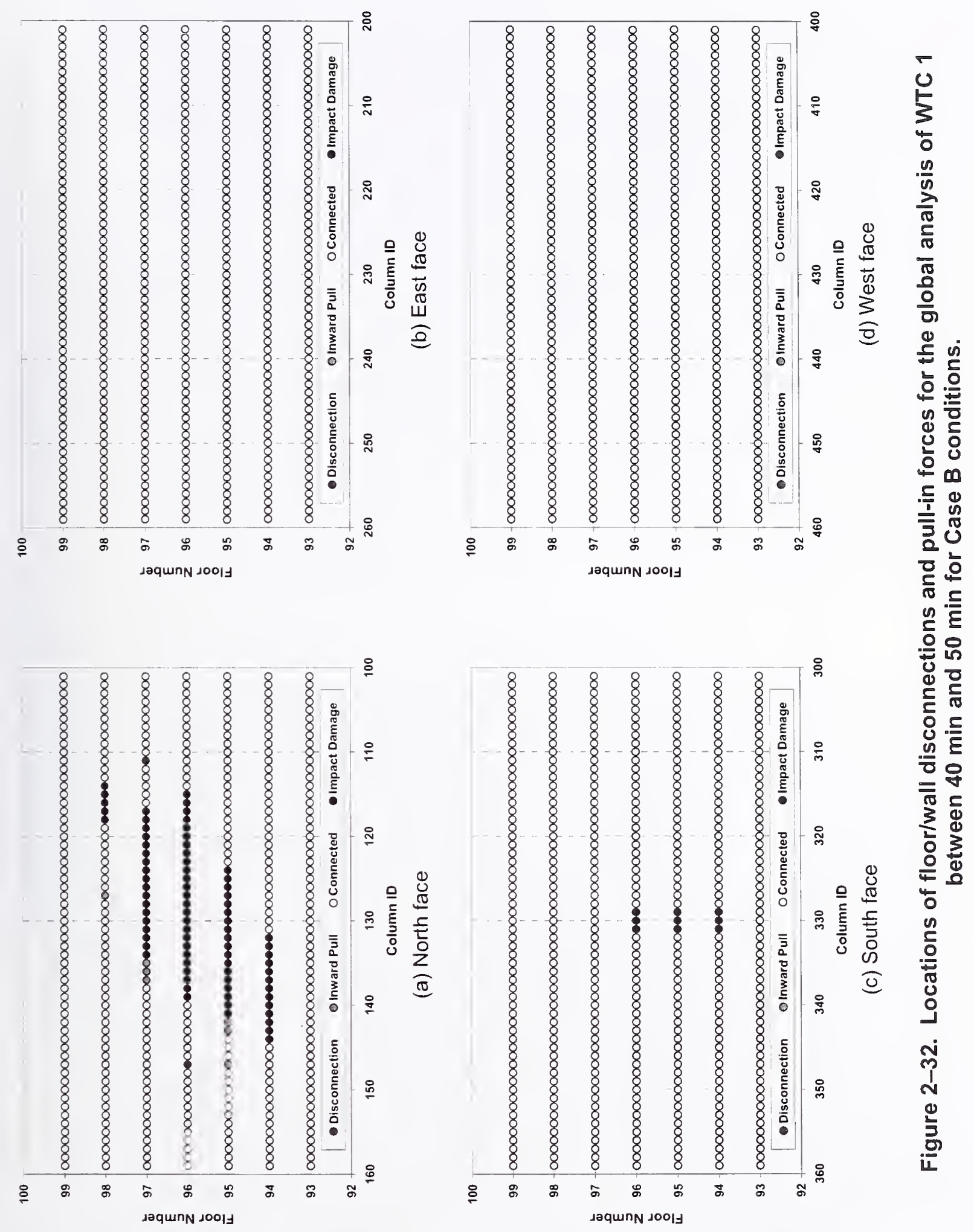

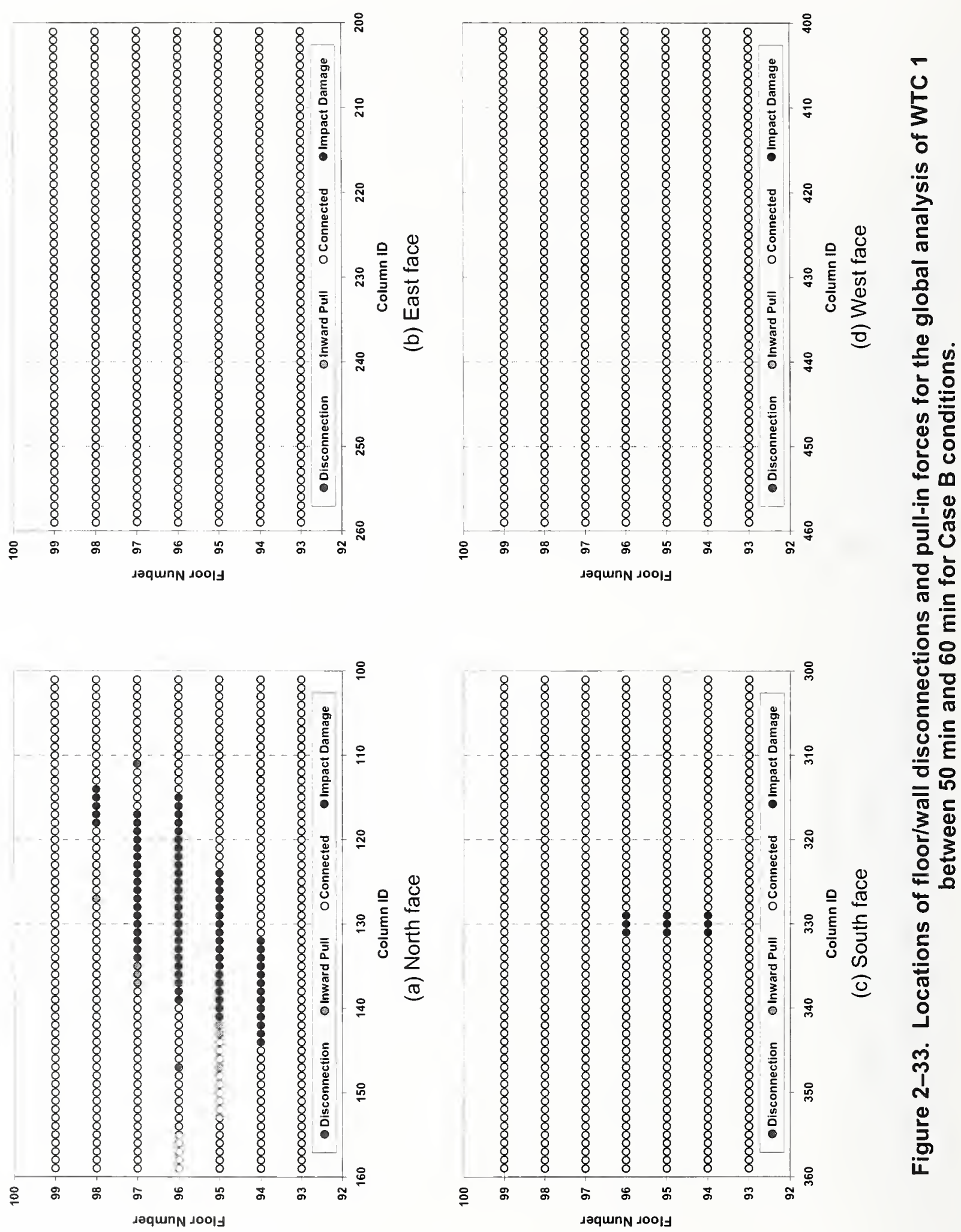

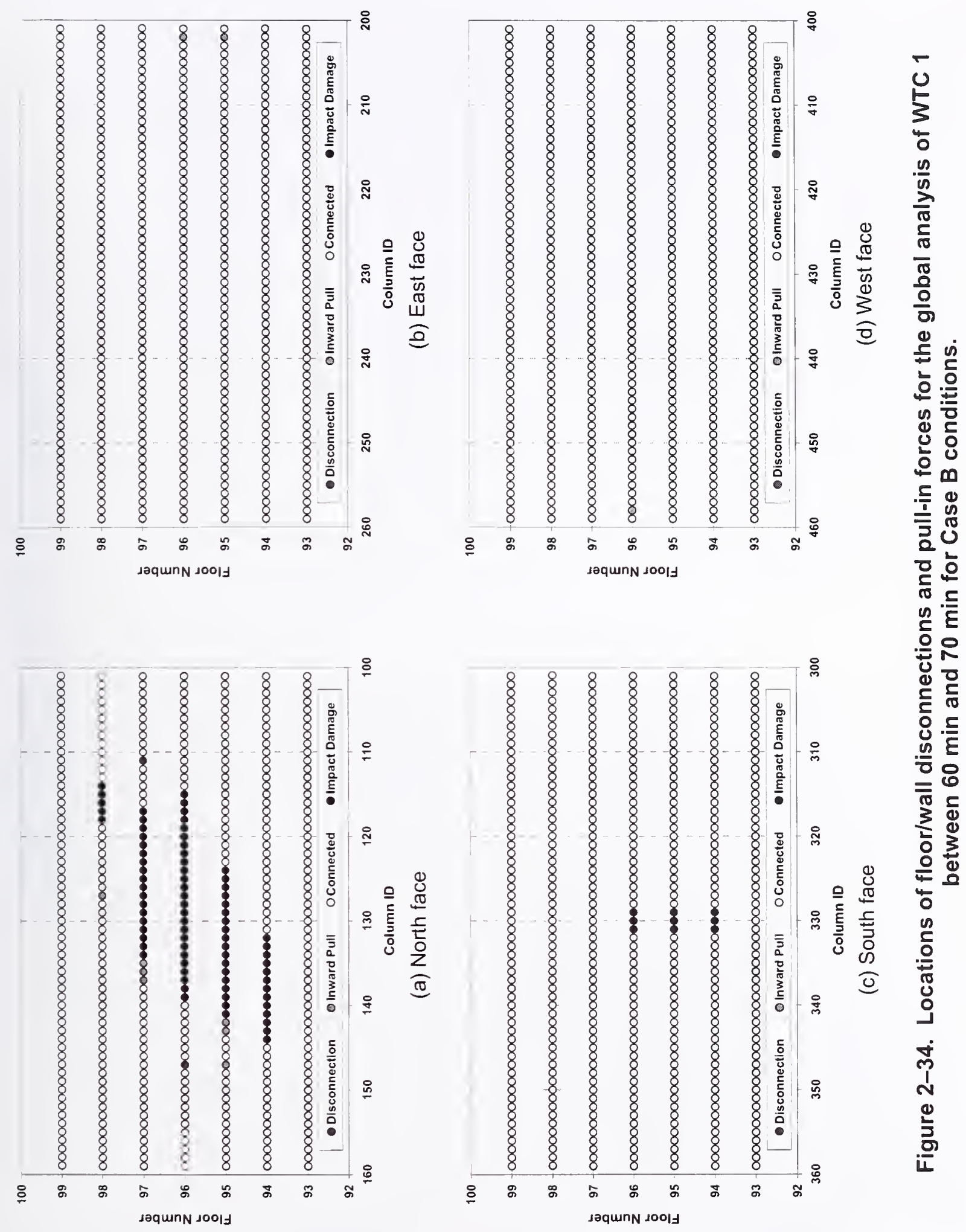

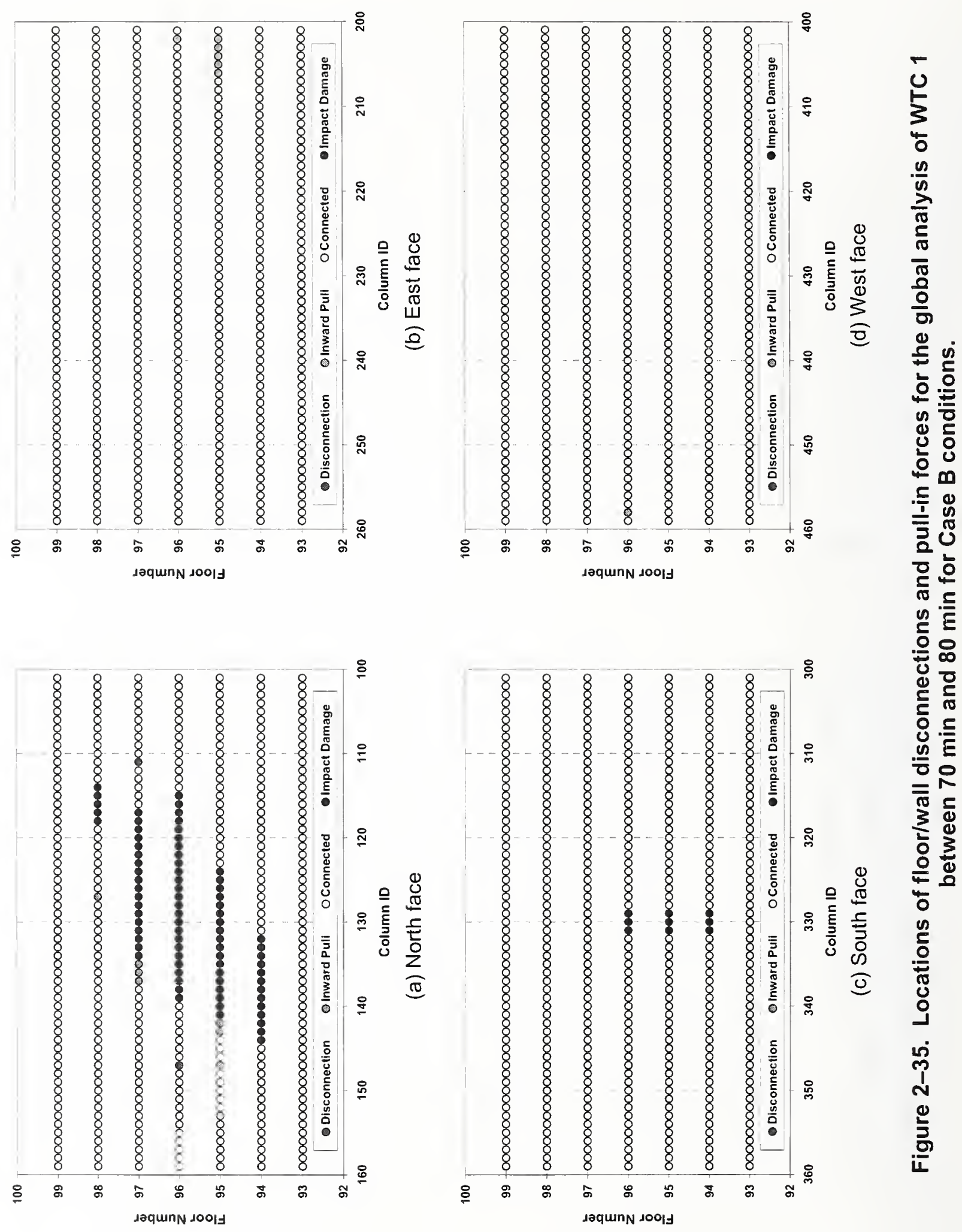

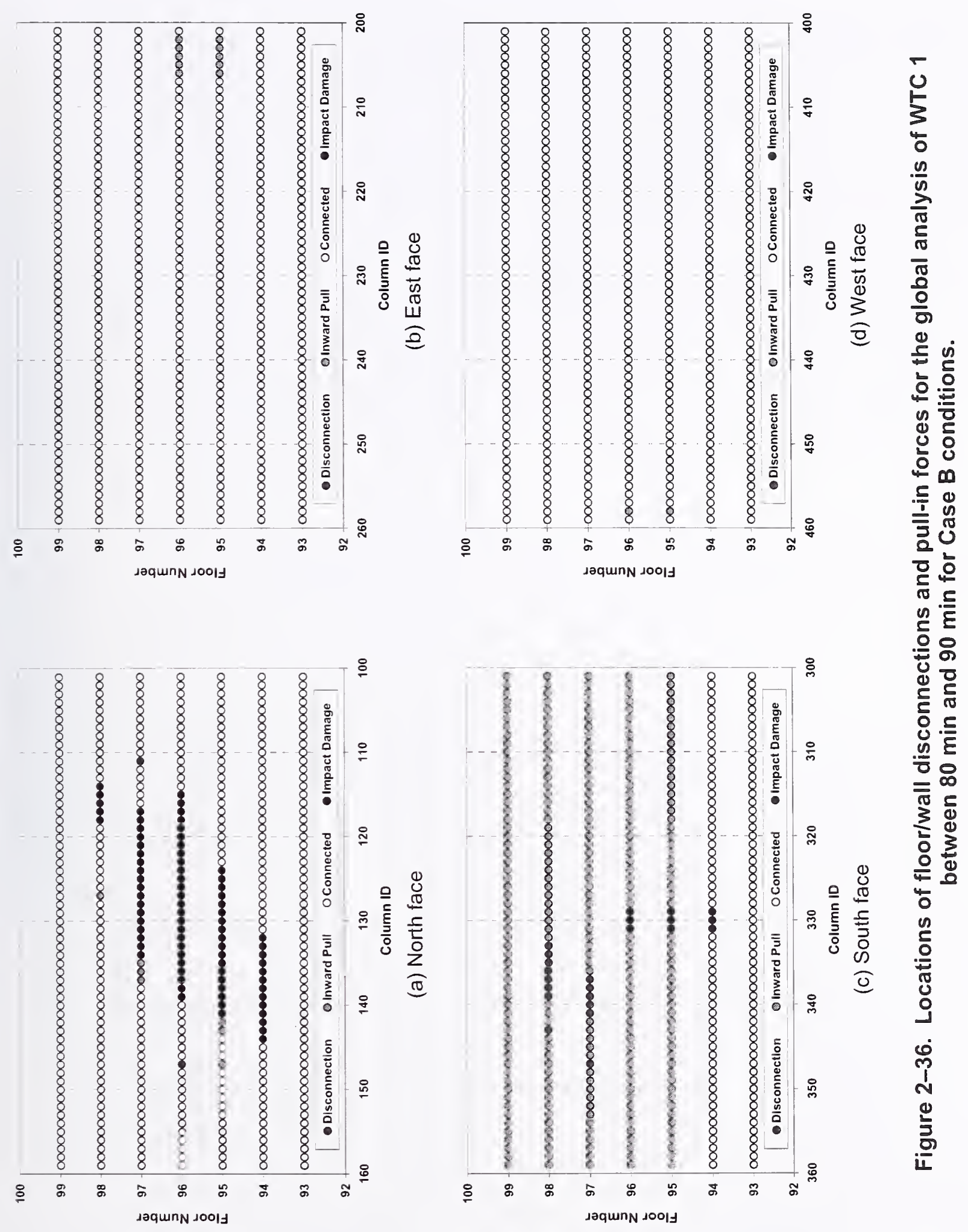

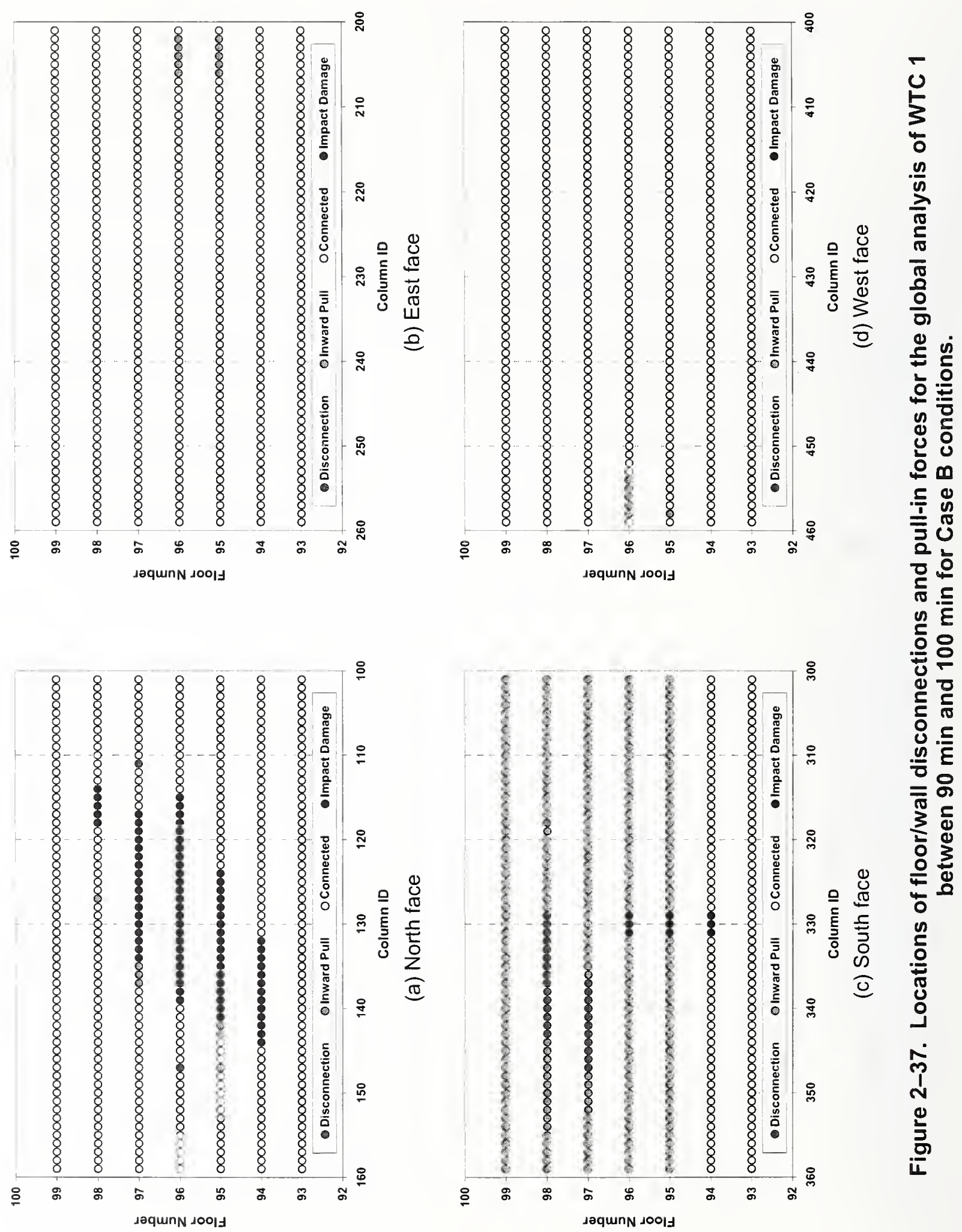


\section{WTC 2}

Figures $2-38$ to $2-43$ show the locations of floor/wall disconnections and pull-in forces imposed on the WTC 2 global model for Case D conditions. Each figure covers a $10 \mathrm{~min}$ time interval, the first initiating at $0 \mathrm{~min}$, when the initial impact occurred, and the last initiating at $50 \mathrm{~min}$.

In determining the locations of floor/wall disconnections from the full floor models, the results of Case $\mathrm{C}_{\mathrm{i}}$ and Case $\mathrm{D}_{\mathrm{i}}$ temperature conditions were considered jointly for the uncertainties in truss seat temperatures. This uncertainty is illustrated in Tables $2-2$ and $2-3$. Table $2-2$ compares the temperature predicted for the exterior truss seats at selected columns of the east wall at Floor 82 at times of $30 \mathrm{~min}, 40$ min, $50 \mathrm{~min}$, and $60 \mathrm{~min}$. Table 2-3 shows demand-to-capacity ratios for vertical support of these same exterior seats. Temperatures of the exterior seats at the east wall of Floor 82 rapidly dropped after 40 min in Case $D_{i}$; whereas, in Case $C_{i}$ they continued to increase with time. Due to this difference, the truss seats that were very close to failure (such as the seat at Column 303) at $40 \mathrm{~min}$ of Case $\mathrm{D}_{i}$ did not fail at $50 \mathrm{~min}$ in the full floor analysis. If high temperatures had continued for a few more minutes for Case $\mathrm{D}_{\mathrm{i}}$, these seats would have failed. The actual temperature time history may not have descended rapidly between $40 \mathrm{~min}$ and $50 \mathrm{~min}$, as is deduced from the consideration of piecewise linear temperature time history in this study.

The state of the floor/wall connections in the full floor analysis were reevaluated considering the effects of uncertainties in the seat capacities by comparing the demands to the seat capacities that were 10 percent lower than the calcuated seat capacities. As a result of this comparison, the seats adjacent to the already disconnected seats at Floors 82 and 83 were found to be progressively failing, and the extent of floor/wall disconnection was extended to nearly the entire width of the east wall. These worst-case floor/wall disconnections were included in the floor/wall disconnections for Case D conditions in the global analysis.

Table 2-2. Temperatures of exterior seats at east wall of Floor 82 of WTC 2.

\begin{tabular}{|c|c|c|c|c|c|c|c|c|}
\hline \multirow{2}{*}{ Column ID } & \multicolumn{4}{|c|}{ Case $\mathbf{C}_{\mathbf{i}}$ Temperatures $\left({ }^{\circ} \mathbf{C}\right)$} & \multicolumn{4}{c|}{ Case $\mathbf{D}_{\mathbf{i}}$ Temperatures $\left({ }^{\circ} \mathbf{C}\right)$} \\
\cline { 2 - 9 } & $\mathbf{3 0} \mathbf{~ m i n}$ & $\mathbf{4 0} \mathbf{~}$ in & $\mathbf{5 0} \mathbf{~ m i n}$ & $\mathbf{6 0} \mathbf{~ m i n}$ & $\mathbf{3 0} \mathbf{~ m i n}$ & $\mathbf{4 0} \mathbf{~ m i n}$ & $\mathbf{5 0} \mathbf{~ m i n}$ & $\mathbf{6 0} \mathbf{~ m i n}$ \\
\hline 301 & 763 & 788 & 811 & 813 & 818 & 819 & 507 & 345 \\
303 & 752 & 774 & 809 & 808 & 822 & 820 & 509 & 348 \\
305 & 750 & 769 & 807 & 804 & 823 & 821 & 513 & 348 \\
307 & 750 & 769 & 804 & 799 & 823 & 821 & 511 & 342 \\
309 & 727 & 748 & 787 & 790 & 822 & 816 & 485 & 334 \\
311 & 677 & 698 & 738 & 758 & 816 & 804 & 458 & 328 \\
313 & 636 & 657 & 700 & 724 & 809 & 803 & 487 & 342 \\
315 & 591 & 605 & 632 & 662 & 816 & 794 & 481 & 347 \\
317 & 574 & 580 & 615 & 637 & 815 & 799 & 494 & 351 \\
\hline
\end{tabular}


Table 2-3. Demand-to-capacity ratios of exterior seats at east wall of Floor 82 of WTC 2 predicted by the full floor model.

\begin{tabular}{|c|c|c|c|c|c|c|c|c|}
\hline \multirow{2}{*}{ Column ID } & \multicolumn{4}{|c|}{ Case $\mathbf{C}_{\mathbf{i}}$ Temperatures $\left({ }^{\circ} \mathbf{C}\right)$} & \multicolumn{4}{c|}{ Case $\mathbf{D}_{\mathbf{i}}$ Temperatures $\left({ }^{\circ} \mathbf{C}\right)$} \\
\cline { 2 - 9 } & $\mathbf{3 0} \mathbf{~}$ in & $\mathbf{4 0} \mathbf{~}$ in & $\mathbf{5 0} \mathbf{~ m i n}$ & $\mathbf{6 0} \mathbf{~ m i n}$ & $\mathbf{3 0} \mathbf{~}$ in & $\mathbf{4 0} \mathbf{~ m i n}$ & $\mathbf{5 0} \mathbf{~ m i n}$ & $\mathbf{6 0} \mathbf{~ m i n}$ \\
\hline 301 & 0.35 & 0.31 & failed & failed & 0.63 & 0.54 & 0.02 & 0.08 \\
303 & 0.66 & 0.81 & failed & failed & 0.92 & 0.97 & 0.18 & 0.14 \\
305 & 0.39 & 0.53 & failed & failed & 0.63 & 0.70 & 0.20 & 0.19 \\
307 & 0.41 & 0.51 & failed & failed & 0.59 & 0.60 & 0.15 & 0.13 \\
309 & 0.35 & 0.43 & failed & failed & 0.60 & 0.60 & 0.13 & 0.13 \\
311 & 0.38 & 0.46 & failed & failed & 0.87 & 0.71 & 0.09 & 0.05 \\
313 & 0.23 & 0.27 & failed & failed & 0.64 & 0.48 & 0.10 & 0.09 \\
315 & 0.20 & 0.24 & failed & failed & 0.49 & 0.41 & 0.08 & 0.09 \\
317 & 0.10 & 0.09 & 0.96 & failed & 0.45 & 0.50 & 0.14 & 0.13 \\
\hline
\end{tabular}

In addition to the reevaluation of the seat capacities, the location of floor/wall disconnections estimated from full floor analyses were compared and were updated based on the floor/wall disconnections observed in the photographs and videos. Observed floor/wall disconnections were provided for the east wall at 9:03 a.m., 9:38 a.m., and 9:55 a.m. and for the north wall at 9:10 a.m., 9:14 a.m., and 9:58 a.m. All observed floor/wall disconnections were included in the global analysis for Case D conditions at appropriate points in time, whether predicted by the full floor analyses or not.

As previosusly described above for the case of WTC 1, the photographic and video evidence was also reviewed by NIST to determine the extent of inward bowing of the east wall of WTC 2. These displacement measurements were used to update the location and the magnitude of the pull-in forces applied to the global model. The earliest observations of inward bowing for WTC 2 were made at 9:21 a.m., 18 min after impact (NIST NCSTAR 1-6), when the east wall was observed to be bowing inward between Column 301 and Column 345 between Floor 78 and Floor 83. At this time, NIST estimated the maximum inward deformation to be about 10 in. at Floors 80 and 81 between Column 322 and Column 329. To replicate this inward bowing, pull-in forces were applied at Floors 79, 80, 81, and 82. The full floor analyses correctly predicted the floors that were pulled in, but underestimated the location of the pull-in forces across the width of the east wall, relative to that required to replicate the observed bowing. The locations of pull-in forces predicted by the full-floor analyses were concentrated toward the south side of the east wall and typically ranged between Columns 329 and 359 at Floor 82 and between Columns 357 and 359 at Floor 79. The locations of pull-in forces estimated from the observation were used to augment those obtained from the full floor analyses. Based on this augmented data, at 20 min after imact, pull-in forces were applied over the entire width of the east wall at Floors 79 , 80,81 , and 82 in the global analysis.

The photographic and video evidence, obtained at 9:53 a.m., about $50 \mathrm{~min}$ after impact (NIST NCSTAR 1-6), show the east wall bowing inward from Column 301 to Column 353 between Floor 77 and Floor 84. At this instant, NIST estimated the maximum inward deformation to be about 15 in. to 20 in. at Floor 81 between Column 320 and Column 330. To replicate this observed bowing geometry, a combination of pull-in forces and floor/wall disconnections were applied between Floor 77 and Floor 84. Except for Floor 78, which was not analyzed using a full floor model, the full floor analyses correctly predicted the floor levels at which the exterior wall was observed to be pulled in, but underestimated the locations of pull-in forces. The locations of the pull-in forces estimated from the full floor analyses were 
concentrated toward the south side of the east wall and typically ranged between Column 333 and Column 359 at Floor 81 and between Column 355 and Column 359 at Floor 79. Based on the full floor analyses and the reevaluated seat capacities, Floor 83 was disconnected from the east wall between Column 302 and Column 357, and Floor 82 was disconnected between Column 301 and Column 349. For this reason, no pull-in forces were applied at these column locations. The locations of the pull-in forces estimated from the observations at $50 \mathrm{~min}$ were used to augment those estimated from the full floor analyses. As a result of this addition, at 50 min after impact, pull-in forces were applied over the entire width of the east wall at Floors 78, 79, 80, and 81, and between Column 350 and Column 359 at Floor 82.

As is discussed in Section 3.2.2, the magnitude of the pull-in force was estimated through a trial and error process by applying different levels of pull-in forces to the isolated wall models and by comparing the resulting inward bowing to that estimated from observations at 9:21 a.m. and 9:53 a.m. From these comparative analyses, the magnitude of pull-in forces were determined to range from 1.0 to $2.0 \mathrm{kip}$ on the south side of the east wall and 4.0 to $5.0 \mathrm{kip}$ on the north side of the east wall. It was necessary to apply larger pull-in forces on the north side than on the south side of the east wall because column temperatures on the north side were higher than the column temperatures on the south side of the east wall. Higher temperatures resulted in more outward bowing of columns, and thus larger pull-in forces were required to overcome this outward bowing. 

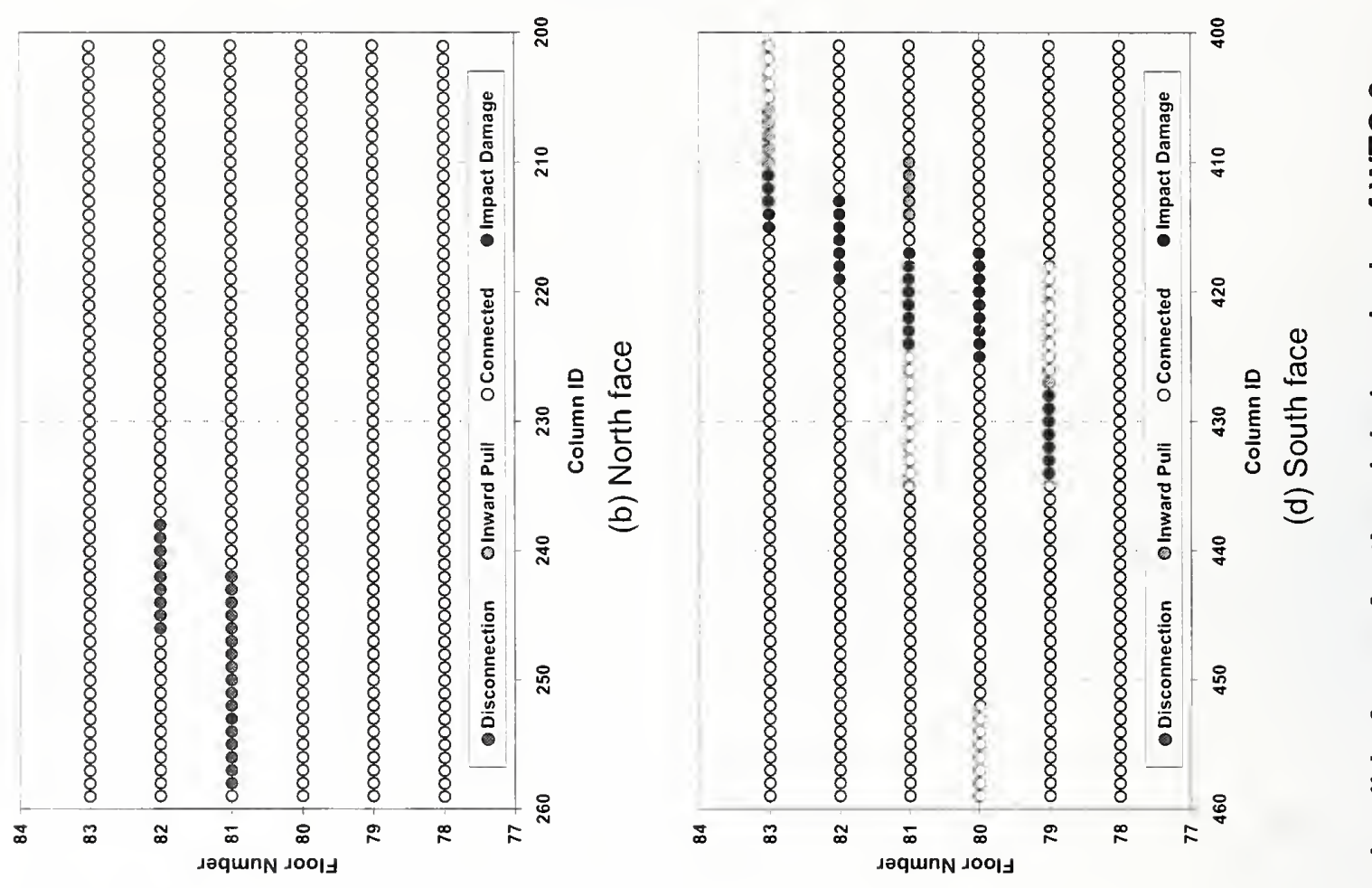

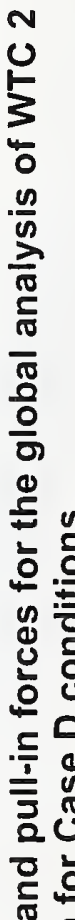
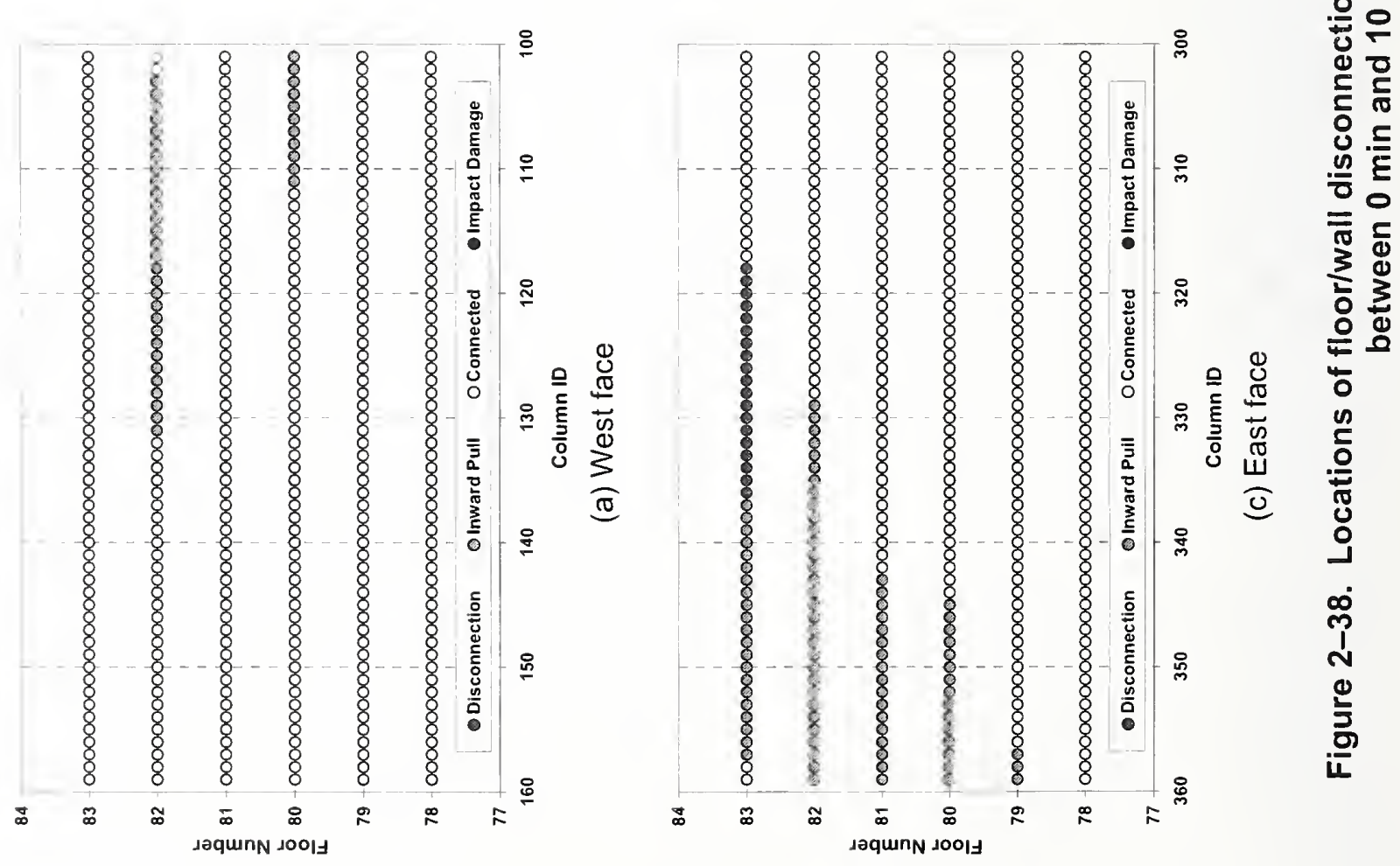

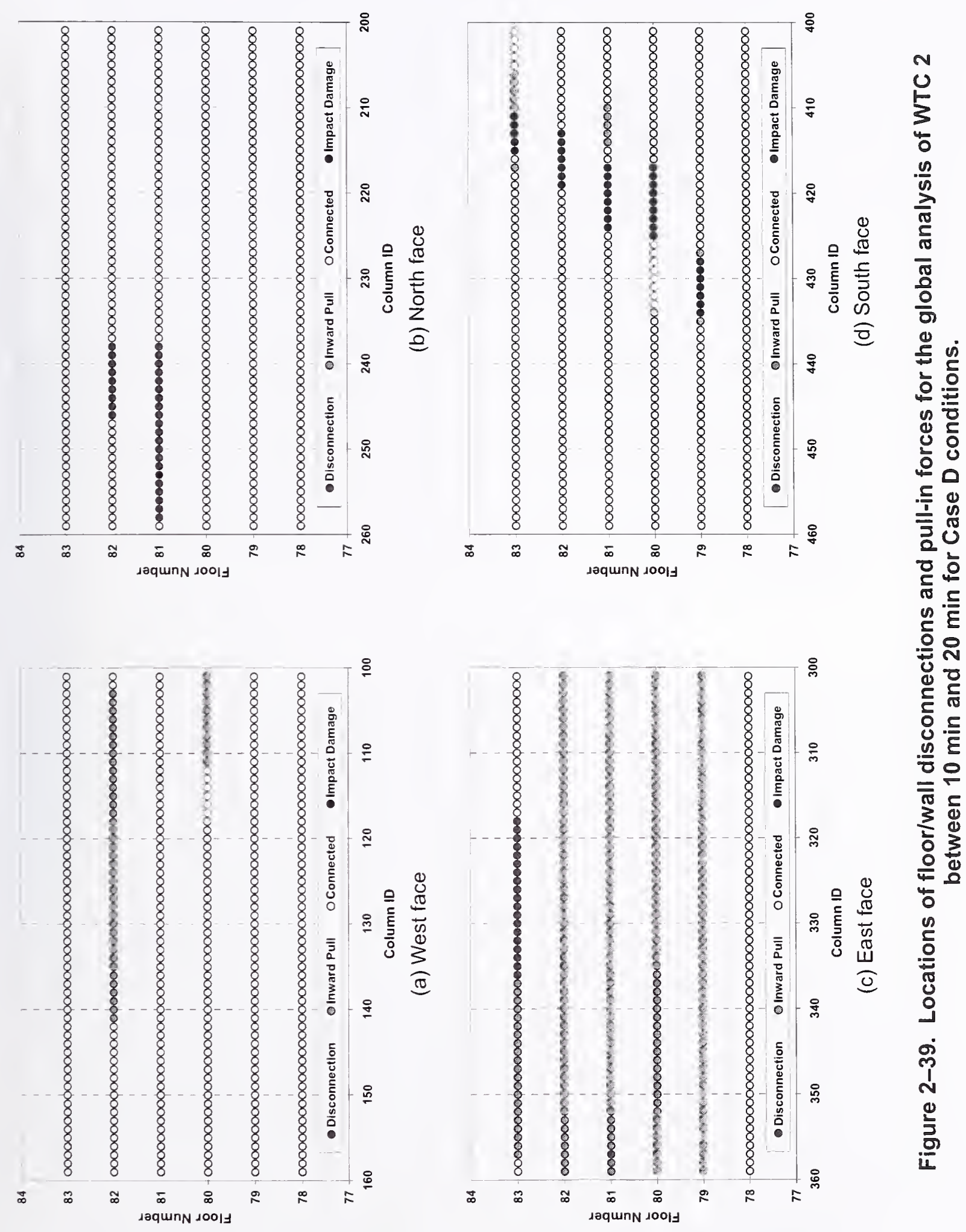

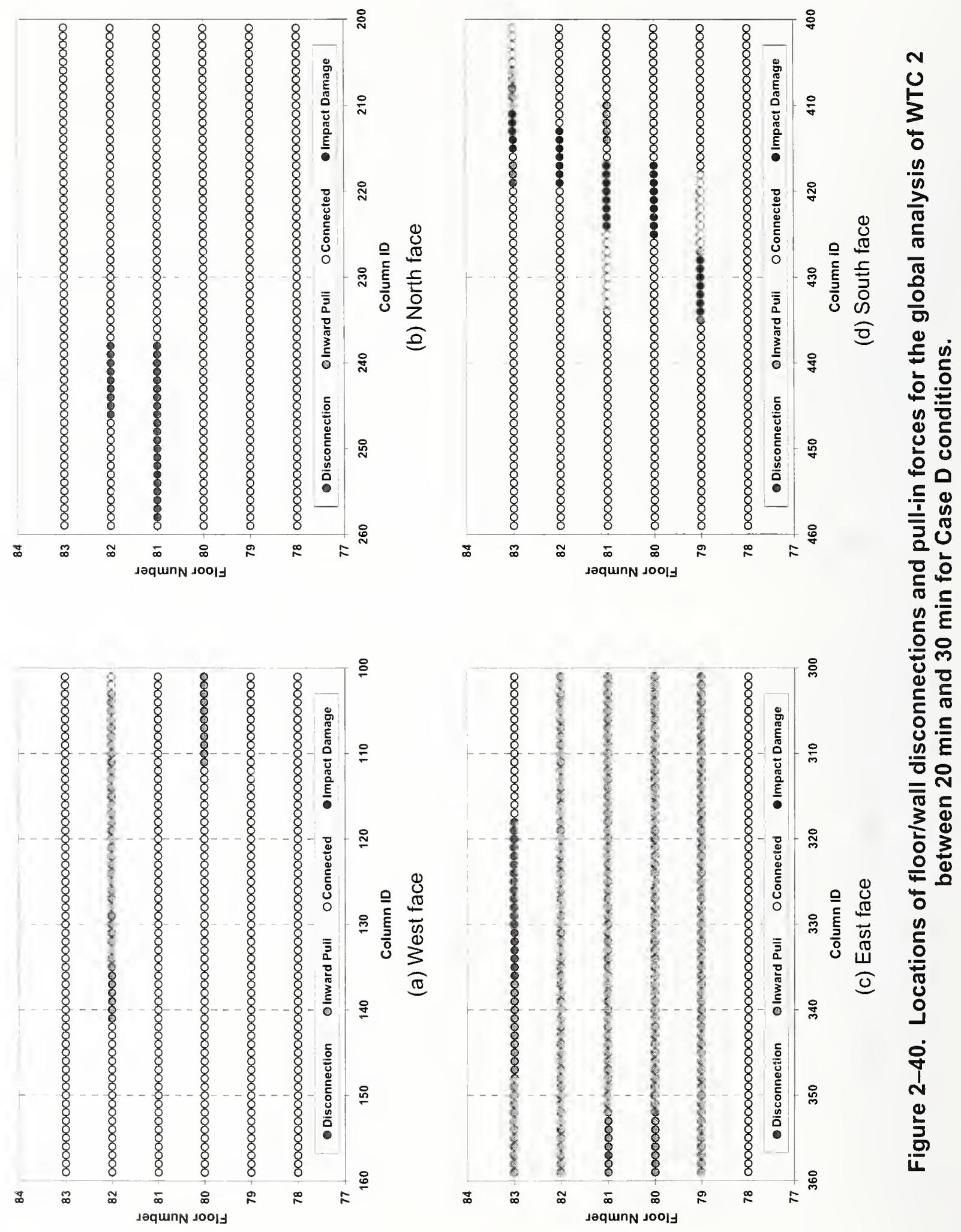

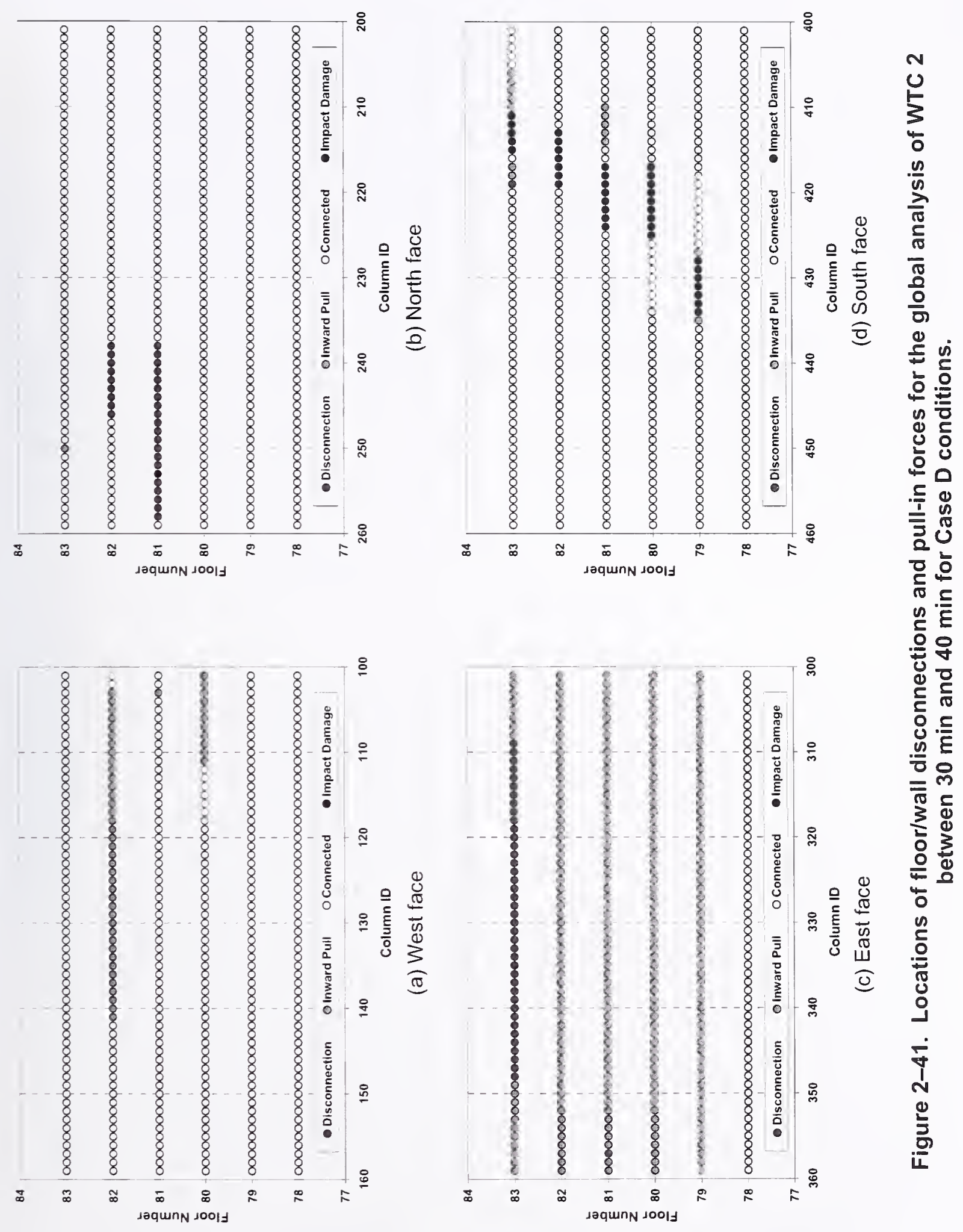

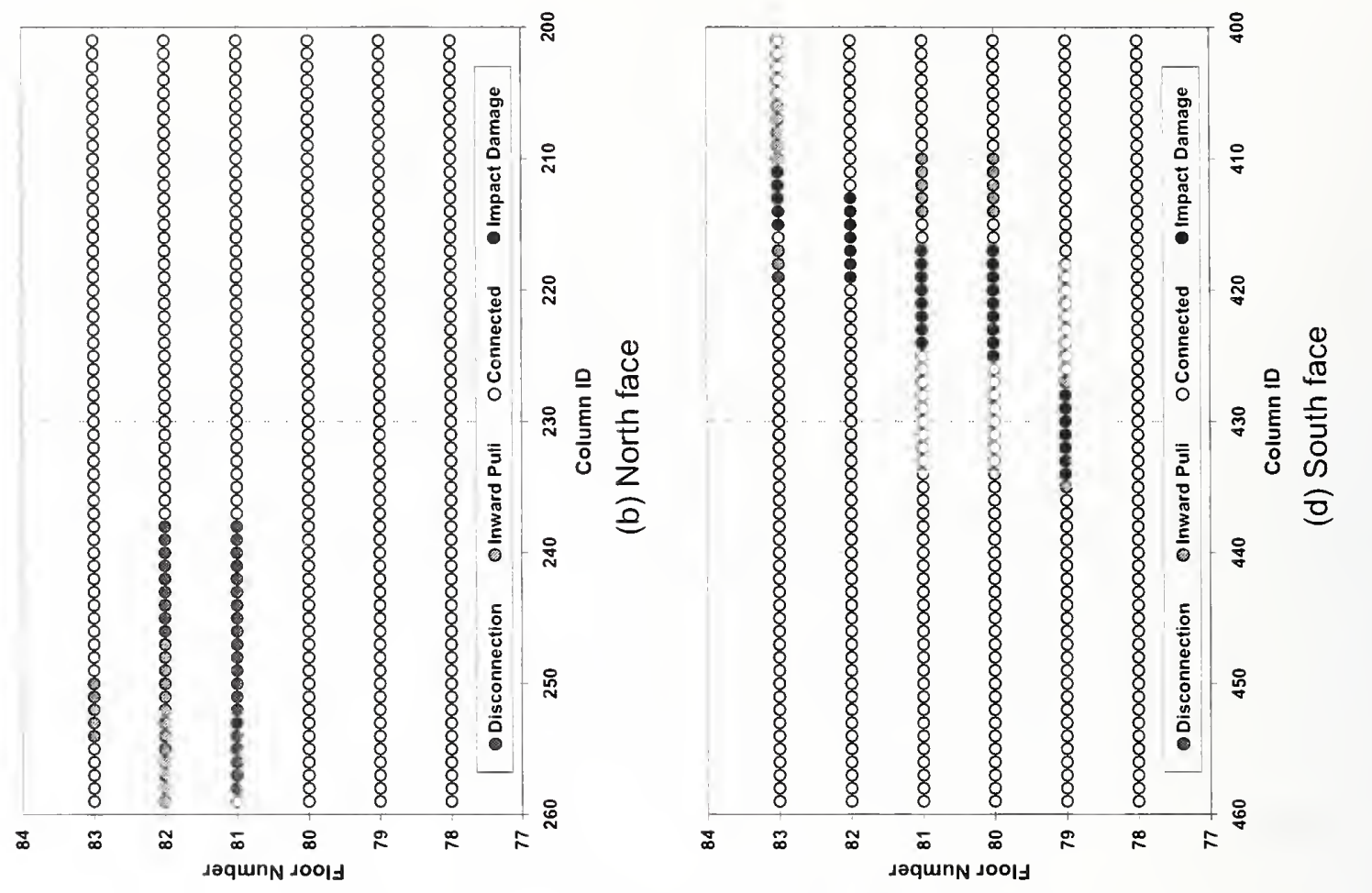

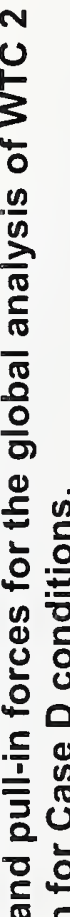
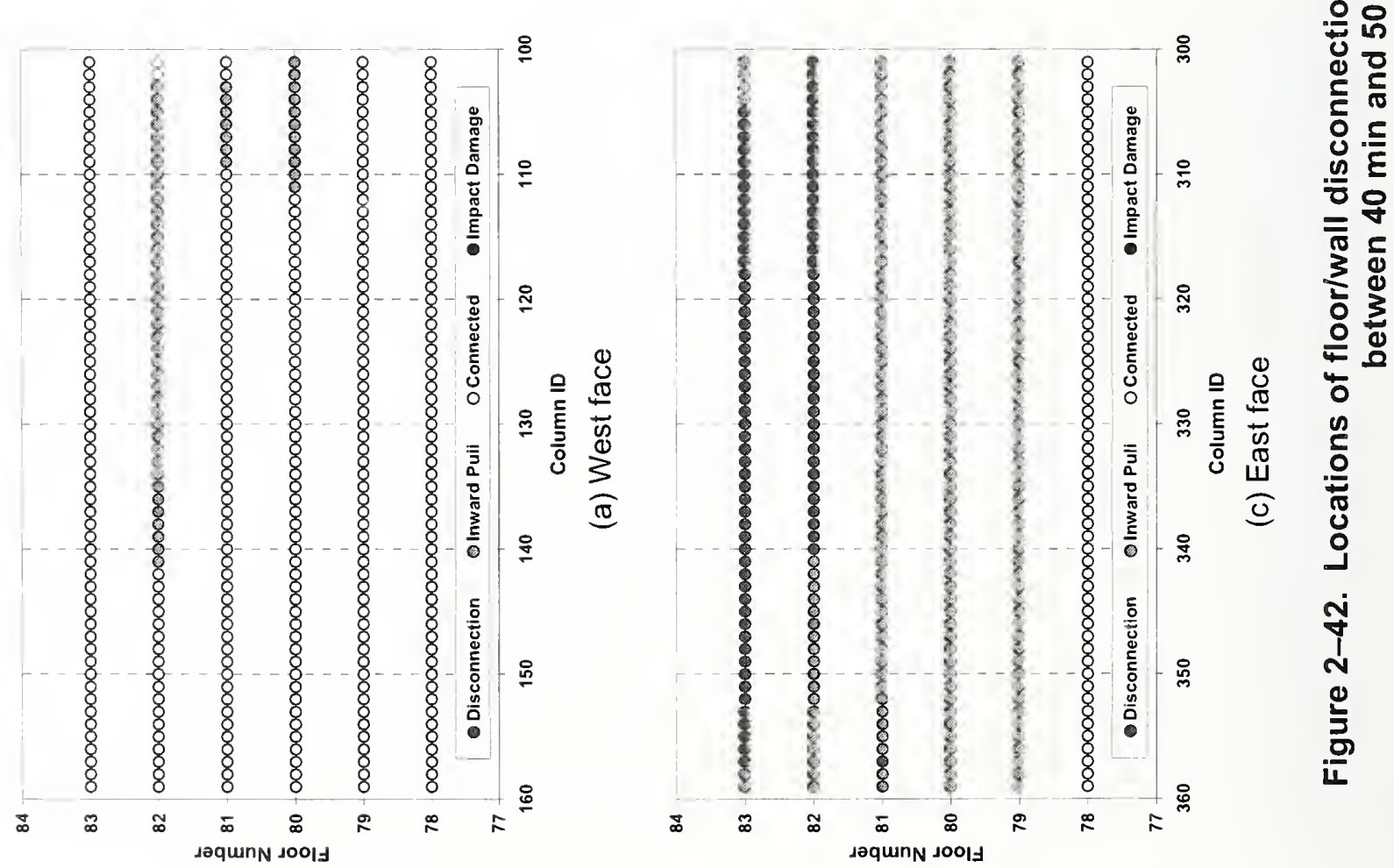

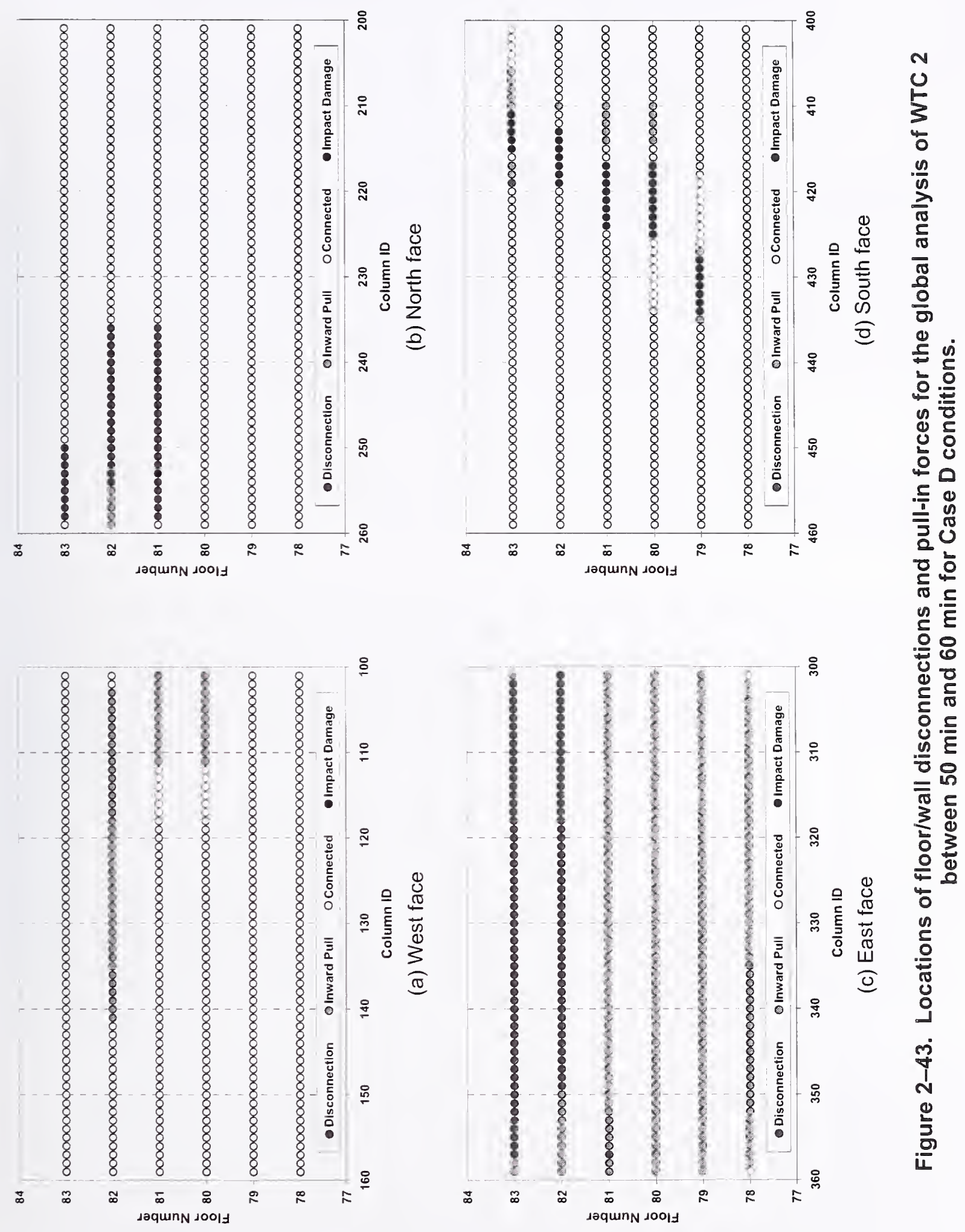
This page intentionally left blank. 


\section{Chapter 3 \\ Isolated Wall ANd CoRe Model Analyses}

\section{$3.1 \quad$ INTRODUCTION}

The isolated models were parts of the global models that were isolated and subjected to the same gravity and thermal loads as the global models. Obviously, the boundary conditions of the isolated models were not realistic, and the results cannot capture the interaction between the isolated model and the rest of the global model. Nevertheless, the isolated models provided insight into the structural behavior of the major parts of the global models under gravity and temperature time histories. Specifically, the trial values of the magnitude of pull-in forces resulted in calculated bowing of the exterior wall that did not agree well with the observed damage. Multiple analyses were required to match the results of calculations with the actual observations. Such multiple analyses could not have been performed on the global models within the time frame of this study and, therefore, were performed on the isolated models.

The isolated model analyses were performed pursuant to the global model analyses without creep and prior to the global model analyses with creep. The results shown in this chapter do not form a major link in the chain of collapse sequence arguments and may be skipped by those interested only in this chain of arguments.

The south exterior wall of WTC 1 and the east exterior wall of WTC 2 bowed and buckled as observed in photographs and videos. Both walls were isolated from the global models of WTC 1 and WTC 2. The isolated models were subjected to both Case A and Case B temperature conditions for WTC 1 and both Case C and Case D temperature conditions for WTC 2. In the following sections, the details of the isolated models, the results, and their comparison with the actual observations for different assumed input parameters are discussed.

\subsection{EXTERIOR WALL BUCKLING}

The south exterior wall of WTC 1 and the east exterior wall of WTC 2 were isolated from the global models and subjected to the combined effects of gravity loads and temperature time histories to determine whether the exterior walls of WTC 1 and WTC 2 would buckle as observed in the photographs and videos, and to determine conditions required to buckle them such as locations and magnitude of pull-in force from the sagging floors, locations of the floor/wall disconnections, and the need for additional vertical loads.

The isolatcd exterior walls from WTC 1 and WTC 2 are shown in Fig. 3-1. The exterior wall segment of WTC 1 included all the exterior columns from Column 301 to Column 359 and floors from Floor 89 to Floor 106. The exterior wall segment of WTC 2 included all the exterior columns from Column 301 to Column 359 and floors from Floor 73 to Floor 90 . The springs at the base of the global models represent the vertical flexibility of the exterior walls below Floor 89 for WTC 1 and Floor 73 for WTC 2 for a uniform loading condition. For the south wall model of WTC 1, members that were severed by the aircraft impact were removed. The east wall of WTC 2 sustained no aircraft impact damage. 


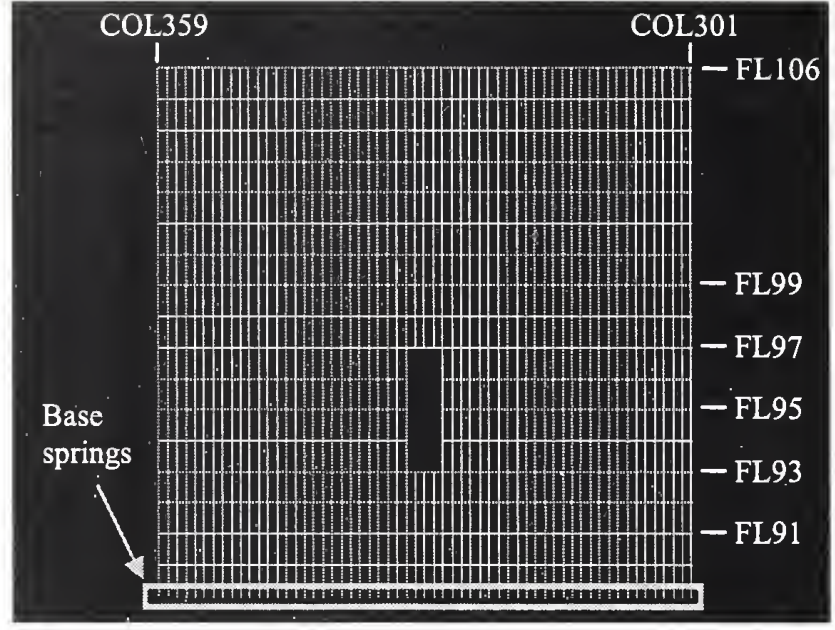

(a) Segment from South wall of WTC 1

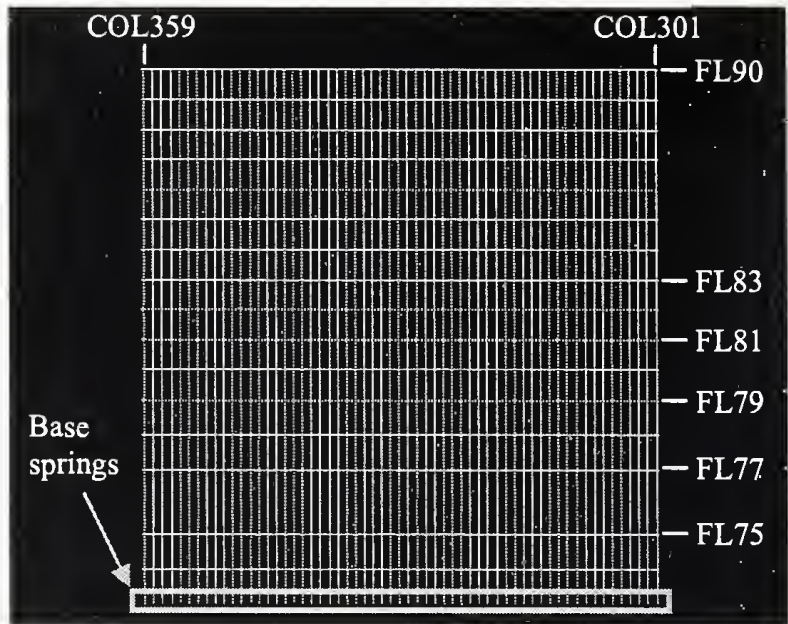

(b) Segment from East wall of WTC 2

Figure 3-1. Isolated exterior wall segments from WTC 1 and WTC 2 (horizontal lines show spandrels and vertical lines show column).

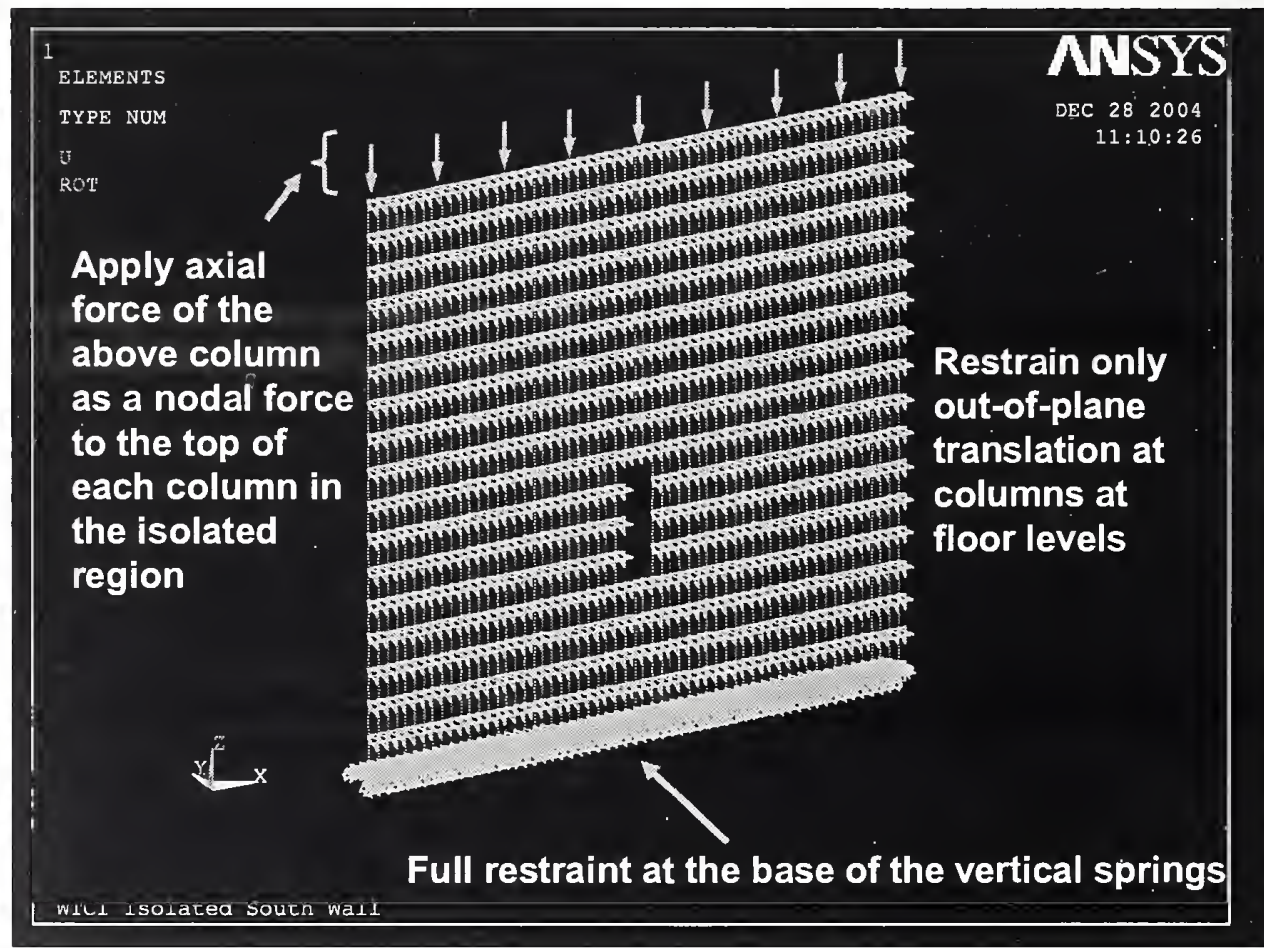

Figure 3-2. Boundary conditions applied on the isolated exterior wall segment on the south wall of WTC 1.

The applied boundary conditions for both isolated exterior wall models were identical and are shown for WTC 1 in Fig. 3-2. The isolated exterior wall models were fully restrained at the base of the vertical 
springs. In the out-of-plane direction (direction y) they were supported at floor levels. At predetermined points in times, these supports were removed at locations where either calculations or observations showed floor/wall disconnections. For the east wall of WTC 2, there were floor/wall disconnections or pull-in forces calculated by the full floor models along the edges of the model (Column 301 and Column 359). In the analyses of the isolated wall model for Case $C$ and Case $D$ temperature conditions, the out-of-plane supports were removed at disconnections located on the edges of the model. However, in the analysis of the pull-in forces needed to match the observed bowing (see Section 3.2.2), the disconnections on the edges of the model were not modeled, and all nodes along the vertical edges of the model were restrained.

To represent the column loads after aircraft impact, a set of axial loads and moments were applied at the top of the isolated wall segments. These axial loads and moments, taken from the preliminary global model analyses with Case A (for WTC 1) and Case C and Case D (for WTC 2) structural damage conditions, represented the axial load and moment in the columns at the floor right above the top of the isolated wall segments after aircraft impact. For instance, for the WTC 2 exterior wall segment, the isolated wall terminates at Floor 90. In order to represent the axial load coming from Floor 90 and above, the axial loads from the columns between Floor 90 and Floor 91 of the global model were extracted at the end of the aircraft impact analysis and were applied on the top of the isolated wall model of WTC 2. In addition to the set of vertical loads applied at the top of the isolated walls, loads representing the dead and 25 percent of the design live loads of the floors were applied at each column node at floor levels.

The isolated exterior wall models were subjected to a set of loading conditions as summarized in Table 3-1 for WTC 1 and Table 3-2 for WTC 2. After the gravity analysis, the isolated exterior wall models were subjected to temperature loads at $10 \mathrm{~min}$ increments. The analyses were conducted with Case A and Case B temperature conditions for WTC 1 and Case C and Case D temperature conditions for WTC 2. For each temperature analysis, the column and spandrel temperatures at time t were ramped to the column and spandrel temperatures at time $=t+10 \mathrm{~min}$. Before applying the temperatures, the out-ofplane supports were removed at disconnected column to exterior wall connections at or prior to $t+$ $10 \mathrm{~min}$. Once the temperature analyses were completed (WTC 1 was analyzed to $100 \mathrm{~min}$ and WTC 2 to $60 \mathrm{~min}$ ), both isolated exterior wall models were pushed down by imposing additional displacements to determine additional axial-load-carrying capacity remaining in the exterior wall system. For push-down analysis, the vertical displacements at the top of the isolated exterior wall models at the end of temperature analyses were extracted. These displacements were applied on top of the isolated exterior wall models, and additional uniform displacement increments were imposed in a displacement-controlled analysis. During push-down analysis, the temperature of the columns and spandrels were kept constant at the values specified at the end of the temperature analyses (WTC 1 column and spandrel tcmperatures were kept at $100 \mathrm{~min}$ temperatures and WTC 2 column and spandrel temperatures werc kept at $60 \mathrm{~min}$ temperatures). The results of isolated exterior wall model analyses are discussed in the following sections. 
Table 3-1. Analysis steps conducted on WTC 1 isolated exterior wall model.

\begin{tabular}{|c|c|c|}
\hline \multicolumn{2}{|c|}{ Analysis Step } & Description \\
\hline 1 & Gravity & Apply gravity loads with aircraft impact \\
\hline 2 & $\begin{array}{l}\text { Temperature } \\
\text { at } 10 \mathrm{~min}\end{array}$ & $\begin{array}{l}\text { Remove the out-of-plane supports at floor to exterior wall connections disconnected at or prior } \\
\text { to } 10 \mathrm{~min} \text {. Apply column and spandrel temperatures at } 10 \mathrm{~min} \text {. }\end{array}$ \\
\hline 3 & $\begin{array}{l}\text { Temperature } \\
\text { at } 20 \mathrm{~min}\end{array}$ & $\begin{array}{l}\text { Remove the out-of-plane supports at floor to exterior wall connections disconnected at or prior } \\
\text { to } 20 \mathrm{~min} \text {. Apply column and spandrel temperatures at } 20 \text { min. }\end{array}$ \\
\hline 4 & $\begin{array}{l}\text { Temperature } \\
\text { at } 30 \mathrm{~min}\end{array}$ & $\begin{array}{l}\text { Remove the out-of-plane supports at floor to exterior wall connections disconnected at or prior } \\
\text { to } 30 \mathrm{~min} \text {. Apply column and spandrel temperatures at } 30 \mathrm{~min} \text {. }\end{array}$ \\
\hline 5 & $\begin{array}{l}\text { Temperature } \\
\text { at } 40 \mathrm{~min}\end{array}$ & $\begin{array}{l}\text { Remove the out-of-plane supports at floor to exterior wall connections disconnected at or prior } \\
\text { to } 40 \mathrm{~min} \text {. Apply column and spandrel temperatures at } 40 \mathrm{~min} \text {. }\end{array}$ \\
\hline 6 & $\begin{array}{l}\text { Temperature } \\
\text { at } 50 \mathrm{~min}\end{array}$ & $\begin{array}{l}\text { Remove the out-of-plane supports at floor to exterior wall connections disconnected at or prior } \\
\text { to } 50 \mathrm{~min} \text {. Apply column and spandrel temperatures at } 50 \mathrm{~min} \text {. }\end{array}$ \\
\hline 7 & $\begin{array}{l}\text { Temperature } \\
\text { at } 60 \mathrm{~min}\end{array}$ & $\begin{array}{l}\text { Remove the out-of-plane supports at floor to exterior wall connections disconnected at or prior } \\
\text { to } 60 \mathrm{~min} \text {. Apply column and spandrel temperatures at } 60 \mathrm{~min} \text {. }\end{array}$ \\
\hline 8 & $\begin{array}{l}\text { Temperature } \\
\text { at } 70 \mathrm{~min}\end{array}$ & $\begin{array}{l}\text { Remove the out-of-plane supports at floor to exterior wall connections disconnected at or prior } \\
\text { to } 70 \mathrm{~min} \text {. Apply column and spandrel temperatures at } 70 \mathrm{~min} \text {. }\end{array}$ \\
\hline 9 & $\begin{array}{l}\text { Temperature } \\
\text { at } 80 \mathrm{~min}\end{array}$ & $\begin{array}{l}\text { Remove the out-of-plane supports at floor to exterior wall connections disconnected at or prior } \\
\text { to } 80 \mathrm{~min} \text {. Apply column and spandrel temperatures at } 80 \mathrm{~min} \text {. }\end{array}$ \\
\hline 10 & $\begin{array}{l}\text { Temperature } \\
\text { at } 90 \text { min }\end{array}$ & $\begin{array}{l}\text { Remove the out-of-plane supports at floor to exterior wall connections disconnected at or prior } \\
\text { to } 90 \mathrm{~min} \text {. Apply column and spandrel temperatures at } 90 \mathrm{~min} \text {. }\end{array}$ \\
\hline 11 & $\begin{array}{l}\text { Temperature } \\
\text { at } 100 \mathrm{~min}\end{array}$ & $\begin{array}{l}\text { Remove the out-of-plane supports at floor to exterior wall connections disconnected at or prior } \\
\text { to } 100 \mathrm{~min} \text {. Apply column and spandrel temperatures at } 100 \mathrm{~min} \text {. }\end{array}$ \\
\hline 12 & Push Down & $\begin{array}{l}\text { Extract the vertical displacements at the top of the isolated wall model and impose these } \\
\text { displacements and additional uniform displacement increments with column and spandrel } \\
\text { temperatures kept at } 100 \text { min. }\end{array}$ \\
\hline
\end{tabular}

Table 3-2. Analysis steps conducted on WTC 2 isolated exterior wall model.

\begin{tabular}{|c|c|c|}
\hline \multicolumn{2}{|c|}{ Analysis Step } & Description \\
\hline 1 & Gravity & Apply gravity loads right after aircraft impact \\
\hline 2 & $\begin{array}{c}\text { Temperature } \\
\text { at } 10 \mathrm{~min}\end{array}$ & $\begin{array}{r}\text { Remove the out-of-plane supports at floor to exterior wall connections that were disconnected } \\
\text { at or prior to } 10 \text { min. Apply column and spandrel temperatures at 10 min. }\end{array}$ \\
\hline 3 & $\begin{array}{c}\text { Temperature } \\
\text { at } 20 \text { min }\end{array}$ & $\begin{array}{r}\text { Remove the out-of-plane supports at floor to exterior wall connections that were disconnected } \\
\text { at } 20 \text { min. Apply column and spandrel temperatures at 20 min. }\end{array}$ \\
\hline 4 & $\begin{array}{c}\text { Temperature } \\
\text { at } 30 \text { min }\end{array}$ & $\begin{array}{r}\text { Remove the out-of-plane supports at floor to exterior wall connections that were disconnected } \\
\text { at 30 min. Apply column and spandrel temperatures at 30 min. }\end{array}$ \\
\hline 5 & $\begin{array}{c}\text { Temperature } \\
\text { at } 40 \text { min }\end{array}$ & $\begin{array}{r}\text { Remove the out-of-plane supports at floor to exterior wall connections that were disconnected } \\
\text { at 40 min. Apply column and spandrel temperatures at 40 min. }\end{array}$ \\
\hline 6 & $\begin{array}{c}\text { Temperature } \\
\text { at } 50 \text { min }\end{array}$ & $\begin{array}{r}\text { Remove the out-of-plane supports at floor to exterior wall connections that were disconnected } \\
\text { at } 50 \text { min. Apply column and spandrel temperatures at } 50 \text { min. }\end{array}$ \\
\hline 7 & $\begin{array}{c}\text { Temperature } \\
\text { at } 60 \text { min }\end{array}$ & $\begin{array}{r}\text { Remove the out-of-plane supports at floor to exterior wall connections that were disconnected } \\
\text { at } 60 \text { min. Apply column and spandrel temperatures at } 60 \text { min. }\end{array}$ \\
\hline 8 & $\begin{array}{c}\text { Push Down } \\
\text { Extract the vertical displacements at the top of the isolated wall model and impose these } \\
\text { displacements and additional uniform displacement increments with column and spandrel } \\
\text { temperatures kept at 60 min. }\end{array}$ \\
\hline
\end{tabular}




\subsubsection{Finite Element Analysis of WTC 1 Exterior Wall}

\section{Case A Temperature Condition}

As calculated in the full-floor model analyses for Case $A_{i}$ condition, described in Appendix A, the floors were assumed to remain connected to the south wall of WTC 1 throughout the temperature history for Case A condition.

Figures 3-3 to 3-12 show the temperature distributions of Case A condition in columns of the WTC 1 south wall from $10 \mathrm{~min}$ to $100 \mathrm{~min}$. A linear temperature gradient in the direction normal to the exterior wall was assumed to exist in the cross section of beam elements for exterior columns. As Figs. 3-3 to 3-12 show, temperatures on the south wall were not very high; the peak temperature was only $455^{\circ} \mathrm{C}$ for Case A temperature condition. The temperature distributions of Case A condition in spandrels are shown in Figs. 3-13 to 3-22. Temperatures were assumed to be uniform over the entire cross section of beam elements for spandrels.

Figure 3-23 shows vertical displacements, out-of-plane displacements, and axial loads in columns of the WTC 1 south wall after the impact. In contour plots created by ANSYS, "MN" and "MX" indicate the locations of the minimum and maximum values, respectively. Columns from Column 329 to Column 331 between Floor 93 and Floor 97 were severed by the aircraft impact, and the maximum displacement occurred at Column 330 at Floor 106. Column 328 and Column 332 between Floor 93 and Floor 97 on both sides of the aircraft impact damage area were heavily loaded, and the maximum axial load was 377 kip at Column 332.

Figures 3-24 to 3-26 show vertical displacements, out-of-plane displacements, and axial loads in the columns of the WTC 1 south wall for Case A temperature condition, respectively. At $100 \mathrm{~min}$, the maximum vertical displacement was nearly the same as the vertical displacement of $2.6 \mathrm{in}$. after the impact. The out-of-plane displacement was insignificant during thermal loading. The maximum out-ofplane displacement was 0.35 in. outward, occurring at Column 332 between Floor 96 and Floor 97. During thermal loading, the axial load in Column 332 between Floor 96 and Floor 97 increased from 377 kip to 756 kip.

Figure 3-27 shows plastic strains in columns at $100 \mathrm{~min}$. The maximum plastic strain of 4 percent occurred in Column 332 between Floor 96 and Floor 97.

As described in Appendix C for the preliminary global model without creep and in Chapter 4 for the final global model with creep, gravity loads on the south wall varied under thermal loads as the loads were redistributed within the tower through the hat truss and the spandrels. Figure 3-28 compares the axial loads in columns derived from the preliminary global model without creep and with Case $A_{i}$ structural damage condition to those of the isolated model wall model with Case A structural damage and temperature conditions. The preliminary global model without creep was the only available source for this comparison at that time. The differences in the axial loads were applied to the columns at Floor 99 as corrective loads. Figure 3-29 shows the response of the south wall after applying these corrective loads. The WTC 1 south wall remained stable after the application of these corrective loads.

To determine the additional load-carrying capacity of the south wall at the end of the temperature analysis at $100 \mathrm{~min}$, the top of the isolated exterior wall model was pushed down by converting the model from a 
force-control analysis to a displacement-control analysis and by imposing additional vertical displacement increments on top of the isolated model. The analysis was terminated at an additional vertical displacement of $13.2 \mathrm{in}$. This model reached a peak total vertical load at an additional vertical displacement of $11.3 \mathrm{in}$. Figure 3-30 shows the relationship between the total additional vertical load and the additional vertical displacement. Figure 3-31 shows additional vertical load per column at different additional vertical displacements of 2 in., 4 in., 6 in., 8 in., and 10 in. Figure 3-32 shows the response of the WTC 1 south wall at the additional displacement of $13.2 \mathrm{in.}$ When an additional $2 \mathrm{in}$. of vertical displacement was imposed, the variation among the additional vertical loads on columns was within $50 \mathrm{kip}$ for the average additional vertical load of about $160 \mathrm{kip}$. However, at an additional displacement of $10 \mathrm{in}$., the variation became large, indicating some columns were softer than others; the softer columns had reached their load-carrying capacities and were in the post-buckling regime. The WTC 1 south wall model carried an additional vertical load of 33,000 kip (560 kip per column on the average). Therefore, the south wall possessed significant reserve capacity after the application of Case A temperature condition.

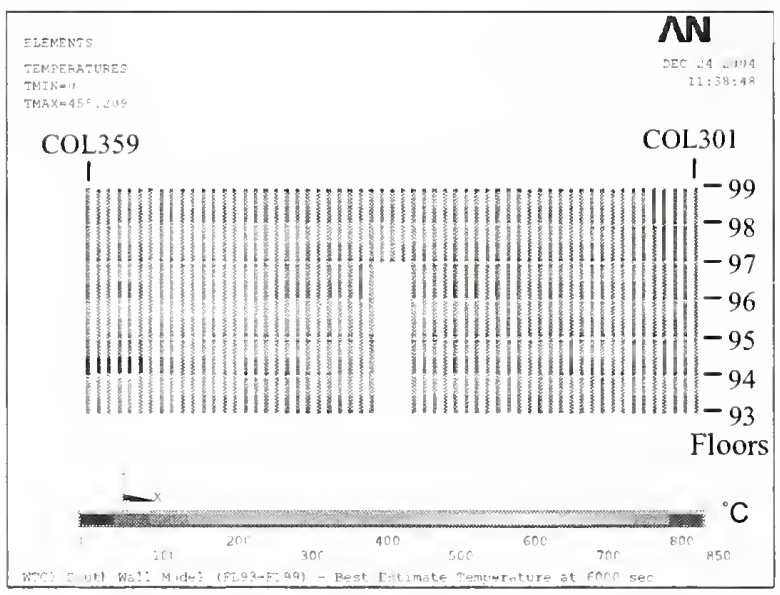

(a) Outside

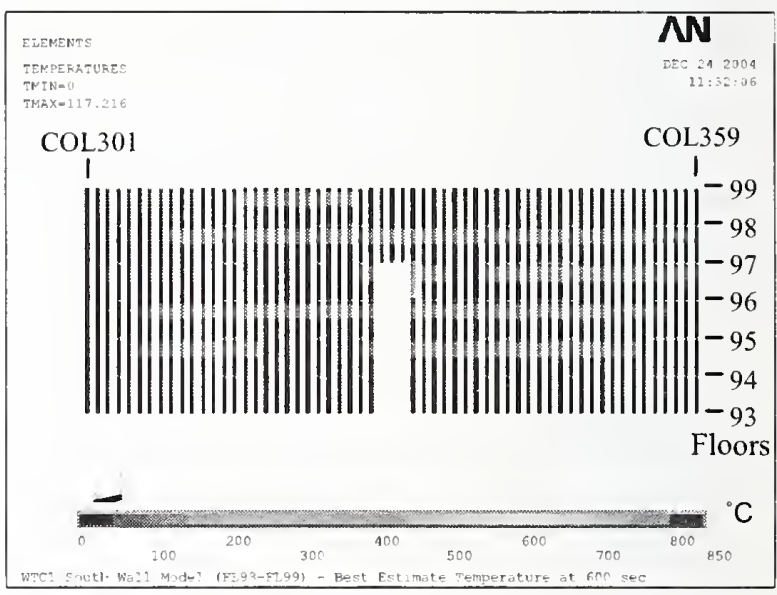

(b) Inside

Figure 3-3. Case A temperature condition of south wall columns of WTC 1 at $10 \mathrm{~min}$.

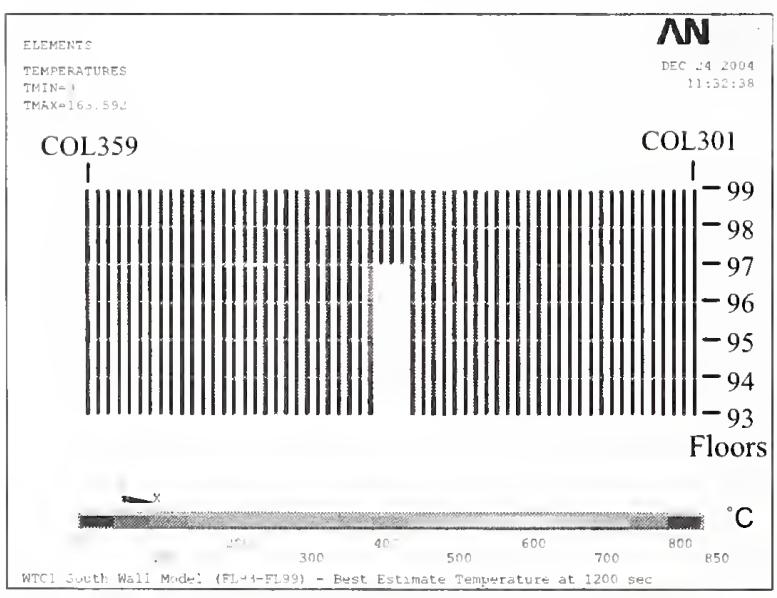

(a) Outside

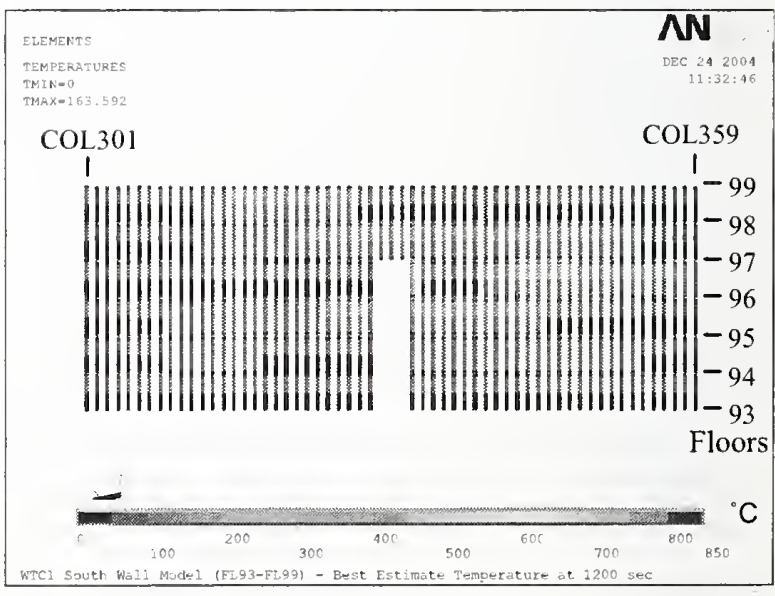

(b) Inside

Figure 3-4. Case A temperature condition of south wall columns of WTC 1 at $20 \mathrm{~min}$. 


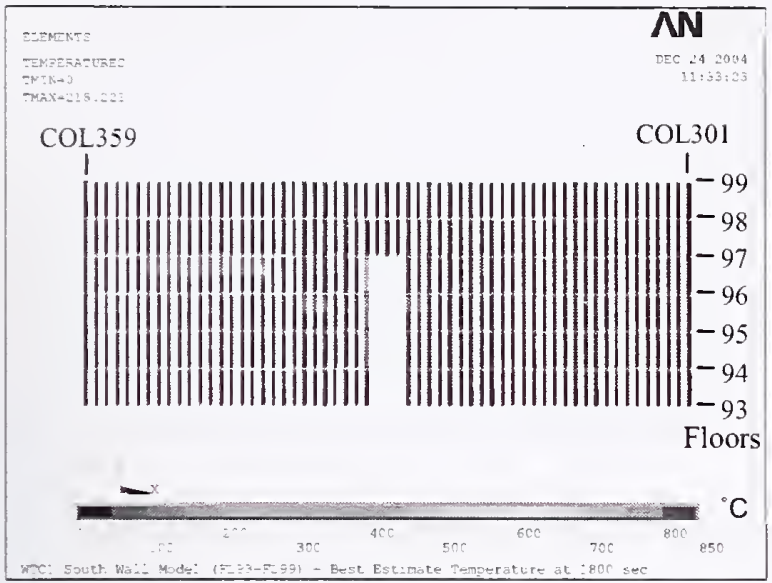

(a) Outside

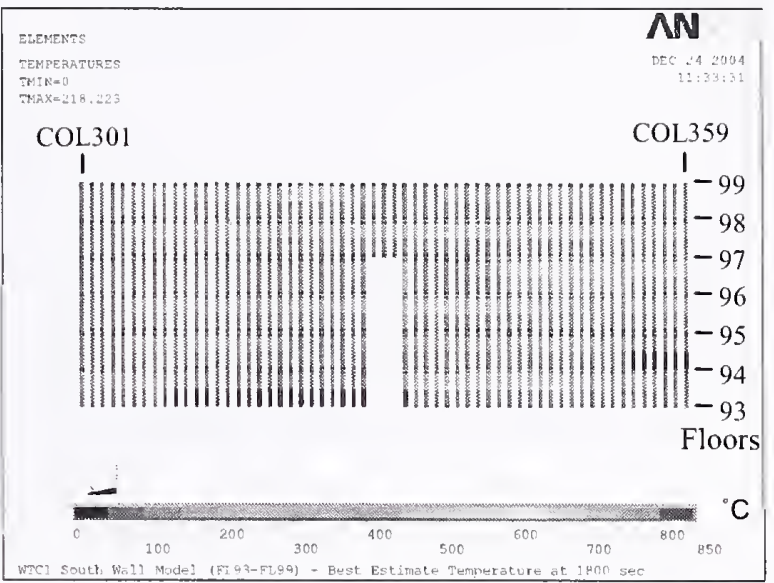

(b) Inside

Figure 3-5. Case A temperature condition of south wall columns of WTC 1 at $30 \mathrm{~min}$.

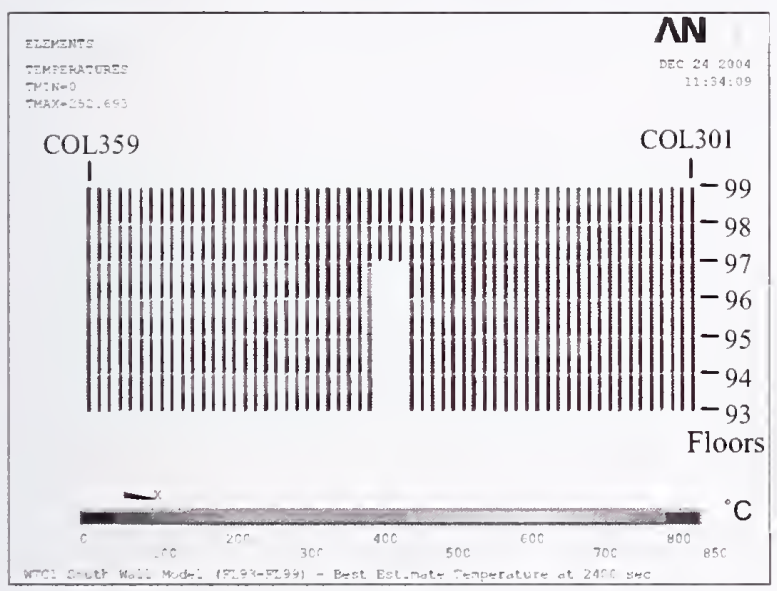

(a) Outside

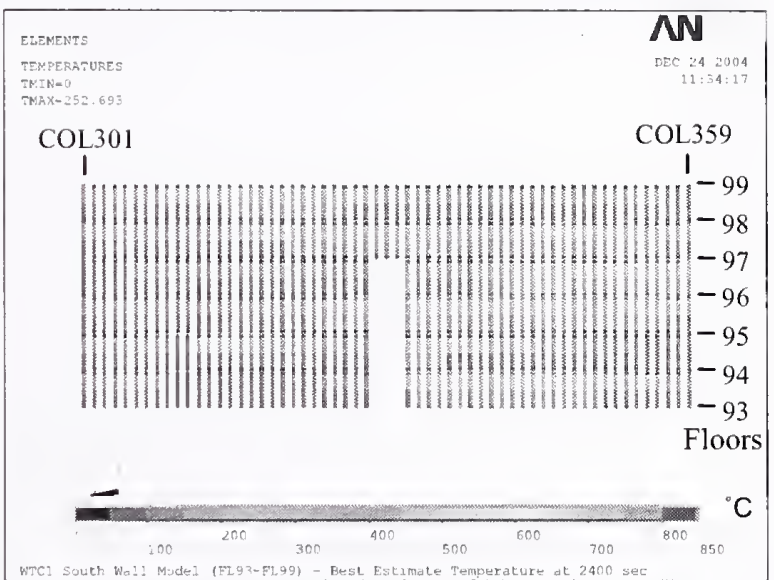

(b) Inside

Figure 3-6. Case A temperature condition of south wall columns of WTC 1 at $40 \mathrm{~min}$.

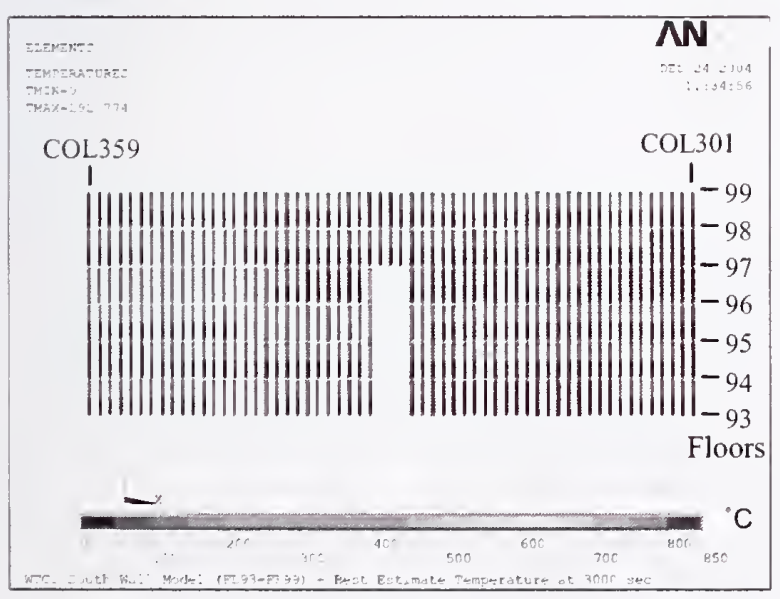

(a) Outside

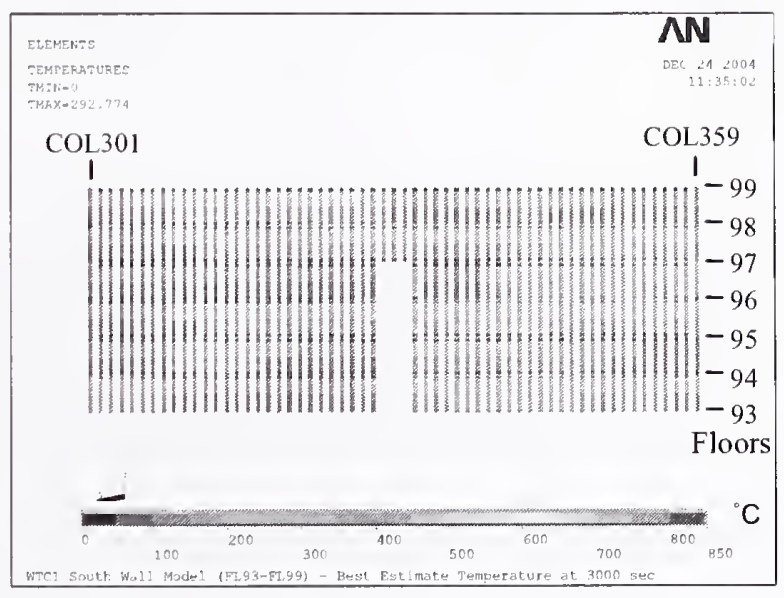

(b) Inside

Figure 3-7. Case A temperature condition of south wall columns of WTC 1 at $50 \mathrm{~min}$. 


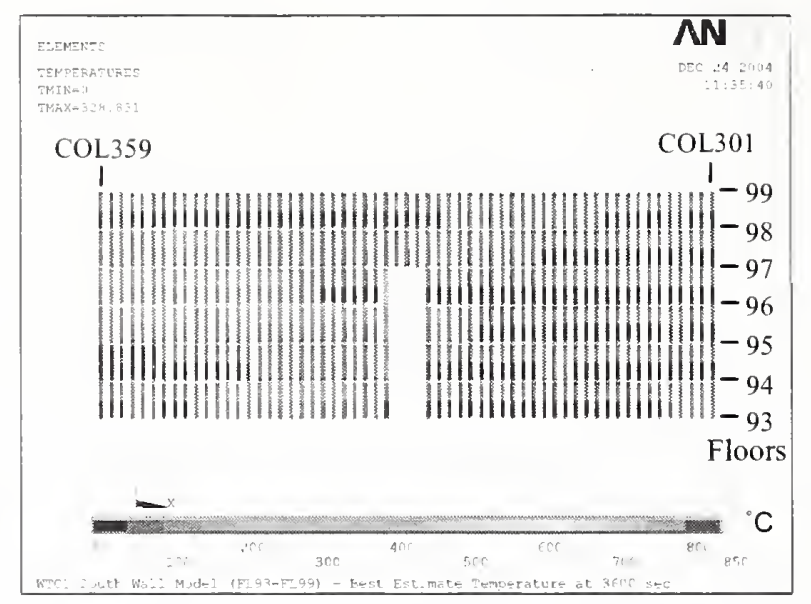

(a) Outside

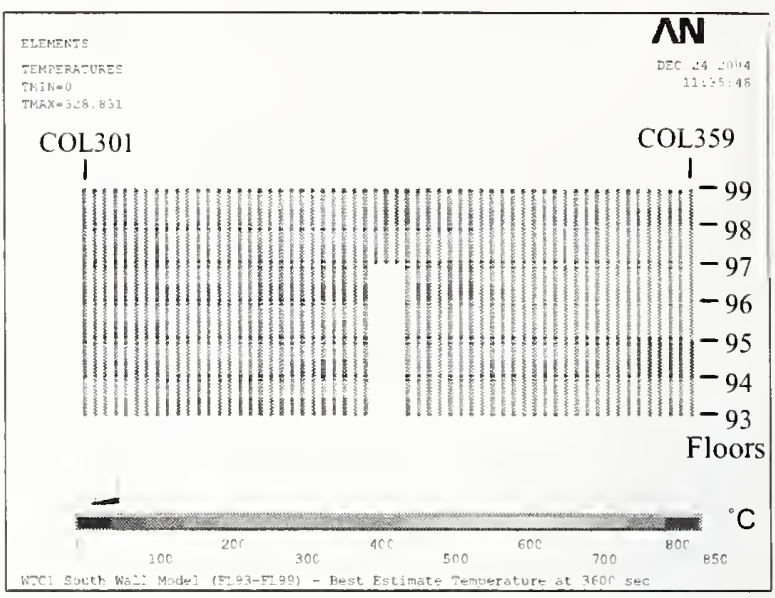

(b) Inside

Figure 3-8. Case A temperature condition of south wall columns of WTC 1 at $60 \mathrm{~min}$.

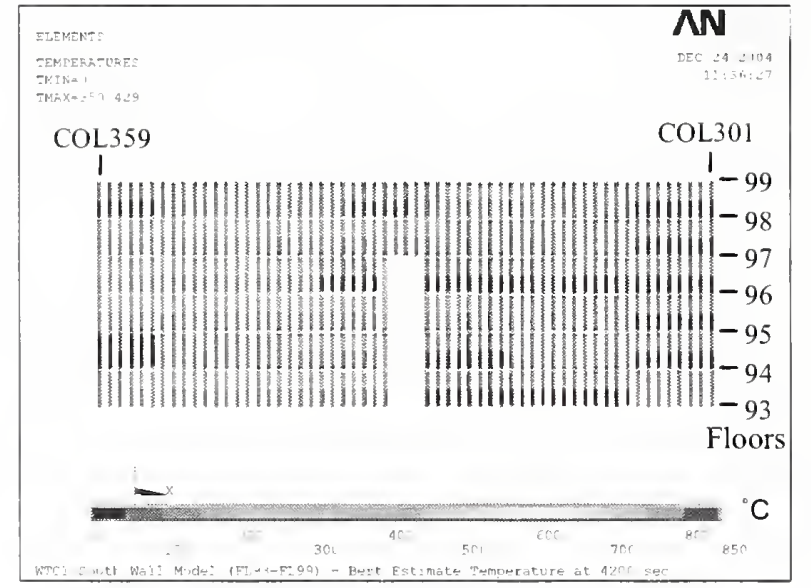

(a) Outside

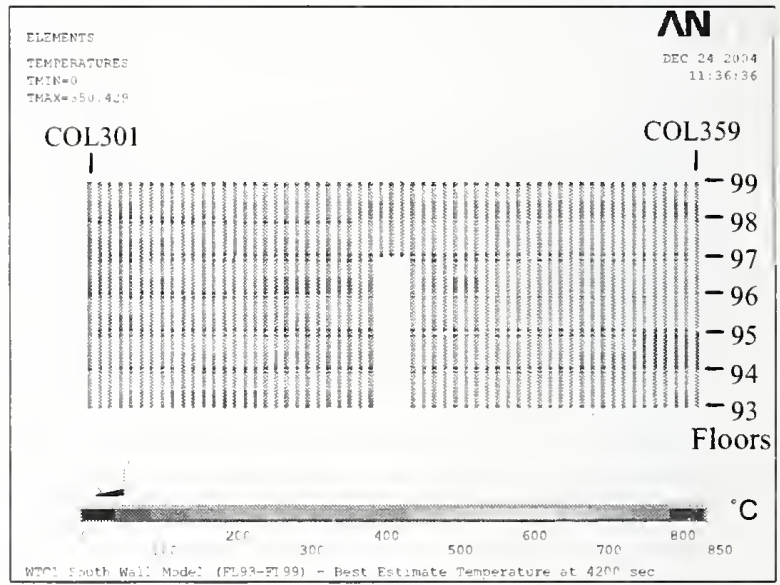

(b) Inside

Figure 3-9. Case A temperature condition of south wall columns of WTC 1 at $70 \mathrm{~min}$.

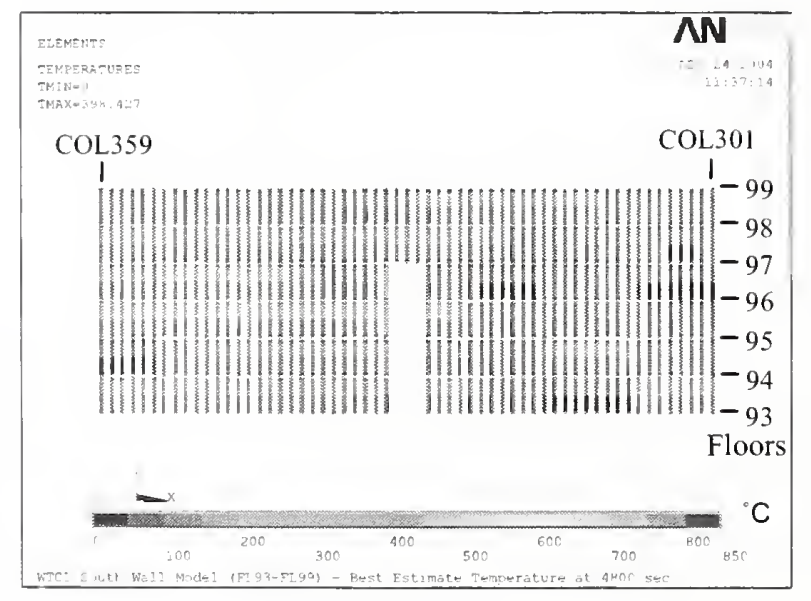

(a) Outside

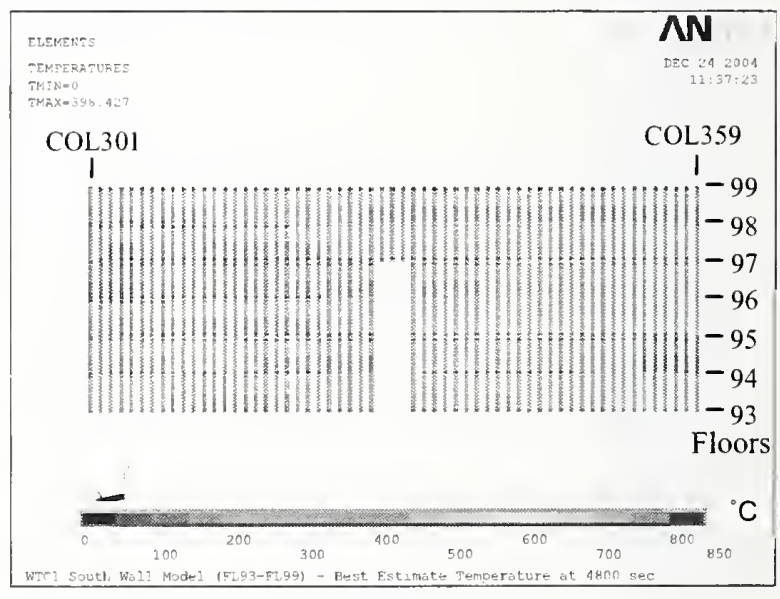

(b) Inside

Figure 3-10. Case A temperature condition of south wall columns of WTC 1 at 80 min. 


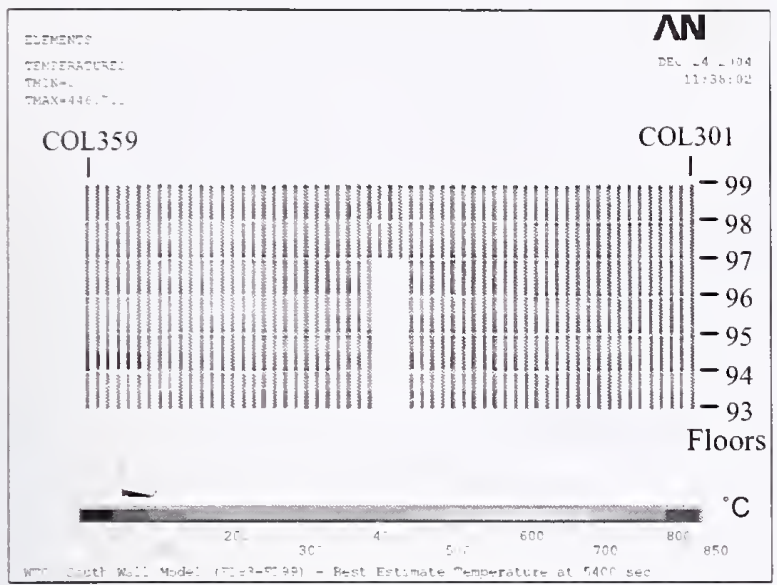

(a) Outside

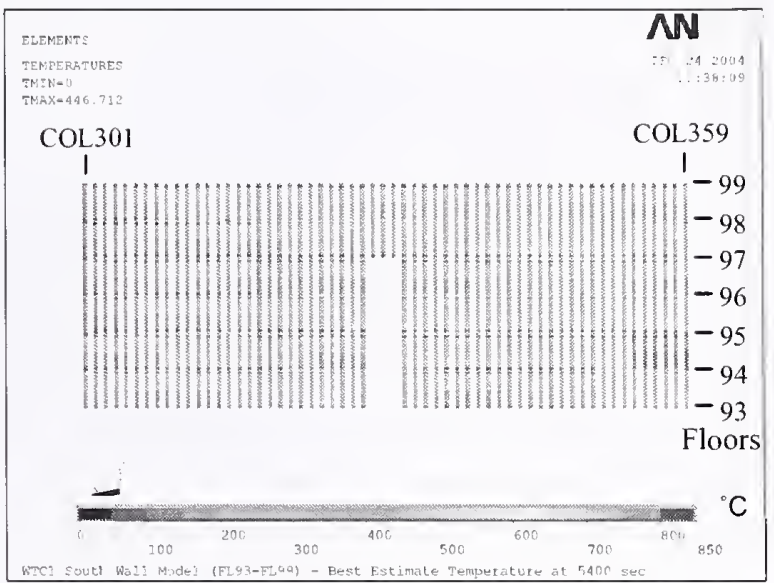

(b) Inside

Figure 3-11. Case A temperature condition of south wall columns of WTC 1 at $90 \mathrm{~min}$.

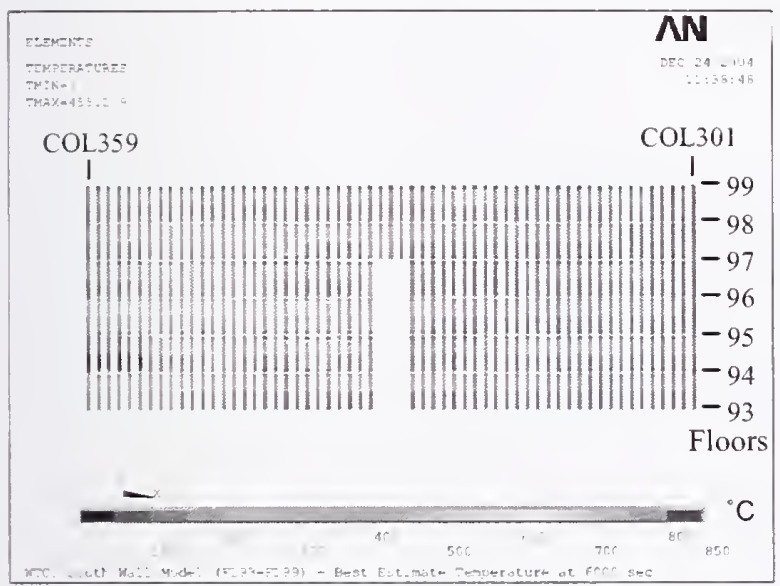

(a) Outside

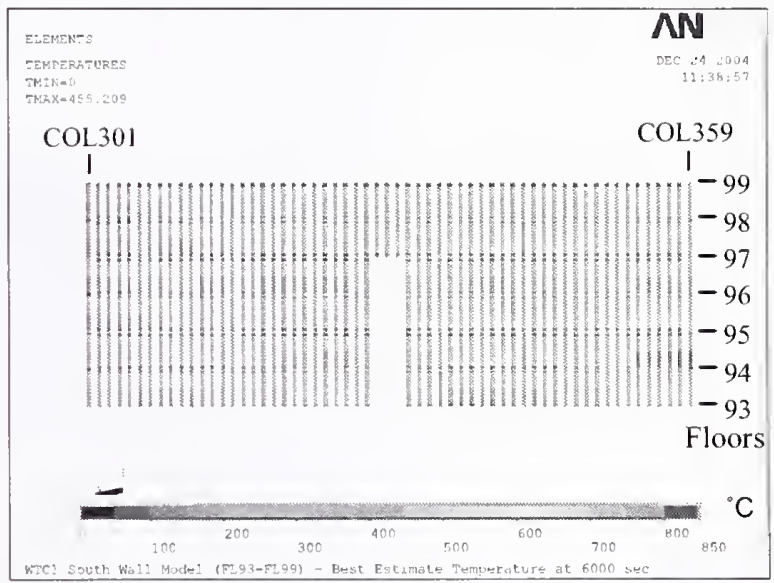

(b) Inside

Figure 3-12. Case A temperature condition of south wall columns of WTC 1 at $100 \mathrm{~min}$.

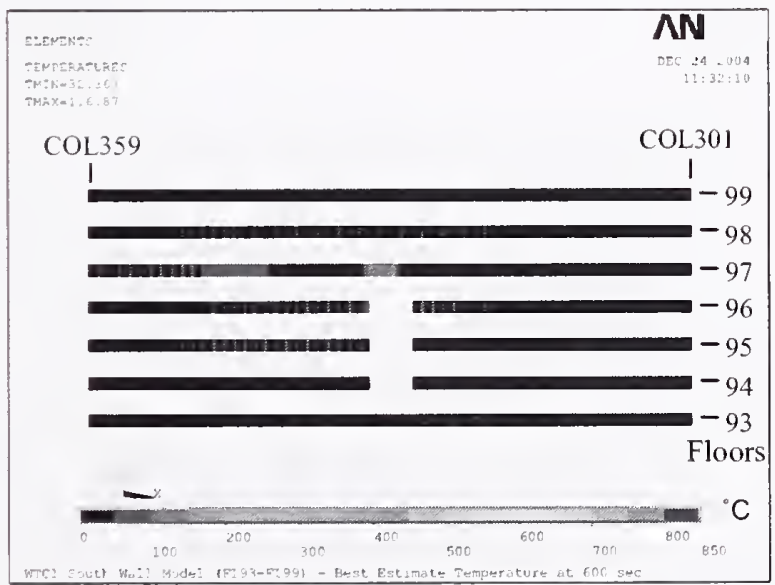

Figure 3-13. Case A temperature condition of south wall spandrels of WTC 1 at $10 \mathrm{~min}$. 


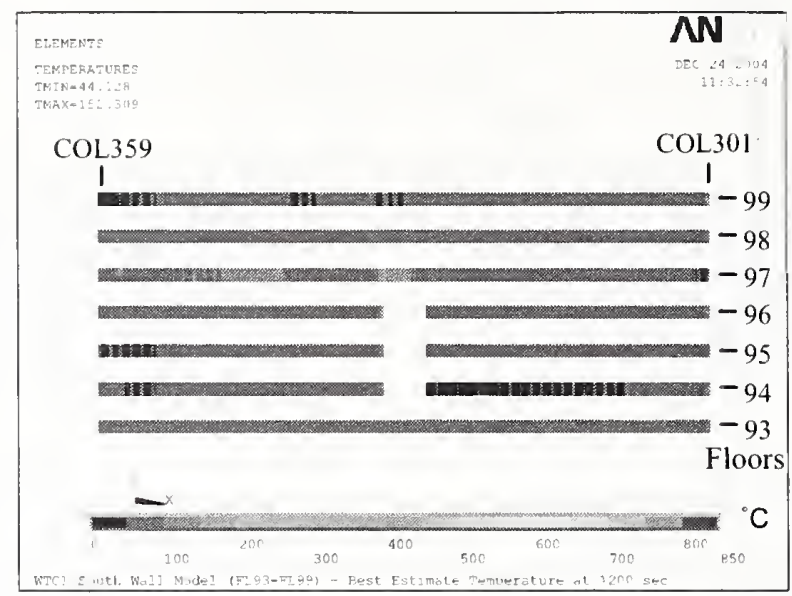

Figure 3-14. Case A temperature condition of south wall spandrels of WTC 1 at $20 \mathrm{~min}$.

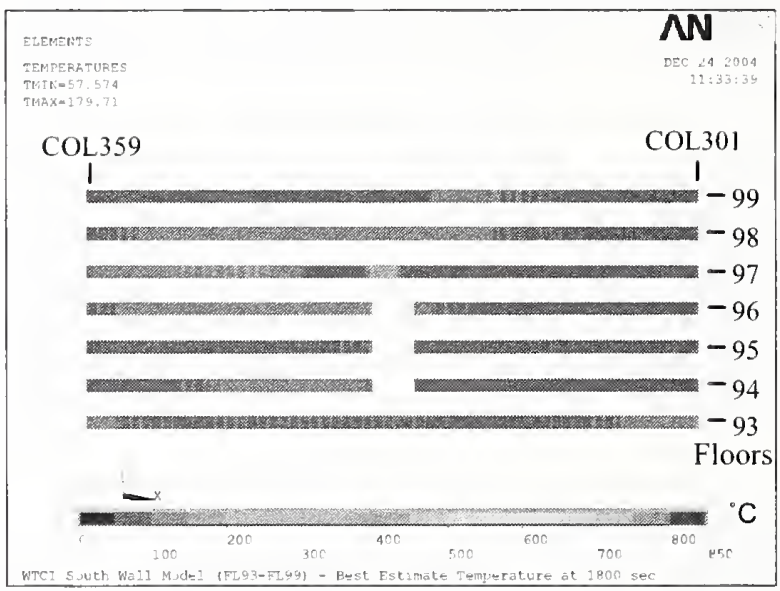

Figure 3-15. Case A temperature condition of south wall spandrels of WTC 1 at $30 \mathrm{~min}$.

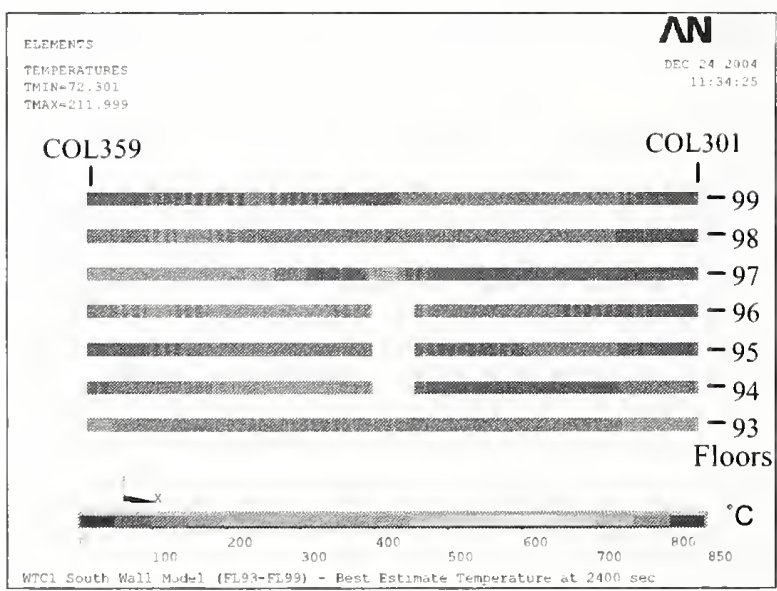

Figure 3-16. Case A temperature condition of south wall spandrels of WTC 1 at $40 \mathrm{~min}$. 


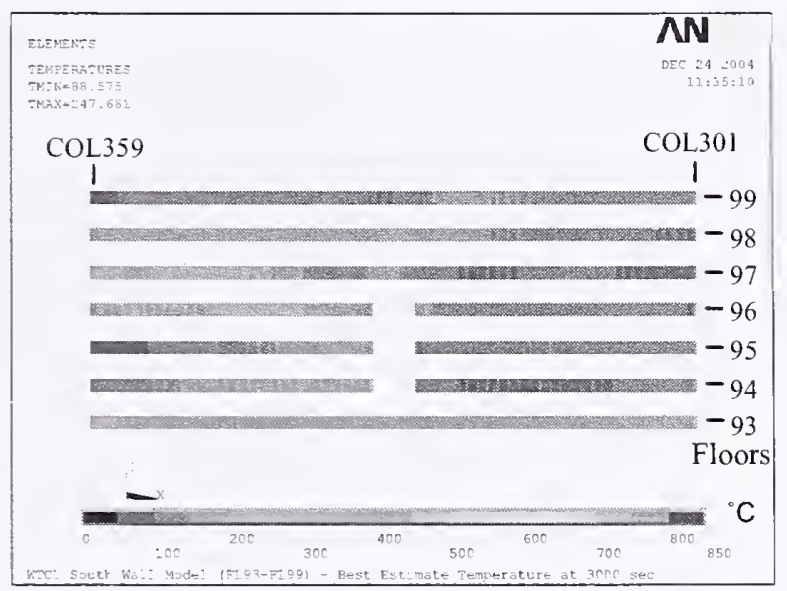

Figure 3-17. Case A temperature condition of south wall spandrels of WTC 1 at $50 \mathrm{~min}$.

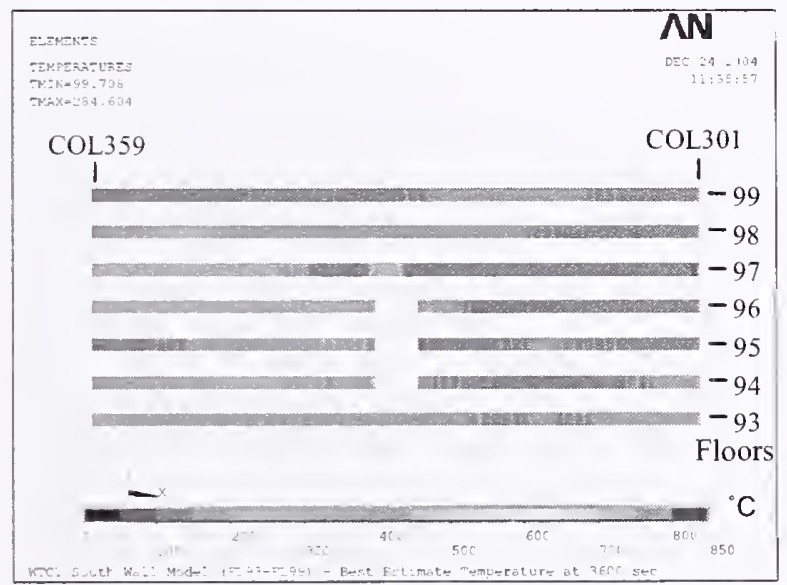

Figure 3-18. Case A temperature condition of south wall spandrels of WTC 1 at $60 \mathrm{~min}$.

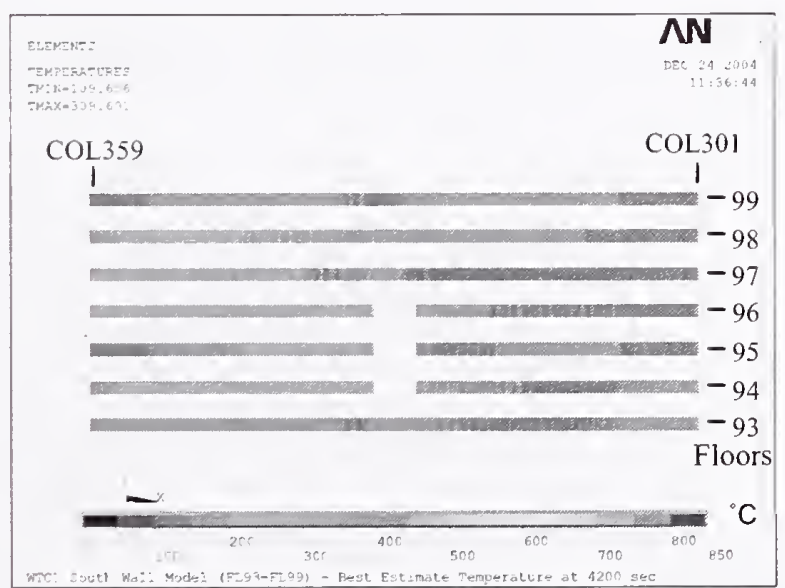

Figure 3-19. Case A temperature condition of south wall spandrels of WTC 1 at $70 \mathrm{~min}$. 


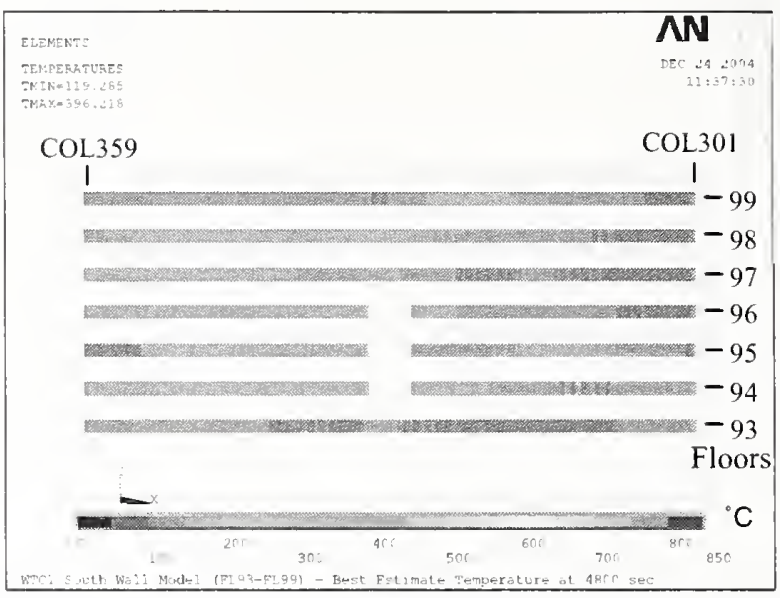

Figure 3-20. Case A temperature condition of south wall spandrels of WTC 1 at $80 \mathrm{~min}$.

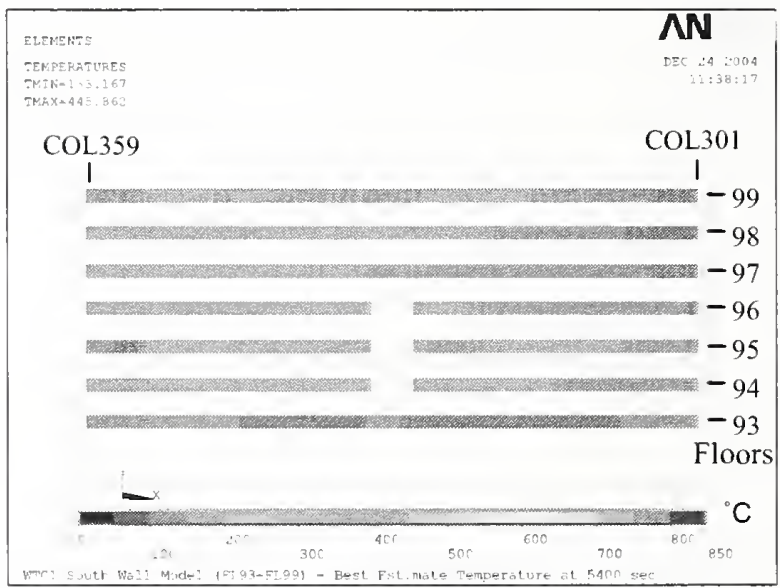

Figure 3-21. Case A temperature condition of south wall spandrels of WTC 1 at $90 \mathrm{~min}$.

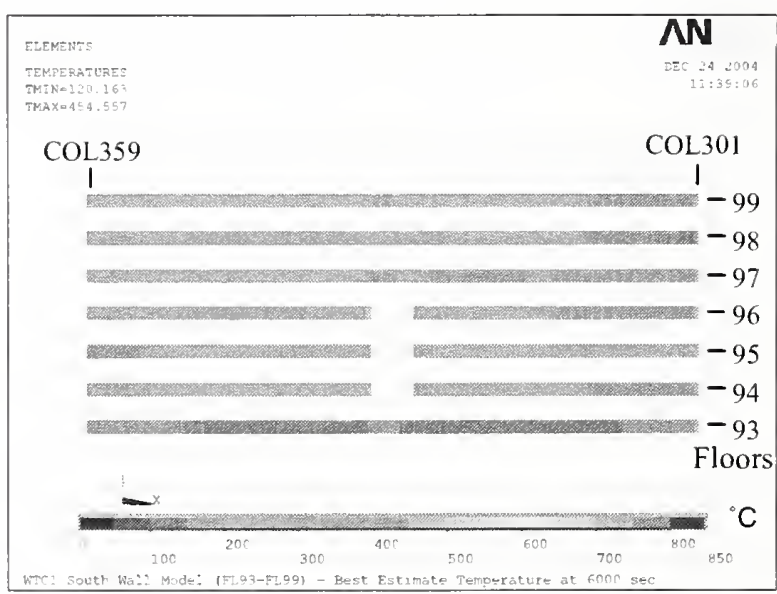

Figure 3-22. Case A temperature condition of south wall spandrels of WTC 1 at $100 \mathrm{~min}$. 


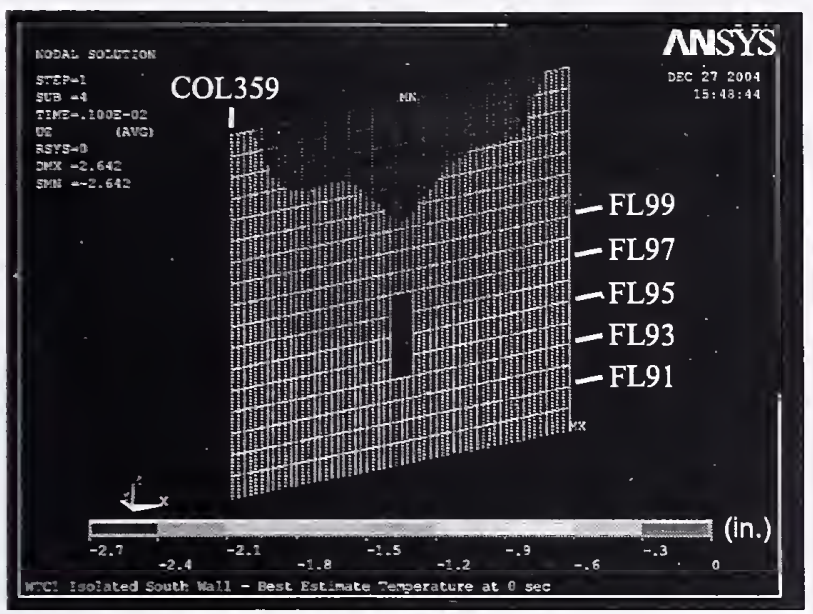

(a) Vertical displacement (downward displacement is negative)

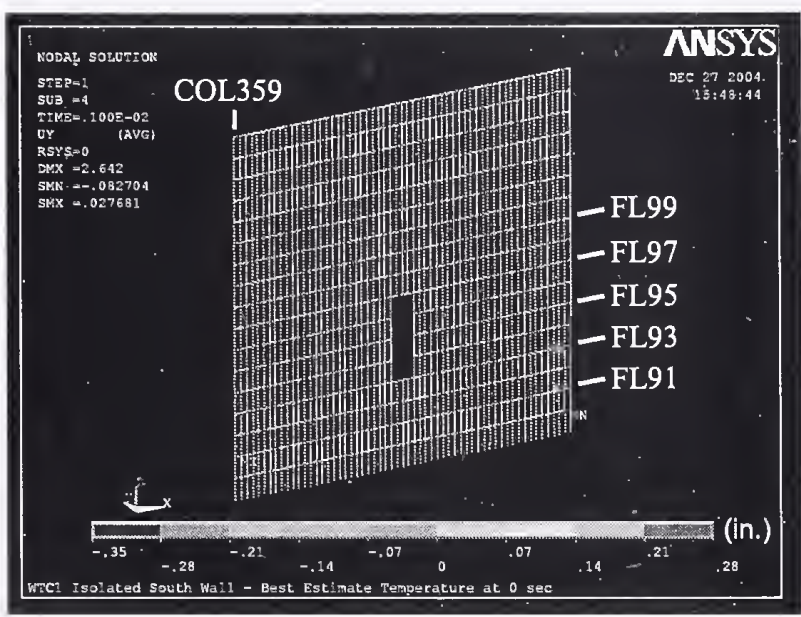

(b) Out-of-plane displacement (inward displacement is positive)

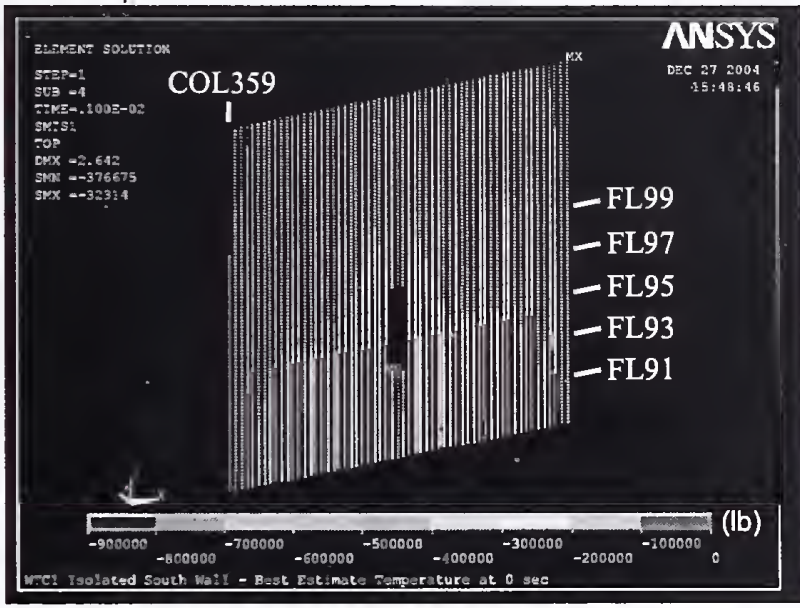

(c) Axial force in columns

(compression is negative)

Figure 3-23. Response of Isolated south wall model of WTC 1 after aircraft impact. 


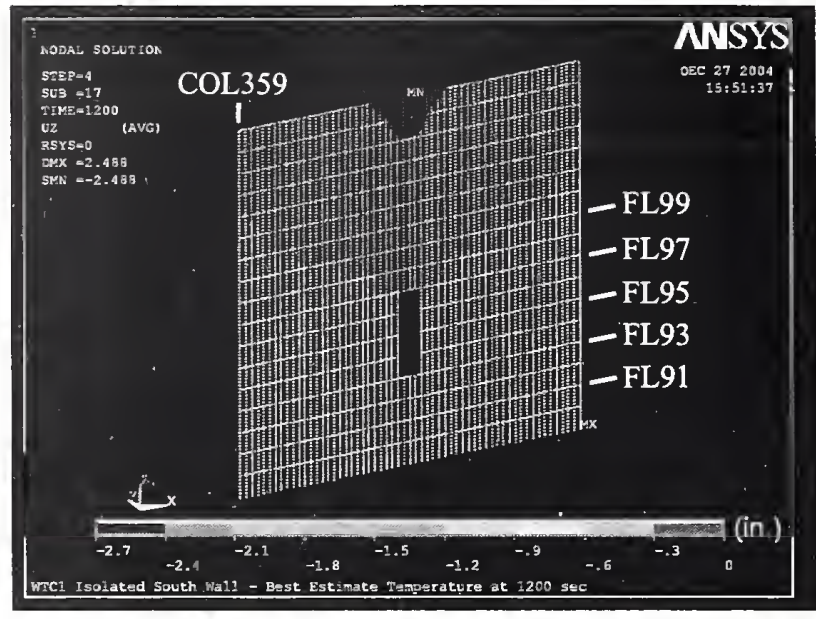

(a) At $20 \mathrm{~min}$

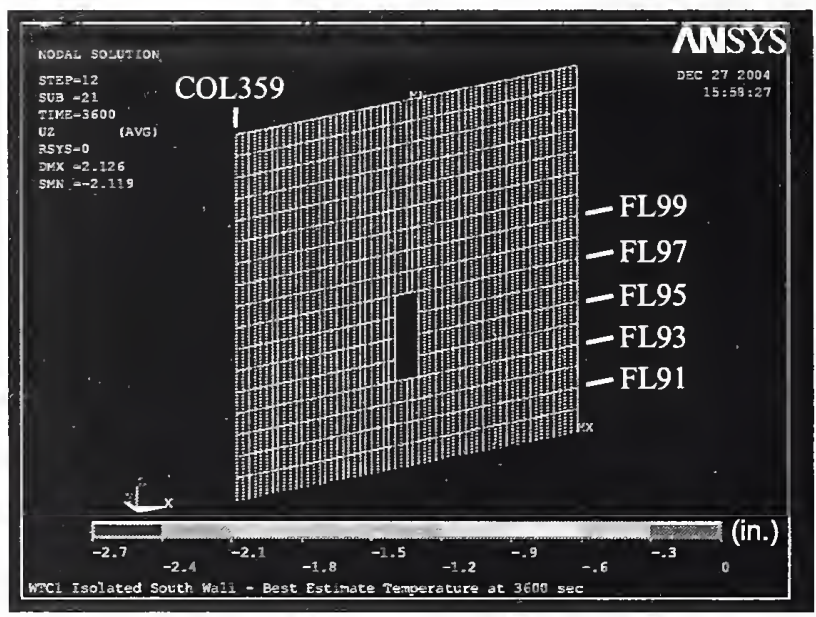

(c) At $60 \mathrm{~min}$

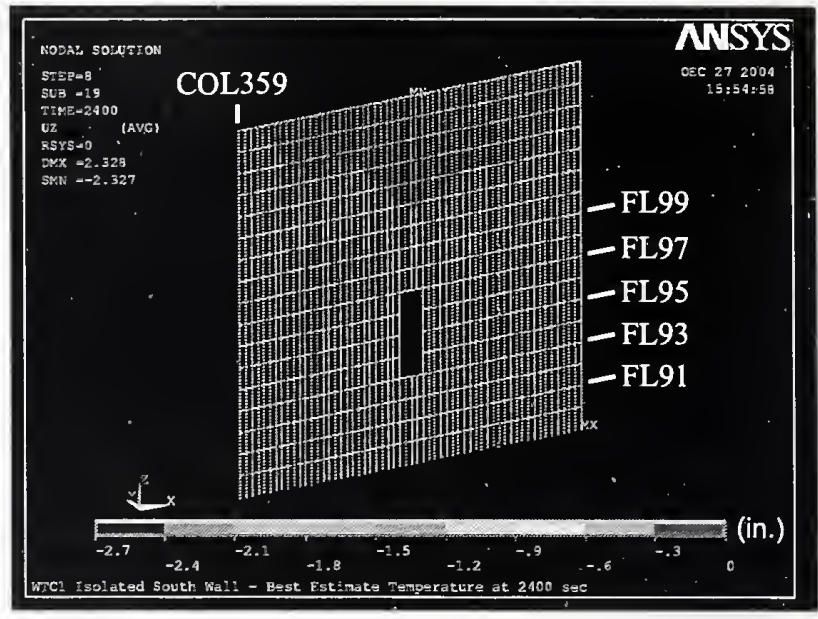

(b) At $40 \mathrm{~min}$

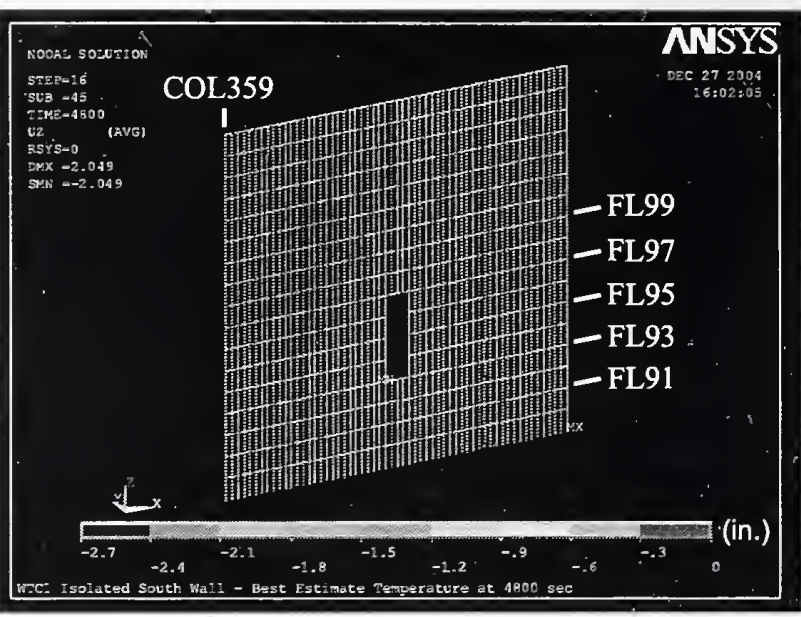

(d) At $80 \mathrm{~min}$

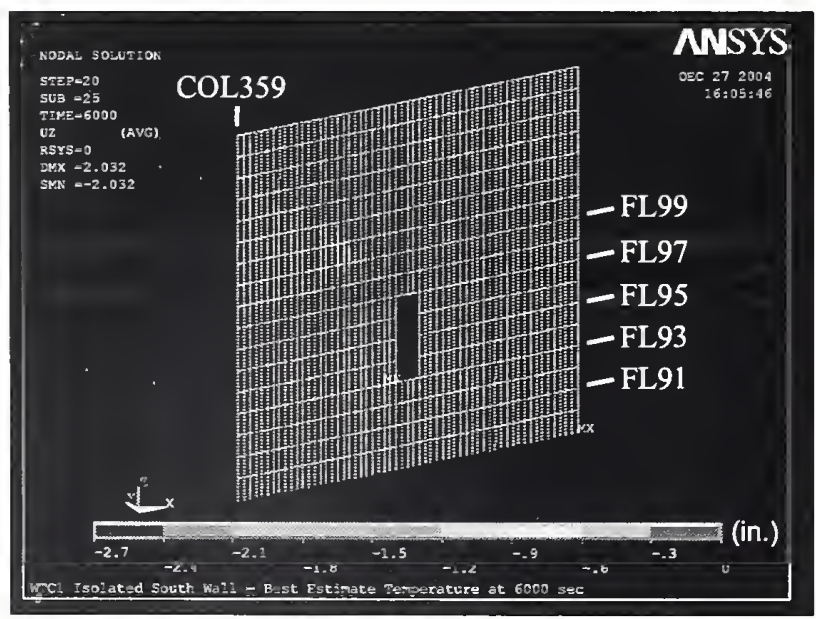

(e) At $100 \mathrm{~min}$

Figure 3-24. Vertical displacements of isolated south wall model of WTC 1 for Case A temperature condition (downward displacement is negative). 


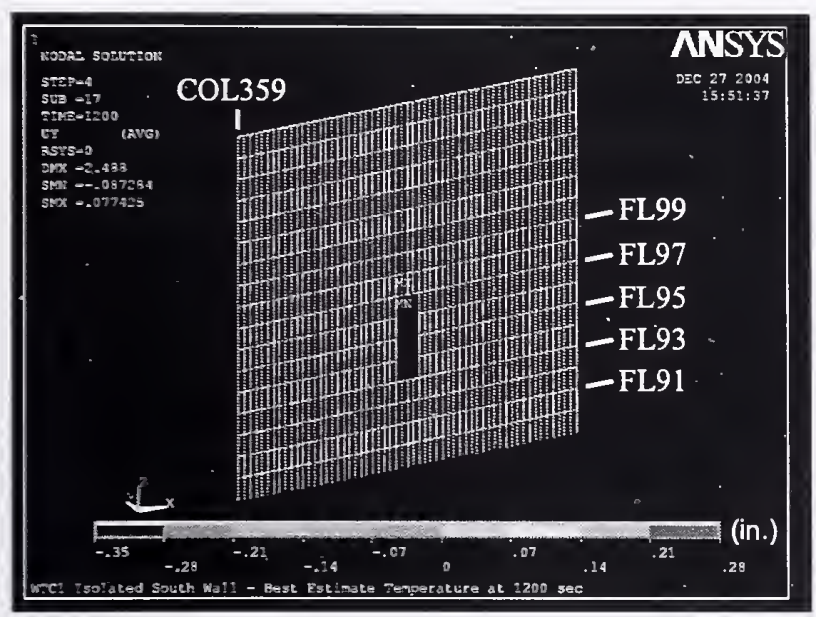

(a) at $20 \mathrm{~min}$

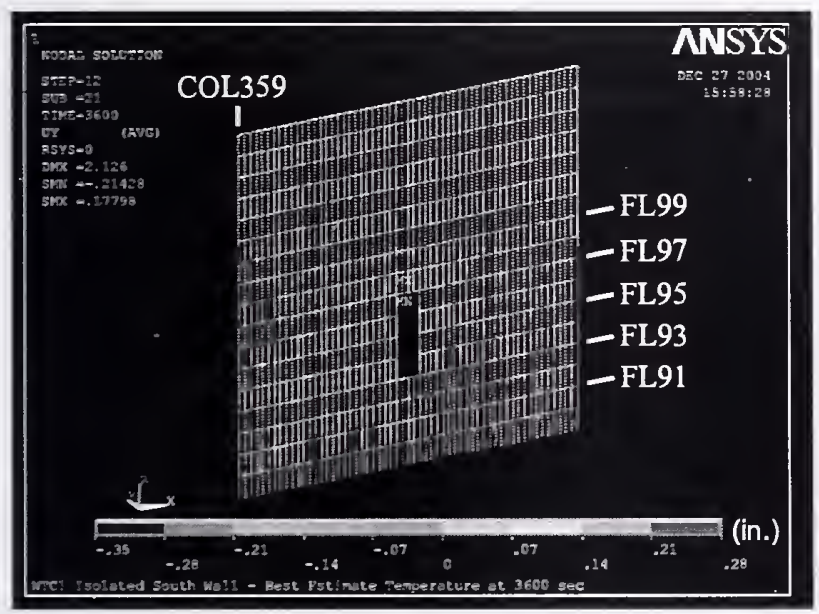

(c) at $60 \mathrm{~min}$

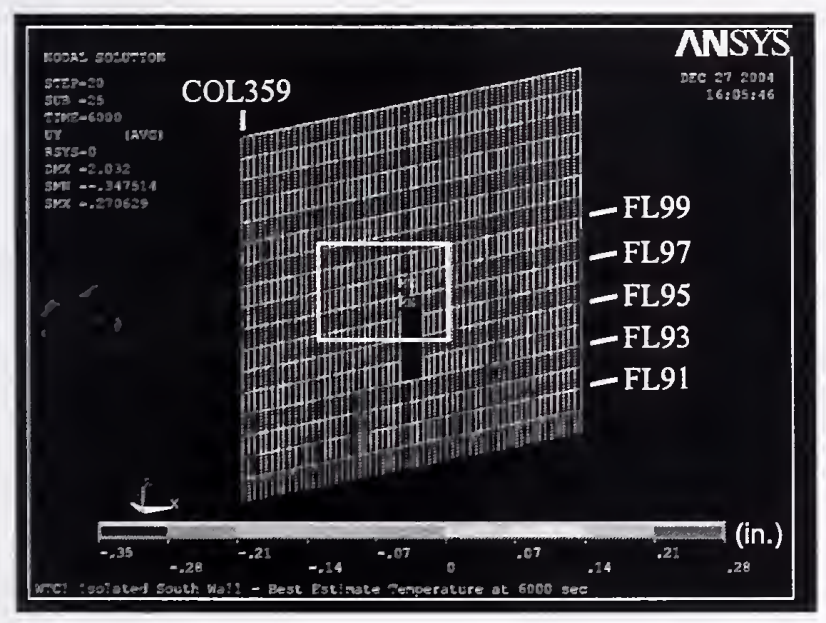

(e) at $100 \mathrm{~min}$

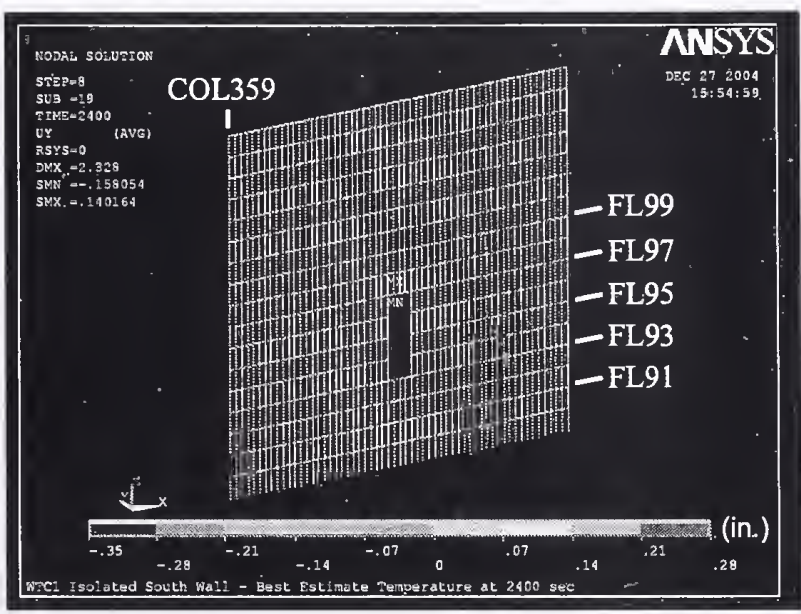

(b) at $40 \mathrm{~min}$

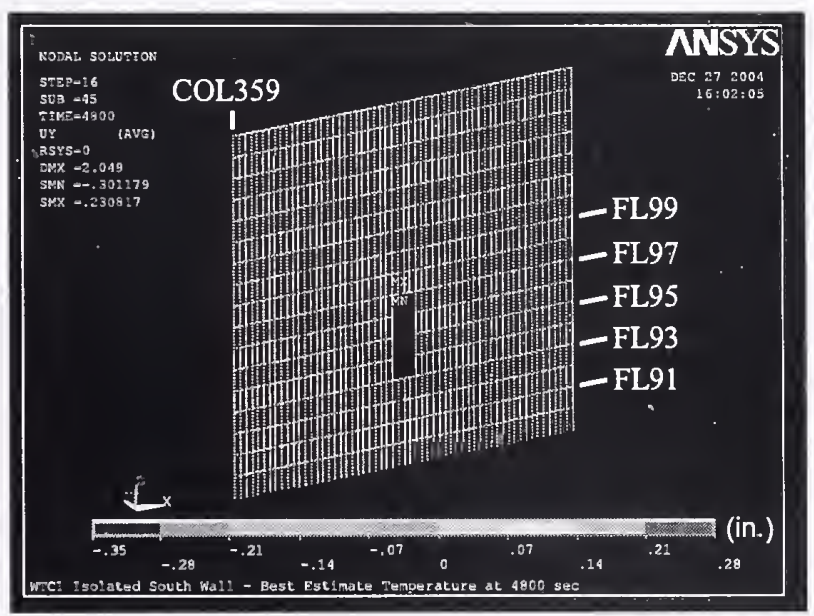

(d) at $80 \mathrm{~min}$

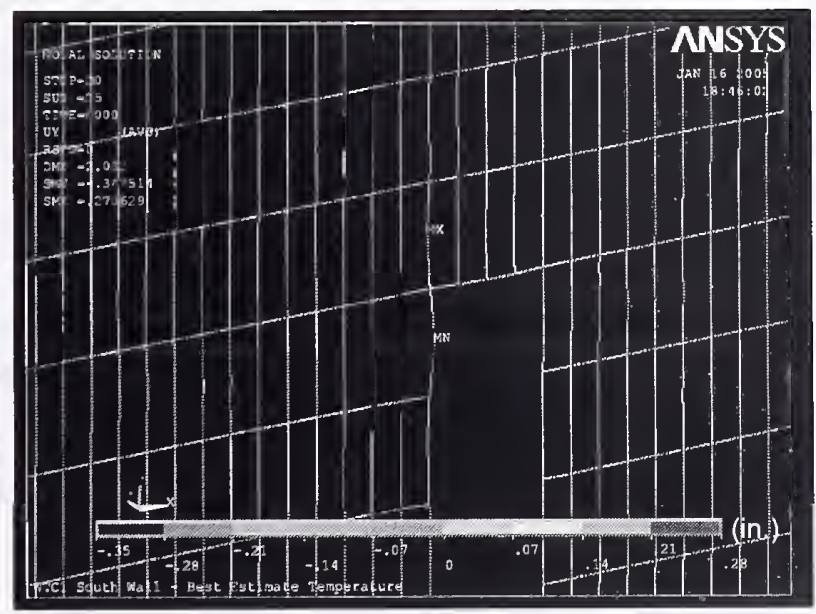

(f) Close-up view at $100 \mathrm{~min}$

(30X displacement magnification)

Figure 3-25. Out-of-plane displacements of isolated south wall model of WTC 1 for Case A temperature condition (inward displacement is positive). 


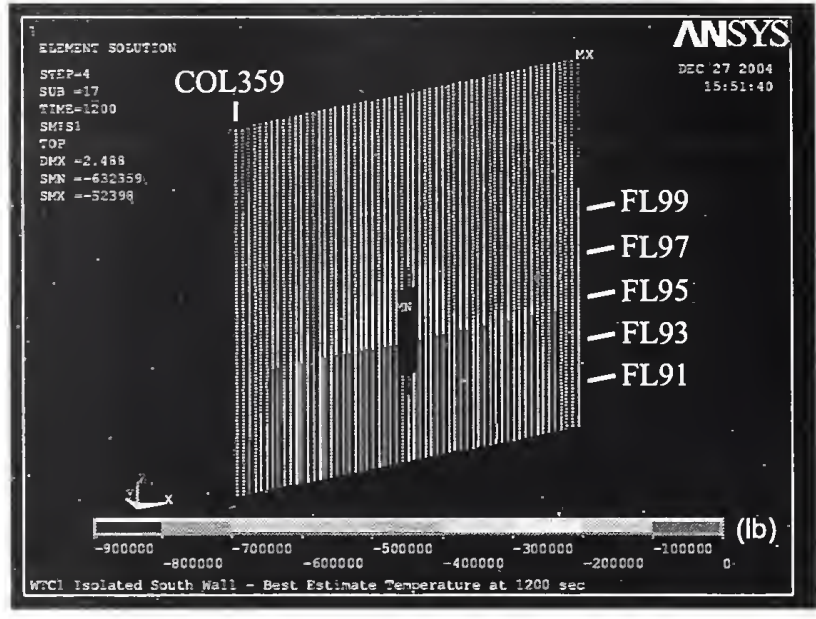

(a) at $20 \mathrm{~min}$

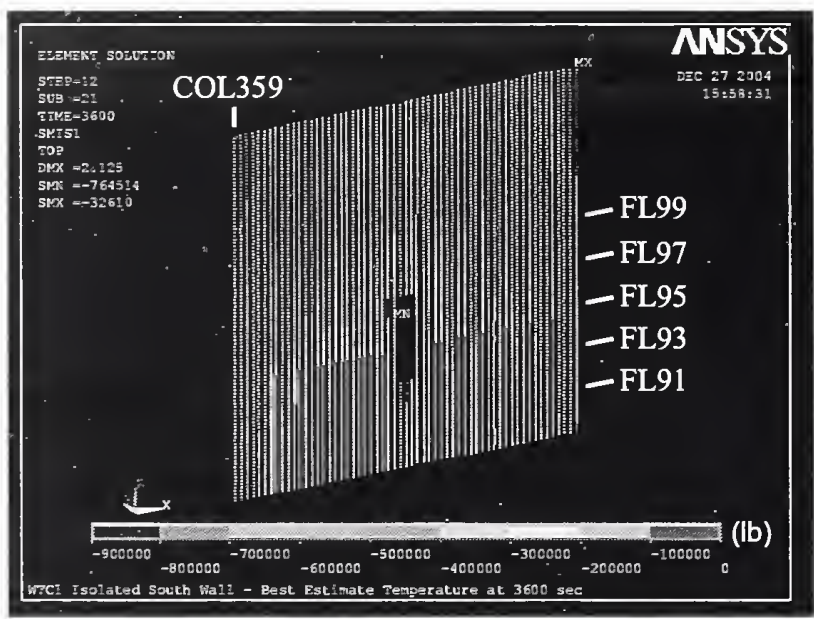

(c) at $60 \mathrm{~min}$

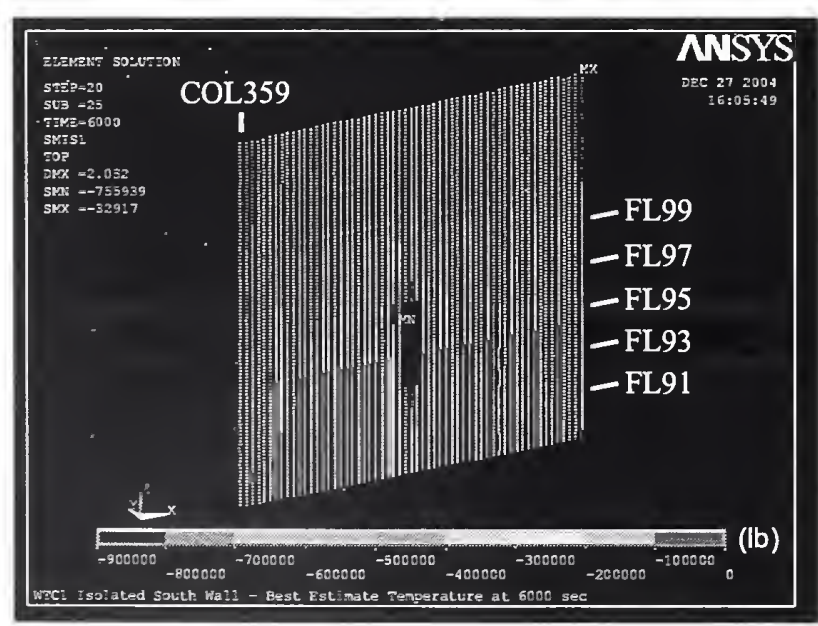

(e) at $100 \mathrm{~min}$

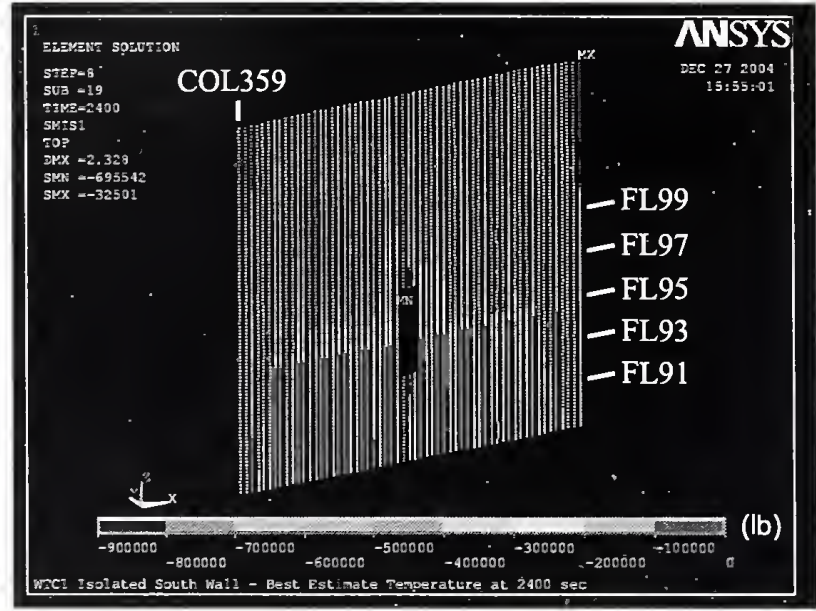

(b) at $40 \mathrm{~min}$

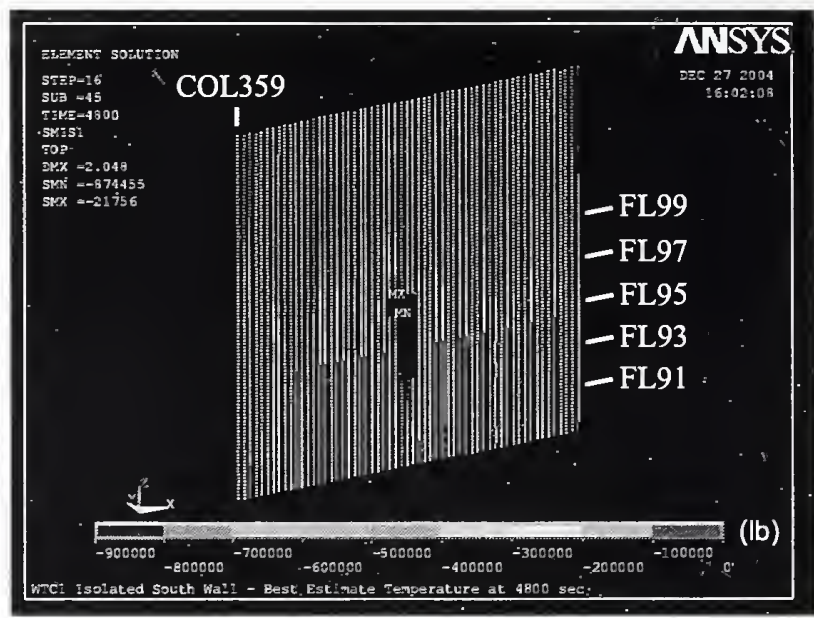

(d) at $80 \mathrm{~min}$ 


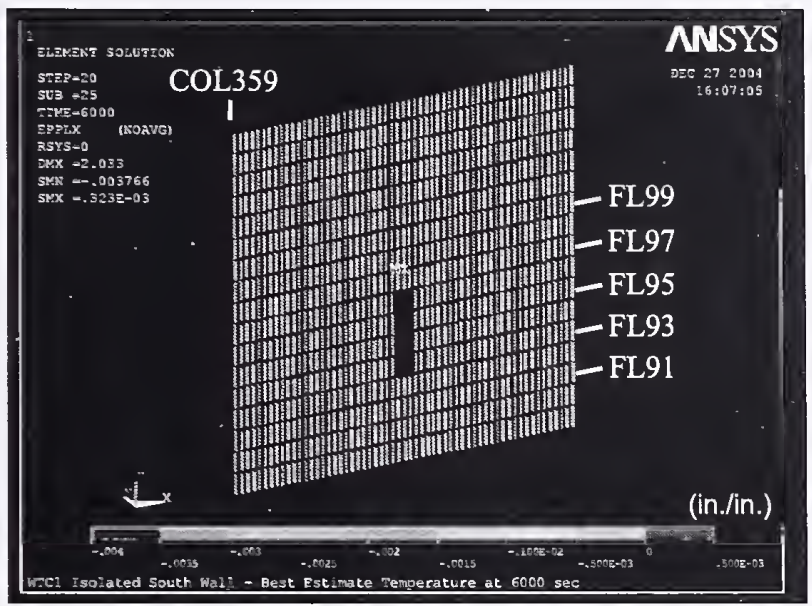

Figure 3-27. Plastic strain in columns of isolated south wall model of WTC 1 for Case A temperature condition at $100 \mathrm{~min}$ (compressive strain is negative).

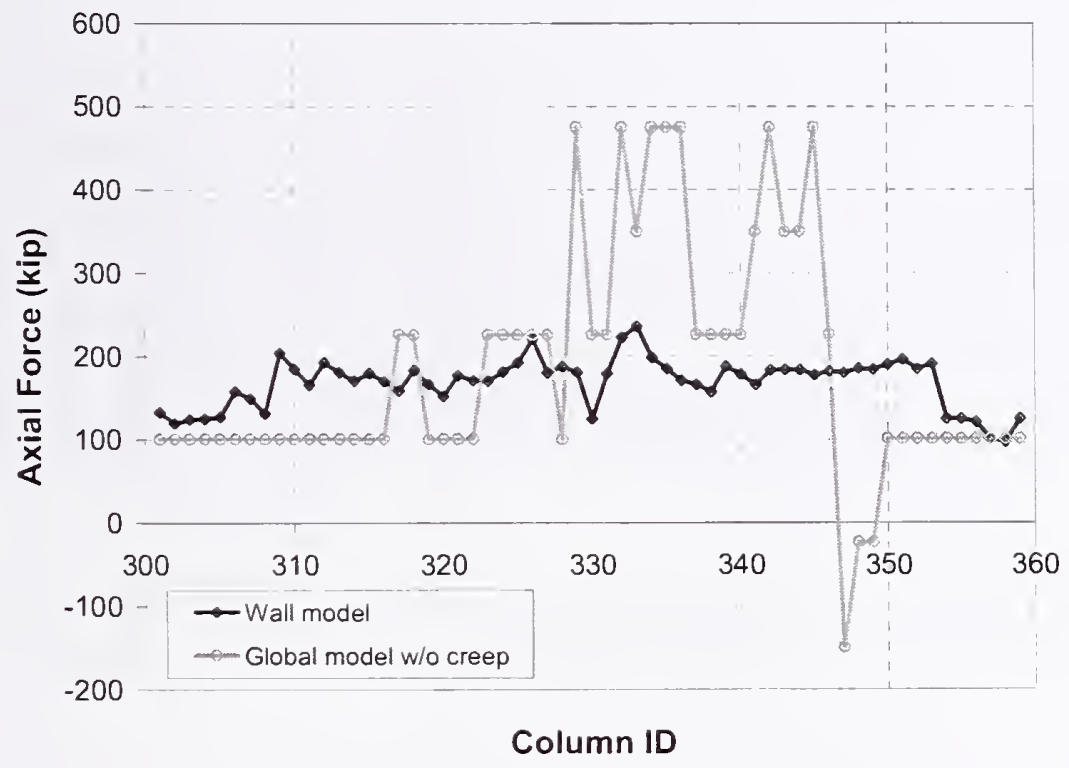

Figure 3-28. Axial load in columns of south wall of WTC 1 at $100 \mathrm{~min}$ : isolated wall model for Case A temperature condition compared to global model without creep for Case $A_{i}$ conditions (compression is positive). 


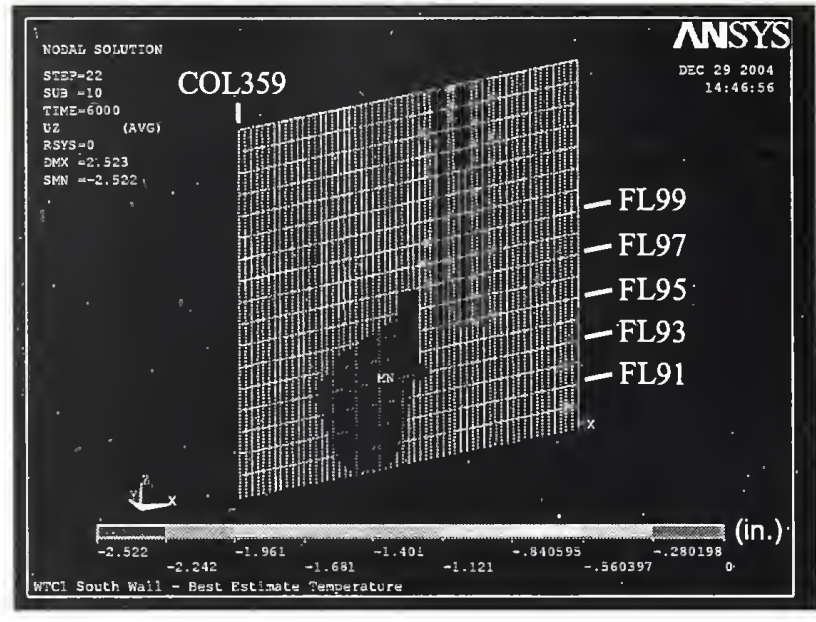

(a) Vertical displacement

(downward displacement is negative)

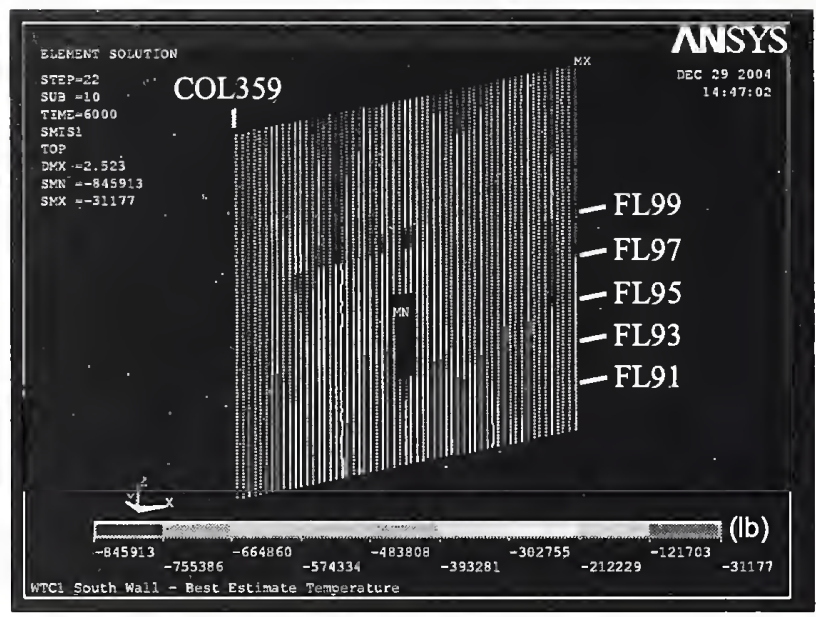

(c) Axial force in columns (compression is negative)

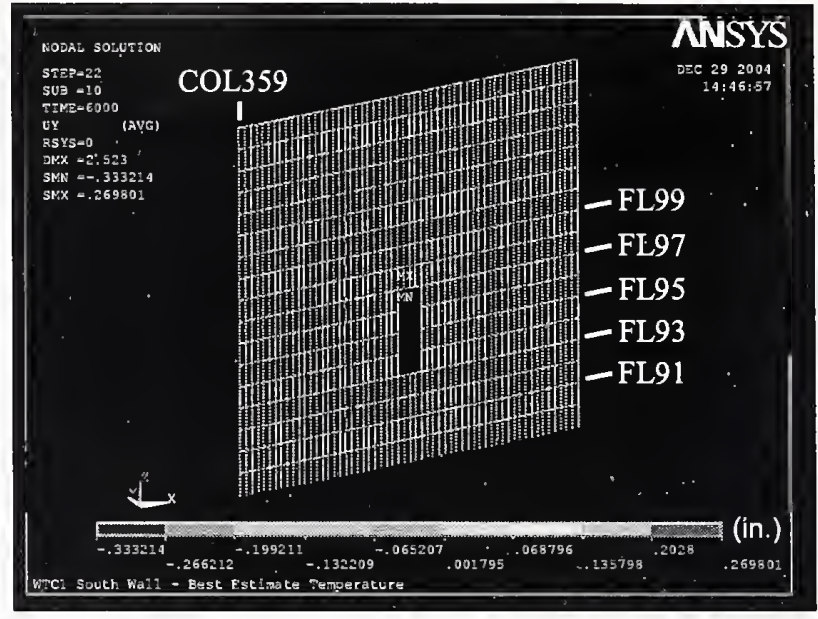

(b) Out-of-plane displacement (inward displacement is positive)

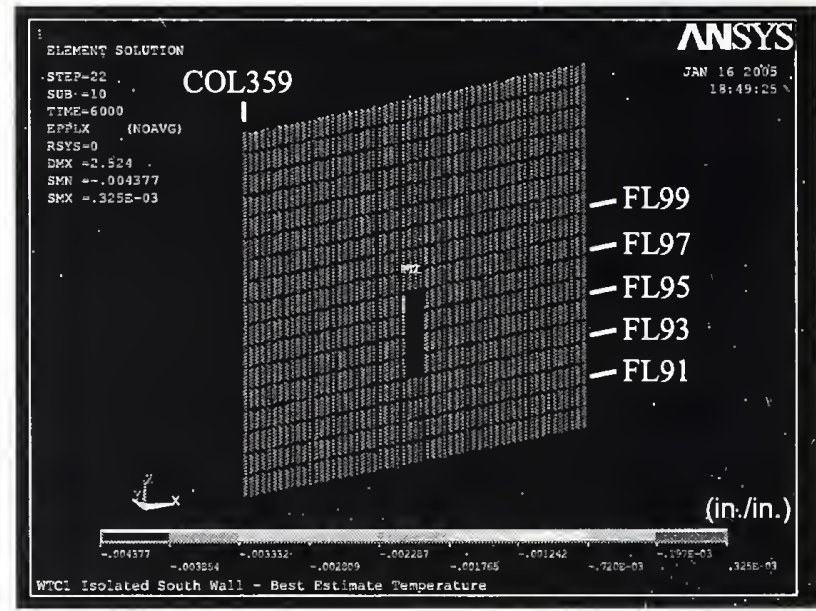

(d) Plastic strain in columns (compressive strain is negative)

Figure 3-29. Responses of isolated south wall model of WTC 1 after corrective loads from the global model were applied (Case A temperature condition at $100 \mathrm{~min}$ ). 


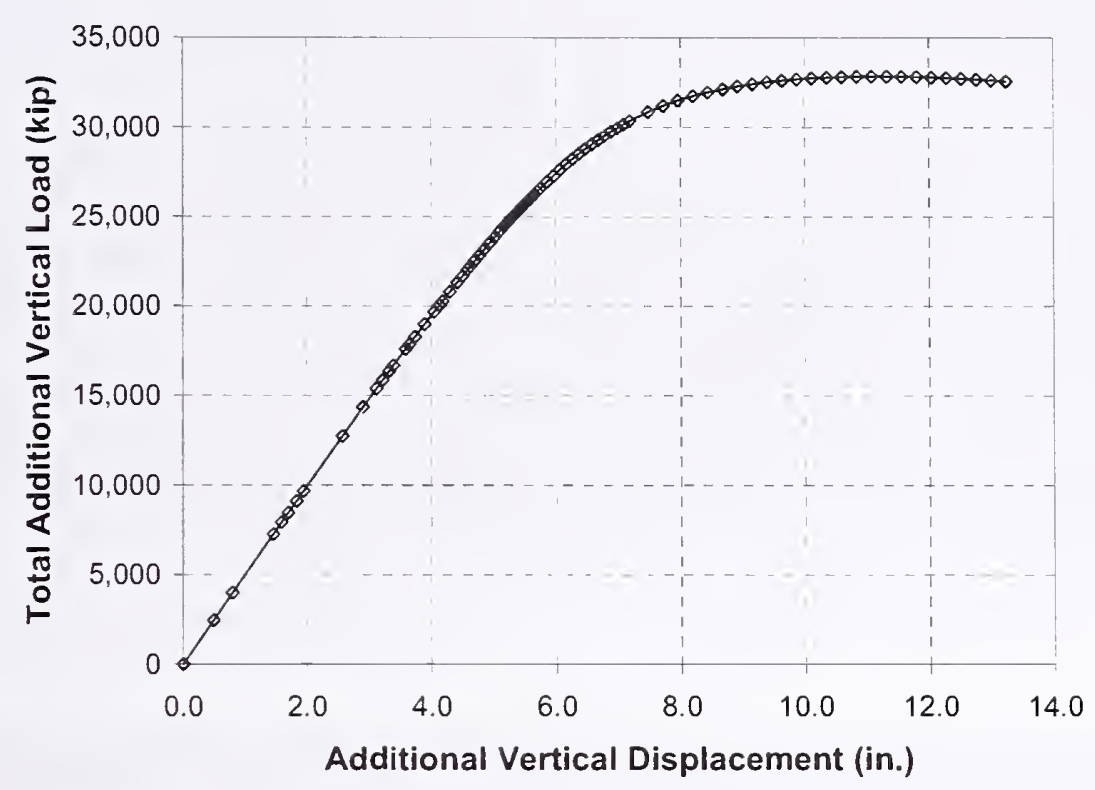

Figure 3-30. Total additional vertical load versus additional vertical displacement during push-down analysis of isolated south wall model of WTC 1 for Case A temperature condition (compression is positive).

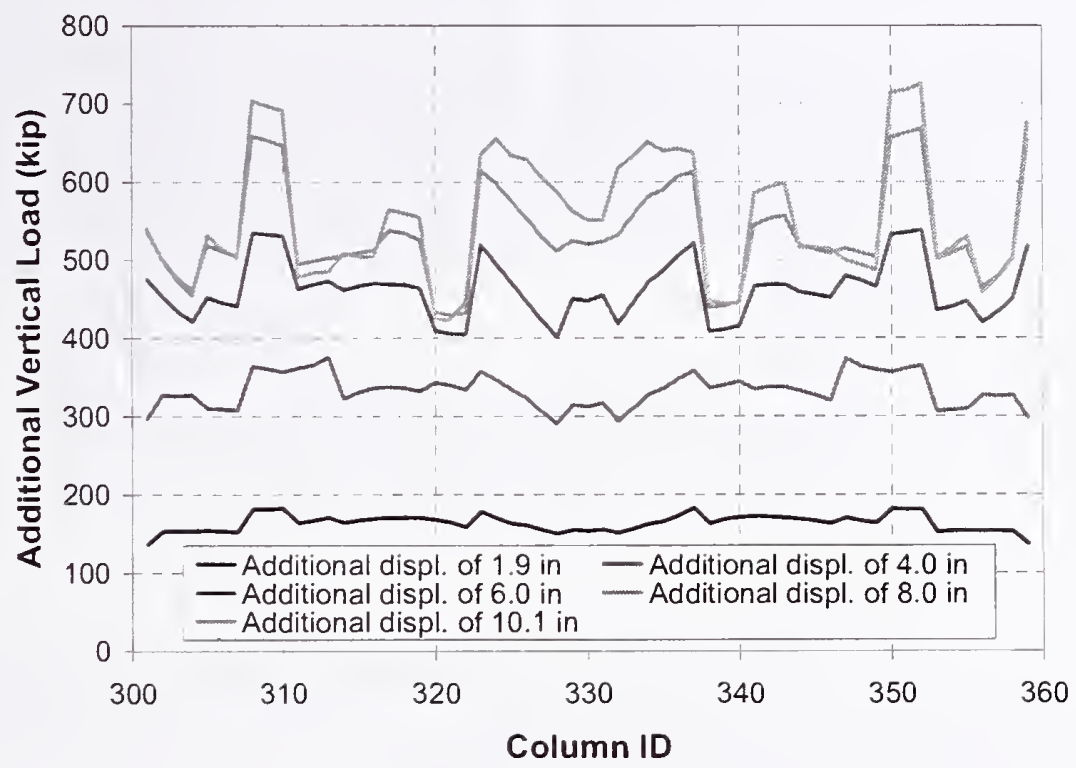

Figure 3-31. Additional vertical load per column at different additional vertical displacements during push-down analysis of isolated south wall model of WTC 1 for Case $\mathrm{A}$ temperature condition (compression is positive). 


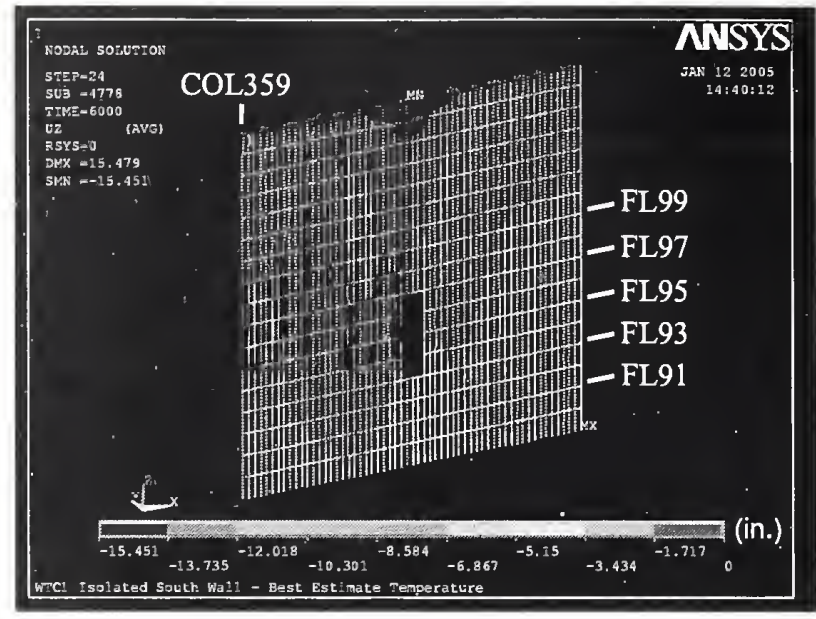

(a) Vertical displacement

(downward displacement is negative)

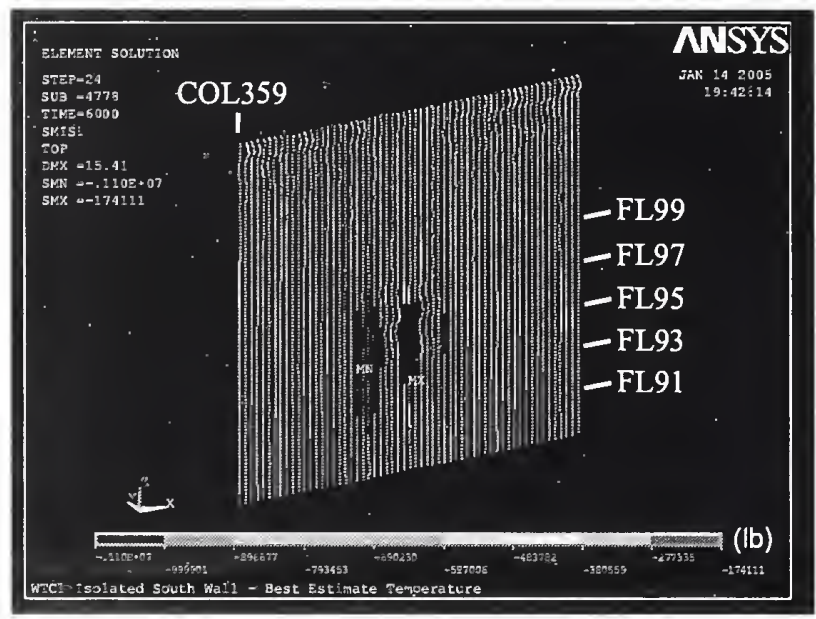

(c) Axial force in columns

(compression is negative, $5 \mathrm{X}$ displacement magnification)

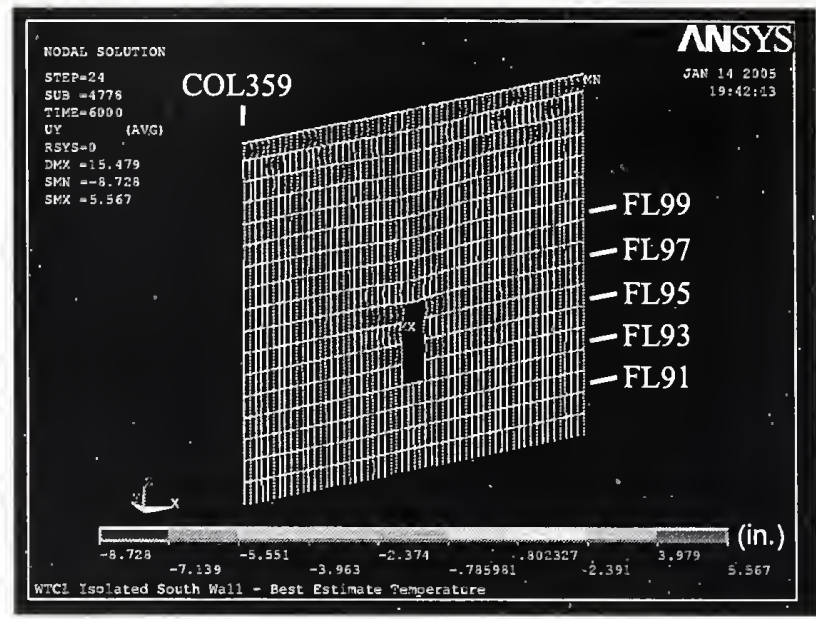

(b) Out-of-plane displacement (inward displacement is positive, $5 \mathrm{X}$ displacement magnification)

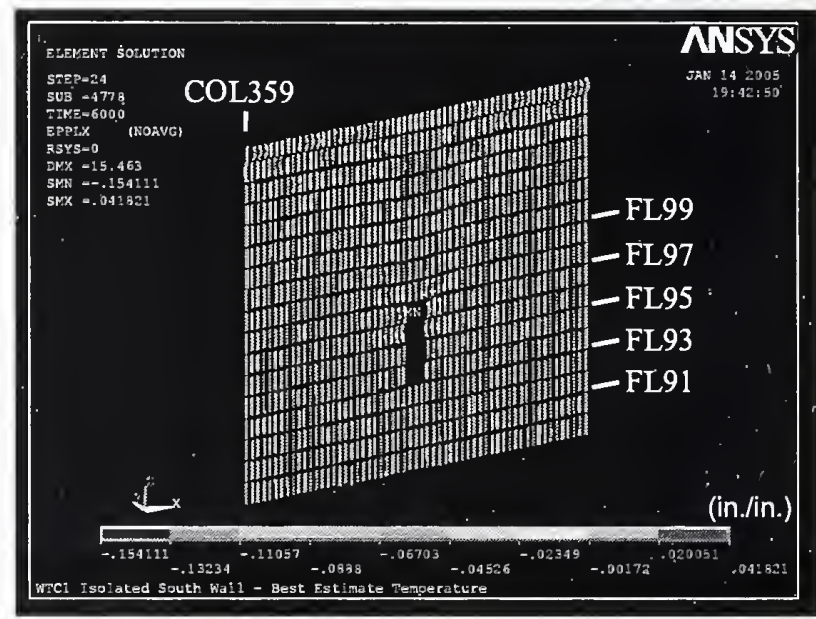

(d) Plastic strain in columns (compressive strain is negative, $5 \mathrm{X}$ displacement magnification)

Figure 3-32. Response of isolated south wall model of WTC 1 to Case A temperature condition and push down at the end of the push-down analysis.

\section{Case B Temperature Condition}

In the full floor model analyses, described in Appendix A, Floors 97 and 98 disconnected from the exterior walls at several columns between $80 \mathrm{~min}$ and $90 \mathrm{~min}$. Figure 3-33 shows locations of the out-ofplane supports of the exterior wall model of WTC 1 at $100 \mathrm{~min}$.

Figures 3-34 to 3-43 show the temperature distributions of Case B condition in the south wall columns of WTC 1 from $10 \mathrm{~min}$ to $100 \mathrm{~min}$. Figures 3-34 to 3-43 show that temperatures on the south wall became very high near the impact damage area, reaching $801^{\circ} \mathrm{C}$. Figures $3-44$ to $3-53$ show the temperature distributions of Case B condition in spandrels. The temperatures of the spandrels are also quite high, reaching $778^{\circ} \mathrm{C}$. 
Figures 3-54 to 3-56 show the vertical displacements, the out-of-plane displacements, and the axial loads, respectively, in the south wall columns of WTC 1 for Case B temperature condition. Throughout the temperature time history the maximum vertical displacement changed negligibly, starting at 2.64 in. immediately after impact and ending at $2.60 \mathrm{in}$. at $100 \mathrm{~min}$. The maximum inward out-of-plane displacement was 0.66 in. at Column 336 at Floor 98 at $100 \mathrm{~min}$, while the maximum outward out-ofplane displacement was 2.3 in. at Column 342 at Floor 97. At these locations, the floor was disconnected from the exterior wall so that the unsupported length of the columns was two to three stories.

Figure 3-57 shows the plastic strains in the south wall columns at $100 \mathrm{~min}$. The maximum plastic strain was only 0.5 percent at Column 325 at Floor 96.

Load redistribution to the south wall was accounted for by comparing the results of the isolated wall model to the global model, using a similar procedure to that described above for Case A (Fig. 3-58). The differences in axial loads in these two models were applied to the isolated wall model as corrective loads. Figure 3-59 shows the response of the south wall after applying these corrective loads. The WTC 1 south wall remained stable after the application of these corrective loads.

To determine the additional load-carrying capacity of the south wall at the end of the temperature analysis at $100 \mathrm{~min}$, the top of the isolated exterior wall model was pushed down by converting the model from a force-control to a displacement-control analysis and by imposing additional vertical displacement increments on top of the isolated model. The analysis was terminated at an additional vertical displacement of 10.3 in. This model reached a peak total vertical load at an additional vertical displacement of 9.0 in. Figure 3-60 shows the relationship between the total additional vertical load applied and the additional vertical displacement applied. Figure 3-61 shows additional vertical load per column at different additional vertical displacements of 2 in., 4 in., 6 in., 8 in., and 10 in. Figure 3-62 shows the response of the WTC 1 south wall with the additional displacement of $10.3 \mathrm{in}$. When an additional 2 in. vertical displacement was imposed, the additional vertical load ranged from $110 \mathrm{kip}$ to $200 \mathrm{kip}$, and the center columns, Column 330 to Column 340, started to buckle. Note that the additional load for the center columns dropped significantly after the onset of buckling. At an additional displacement of 10 in., the variation in columns loads became extremely large, and the additional column loads became negative at Column 332 to Column 337, indicating local instability of the exterior wall around Column 335. At the end of analysis, the outward displacement at Floor 97 increased as Column 332 to Column 337 between Floor 95 and Floor 96 buckled inward. If local instability of the cxterior wall does not initiate a progressive instability (not captured by this model), the WTC 1 isolated south wall model could carry an additional vertical load of 23,000 kip (average column load of $390 \mathrm{kip}$ ). 


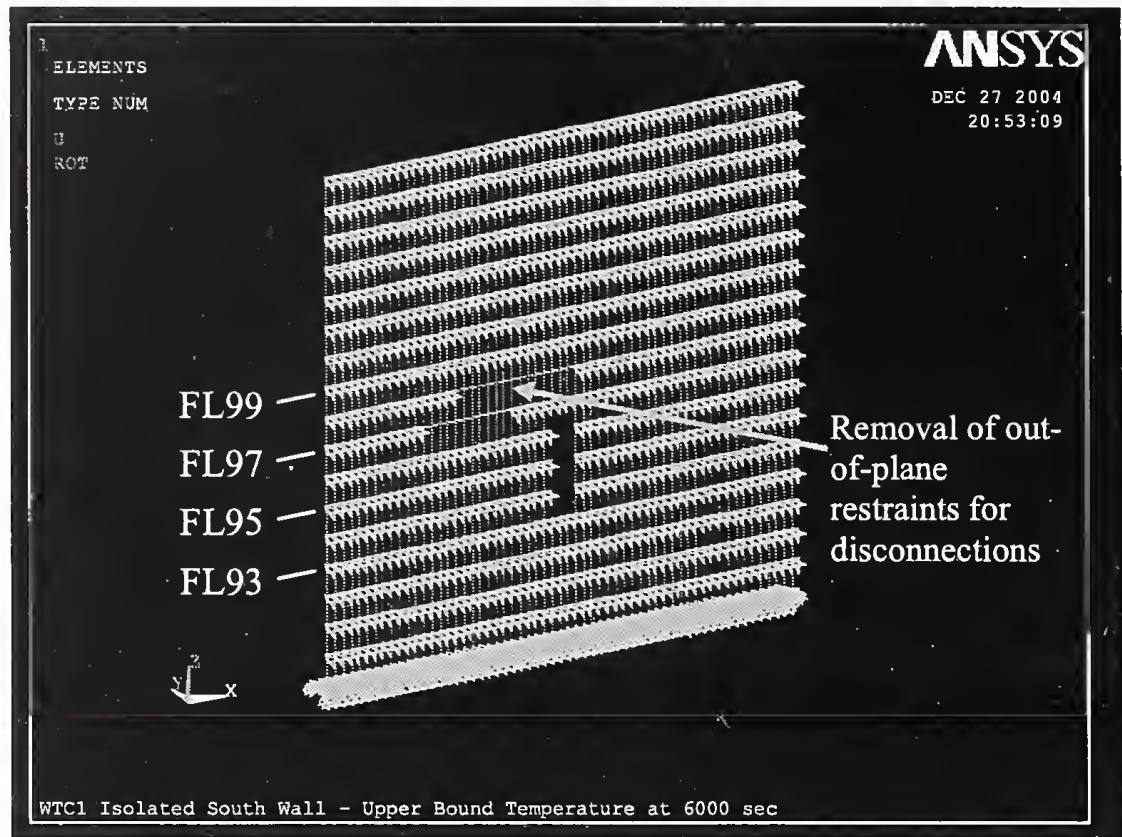

Figure 3-33. Location of the out-of-plane supports and floor/wall disconnections between exterior wall and the floor (WTC 1 south wall for Case B conditions at $100 \mathrm{~min}$ ).

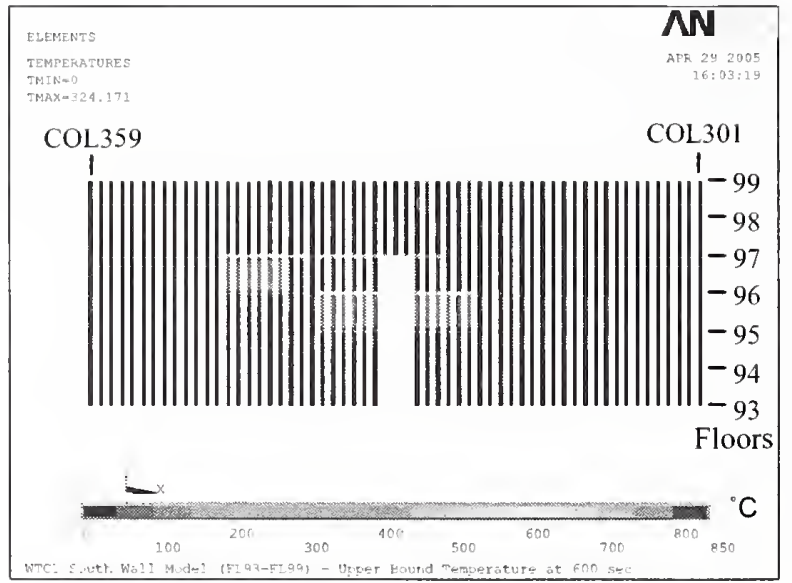

(a) Outside

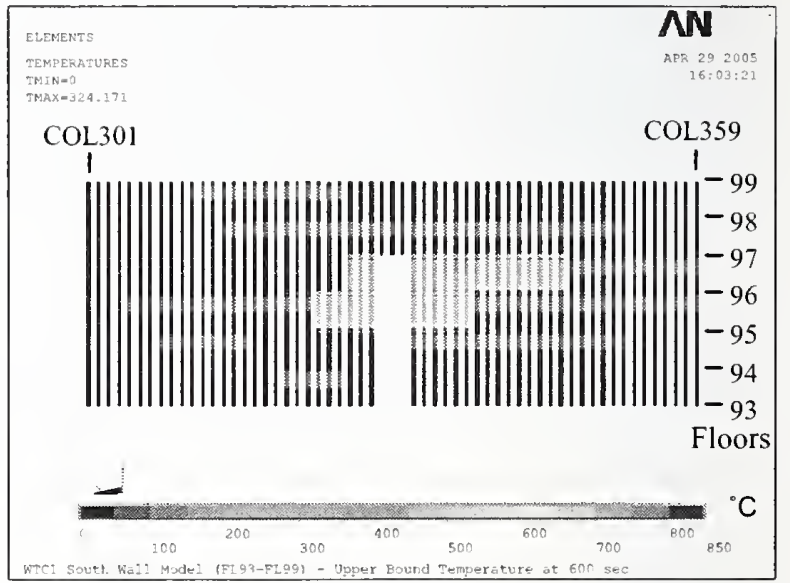

(b) Inside

Figure 3-34. Case B temperature condition of south wall columns of WTC 1 at $10 \mathrm{~min}$. 


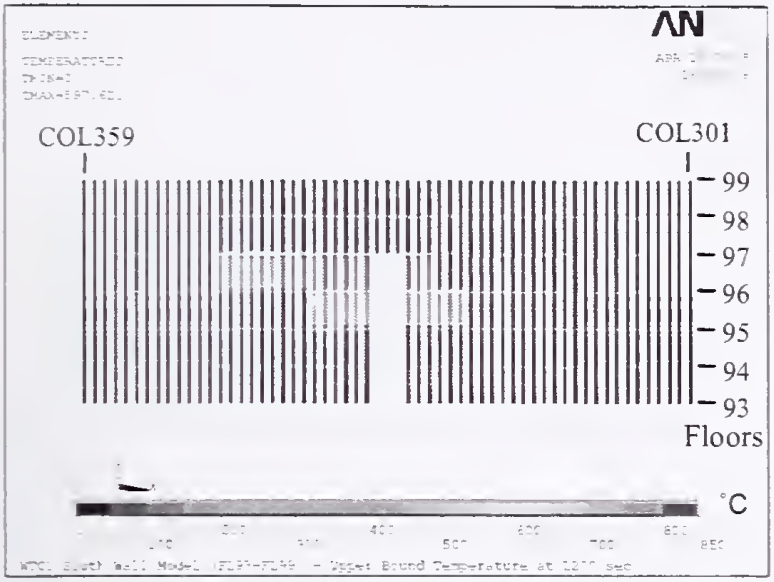

(a) Outside

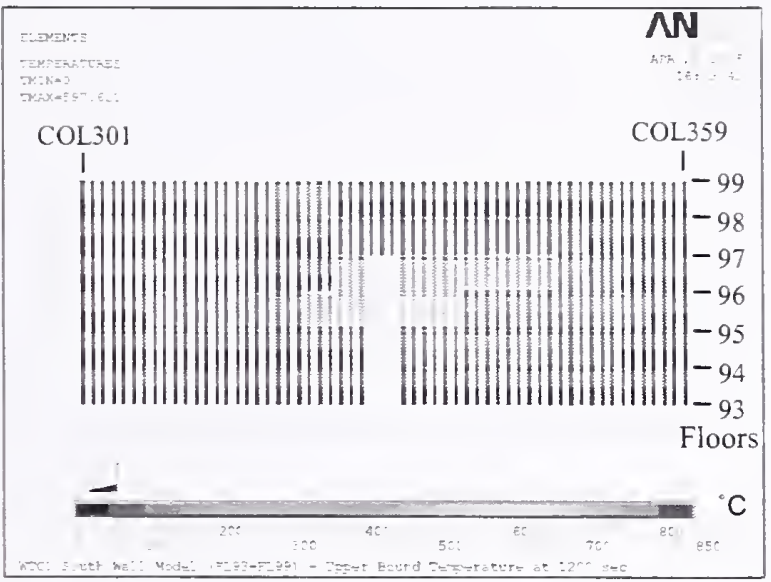

(b) Inside

Figure 3-35. Case B temperature condition of south wall columns of WTC 1 at $20 \mathrm{~min}$.

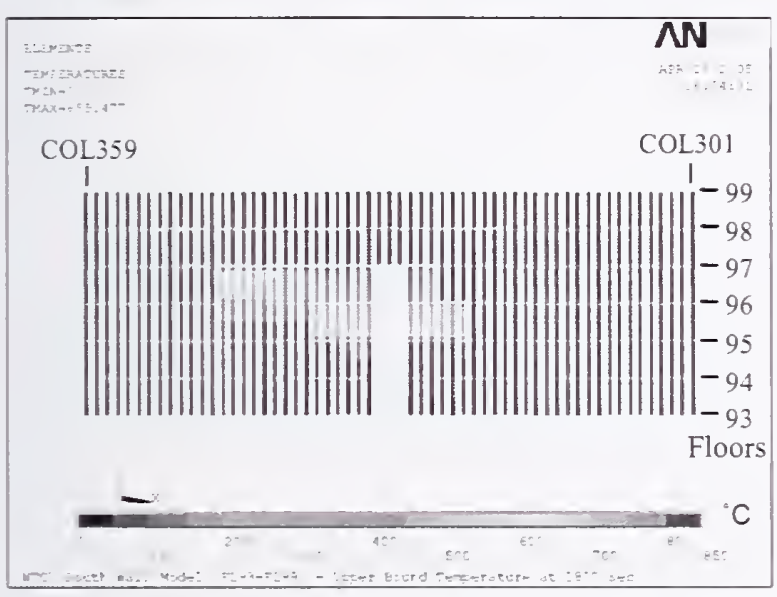

(a) Outside

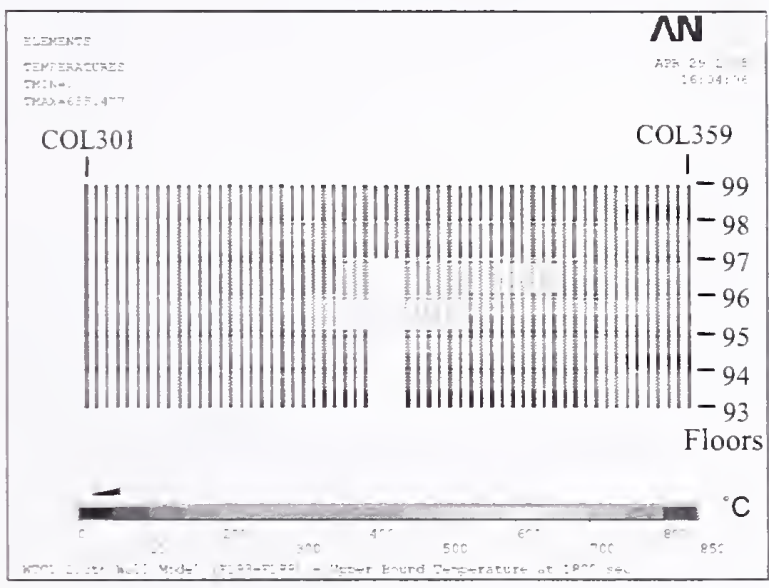

(b) Inside

Figure 3-36. Case B temperature condition of south wall columns of WTC 1 at $30 \mathrm{~min}$.

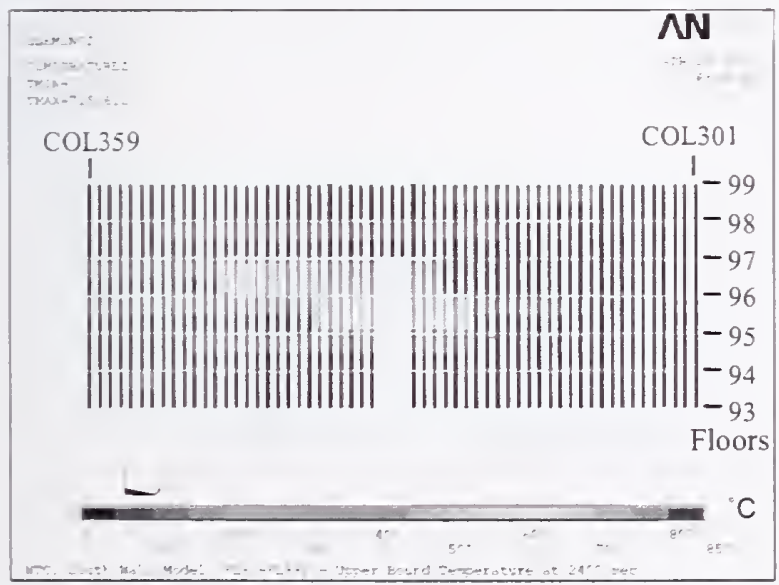

(a) Outside

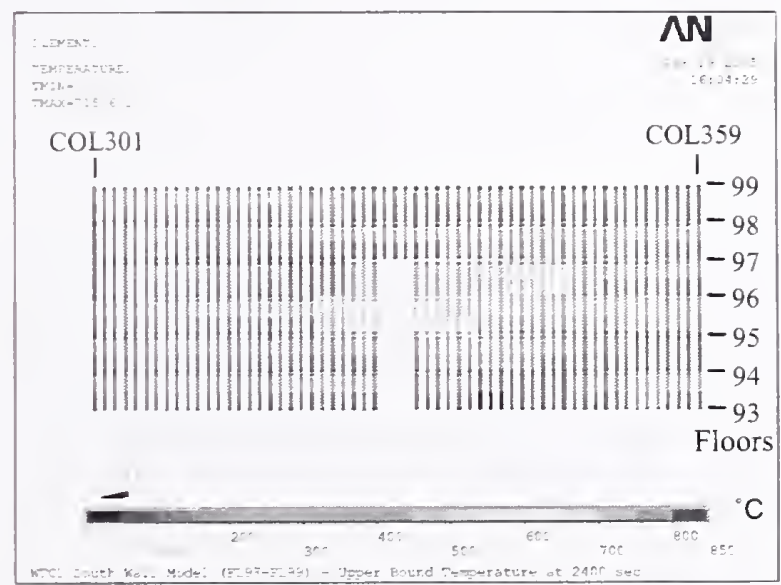

(b) Inside

Figure 3-37. Case B temperature condition of south wall columns of WTC 1 at $40 \mathrm{~min}$. 


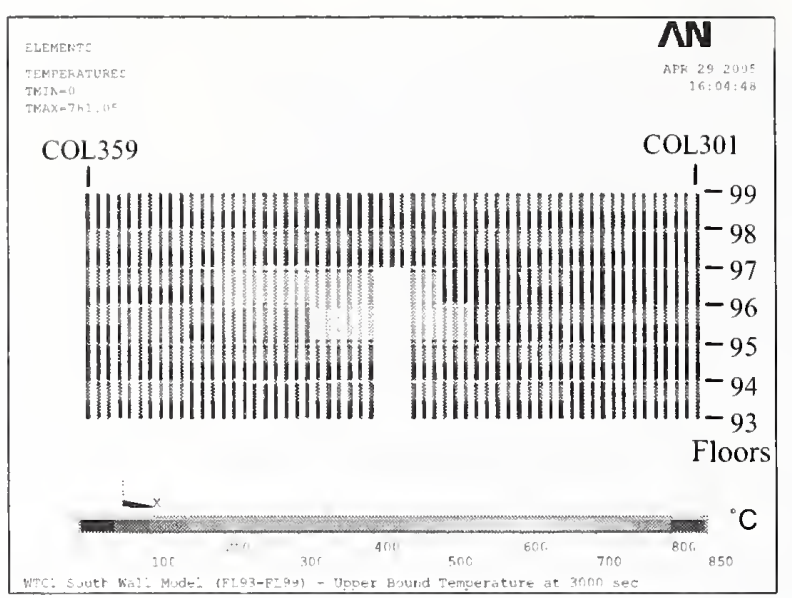

(a) Outside

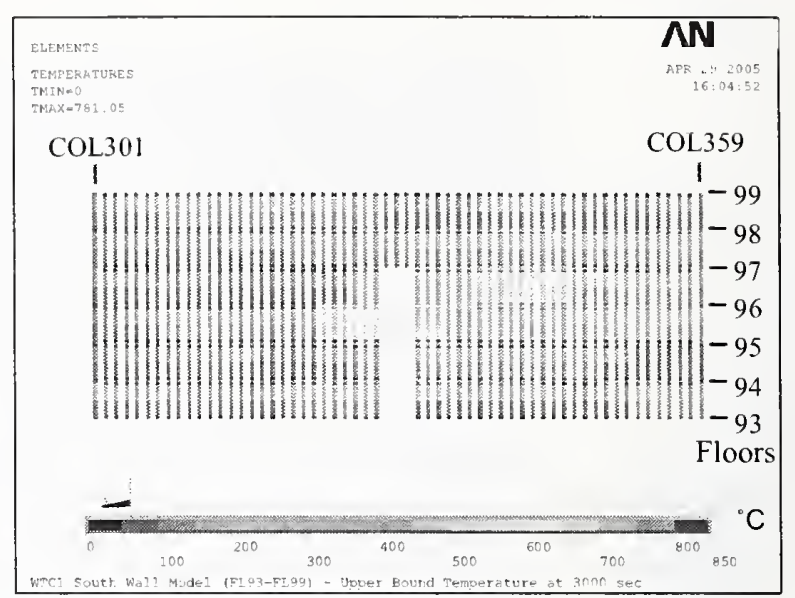

(b) Inside

Figure 3-38. Case B temperature condition of south wall columns of WTC 1 at $50 \mathrm{~min}$.

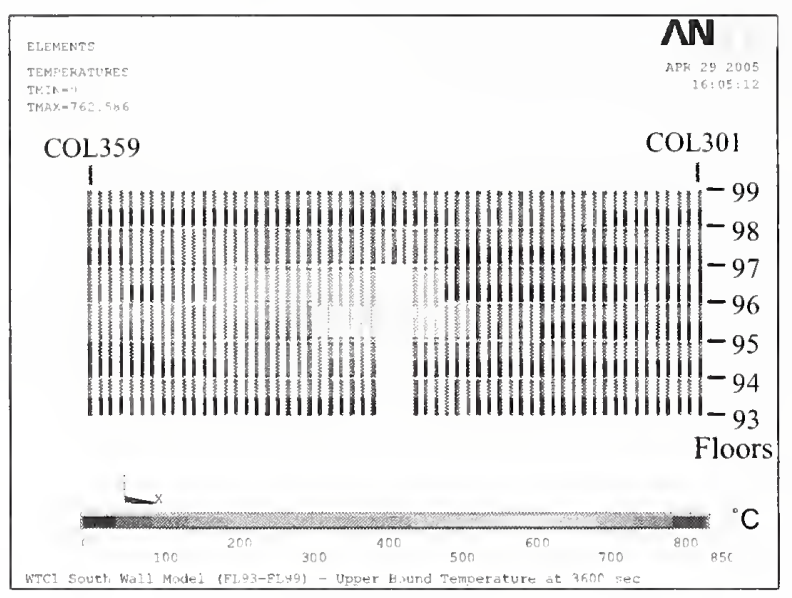

(a) Outside

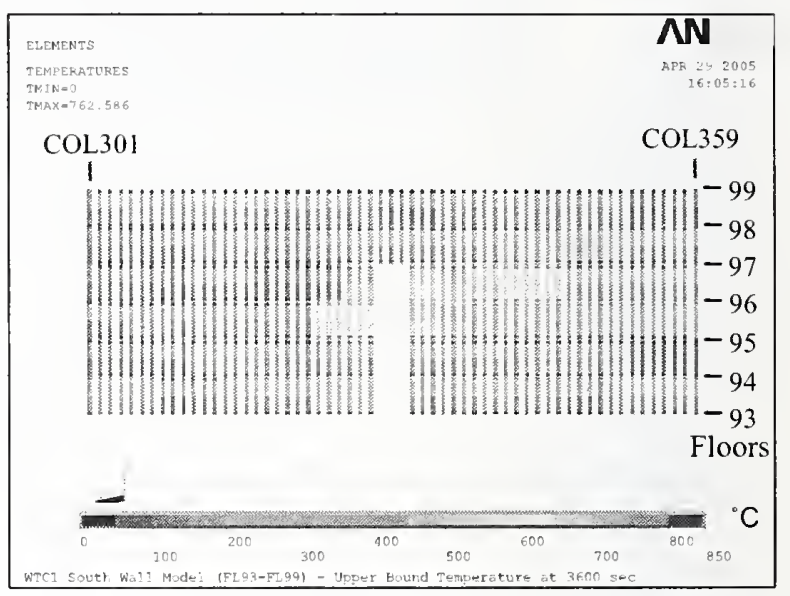

(b) Inside

Figure 3-39. Case B temperature condition of south wall columns of WTC 1 at $60 \mathrm{~min}$.

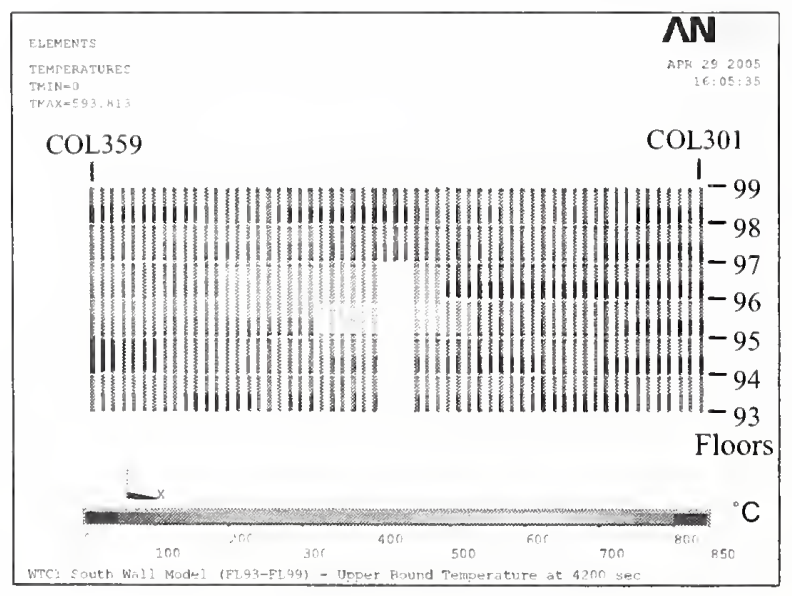

(a) Outside

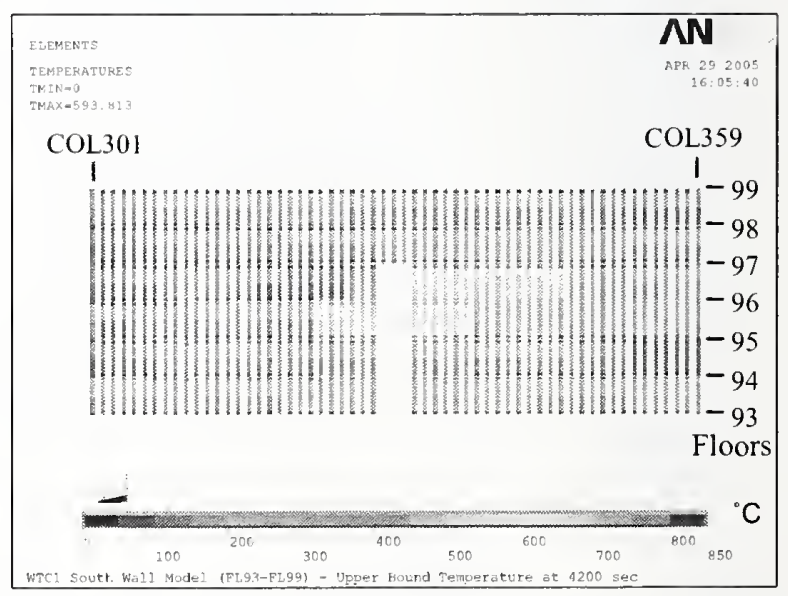

(b) Inside

Figure 3-40. Case B temperature condition of south wall columns of WTC 1 at $70 \mathrm{~min}$. 


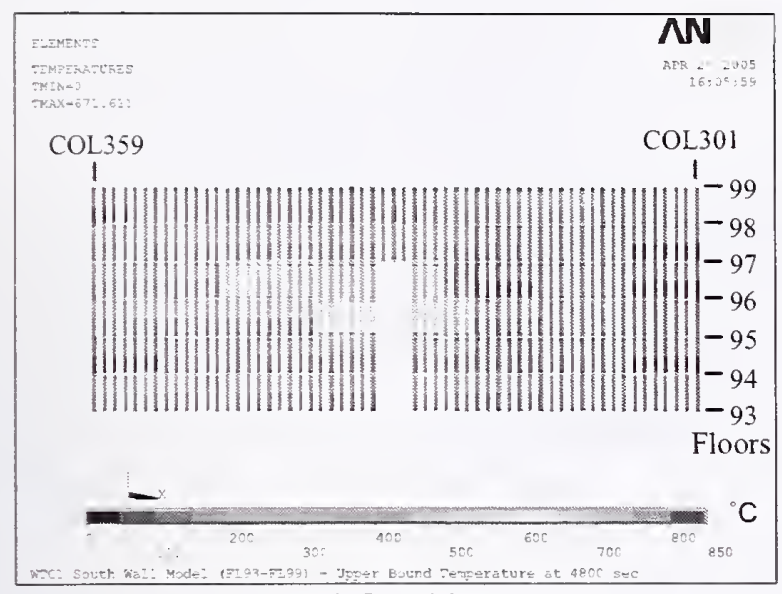

(a) Outside

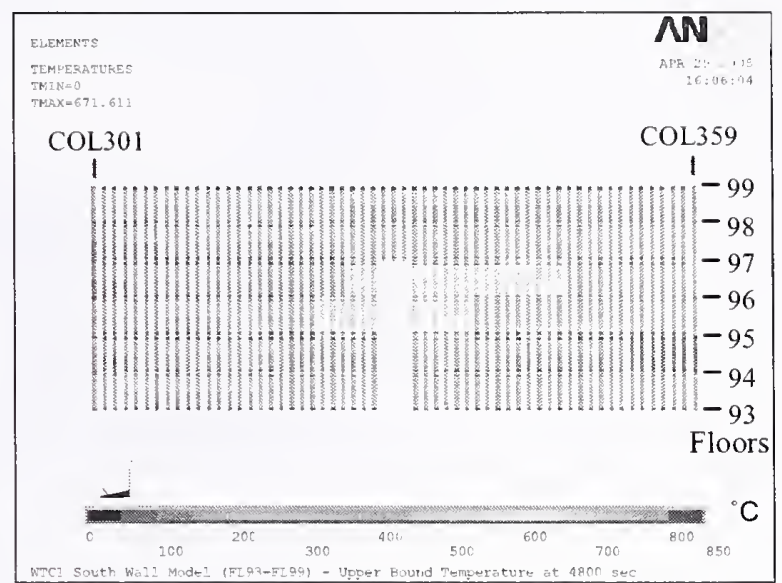

(b) Inside

Figure 3-41. Case B temperature condition of south wall columns of WTC 1 at $80 \mathrm{~min}$.

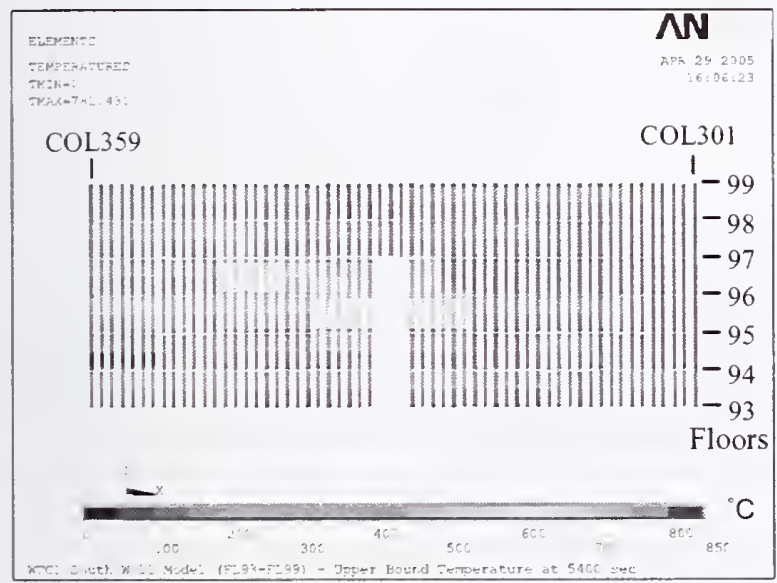

(a) Outside

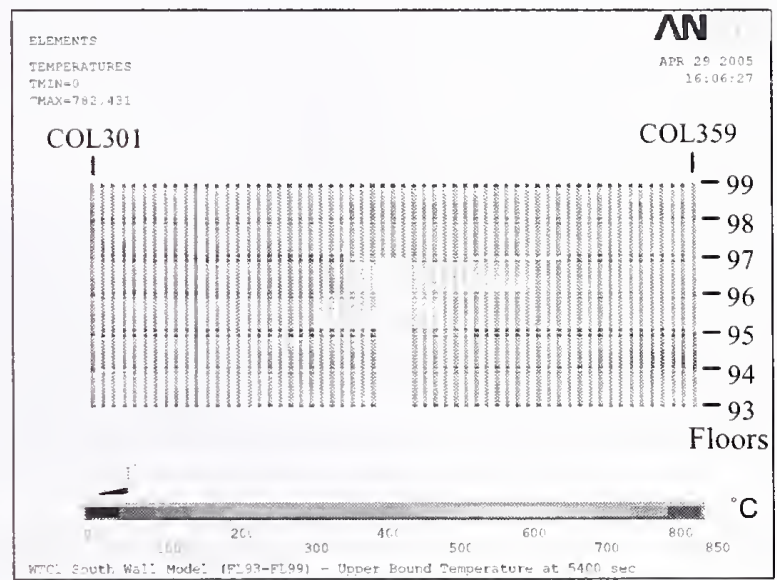

(b) Inside

Figure 3-42. Case B temperature condition of south wall columns of WTC 1 at $90 \mathrm{~min}$.

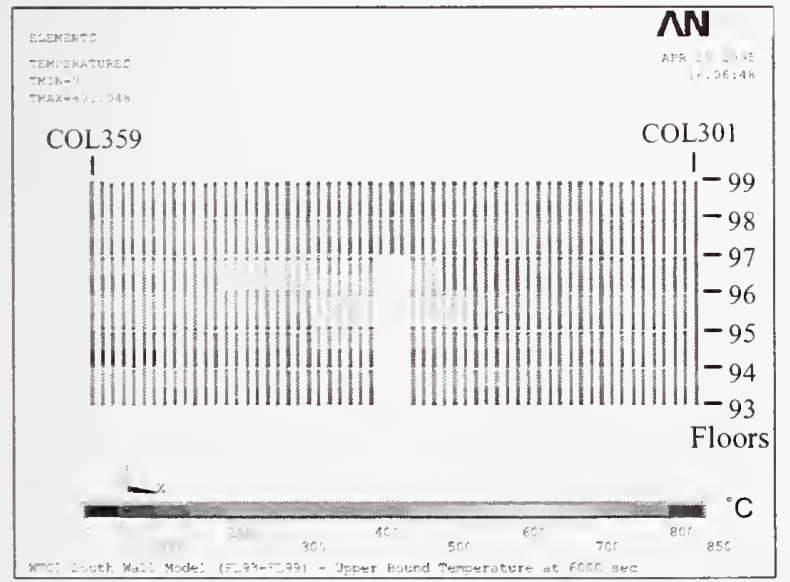

(a) Outside

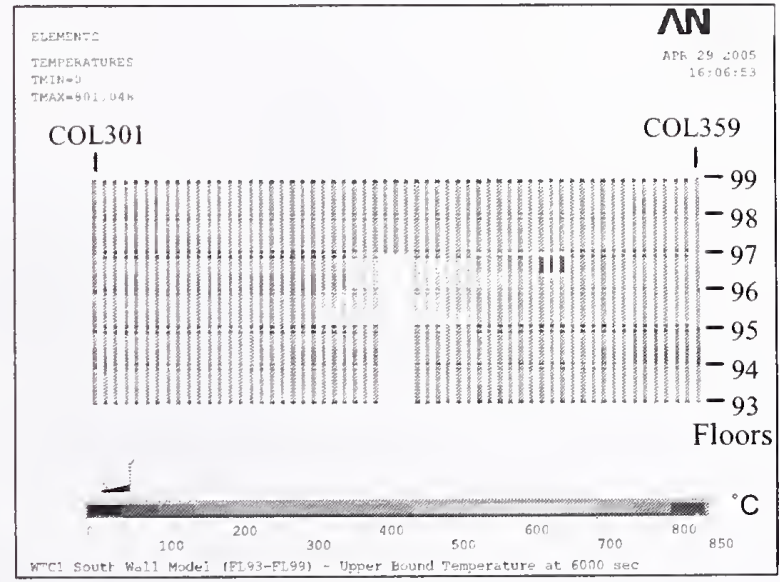

(b) Inside

Figure 3-43. Case B temperature condition of south wall columns of WTC 1 at $100 \mathrm{~min}$. 


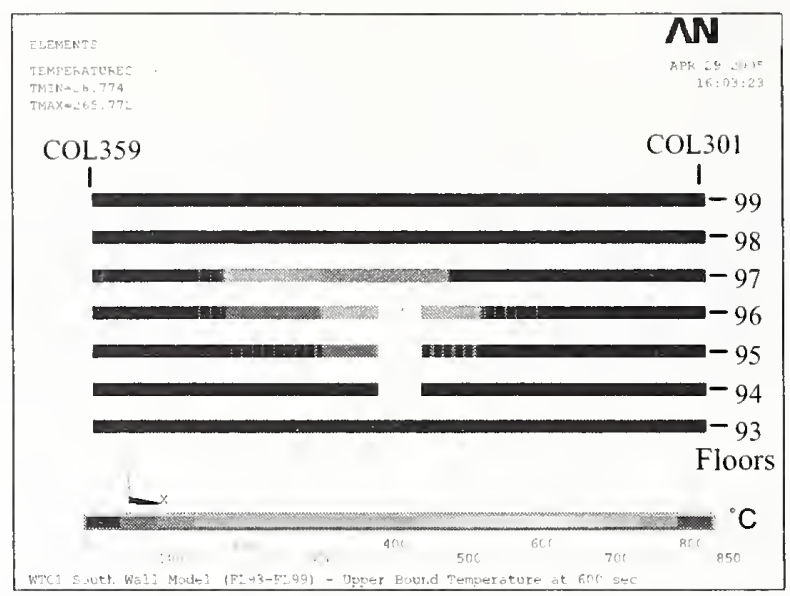

Figure 3-44. Case B temperature condition of south wall spandrels of WTC 1 at $10 \mathrm{~min}$.

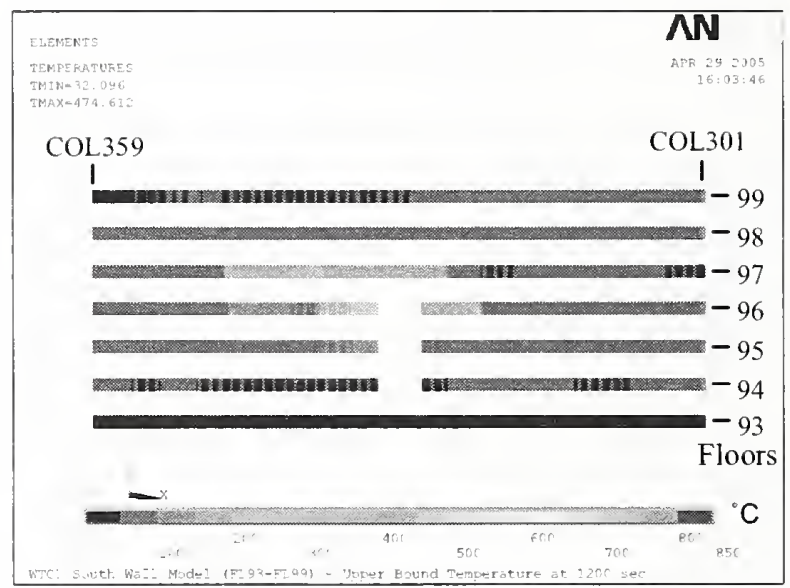

Figure 3-45. Case B temperature condition of south wall spandrels of WTC 1 at $20 \mathrm{~min}$.

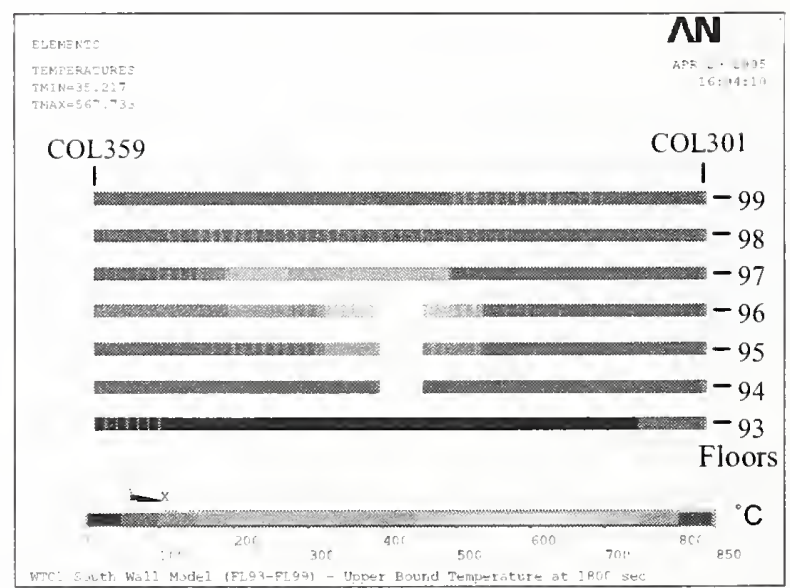

Figure 3-46. Case B temperature condition of south wall spandrels of WTC 1 at $30 \mathrm{~min}$. 


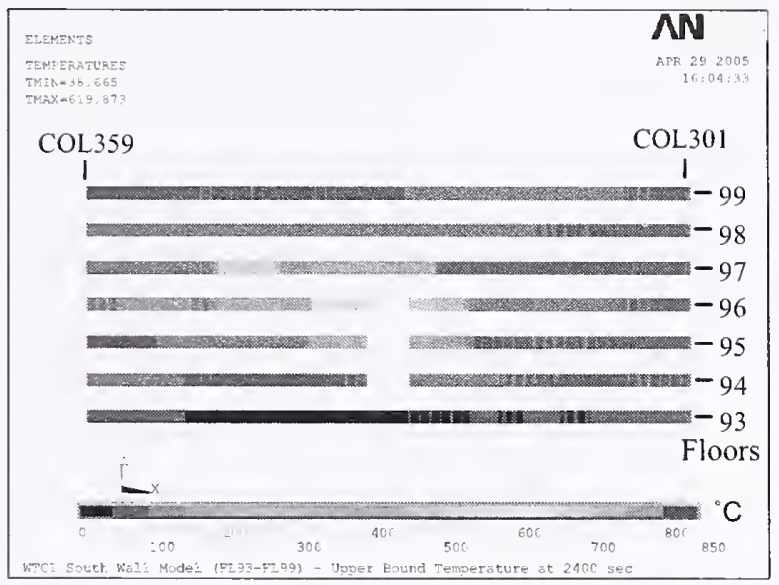

Figure 3-47. Case B temperature condition of south wall spandrels of WTC 1 at $40 \mathrm{~min}$.

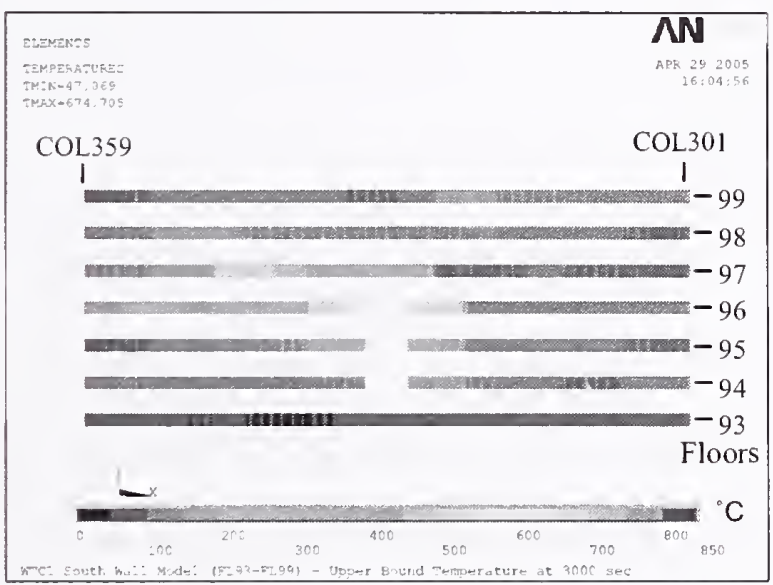

Figure 3-48. Case B temperature condition of south wall spandrels of WTC 1 at $50 \mathrm{~min}$.

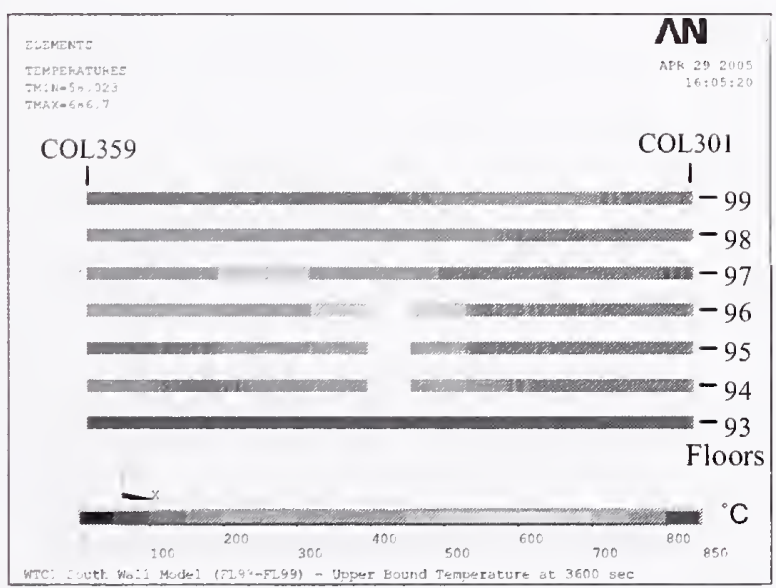

Figure 3-49. Case B temperature condition of south wall spandrels of WTC 1 at $60 \mathrm{~min}$. 


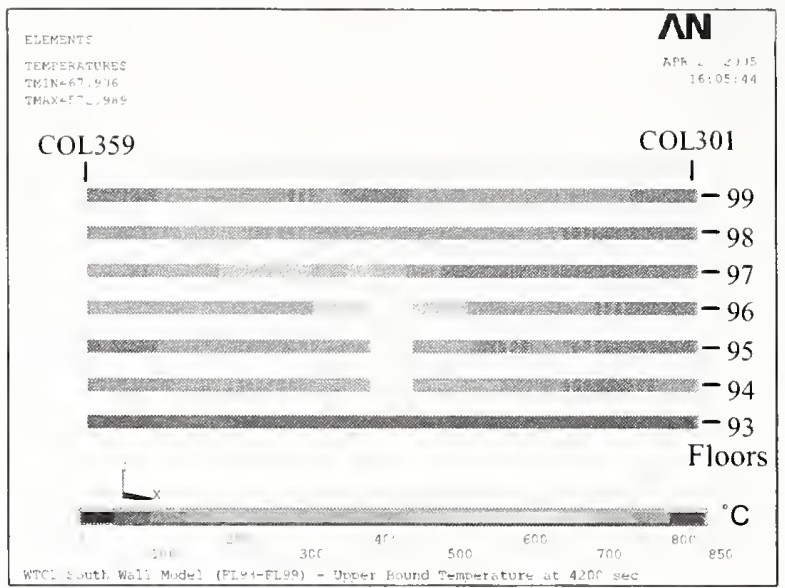

Figure 3-50. Case B temperature condition of south wall spandrels of WTC 1 at $70 \mathrm{~min}$.

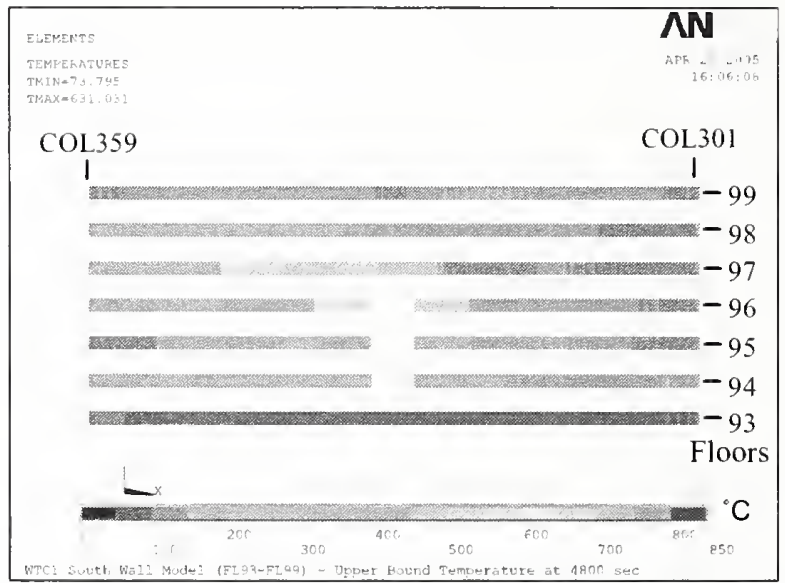

Figure 3-51. Case B temperature condition of south wall spandrels of WTC 1 at $80 \mathrm{~min}$.

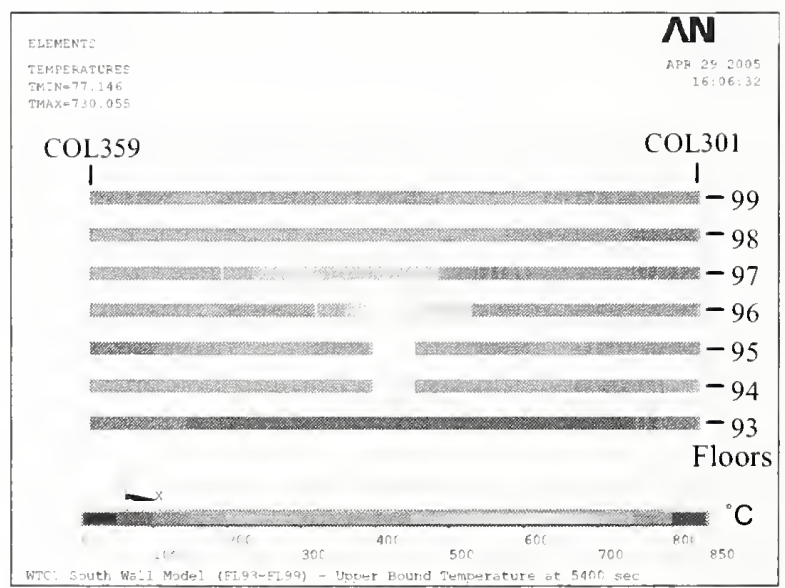

Figure 3-52. Case B temperature condition of south wall spandrels of WTC 1 at $90 \mathrm{~min}$. 


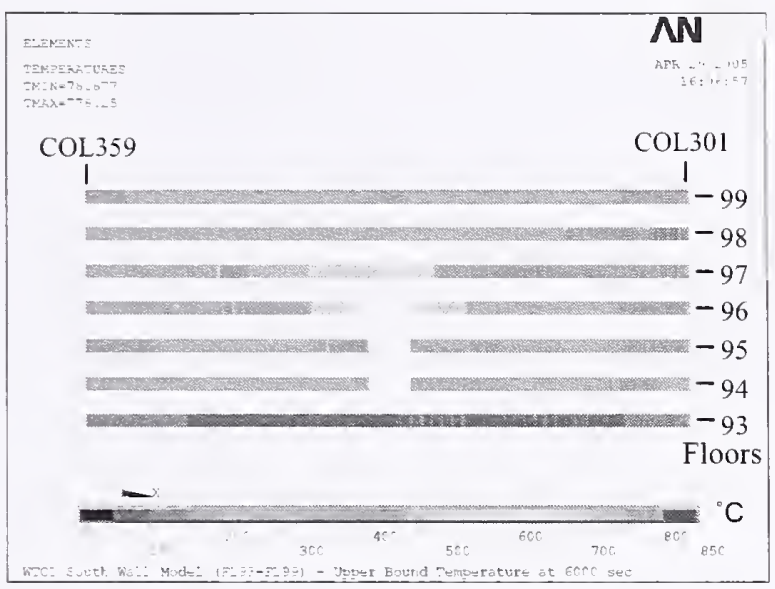

Figure 3-53. Case B temperature condition of south wall spandrels of WTC 1 at $100 \mathrm{~min}$. 


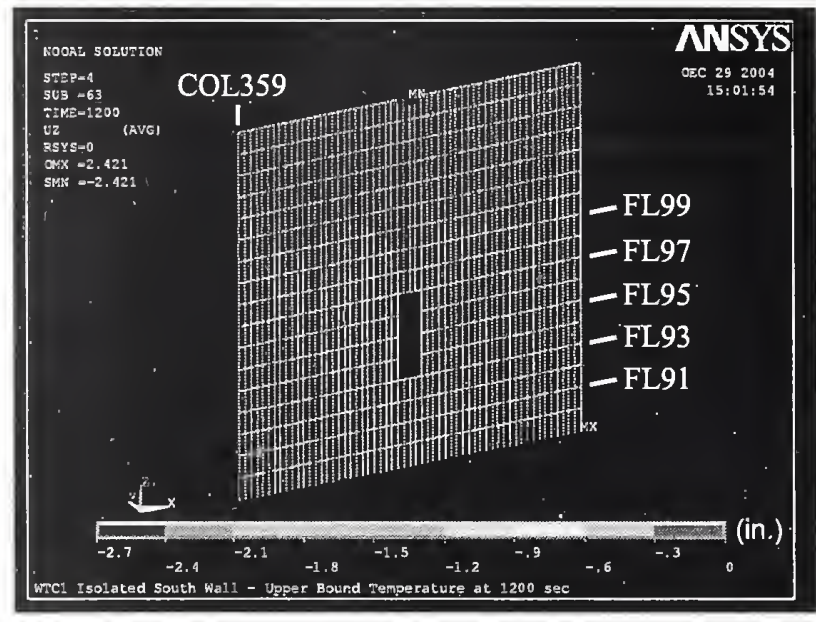

(a) At $20 \mathrm{~min}$

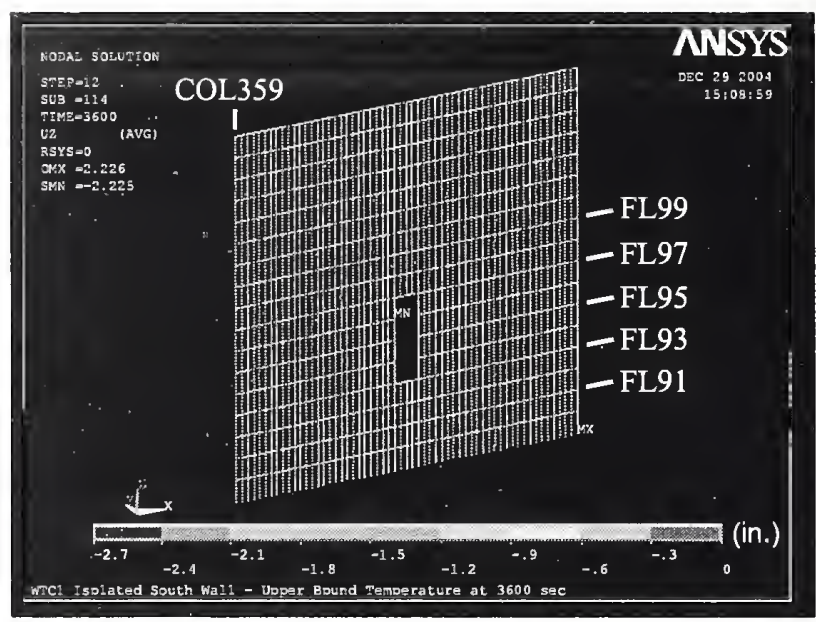

(c) At $60 \mathrm{~min}$

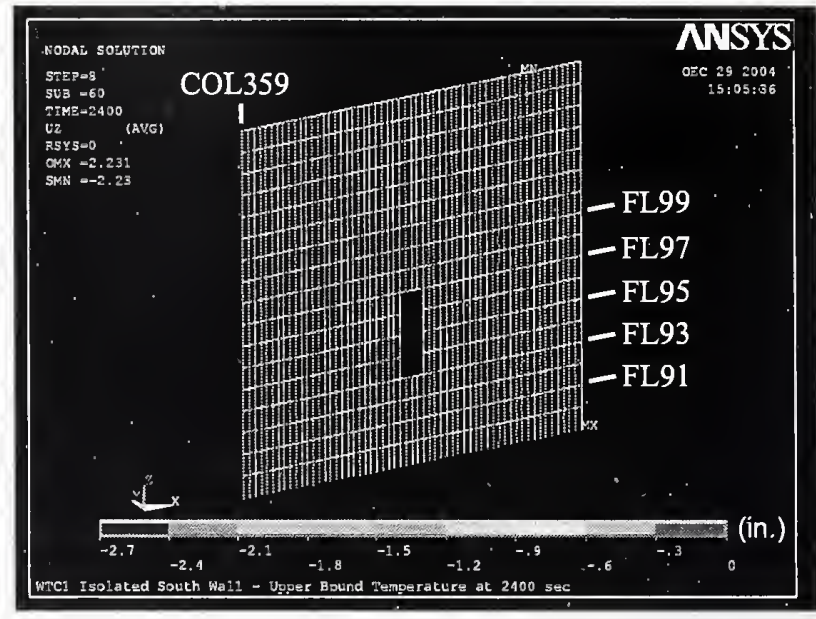

(b) At $40 \mathrm{~min}$

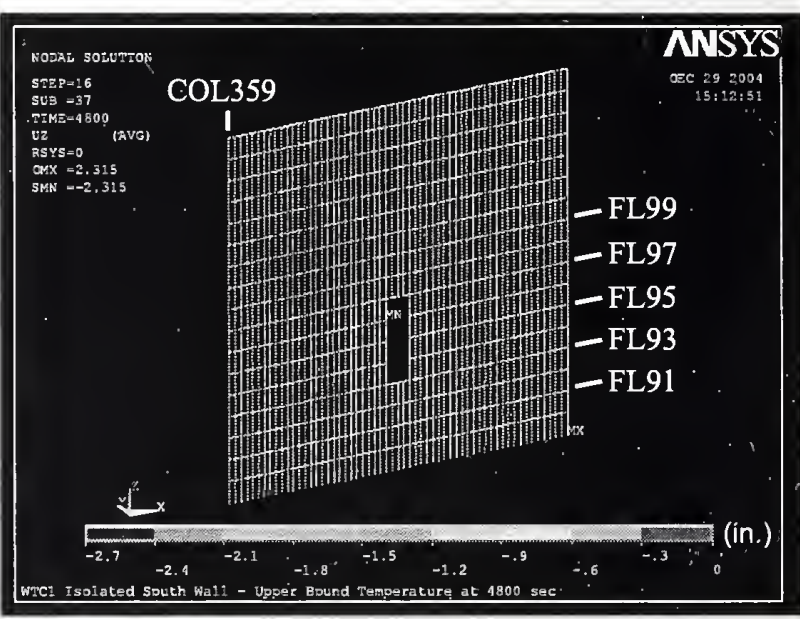

(d) At $80 \mathrm{~min}$

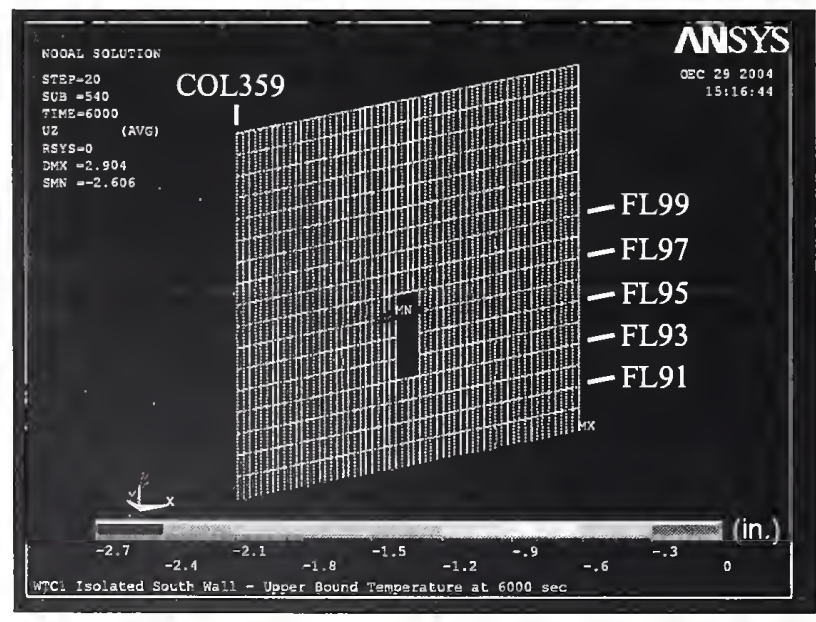

(e) At $100 \mathrm{~min}$

Figure 3-54. Vertical displacement of isolated south wall model of WTC 1 for Case B temperature condition (downward displacement is negative). 


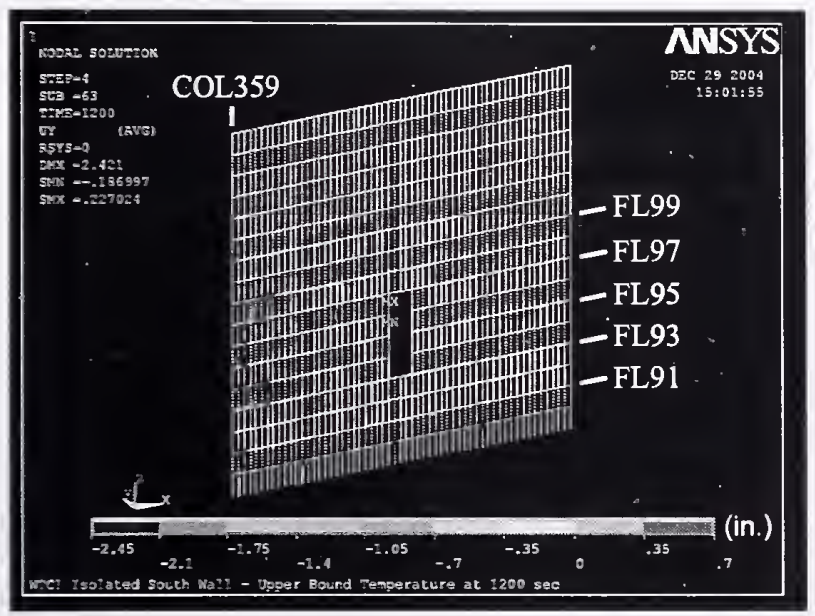

(a) At $20 \mathrm{~min}$

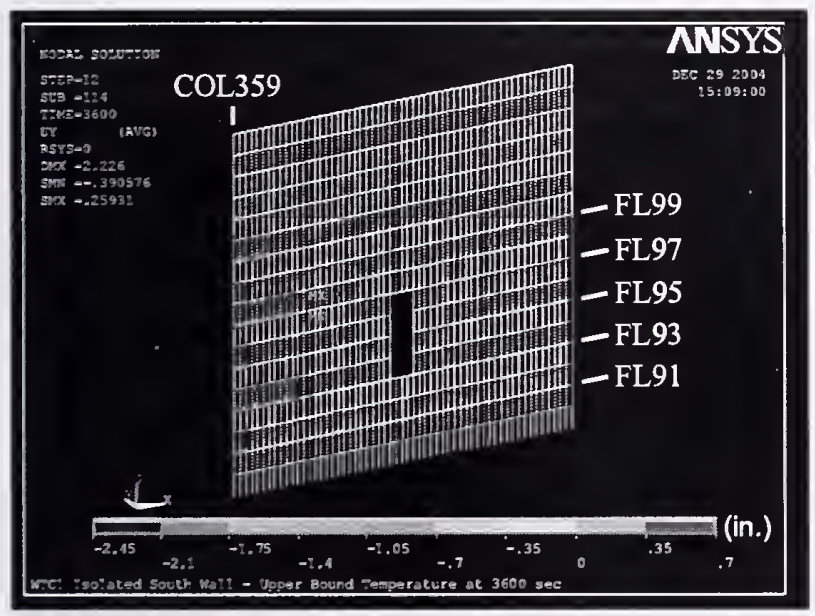

(c) At $60 \mathrm{~min}$

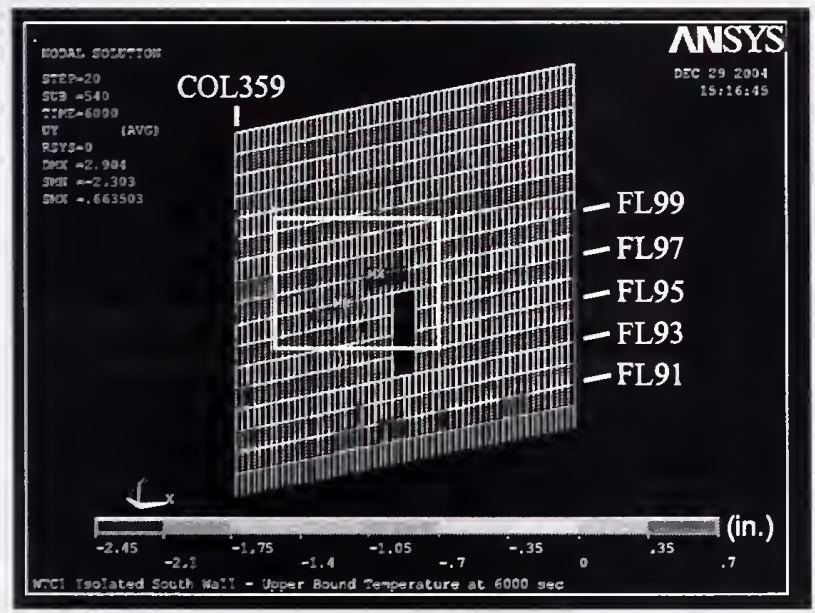

(e) At $100 \mathrm{~min}$

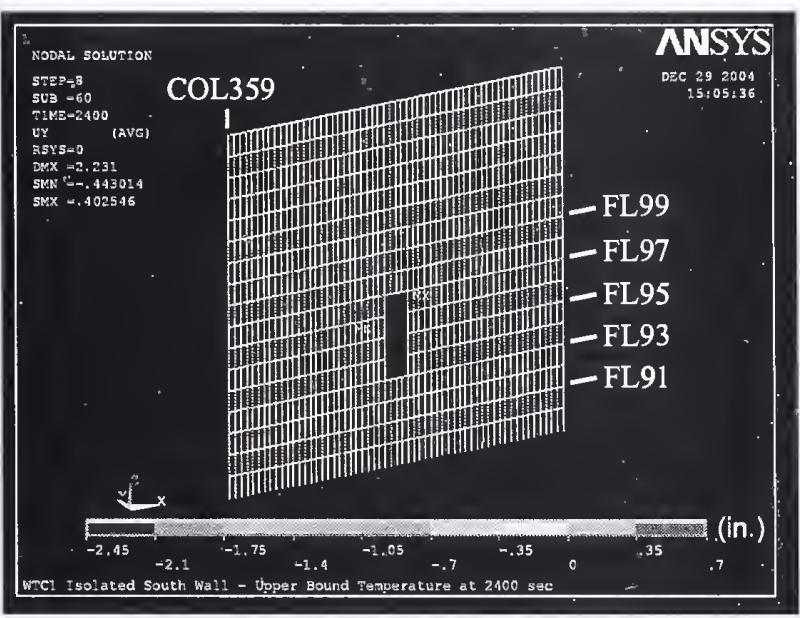

(b) At $40 \mathrm{~min}$

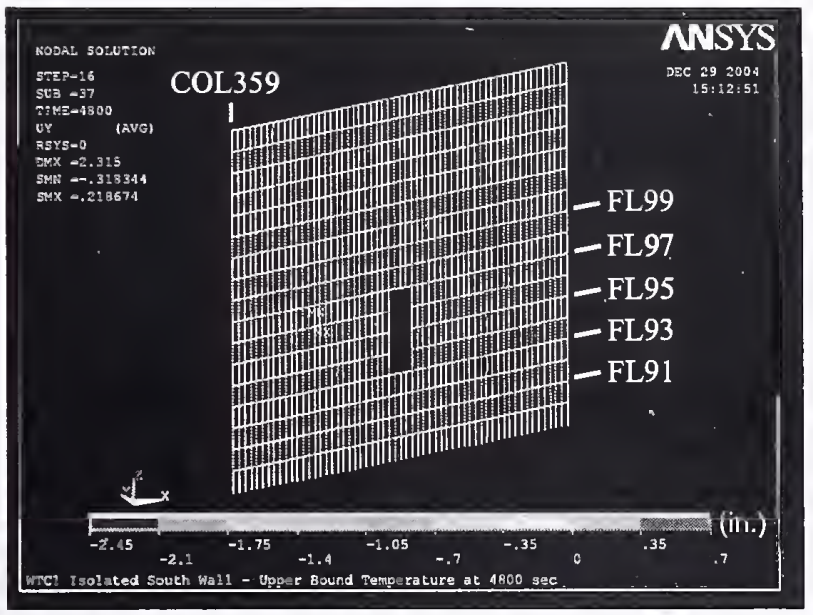

(d) At $80 \mathrm{~min}$

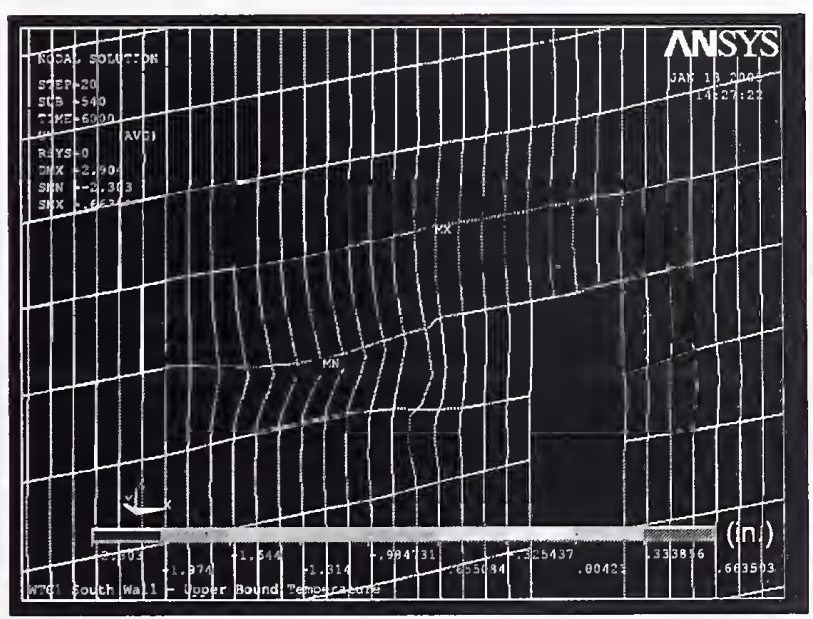

(f) At $100 \mathrm{~min}$

(30X displacement magnification)

Figure 3-55. Out-of-plane displacement of isolated south wall model of WTC 1 for Case $\mathrm{B}$ temperature condition (inward displacement is positive). 


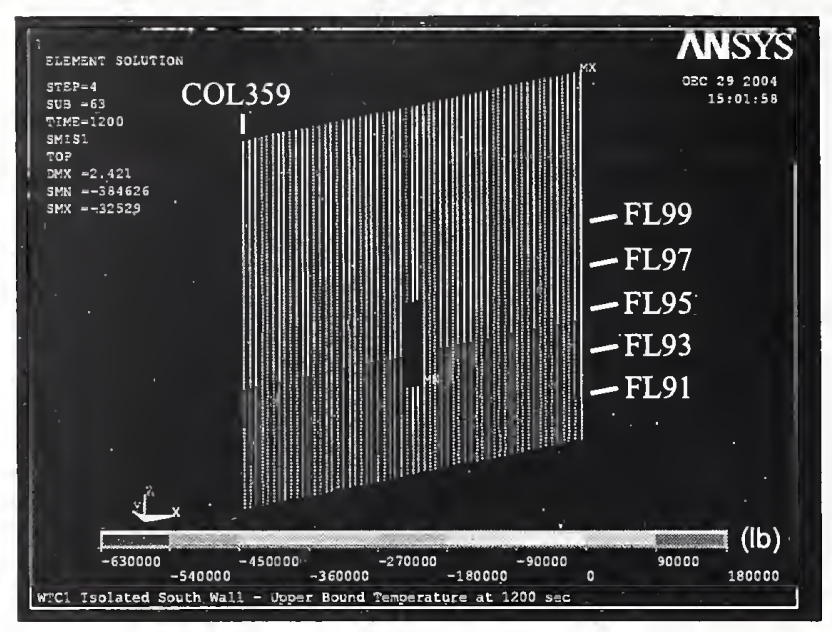

(a) At 20 min

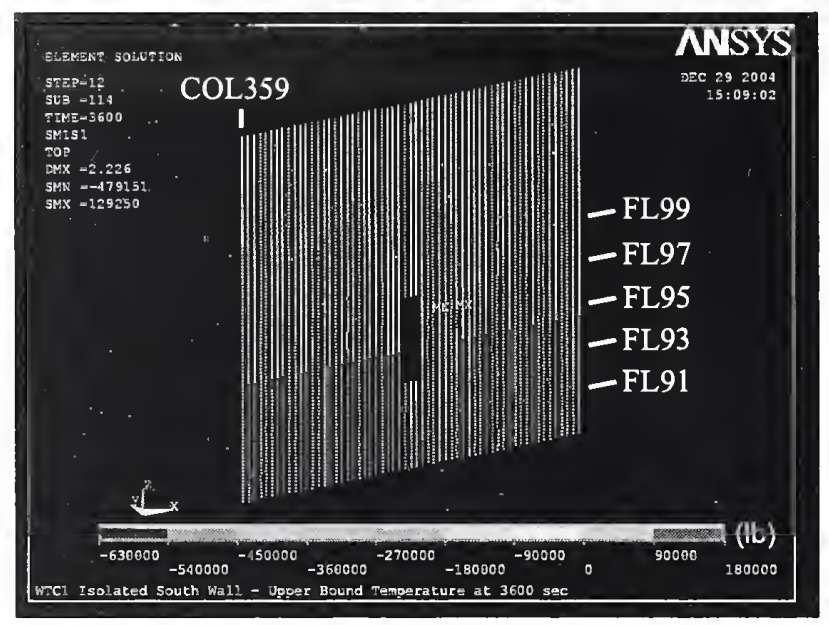

(c) At $60 \mathrm{~min}$

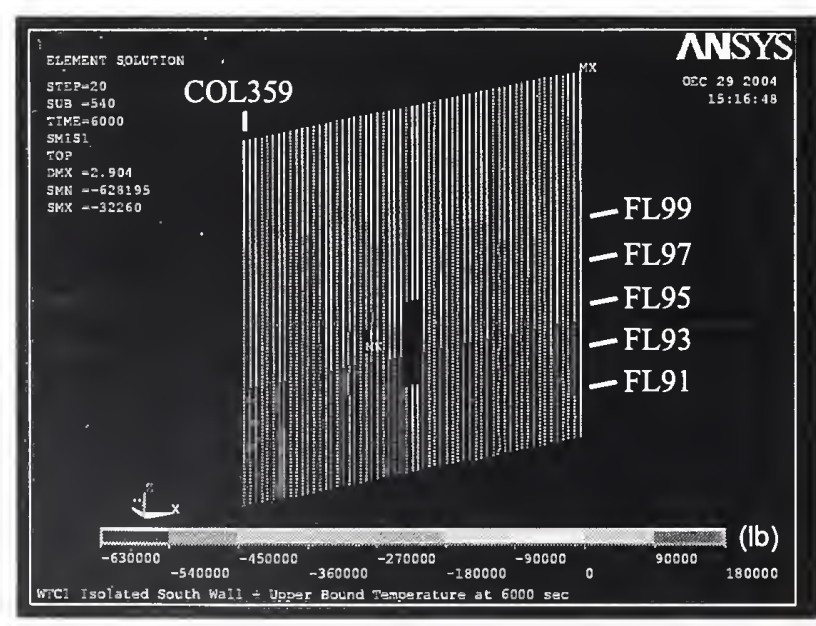

(e) At $100 \mathrm{~min}$

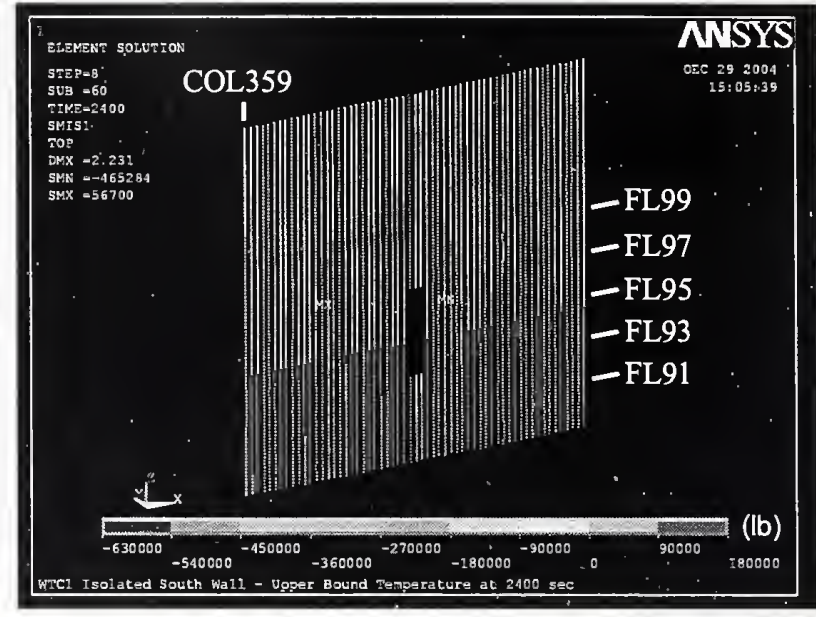

(b) At $40 \mathrm{~min}$

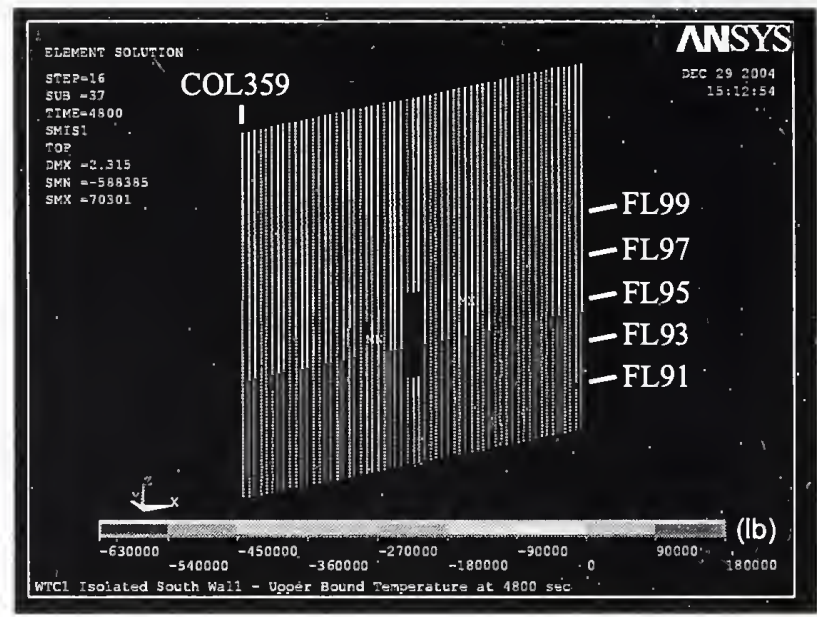

(d) At $80 \mathrm{~min}$

Figure 3-56. Axial load in columns of isolated south wall model of WTC 1 for Case B temperature condition (compression is negative). 


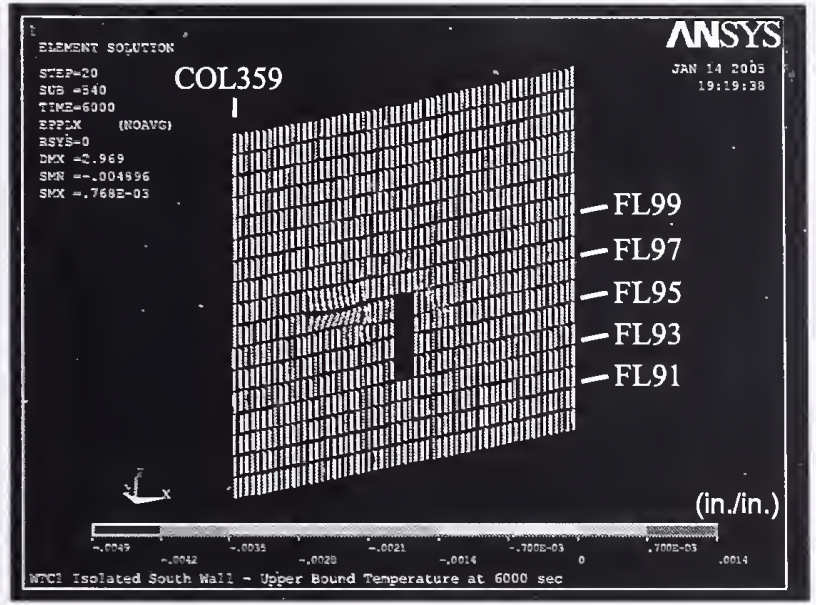

(30X displacement magnification)

Figure 3-57. Plastic strain in columns of isolated south wall model of WTC 1 for Case B temperature condition at $100 \mathrm{~min}$ (compressive strain is negative).

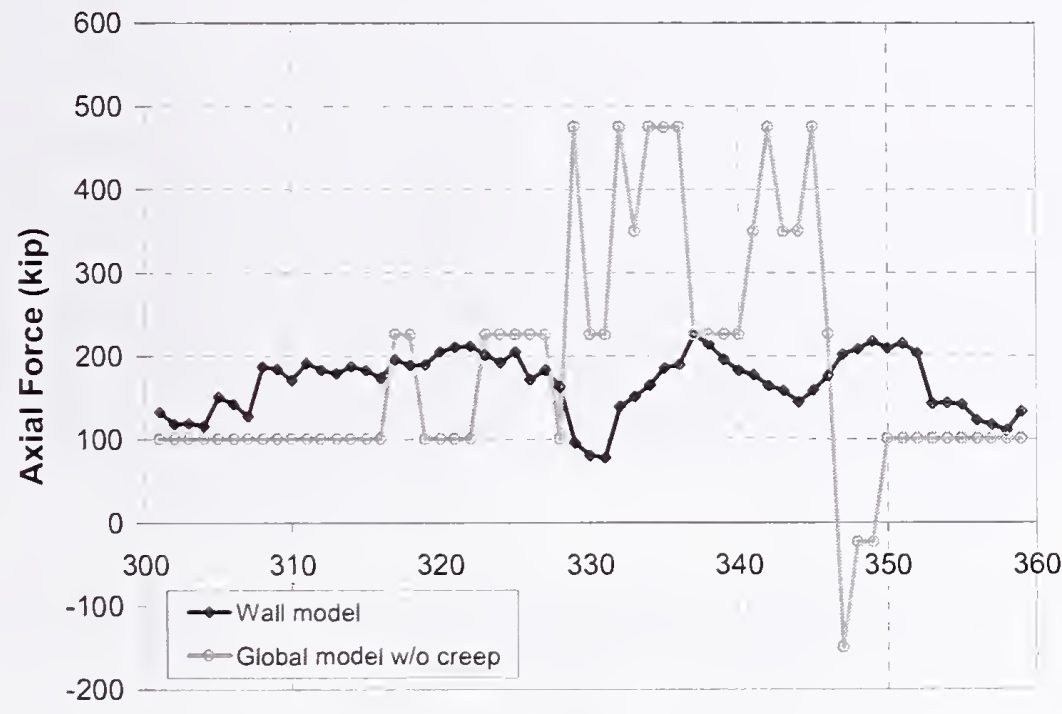

Column ID

Figure 3-58. Axial load in columns of south wall of WTC 1 at $100 \mathrm{~min}$ : isolated wall model for Case $B$ temperature condition compared to global model without creep for Case $A_{i}$ conditions (compression is positive). 


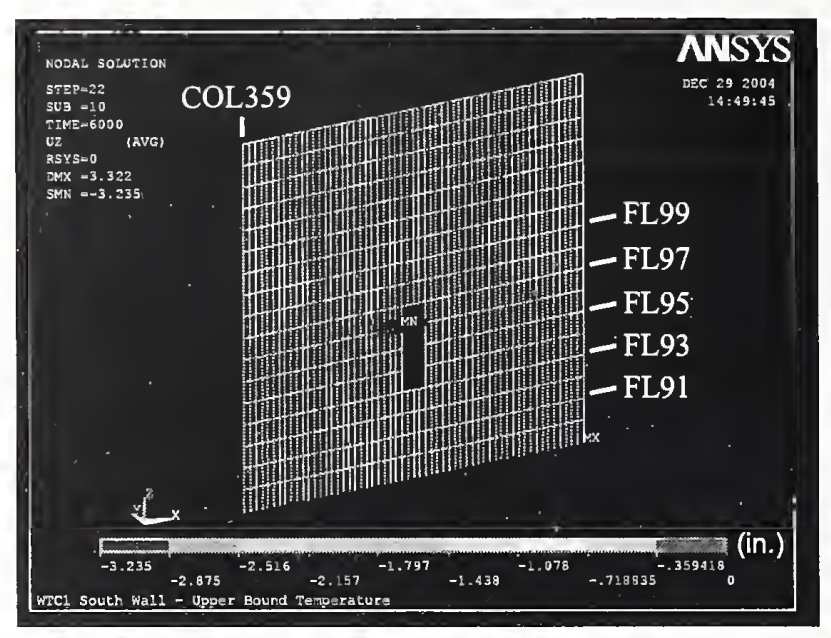

(a) Vertical displacement

(downward displacement is negative)

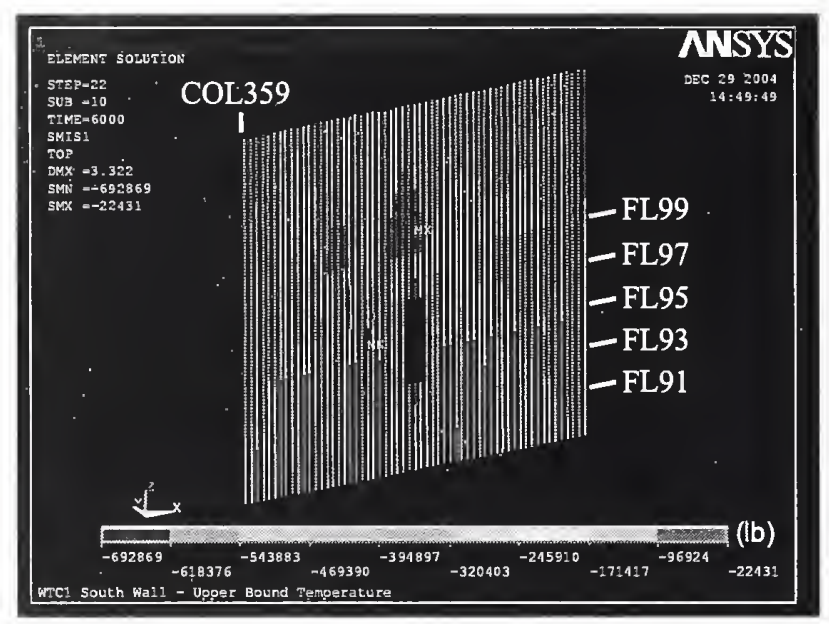

(c) Axial force in columns (compression is negative)

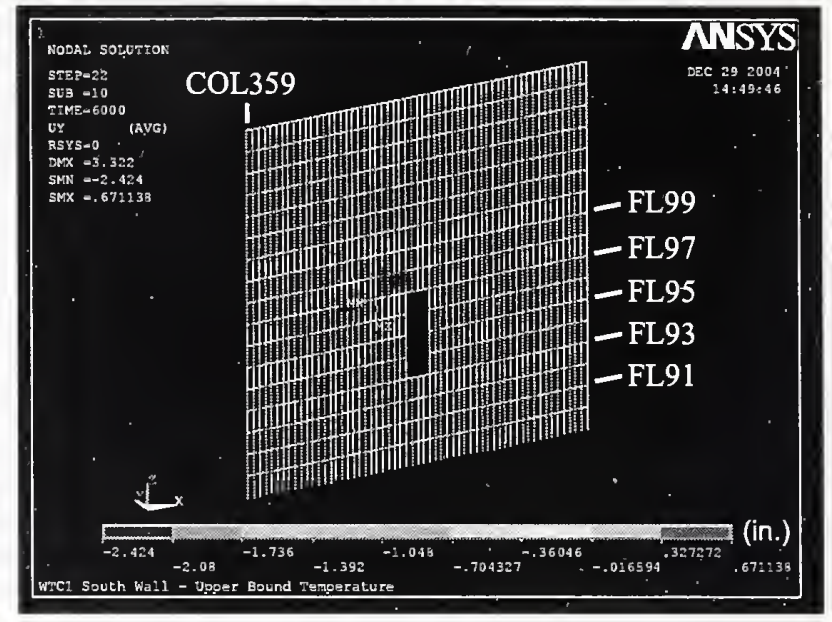

(b) Out-of-plane displacement (inward displacement is positive)

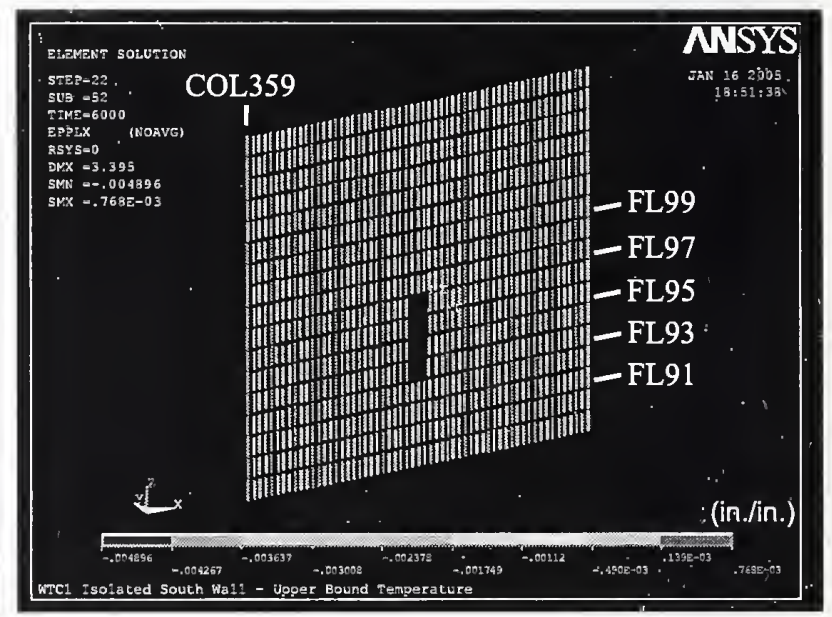

(d) Plastic strain in columns (compressive strain is negative)

Figure 3-59. Response of isolated south wall model of WTC 1 after corrective loads from the global model were applied (Case B temperature condition at $100 \mathrm{~min}$ ). 


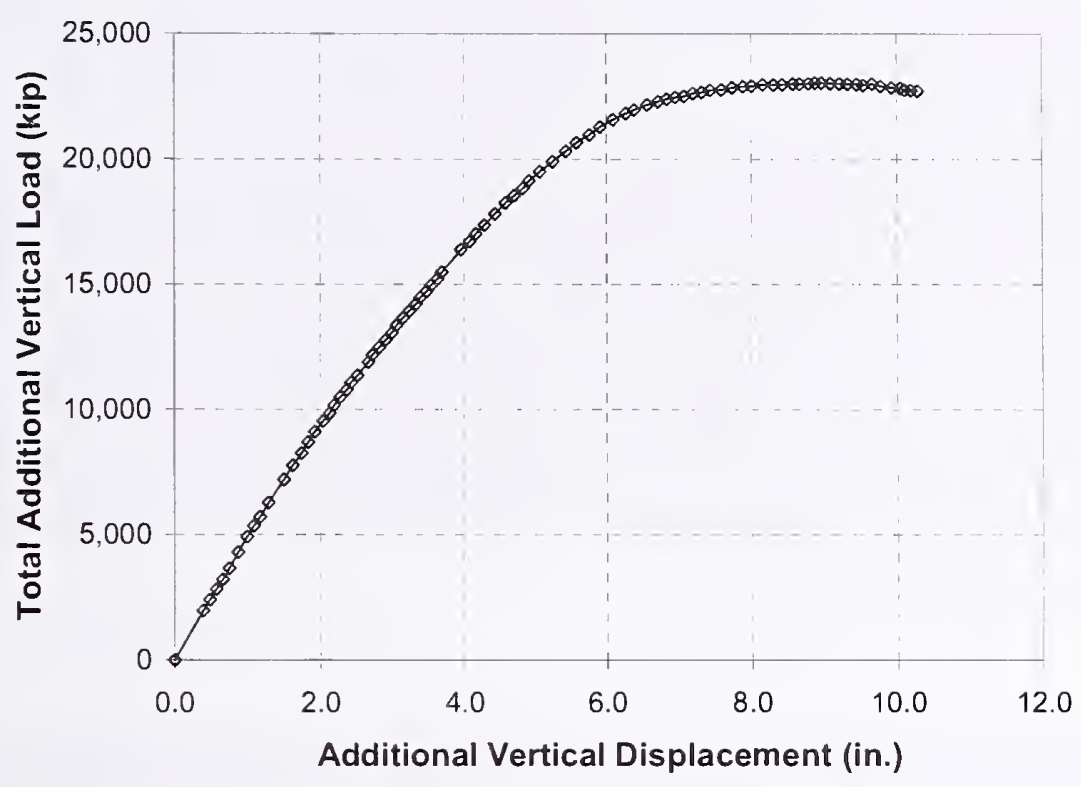

Figure 3-60. Total additional vertical load versus additional vertical displacement during push-down analysis of isolated south wall model of WTC 1 for Case B temperature condition (compression is positive).

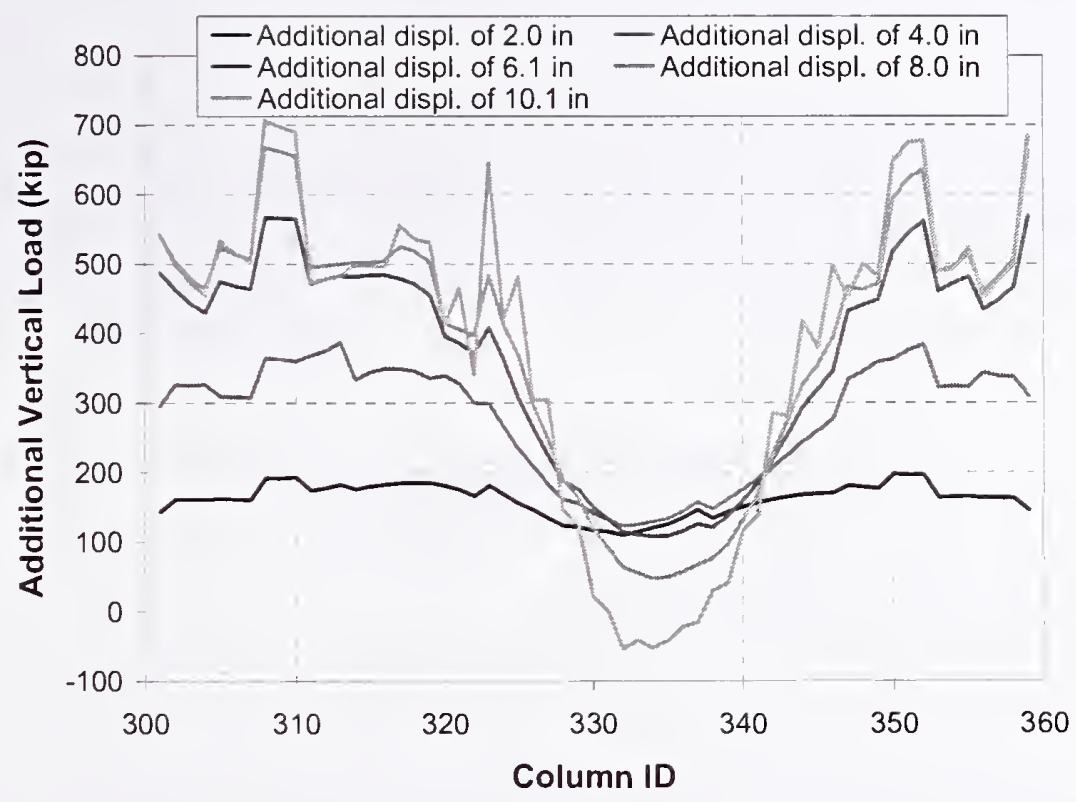

Figure 3-61. Additional load per column at different additional vertical displacements during push-down analysis of isolated south wall model of WTC 1 for Case B temperature condition (compression is positive). 


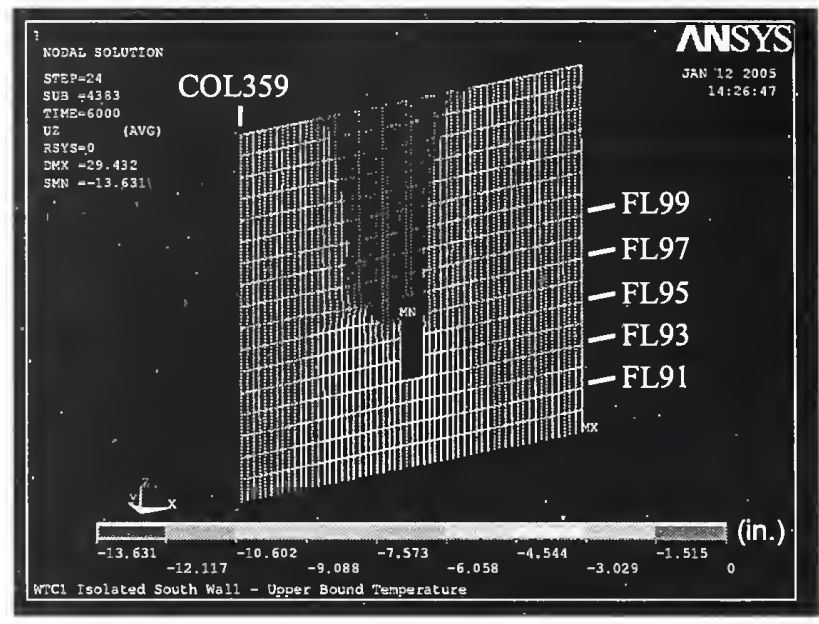

(a) Vertical displacement

(downward displacement is negative)

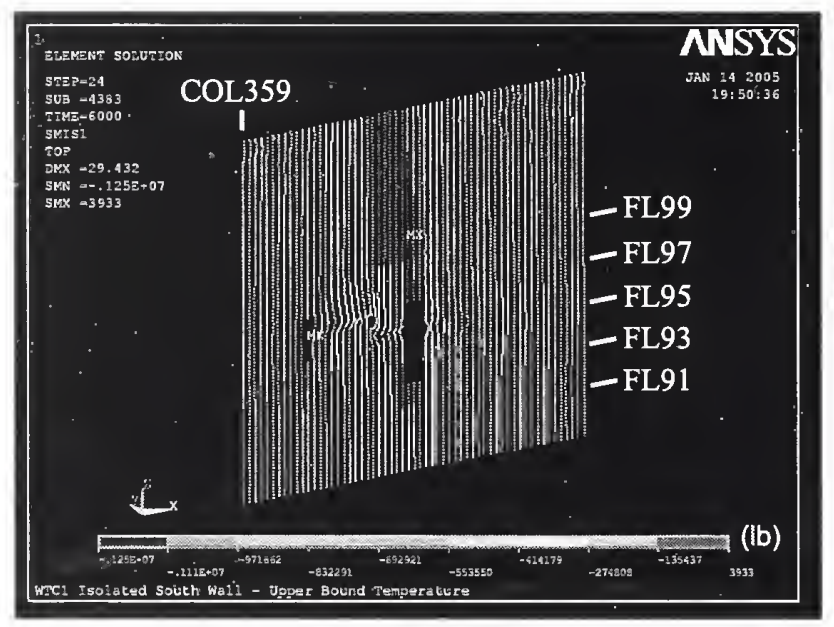

(c) Axial force in columns

(compression is negative,

$3 X$ displacement magnification)

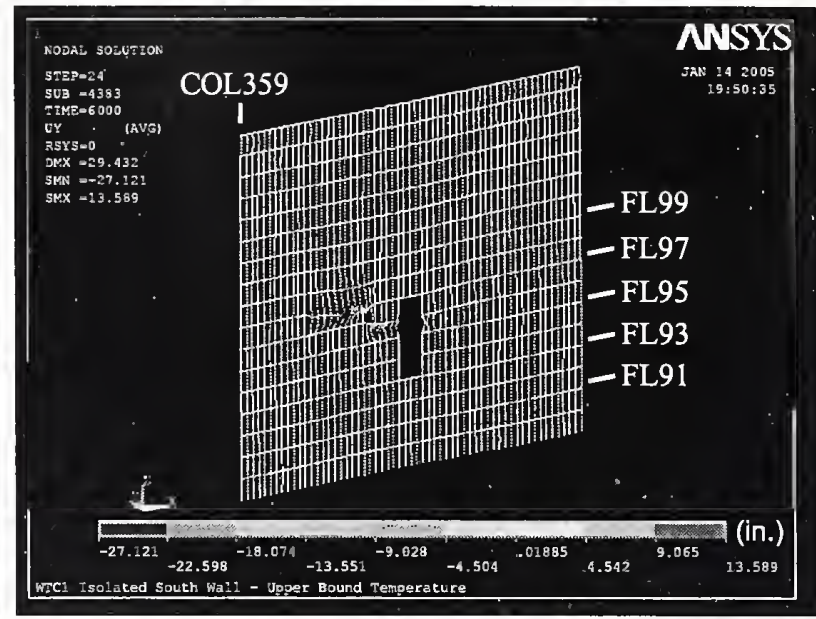

(b) Out-of-plane displacement (inward displacement is positive, $3 \mathrm{X}$ displacement magnification)

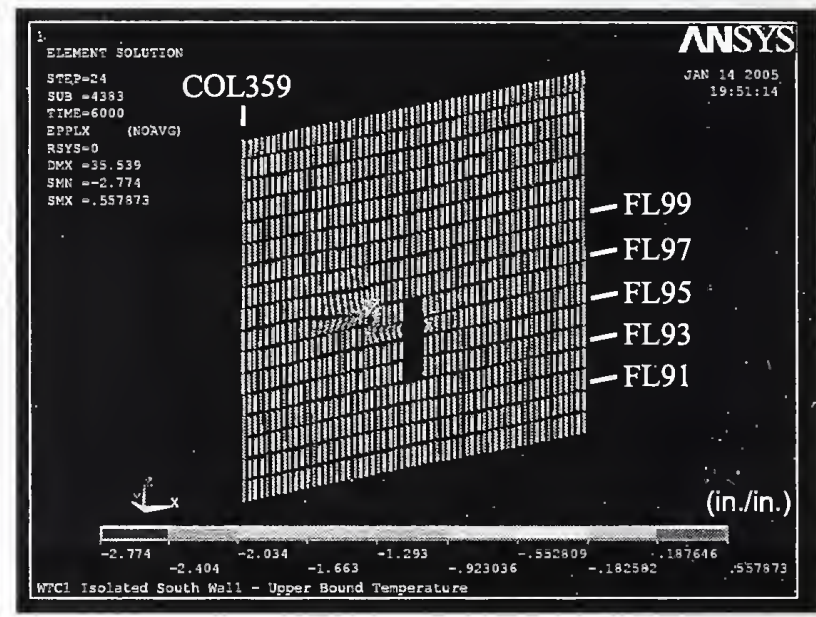

(d) Plastic strain in columns (compressive strain is negative, $3 \mathrm{X}$ displacement magnification)

\section{Figure 3-62. Response of isolated south wall model of WTC 1 to Case B temperature condition and push-down.}

\section{Pull-in Forces to Cause Observed Bowing}

As discussed in Chapter 5, inward bowing of the exterior wall on the south face of WTC 1 can be seen in photographs of the event at 10:23 am (about $97 \mathrm{~min}$ after the aircraft impact), while no bowing of the south wall is evident at 9:55 am (about $68 \mathrm{~min}$ after the aircraft impact). The inward bowing at $97 \mathrm{~min}$ extended from Floors 95 to 99 between Columns 308 to 326 (possibly to 340); NIST estimated the maximum bowing to be $55 \mathrm{in}$. at Floor 97.

The isolated south wall model of WTC 1 did not bow inward under Case A temperature condition, and it bowed slightly over a very limited area under Case B temperature condition. The isolated wall model results did not capture the actual bowing. 
The most plausible explanation for the discrepancy between the observed and modeled bowing of the exterior walls is that the pull-in forces were not captured in the full floor models, and floors sagged to a greater extent than these models predicted. Following are reasons the floor models likely underestimated sagging and did not accurately calculate pull-in forces.

- The exterior wall boundary conditions used in the floor models were realistic only if a single floor was heated. The floor trusses were supported on exterior columns that extended one story above and one story below the floor modeled. The far ends of the columns were restrained against translation in the direction normal to the exterior wall and rotation about the axis parallel to the exterior wall. This boundary condition was much stiffer in translation normal to the exterior wall than actually occurred for sequential floors heating simultaneously.

- The floor models did not include creep behavior in the steel or cracking of the concrete floors.

- The floor models did not include strap anchors or studs.

- More thermal insulation may have been dislodged from the trusses than estimated from the impact analysis. The impact analysis did not account for the effect of impact or vibrations on dislodging insulation.

- The floor models assumed a uniform live load. Debris accumulated in large piles was observed in some floor areas.

To model the effect of pull-in forces on inward bowing of the columns, trial values of pull-in forces were applied to the exterior columns of the south wall over five floors from Floor 95 to Floor 99 where bowing was observed.

The magnitudes of the pull-in forces were determined by trial and error, matching the observed inward bowing of exterior walls for Case B temperature condition. The Case B temperature condition was used because temperatures of the south office area floors and south wall columns were much higher than those of the Case A temperature condition, and because the full floor models with the Case $\mathrm{B}_{\mathrm{i}}$ temperature condition showed much larger floor sagging in the south office area than did the floor models with the Case $\mathrm{A}_{\mathrm{i}}$ temperature condition.

The floor models for Case B temperature condition showed that floors began to disconnect from the south wall about 80 min after impact. In the temperature time histories of the Case B condition, temperatures of the south wall and south office area had begun to rise again after $80 \mathrm{~min}$, having been relatively constant for some time. Consequently, pull-in forces were applied to the exterior wall model starting at $80 \mathrm{~min}$ and, the temperature time history was analyzed with these pull-in forces to $100 \mathrm{~min}$. Figure 3-63 shows locations of floor/wall disconnections and pull-in forces for this analysis.

Figures 3-64, 3-65, and 3-66 show the results of the analysis performed with a 6 kip pull-in force per column. After applying 6 kip pull-in forces at $80 \mathrm{~min}$, the maximum inward bowing increased to $12.2 \mathrm{in}$. as shown in Fig. 3-64. At $90 \mathrm{~min}$, the maximum inward bowing became $19.0 \mathrm{in}$, and at $100 \mathrm{~min}$, it reached 31.3 in., as shown in Figs. 3-65 and 3-66. The thermal loading from 80 min to $100 \mathrm{~min}$ increased the inward bowing significantly where there was inward bowing initially. Figure 3-67 shows the axial loads in columns between Floors 98 and 99 at $80 \mathrm{~min}, 90 \mathrm{~min}$, and $100 \mathrm{~min}$. At $100 \mathrm{~min}$, 
Columns 320 to 346 were in the post-buckling regime and were unloading. The maximum bowing of $31.3 \mathrm{in}$. was smaller than the observed maximum bowing of $55 \mathrm{in}$.. The wall remained stable at $100 \mathrm{~min}$.

In the global model, the extcrior wall boundary conditions were different from the isolated wall model: generally the stiffness against inward bowing in the global models was softer. In addition, the exterior walls were expected to carry additional gravity loads redistributed from the core due to downward displacement of the core resulting from creep and inelastic buckling. Consequently, it is likely that the inward bowing of the global model would be significantly larger than $31 \mathrm{in}$. with the same 6 kip pull-in forces. Therefore, 4 or 5 kip pull-in forces were selected for the WTC 1 global analysis.

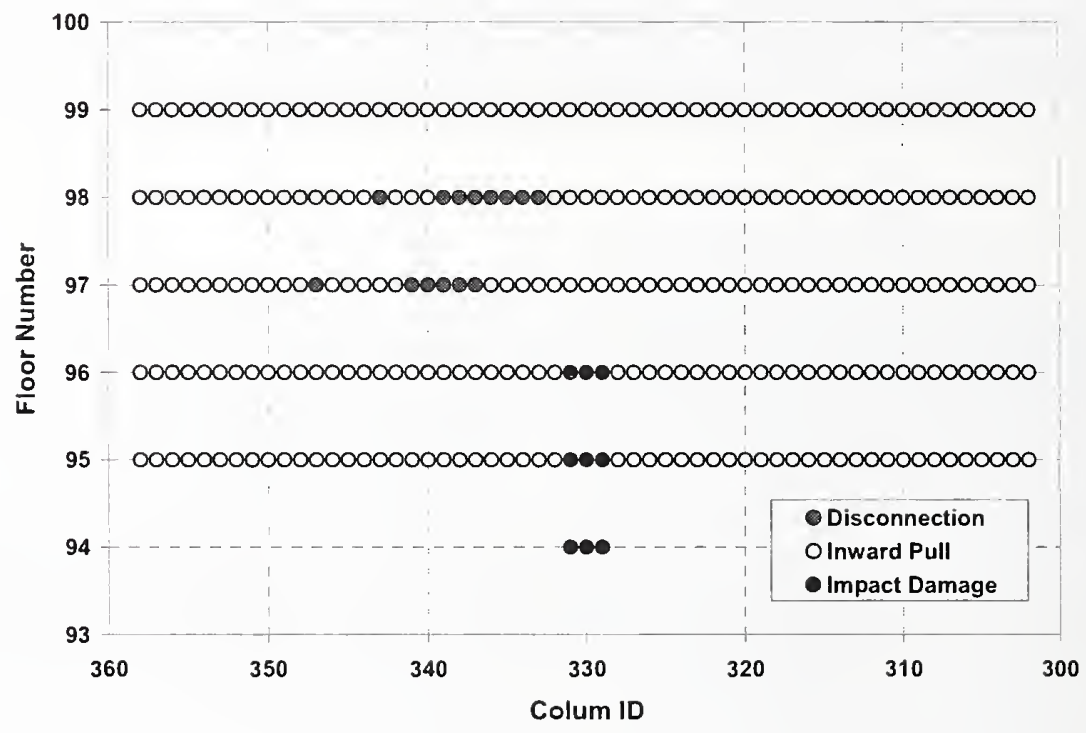

(a) Between $80 \mathrm{~min}$ and $90 \mathrm{~min}$

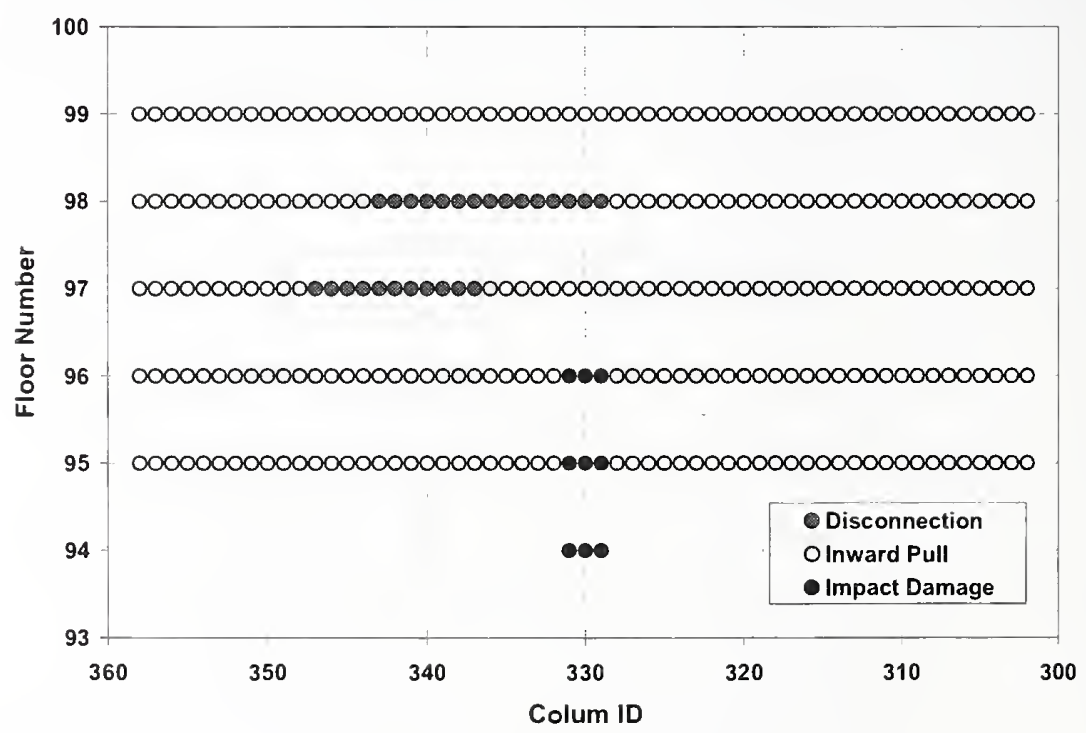

(b) Between 90 min and 100 min

Figure 3-63. Locations of floor/wall disconnections and pull-in forces used between $80 \mathrm{~min}$ and $100 \mathrm{~min}$ of Case B temperature for south wall of WTC 1. 


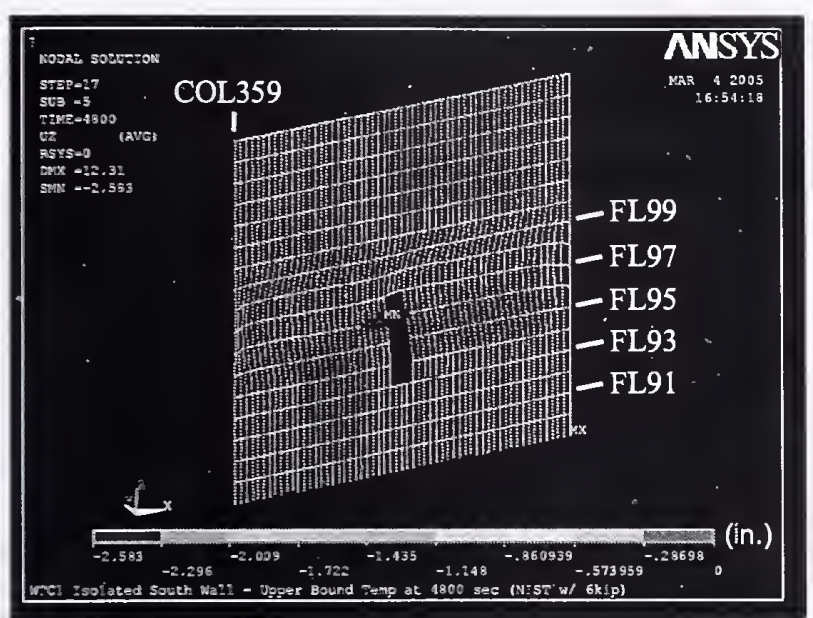

(a) Vertical displacement (downward displacement is negative, $10 \mathrm{X}$ displacement magnification)

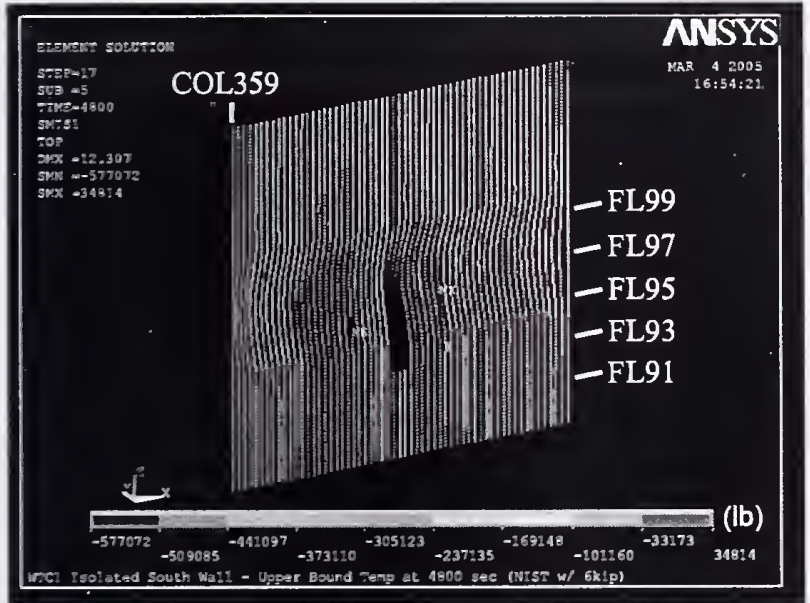

(c) Axial force in columns (compressive is negative, $10 \mathrm{X}$ displacement magnification)

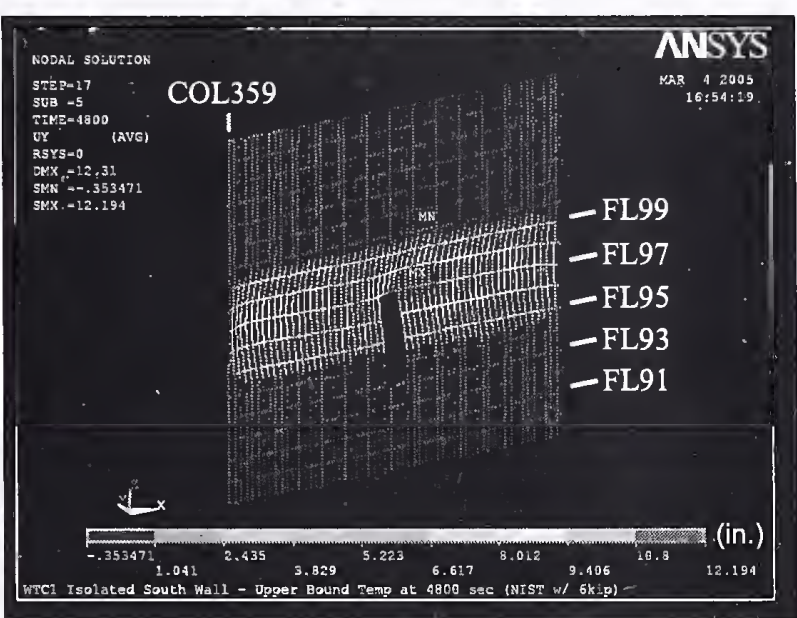

(b) Out-of-plane displacement (inward displacement is positive, $10 \mathrm{X}$ displacement magnification)

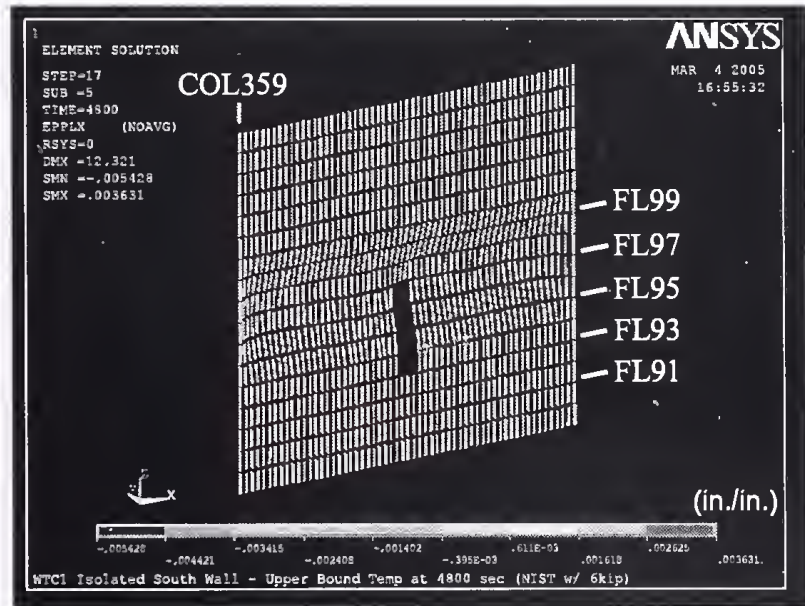

(d) Plastic strain in columns (compressive strain is negative, $10 \mathrm{X}$ displacement magnification)

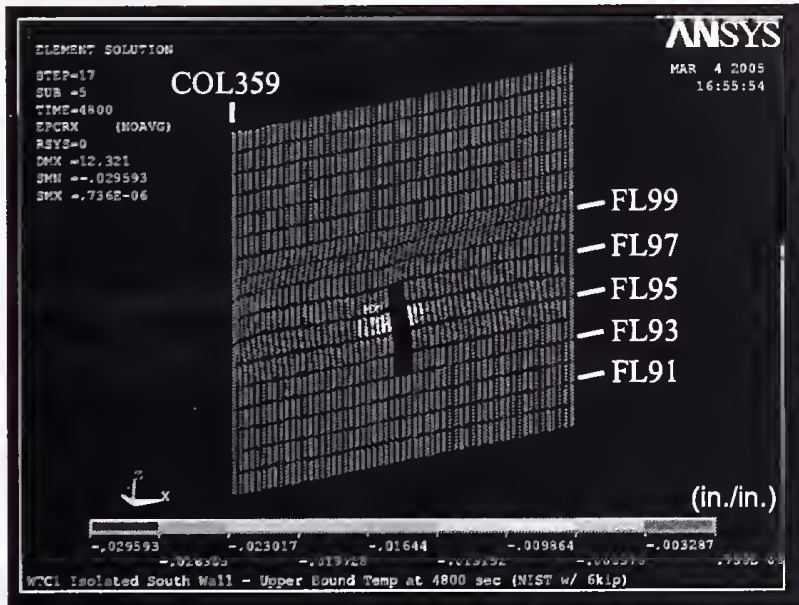

(e) Creep strain in columns (compressive strain is negative, 10X displacement magnification)

Figure 3-64. Response of isolated south wall model of WTC 1 at $80 \mathrm{~min}$ of Case B temperature condition with floor/wall disconnections and 6 kip pull-in forces over five floors. 


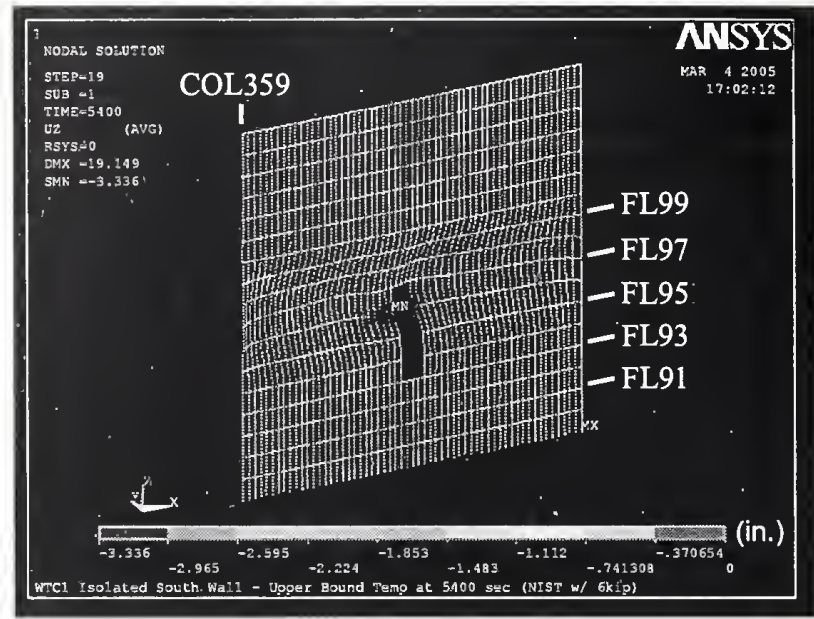

(a) Vertical displacement (downward displacement is negative, 10X displacement magnification)

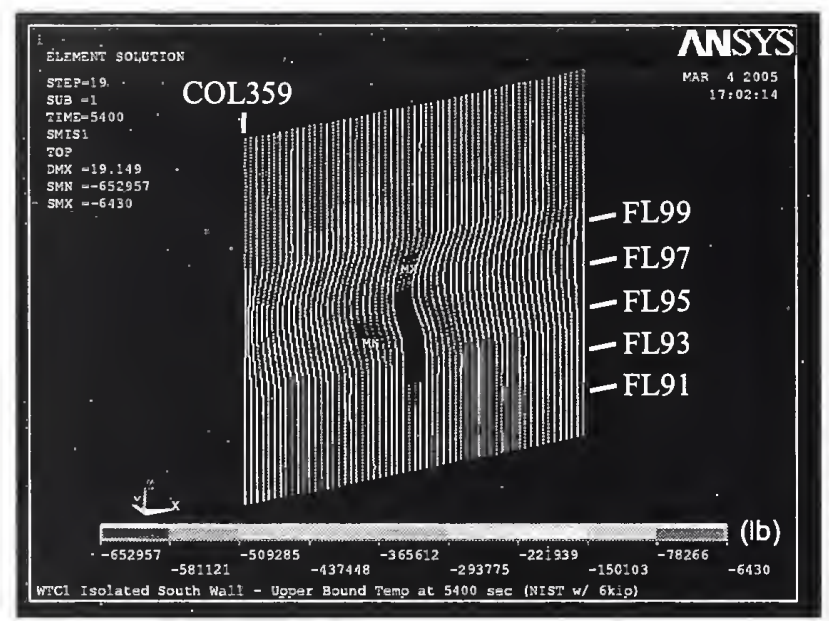

(c) Axial force in columns (compressive is negative, $10 \mathrm{X}$ displacement magnification)

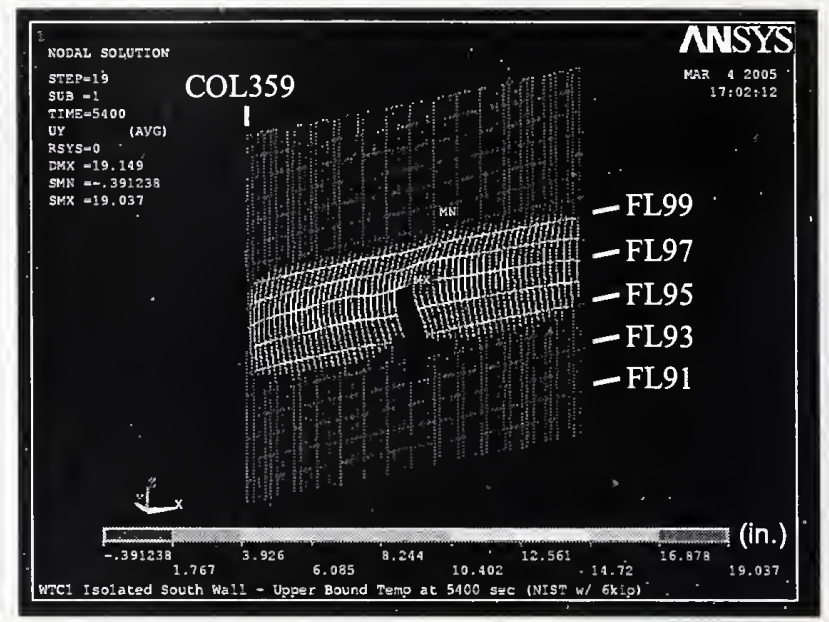

(b) Out-of-plane displacement (inward displacement is positive, 10X displacement magnification)

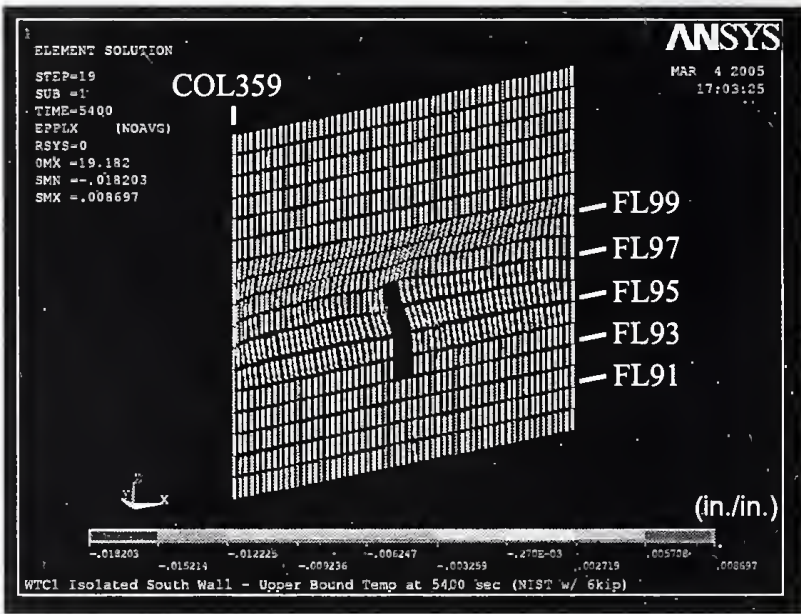

(d) Plastic strain in columns (compressive strain is negative, $10 \mathrm{X}$ displacement magnification)

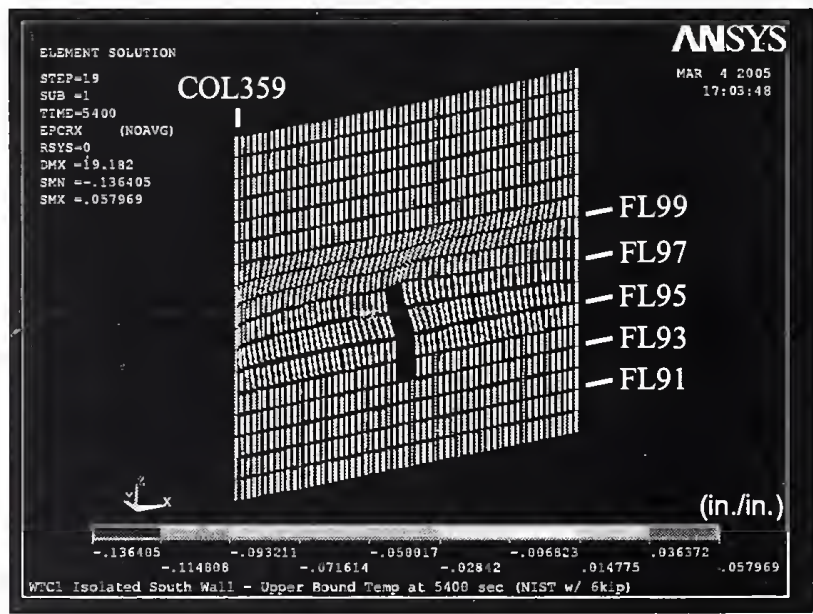

(e) Creep strain in columns (compressive strain is negative, 10X displacement magnification)

Figure 3-65. Response of isolated south wall model of WTC 1 at $90 \mathrm{~min}$ of Case B temperature condition with floor/wall disconnections and 6 kip pull-in forces over five floors. 


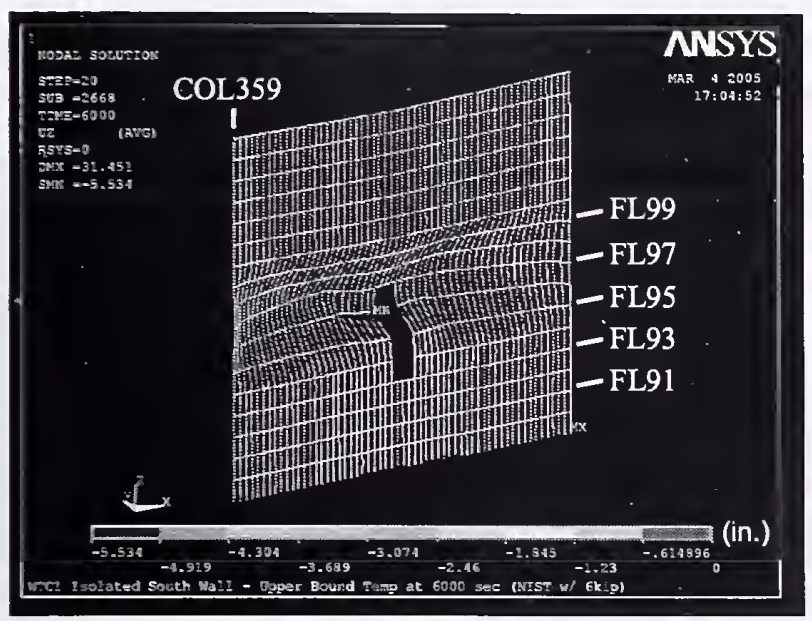

(a) Vertical displacement (downward displacement is negative, 10X displacement magnification)

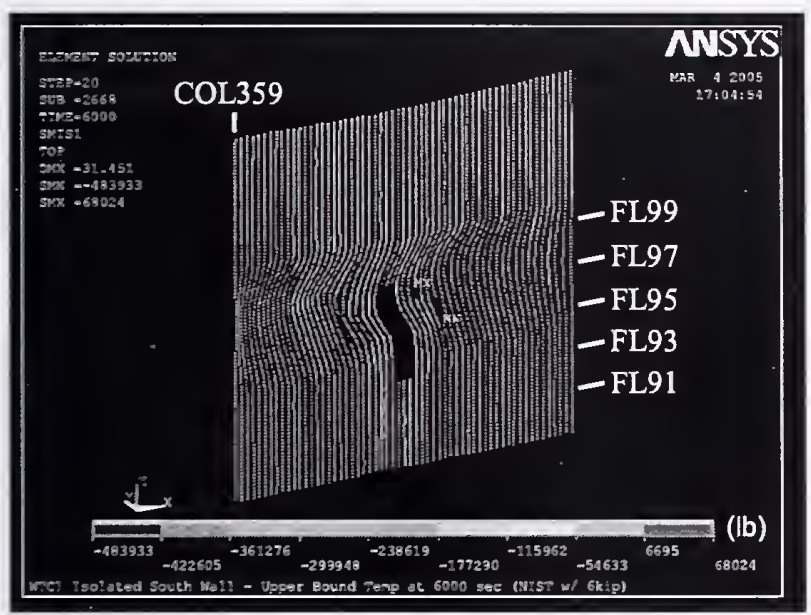

(c) Axial force in columns (compressive is negative, $10 \mathrm{X}$ displacement magnification)

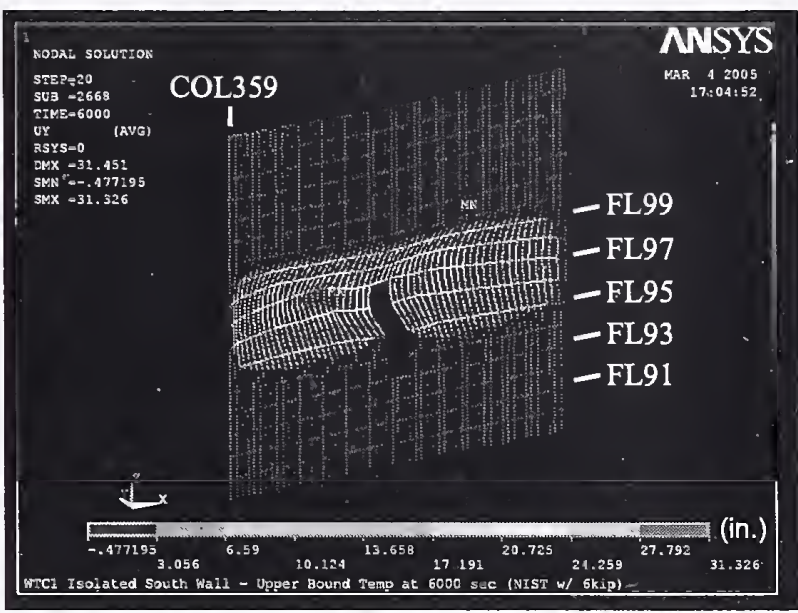

(b) Out-of-plane displacement (inward displacement is positive, 10X displacement magnification)

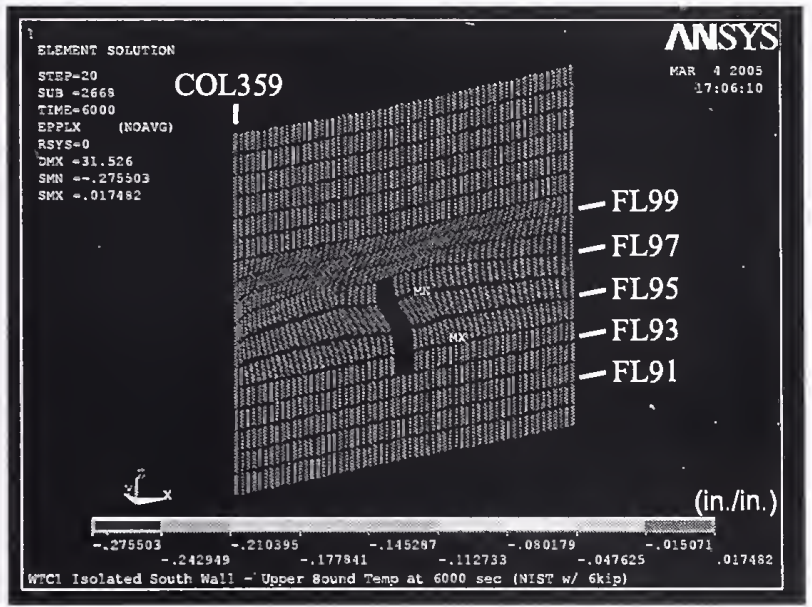

(d) Plastic strain in columns (compressive strain is negative, $10 \mathrm{X}$ displacement magnification)

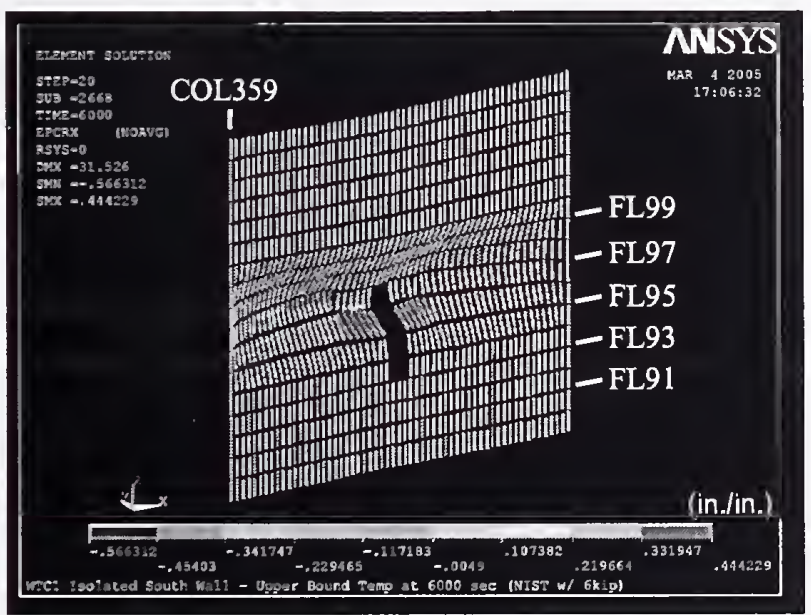

(e) Creep strain in columns (compressive strain is negative, 10X displacement magnification)

Figure 3-66. Response of isolated south wall model of WTC 1 at 100 min of Case B temperature condition with floor/wall disconnections and 6 kip pull-in forces over five floors. 


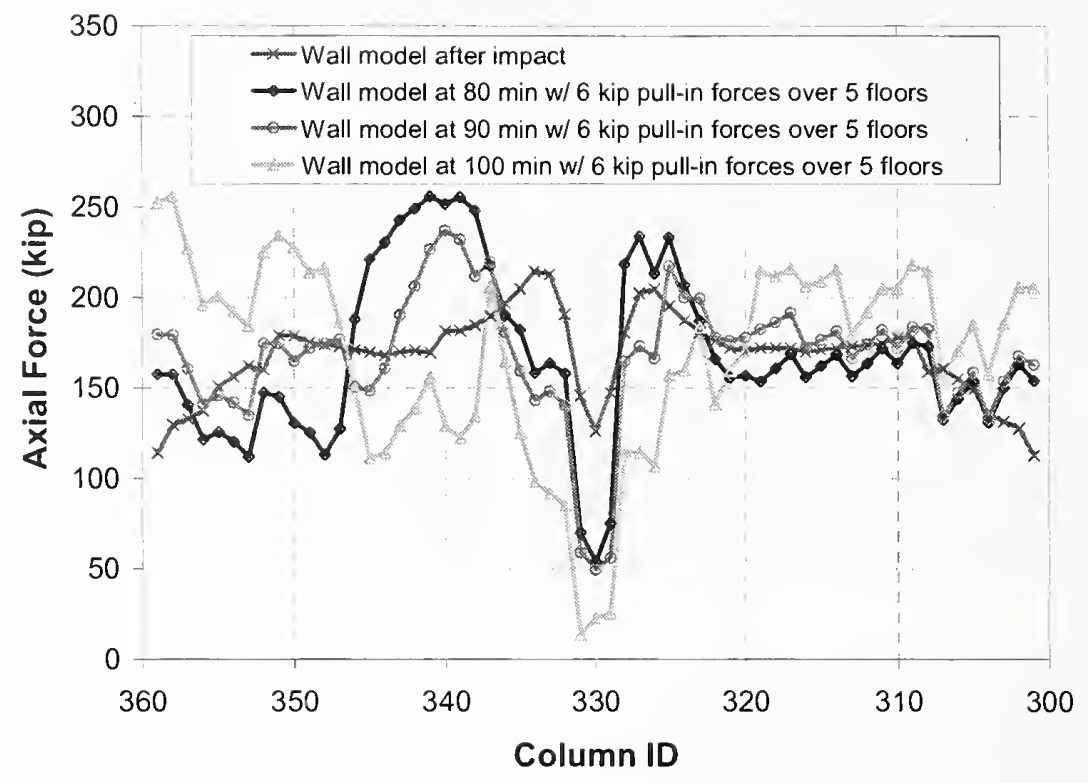

Figure 3-67. Axial load in columns between Floors 98 and 99 of isolated south wall model of WTC 1 at $80 \mathrm{~min}, 90 \mathrm{~min}$, and $100 \mathrm{~min}$ of Case B temperature condition with floor/wall disconnections and 6 kip pull-in forces over five floors (compression is positive).

\subsubsection{FEA of WTC 2 Exterior Wall}

\section{Case C Temperature Condition}

Figures 3-68 and 3-69 show Case $\mathrm{C}$ temperature distributions in the columns of the isolated east exterior wall of WTC 2. The highest tcmperature, $850^{\circ} \mathrm{C}$, occurred at $60 \mathrm{~min}$ in Column 303 between Floor 81 and Floor 82 for Case $\mathrm{C}$ temperature condition. Column temperatures were higher on the inside face of the exterior wall. Figure 3-70 shows the locations of the out-of-plane supports for Case $\mathrm{C}$ conditions at $60 \mathrm{~min}$.

The vertical and the out-of-plane displacements at the end of the gravity load step after aircraft impact and at the end of each temperature step are shown in Figs. 3-71,3-72, 3-73, and 3-74. The maximum vertical displacement of $3.6 \mathrm{in}$. occurred at Column 301 at Floor 90 at $60 \mathrm{~min}$. The maximum out-ofplane deflection of $4.0 \mathrm{in}$. occurred at Column 302 at Floor 82 at $60 \mathrm{~min}$ (out-of-plane displacement is positive outward). The south side of the isolated east exterior wall displaced vertically after aircraft impact more than other parts of the east wall, as the impact damage was concentrated mostly on the southeast corner of the WTC 2. The maximum vertical displacement shifted to the north during the heating period. As time approached $60 \mathrm{~min}$ after the aircraft impact, the columns on the north side buckled, and the out-of-plane displacement increased.

The axial load distributions of the columns at the end of the gravity load step and each 10 min time interval are shown in Figs. 3-75 and 3-76. The maximum axial load occurred at Column 332 between Floor 83 and Floor 84 at $50 \mathrm{~min}$. The axial load in this column increased from 330 kip after the aircraft 
impact to $750 \mathrm{kip}$ at $50 \mathrm{~min}$. The axial load on the buckled columns on the north side of the isolated wall remained approximately constant throughout the temperature time history.

To consider the effect of load redistribution within the tower, the same corrective technique described earlier in this chapter for WTC 1 was used. The axial loads in columns between Floor 83 and Floor 84 in the isolated east wall model were compared with those obtained from the preliminary global model analysis without creep and with Case $C_{i}$ temperature and impact damage conditions (Appendix $C$ ). Column loads obtained from the preliminary global model and isolated exterior wall model at 60 min are shown in Fig. 3-77. The difference between the two column loads was applied to the columns of the isolated wall model at Floor 84 as corrective loads. The resulting vertical and out-of-plane displacements are shown in Fig. 3-78. The additional column loads increased the maximum vertical displacement by only $0.1 \mathrm{in}$., and the maximum out-of-plane displacement by less than $0.1 \mathrm{in}$.

Also as described earlier for the WTC 1 isolated wall model, a push-down analysis of the WTC 2 isolated exterior wall model was performed. At an additional 5.6 in. of vertical displacement the model failed to converge, and the analysis was terminated. The vertical and out-of-plane displacements at the end of 5.6 in. of push down are shown in Fig. 3-79. At the end of push down, the maximum total vertical displacement increased to $9.4 \mathrm{in}$., and the maximum out-of-plane displacement increased to $17.2 \mathrm{in}$. Axial column loads are shown in Fig. 3-80. This figure also shows the location of the columns for which the load-deflection relationships are shown in Fig. 3-81. As can be seen from Fig. 3-81, the buckled columns on the north side of the isolated east exterior wall carried, on average, an additional 300 kip at 60 min temperatures, compared to $470 \mathrm{kip}$ for the average of the entire east wall columns. The additional axial loads on individual columns at different additional vertical displacements are shown in Fig. 3-82. 


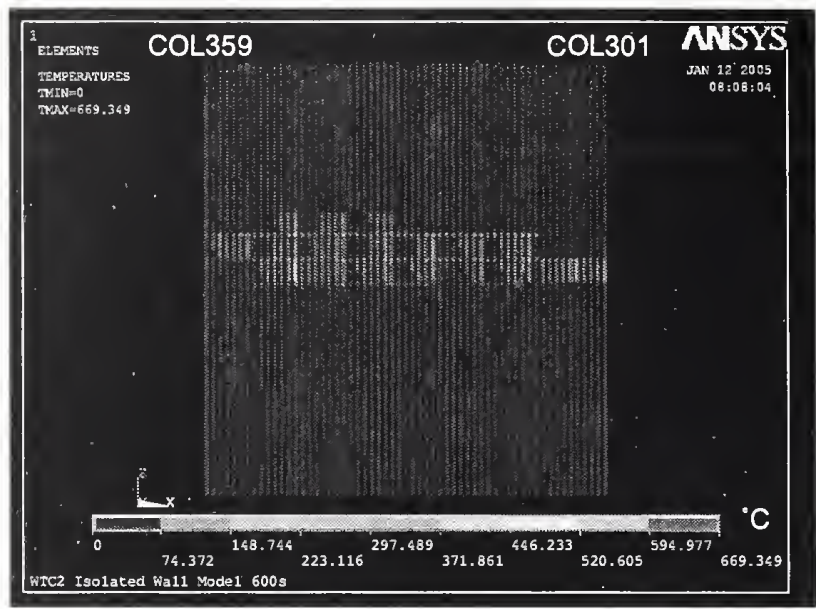

(a) Outside at $10 \mathrm{~min}$

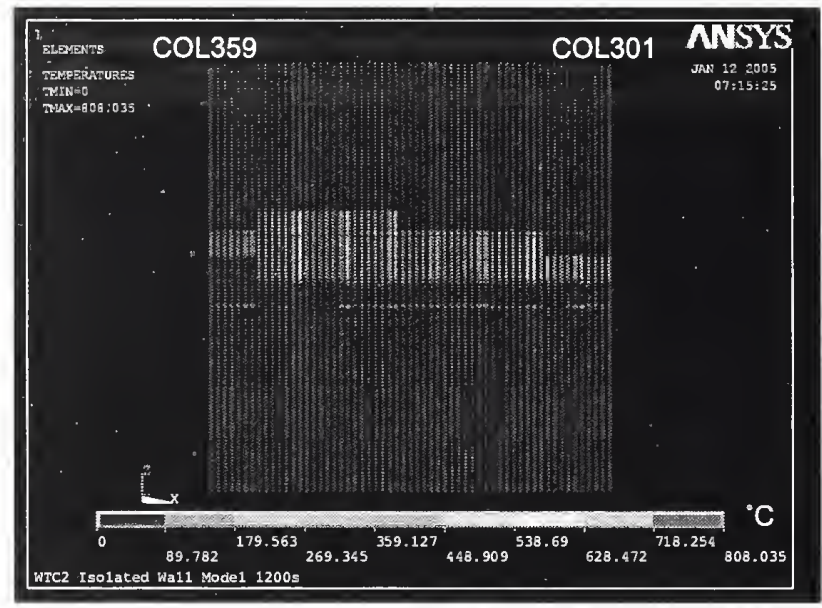

(c) Outside at $20 \mathrm{~min}$

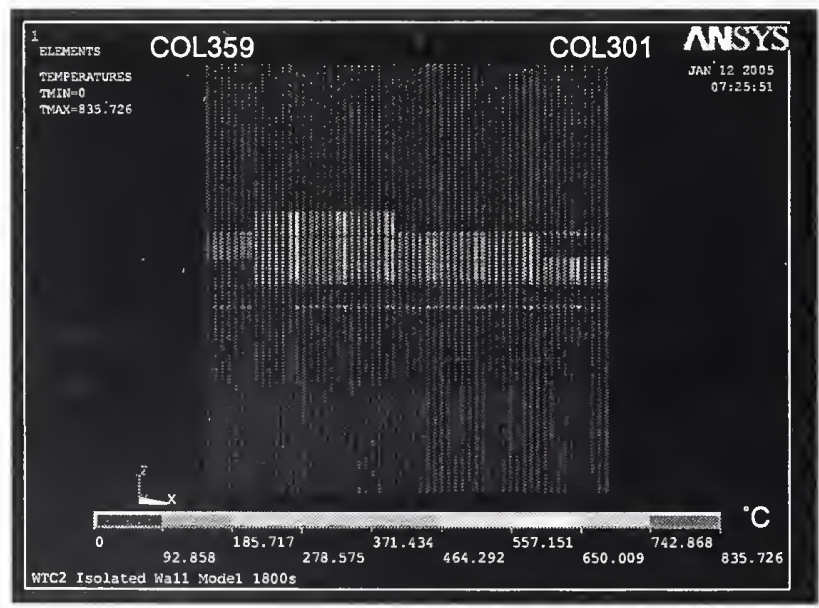

(e) Outside at $30 \mathrm{~min}$

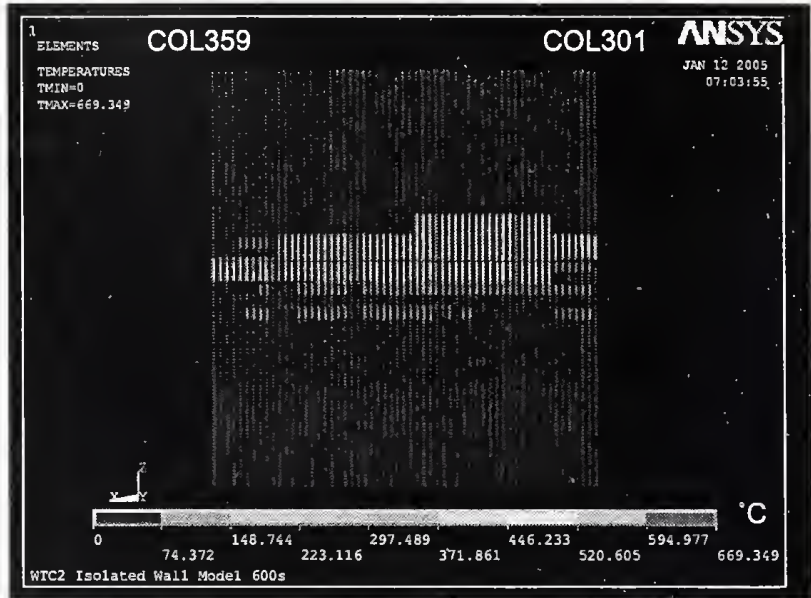

(b) Inside at $10 \mathrm{~min}$

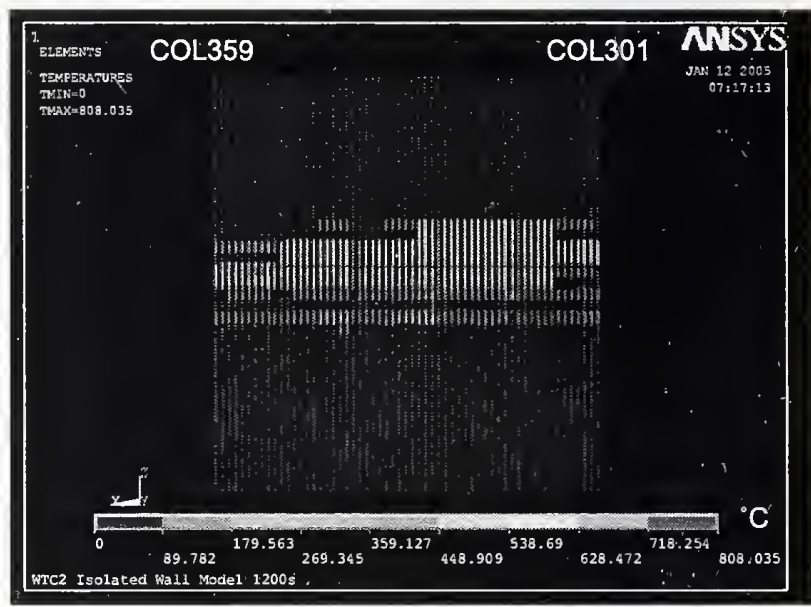

(d) Inside at $20 \mathrm{~min}$

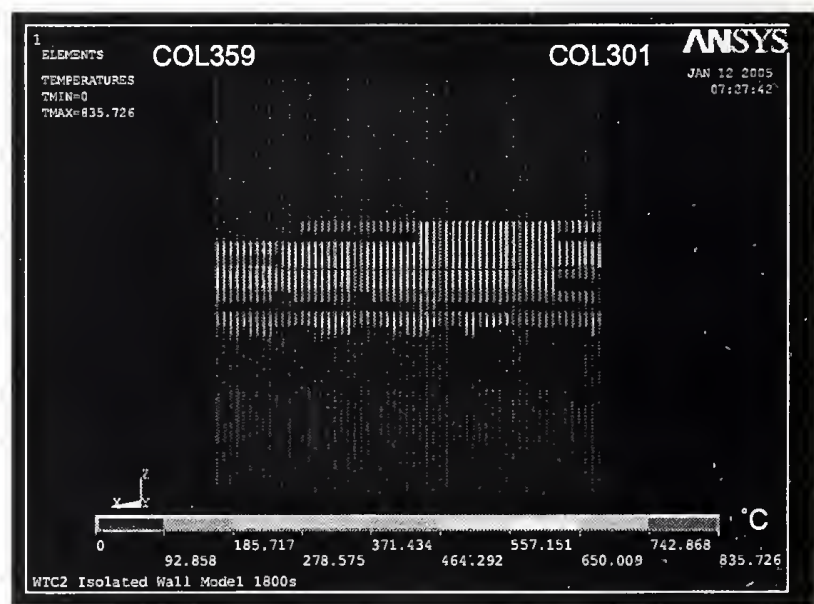

(f) Inside at $30 \mathrm{~min}$

Figure 3-68. Column temperatures on the east wall of WTC 2 for Case C temperature condition at $10 \mathrm{~min}, 20 \mathrm{~min}$, and $30 \mathrm{~min}$. 


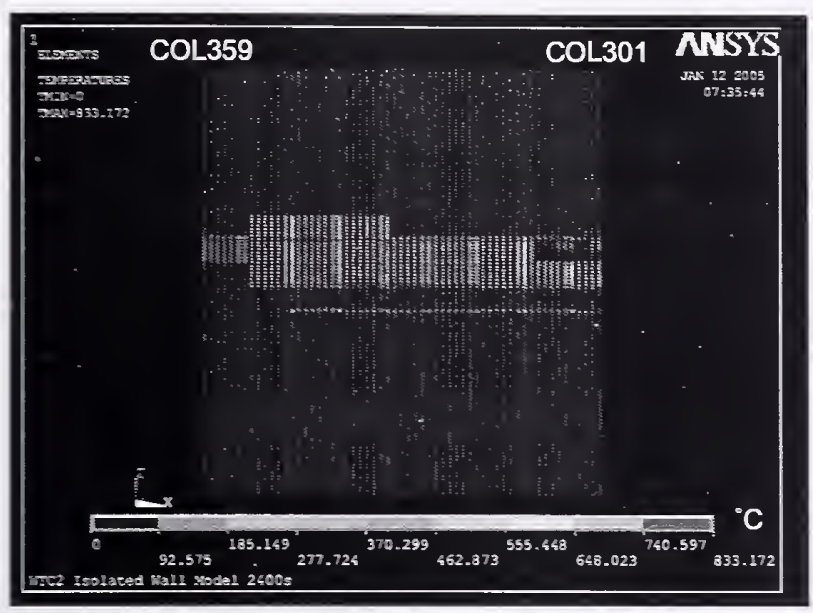

(a) Outside at $40 \mathrm{~min}$

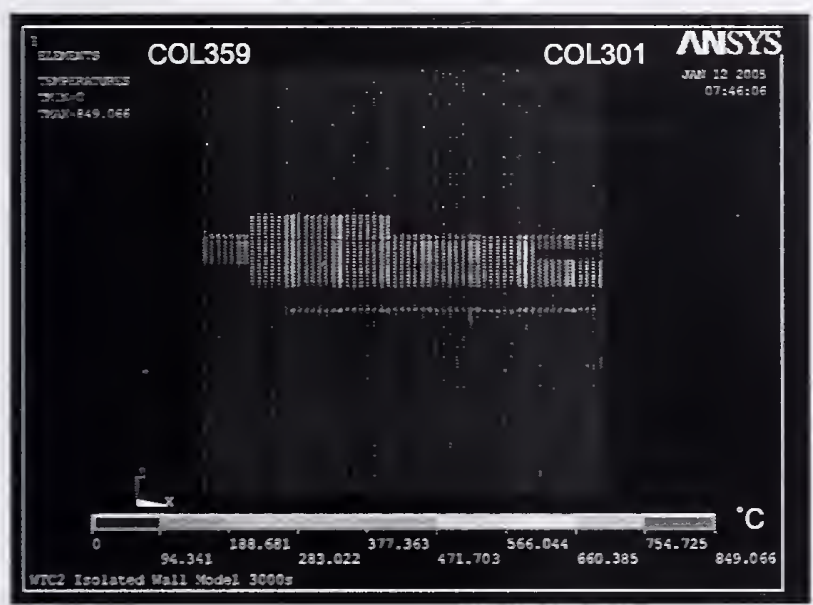

(c) Outside at $50 \mathrm{~min}$

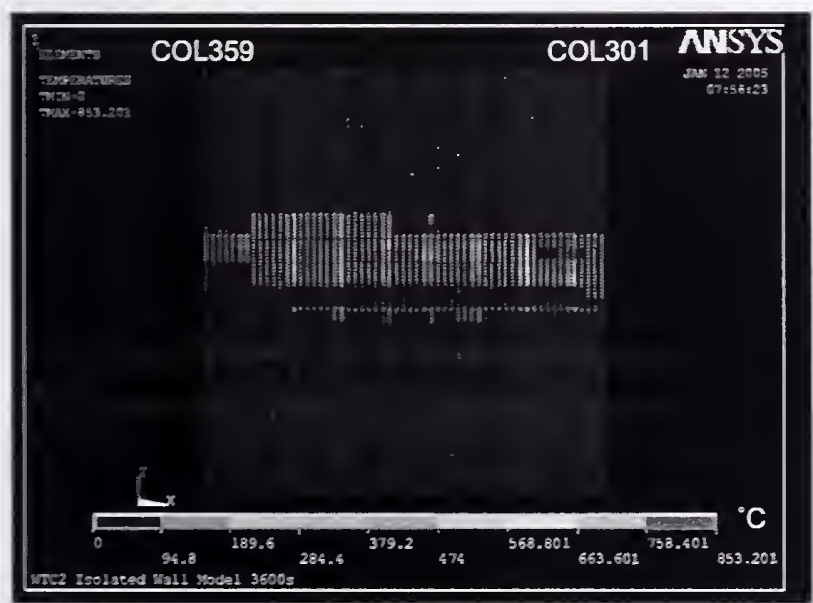

(e) Outside at $60 \mathrm{~min}$

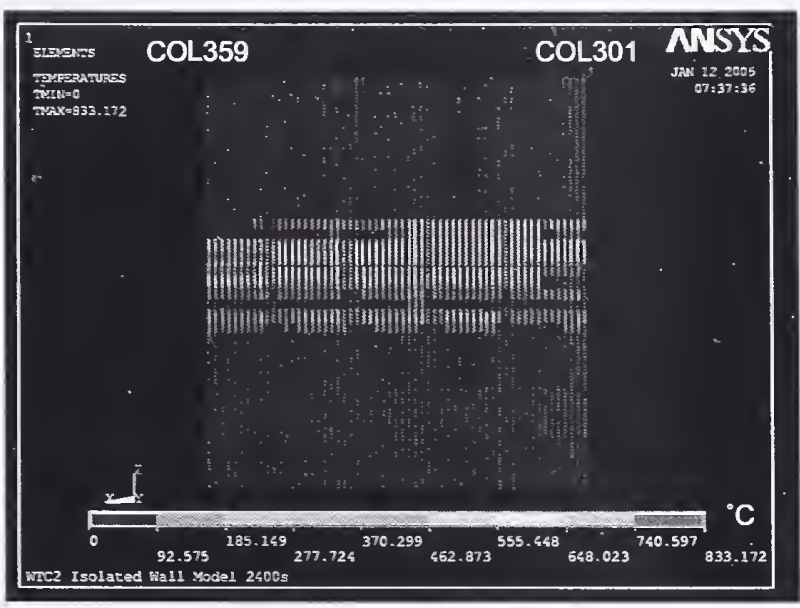

(b) Inside at $40 \mathrm{~min}$

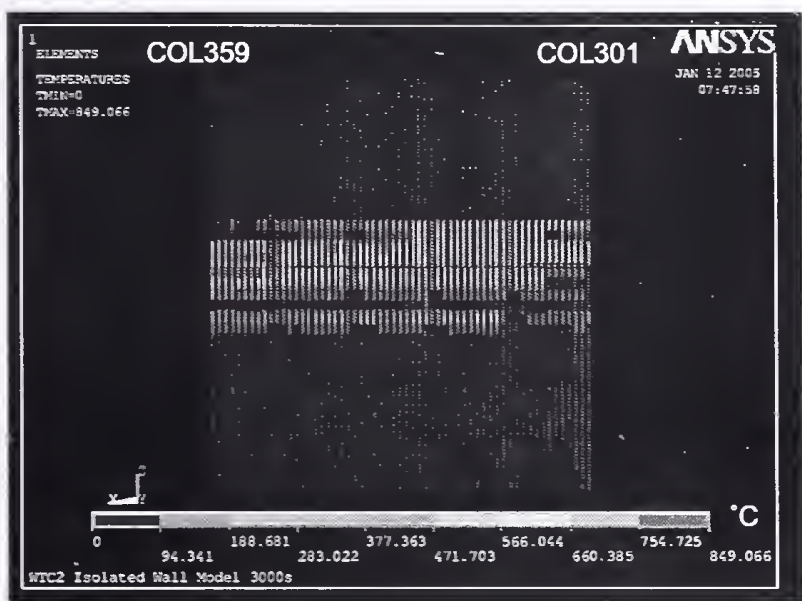

(d) Inside at $50 \mathrm{~min}$

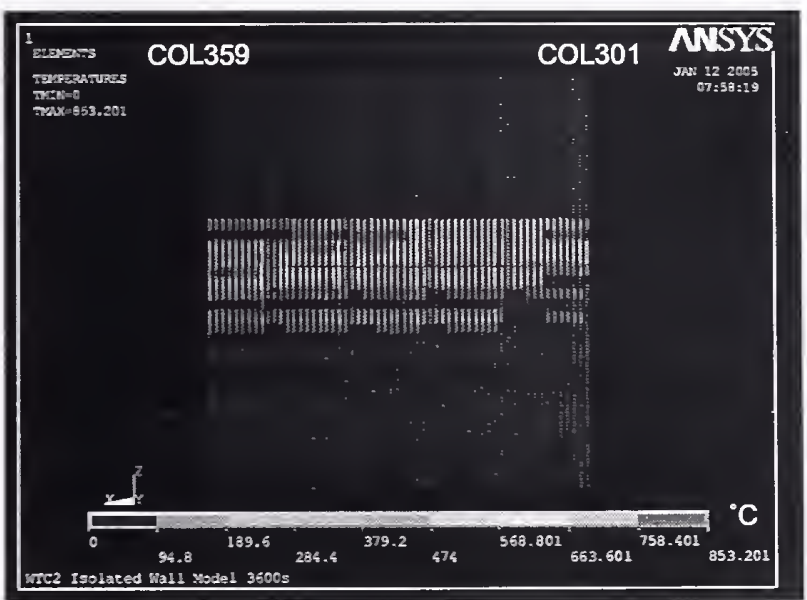

(f) Inside at $60 \mathrm{~min}$

Figure 3-69. Column temperatures on the east wall of WTC 2 for Case C temperature condition at $40 \mathrm{~min}, 50 \mathrm{~min}$, and $60 \mathrm{~min}$. 


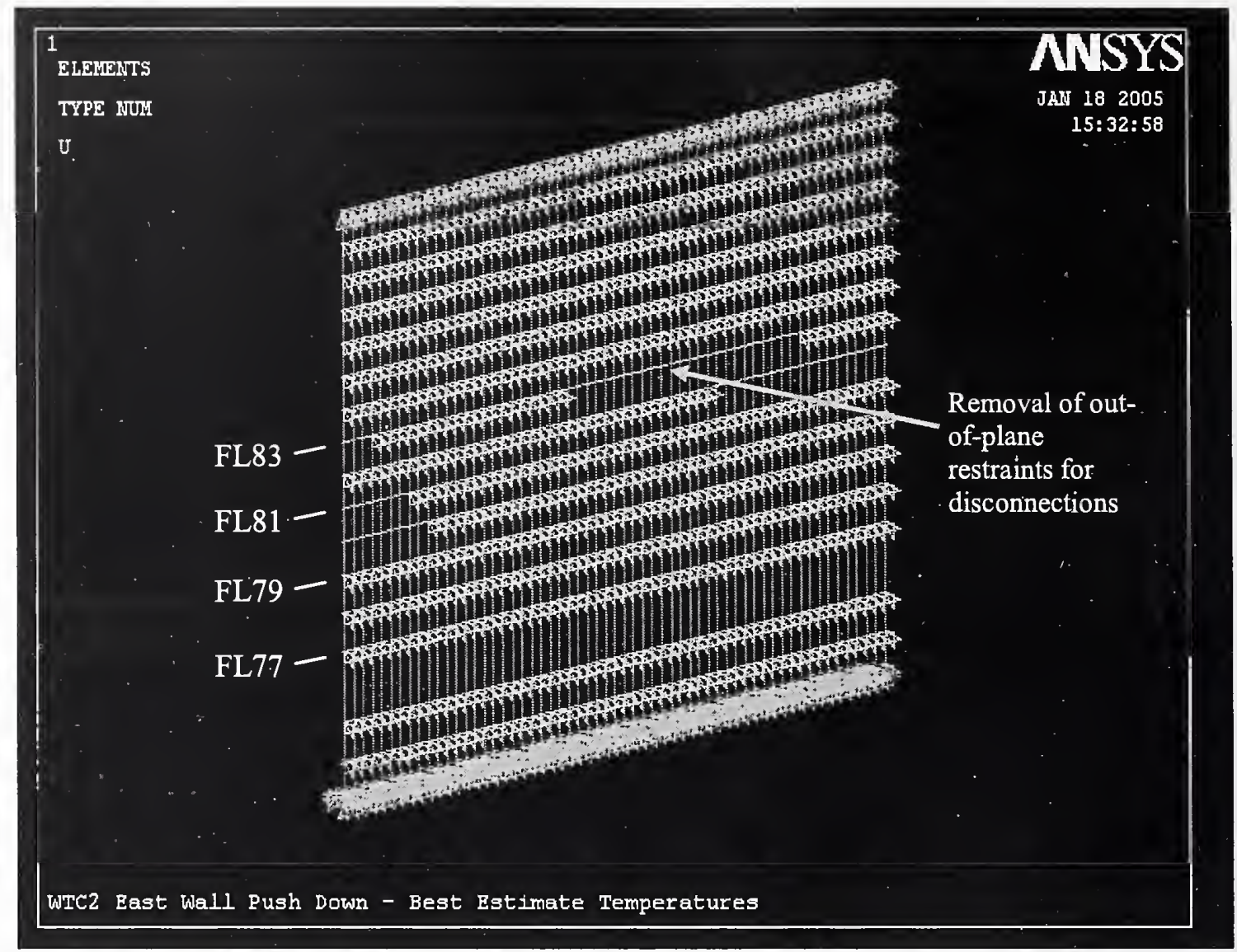

Figure 3-70. Location of the out-of-plane supports and floor/wall disconnections between exterior wall and the floor (WTC 2 east wall for Case C conditions at $60 \mathrm{~min}$ ). 


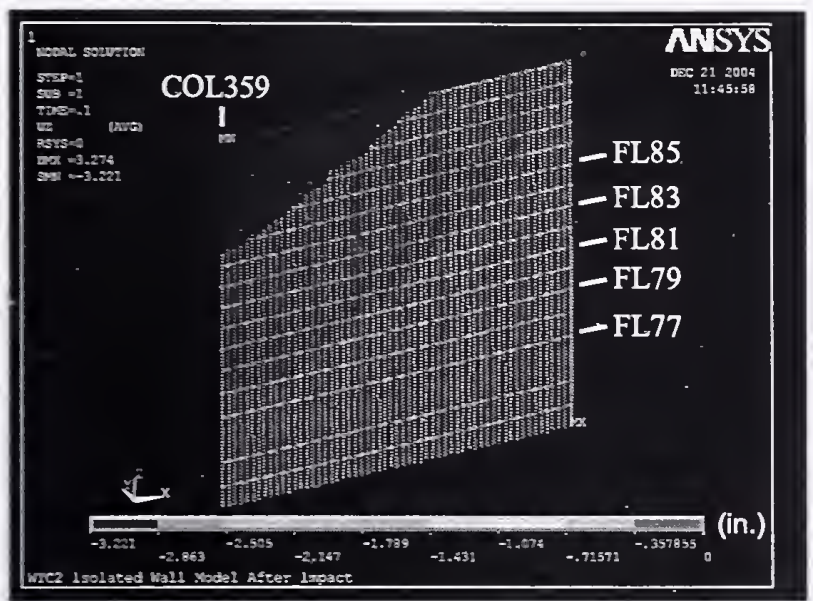

(a) After aircraft impact

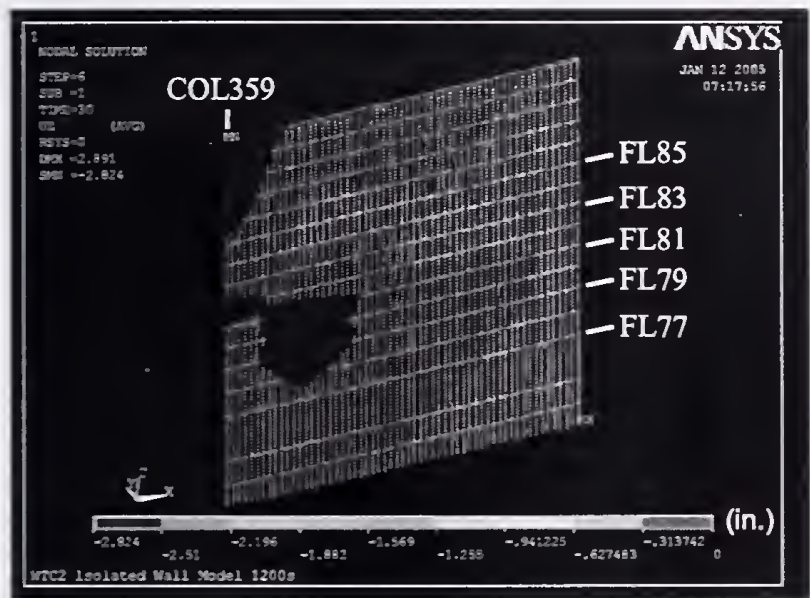

(c)At $20 \mathrm{~min}$

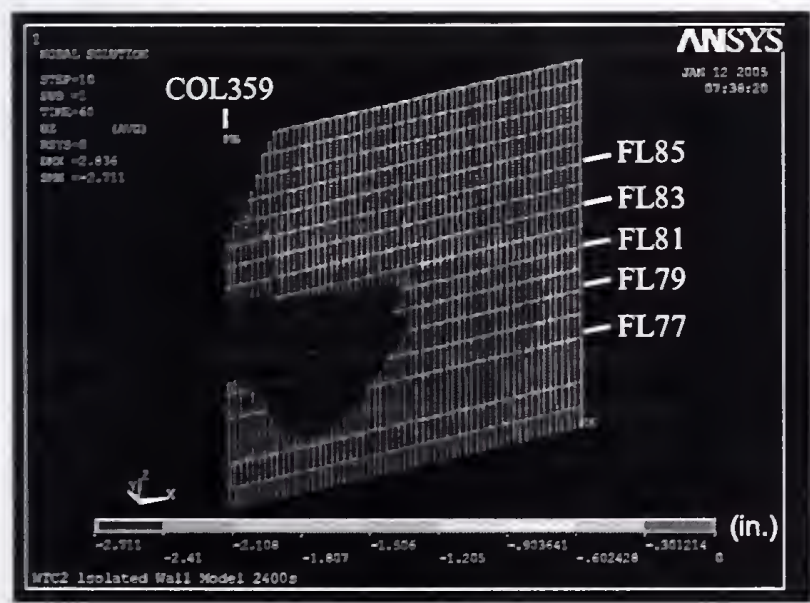

(e) At $40 \mathrm{~min}$

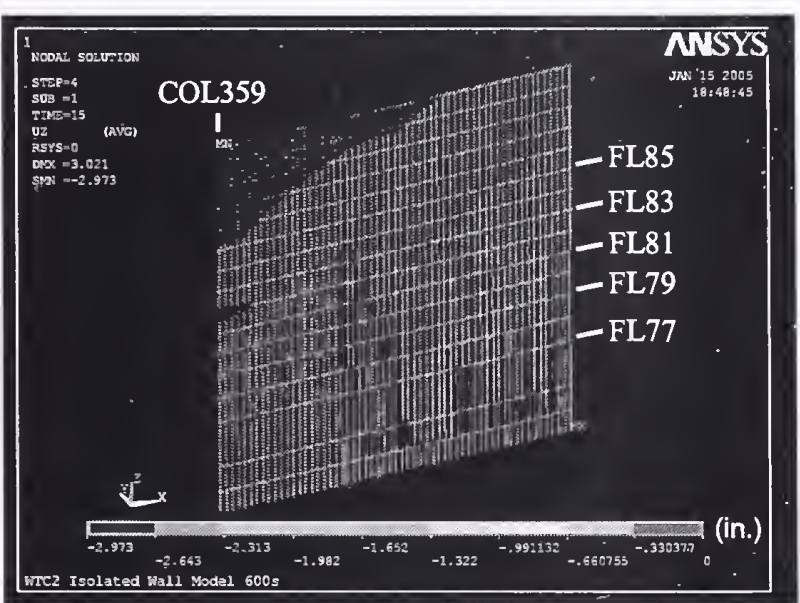

(b) At $10 \mathrm{~min}$

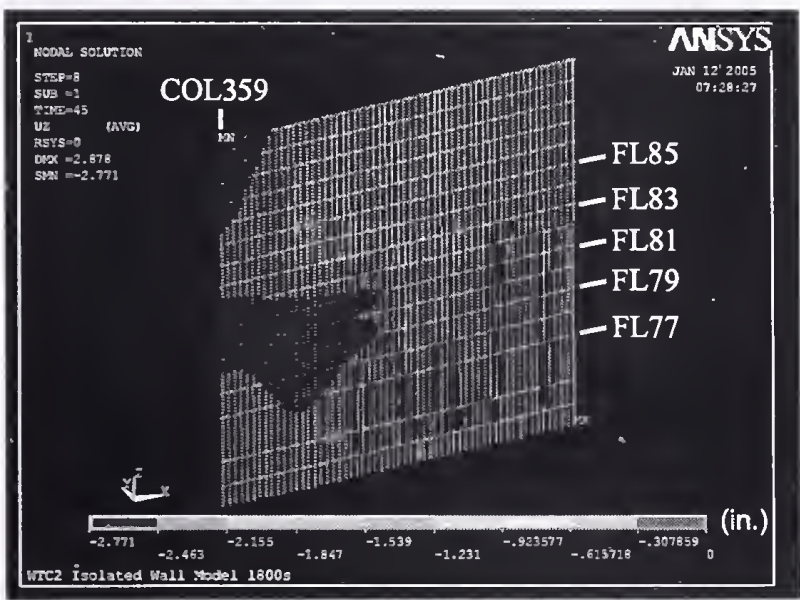

(d) At $30 \mathrm{~min}$

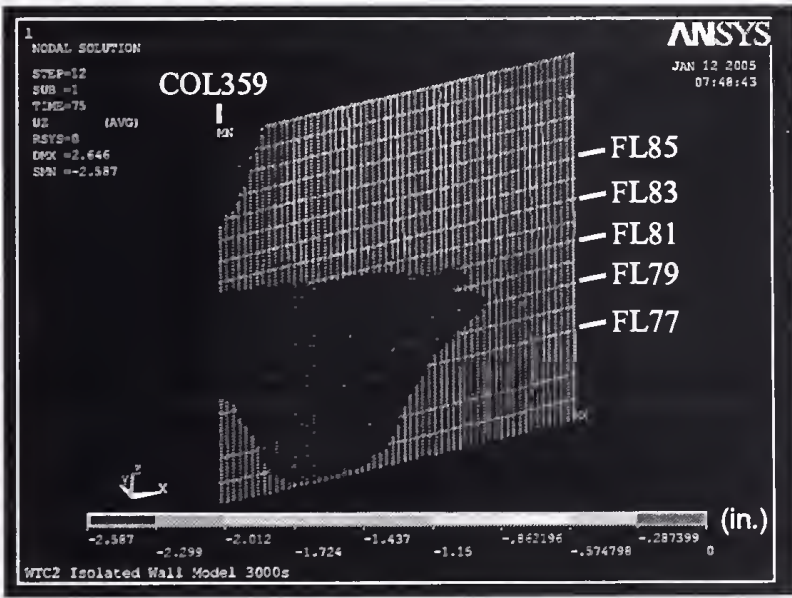

(f) At $50 \mathrm{~min}$

Figure 3-71. Vertical displacement of isolated east wall model of WTC 2 for Case C temperature distribution (downward displacement is negative; displacements scaled ten times). 


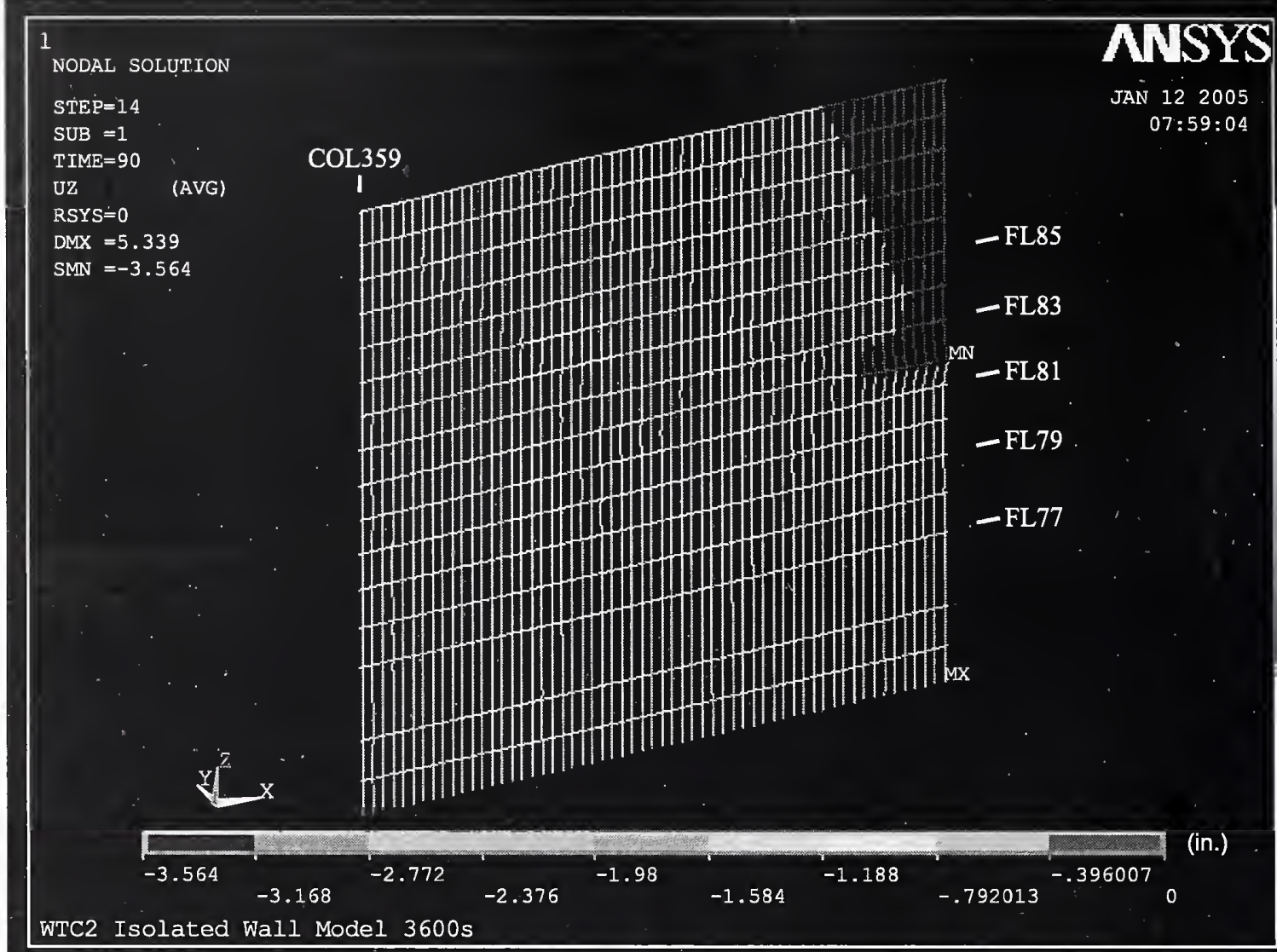

Figure 3-72. Vertical displacement of isolated east wall model of WTC 2 for Case C temperature distribution at $60 \mathrm{~min}$ (downward displacement is negative; displacements scaled ten times). 


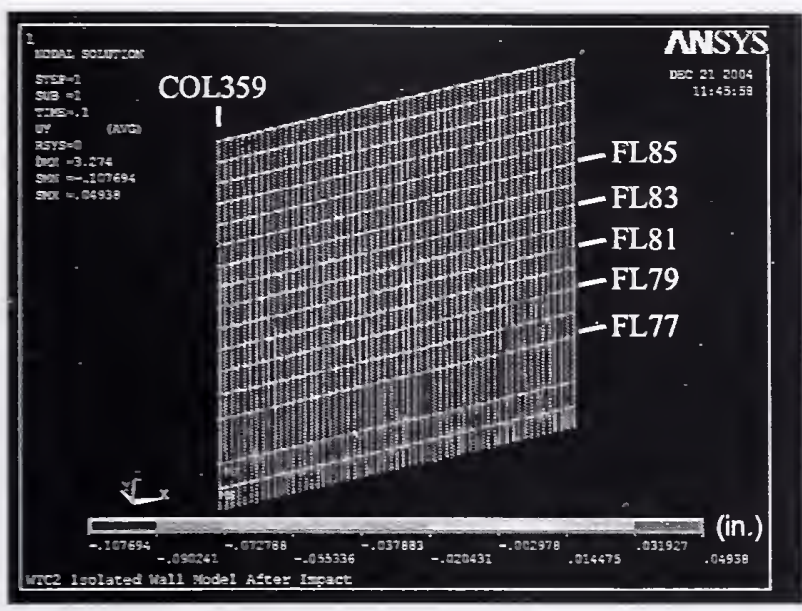

(a) After aircraft impact

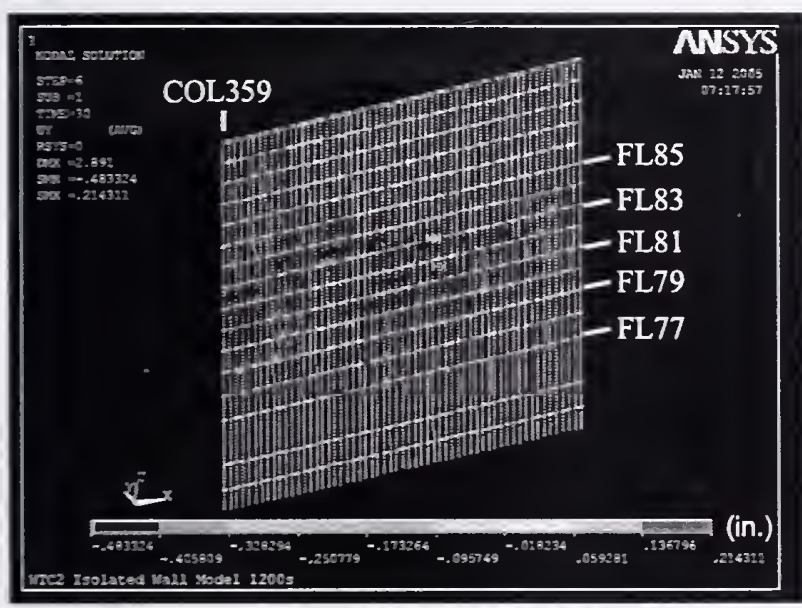

(c) At $20 \mathrm{~min}$

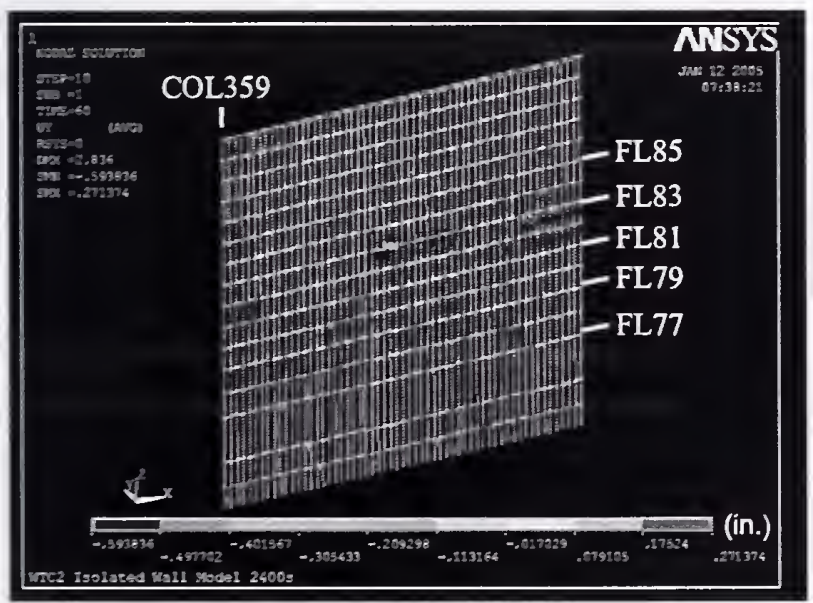

(e) At $40 \mathrm{~min}$

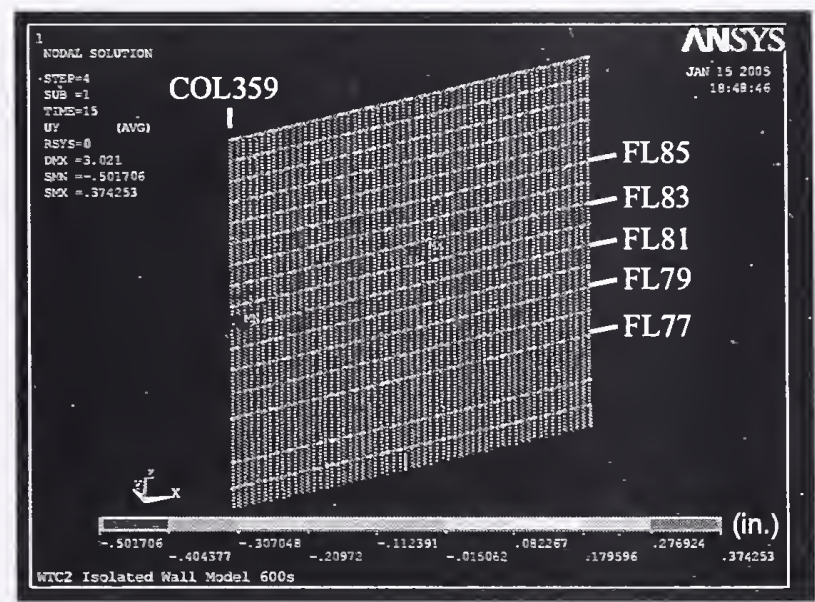

(b) At $10 \mathrm{~min}$

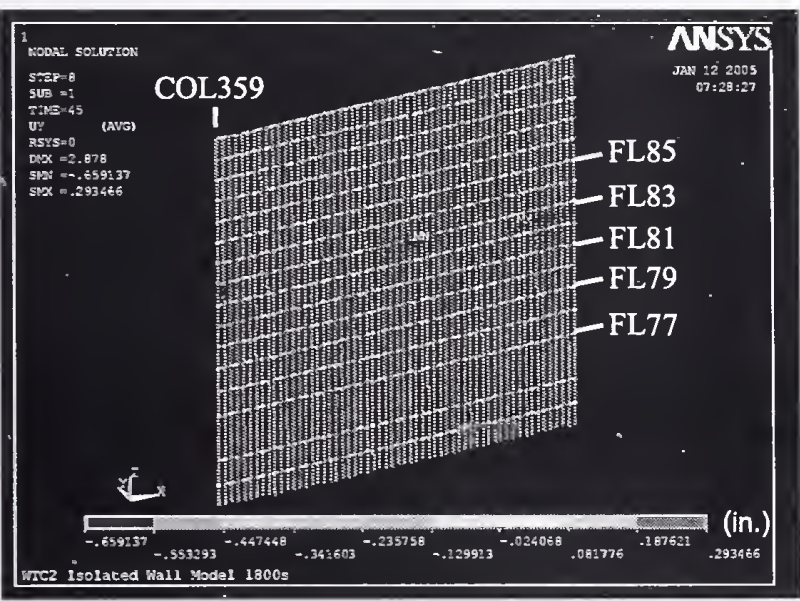

(d) At $30 \mathrm{~min}$

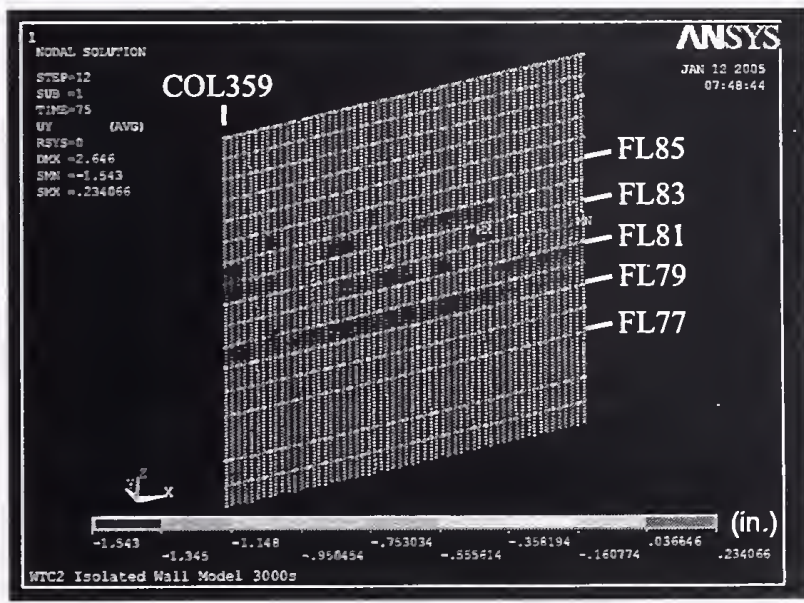

(f) At $50 \mathrm{~min}$

Figure 3-73. Out-of-plane displacement of isolated east wall model of WTC 2 for Case C temperature condition (inward displacement is positive; displacements scaled ten times). 


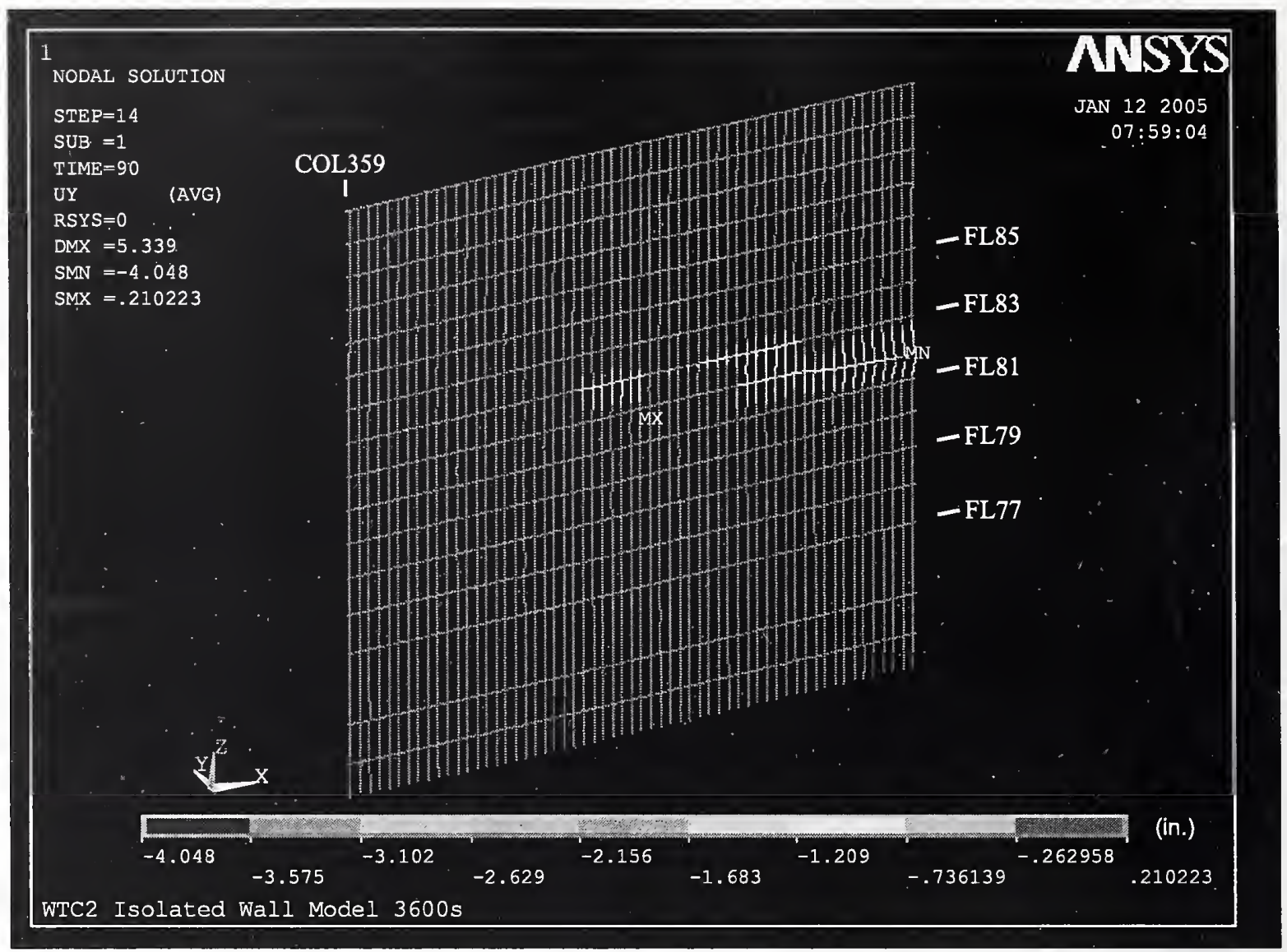

Figure 3-74. Out-of-plane displacement of isolated east wall model of WTC 2 for Case C temperature distribution at $60 \mathrm{~min}$ (inward displacement is positive; displacements scaled ten times). 


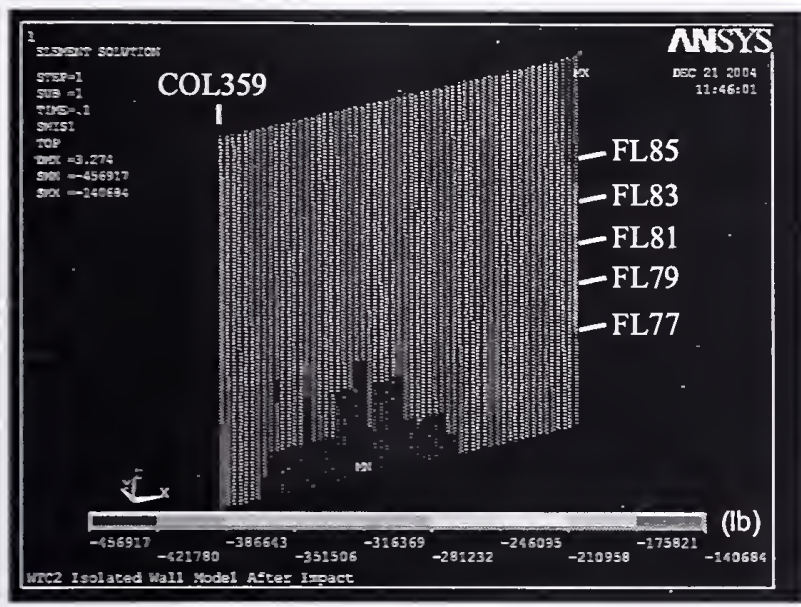

(a) After aircraft impact

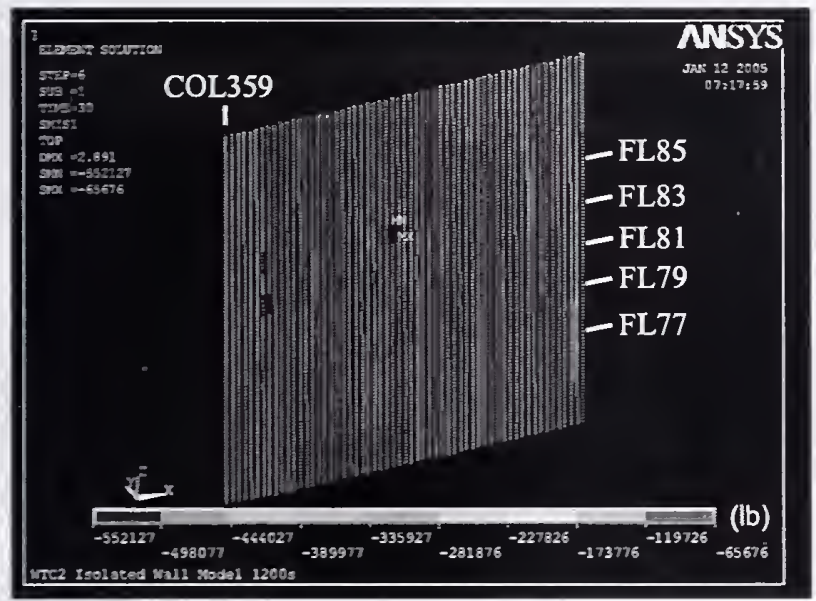

(c) At $20 \mathrm{~min}$

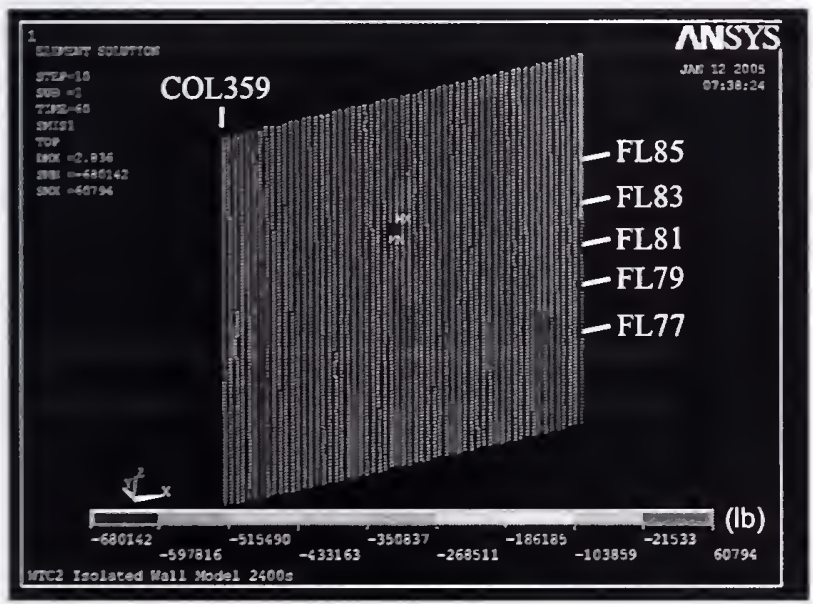

(e) At 40 min

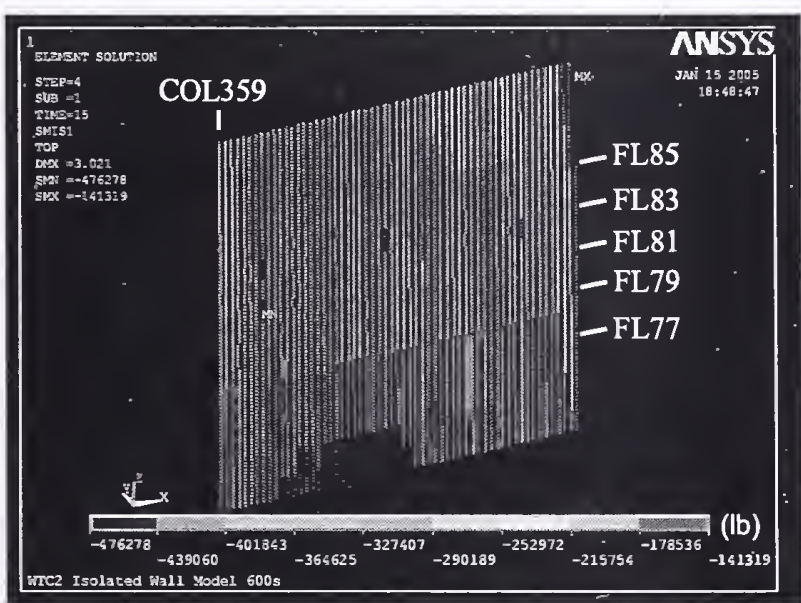

(b) At $10 \mathrm{~min}$

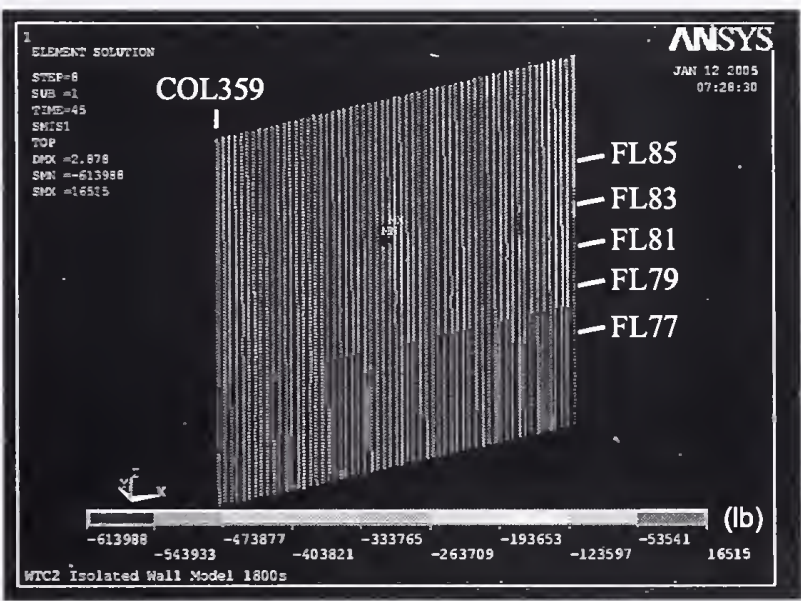

(d) At $30 \mathrm{~min}$

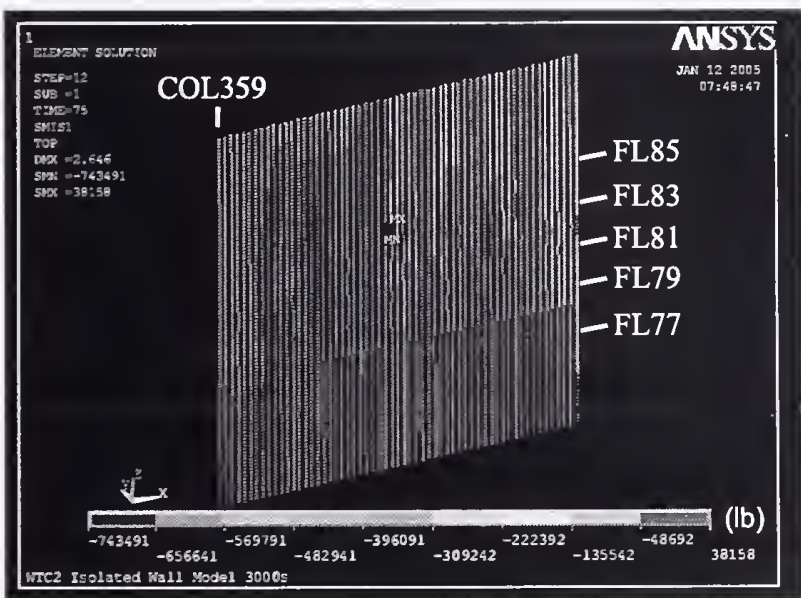

(f) At $50 \mathrm{~min}$

Figure 3-75. Axial load on columns of isolated east wall model of WTC 2 under Case C temperature condition (compression is negative). 


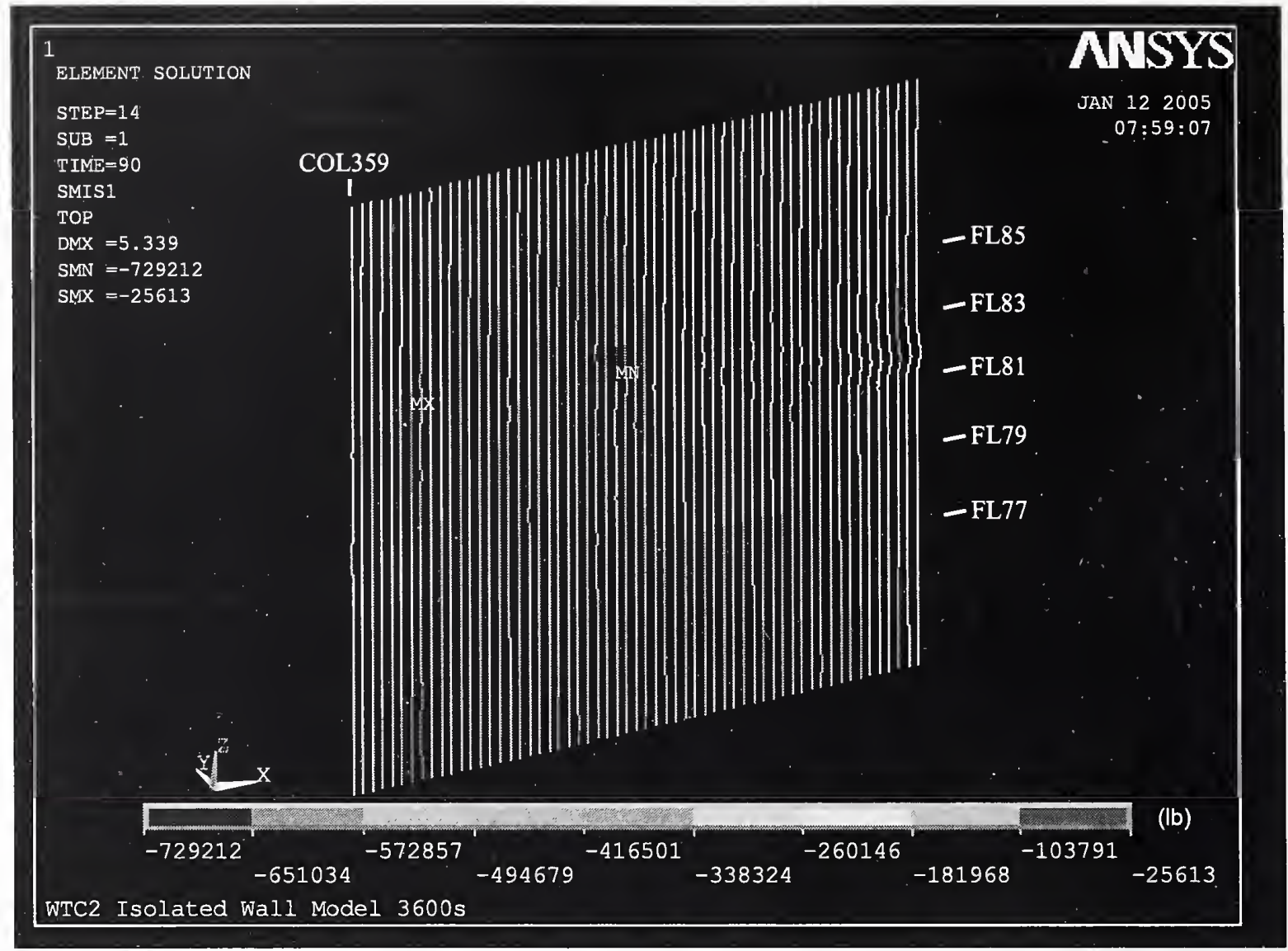

Figure 3-76. Axial load on columns of isolated east wall model of WTC 2 for Case C temperatures distribution at $\mathbf{6 0}$ min (compression is negative). 


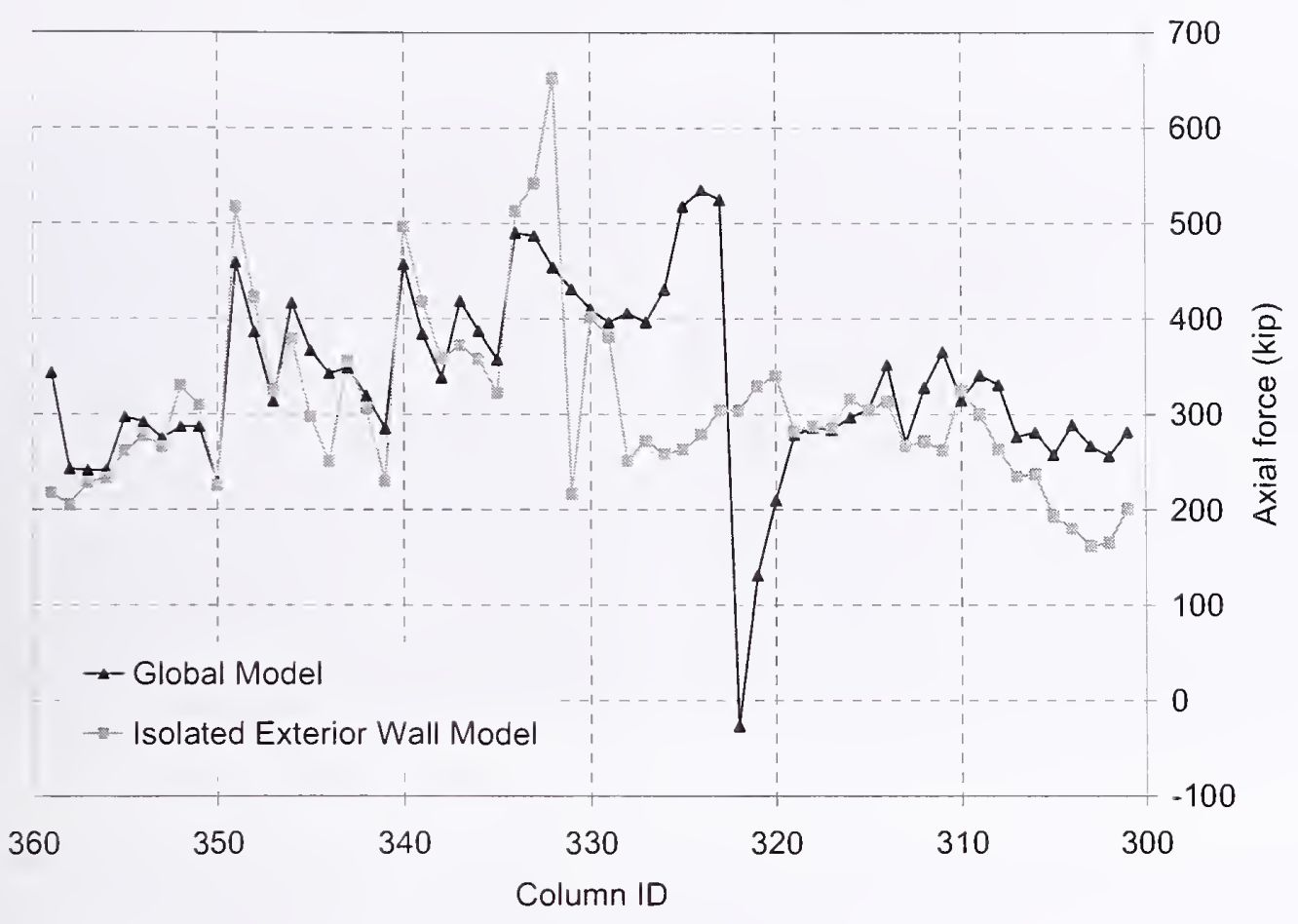

Figure 3-77. Comparison of axial load in columns at Floor 83 of isolated east wall model of WTC 2 at $60 \mathrm{~min}$ for Case C temperature conditions and the global model without creep for Case $C_{i}$ conditions (compression is positive).

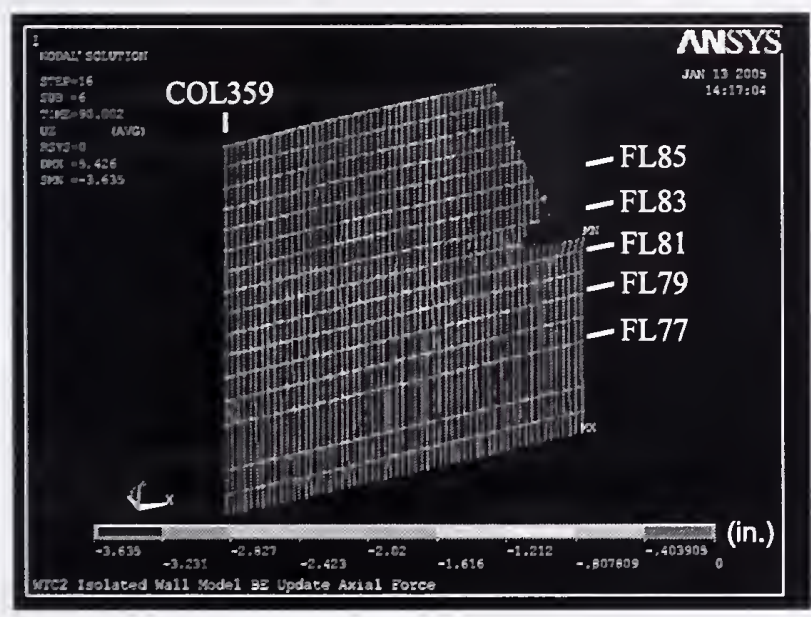

(a) Vertical displacement

(Downward displacement is negative)

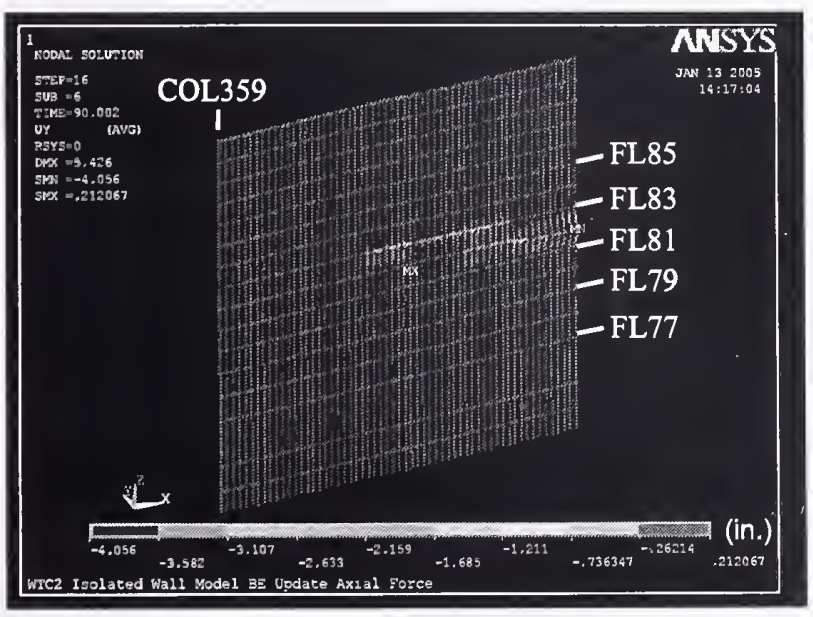

(b) Out-of-plane displacement (Inward displacement is positive)

Figure 3-78. Vertical and out-of-plane displacements of isolated east wall model of WTC 2 after column forces were corrected to those of global modal without creep for Case $\mathrm{C}_{\mathrm{i}}$ conditions (displacements scaled ten times). 


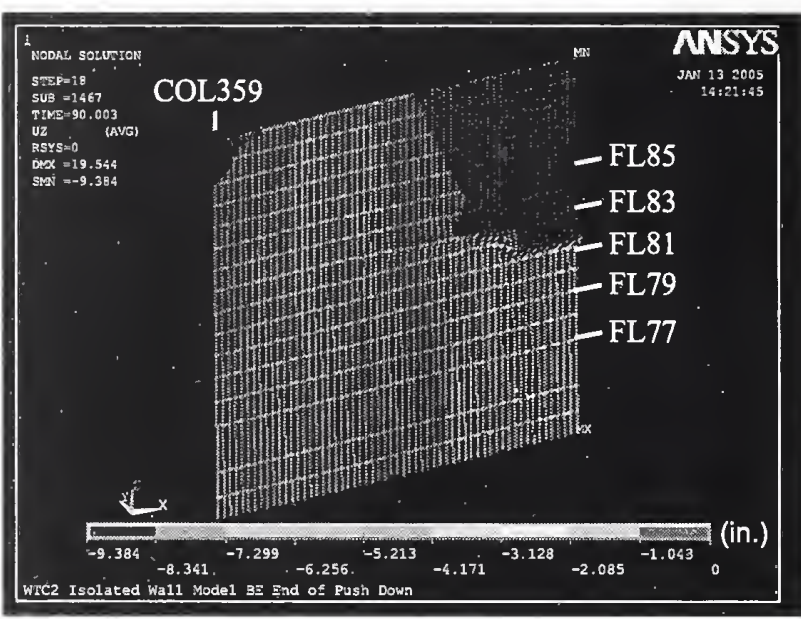

(a) Vertical displacement

(downward displacement is negative)

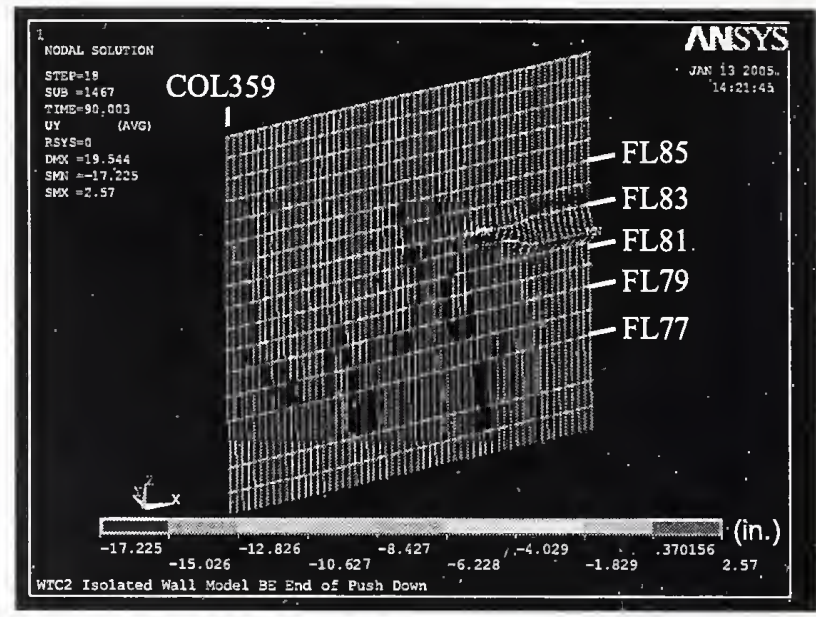

(b) Out-of-plane displacement (Inward displacement is positive)

Figure 3-79. Vertical and out-of-plane displacements of isolated east wall model of WTC 2 after Case $\mathrm{C}$ temperature condition and push down analysis (displacements scaled five times).

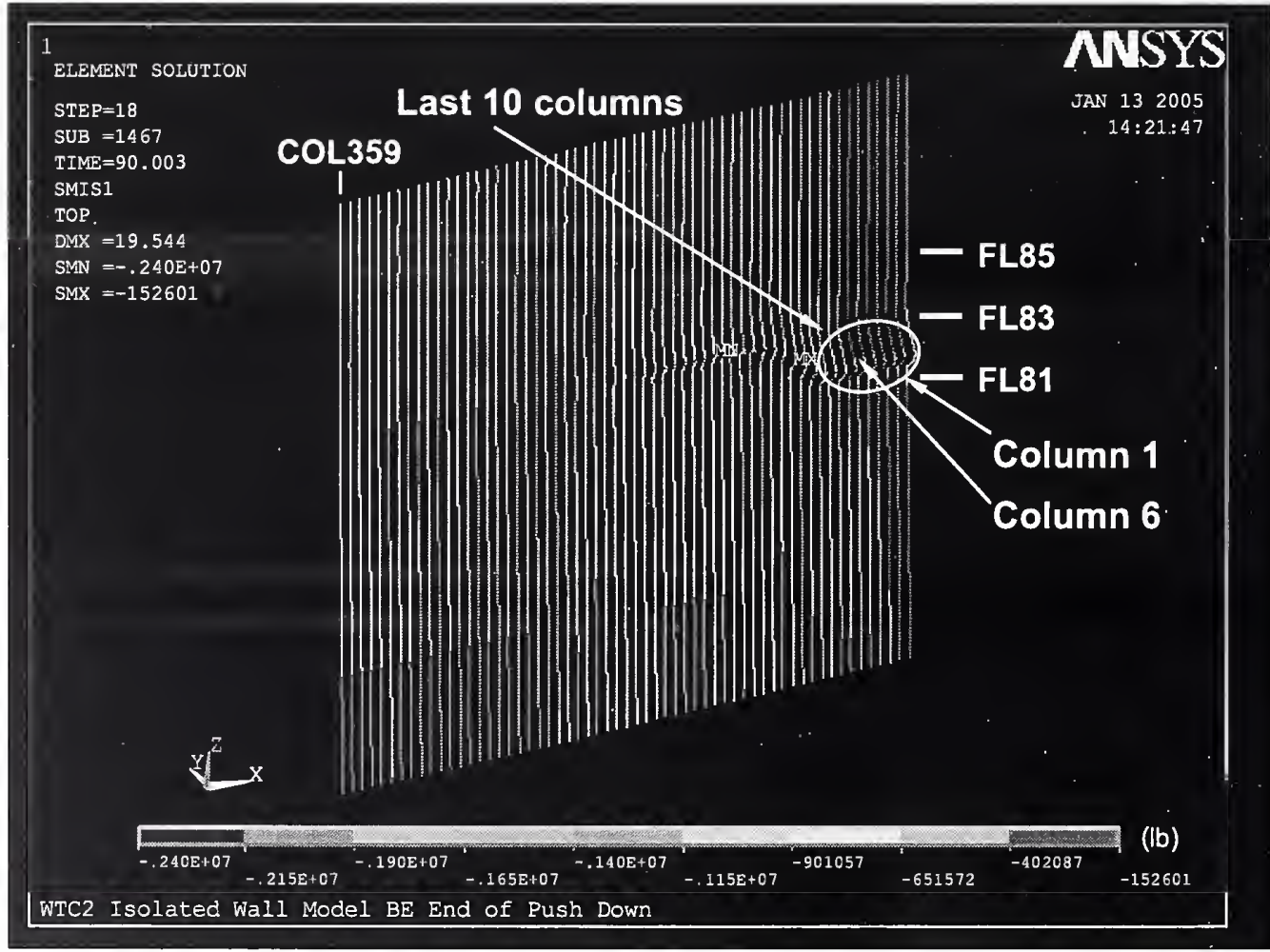

Figure 3-80. Axial load on east wall columns of isolated east wall model of WTC 2 after Case $\mathrm{C}$ temperature condition and push-down (compression is negative). 


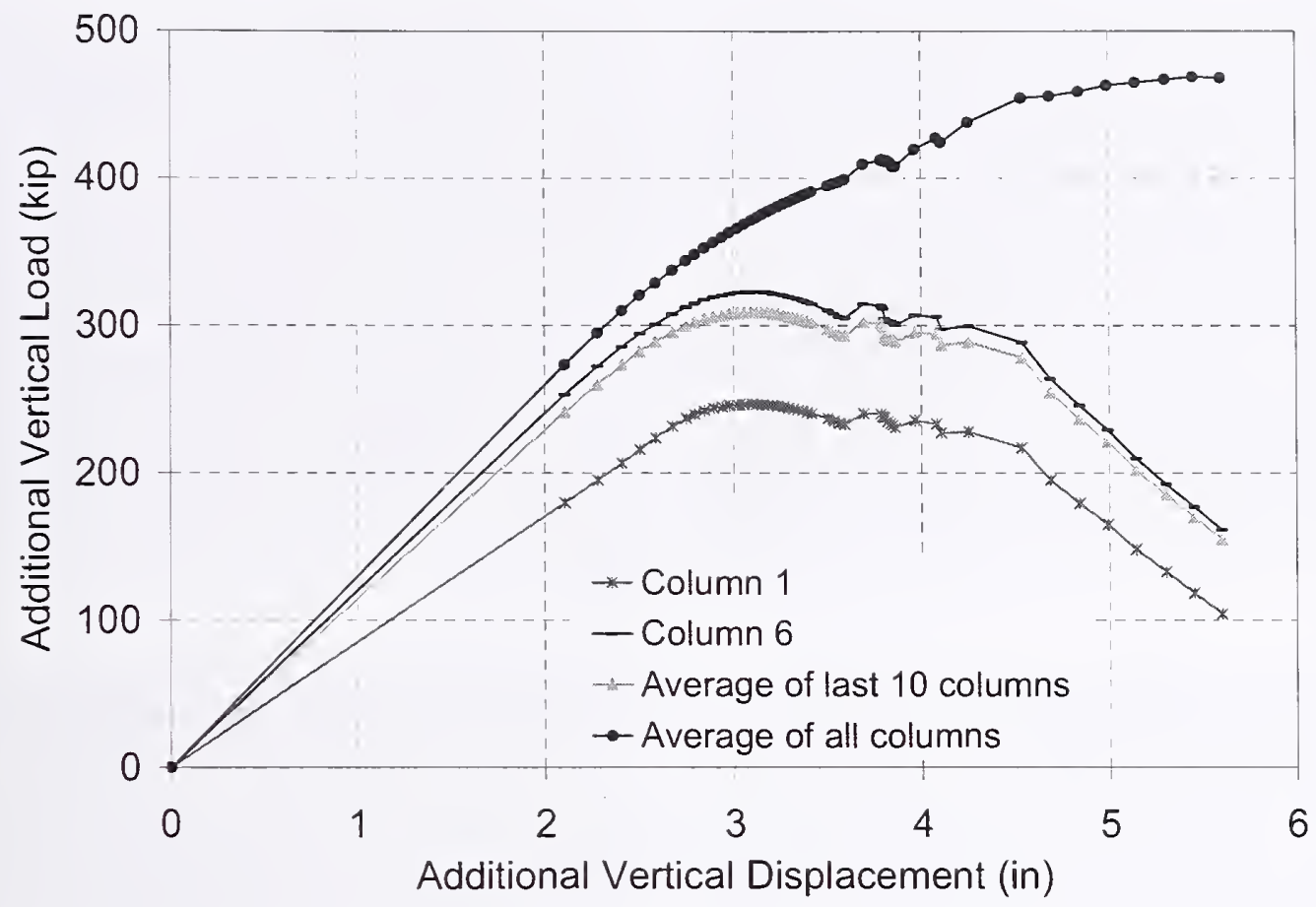

Figure 3-81. Additional vertical load versus additional vertical displacement during push-down analysis of isolated east wall model of WTC 2 for Case C temperature condition (compression is positive; see Fig. 3-80 for column locations).

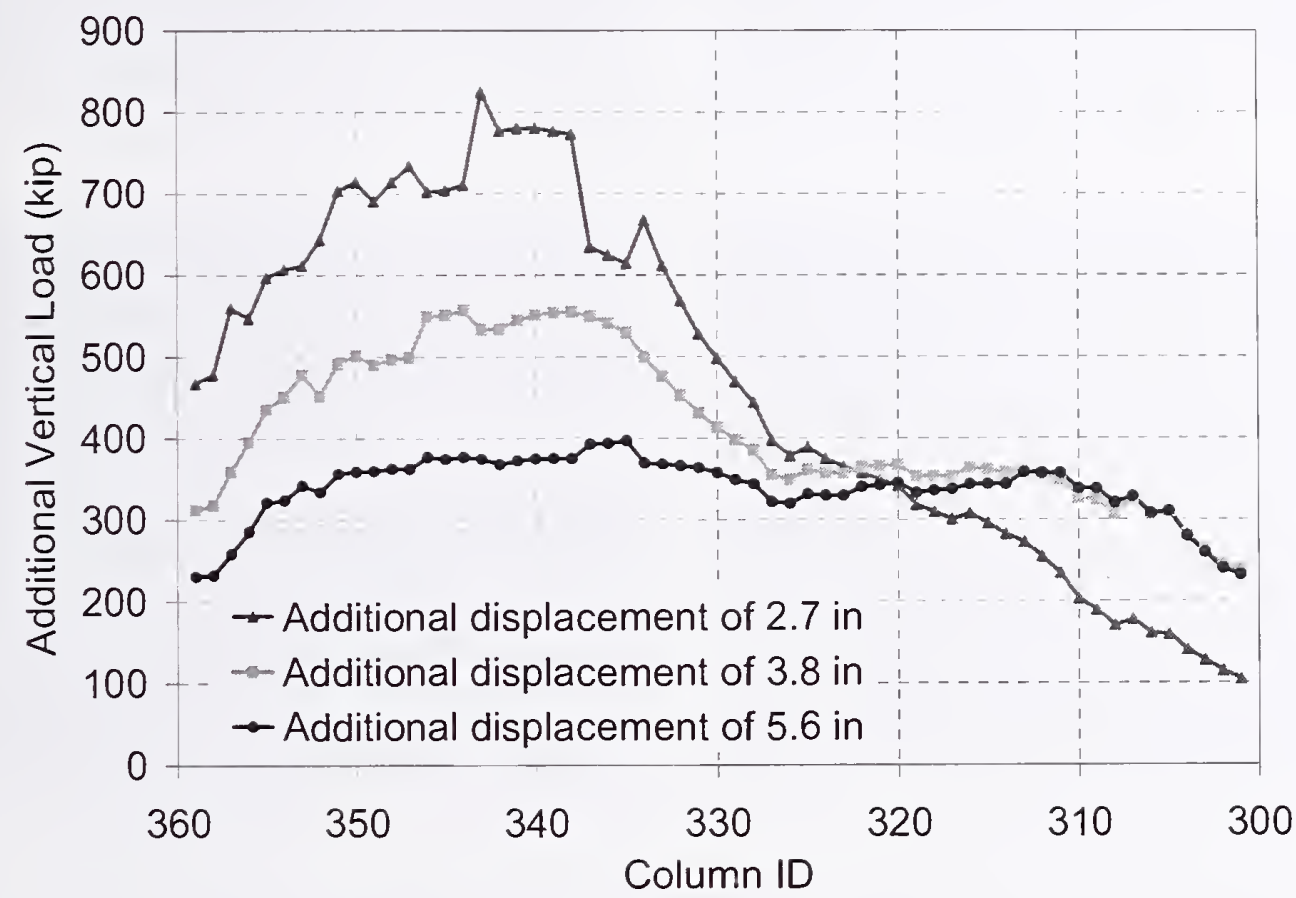

Figure 3-82. Variation of additional vertical load applied to columns of isolated east wall model of WTC 2 at different levels of additional vertical displacements imposed after Case $\mathrm{C}$ temperature condition (compression is positive). 


\section{Case D Temperature Condition}

Figures 3-83 and 3-84 show Case D temperature distributions in the columns of the isolated east exterior wall model of WTC 2. The highest temperature, $845^{\circ} \mathrm{C}$, occurred at $20 \mathrm{~min}$ in Column 307 between Floor 81 and Floor 82. Column temperatures were higher on the inside face of the exterior wall. Figure 3-85 shows the locations of the out-of-plane supports for Case D conditions at $60 \mathrm{~min}$.

The vertical and the out-of-plane displacements at the end of the gravity load step after aircraft impact and at the end of each temperature step are shown in Figs. 3-86, 3-87, 3-88, and 3-89. The maximum vertical displacement of 3.2 in. occurred at Column 359 at Floor 90 immediately after aircraft impact. The maximum out-of-plane displacement of $7.8 \mathrm{in}$. occurred at Column 359 at Floor 81 at $60 \mathrm{~min}$. (The out-of-plane displacement is positive inward.) The south side of the isolated exterior wall displaced vertically after aircraft impact more than other parts of the east wall, as impact damage was concentrated mostly on the southeast corner of the WTC 2. As time approached $60 \mathrm{~min}$, the columns on the south side buckled, and the out-of-plane displacements increased.

The axial load distributions on the columns at the end of the gravity load step and each time interval are shown in Figs. 3-90 and 3-91. The maximum axial load occurred at Column 301 between Floor 82 and Floor 83 at $10 \mathrm{~min}$. The axial load in this column increased from $200 \mathrm{kip}$ after aircraft impact to $920 \mathrm{kip}$ at $10 \mathrm{~min}$. The axial load of $920 \mathrm{kip}$ was very close to the theoretical local buckling load of $985 \mathrm{kip}$ for Column 301 at $314{ }^{\circ} \mathrm{C}$ and less than the yielding or Euler buckling load of the column. Since local buckling of plates in exterior columns could not be captured by the beam elements that were used in the model of the exterior wall, the model overestimated the buckling capacity of exterior columns. The axial loads on the buckled columns on the south side of the isolated wall remained approximately constant throughout the temperature time history.

To consider the effect of load redistribution within WTC 2, the same corrective technique as described earlier in this chapter for WTC 1 was used. The axial loads at $60 \mathrm{~min}$ in columns between Floor 83 and Floor 84 in the isolated exterior wall model were compared to the corresponding values from the global model without creep and with Case $\mathrm{C}_{\mathrm{i}}$ structural damage condition and $\mathrm{Case}_{\mathrm{i}} \mathrm{D}_{\mathrm{i}}$ temperature condition, as shown in Fig. 3-92. The difference between the two curves in Fig. 3-92 was then applied to the columns at Floor 84 as corrective loads. The resulting vertical and out-of-plane displacements are shown in Fig. 3-93. As can be seen, the additional loads increased the maximum vertical displacement by $0.4 \mathrm{in}$. and the maximum out-of-plane displacement by about 0.8 in.

Also as described earlier for the WTC 1 isolated wall models, a push-down analysis of the WTC 2 isolated exterior wall model was performed. At an additional $5.3 \mathrm{in}$. of vertical displacement the model failed to converge, and the analysis was terminated. The vertical and out-of-plane displacements at the end of $5.3 \mathrm{in}$. of push down are shown in Fig. 3-94. At the end of push down, the maximum vertical displacement reached $8.0 \mathrm{in}$. and the maximum out-of-plane displacement reached $26.1 \mathrm{in}$. Figure 3-95 shows the column loads. This figure also shows the location of the columns, for which the loaddeflection relationships are shown in Fig. 3-96. As can be seen from Fig. 3-96, the buckled columns on the south side of the isolated east exterior wall carried, on the average, an additional load of $410 \mathrm{kip}$ at 60 min, compared to $630 \mathrm{kip}$ for the average of the entire east wall columns. The additional axial loads on individual columns at different levels of additional vertical displacements are shown in Fig. 3-97. 


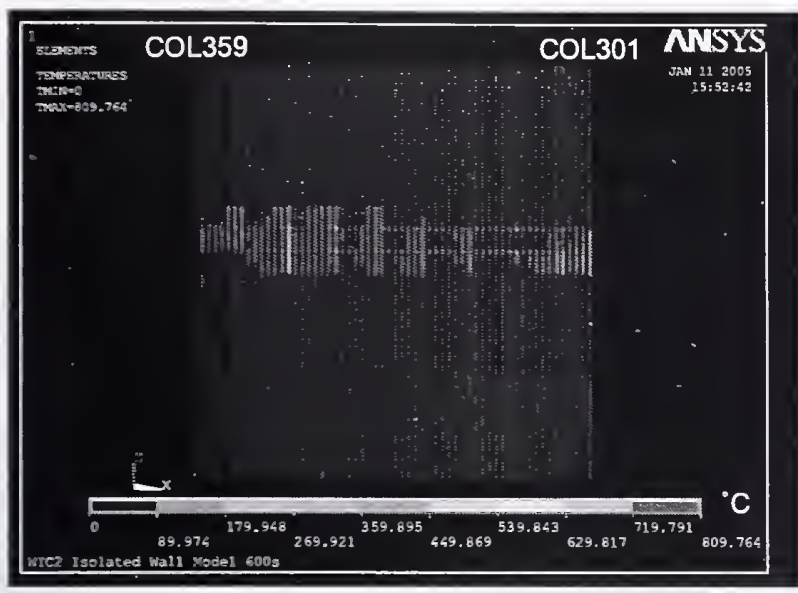

(a) Outside at $10 \mathrm{~min}$

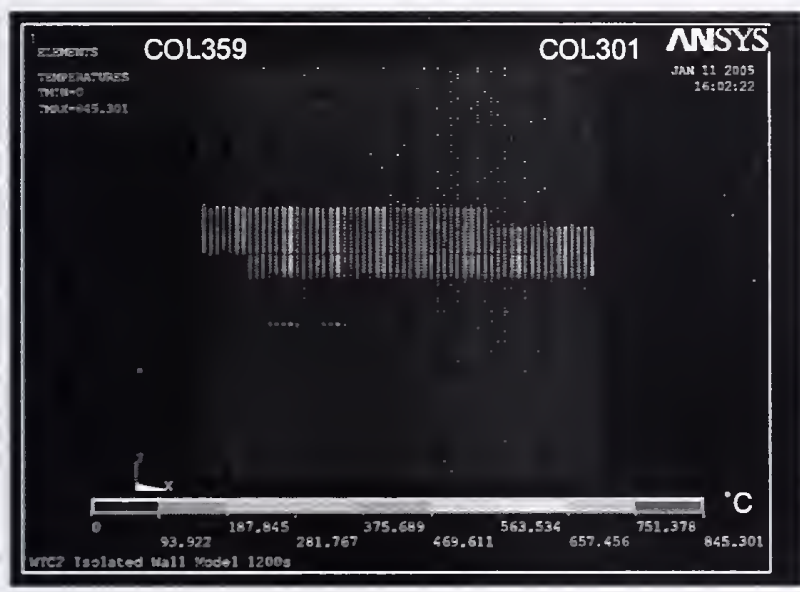

(c) Outside at $20 \mathrm{~min}$

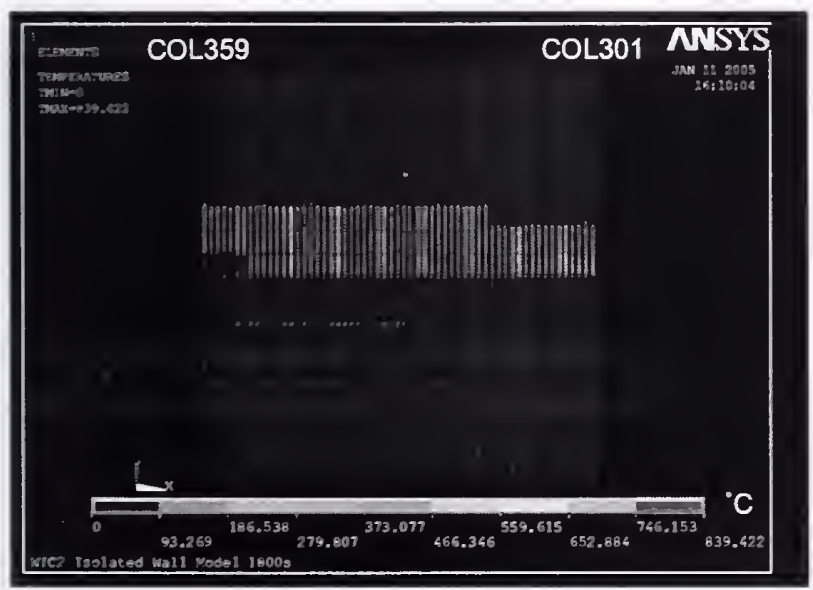

(e) Outside at $30 \mathrm{~min}$

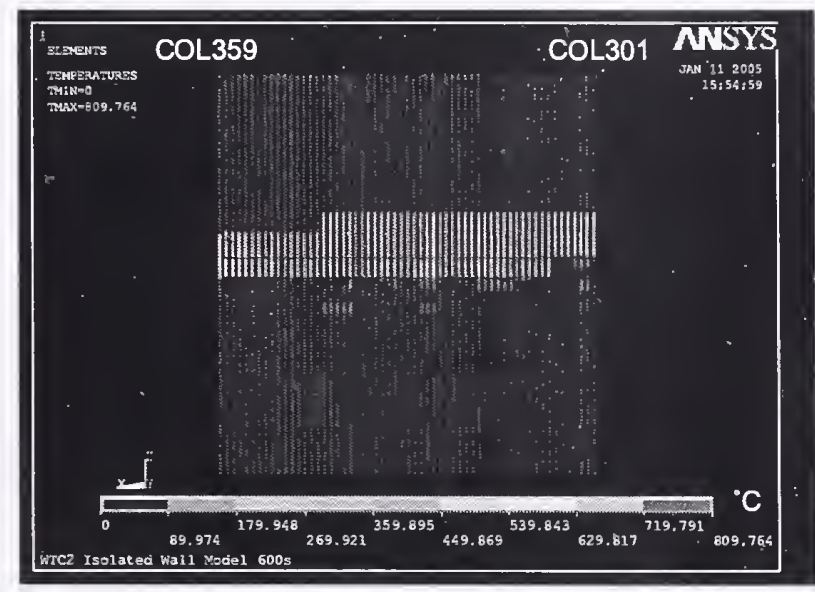

(b) Inside at $10 \mathrm{~min}$

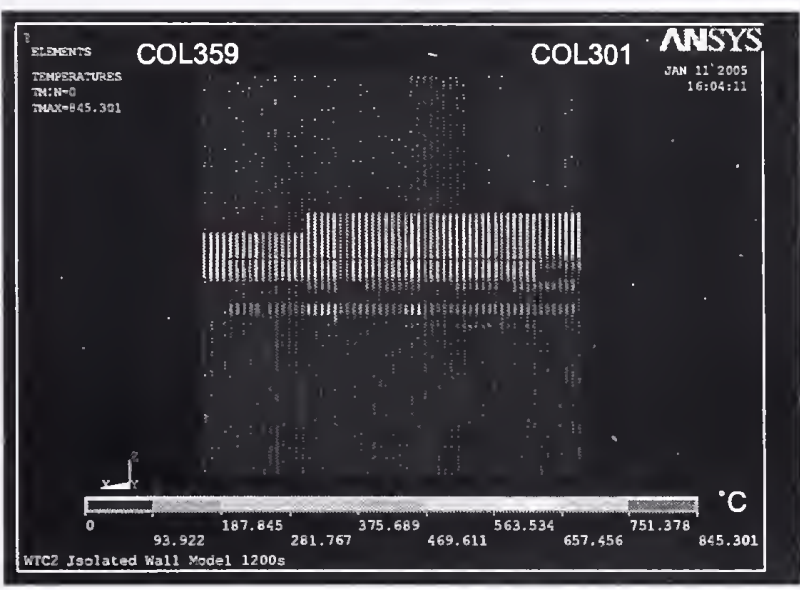

(d) Inside at $20 \mathrm{~min}$

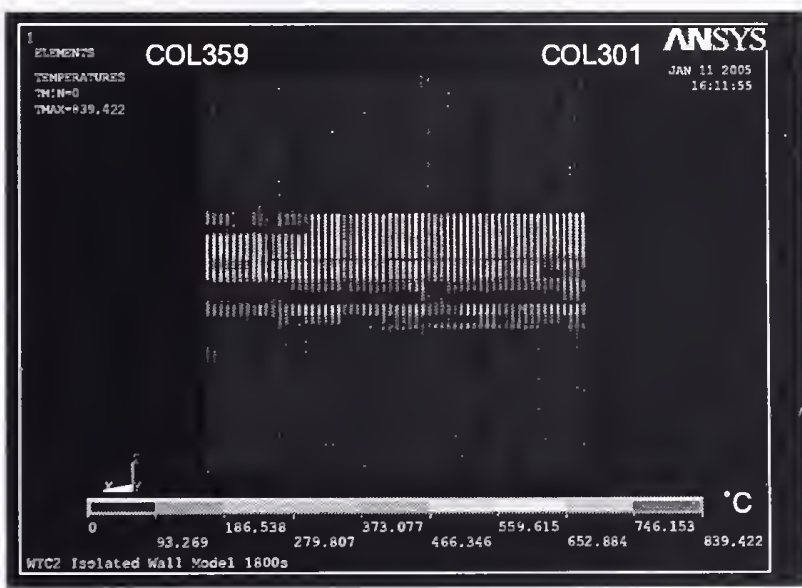

(f) Inside at $30 \mathrm{~min}$

Figure 3-83. Column temperatures on the east wall of WTC 2 for Case D temperature condition at $10 \mathrm{~min}, 20 \mathrm{~min}$, and $30 \mathrm{~min}$. 


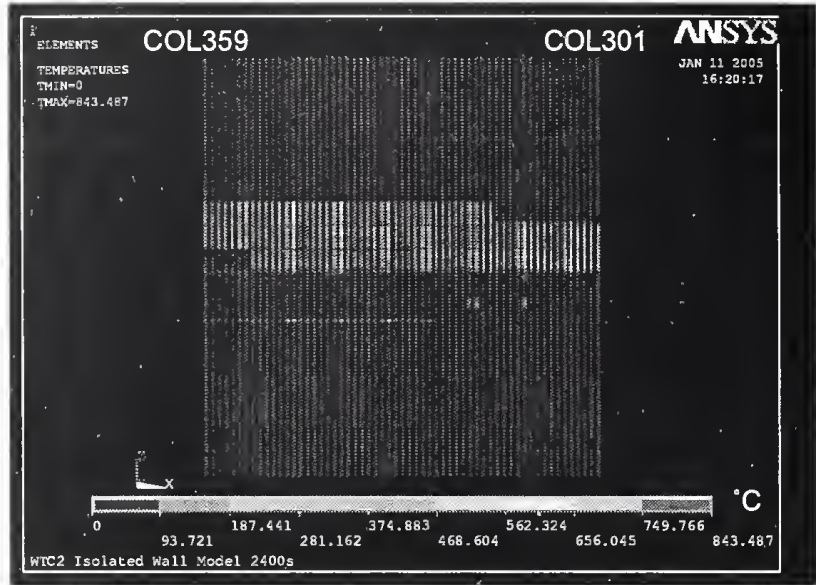

(a) Outside at $40 \mathrm{~min}$

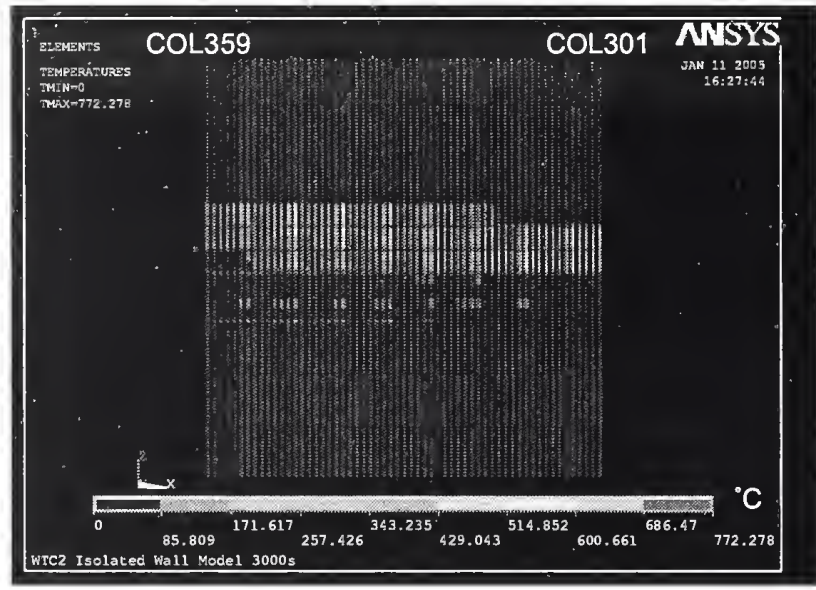

(c) Outside at $50 \mathrm{~min}$

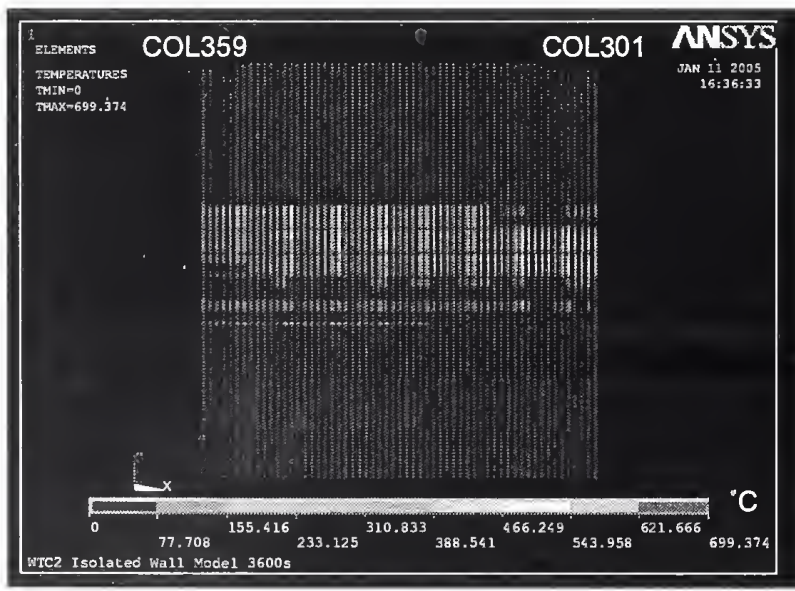

(e) Outside at $60 \mathrm{~min}$

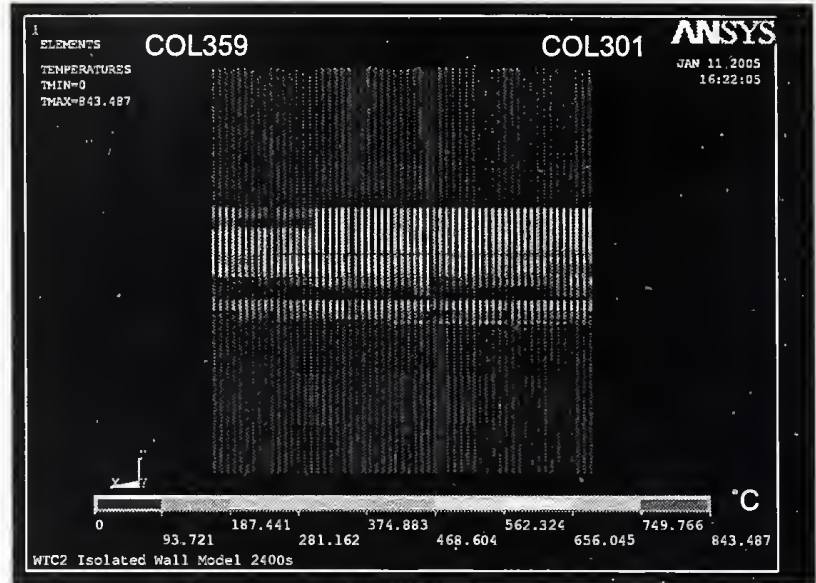

(b) Inside at $40 \mathrm{~min}$

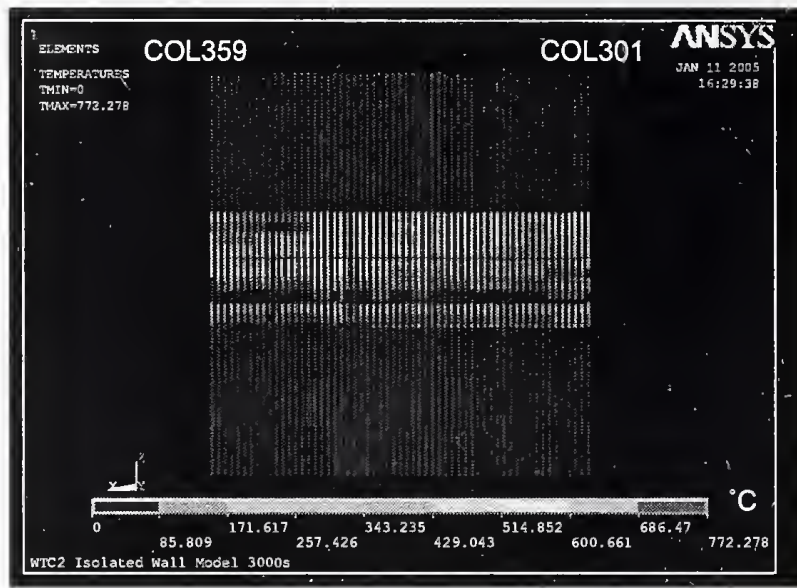

(d) Inside at $50 \mathrm{~min}$

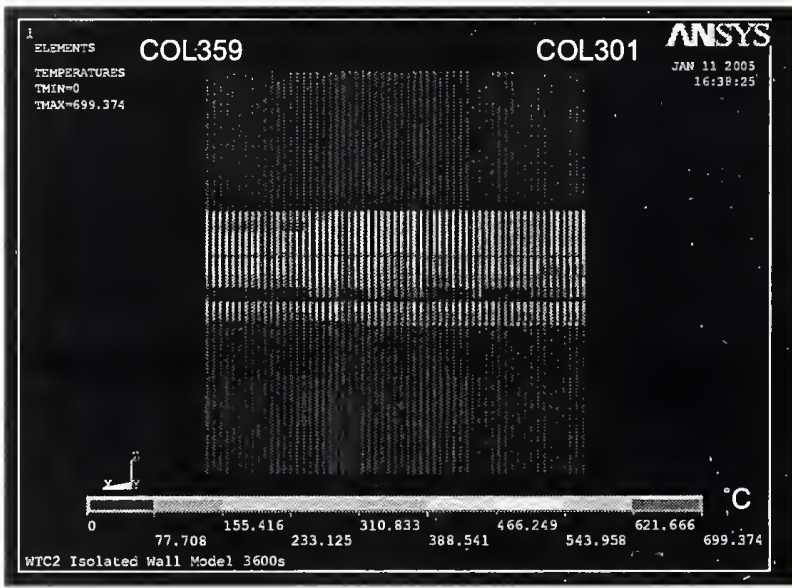

(f) Inside at $60 \mathrm{~min}$

Figure 3-84. Column temperatures on the east wall of WTC 2 for Case D temperature condition at $40 \mathrm{~min}, 50 \mathrm{~min}$, and $60 \mathrm{~min}$. 


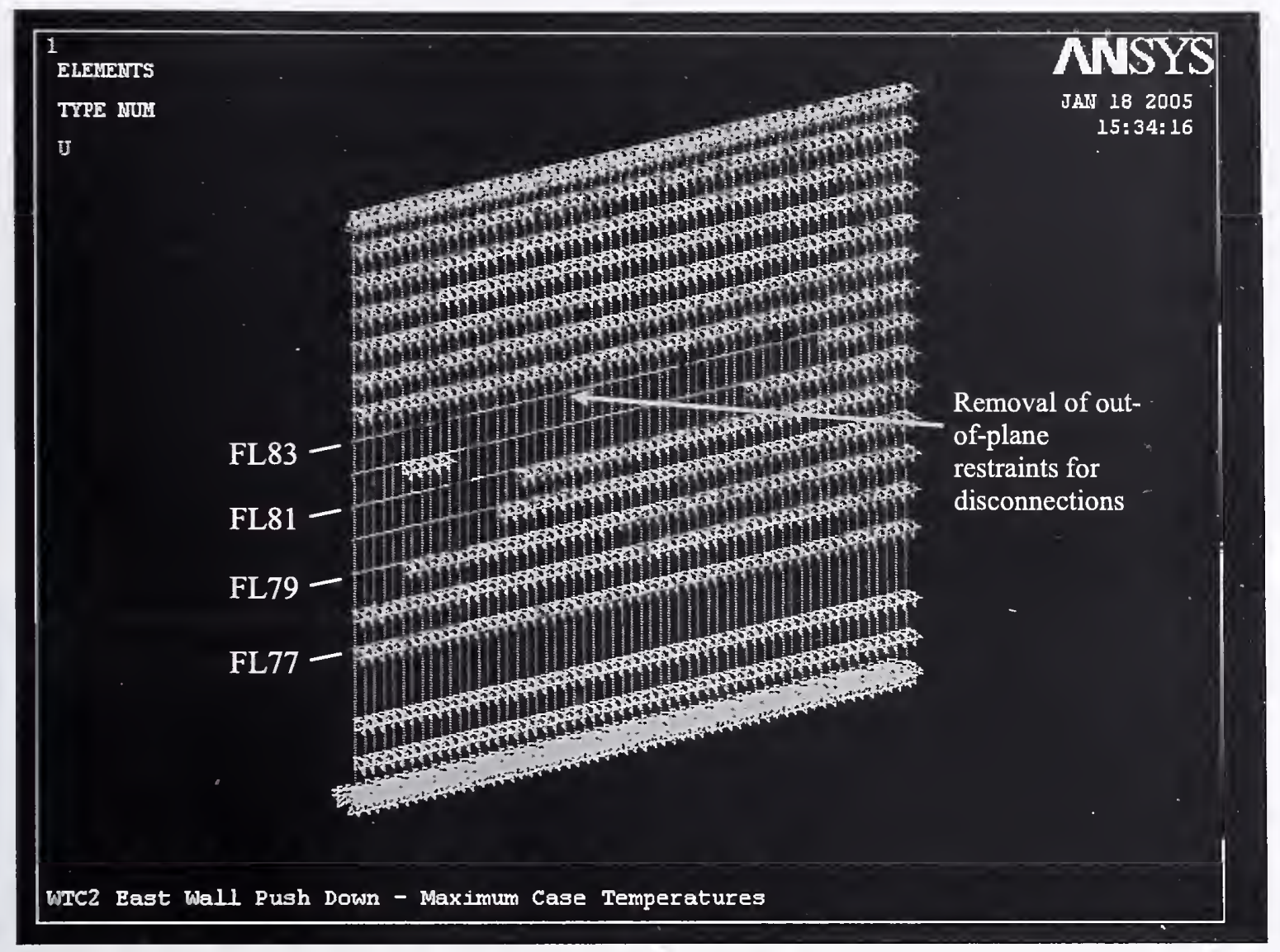

Figure 3-85. Location of the out-of-plane supports and floor/wall disconnections between exterior wall and the floor (WTC 2 east wall for Case D conditions at $60 \mathrm{~min}$ ). 


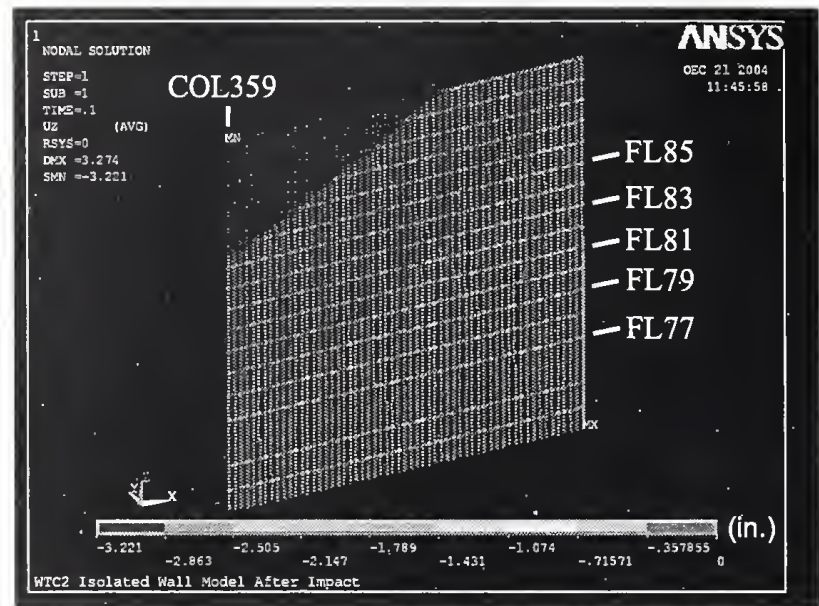

(a) After aircraft impact

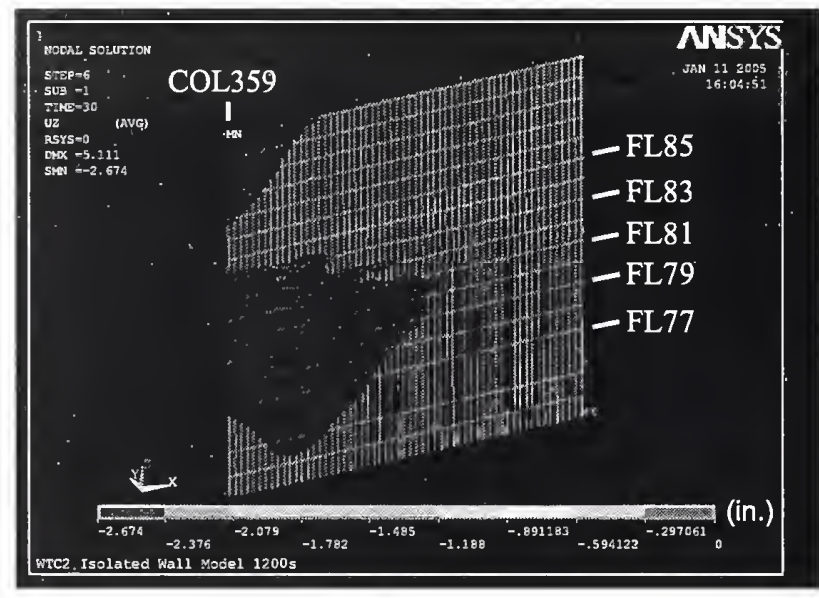

(c) At $20 \mathrm{~min}$

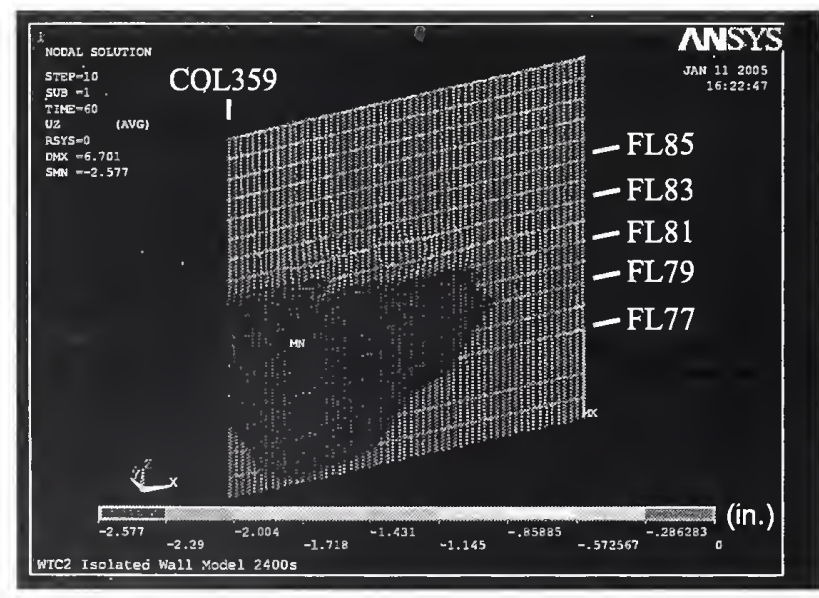

(e) At $40 \mathrm{~min}$

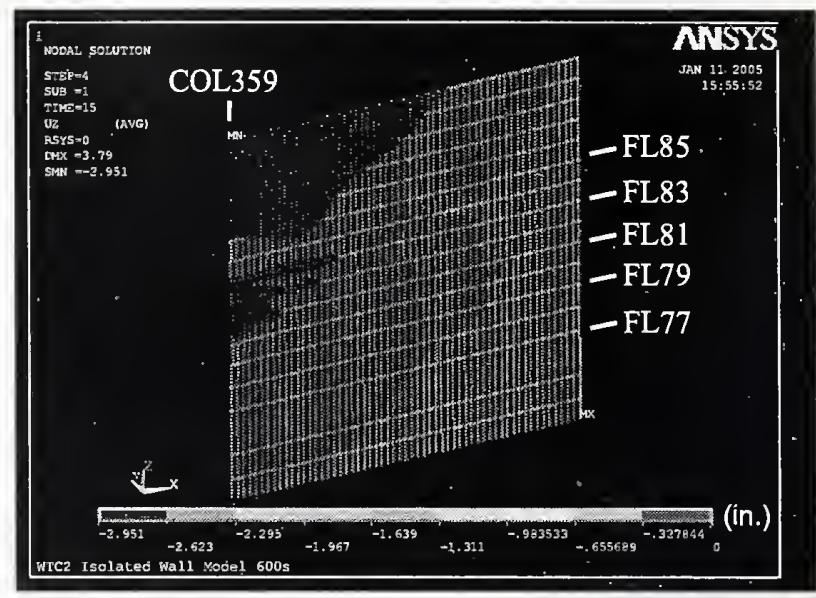

(b) At $10 \mathrm{~min}$

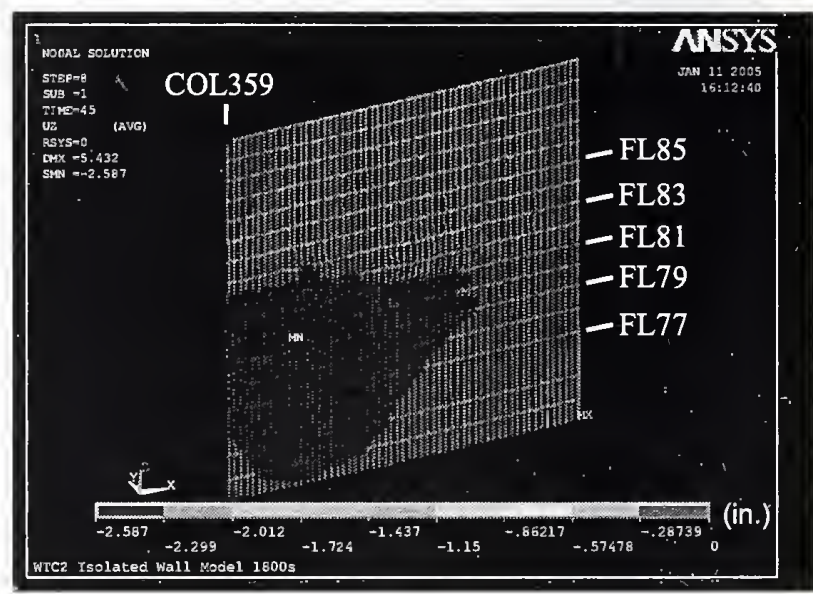

(d) At $30 \mathrm{~min}$

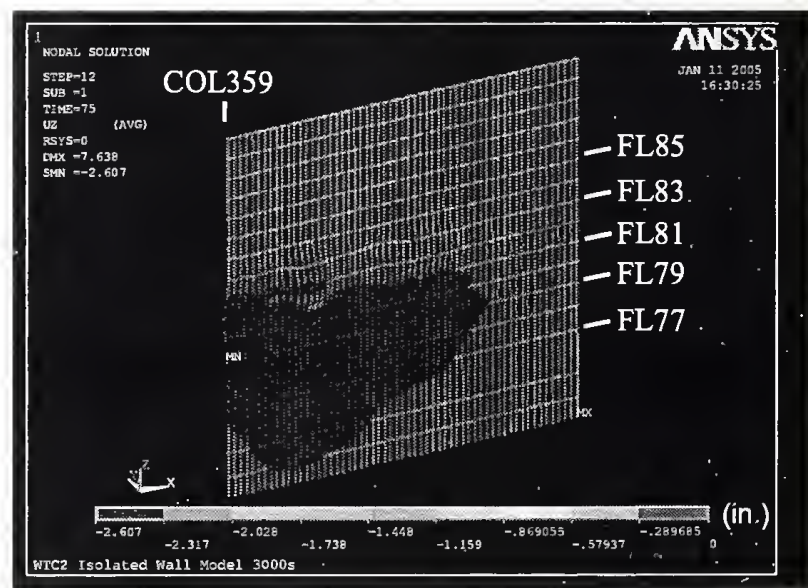

(f) At $50 \mathrm{~min}$

Figure 3-86. Vertical displacement of isolated east wall model of WTC 2 for Case D temperature condition (downward displacement is negative; displacements scaled ten times). 


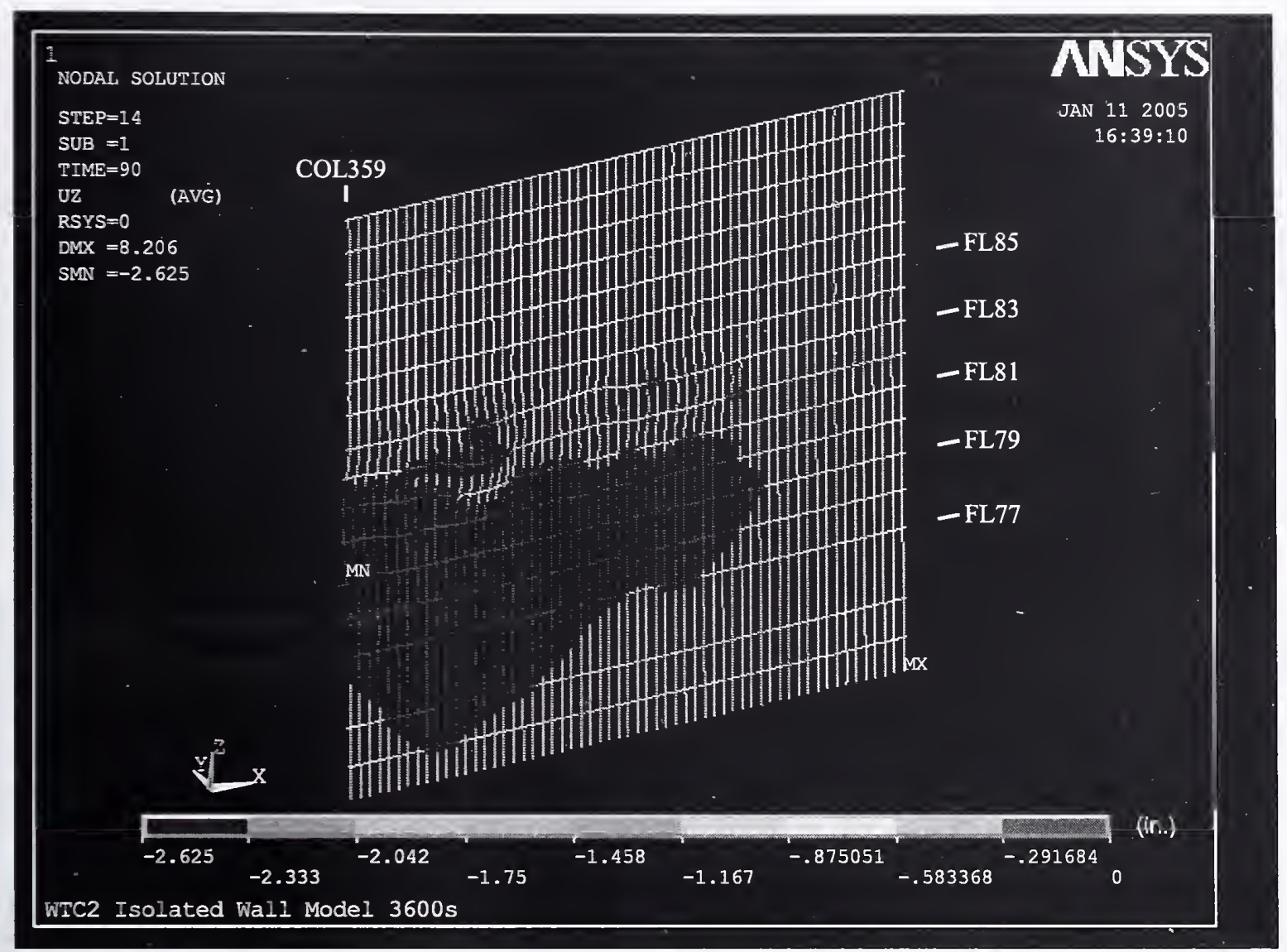

Figure 3-87. Vertical displacement of isolated east wall model of WTC 2 for Case D temperature condition at $60 \mathrm{~min}$ (downward displacement is negative; displacements scaled ten times). 


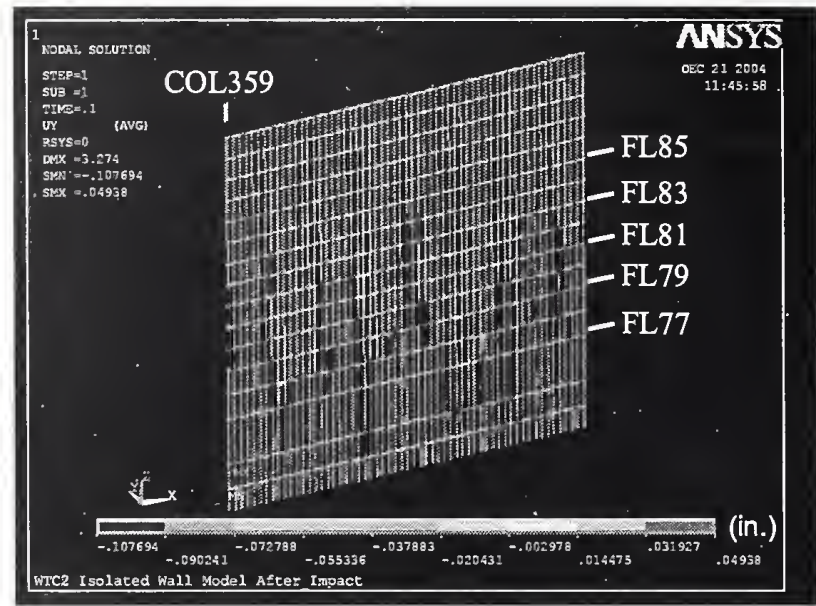

(a) After aircraft impact

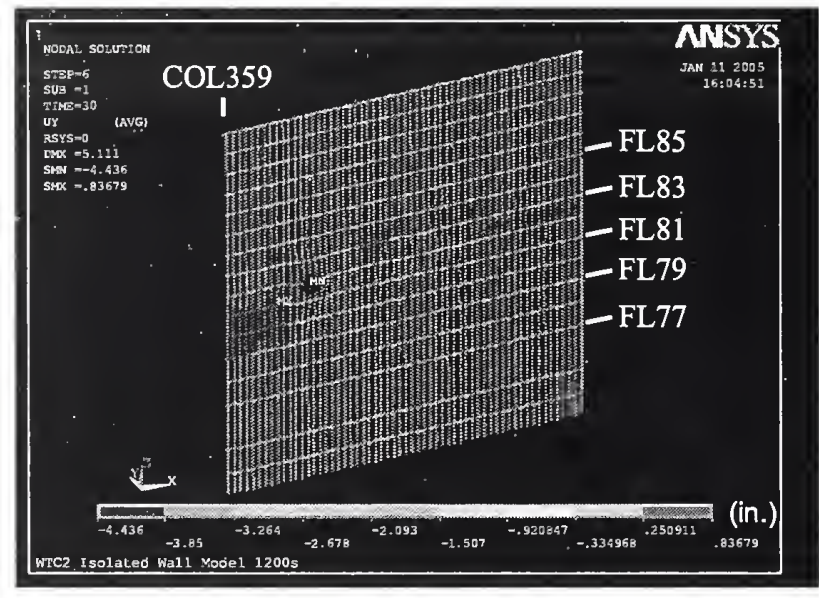

(c) At $20 \mathrm{~min}$

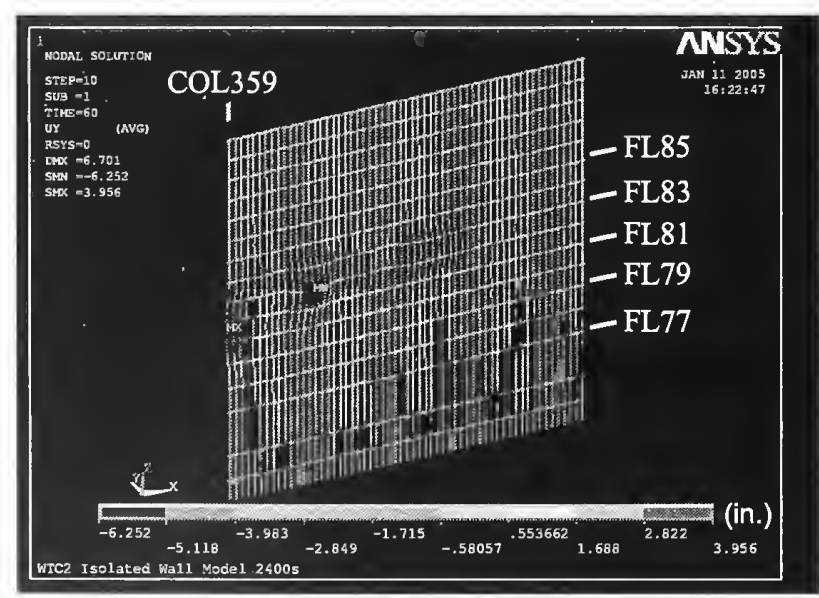

(e) At $40 \mathrm{~min}$

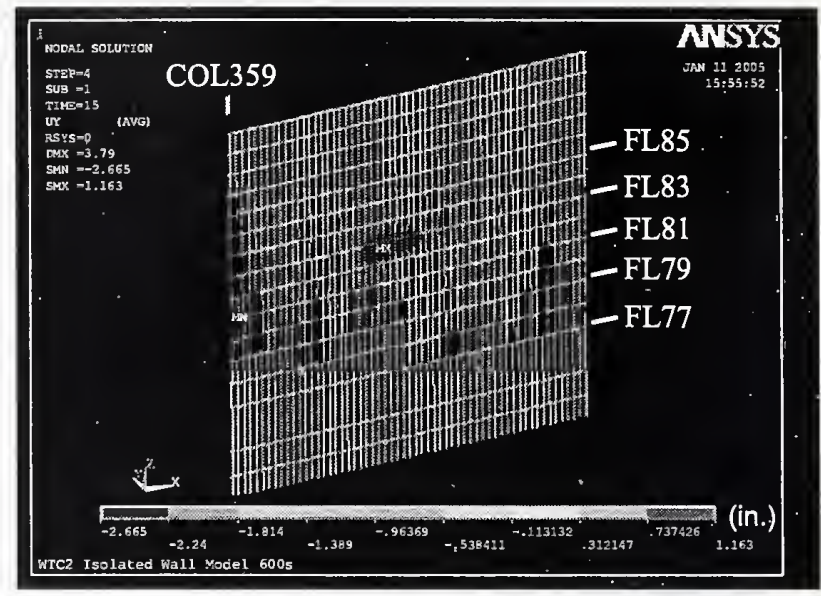

(b) At $10 \mathrm{~min}$

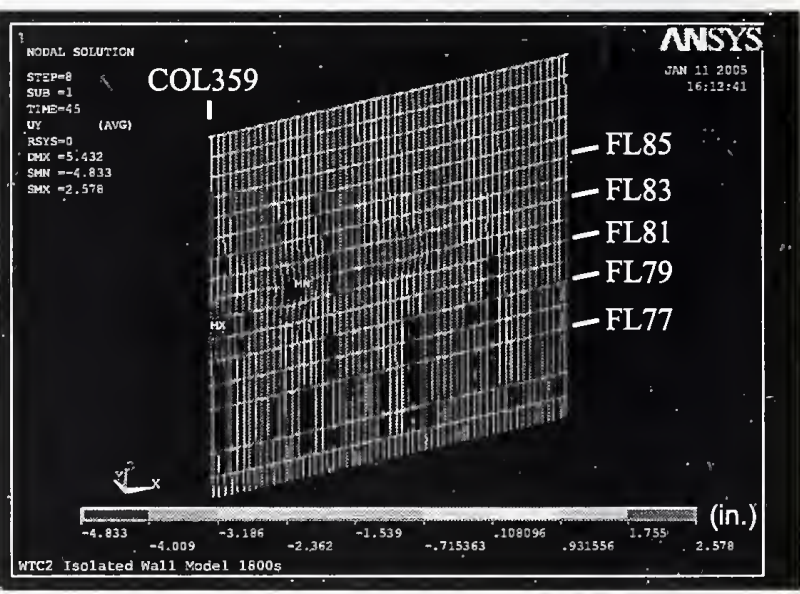

(d) At $30 \mathrm{~min}$

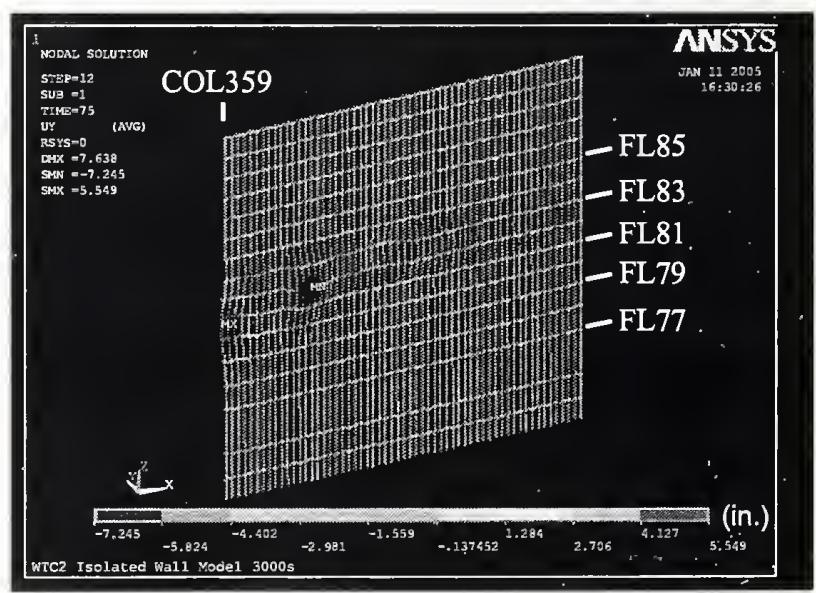

(f) At $50 \mathrm{~min}$

Figure 3-88. Out-of-plane displacement of isolated east wall model of WTC 2 for Case D temperature condition (inward displacement is positive; displacements scaled ten times). 


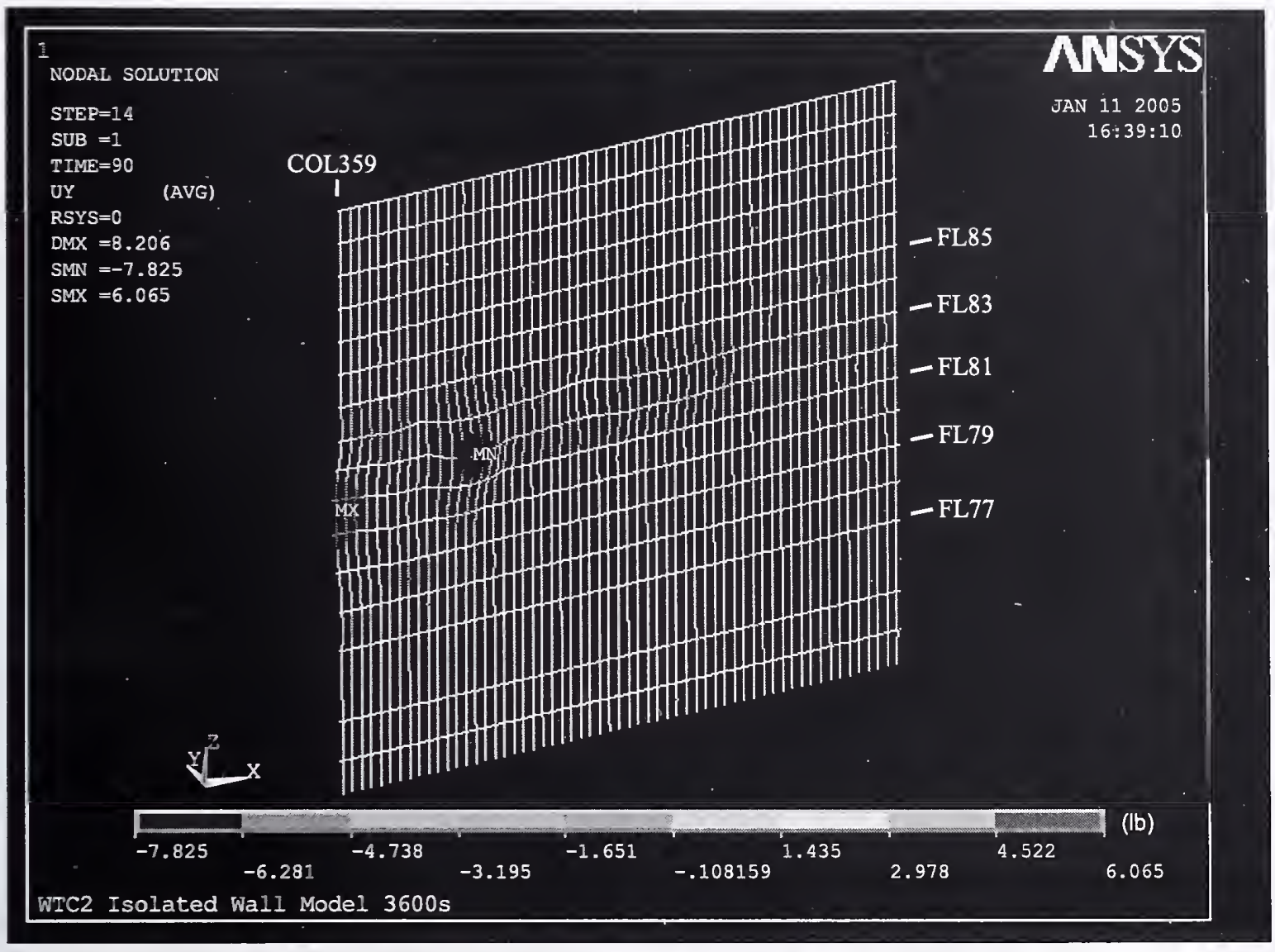

Figure 3-89 Out-of-plane displacement of isolated east wall model of WTC 2 for Case D temperature condition at $60 \mathrm{~min}$ (inward displacement is positive; displacements scaled ten times). 


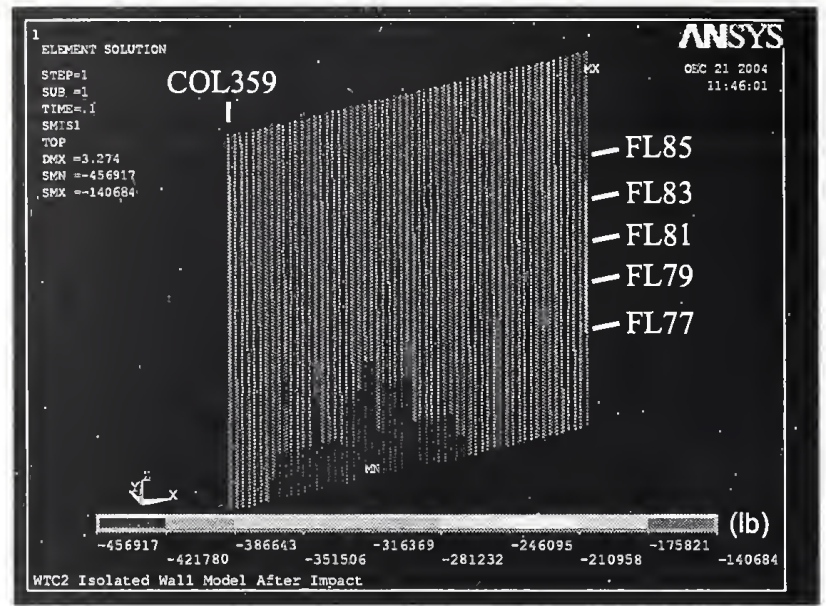

(a) After aircraft impact

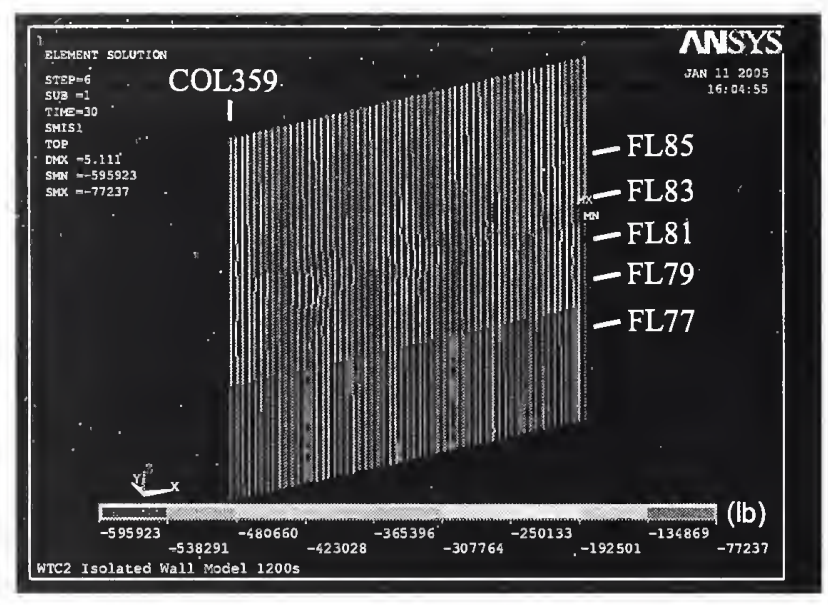

(c) At $20 \mathrm{~min}$

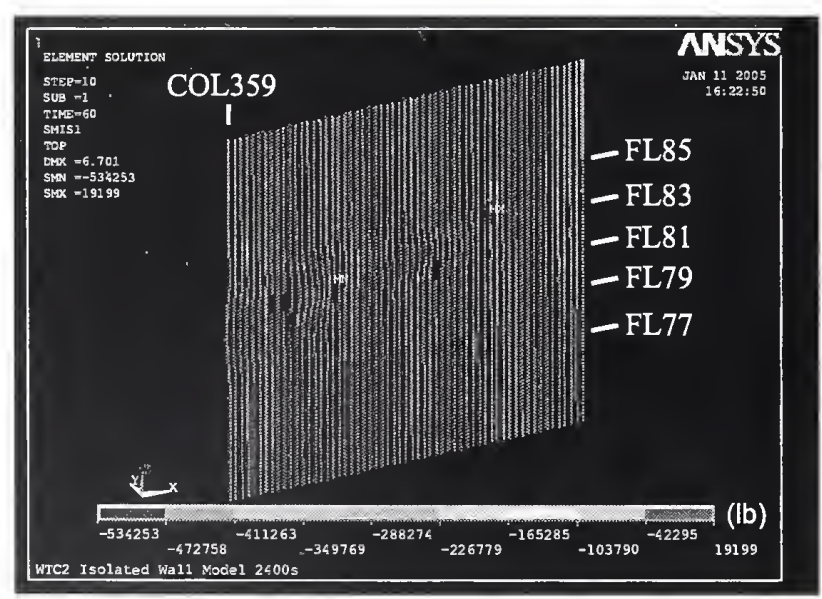

(e) At $40 \mathrm{~min}$

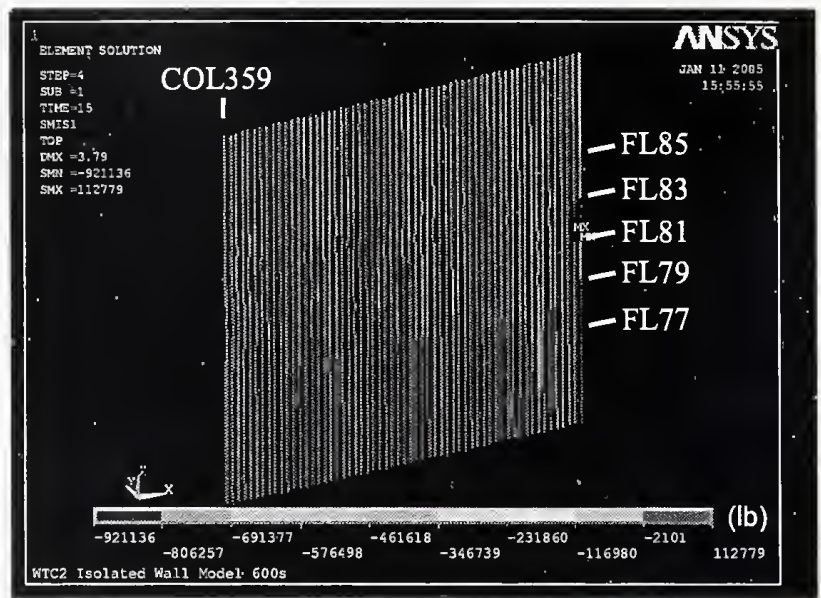

(b) At $10 \mathrm{~min}$

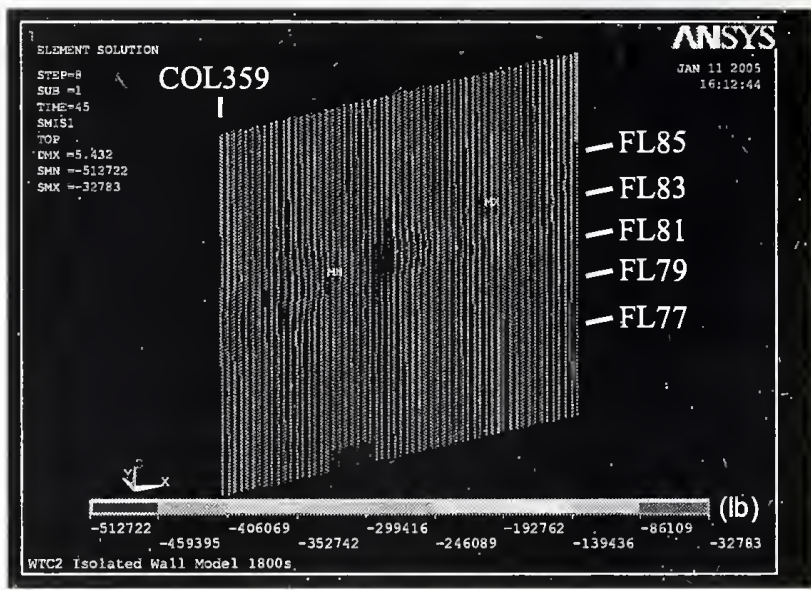

(d) At $30 \mathrm{~min}$

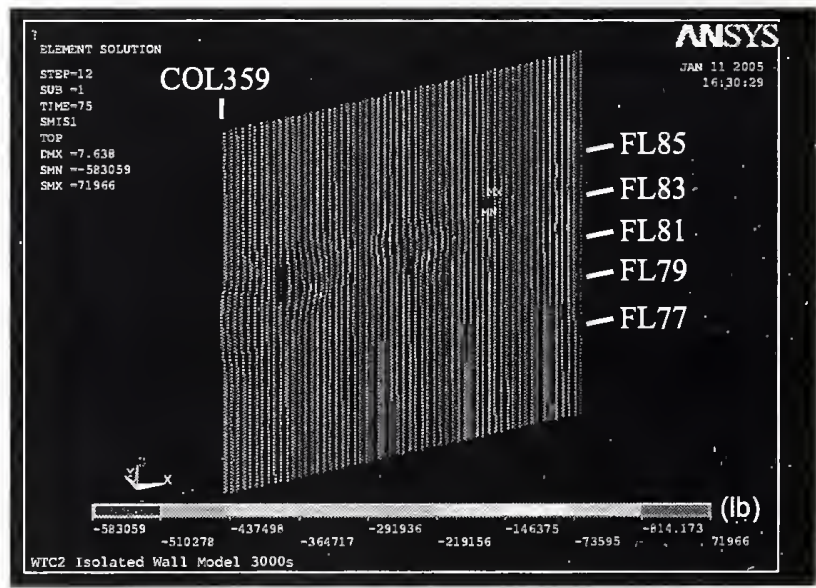

(f) At $50 \mathrm{~min}$

Figure 3-90. Axial load on east wall columns of isolated east wall model of WTC 2 for Case $\mathbf{D}$ temperature condition (compression is negative). 


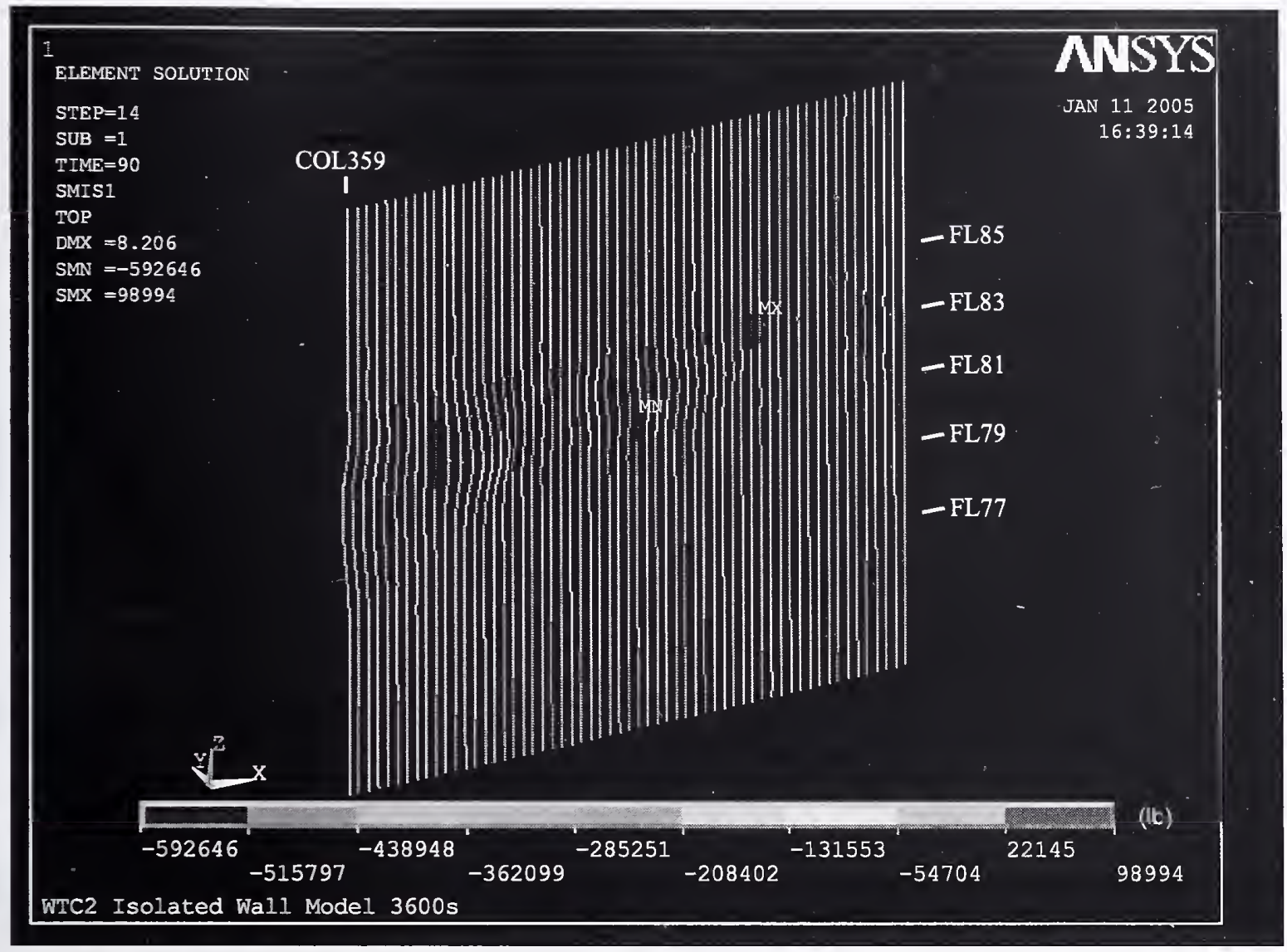

Figure 3-91. Axial load on east wall columns of isolated east wall model of WTC 2 for Case $D$ temperature condition at $60 \mathrm{~min}$ (compression is negative). 


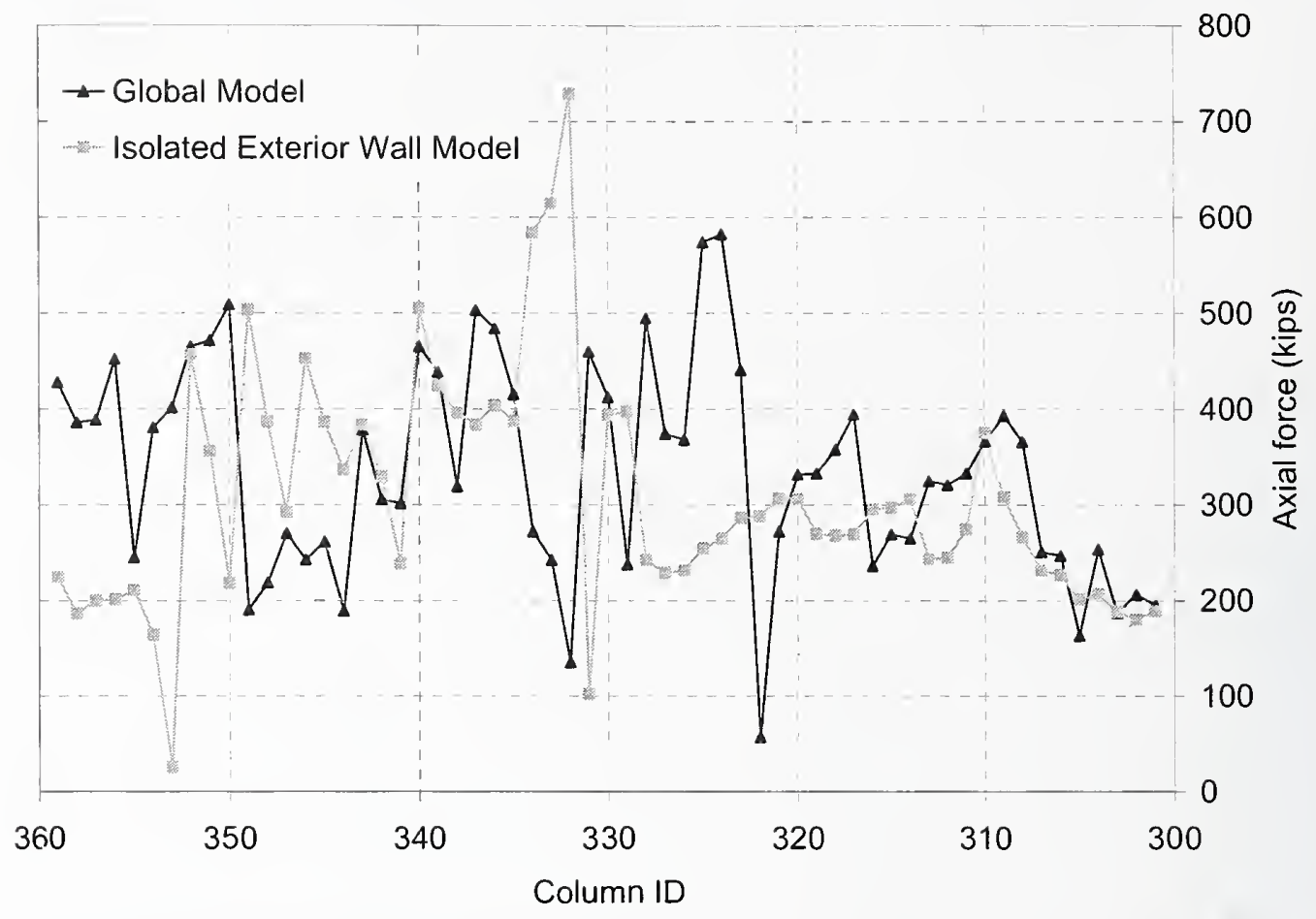

Figure 3-92. Comparison of axial load in columns at Floor 83 of isolated east wall model of WTC 2 at $60 \mathrm{~min}$ for Case D temperature conditions and the global model without creep for Case $C_{i}$ structural damage condition and Case $D_{i}$ temperature condition (compression is positive).

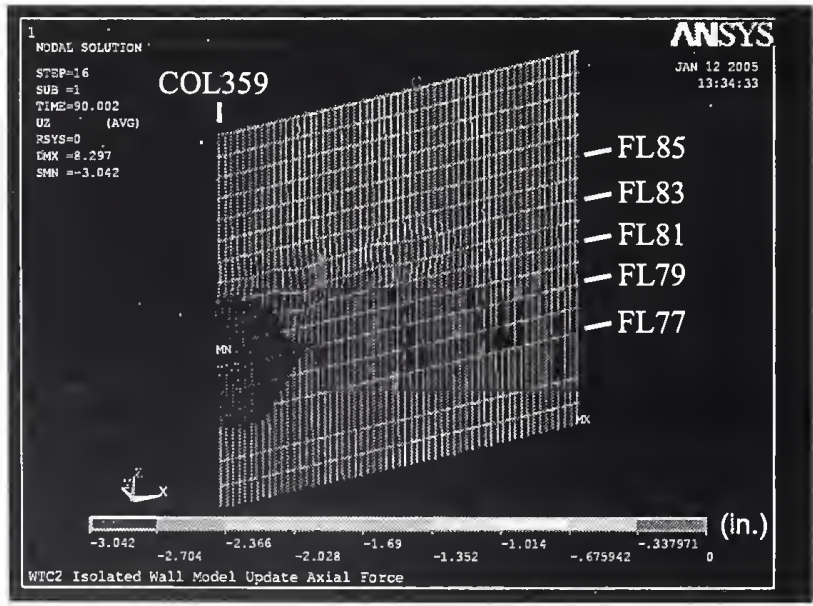

(a) Vertical displacement

(downward displacement is negative)

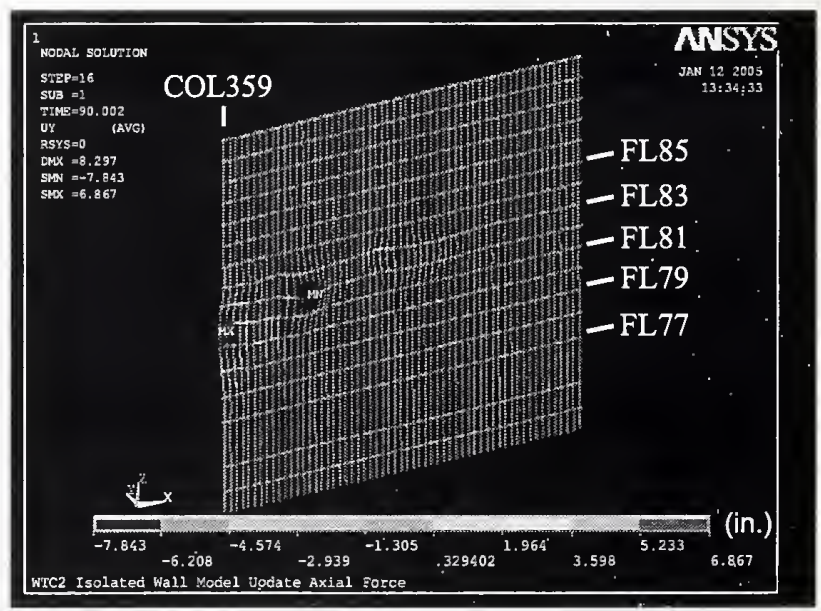

(b) Out-of-plane displacement (inward displacement is positive)

Figure 3-93. Vertical and out-of-plane displacements of columns of isolated east wall model of WTC 2 after column forces were corrected to those of global model without creep for Case $C_{i}$ structural damage condition and Case $D_{i}$ temperature condition (displacements scaled ten times). 


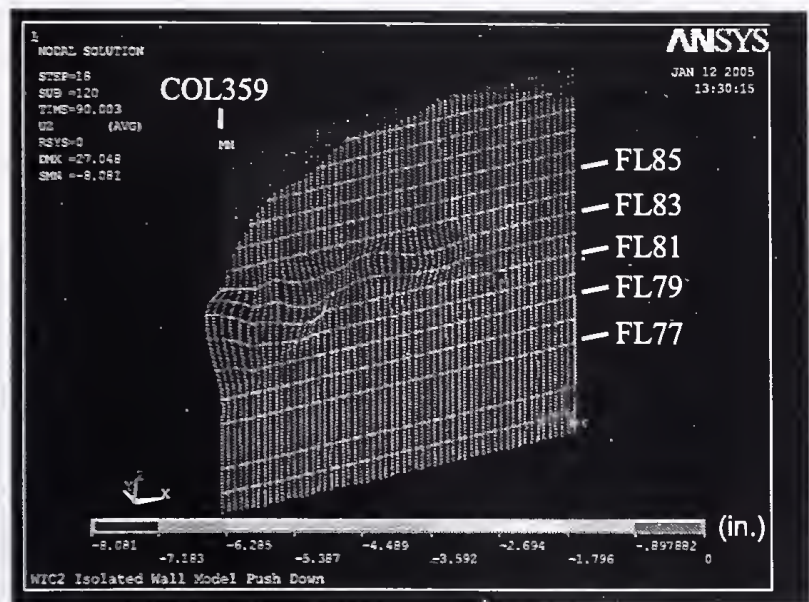

(a) Vertical displacement

(downward displacement is negative)

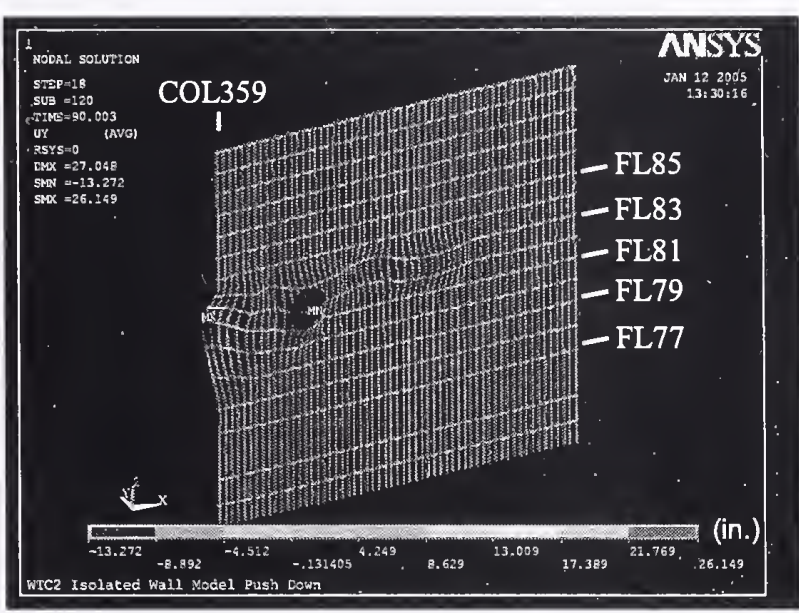

(b) Out-of-plane displacement (inward displacement is positive)

Figure 3-94. Vertical and out-of-plane displacements of isolated east wall model of WTC 2 after Case D temperature condition and push down (displacements scaled five times).

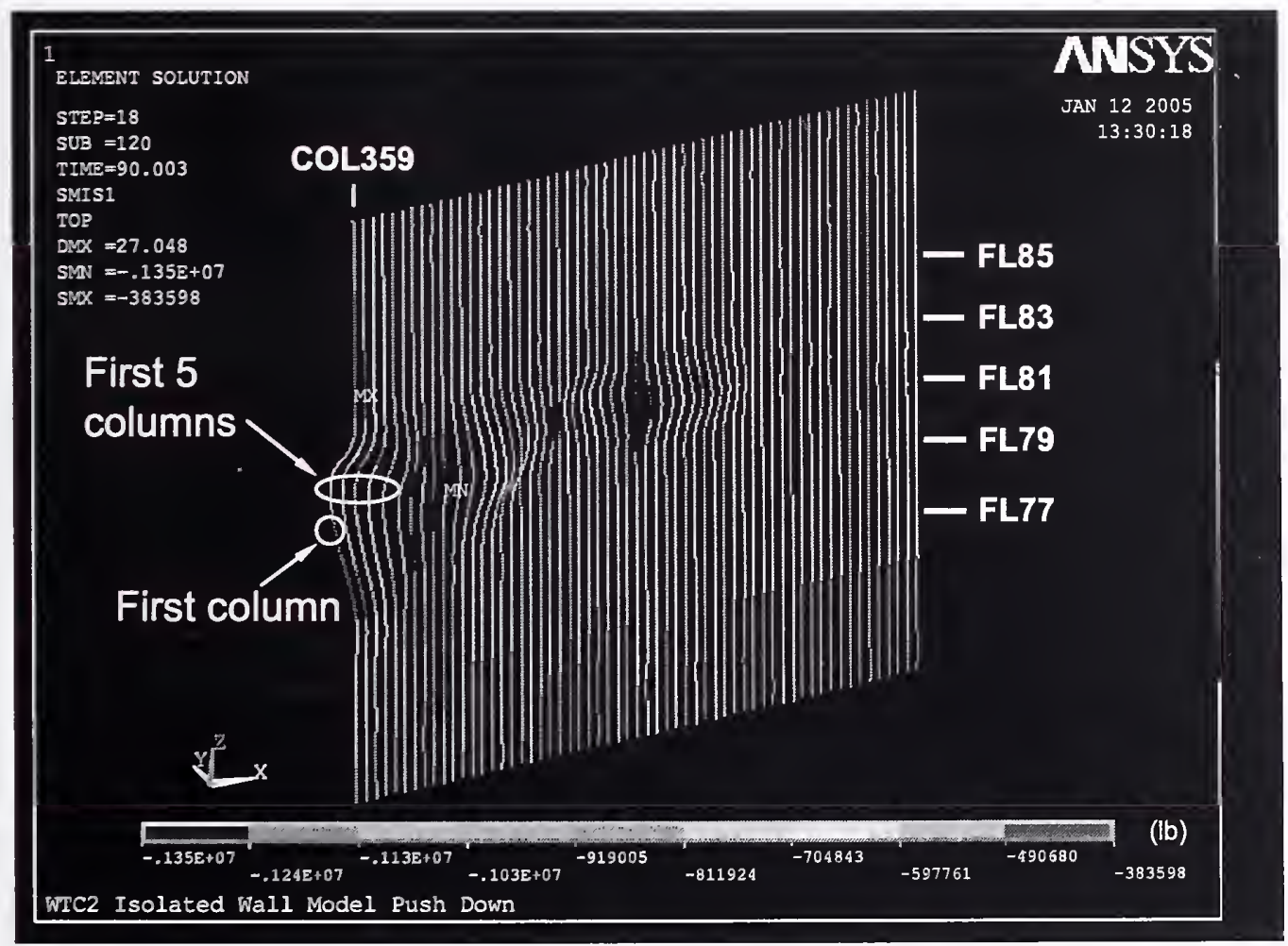

Figure 3-95. Axial load on east wall columns of isolated east wall model of WTC 2 after Case $D$ temperature condition and push down (compression is negative). 


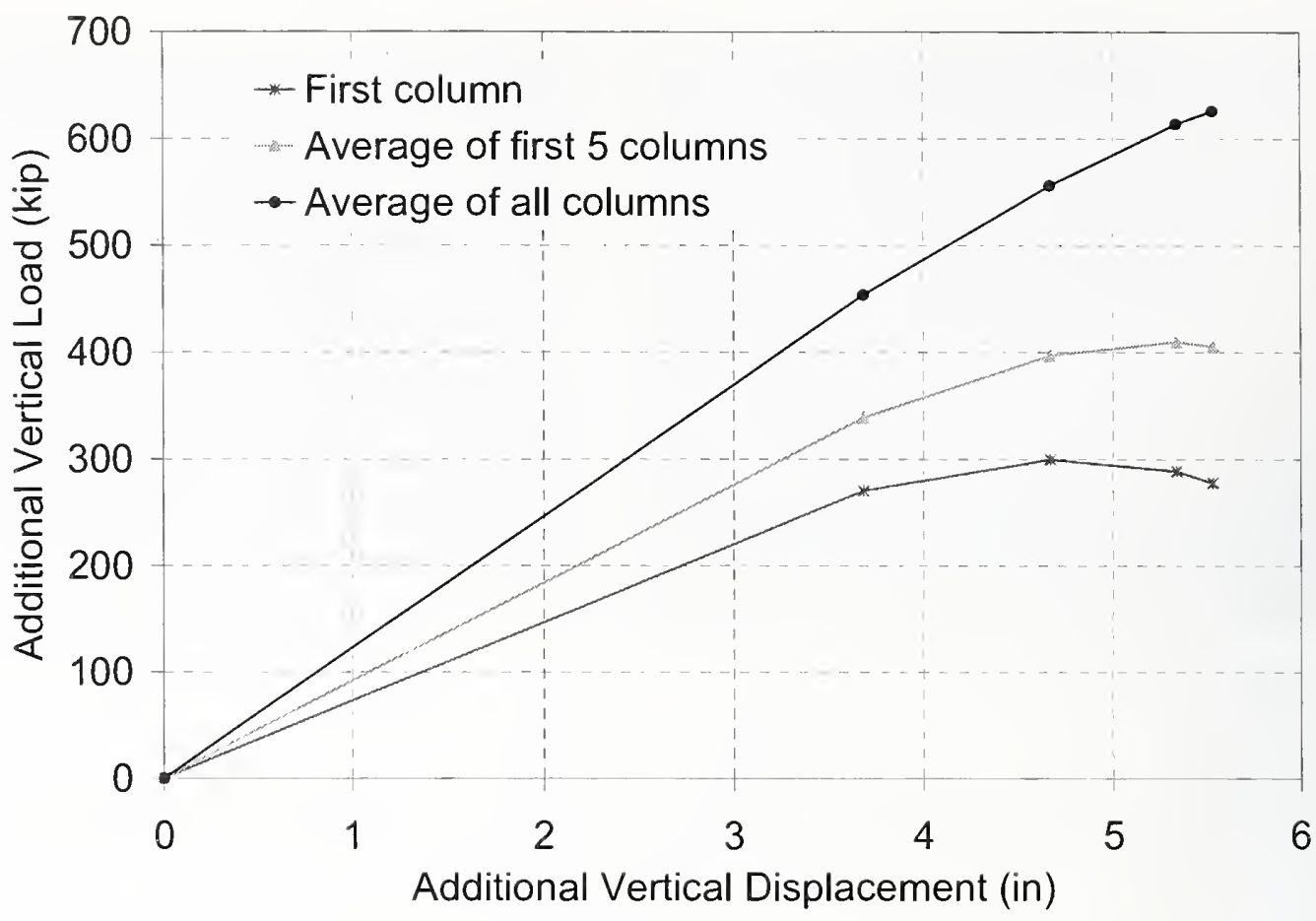

Figure 3-96. Additional vertical load applied to columns versus additional vertical during displacement for push-down analysis of isolated east wall model of WTC 2 for after Case D temperature condition (compression is positive; see Fig. 3-95 for column locations).

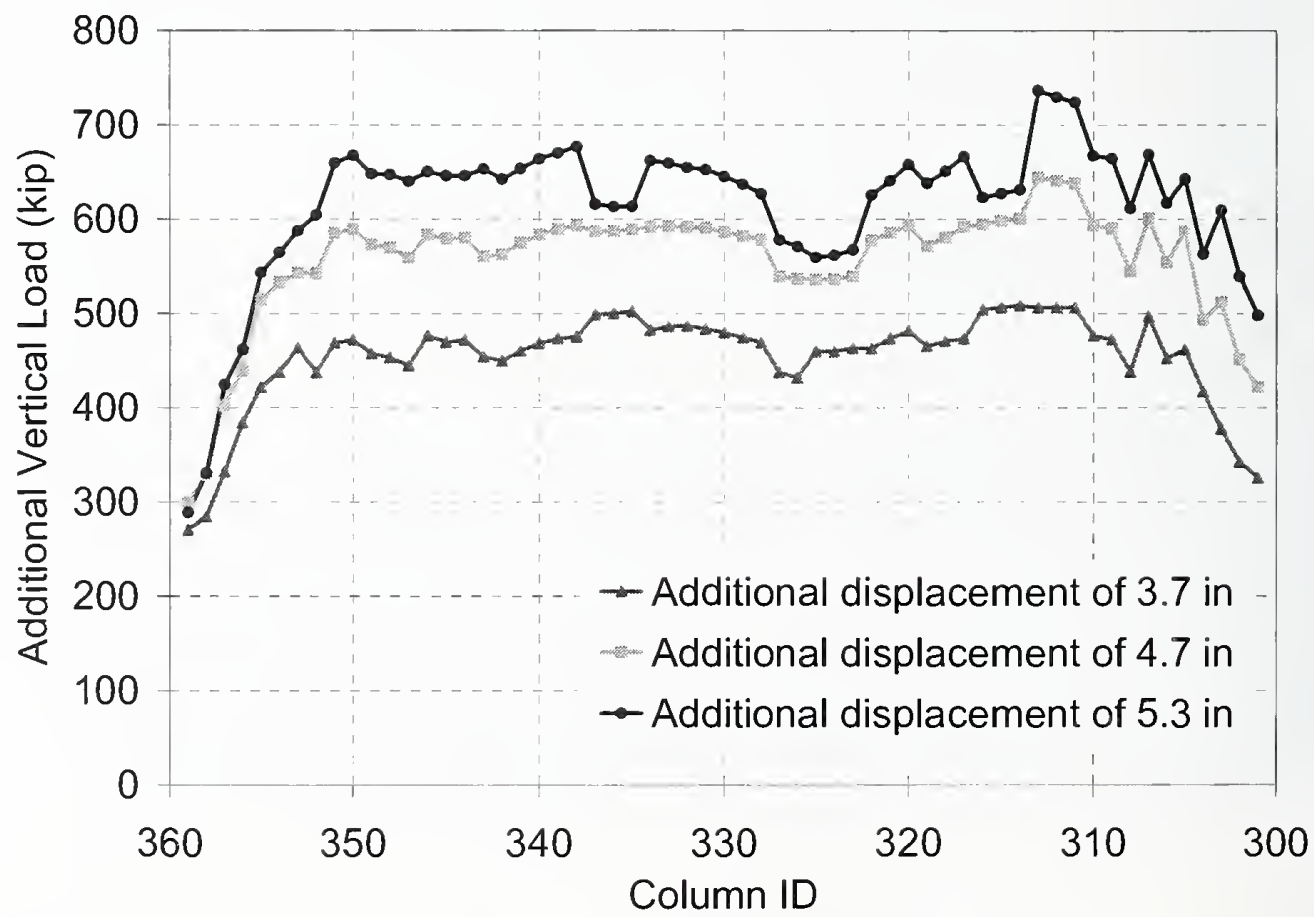

Figure 3-97. Variation of additional vertical load applied to columns of isolated east wall model of WTC 2 at different levels of additional vertical displacements imposed after Case $\mathrm{D}$ temperature condition (compression is positive). 


\section{Pull-in Forces to Cause Observed Bowing}

As discussed in Section 2.5, the pull-in forces and their locations and the calculated floor/wall disconnections and pull-in locations were updated based on the observations from the photographs and videos. This section describes the analyses performed on the isolated wall model to estimate the magnitude of pull-in forces on the east wall of WTC 2, which would result in an inward bowing shape similar to that estimated from the photographs and videos. The estimated pull-in forces were used in the global analysis with Case D temperature condition.

The load steps that were used in the current analyses are similar to the load steps used in the earlier wall runs. At the beginning of each temperature load step, disconnections and lateral pull-in forces were applied to each floor connection to the east wall, as shown in Section 2.5. The magnitude and the distribution of the pull-in forces were obtained by trial and error. The magnitude of the pull-in force was kept constant till the end of the analysis, unless the column-floor connection fully disconnected before the analysis ended; at which point the pull-in force was set to zero. For each trial, the wall model was analyzed from the beginning (time $=0 \mathrm{~min}$ ), accounting for large deflections and temperature-dependent plasticity and creep. The out-of-plane displacements calculated at the end of $20 \mathrm{~min}$ and $50 \mathrm{~min}$ were compared to the displacements estimated at the same points in time from the photographs, as shown in Fig. 3-98.

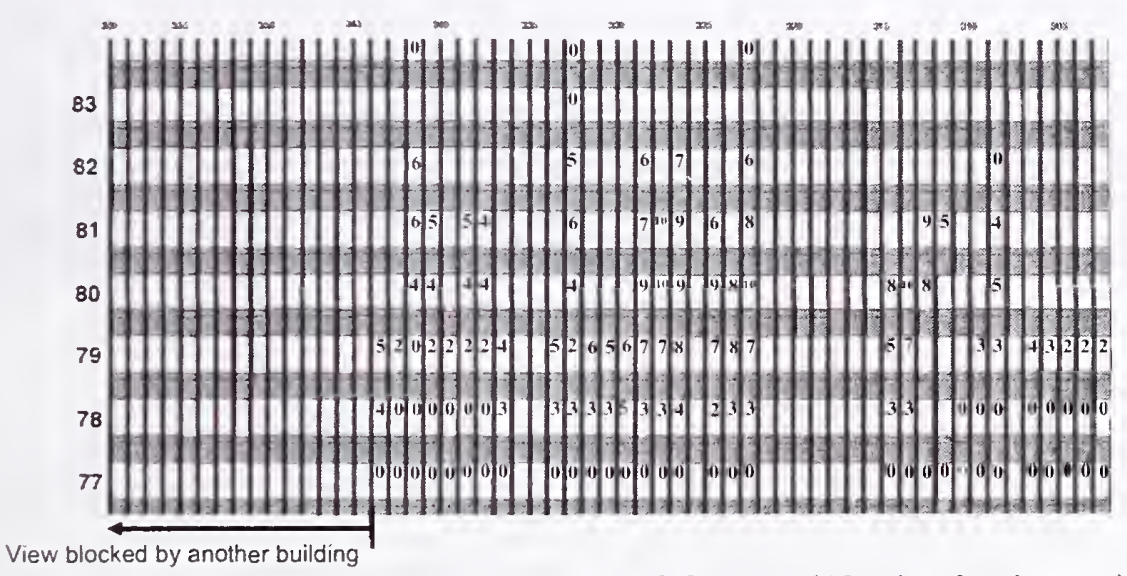

(a) Displacement measurements at 9:21 a.m. (18 min after impact)

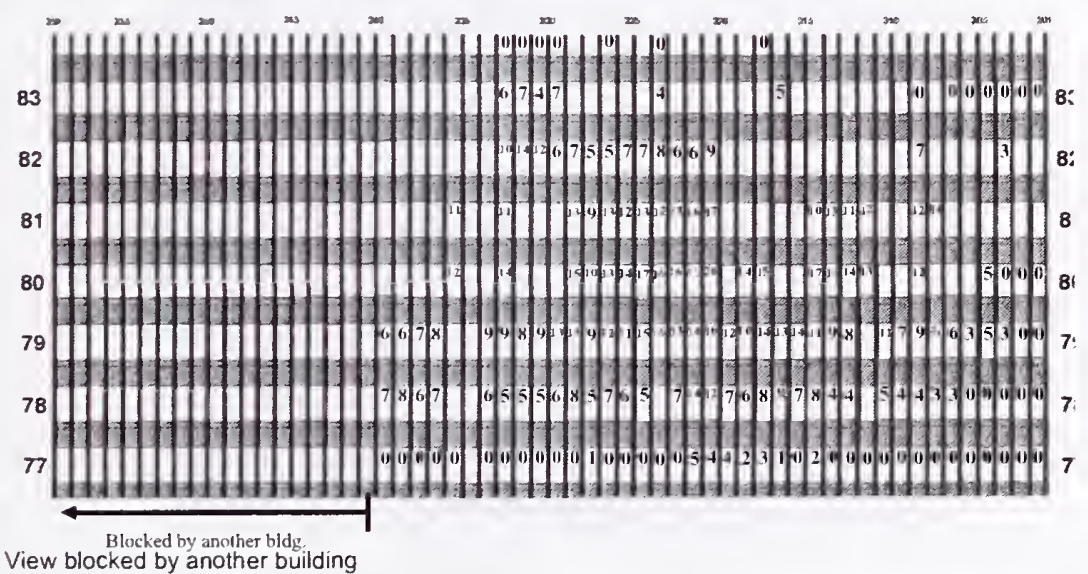

(b) Displacement measurements at 9:53 a.m. (50 min after impact)

Figure 3-98. Out-of-plane displacements of the east wall of WTC 2 estimated by NIST from photographs (inward displacement is positive; displacements are in in.). 
For the first set of trials, the pull-in forces were assumed to be uniformly distributed over the entire width of the model. Two different magnitudes for pull-in forces were tried: $0.5 \mathrm{kip}$ and $5.0 \mathrm{kip}$. The analysis for $0.5 \mathrm{kip}$ ran to $32 \mathrm{~min}$, at which point it failed to converge. As shown in Fig. 3-99(a), the wall primarily bowed outward at $20 \mathrm{~min}$ (positive displacement direction is inward). These results disagreed with what was observed in the photographs and videos, indicating that the assumed magnitude of pull-in force of $0.5 \mathrm{kip}$ was not sufficient to cause inward bowing. In a second trial, the $5.0 \mathrm{kip}$ pull-in force was used. This analysis ran to $18 \mathrm{~min}$, at which point it failed to converge. Contrary to the first trial with 0.5 kip pull-in force, the wall bowed inward, as shown in Fig. 3-99(b). The maximum inward displacement in this trial was $31 \mathrm{in}$. This value is about three times larger than the displacement estimated from photographs, indicating that the $5.0 \mathrm{kip}$ pull-in force is greater than the actual magnitude of pull-in force. Based on these two runs, it was concluded that the magnitude of the pull-in forces for a uniform distribution is between $0.5 \mathrm{kip}$ and $5.0 \mathrm{kip}$.

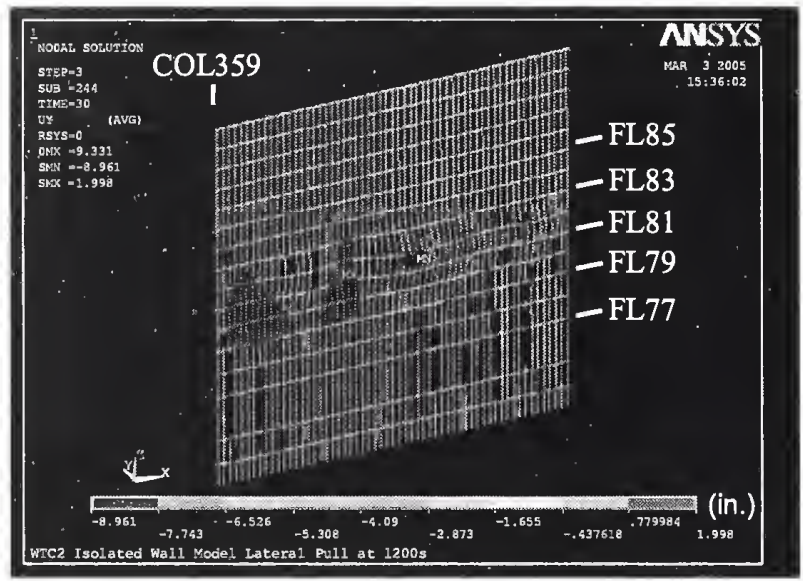

(a) Pull-in force $=0.5 \mathrm{kip}$ $\mathrm{t}=20 \mathrm{~min}$

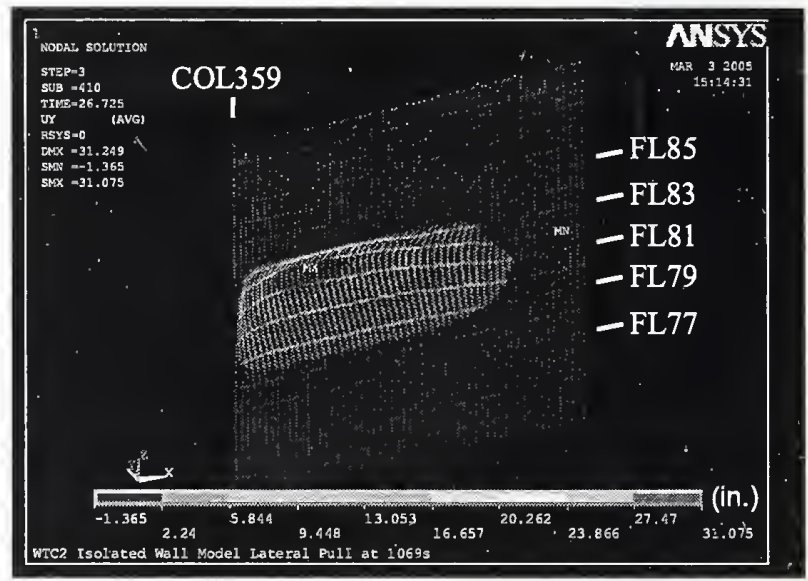

(b) Pull-in force $=5.0 \mathrm{kip}$ $\mathrm{t}=18 \mathrm{~min}$

Figure 3-99. Out-of-plane displacement of isolated east wall model of WTC 2 with 0.5 kip and 5.0 kip pull-in force with uniform magnitude distribution at $20 \mathrm{~min}$ and $18 \mathrm{~min}$ (inward displacement is positive).

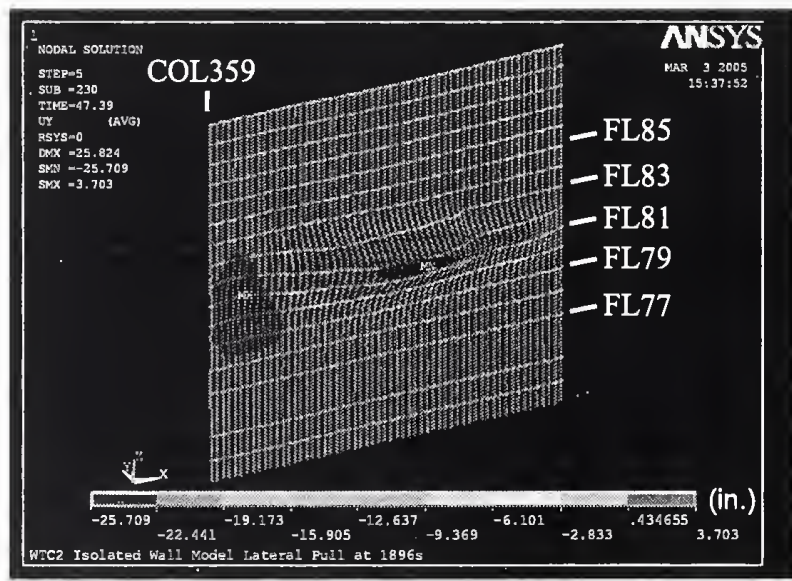

Pull-in force $=0.5 \mathrm{kip}$

$$
t=32 \mathrm{~min}
$$

Figure 3-100. Out-of-plane displacement of isolated east wall model of WTC 2 with 0.5 kip pull-in force with uniform magnitude distribution at $\mathbf{3 2} \mathrm{min}$ (inward displacement is positive). 
From these two runs, it was also possible to learn about the distribution of the pull-in forces over the width of the east wall. When a uniform distribution of a 0.5 kip pull-in force was used at 20 min over the entire width of the east wall, the resulting out-of-plane displacements were inward on the south side and outward on the north side of the wall, as shown in Fig. 3-99. The primary reasons for the outward bowing on the north side of the east wall are as follows: (1) the higher temperatures in the north side of the wall resulted in restrained thermal expansion and larger column loads; (2) the higher temperatures of the inside face of the columns, relative to the outside, caused higher plastic and creep strains and resulted in differential shortening of the inside relative to the outside; and (3) the plastic softening and creep of the inside caused an outward shift in the neutral axis, and a resulting outward bow of the columns. This phenomenon can be seen in the displacement results presented in Figs. 3-99 and 3-100, where inward displacements on the south side of the east wall became smaller and smaller and eventually changed to outward displacements toward the north side of the east wall. Consequently, a simple non-uniform pullin force distribution was selected with higher loads on the north side to ensure inward bowing as observed in photographs and videos.

Two cases were analyzed for the second set of trials. In the first case, the magnitude of the pull-in forces on the south half of the east wall was set to $1.0 \mathrm{kip}$ and the magnitude of the pull-in forces on the north half was set to $4.0 \mathrm{kip}$. The wall analysis with these pull-in force magnitudes ran to $60 \mathrm{~min}$.

Figure 3-101 shows the out-of-plane displacements at different stages of the analysis. As can be seen, the maximum inward bowing was $7.5 \mathrm{in}$. at $20 \mathrm{~min}$, located approximately at the middle of Floor 81 of the east wall. This agreed well with the observed displacements, which showed maximum inward displacement of about $10 \mathrm{in}$. around the middle of Floor 81 . In the earlier trial with a uniform $0.5 \mathrm{kip}$ magnitude of pull-in force, the inward bowing started to decrease with increasing time after $20 \mathrm{~min}$, and at around $40 \mathrm{~min}$ it bowed outward The bowing at $50 \mathrm{~min}$ was mostly outward, disagreeing with the observed displacements. In the second trial, the magnitude of the pull-in force on the south half was increased from 1.0 to $1.5 \mathrm{kip}$, and on the north half was increased from 4.0 to $5.0 \mathrm{kip}$. This analysis ran to $50 \mathrm{~min}$, at which point the analysis failed to converge. Figure 3-102 shows the magnitude of inward bowing at different stages of the analysis. The maximum inward bowing in this trial was 9.5 in. at 20 min, located approximately at the middle of Floor 81 of the east wall. This result agreed well with the observed displacements. The inward bowing continued to increase with time and reached a maximum of 37 in. at $50 \mathrm{~min}$. As seen in Fig. 3-102, the location of the maximum displacements agreed well with the observations. However, the magnitude of the calculated displacements was about twice the magnitude of the observed displacements.

From these trial runs, it was concluded that the magnitude of pull-in forces ranged from $1.0 \mathrm{kip}$ to $1.5 \mathrm{kip}$ on the south half and from 4.0 kip to $5.0 \mathrm{kip}$ on the north half of the east wall. Based on these ranges, and also considering the possible increase in column loads of the east face after impact for Case D conditions, a pull-in force of $1.0 \mathrm{kip}$ on the south half and $4.0 \mathrm{kip}$ on the north half of the east wall was initially selected for the global model analysis with creep. As will be discussed in Chapter 4, at $30 \mathrm{~min}$, the magnitude of the pull-in force was increased to $1.5 \mathrm{kip}$ on the south half and decreased to $3.0 \mathrm{kip}$ on the north half of the east wall and kept constant after that time. 


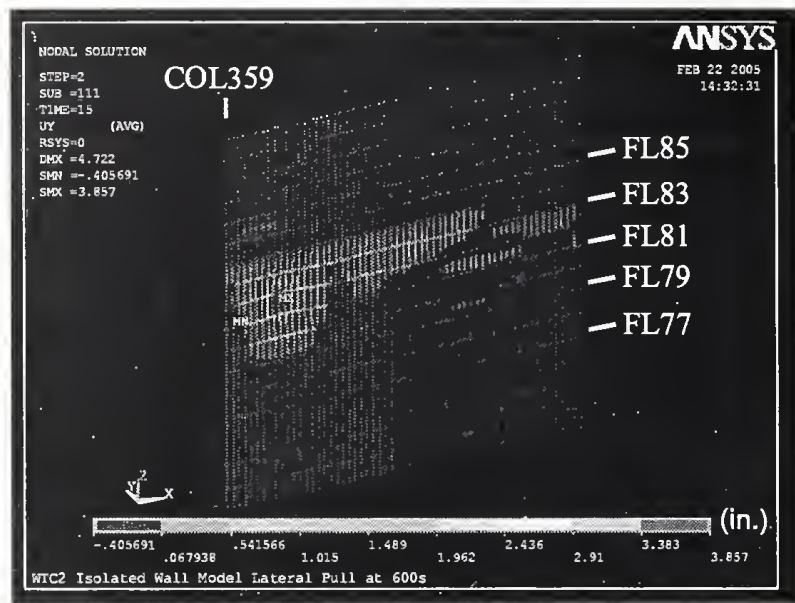

(a) At $10 \mathrm{~min}$

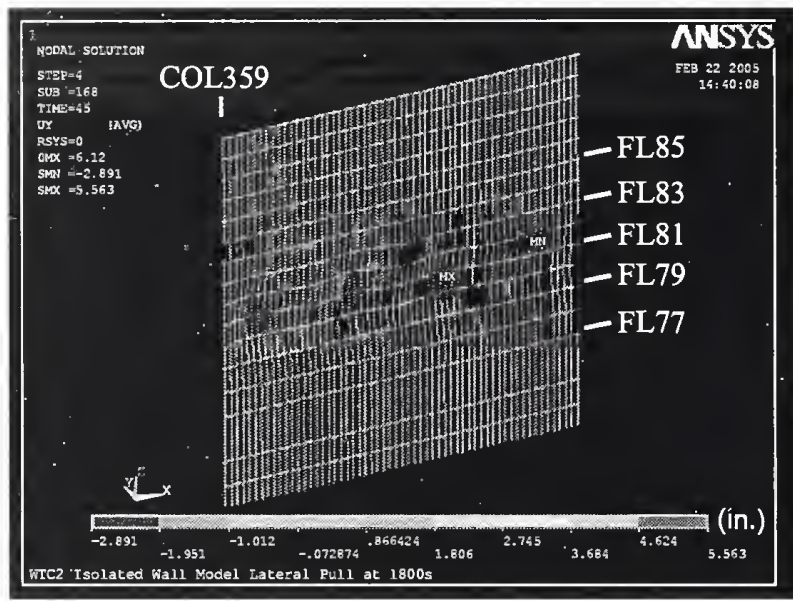

(c) At $30 \mathrm{~min}$

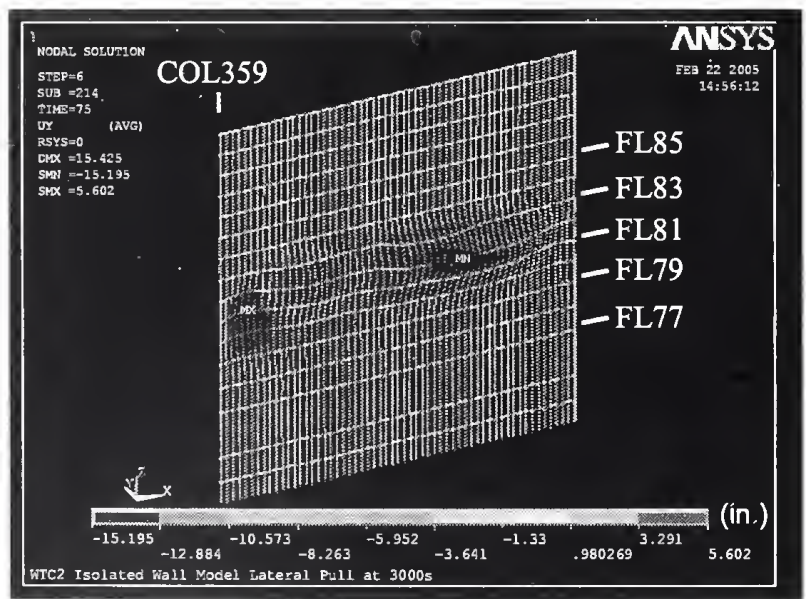

(e) At $50 \mathrm{~min}$

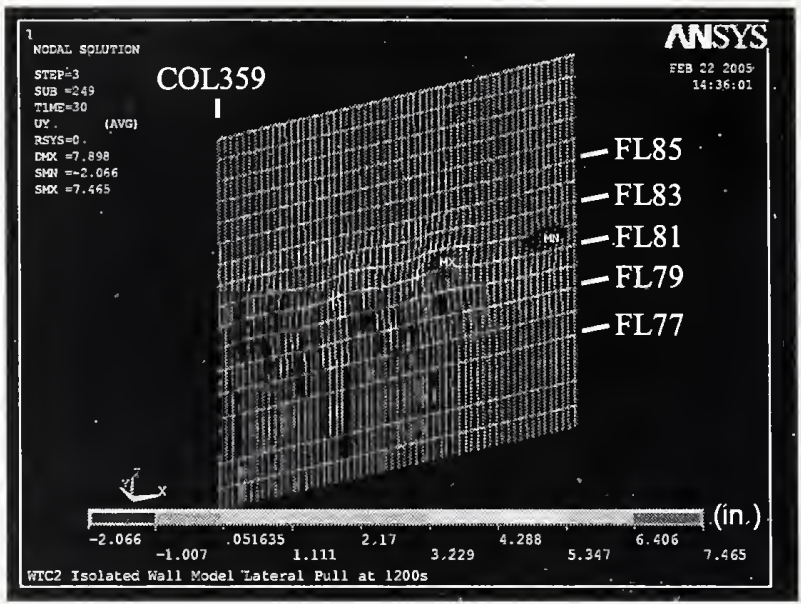

(b) At $20 \mathrm{~min}$

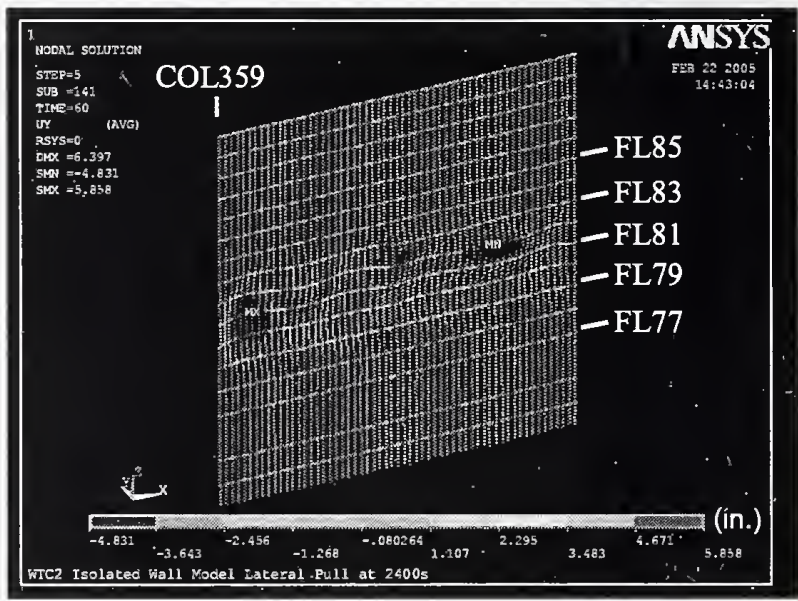

(d) At $40 \mathrm{~min}$

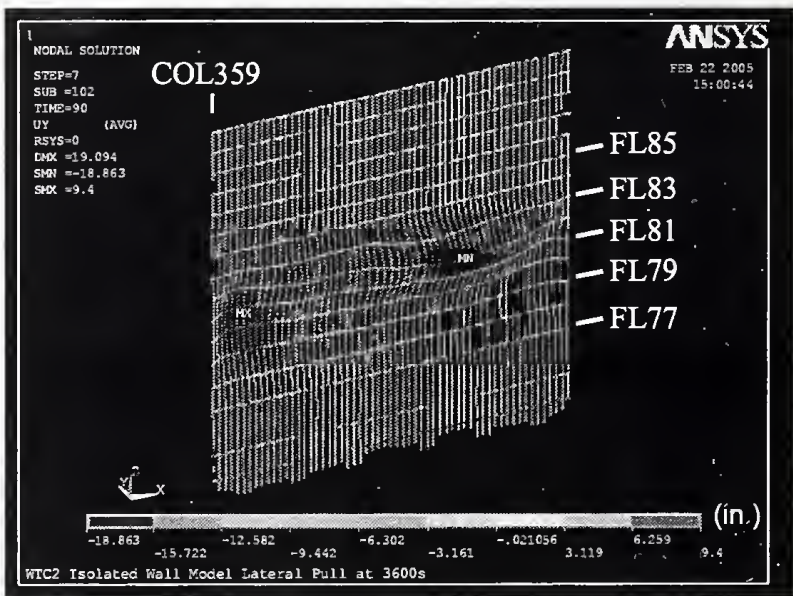

(f) At $60 \mathrm{~min}$

Figure 3-101. Out-of-plane displacement of isolated east wall model of WTC 2 with nonuniform pull-in force with magnitude of $1.0 \mathrm{kip}$ on the south half and $4.0 \mathrm{kip}$ on the north half (inward displacement is positive). 


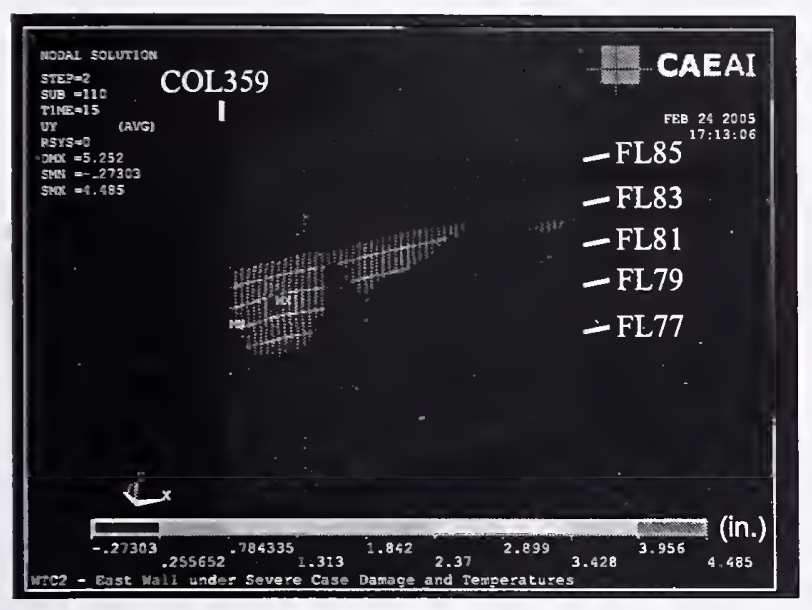

(a) At $10 \mathrm{~min}$

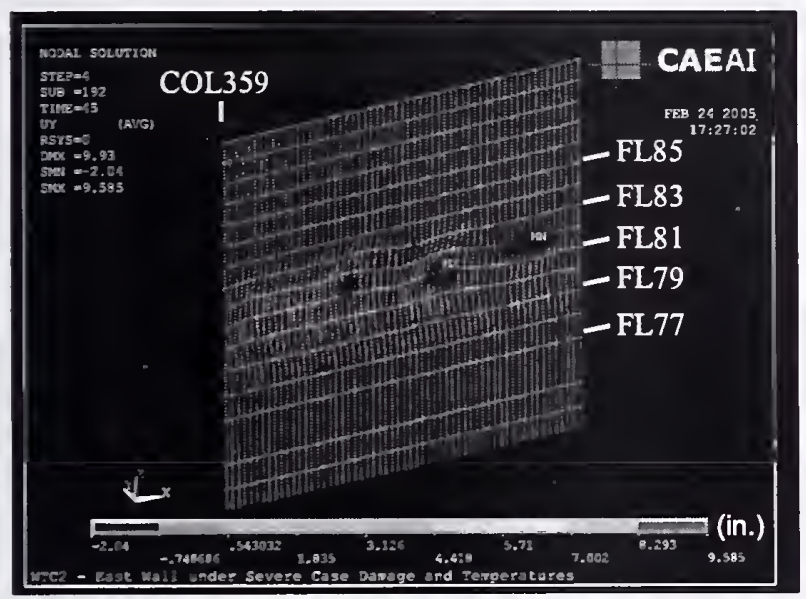

(c) At $30 \mathrm{~min}$

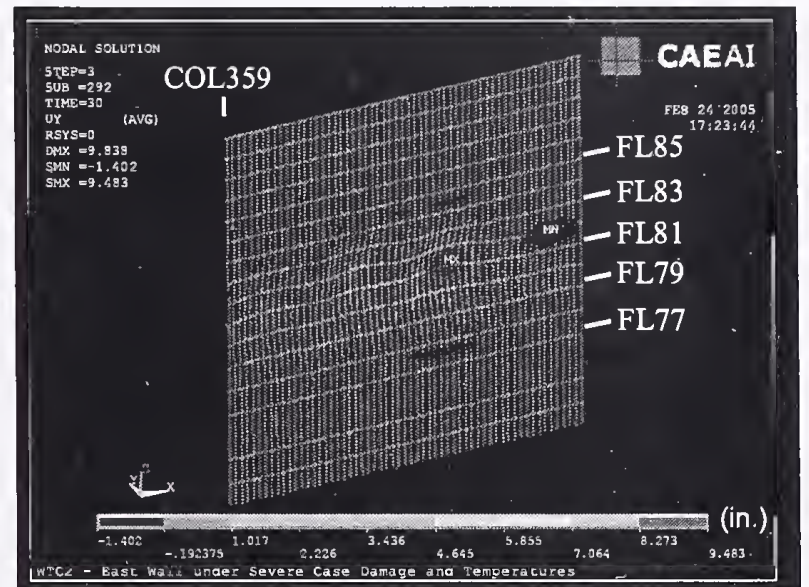

(b) At $20 \mathrm{~min}$

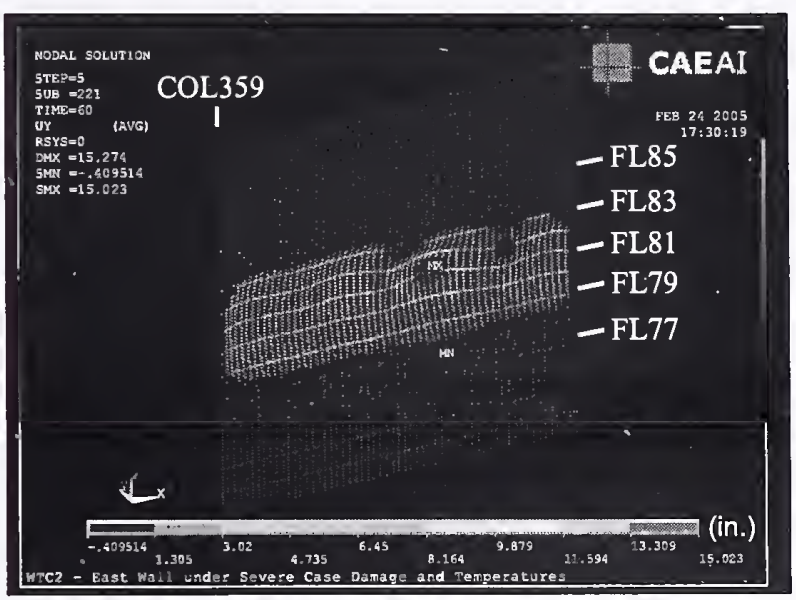

(d) At $40 \mathrm{~min}$

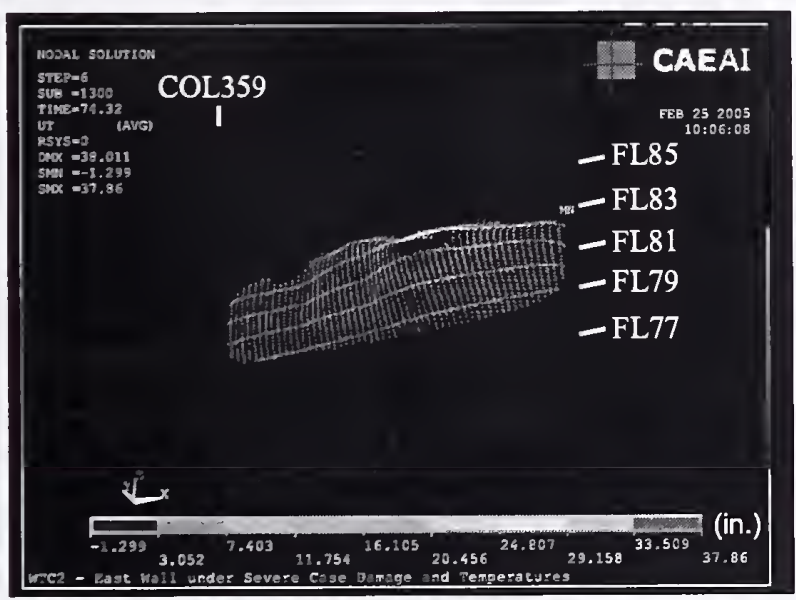

(e) At $50 \mathrm{~min}$

Figure 3-102. Out-of-plane displacement of isolated east wall model of WTC 2 with nonuniform pull-in force with magnitude of $1.5 \mathrm{kip}$ on the south half and $5.0 \mathrm{kip}$ on the north half (inward displacement is positive). 


\subsection{CORE COLUMN SHORTENING AND DOWNWARD DISPLACEMENT OF CORE}

To examine whethcr or not the core columns shortened and the core displaced downward when subjected to fire-induced temperature loads, the core models were isolated from the global models of WTC 1 and WTC 2. The isolated core models extended from Floor 89 to Floor 106 for WTC 1 and from Floor 73 to Floor 106 for WTC 2, and did not include any parts of their hat trusses. At the base of the models, vertical springs connected Floor 89 and Floor 73 to fixed ground; the spring stiffness represented the vertical stiffness of the columns below. The isolated core models included core columns, core beams, and core slabs, as in the global models (see Chapter 4 for dctails).

The WTC 2 core model was restrained in two horizontal directions at every floor level to represent the lateral restraint of the exterior walls. Without the lateral restraints, the WTC 2 core model would tilt significantly, due to the extensive impact damage to the southeast part of the core. The WTC 1 core model was not restrained in the horizontal directions at floor levels.

Gravity dead and live loads were directly obtained from the global models and applied to the core model nodes. Internal forces and moments of the columns of Floor 106 of the global models after aircraft impact were imposed at the ends of the Floor 106 columns of the isolated core models. Only the Case A structural damage condition was used for the WTC 1 core model, and only the Case C structural damage condition was used for the WTC 2 core model. The isolated core models with Case B and Case D structural damage conditions were also run, but the models did not converge, even with lateral restraints.

The models were then subjected to two temperature conditions for each tower: Case $\mathrm{A}$ and Case $\mathrm{B}$ (for WTC 1) and Case C and Case D (for WTC 2). Temperature data were provided at 10 min intervals up to $100 \mathrm{~min}$ for WTC 1 and up to $60 \mathrm{~min}$ for WTC 2.

Since the models included only the core, the load transfer between the core and the exterior wall through either the hat truss or floors was not captured.

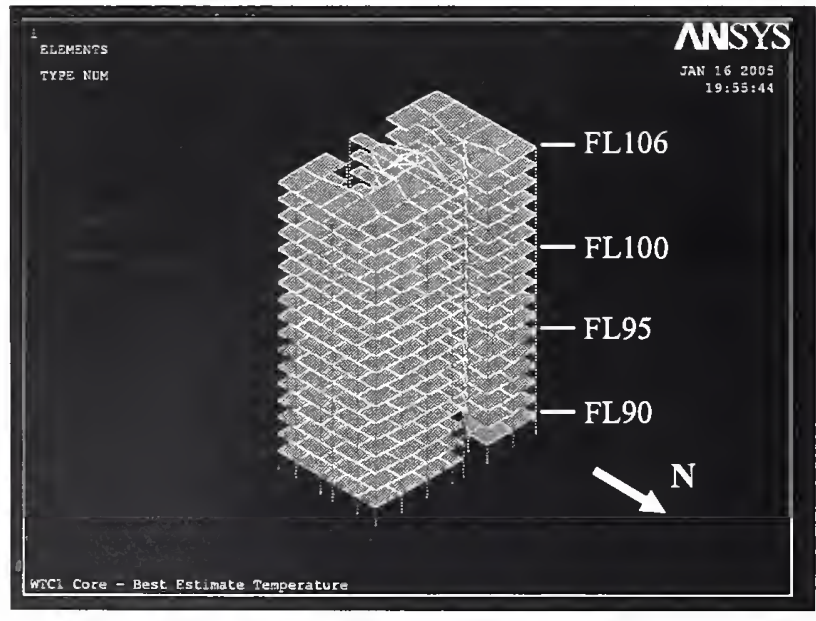

(a) WTC 1

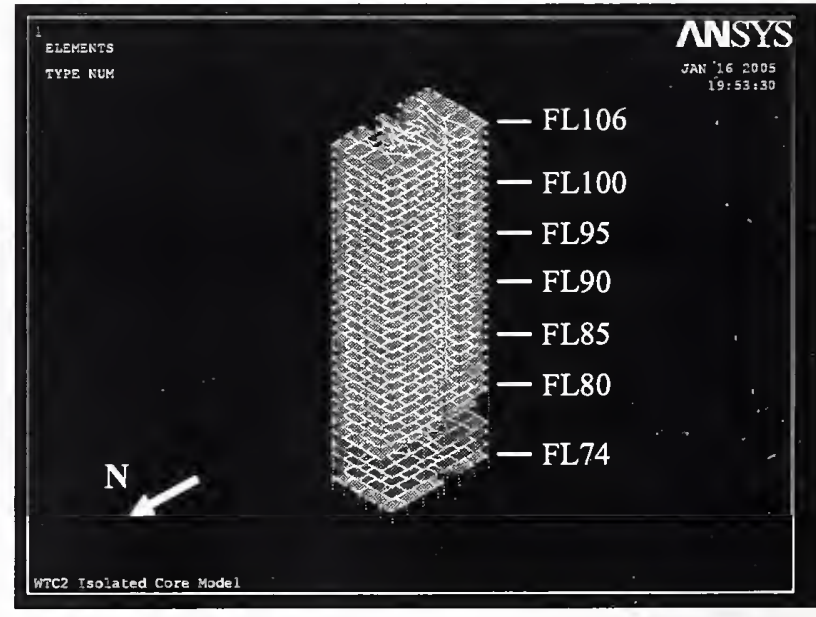

(b) WTC 2

Figure 3-103. Isolated core models. 


\subsubsection{FEA of WTC 1 Core}

\section{Case A Temperature Condition}

Figures 3-104 to 3-111 show the vertical displacements of the WTC 1 isolated core model subjected to Case A temperatures from aircraft impact to $100 \mathrm{~min}$. At $30 \mathrm{~min}$, the vertical displacement of the northwest corner at Column 501 became large above Floor 98, and grew larger with time. The core started to tilt toward the northwest corner at $30 \mathrm{~min}$, and the analysis was terminated due to nonconvergence. The analysis was restarted at $30 \mathrm{~min}$ by restraining corner Column 501 in the horizontal directions at floor levels above Floor 98 to represent lateral restraint from the exterior walls and office floors. At $100 \mathrm{~min}$, the maximum vertical displacement of $21.7 \mathrm{in}$. occurred at Column 501 . Figures 3-114 and 3-115 show axial loads and plastic strains in the core columns at $100 \mathrm{~min}$. Columns at the northwest corner experienced large plastic strains. The maximum plastic strain was about 14 percent.

The vertical displacement at Floor 106 at 100 min ranged from 3.3 in. to 21.7 in. The maximum vertical displacement of the south side was limited to 11.2 in. at Column 1004. The average vertical displacement of Floor 106 was 7.4 in. The average vertical displacement of the south side at Floor 106 was 6.0 in. Considering the average vertical displacement of $5 \mathrm{in}$. after the aircraft impact, the average additional downward displacement of the core due to thermal loads was about 2 in.

To determine the additional axial load-carrying capacity of the core, the isolated core model at 100 min was pushed down by imposing additional incremental vertical displacement. The analysis was converted from a force-control analysis to a displacement-control analysis by imposing the vertical displacements calculated at $100 \mathrm{~min}$ under force control and then imposing additional vertical displacement increments on the top of the columns at Floor 106. The analysis was terminated when the additional vertical displacement reached 9.5 in. Figure 3-116 shows the total vertical displacements of the modcl at the end of the push-down analysis. Figure 3-117 shows the relationship between the total additional vertical force and the additional vertical displacement. The additional vertical force reached its maximum at 7.2 in. of additional vertical displacement. Figure 3-118 shows the additional axial loads in columns of Floor 98 when the total additional vertical force is at its maximum. The maximum total additional vertical force of 37,142 kip was about 95 percent of the total column force at Floor 98 prior to push-down. Thcrefore, the core still had significant reserve capacity at the end of Case A temperature condition. 


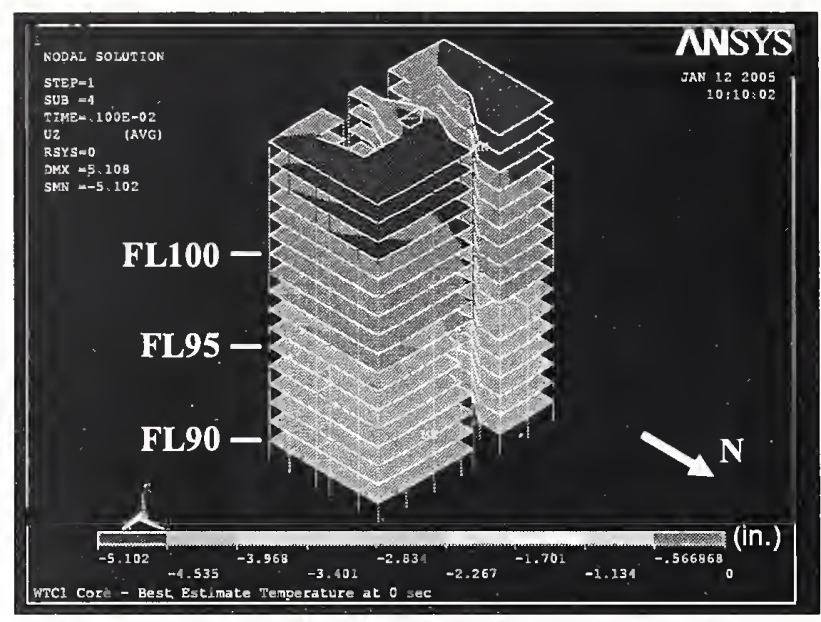

(a) North and east sides

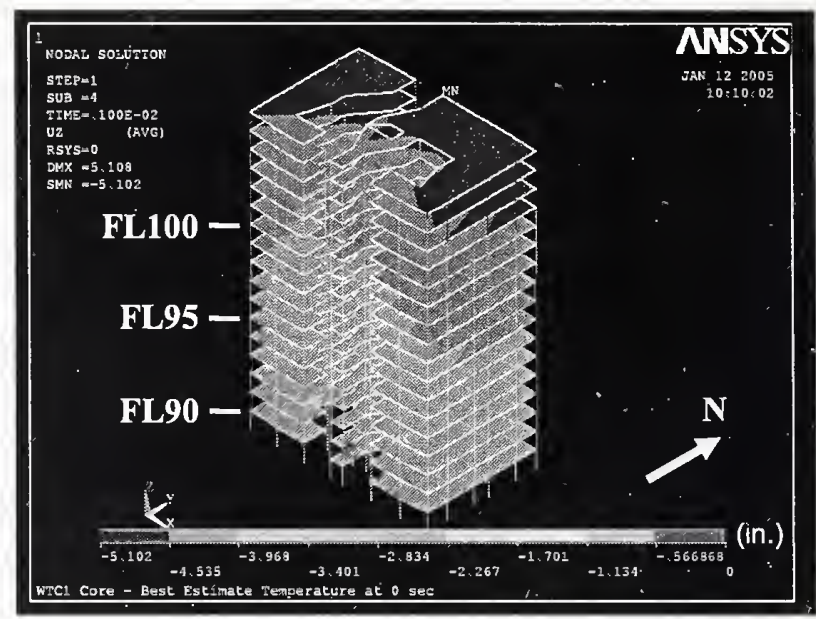

(b) South and east sides

Figure 3-104. Vertical displacement of isolated core model of WTC 1 after aircraft impact (downward displacement is negative).

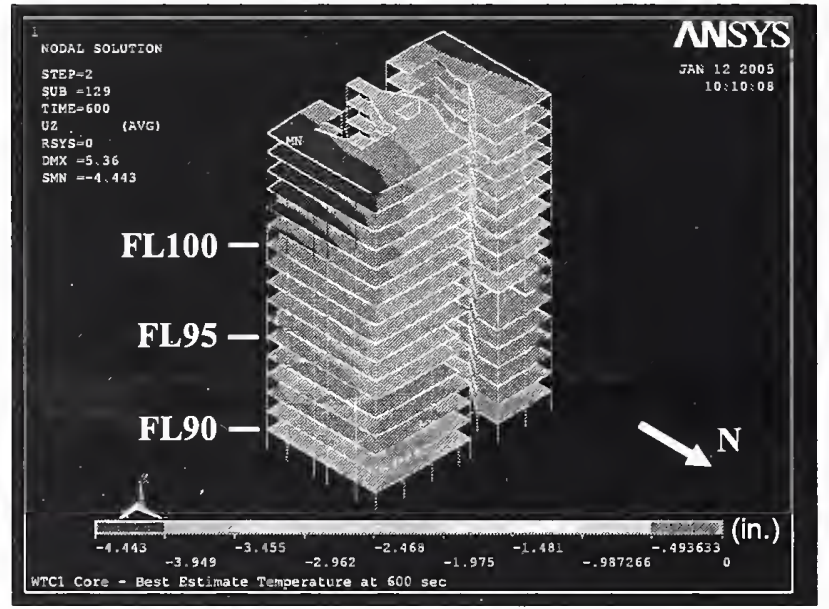

(a) North and east sides

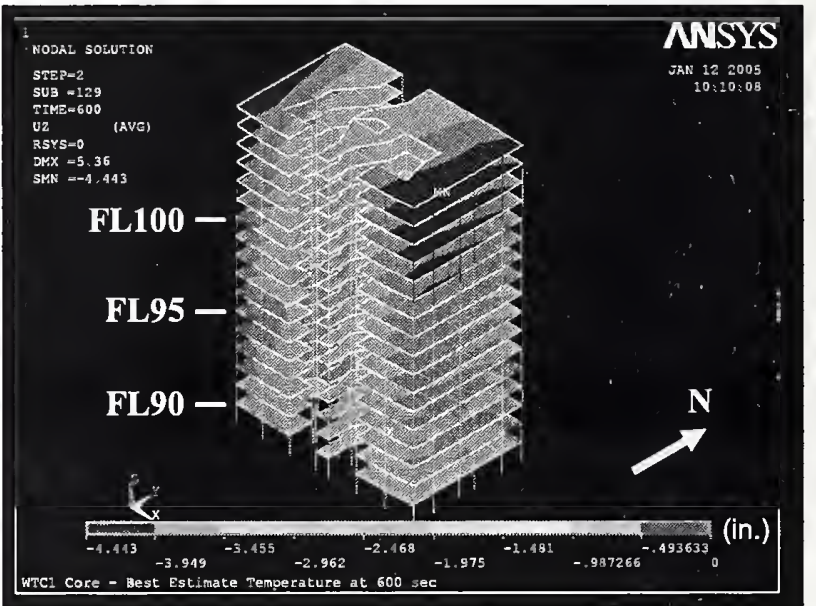

(b) South and east sides

Figure 3-105. Vertical displacement of isolated core model of WTC 1 for Case A temperature condition at $10 \mathrm{~min}$ (downward displacement is negative). 


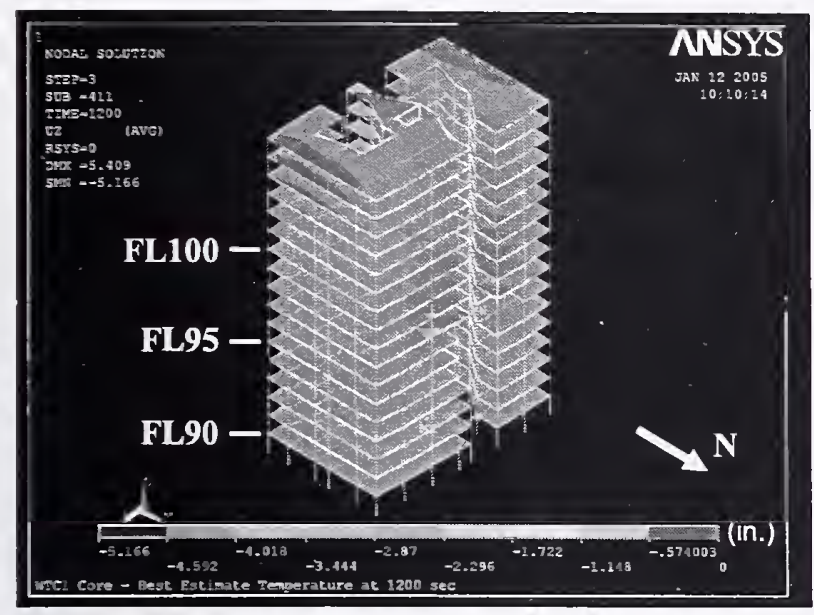

(a) North and east sides

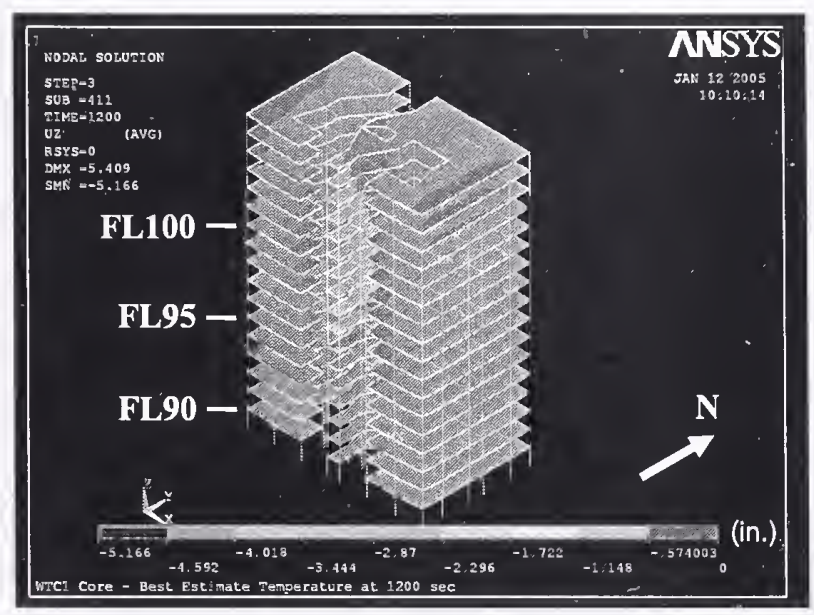

(b) South and east sides

Figure 3-106. Vertical displacement of isolated core model of WTC 1 for Case A temperature condition at $\mathbf{2 0}$ min (downward displacement is negative).

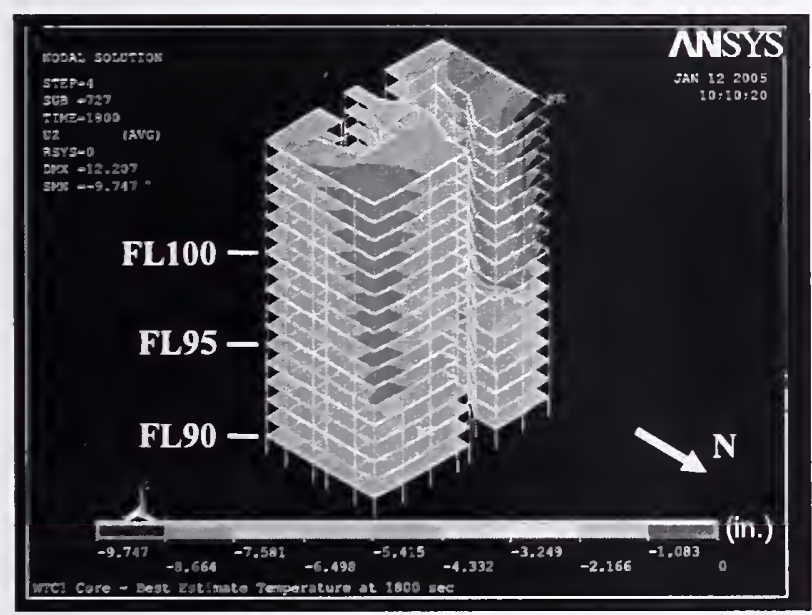

(a) North and east sides

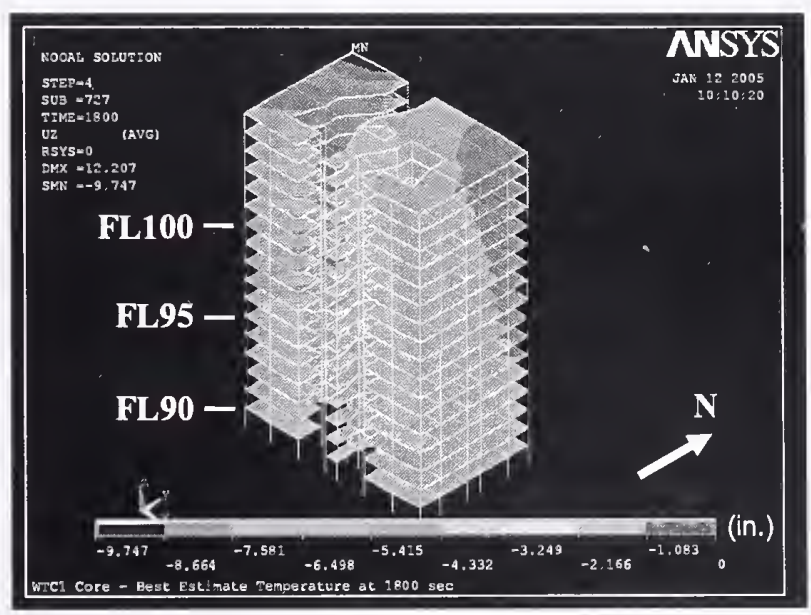

(b) South and east sides

Figure 3-107. Vertical displacement of isolated core model of WTC 1 for Case A temperature condition at $\mathbf{3 0}$ min (downward displacement is negative). 


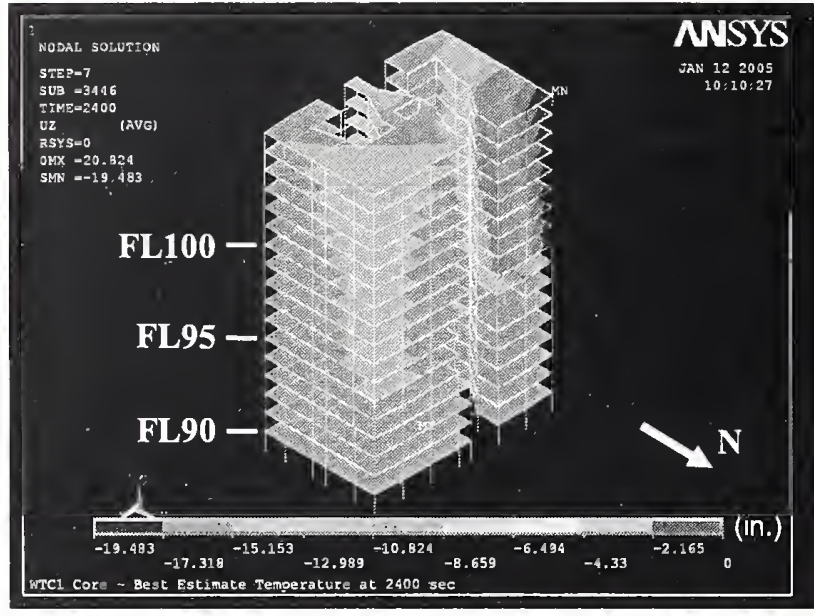

(a) North and east sides

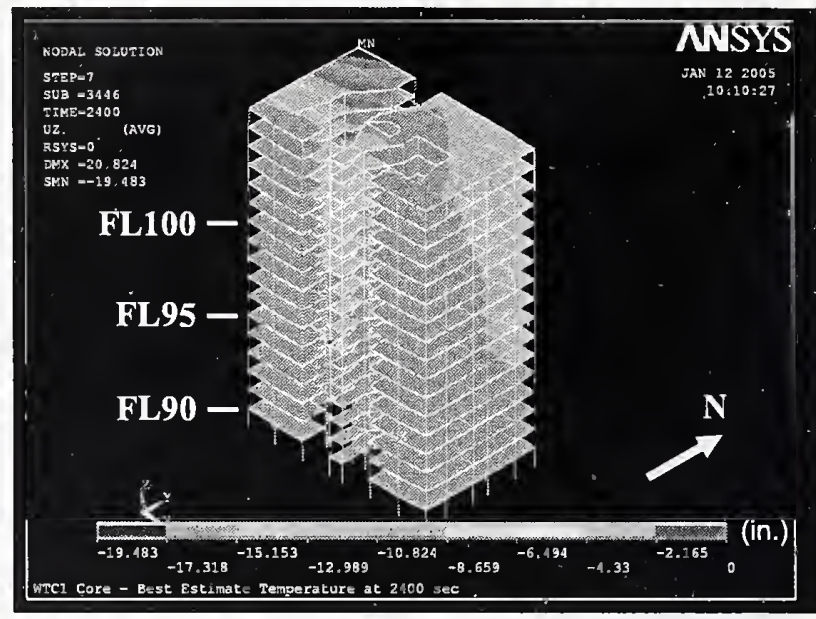

(b) South and east sides

Figure 3-108. Vertical displacement of isolated core model of WTC 1 for Case A temperature condition at $\mathbf{4 0} \mathrm{min}$ (downward displacement is negative).

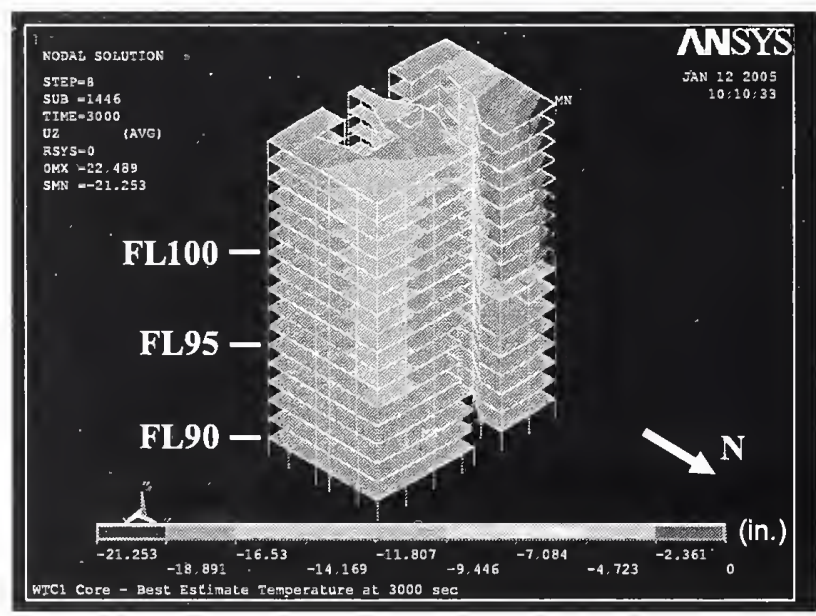

(a) North and east sides

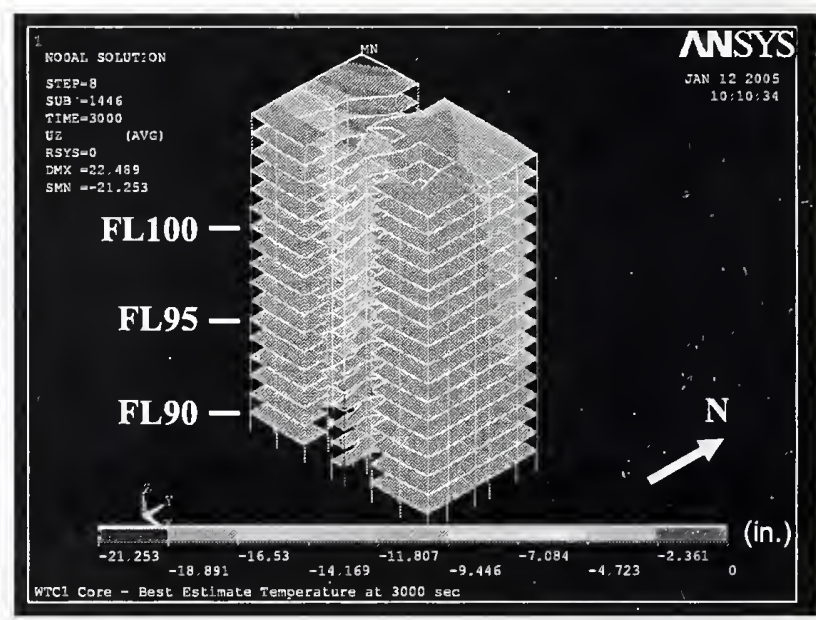

(b) South and east sides

Figure 3-109. Vertical displacement of isolated core model of WTC 1 for Case A temperature condition at $\mathbf{5 0}$ min (downward displacement is negative). 


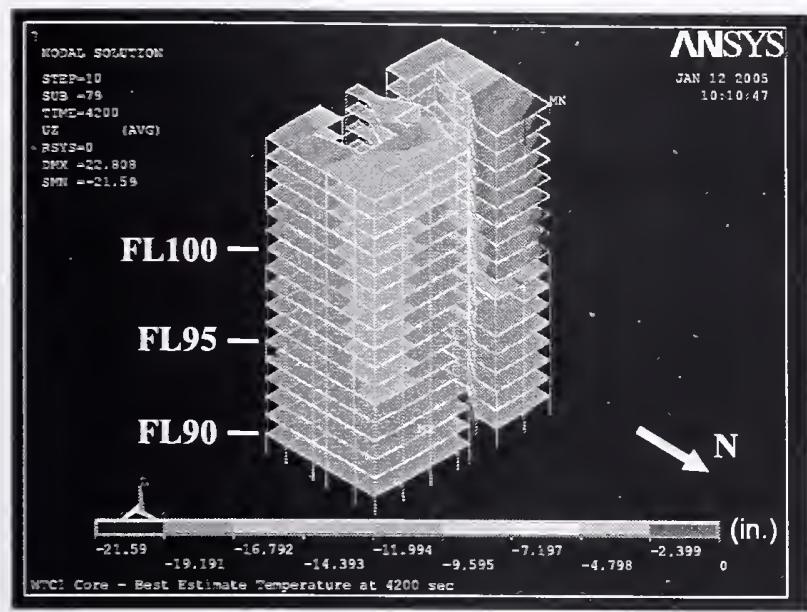

(a) North and east sides

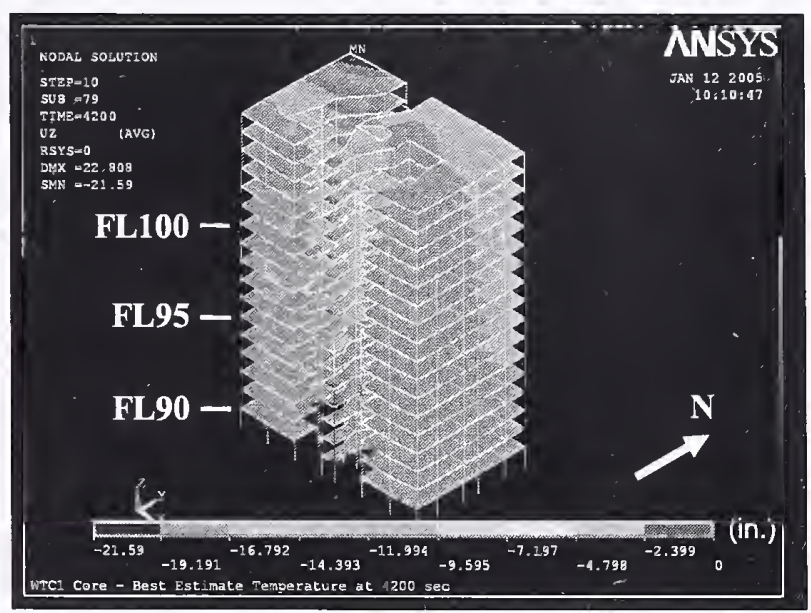

(b) South and east sides

Figure 3-110. Vertical displacement of isolated core model of WTC 1 for Case A temperature condition at $70 \mathrm{~min}$ (downward displacement is negative).

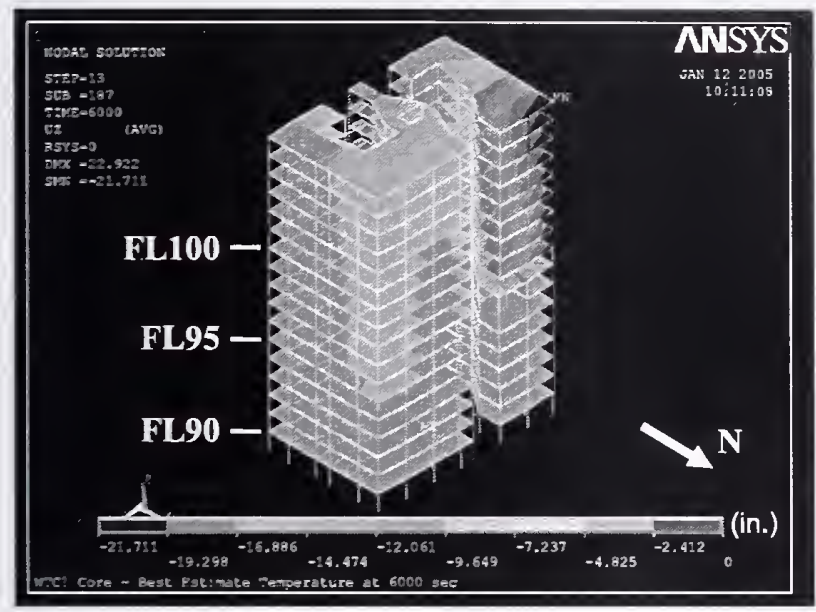

(a) North and east sides

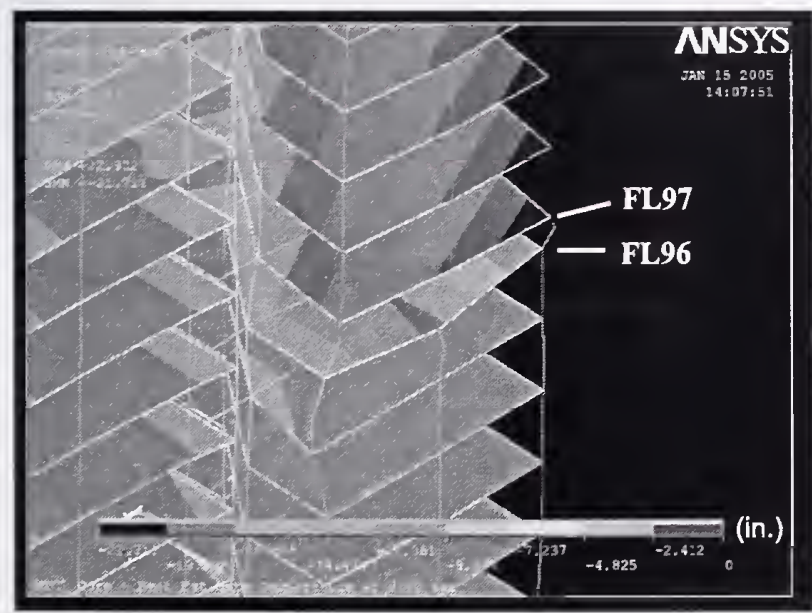

(c) Northwest corner

(5X displacement magnification)

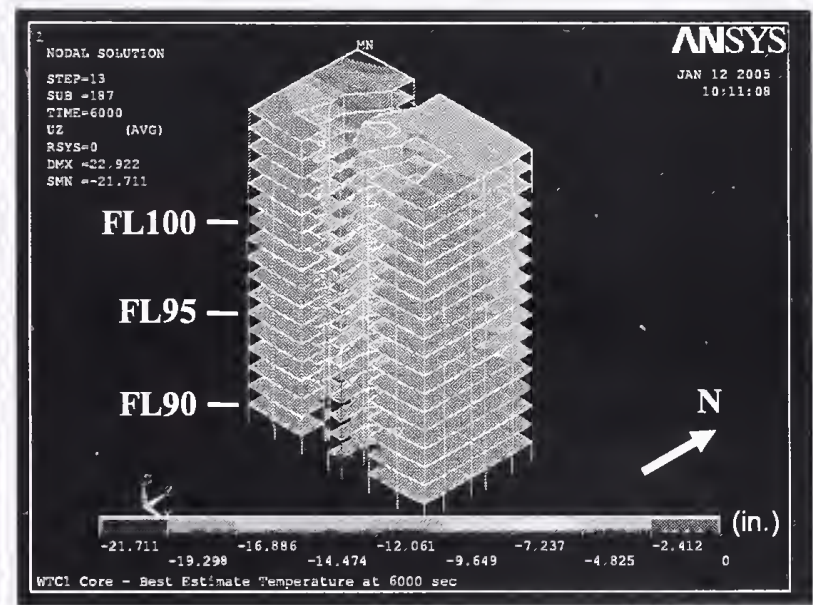

(b) South and east sides

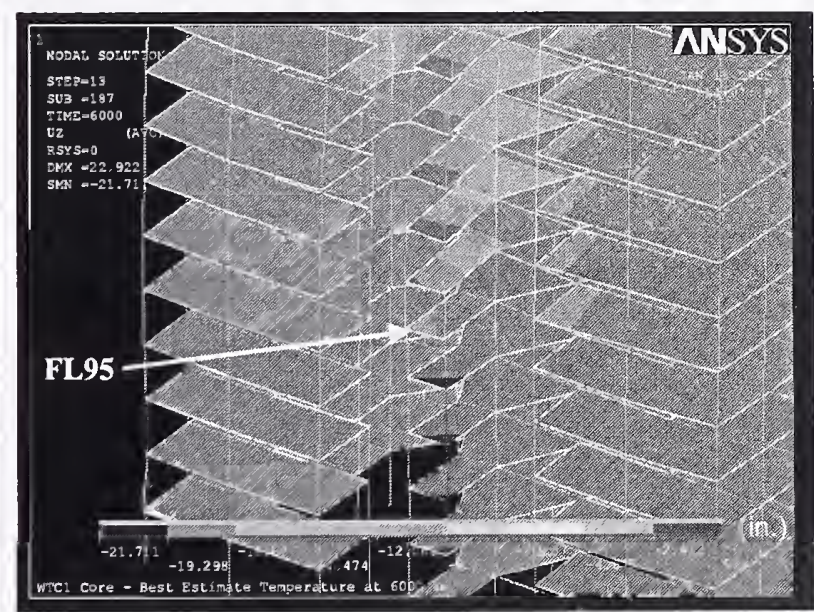

(b) South side

(5X displacement magnification)

Figure 3-111. Vertical displacement of isolated core model of WTC 1 for Case A temperature condition at $100 \mathrm{~min}$ (downward displacement is negative). 


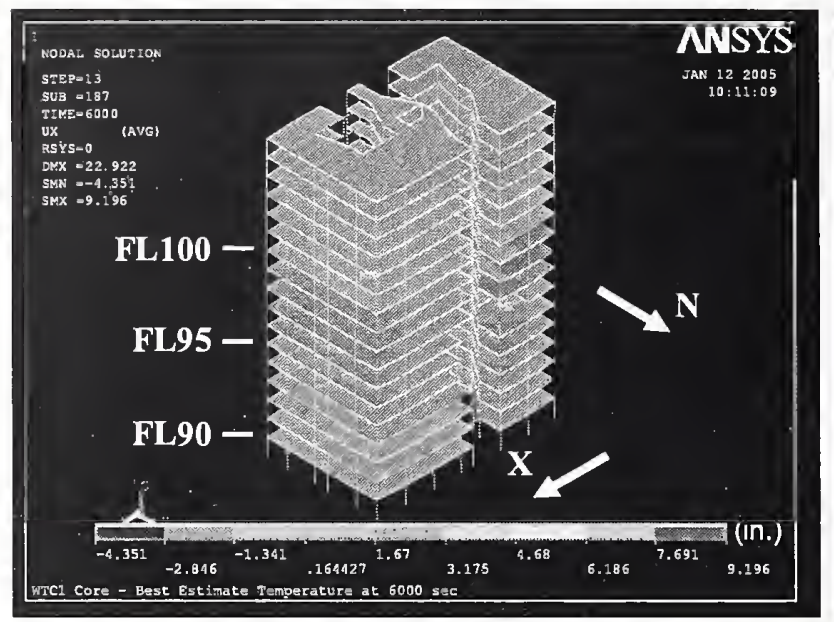

(a) X-displacement of north and east sides

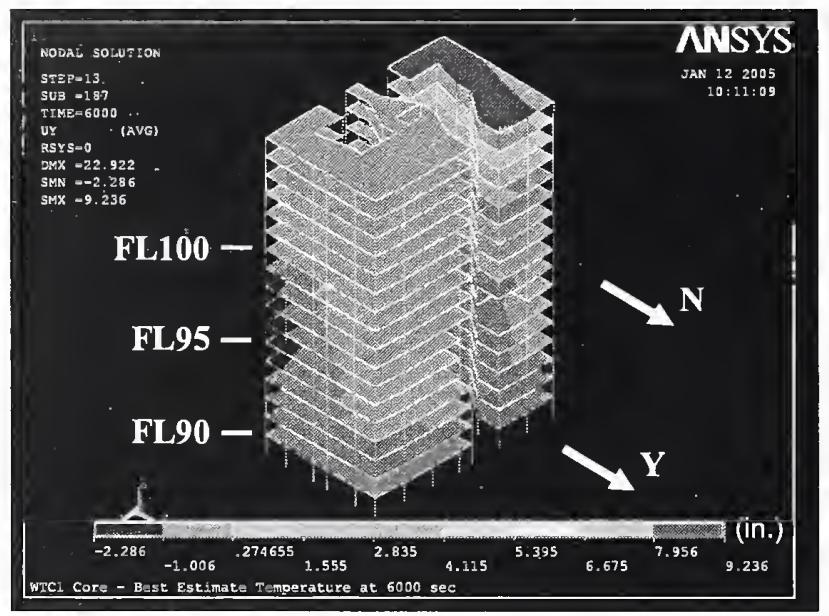

(c) Y-displacement of north and east sides

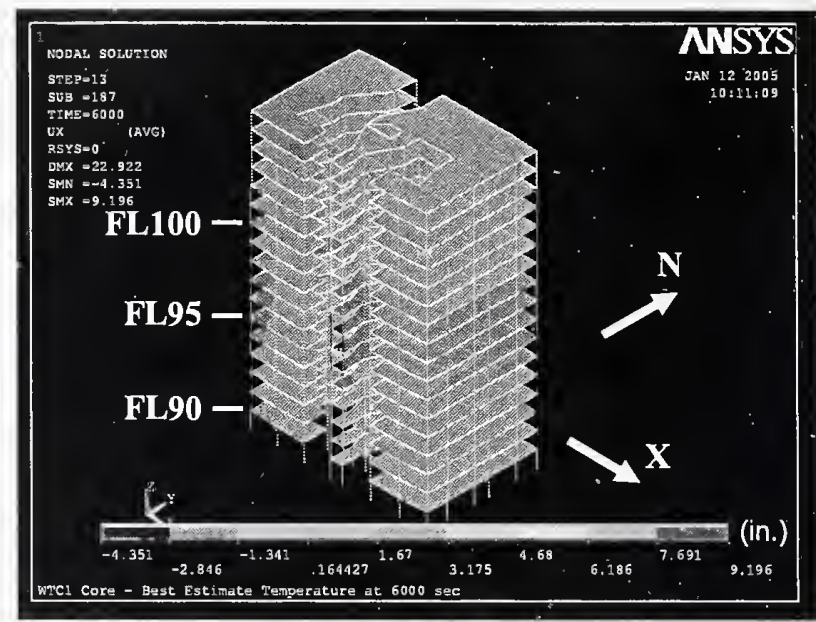

(b) X-displacement of south and east sides

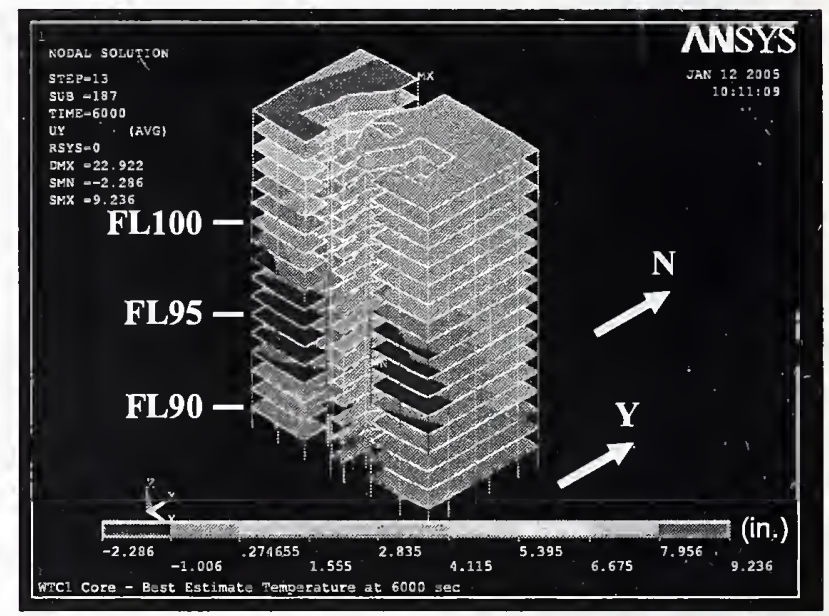

(d) Y-displacement of south and east sides

Figure 3-112. Horizontal displacement of isolated core model of WTC 1 for Case A temperature condition at $100 \mathrm{~min}$. 


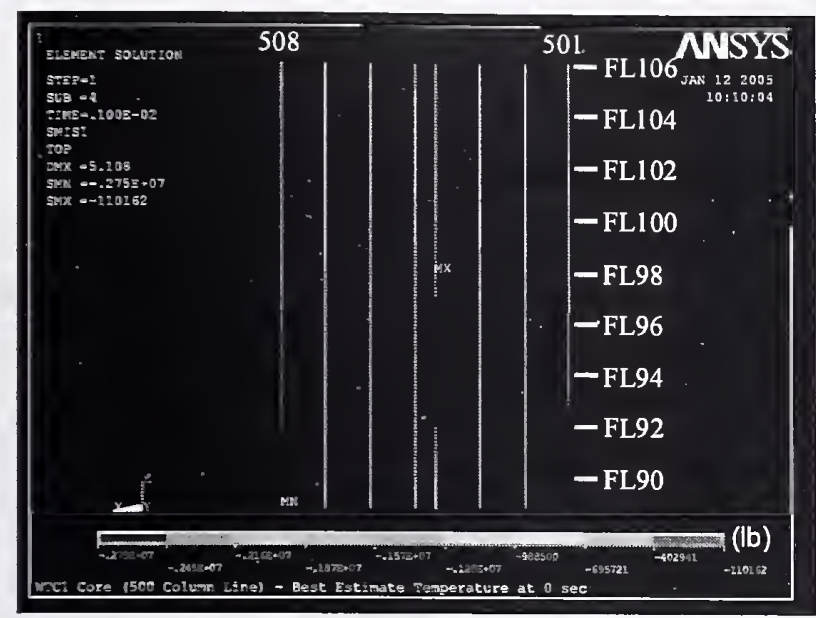

(a) 500 series columns

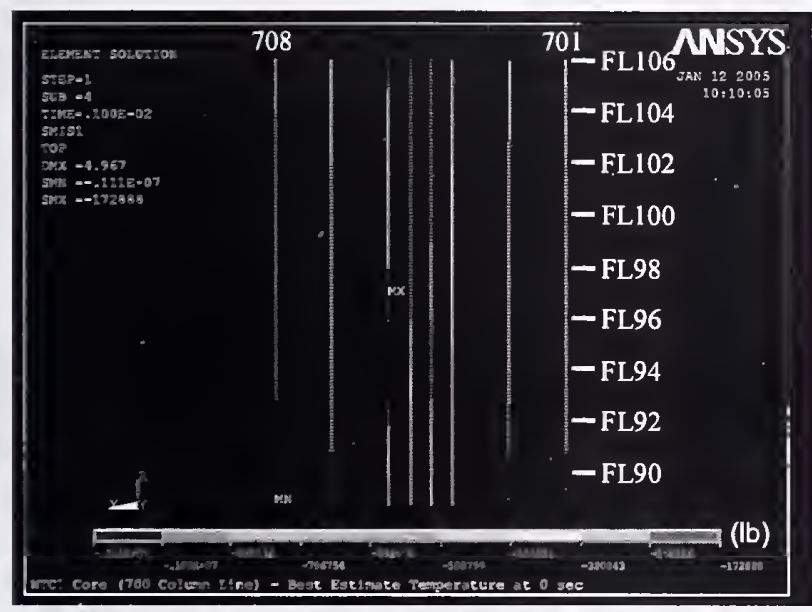

(c) 700 series columns

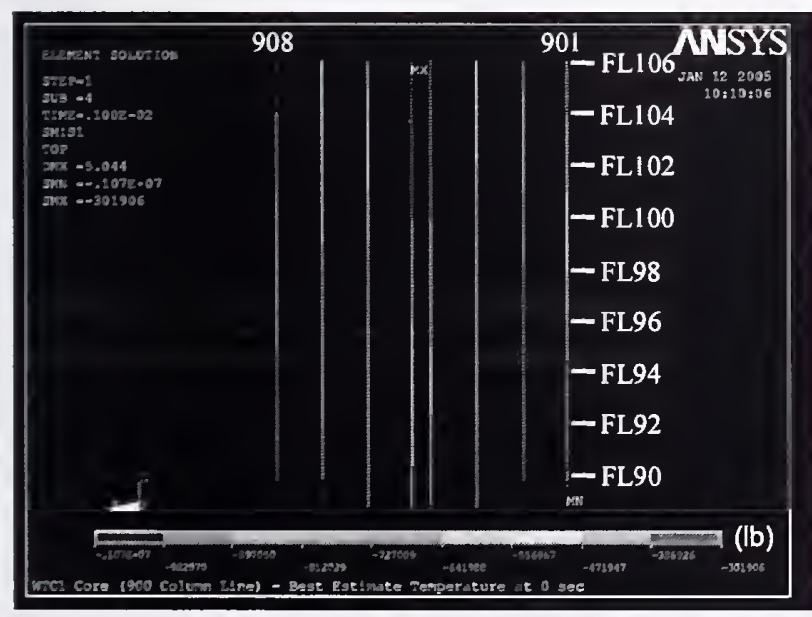

(e) 900 series columns

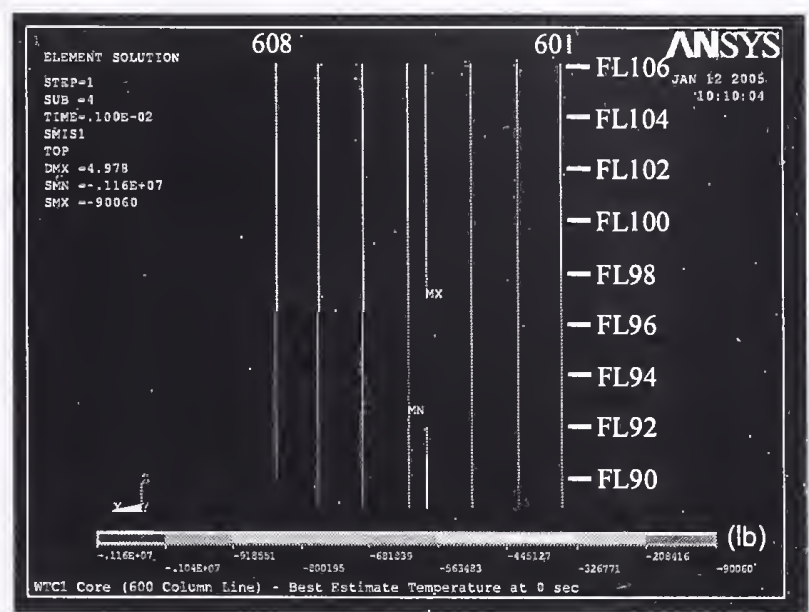

(b) 600 series columns

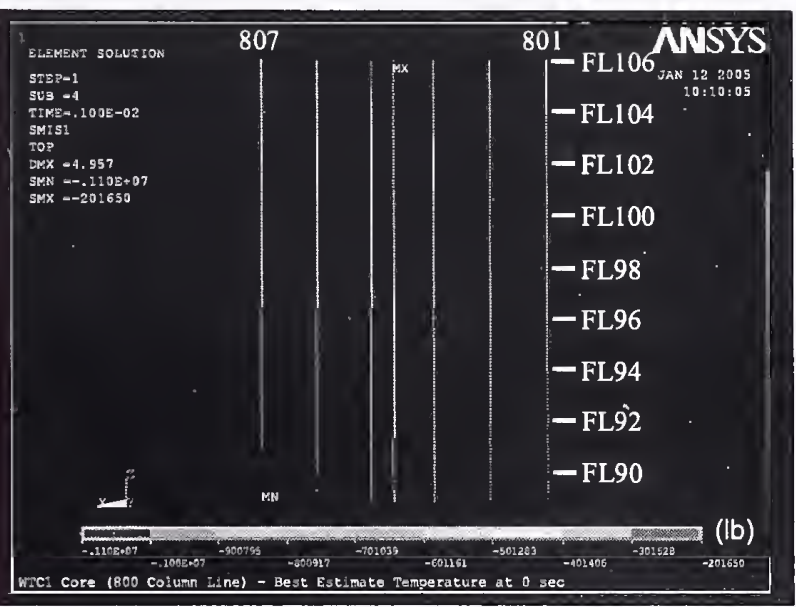

(d) 800 series columns

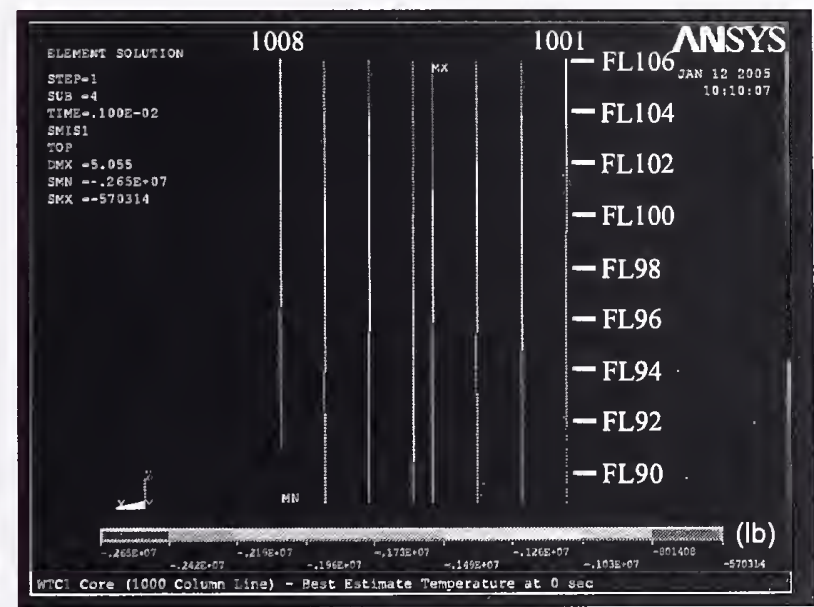

(f) 1000 series columns

Figure 3-113. Axial load in columns of isolated core model of WTC 1 after aircraft impact (compression is negative). 


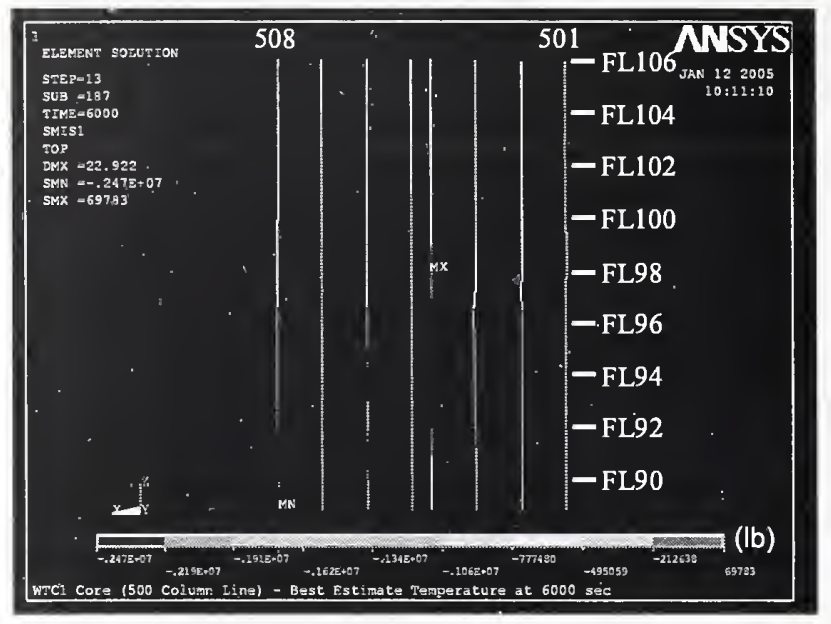

(a) 500 series columns

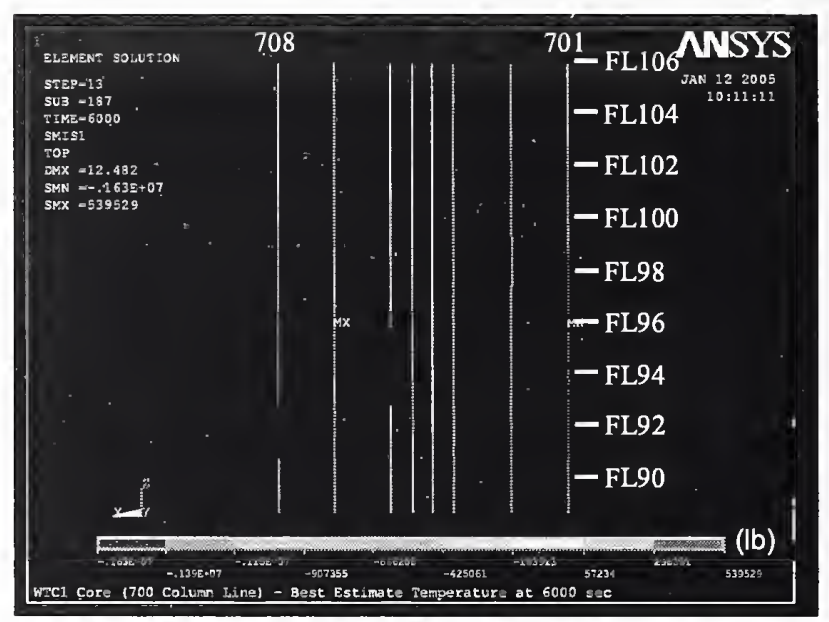

(c) 700 series columns

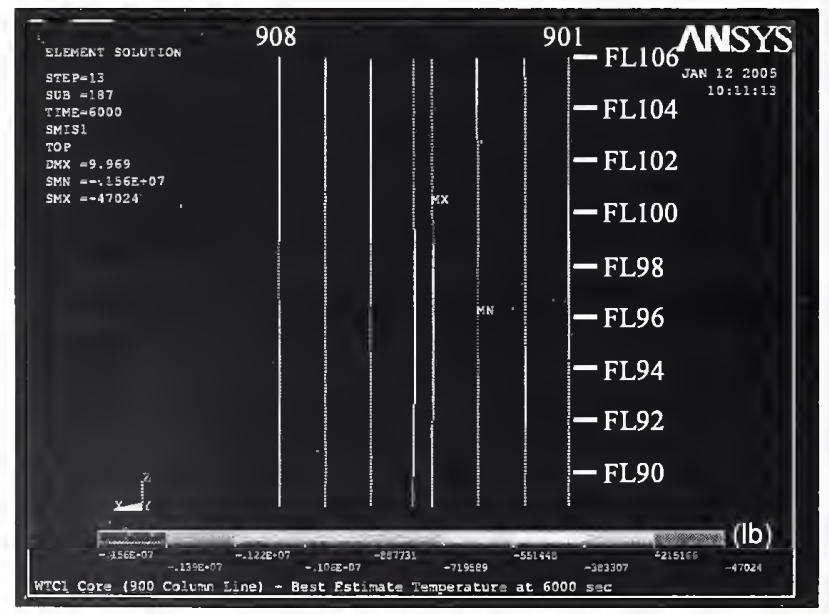

(e) 900 series columns

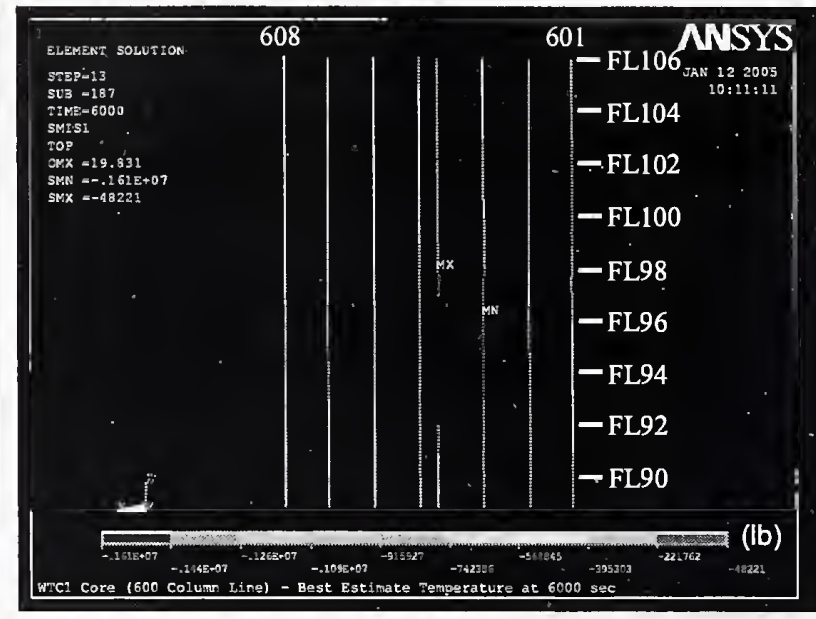

(b) 600 series columns

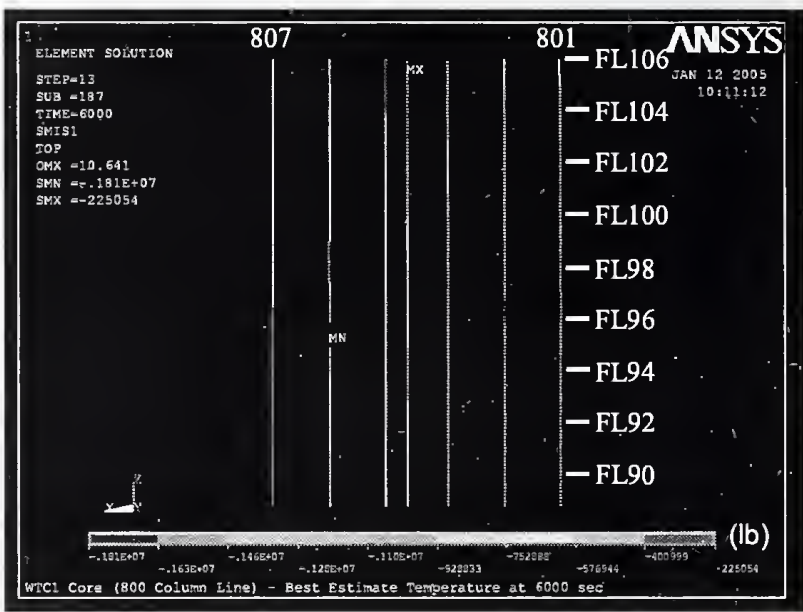

(d) 800 series columns

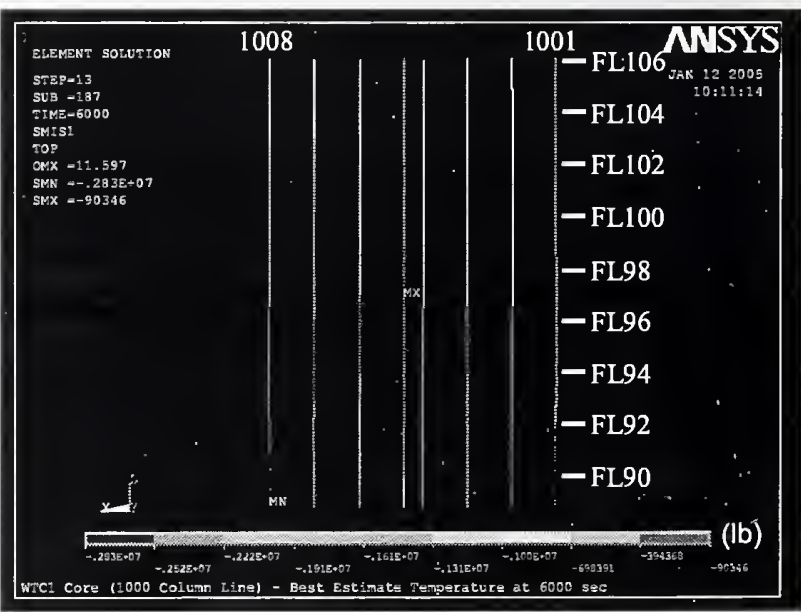

(f) 1000 series columns

Figure 3-114. Axial load in columns of isolated core model of WTC 1 for Case A temperature condition at 100 min (compression is negative). 


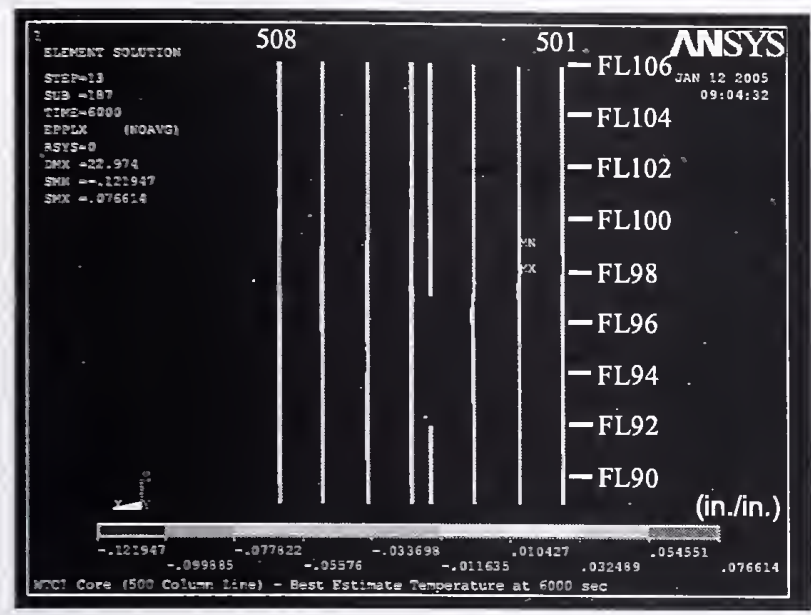

(a) 500 series columns

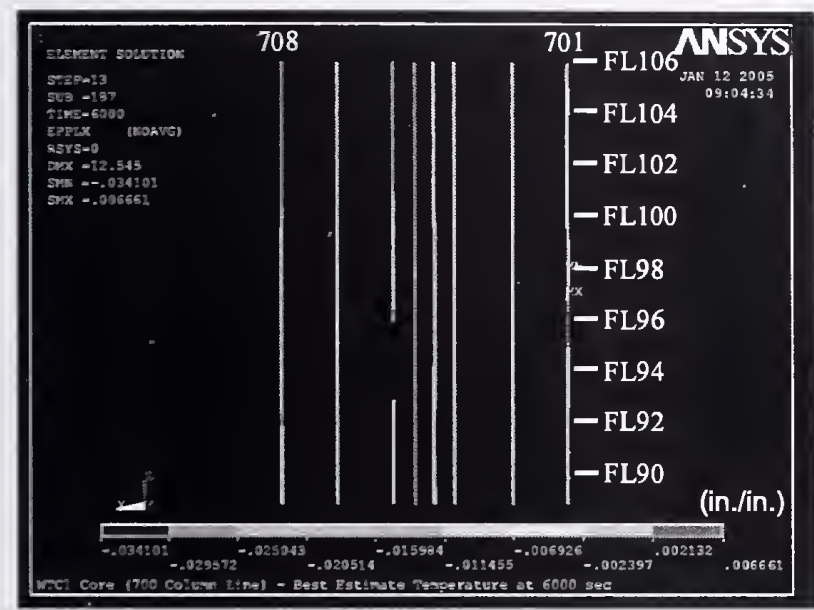

(c) 700 series columns

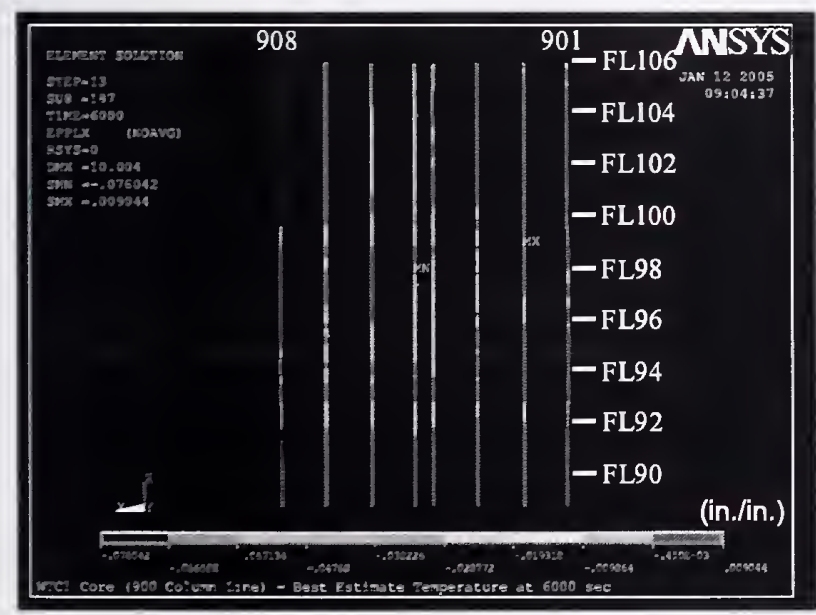

(e) 900 series columns

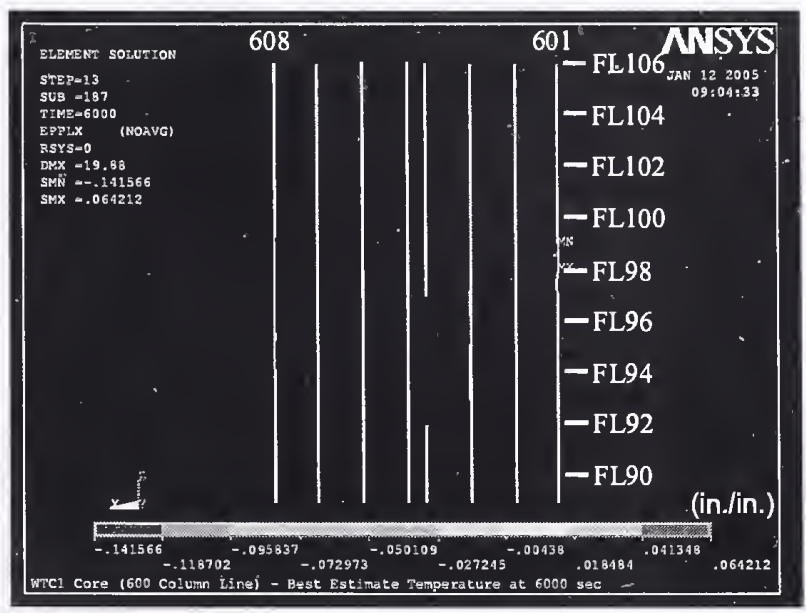

(b) 600 series columns

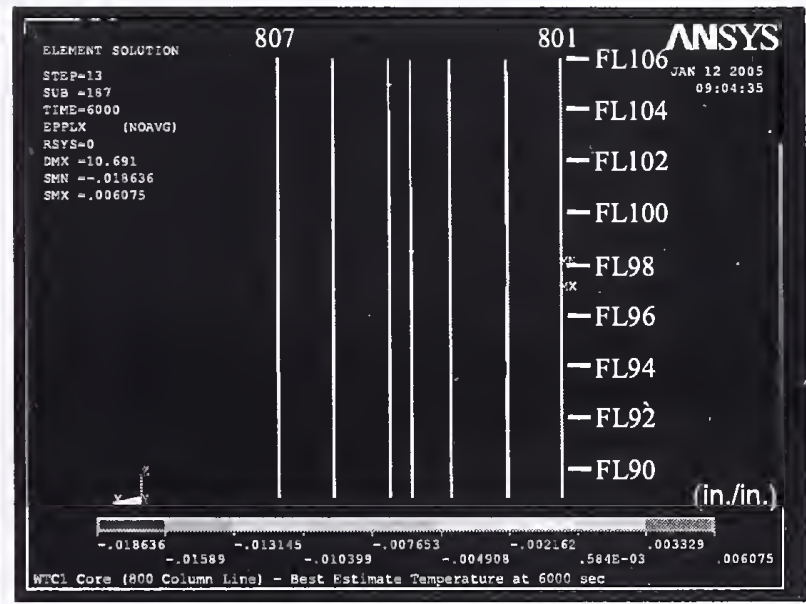

(d) 800 series columns

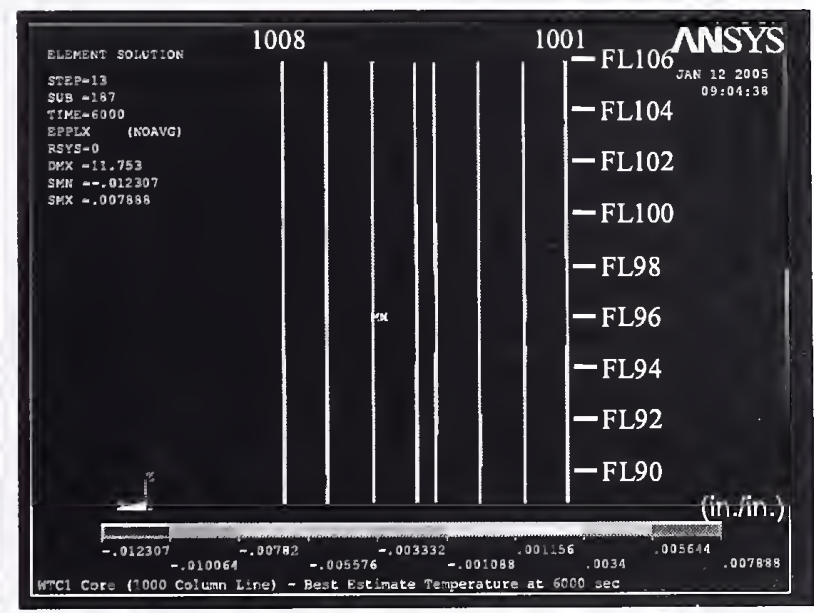

(f) 1000 series columns

Figure 3-115. Plastic strain in columns of isolated core model of WTC 1 for Case A temperature condition at 100 min (compressive strain is negative). 


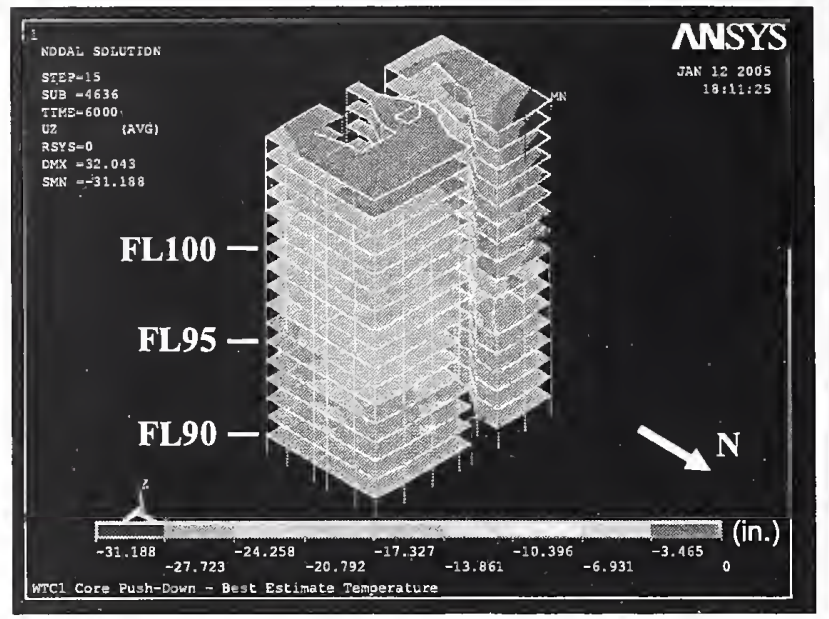

(a) North and east sides

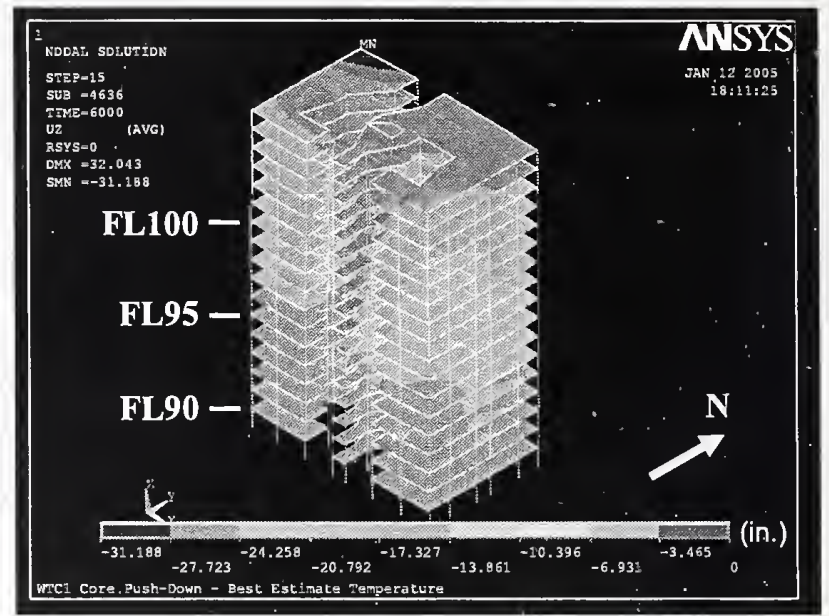

(b) South and east sides

Figure 3-116. Vertical displacement after push down of isolated core model of WTC 1 for Case A temperature condition (downward displacement is negative).

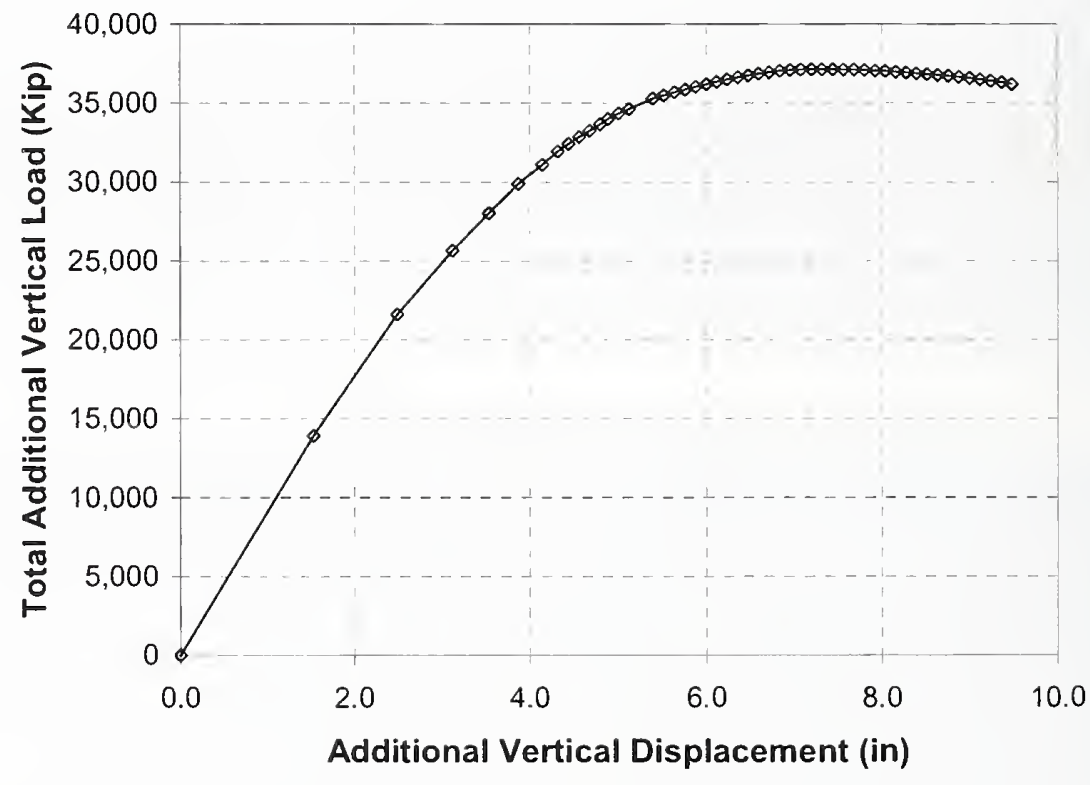

Figure 3-117. Total additional vertical load versus additional vertical displacement during push-down analysis of isolated core model of WTC 1 for Case A temperature condition (compression is positive). 


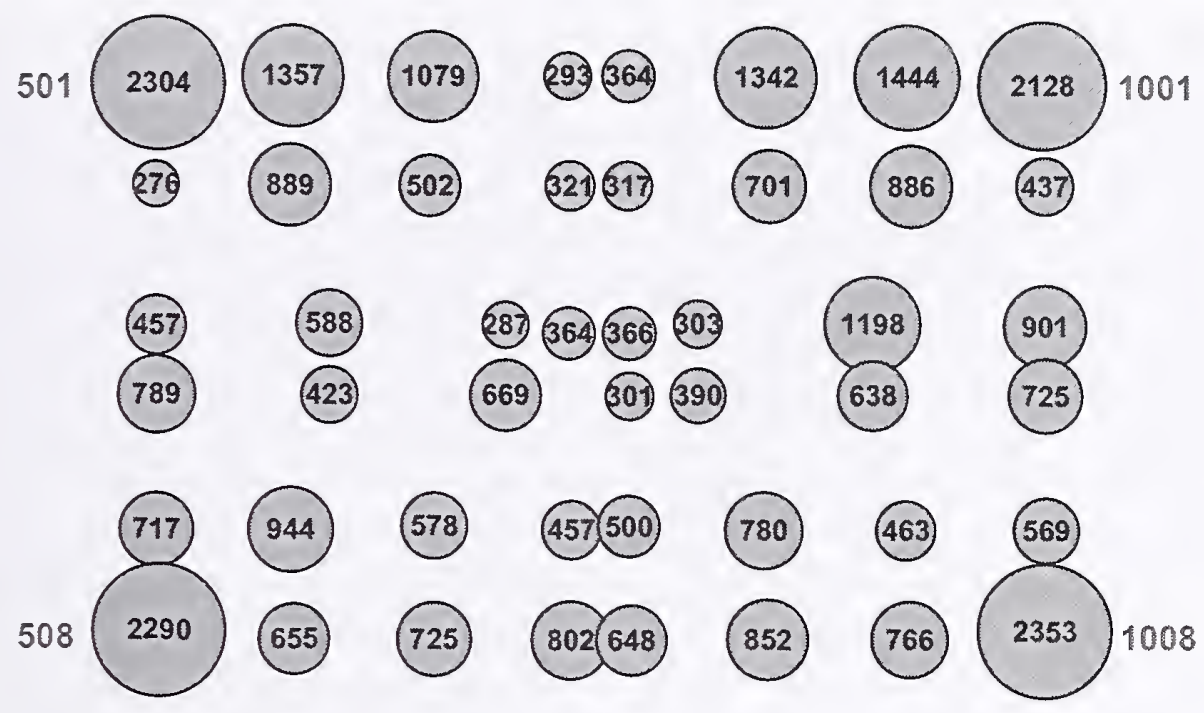

Figure 3-118. Additional axial load (kip) in columns at Floor 98 when the total axial load reached the maximum during push down analysis of isolated core model of WTC 1 for Case A temperature condition (compression is positive).

\section{Case B Temperature Condition}

Figures 3-119 to 3-125 show the vertical displacements of the WTC 1 isolated core model subjected to Case B temperature condition. At $30 \mathrm{~min}$, the vertical displacement of the south side above Floor 96 between Column 1004 and Column 1005 became large. At $100 \mathrm{~min}$, the maximum vertical displacement was $44.2 \mathrm{in.}$ on the south side at Column 1005.

Figures 3-127 and 3-128 show axial loads and plastic strains in columns at $100 \mathrm{~min}$. The following columns buckled: Column 904 spanning Floor 97 and Floor 98, Column 1004 spanning Floor 97 and Floor 98, Column 1005 spanning Floor 95 and Floor 96, and Column 1006 spanning Floor 95 and Floor 96. These columns also experienced large localized plastic strains.

The northeast corner, where the largest displacement occurred for Case A temperature condition, did not displace significantly for Case B temperature condition. The vertical displacement at Floor 106 ranged from 4.8 to $44.2 \mathrm{in}$. The average vertical displacement of Floor 106 was $11.9 \mathrm{in}$. The average

displacement of the south face was $20 \mathrm{in}$. Considering the $5 \mathrm{in}$. displacement after the aircraft impact, the average additional downward displacement of the core due to thermal loads was about 7 in.

To determine the additional axial load-carrying capacity of the core, a push-down analysis was performed for Case B temperature condition in the same manner as described for the isolated core model for Case A temperature condition. The analysis was terminated when an additional vertical displacement of 9.4 in. was applied to the top. Figure 3-129 shows vertical displacements of the model at the end of analysis. Figure 3-130 shows the relationship between the total additional vertical force and the additional vertical displacement. The total additional vertical force reached its maximum at an additional displacement of 4.9 in. Figure 3-131 shows the additional axial loads in columns of Floor 98 when the total additional vertical force was at its maximum. The maximum total additional vertical force of 24,002 kip was about 
61 percent of the total column force at Floor 98 prior to push-down. Thus, the reserve capacity of the core at the end of Case B temperature condition was substantial, but less than that of Case A temperature condition.

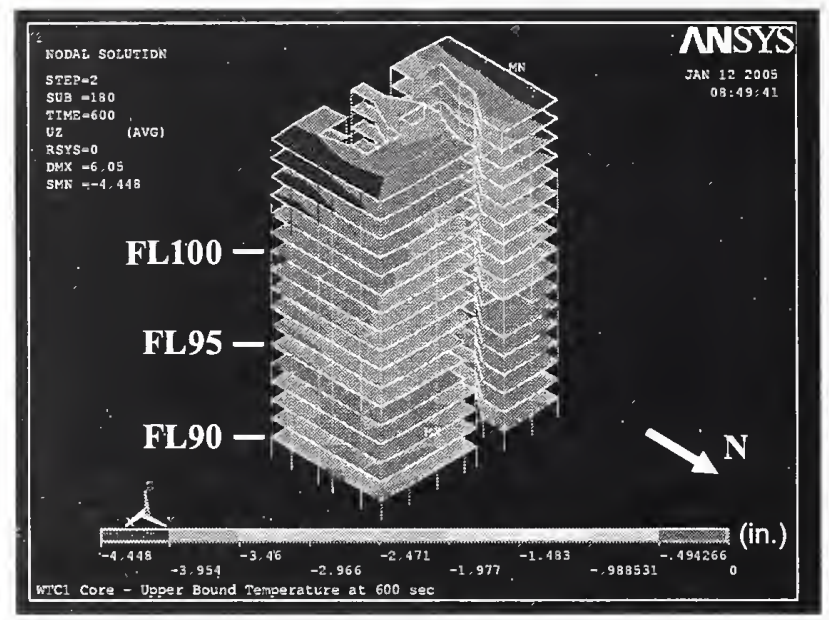

(a) North and east sides

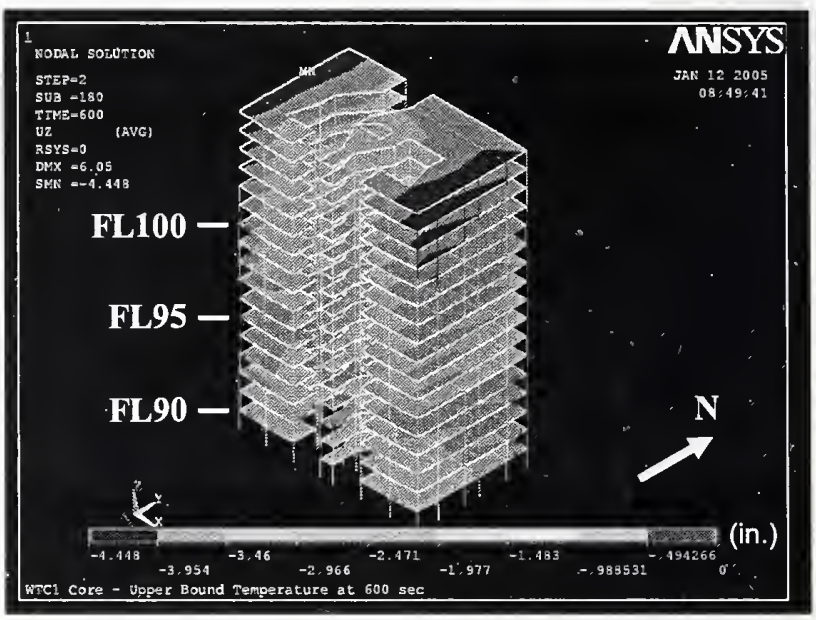

(b) South and east sides

Figure 3-119. Vertical displacement of isolated core model of WTC 1 for Case B temperature condition at $10 \mathrm{~min}$ (downward displacement is negative).

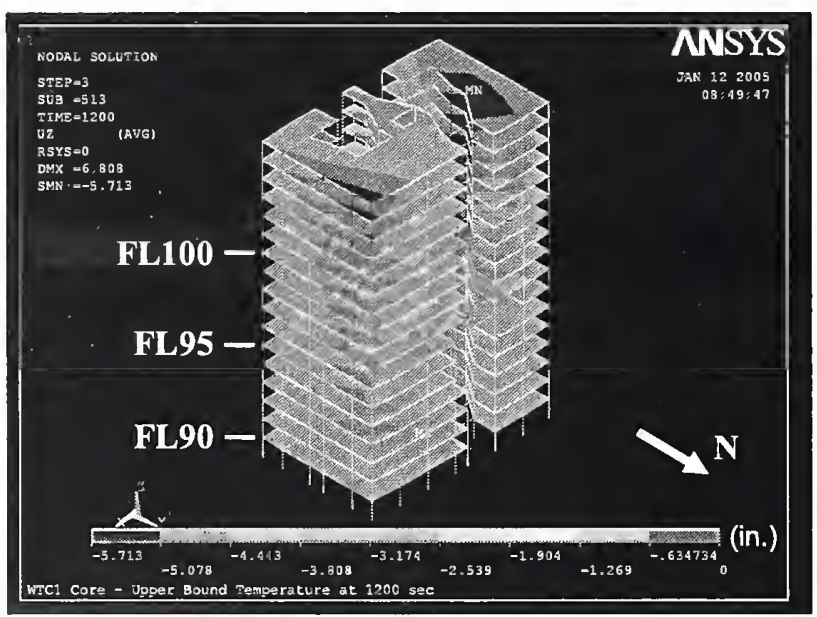

(a) North and east sides

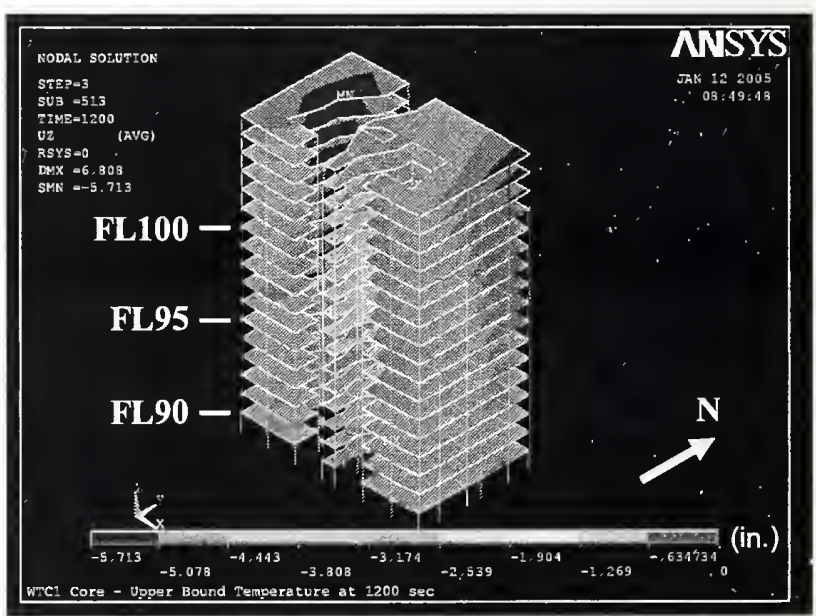

(b) South and east sides

Figure 3-120. Vertical displacement of isolated core model of WTC 1 for Case B temperature condition at $\mathbf{2 0}$ min (downward displacement is negative). 


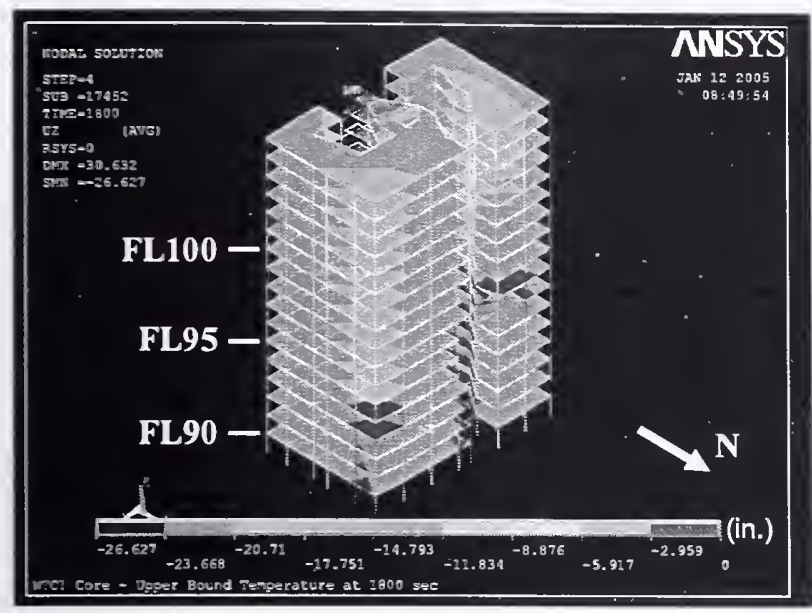

(a) North and east sides

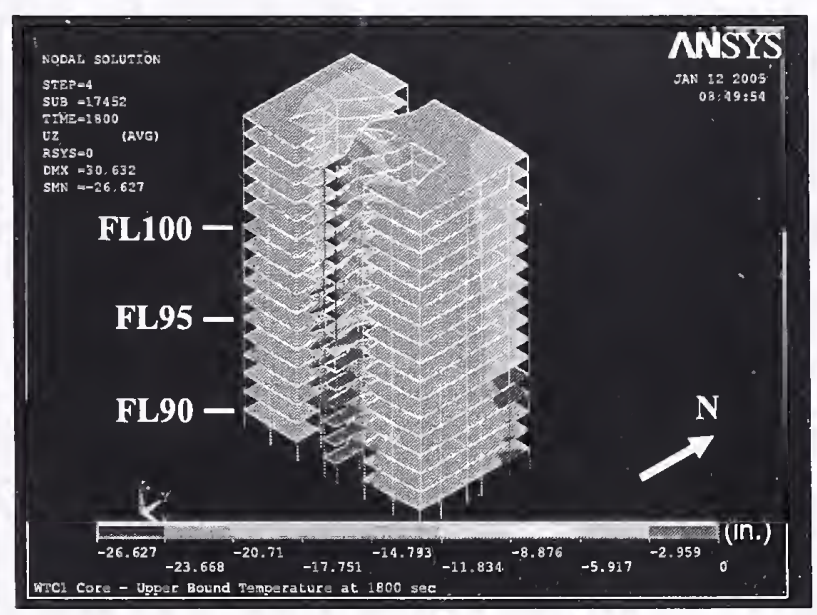

(b) South and east sides

Figure 3-121. Vertical displacement of isolated core model of WTC 1 for Case B temperature condition at $\mathbf{3 0}$ min (downward displacement is negative).

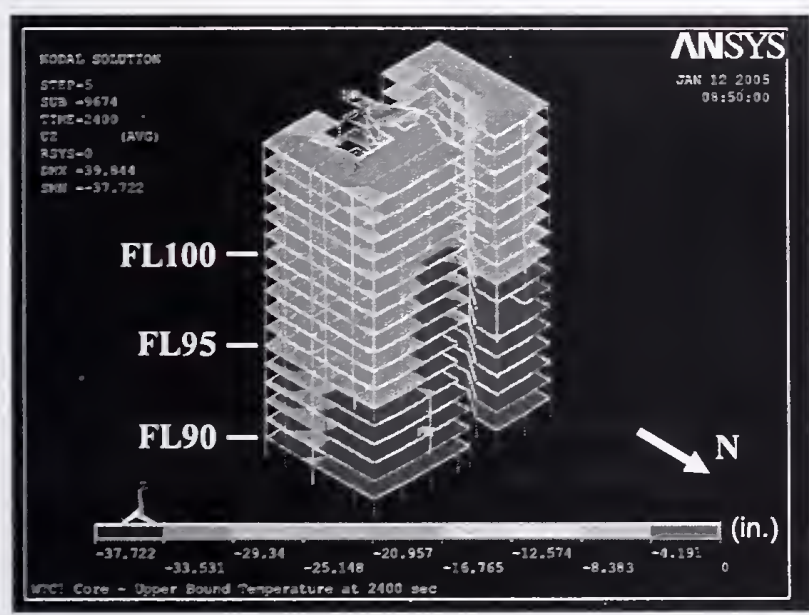

(a) North and east sides

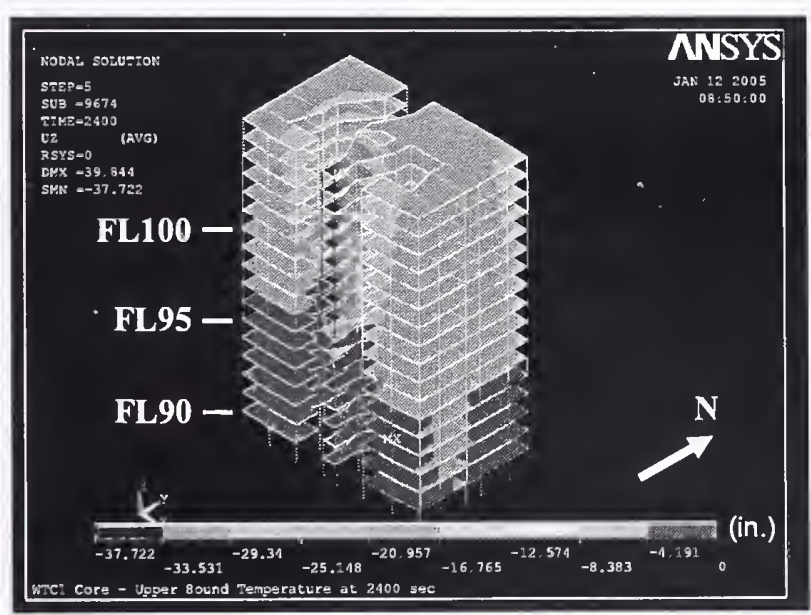

(b) South and east sides

Figure 3-122. Vertical displacement of isolated core model of WTC 1 for Case B temperature condition at $\mathbf{4 0} \mathrm{min}$ (downward displacement is negative). 


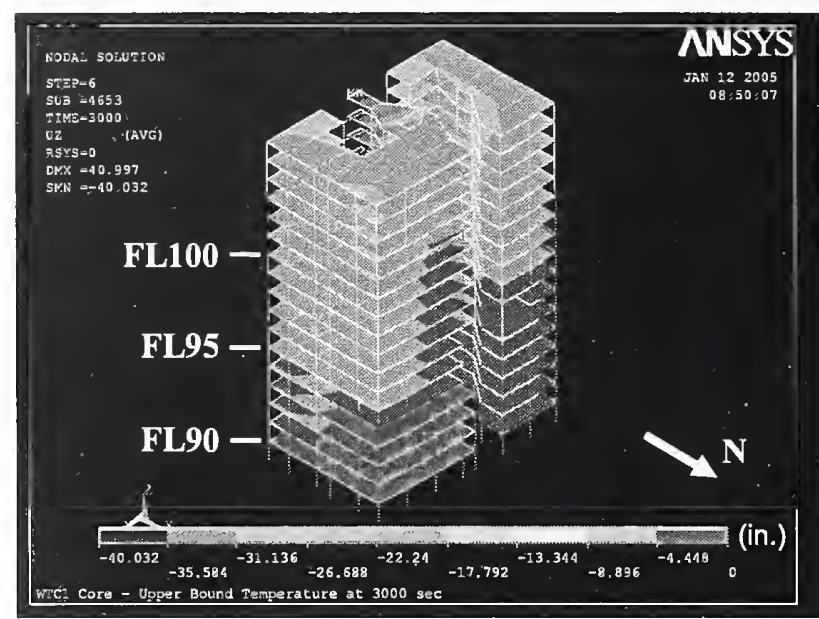

(a) North and east sides

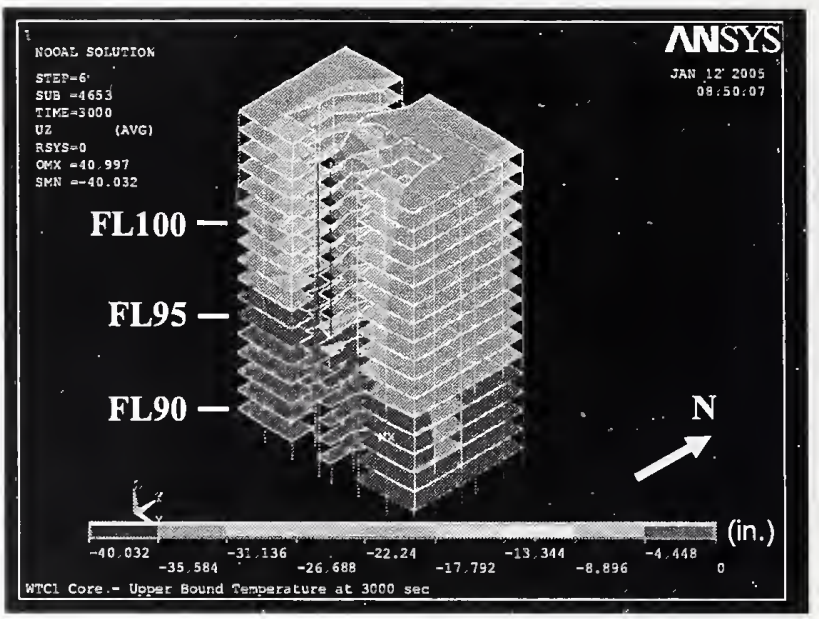

(b) South and east sides

Figure 3-123. Vertical displacement of isolated core model of WTC 1 for Case B temperature condition at $\mathbf{5 0}$ min (downward displacement is negative).

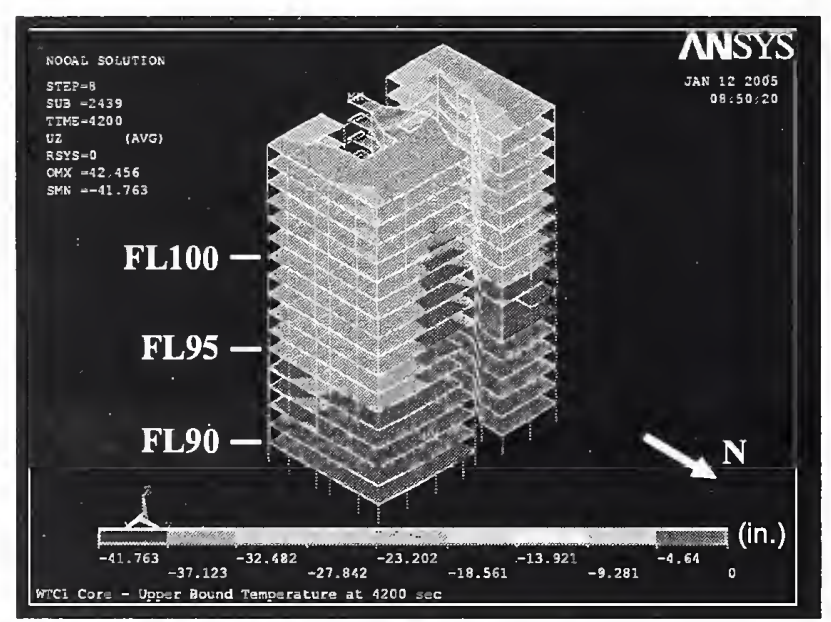

(a) North and east sides

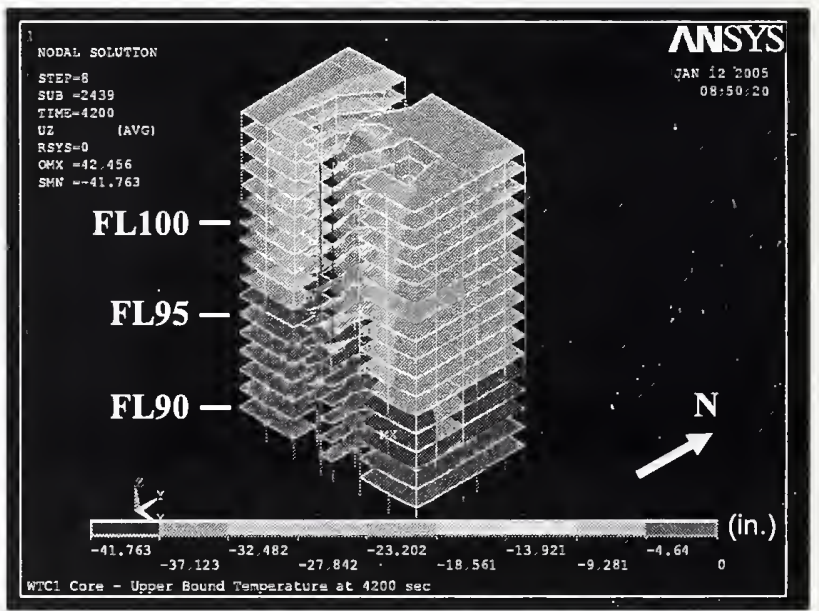

(b) South and east sides

Figure 3-124. Vertical displacement of isolated core model of WTC 1 for Case B temperature condition at $70 \mathrm{~min}$ (downward displacement is negative). 


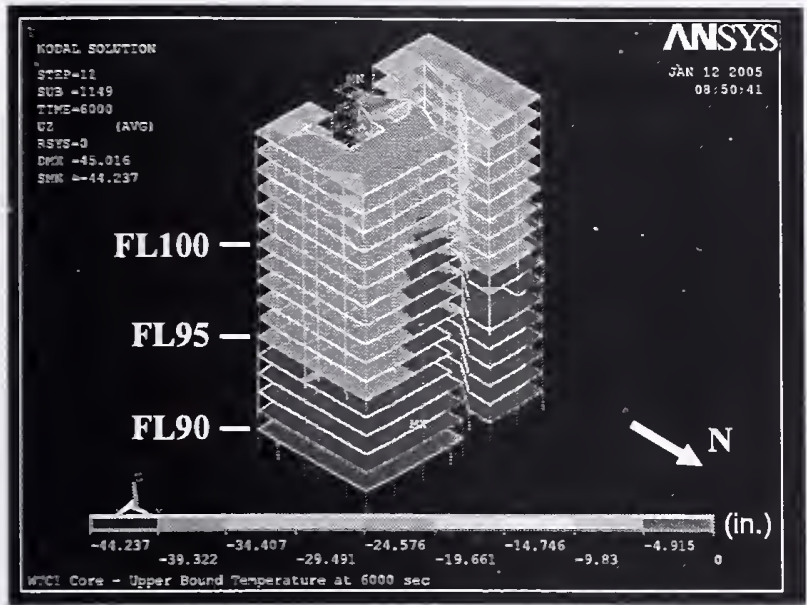

(a) North and east sides

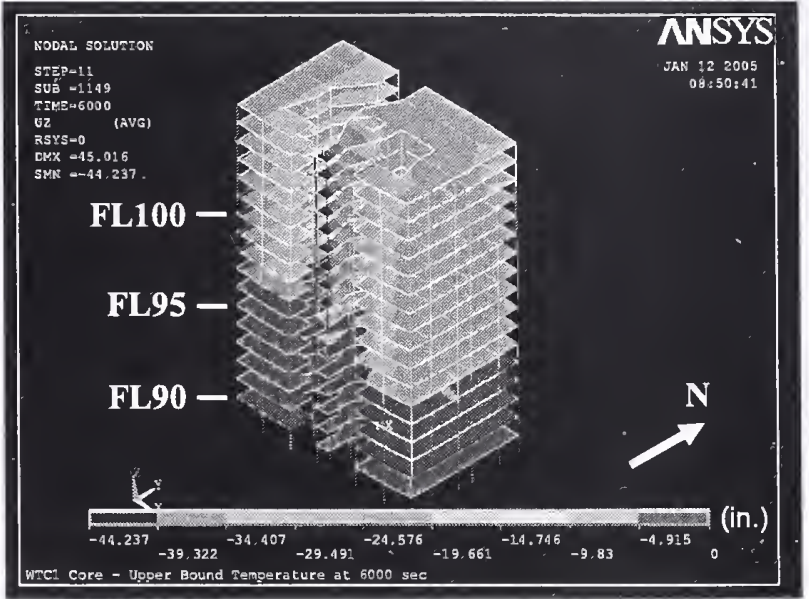

(b) South and east sides

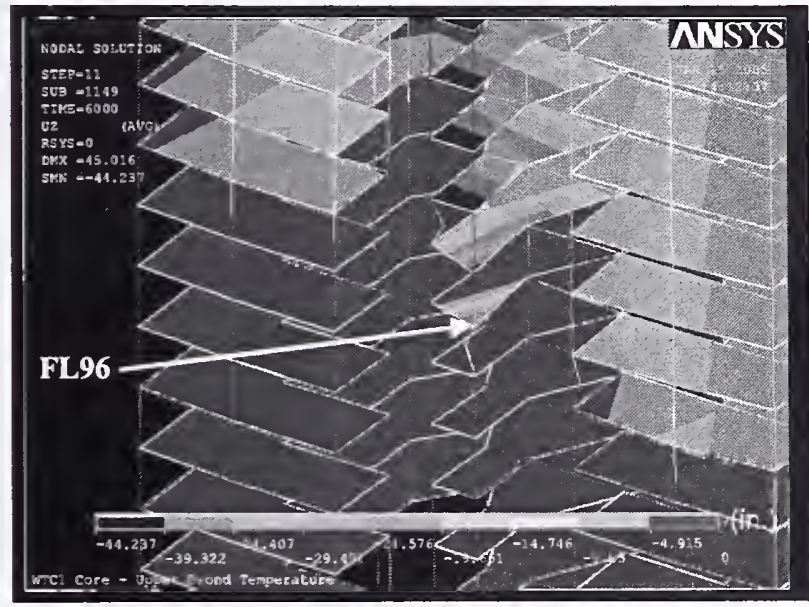

(c) South side

(1X displacement magnification)

Figure 3-125. Vertical displacement of isolated core model of WTC 1 for Case B temperature condition at 100 min (downward displacement is negative). 


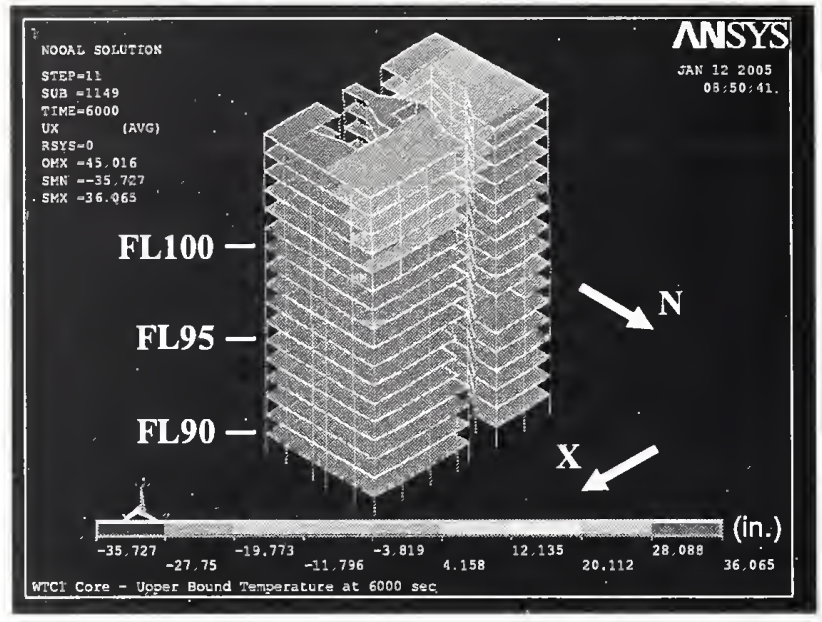

(a) X-displacement of north and east sides

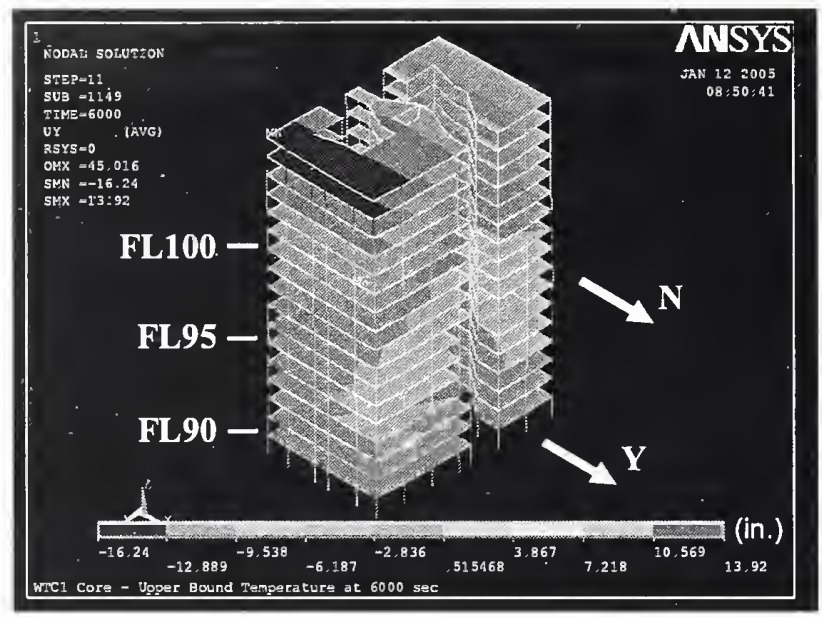

(c) Y-displacement of north and east sides

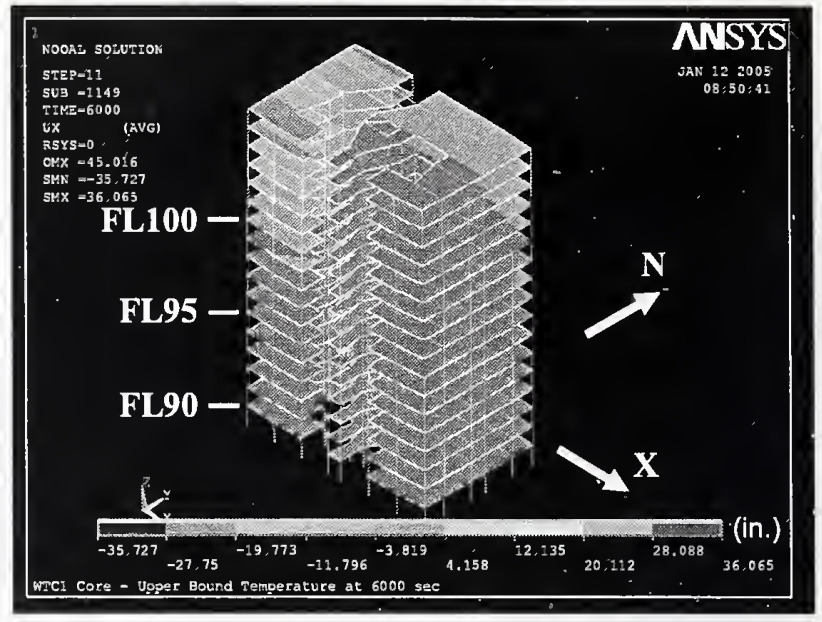

(b) X-displacement of south and east sides

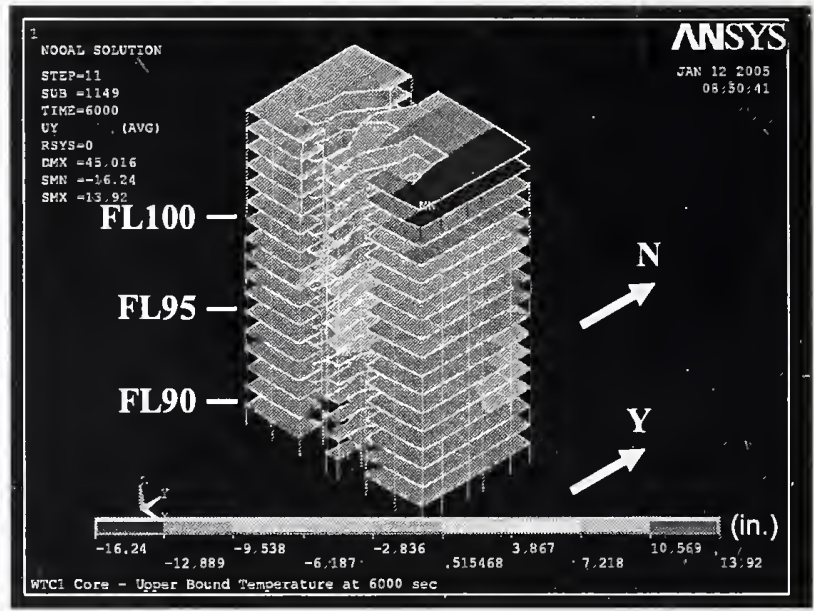

(d) Y-displacement of south and east sides

Figure 3-126. Horizontal displacement of isolated core model of WTC 1 for Case B temperature condition at $\mathbf{1 0 0} \mathrm{min}$. 


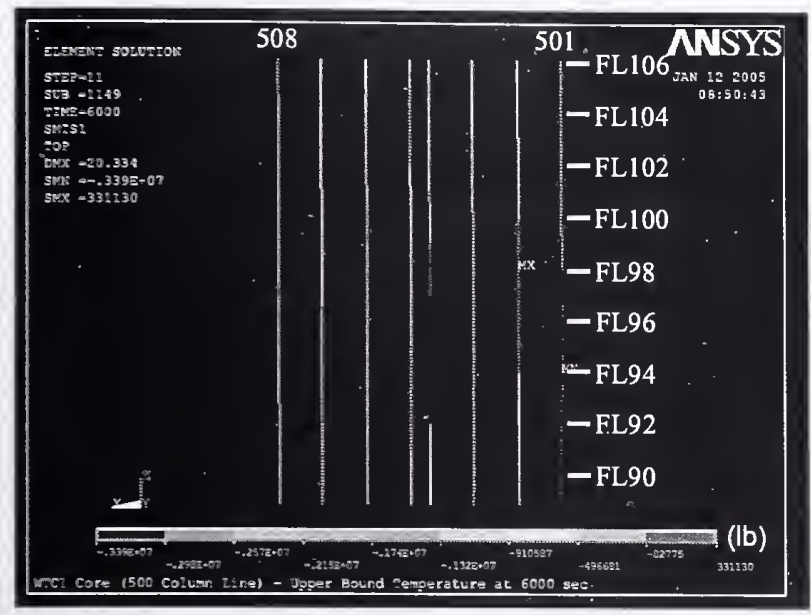

(a) 500 series columns

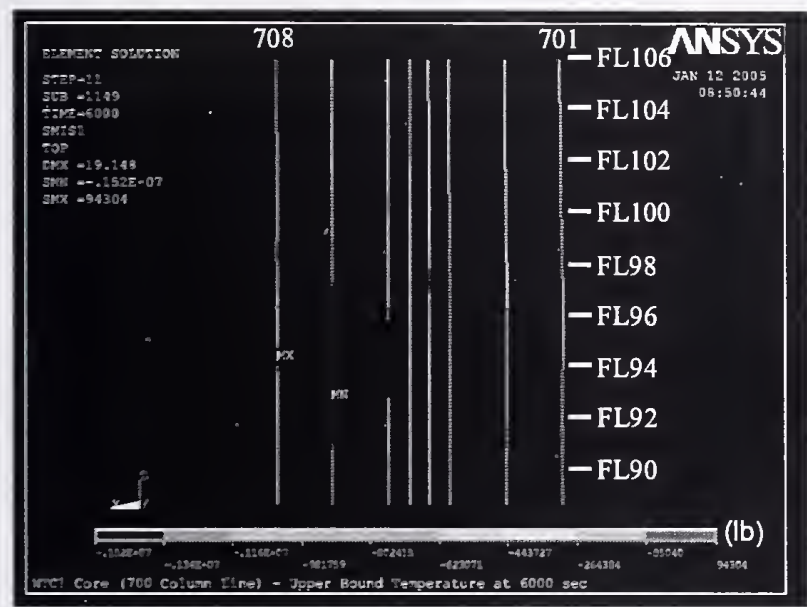

(c) 700 series columns

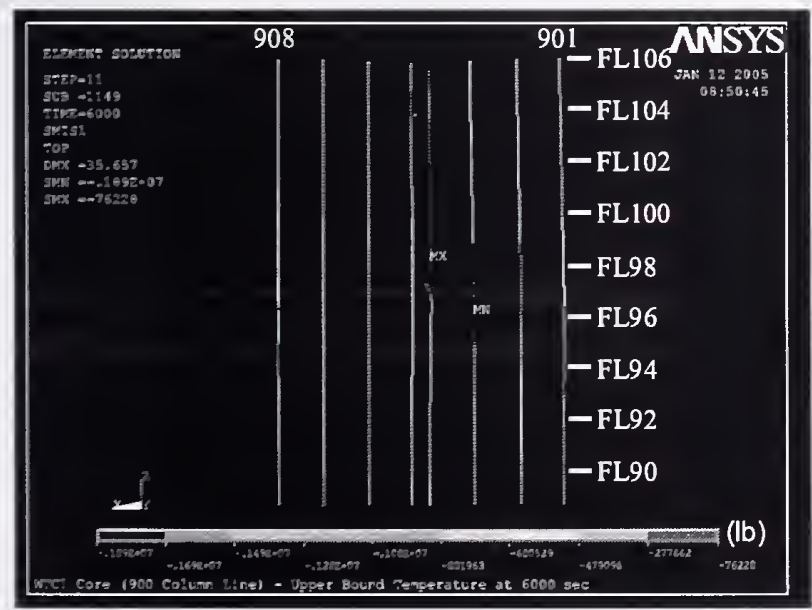

(e) 900 series columns

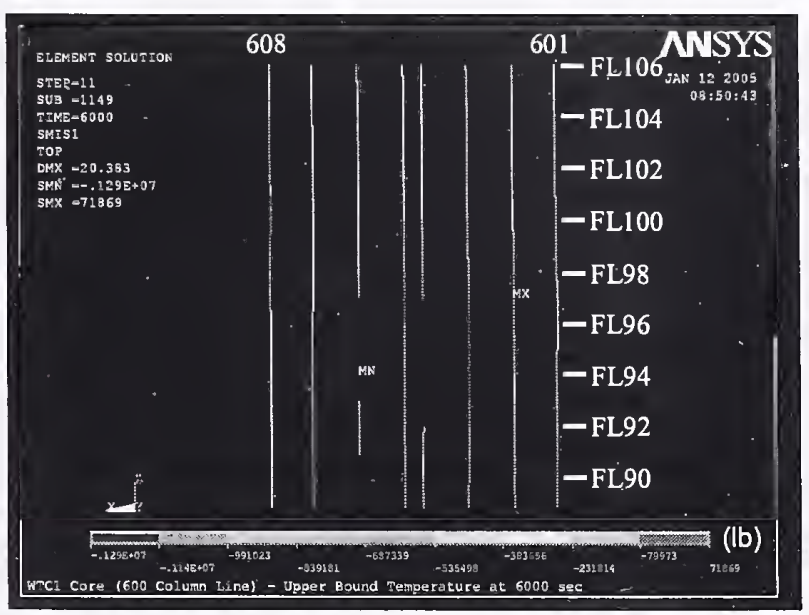

(b) 600 series columns

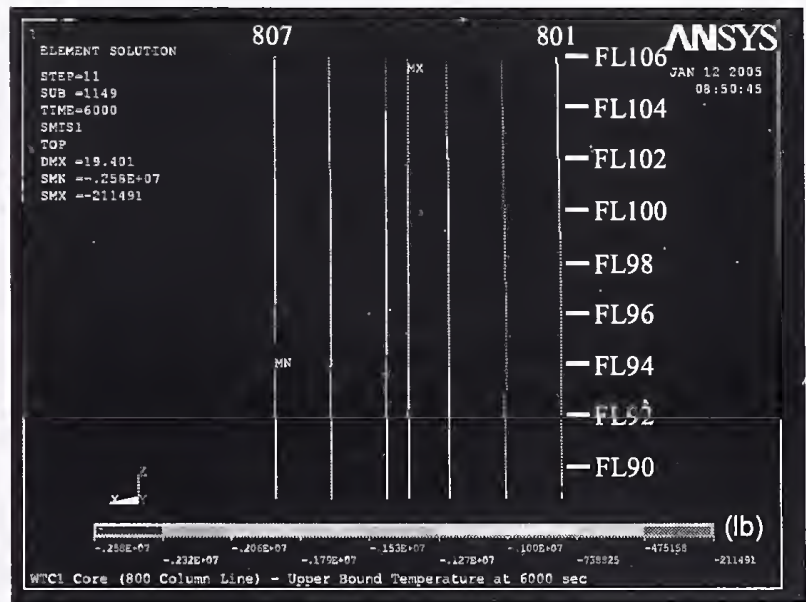

(d) 800 series columns

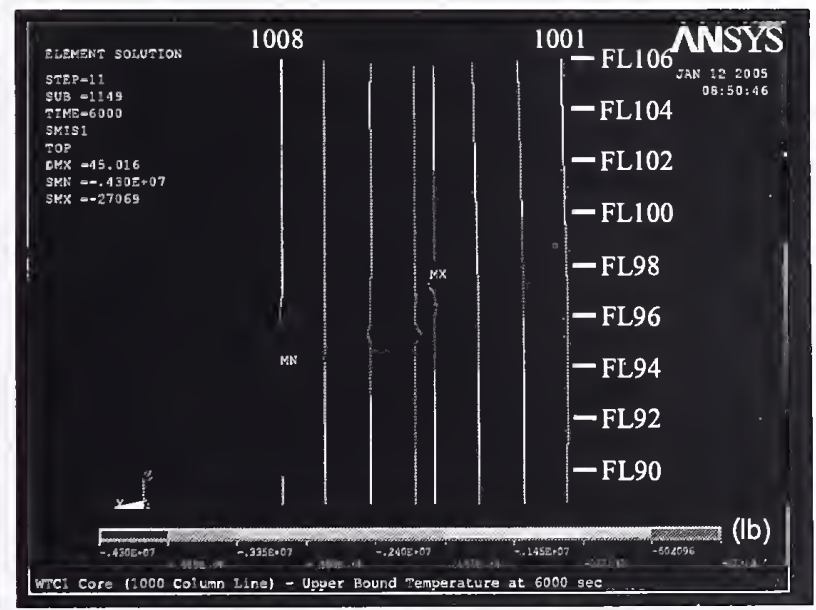

(f) 1000 series columns

Figure 3-127. Axial load in columns of isolated core model of WTC 1 for Case B temperature condition at $100 \mathrm{~min}$ (compression is negative). 


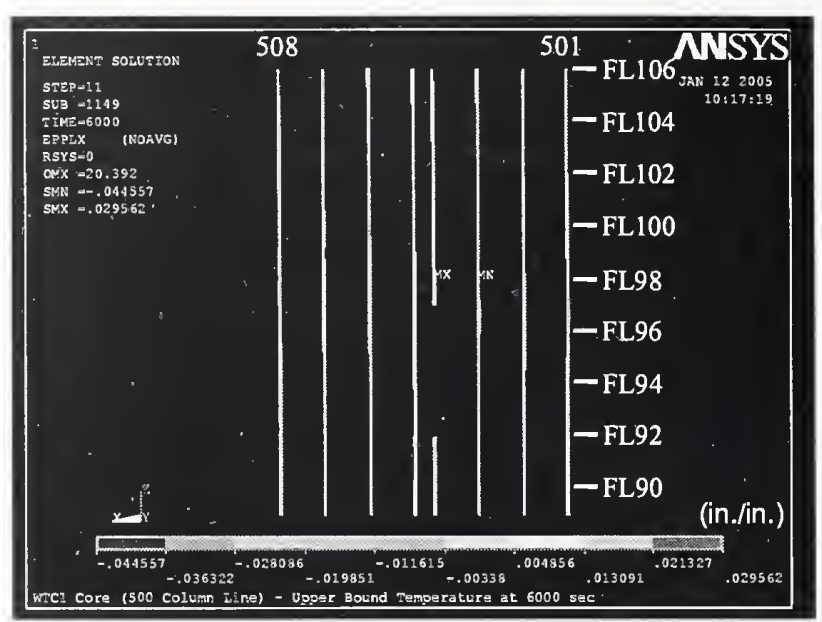

(a) 500 series columns

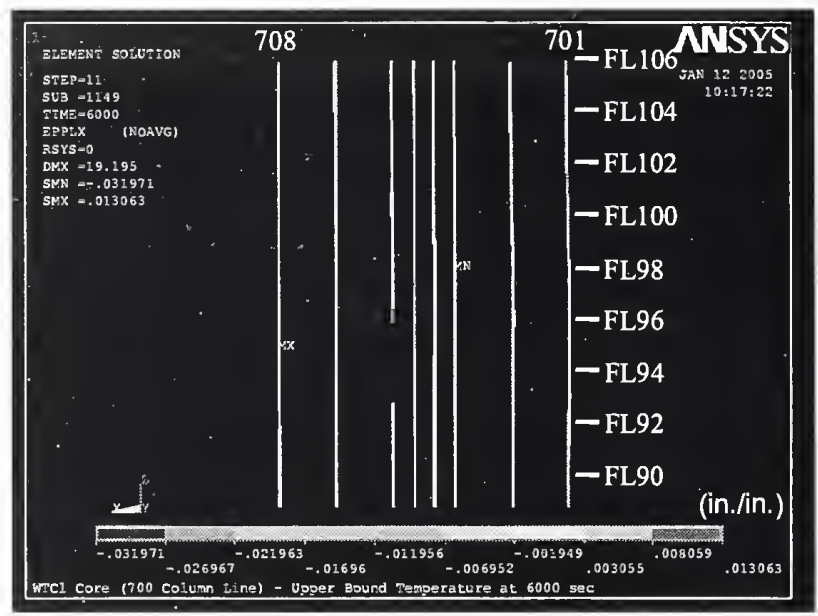

(c) 700 series columns

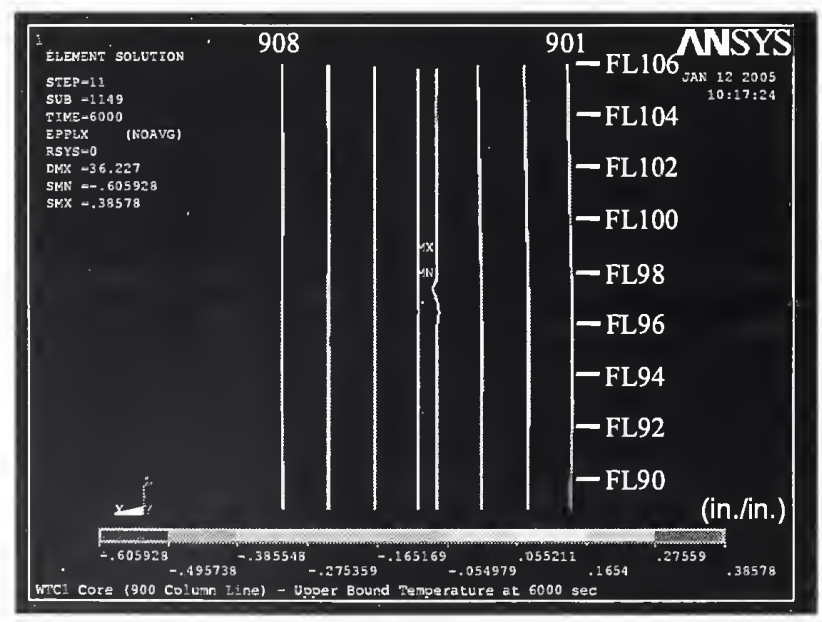

(e) 900 series columns

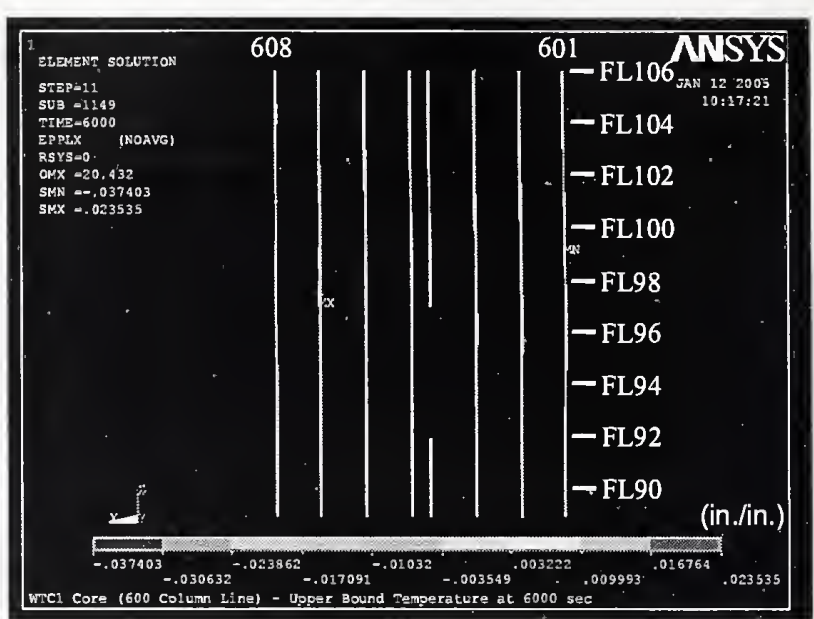

(b) 600 series columns

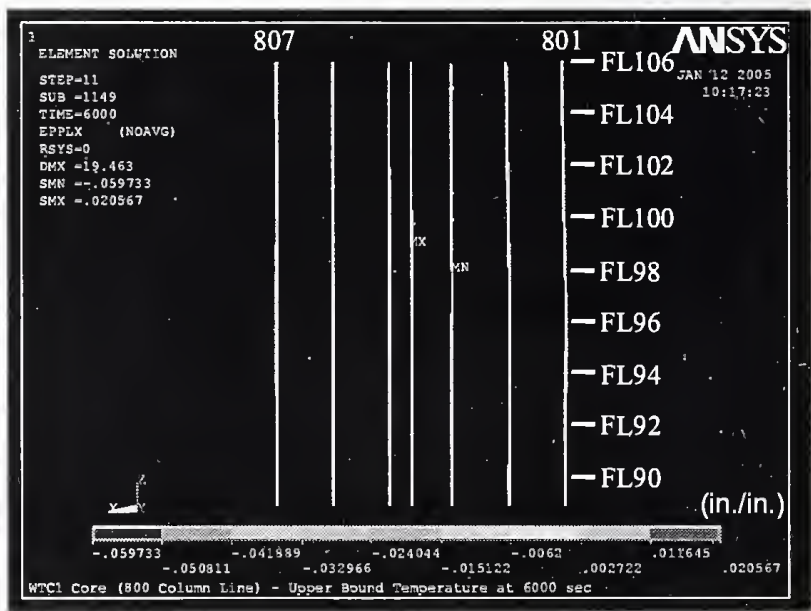

(d) 800 series columns

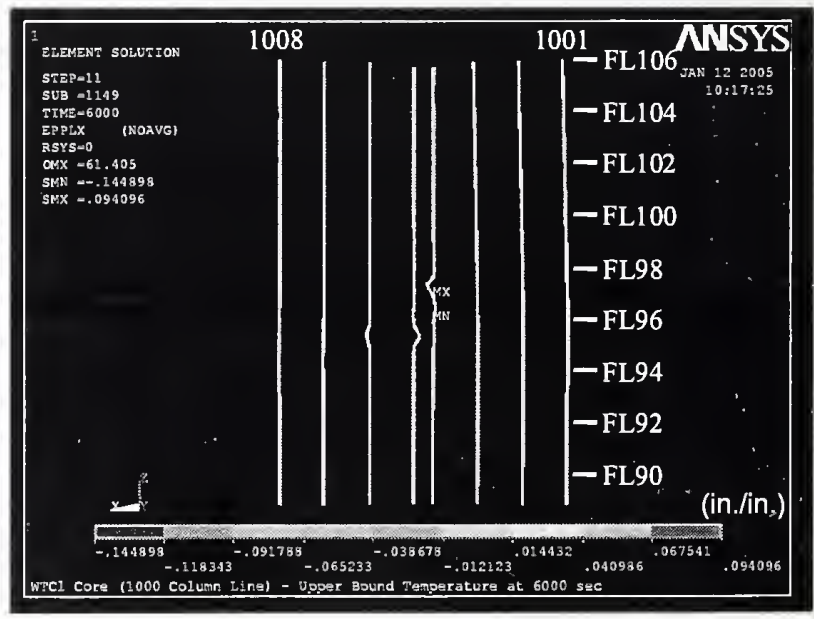

(f) 1000 series columns

Figure 3-128. Plastic strain in columns of isolated core model of WTC 1 for Case B temperature condition at $100 \mathrm{~min}$ (compressive strain is negative). 


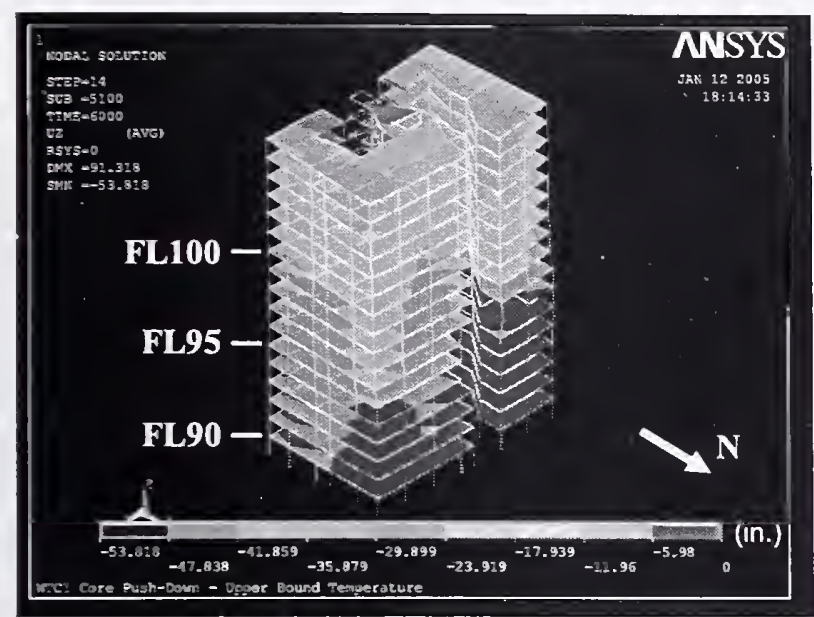

(a) North and east sides

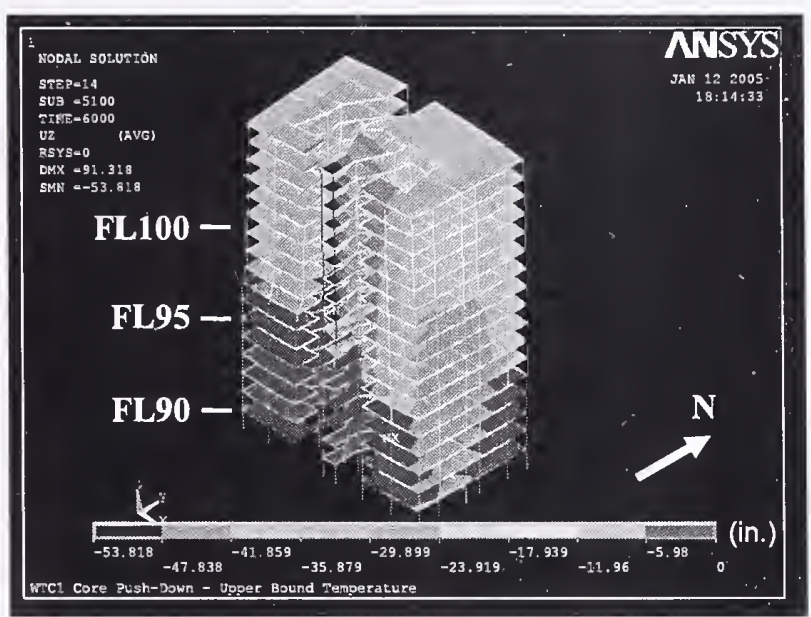

(b) South and east sides

Figure 3-129. Vertical displacement after push down of isolated core model of WTC 1 for Case $B$ temperature condition (downward displacement is negative).

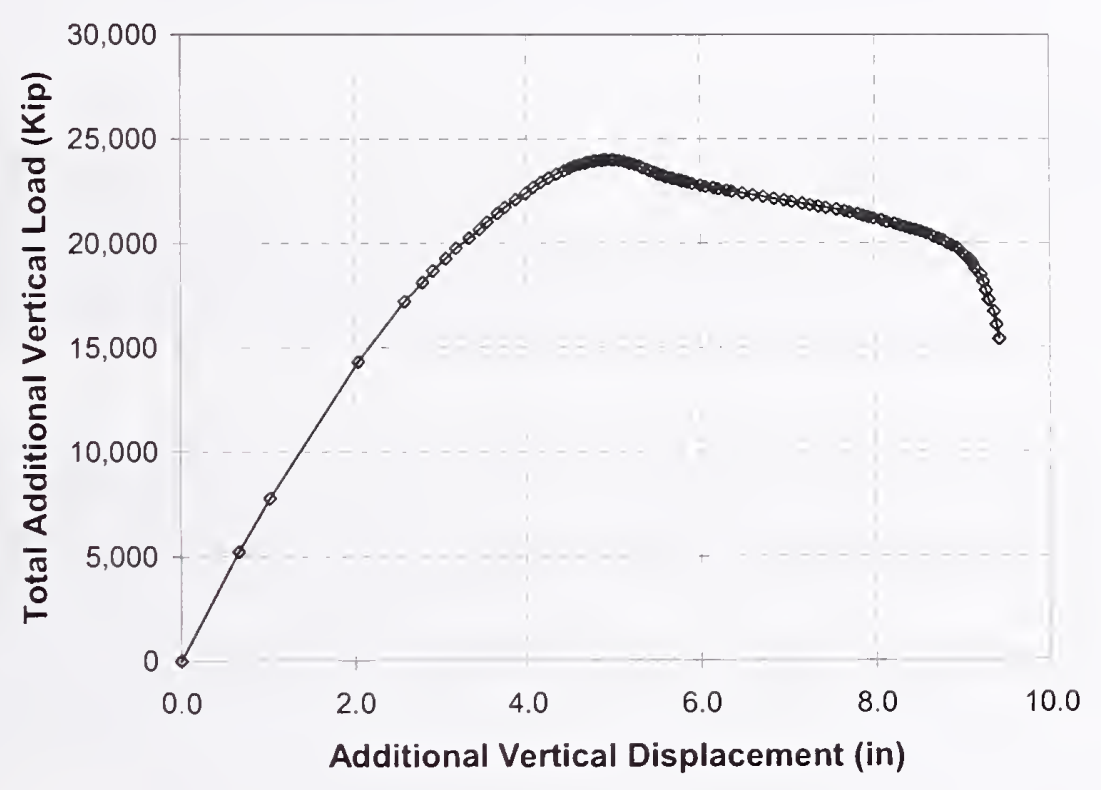

Figure 3-130. Total additional vertical load versus additional vertical displacement relationship obtained from push down analysis of isolated core model of WTC 1 for Case B temperature condition (compression is positive). 


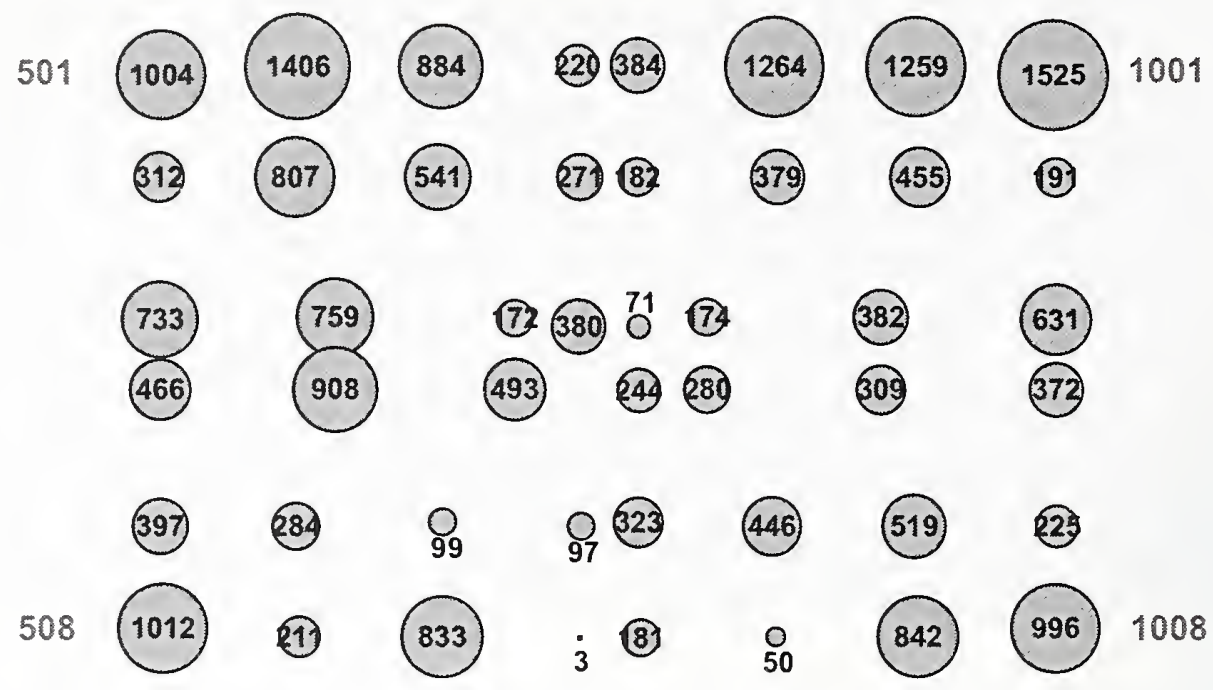

\section{Figure 3-131. Additional axial load (kip) in columns at Floor 98 when the total axial load reached the maximum during push down analysis of the WTC 1 core for Case B temperature condition (compression is positive).}

\subsubsection{FEA of WTC 2 Core}

\section{Case C Temperature Condition}

The isolated core model of WTC 2 was unstable after the aircraft impact damage, tilting excessively towards the southeast corner. To simulate the restraining effect of office floors and the exterior walls, the isolated core model was restrained in the horizontal directions at all floors.

Figures 3-132 to 3-133 show the vertical displacements of the WTC 2 isolated core model when subjected to Case $\mathrm{C}$ temperature condition from just after the aircraft impact to $60 \mathrm{~min}$. The vertical displacement was always the highest at the southeast corner of the core as the aircraft impact severed the southeast corner core columns in Floors 79 to 82. After aircraft impact damage, the vertical displacement of the southeast corner was $5.6 \mathrm{in}$. This displacement increased to $6.1 \mathrm{in}$. at $60 \mathrm{~min}$. Figures 3-134 and 3-135 show axial load and plastic strain in columns at $60 \mathrm{~min}$. Columns at the southeast corner experienced plastic strains immediately following aircraft impact. The maximum plastic strain in the 900 -series core columns was 1.2 percent, and 0.5 percent in the 1000 series core.

The vertical displacement of the core at Floor 106 at 60 min ranged from 2.3 in. to 5.3 in. The maximum vertical displacement of the southeast corner was less than 5.3 in. at Column 1001. The average vertical displacement of Floor 106 at $60 \mathrm{~min}$ was 3.7 in., close to the 3.9 in. average vertical displacement after the aircraft impact. None of core columns buckled during thermal loading.

Similar to the WTC 1 isolated core models, the WTC 2 isolated core model was pushed down following the analysis for Case $\mathrm{C}$ temperature condition to determine the additional axial load-carrying capacity of the core. The analysis was terminated at an additional vertical displacement of $17.0 \mathrm{in}$. even though the core was still continuing to carry more axial load. The vertical displacements at the end of $17.0 \mathrm{in}$. pushdown are shown in Fig. 3-136. Figure 3-137 shows the relationship between the additional 
displacements and the average additional vertical load of corner columns, corner and middle columns on the east face, and all core columns (there column locations are shown in Fig. 3-136). The columns on the southeast corner of the isolated core at $60 \mathrm{~min}$ temperature condition carried an additional load of about $900 \mathrm{kip}$ without failure, compared to about 1,500 kip for the average of the entire core columns prior to push-down. The additional load was about 1.6 times that of the average load in Floor 82 columns at 60 min temperature condition. 


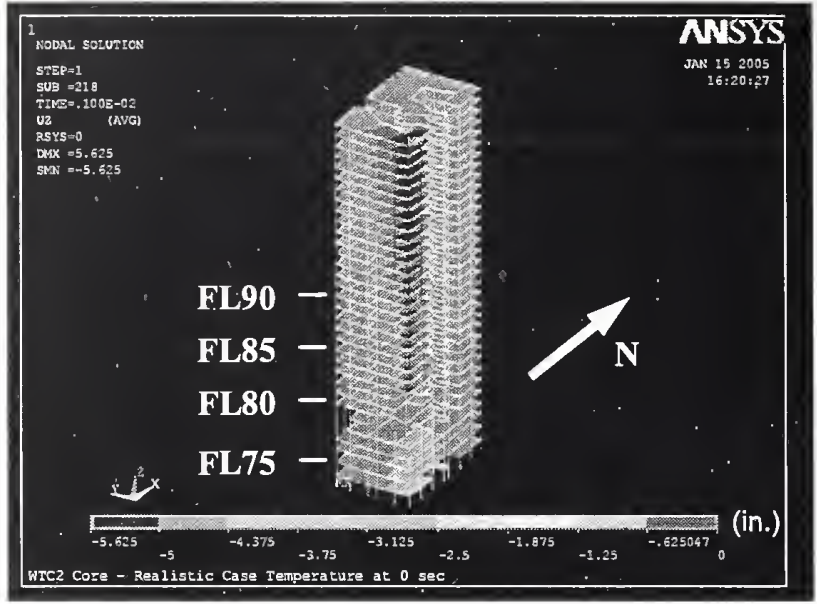

(a) After aircraft impact

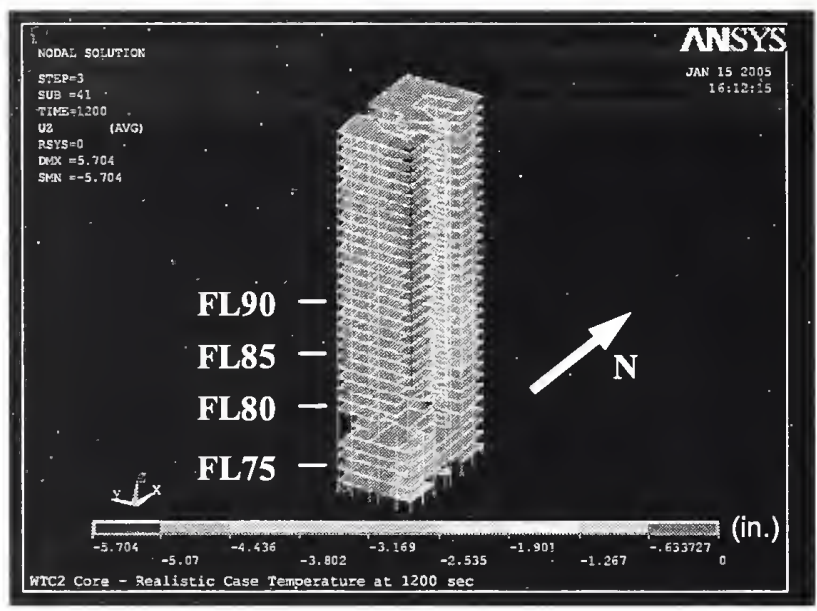

(c) At $20 \mathrm{~min}$

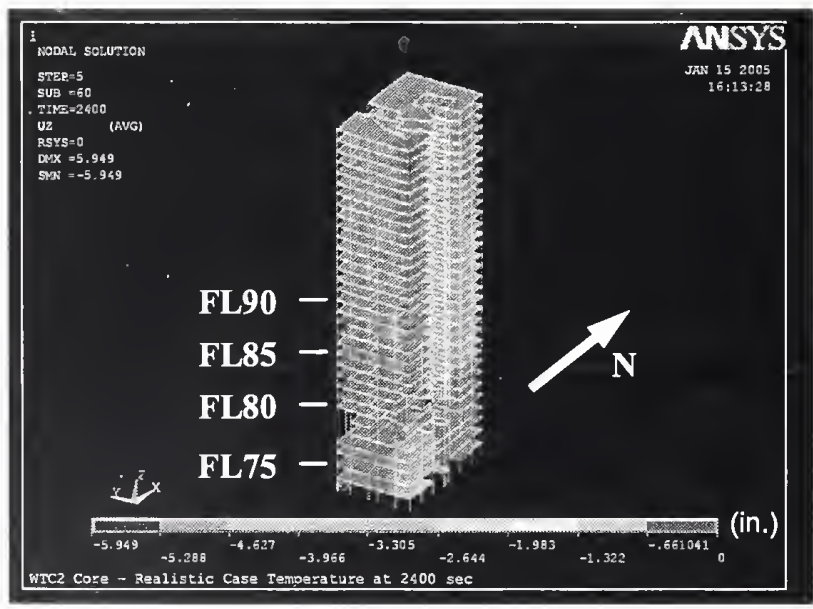

(e) At $40 \mathrm{~min}$

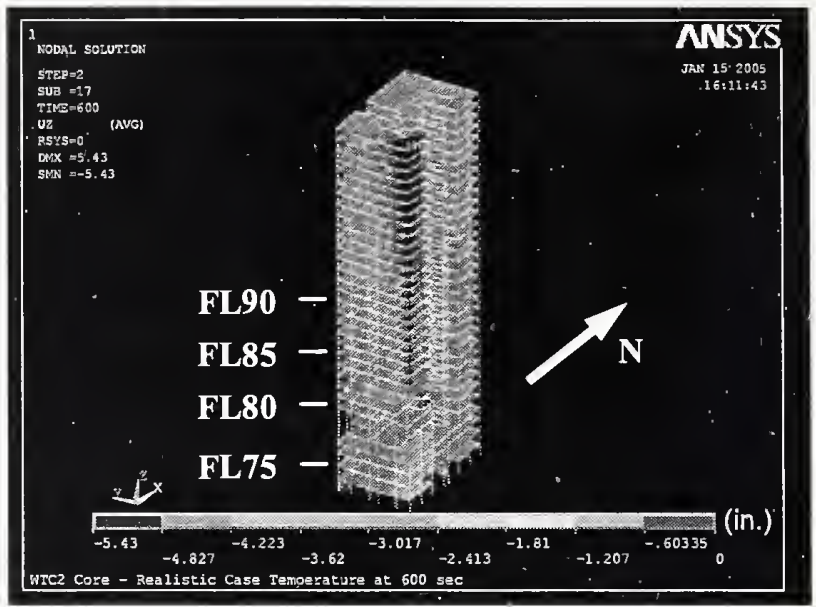

(b) At $10 \mathrm{~min}$

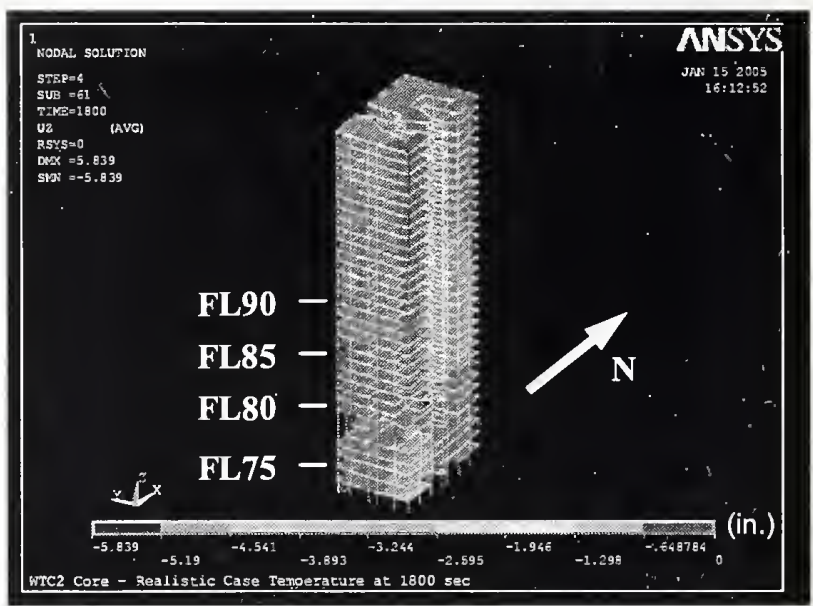

(d) At $30 \mathrm{~min}$

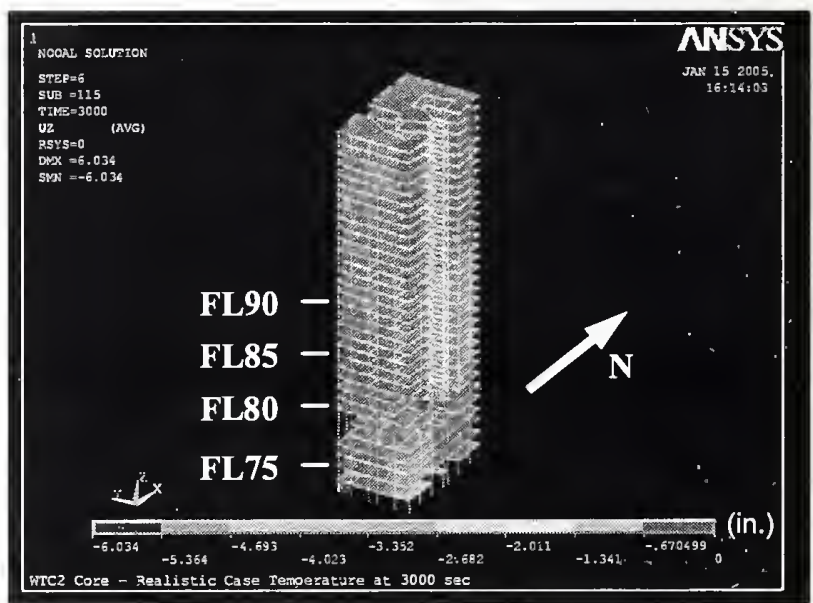

(f) At $50 \mathrm{~min}$

Figure 3-132. Vertical displacement of isolated core model of WTC 2 for Case C temperature condition (downward displacement is negative). 


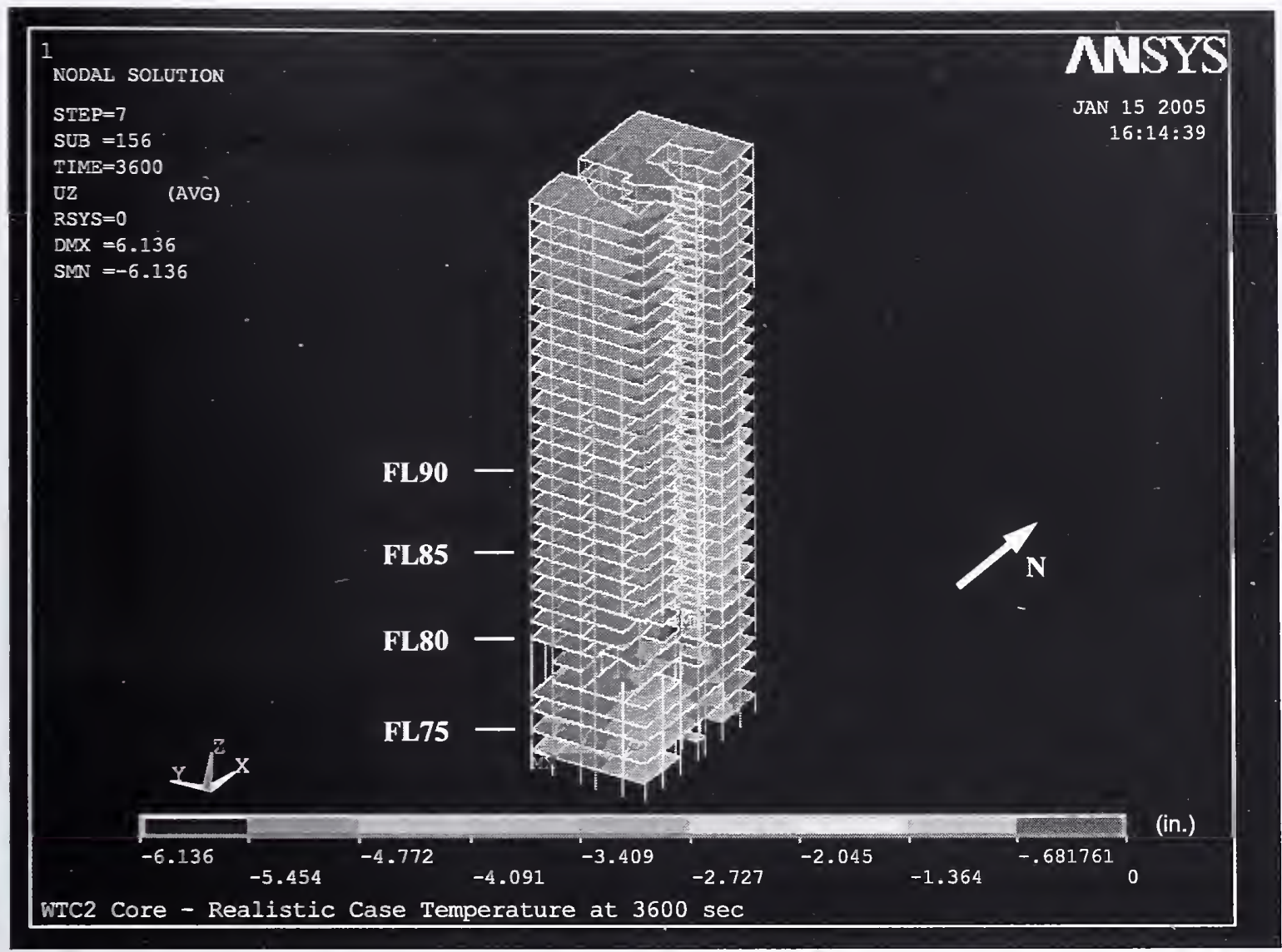

Figure 3-133. Vertical displacement of isolated core model of WTC 2 for Case C temperature condition at $60 \mathrm{~min}$ (downward displacement is negative). 


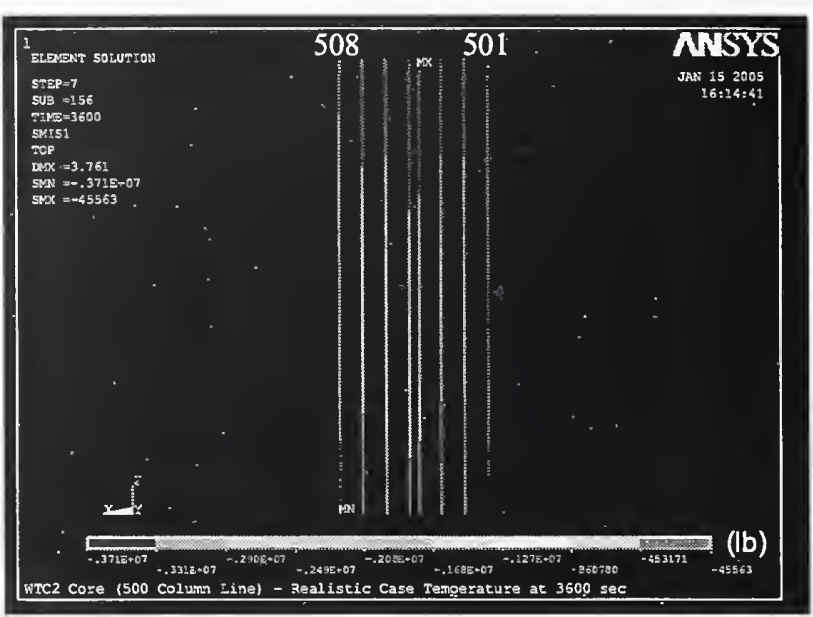

(a) 500 series columns

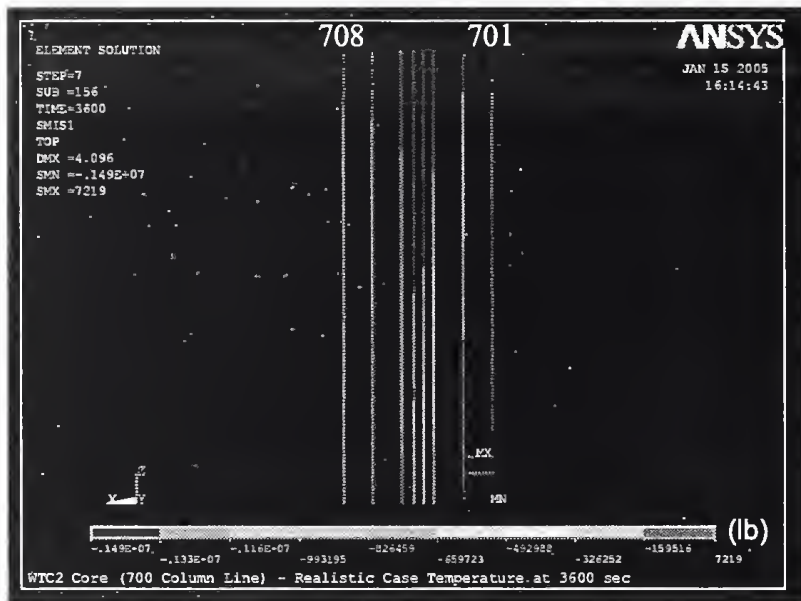

(c) 700 series columns

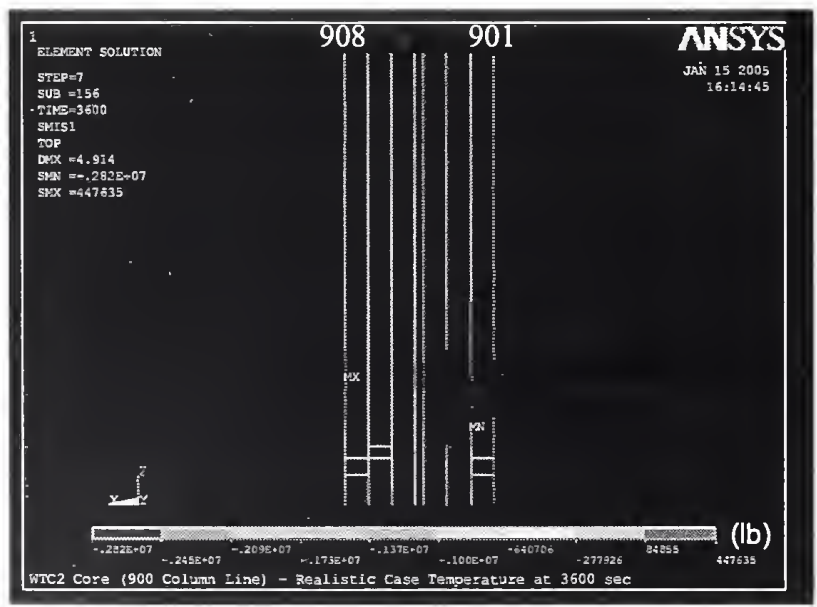

(e) 900 series columns

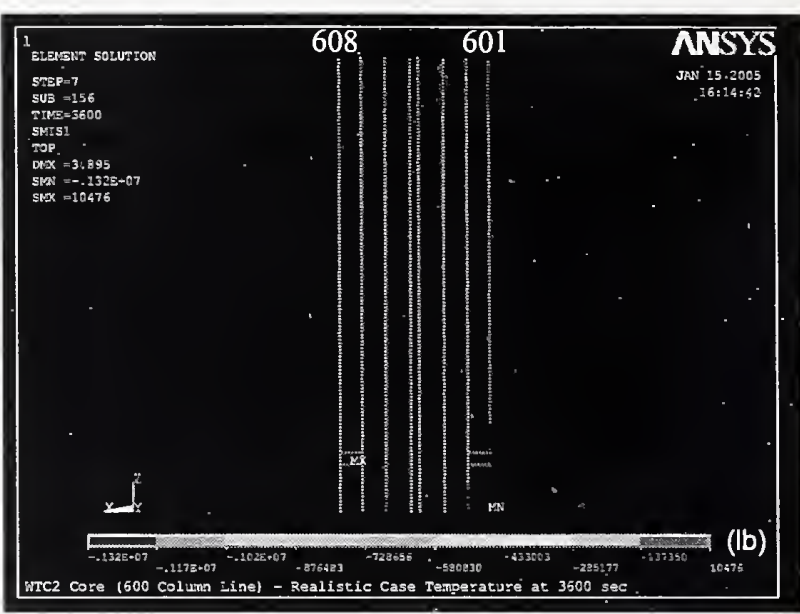

(b) 600 series columns

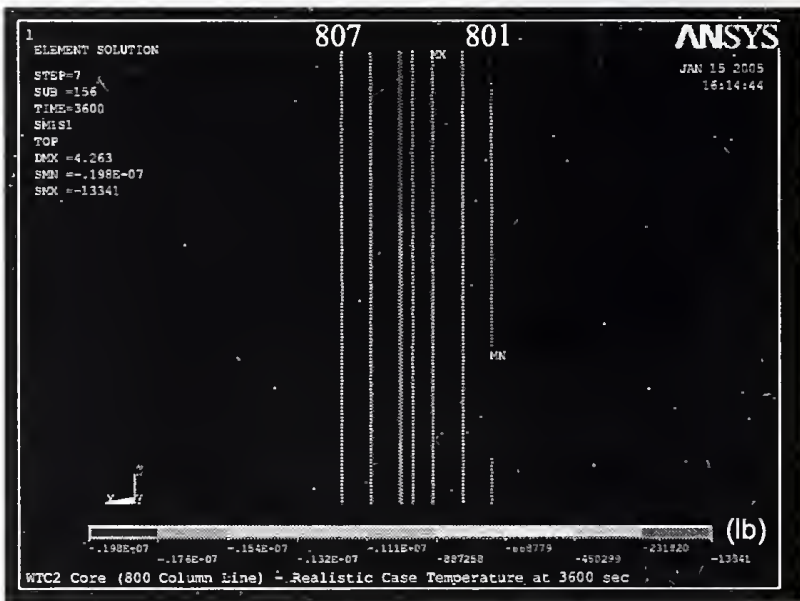

(d) 800 series columns

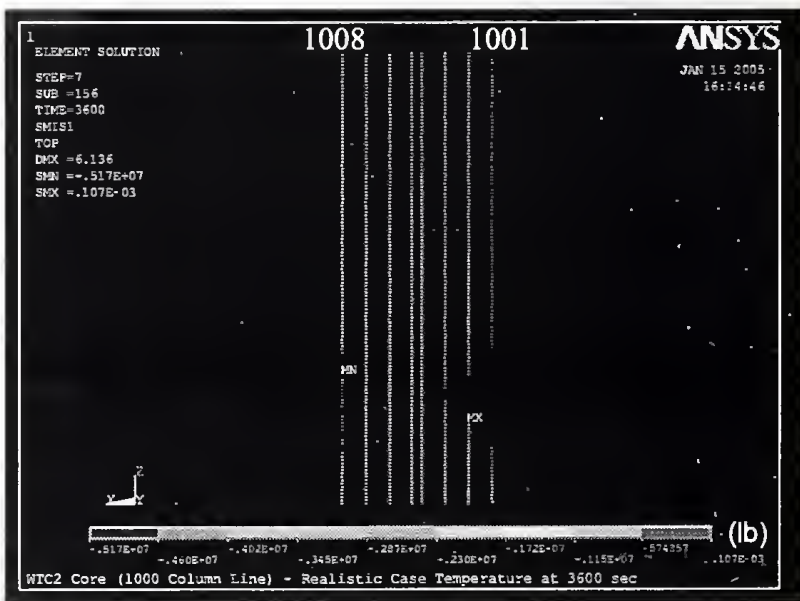

(f) 1000 series columns

Figure 3-134. Axial load in core columns of isolated core model of WTC 2 for Case C temperature condition at $60 \mathrm{~min}$ (compression is negative). 


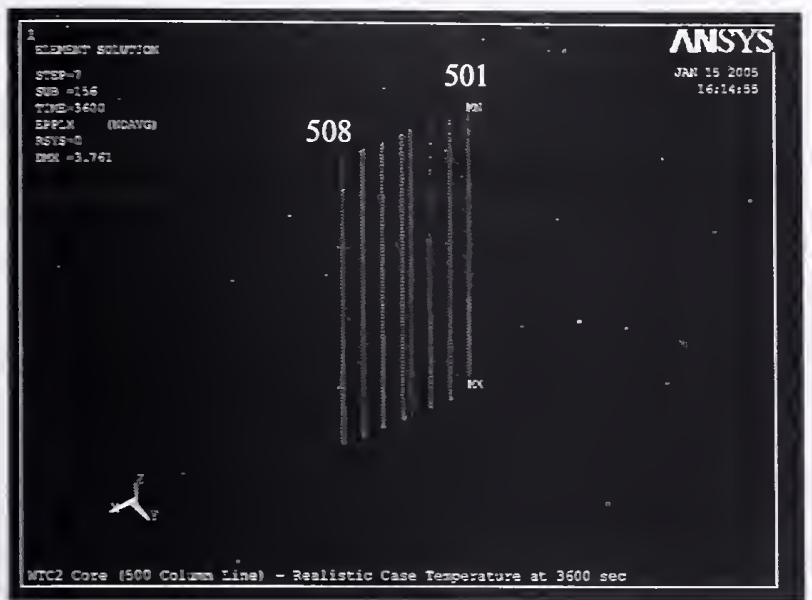

(a) 500 series columns

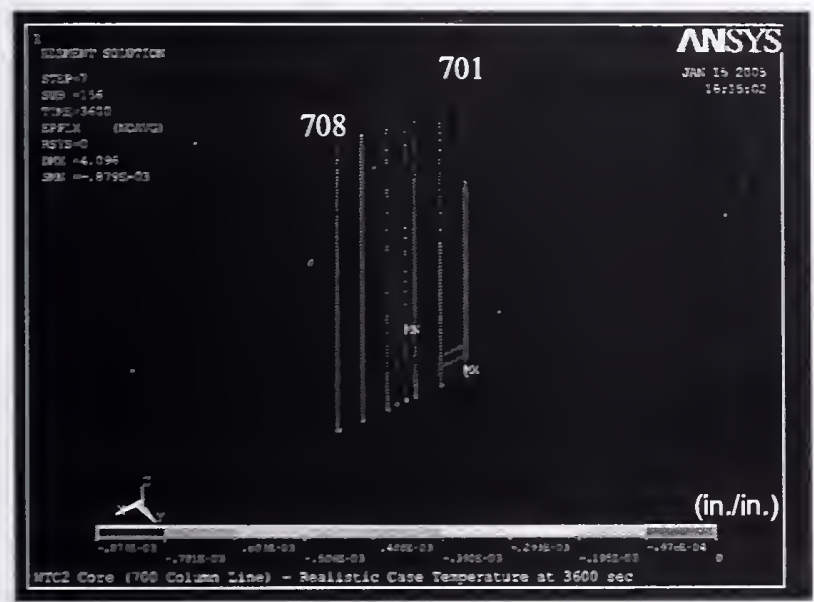

(c) 700 series columns

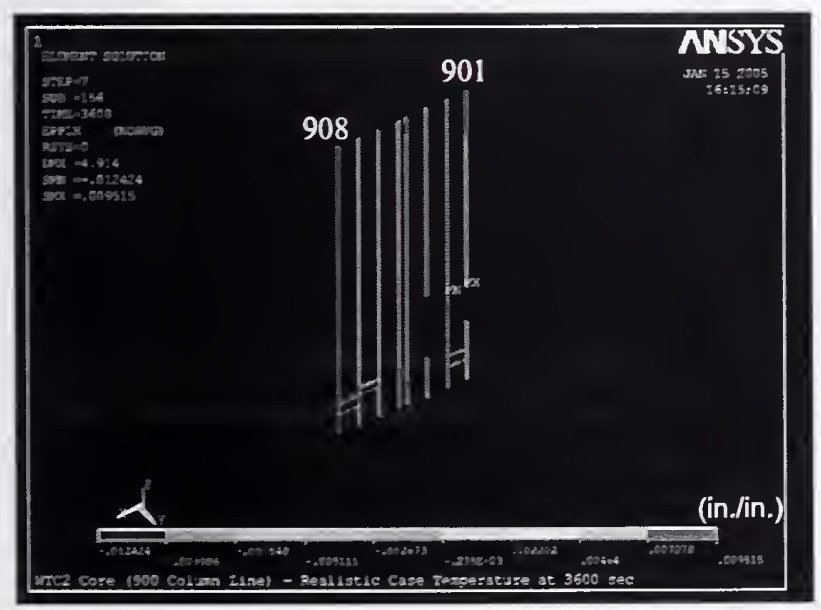

(e) 900 series columns

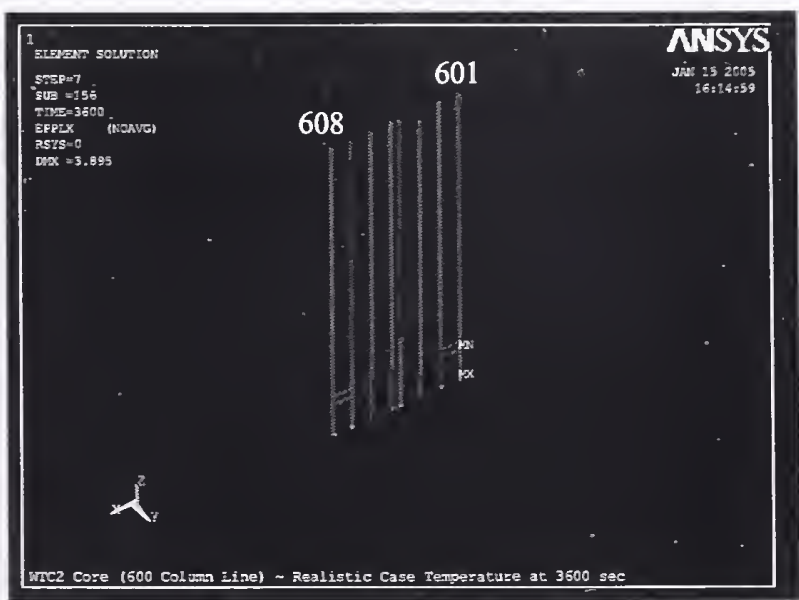

(b) 600 series columns

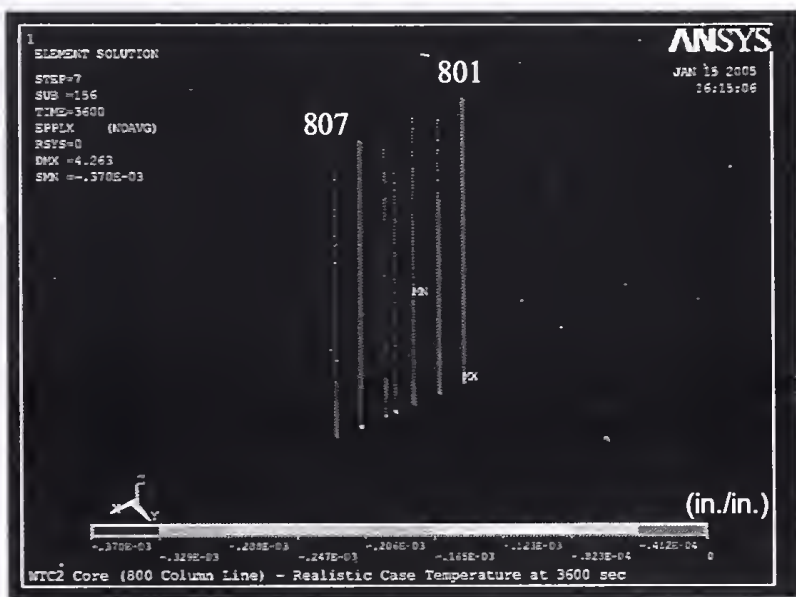

(d) 800 series columns

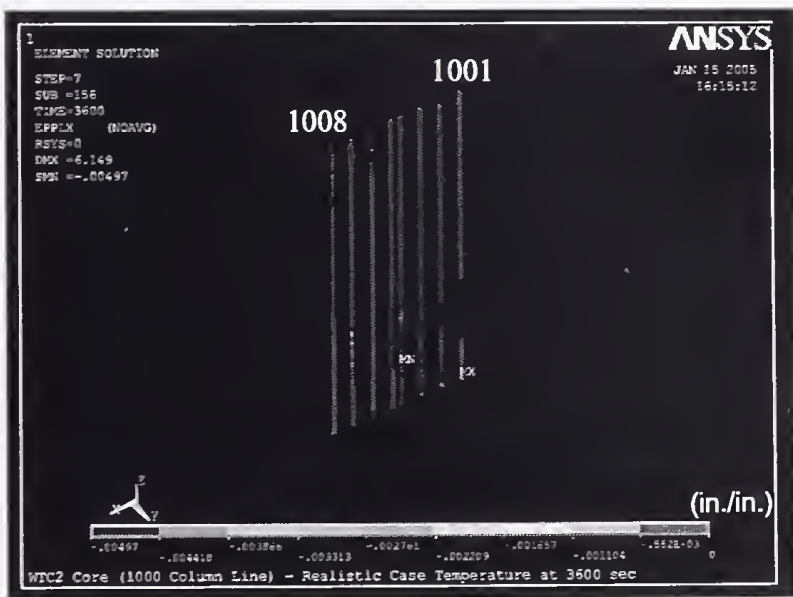

(f) 1000 series columns

Figure 3-135. Axial plastic strains in core columns of isolated core model of WTC 2 for Case $C$ temperature condition at $60 \mathrm{~min}$ (compressive strain is negative). 


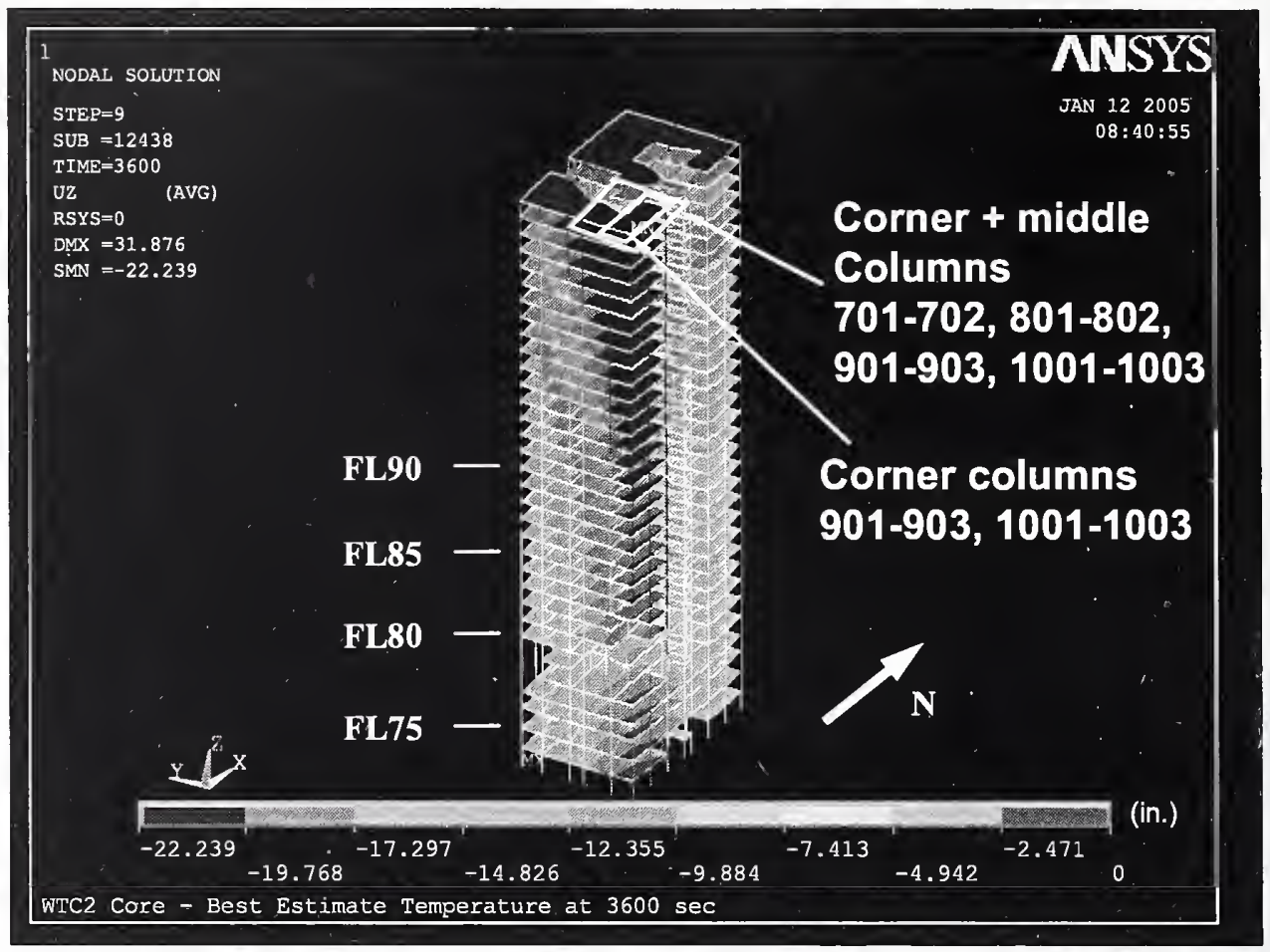

Figure 3-136. Vertical displacement after push down of isolated core model of WTC 2 for Case $\mathrm{C}$ temperature condition (downward displacement is negative).

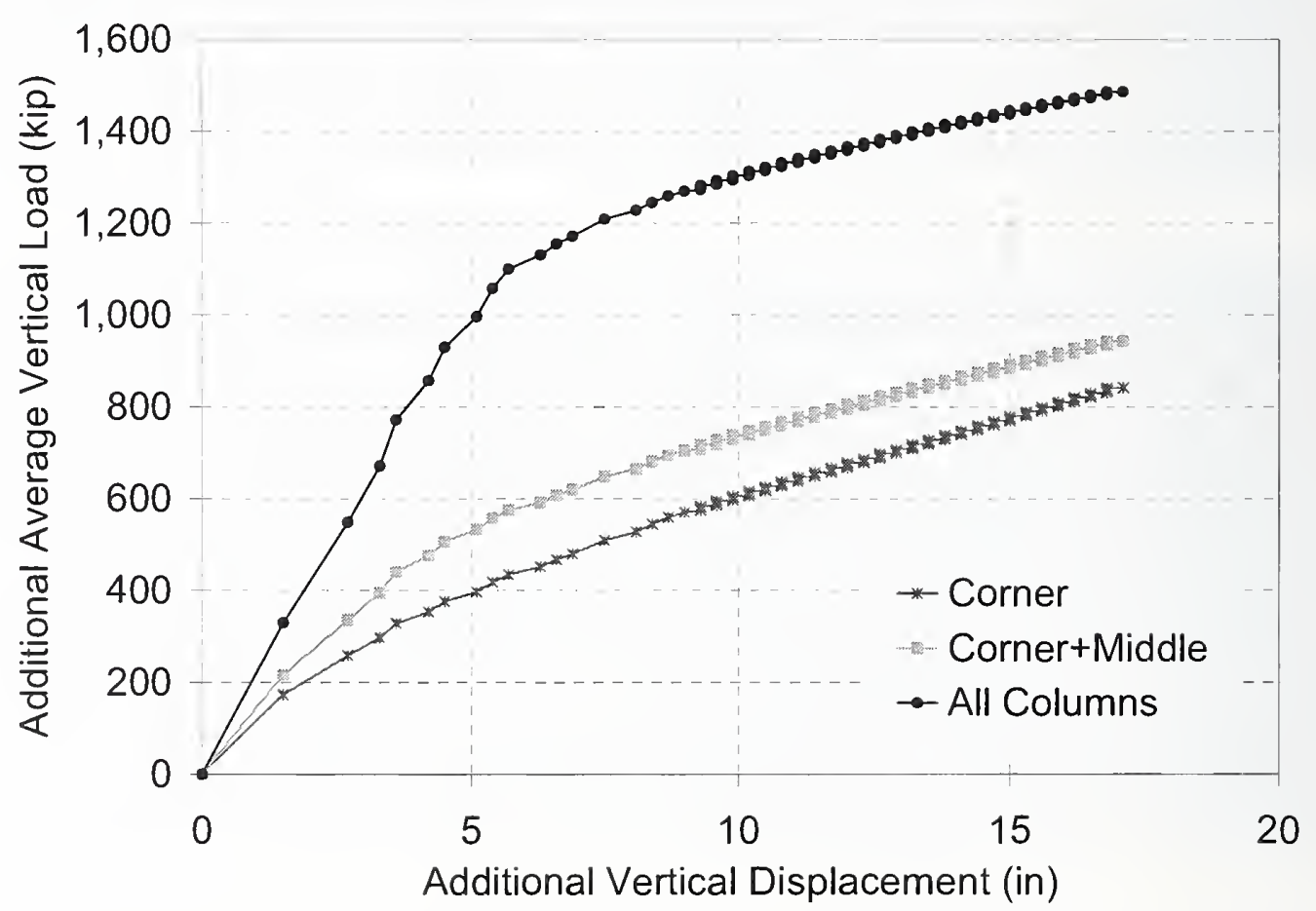

Figure 3-137. Additional average vertical load versus additional vertical displacement during push-down analysis of isolated core model of WTC 2 for Case C temperature condition (compression is positive; core column locations are shown in Fig. 3-136). 


\section{Case D Temperature Condition}

As mentioned in the previous section for Case $\mathrm{C}$ temperature condition, the isolated core model of WTC 2 was unstable after the aircraft impact damage, so the model was restrained in the horizontal directions.

Figures 3-138 to 3-139 show the vertical displacements of the WTC 2 isolated core model subjected to Case D temperature condition from just after the aircraft impact to $60 \mathrm{~min}$. The vertical displacement was always the highest at the southeast corner of the core as the aircraft impact severed the southeast corner core columns in Floors 79 to 82. After aircraft impact damage, the vertical displacement of the southeast corner was $5.6 \mathrm{in}$. This displacement increased to $8.2 \mathrm{in}$. at 60 min. Figures 3-140 and 3-141 show axial load and plastic strain in columns at $60 \mathrm{~min}$. Columns at the southeast corner experienced plastic strains immediately following aircraft impact. The maximum plastic strain in the 900 -series core columns was 2.5 percent, and 0.7 percent in the 1000 series core columns.

The vertical displacement of the core at Floor 106 at 60 min ranged from 3.3 in. to $6.0 \mathrm{in}$. The maximum vertical displacement of the southeast corner was less than $6.0 \mathrm{in}$. at Column 1001. The average vertical displacement of Floor 106 after thermal loading at 60 min was $4.1 \mathrm{in}$., similar to the $3.9 \mathrm{in}$. average vertical displacement after the aircraft impact. None of core columns buckled during thermal loading.

To determine the additional axial load-carrying capacity of the core, the isolated core model was pushed down following the analysis for Case D temperature condition as described before. The top of the isolated core was pushed down an additional 30.0 in. The analysis was stopped even though the core was continued to carry additional load. The vertical displacement at the end of $30.0 \mathrm{in}$. push-down is shown in Fig. 3-142. Figure 3-143 shows the relationship between the additional vertical displacement and the average additional vertical load on core columns, the corner columns, and the corner and middle columns shown in Fig. 3-143. As it can be seen from Fig. 3-143 at 60 min temperature condition, the columns on the southeast corner of the isolated core continued to carry, on the average, an additional load of about $1,200 \mathrm{kip}$ without failure, compared to about 1,700 kip for the average of the entire core columns prior to push down. The additional load on the core columns was about 1.8 times that of the average load in Floor 82 columns at 60 min temperature condition.

The results of the isolated core models of WTC 2 show that significant downward displacement of the core and core column buckling are not likely to occur for WTC 2 during the global analysis. 


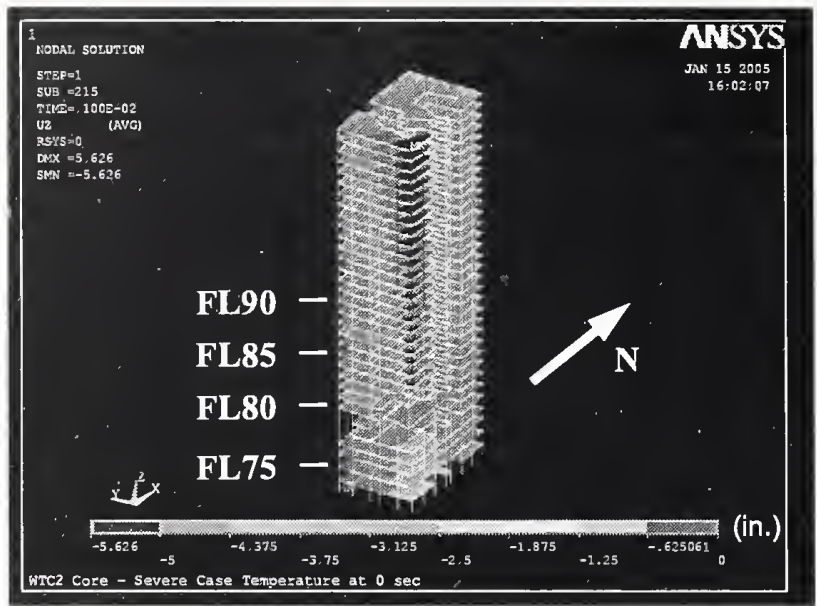

(a) After aircraft impact

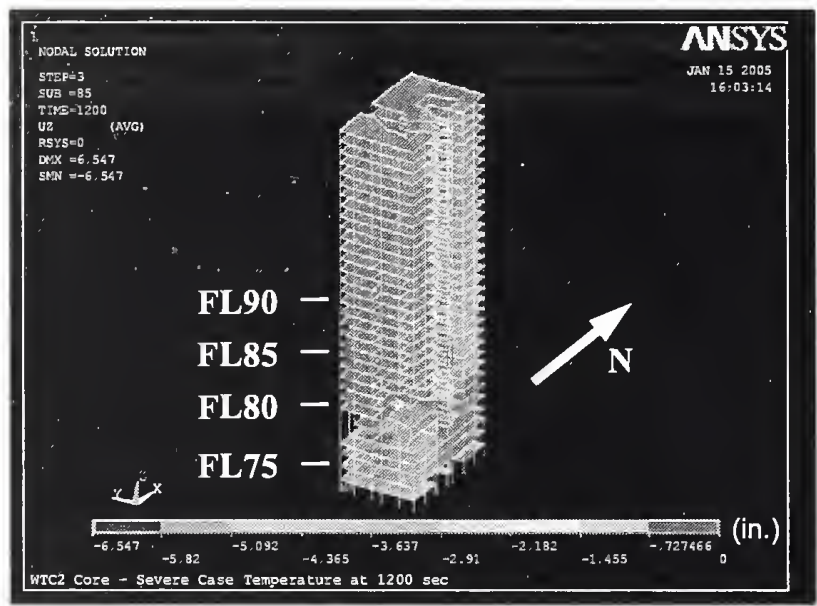

(c) At $20 \mathrm{~min}$

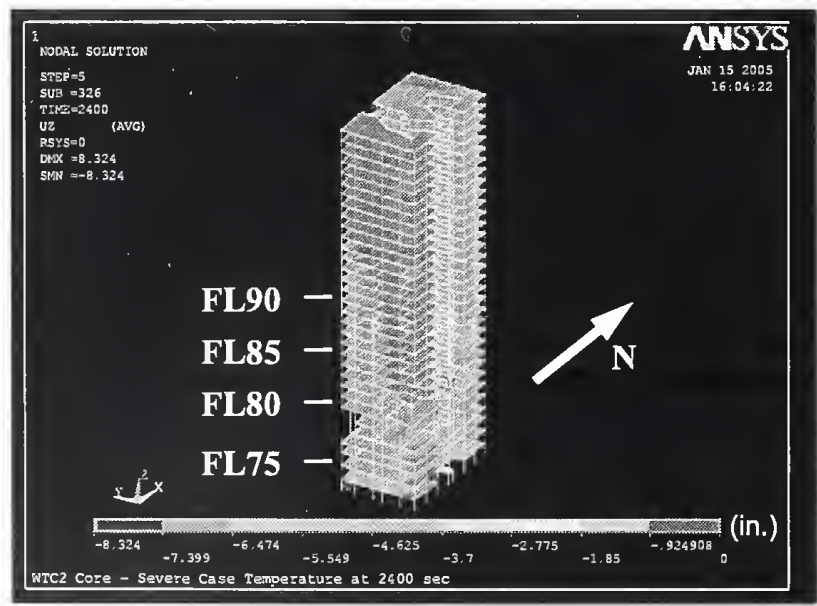

(e) At $40 \mathrm{~min}$

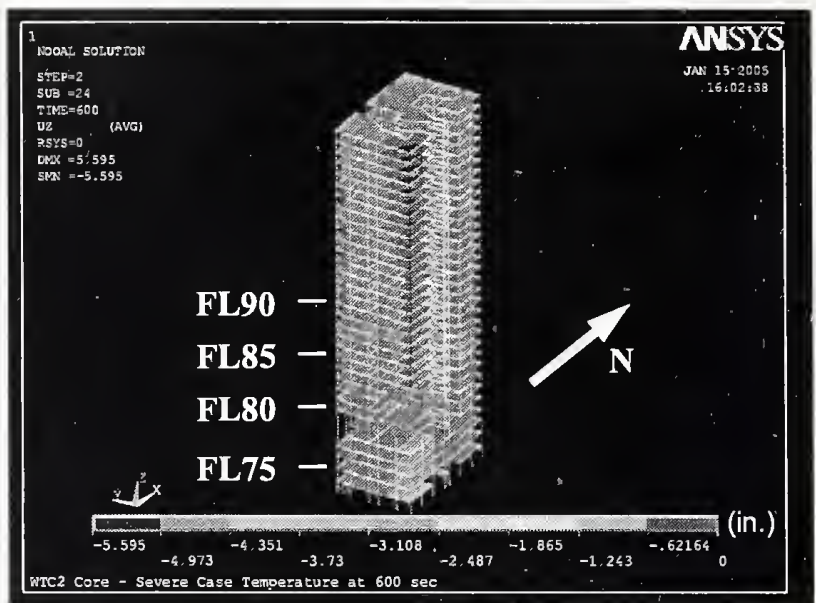

(b) At $10 \mathrm{~min}$

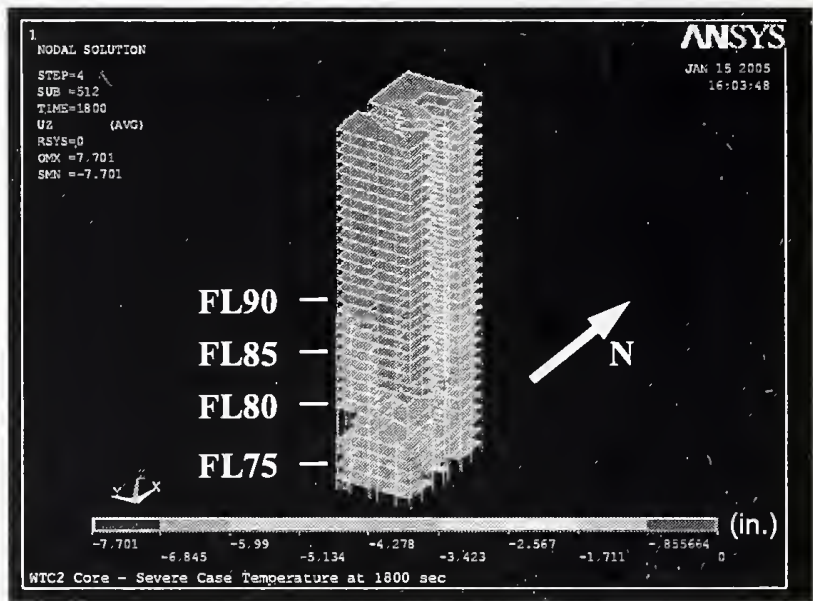

(d) At $30 \mathrm{~min}$

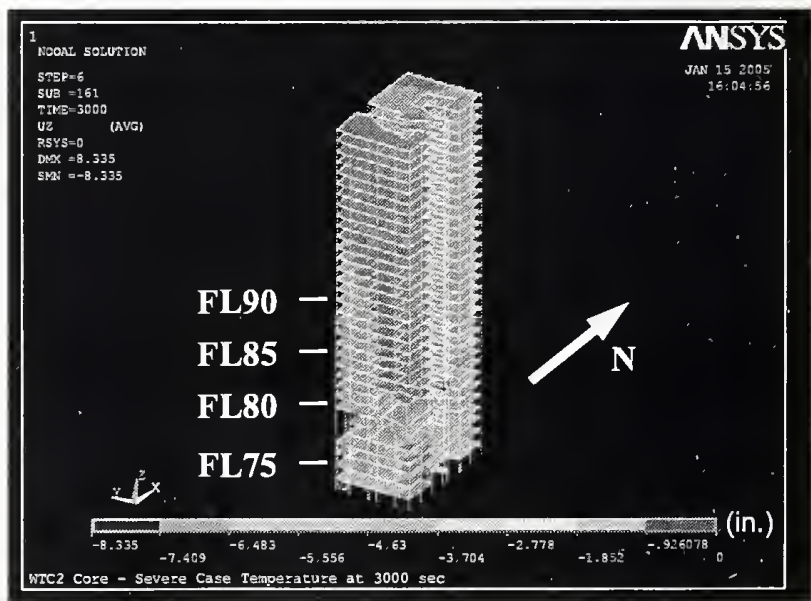

(f) At $50 \mathrm{~min}$

Figure 3-138. Vertical displacement of isolated core model of WTC 2 for Case D temperature condition (downward displacement is negative). 
NODAL SOLUTION

STEP $=7$

SUB $=80$

TIME $=3600$

UZ

RSYS $=0$

$\mathrm{DMX}=8.16$

SMN $=-8.16$
JAN 152005 $16: 05: 31$
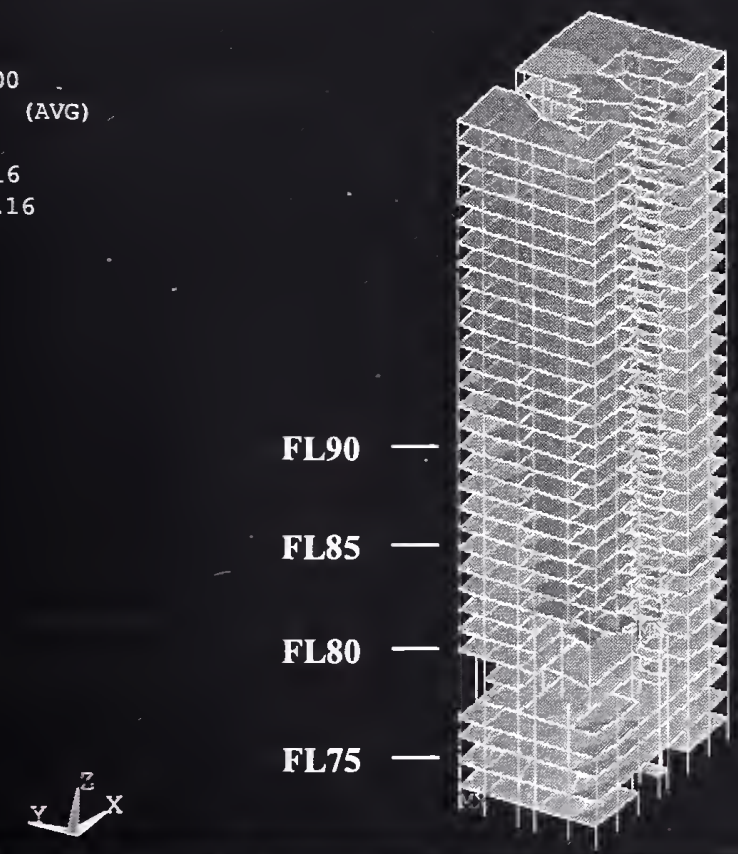

\section{.}

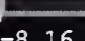

$$
-7.254
$$

$-6.347$

$-5.44$

$-4.533$

$-3.627$

$-2.72$

$-.906695$

WTC2 Core - Severe Case Temperature at $3600 \mathrm{sec}$

Figure 3-139. Vertical displacement of isolated core model of WTC 2 for Case D temperature condition at $60 \mathrm{~min}$ (downward displacement is negative). 


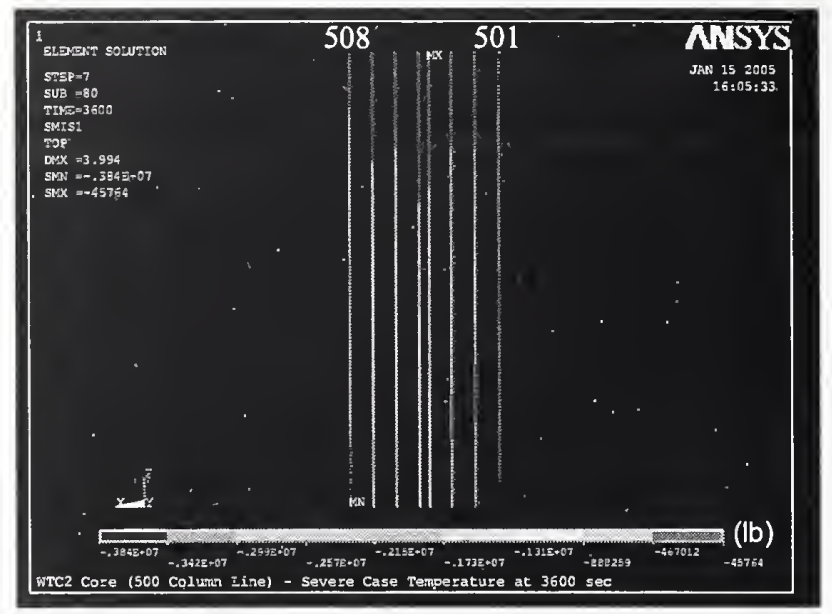

(a) 500 series columns

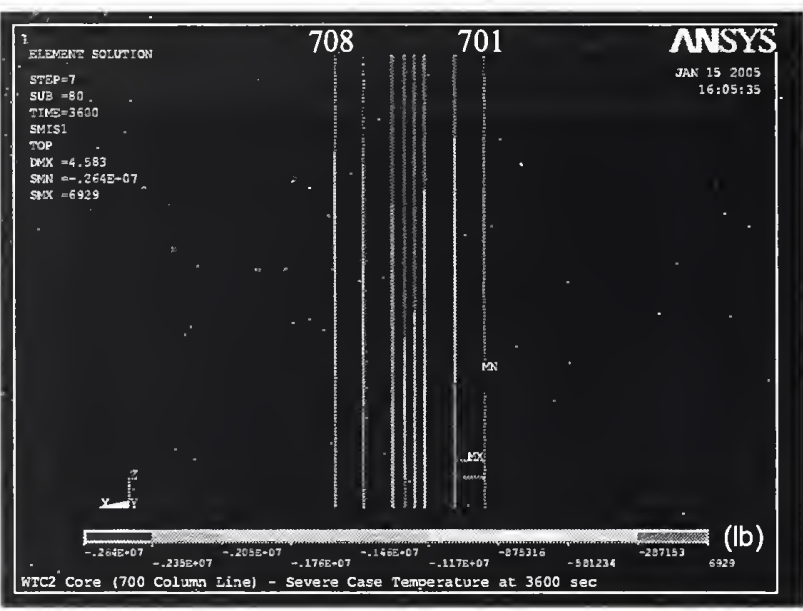

(c) 700 series columns

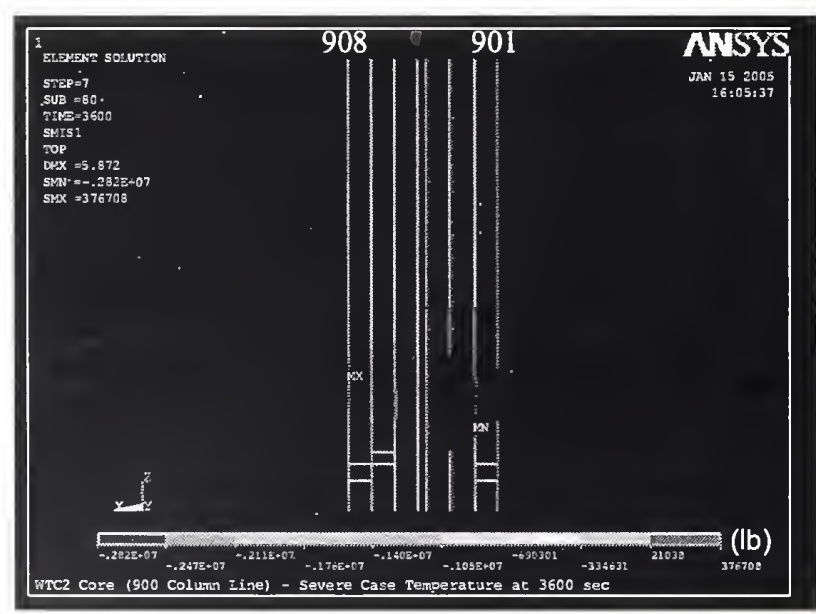

(e) 900 series columns

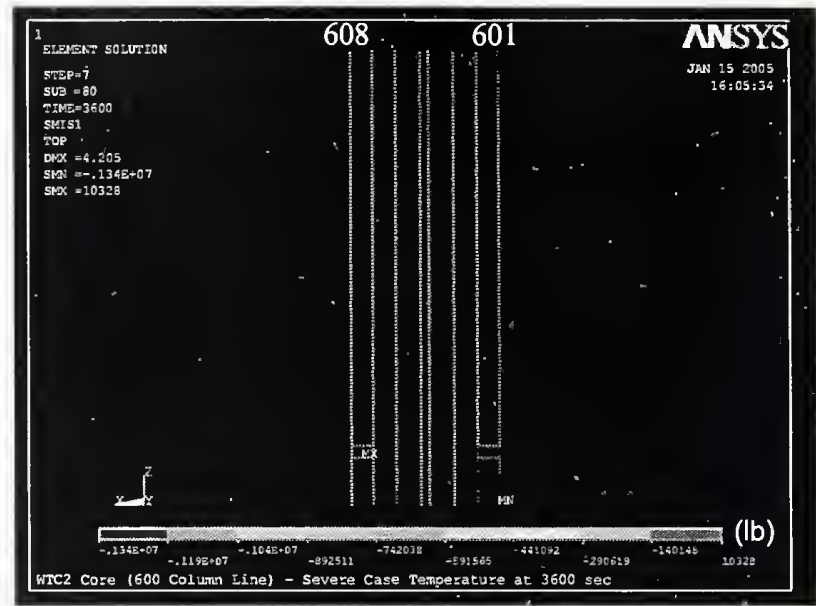

(b) 600 series columns

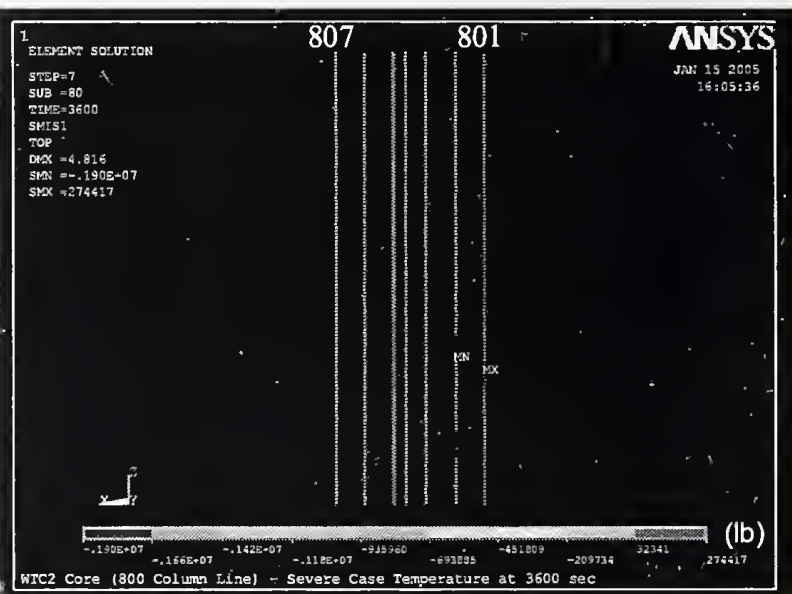

(d) 800 series columns

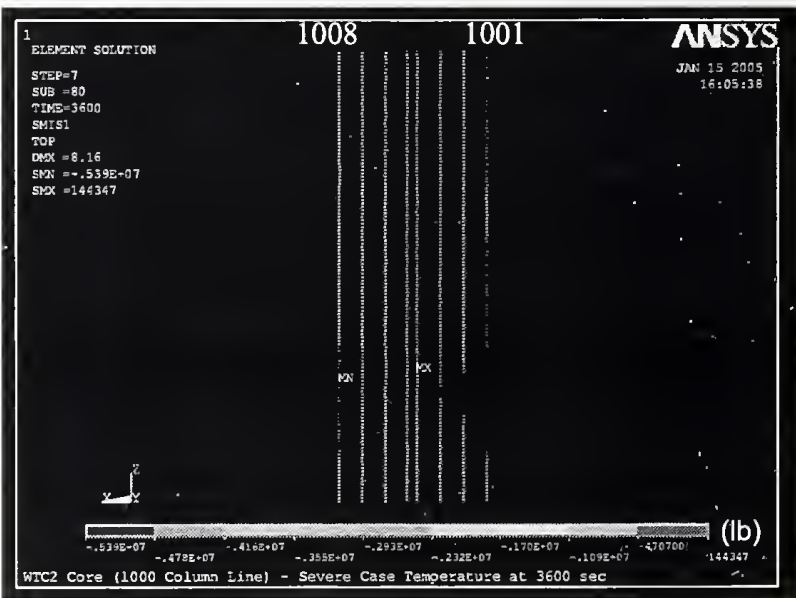

(f) 1000 series columns

Figure 3-140. Axial load in core columns of isolated core model of WTC 2 for Case D temperature condition at $60 \mathrm{~min}$ (compression is negative). 


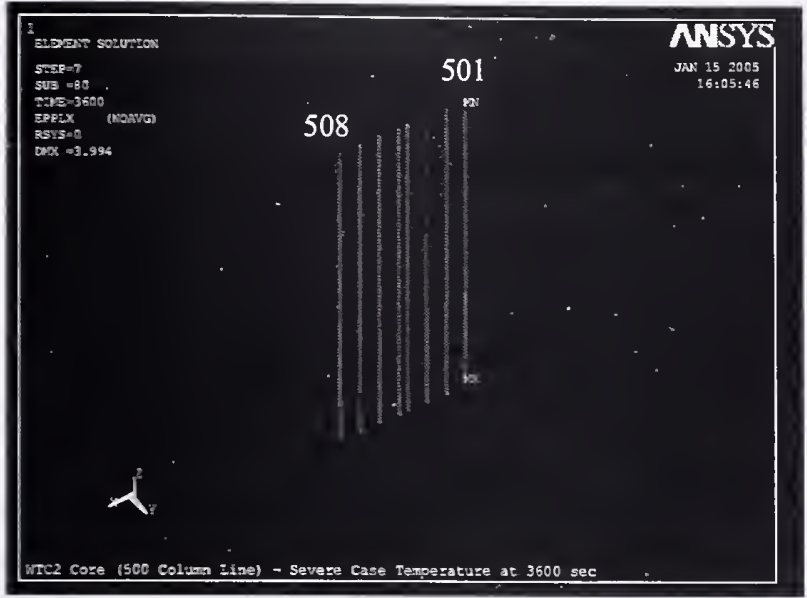

(a) 500 series columns

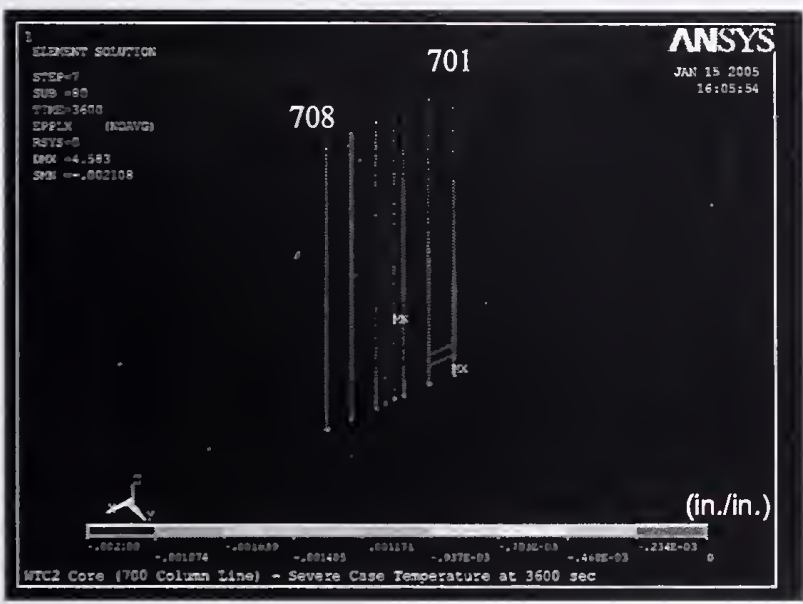

(c) 700 series columns

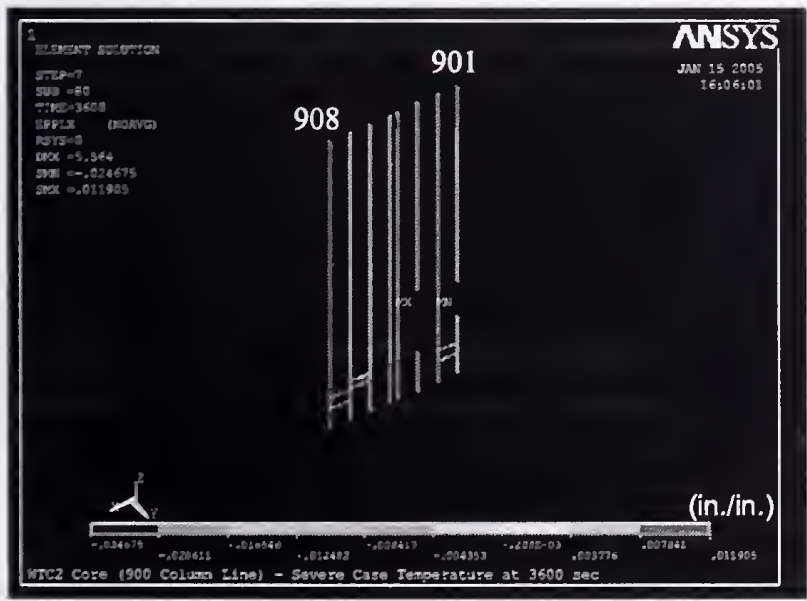

(e) 900 series columns

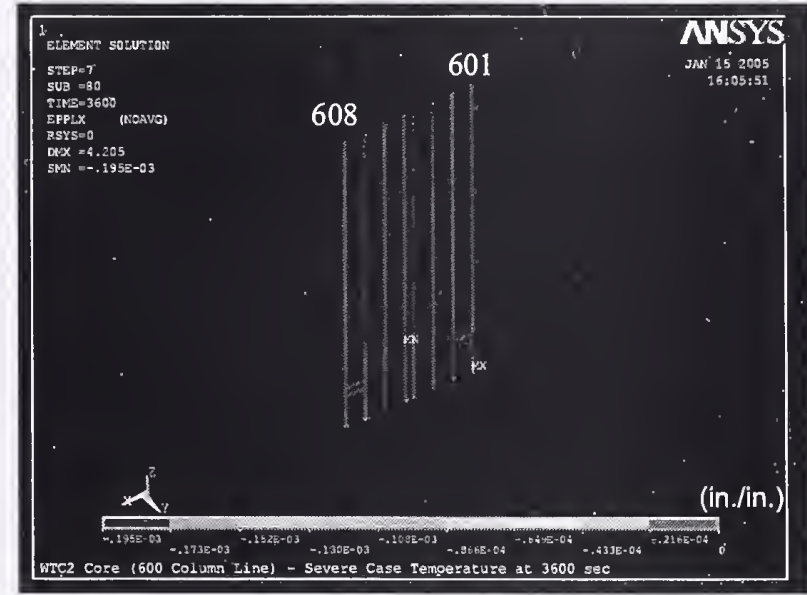

(b) 600 series columns

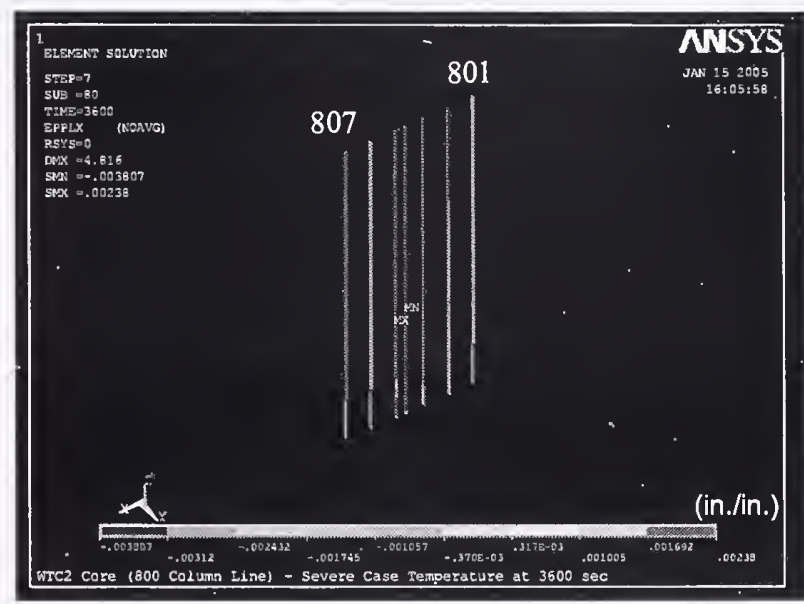

(d) 800 series columns

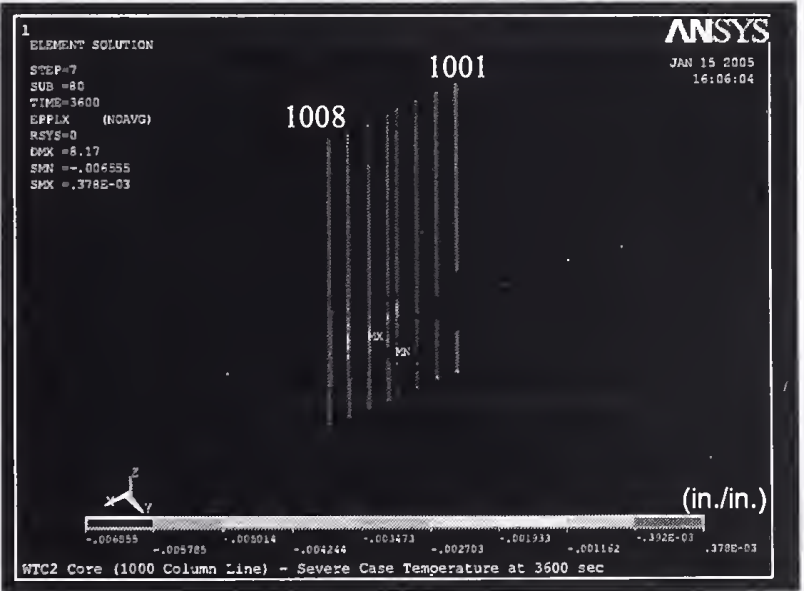

(f) 1000 series columns

Figure 3-141. Axial plastic strains in core columns of isolated core model of WTC 2 for Case $D$ temperature condition at $60 \mathrm{~min}$ (compressive strain is negative). 


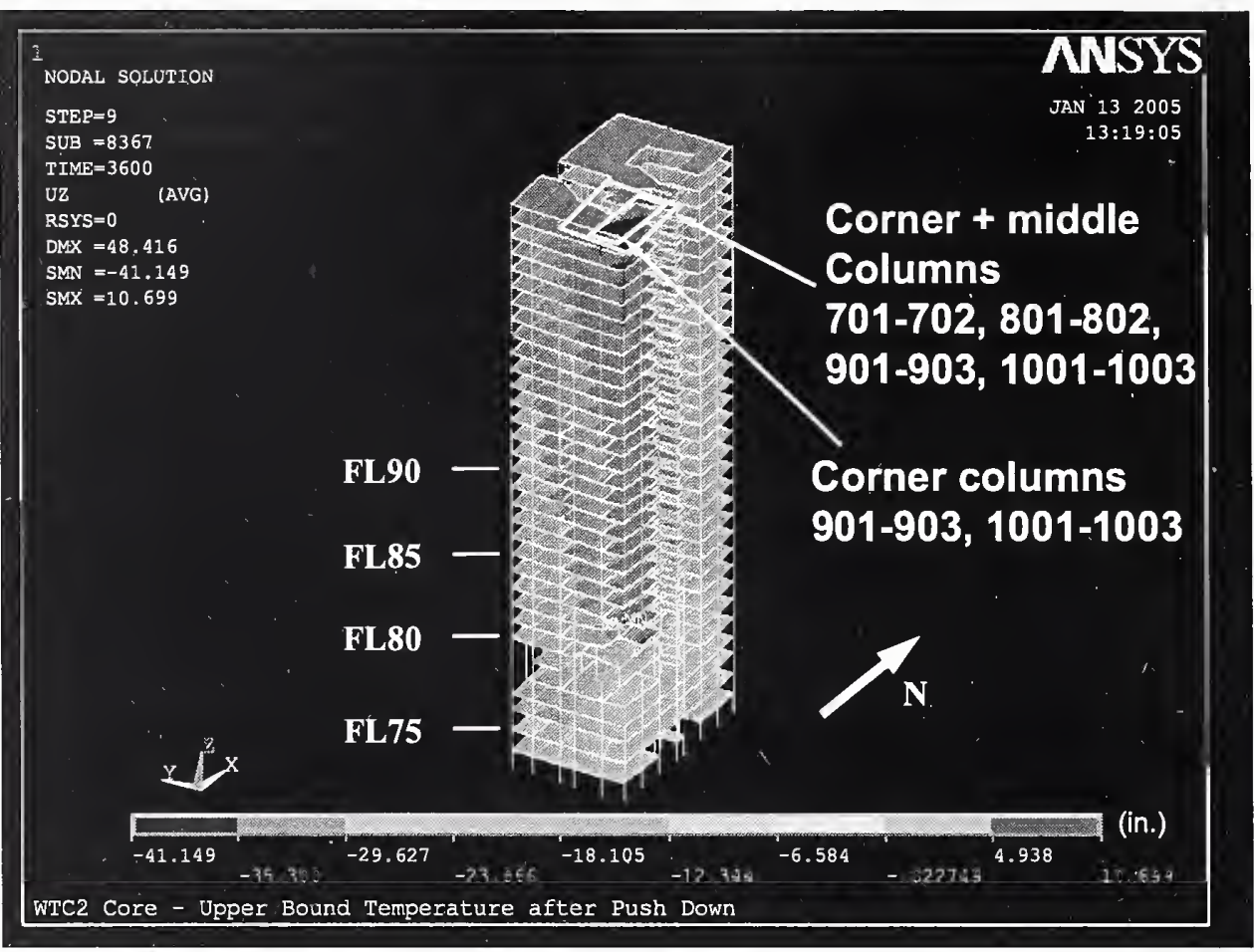

Figure 3-142. Vertical displacement after push down of isolated core model of WTC 2 for Case $D$ temperature condition (downward displacement is negative).

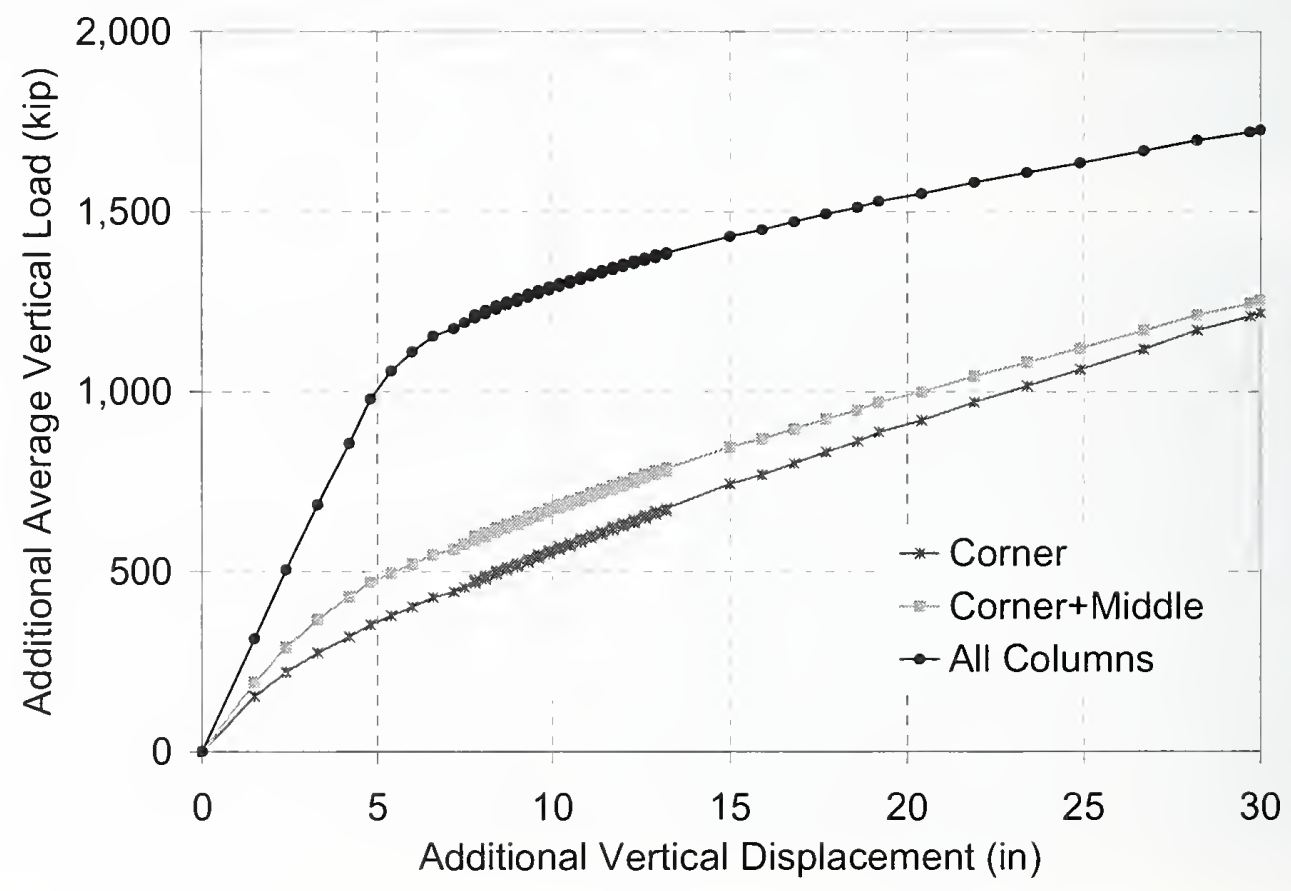

Figure 3-143. Additional average vertical load versus additional vertical displacement during push-down analysis of isolated core model of WTC 2 for Case D temperature condition. (compression is positive; core column locations are indicated in Fig. 3-142.) 

